Nevada

Environmental

Restoration

Project

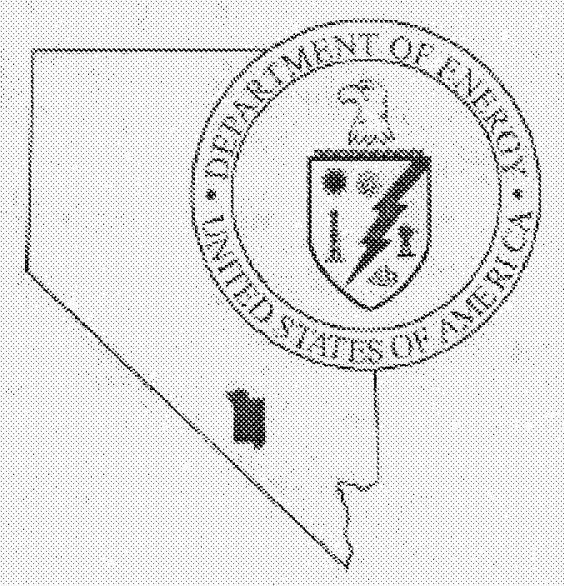

ANNUAL REPORT

RCRA POST CLOSURE MONITORING

AND INSPECTIONS FOR

CORRECTIVE ACTION UNIT 112:

AREA 23 HAZARDOUS WASTE TRENCHES,

NEVADA TEST SITE, NEVADA

FOR THE PERIOD

OCTOBER 1997 - OCTOBER 1998

Revision: 0

January 1999

Environmental Restoration

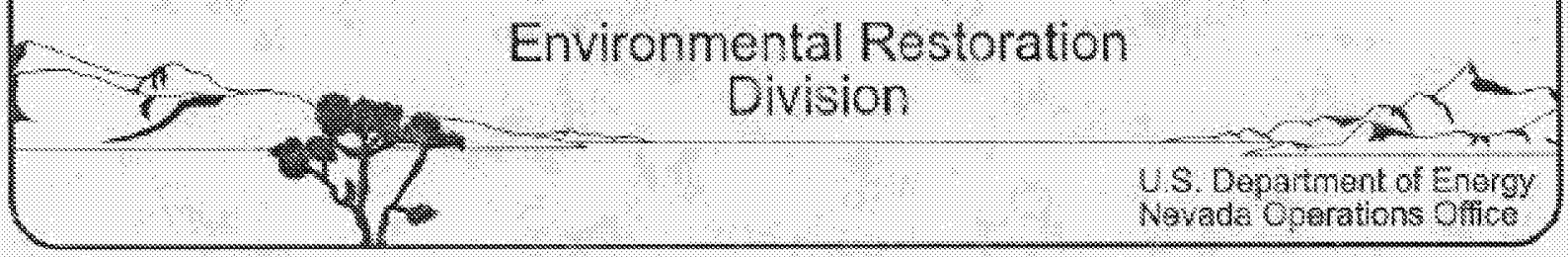


Available to the public from:

U.S. Department of Commerce

National Technical Information Service

5285 Port Royal Road

Springfield, VA 22161-0002

Available electronically at http:/www. doegov/bridge. Available to U.S. Department of Energy and its contractors in paper from:

U.S. Department of Energy

Office of Scientific and Technical Information

P.O. Box 62

Oak Ridge, TN 37831-0062

(423) 576-8401

Reference herein to any specific commercial product, process, or service by trade name, trademark, manufacturer, or otherwise, does not necessarily constitute or imply its endorsement, recommendation, or favoring by the U.S. Government or any agency thereof or its contractors or subcontractors. 


\author{
ANNUAL REPORT \\ RCRA POST-CLOSURE MONITORING \\ AND INSPECTIONS FOR \\ CORRECTIVE ACTION UNIT 112: \\ AREA 23 HAZARDOUS WASTE TRENCHES, \\ NEVADA TEST SITE, NEVADA \\ FOR THE PERIOD \\ OCTOBER 1997 - OCTOBER 1998
}

Controlled Copy No.

Revision: 0

January 1999

\author{
Prepared for \\ U.S. Department of Energy \\ Nevada Operations \\ Under Contract No. DE-AC08-96NV11718
}




\section{ANNUAL REPORT \\ RCRA POST-CLOSURE MONITORING \\ AND INSPECTIONS FOR \\ CORRECTIVE ACTION UNIT 112: \\ AREA 23 HAZARDOUS WASTE TRENCHES \\ NEVADA TEST SITE, NEVADA}

FOR THE PERIOD

OCTOBER 1997 - OCTOBER 1998

Approved by: $\frac{\int_{\text {Janet L. Appenzeller-Wing, Project Manager }}^{\text {Industrial Sites Subproject }}}{=}$

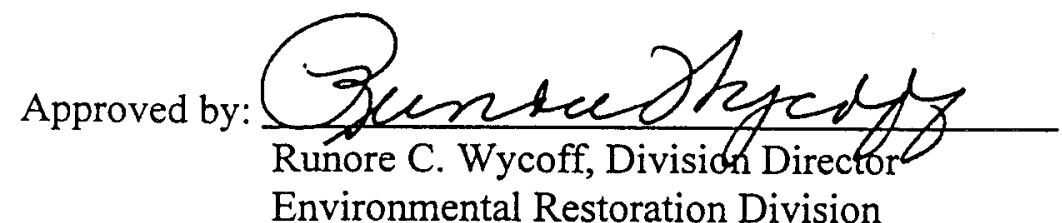

Date: $2 / 2 / 99=$

Date: $2-2-99$ 


\section{TABLE OF CONTENTS}

FIGURES vii

TABLES $\ldots \ldots \ldots \ldots \ldots \ldots \ldots \ldots \ldots \ldots \ldots \ldots \ldots \ldots \ldots \ldots \ldots \ldots \ldots \ldots \ldots$

LIST OF ABBREVIATIONS AND ACRONYMS $\ldots \ldots \ldots \ldots \ldots \ldots \ldots \ldots \ldots \ldots$ ix

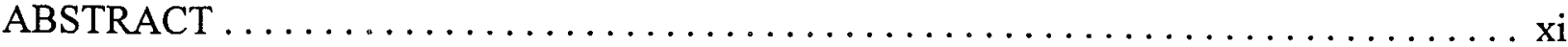

EXECUTIVE SUMMARY $\ldots \ldots \ldots \ldots \ldots \ldots \ldots \ldots \ldots \ldots \ldots \ldots \ldots \ldots \ldots \ldots \ldots \ldots$

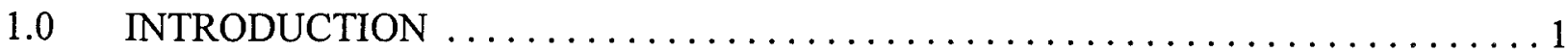

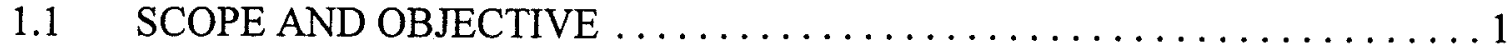

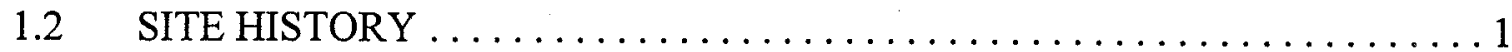

1.3 SITE GEOLOGY AND HYDROLOGY $\ldots \ldots \ldots \ldots \ldots \ldots \ldots \ldots$

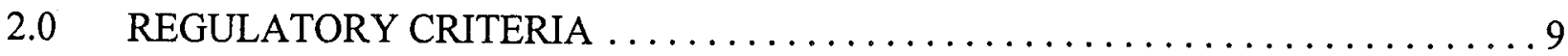

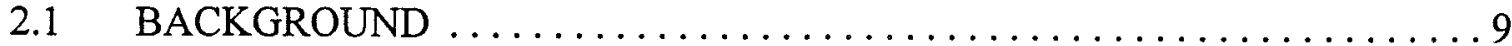

2.2 SITE INSPECTION COMPLIANCE CRITERIA $\ldots \ldots \ldots \ldots \ldots \ldots \ldots \ldots 11$

2.3 SOIL MOISTURE MONITORING COMPLIANCE CRITERIA $\ldots \ldots \ldots \ldots 12$

3.0 SITE INSPECTIONS AND ANNUAL SUBSIDENCE SURVEY $\ldots \ldots \ldots \ldots \ldots 15$

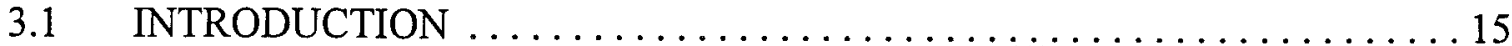

$3.2 \quad$ FINDINGS FROM QUARTERLY INSPECTIONS . . . . . . . . . . . . 15

3.2.1 FOURTH QUARTER INSPECTION (OCTOBER-DECEMBER 1997) 15

3.2.2 FIRST QUARTER INSPECTION (JANUARY-MARCH 1998) . . . . . 15

3.2.3 SECOND QUARTER INSPECTION (APRIL-JUNE 1998) . . . . ... . 16

3.2.4 THIRD QUARTER INSPECTION (JULY-SEPTEMBER 1998) . . . 16

3.2.5 FOURTH QUARTER INSPECTION (OCTOBER 1998) . . . . . . . . 16

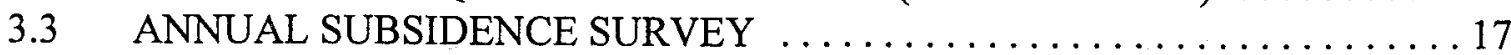

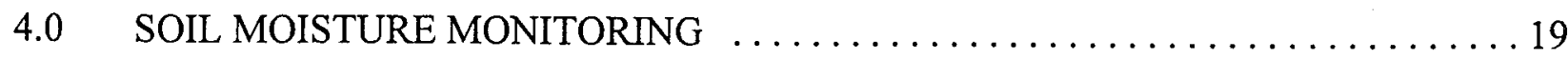

4.1 INTRODUCTION . . . . . . . . . . . . . . . . . . . . . 19

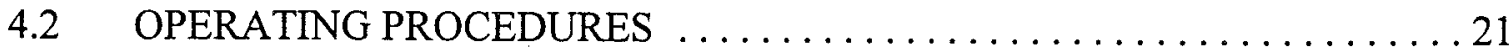

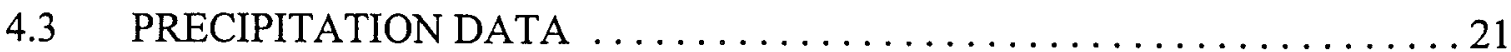




\section{TABLE OF CONTENTS (Continued)}

4.4 SOIL MOISTURE MONITORING RESULTS $\ldots \ldots \ldots \ldots \ldots \ldots \ldots \ldots \ldots$

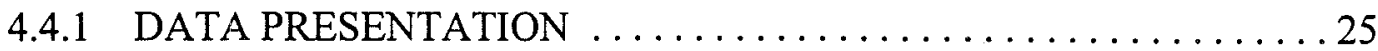

4.4.1.2 DISCUSSION OF ANALYTICAL DATA TRENDS ..... 31

4.4.1.2.1 HAZARDOUS WASTE TRENCH A (ROW A) . . . 31

4.4.1.2.2 HAZARDOUS WASTE TRENCH B (ROW B) . . . 32

4.4.1.2.3 HAZARDOUS WASTE TRENCH C (ROW C) . . . 33

4.4.1.2.4 HAZARDOUS WASTE TRENCH S-1 (ROW S-1) 34

4.4.1.2.5 HAZARDOUS WASTE TRENCH S-2 (ROW S-2) 34

4.4.1.2.6 VERTICAL CONTROL TUBE V-1 ....... 35

5.0 SUMMARY, CONCLUSIONS, AND RECOMMENDATIONS $\ldots \ldots \ldots \ldots \ldots \ldots 37$

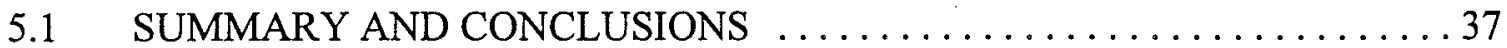

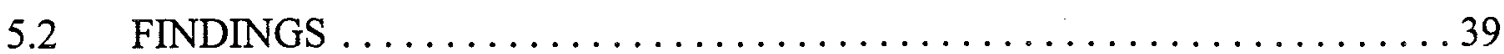

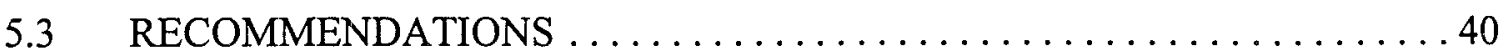

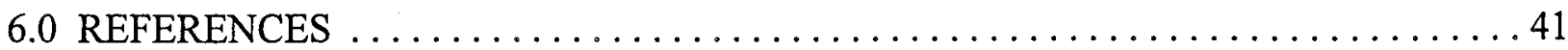

\section{APPENDICES}
A. NEUTRON ACCESS TUBE INSTALLATION SUMMARY
B. MONTHLY INSPECTION CHECKLISTS
C. SUBSIDENCE SURVEY PLAT
D. PRECIPITATION RECORDS
E. BASELINE DIFFERENCE GRAPHS 


\section{TABLE OF CONTENTS (Continued)}

\section{FIGURES}

FIGURE ES-1. ROW A CUMULATIVE RESIDUAL MOISTURE CONTENT . . . . . . ES-8 FIGURE ES-2. ROW B CUMULATIVE RESIDUAL MOISTURE CONTENT ... . . . . ES-9 FIGURE ES-3. ROW C CUMULATIVE RESIDUAL MOISTURE CONTENT . . . . . ES-10 FIGURE ES-4. ROW S1 CUMULATIVE RESIDUAL MOISTURE CONTENT ...... ES-11 FIGURE ES-5. ROW S2, V1 CUMULATIVE RESIDUAL MOISTURE CONTENT .. ES-12

FIGURE 1. SITE LOCATION, AREA 23 LANDFILL HAZARDOUS WASTE

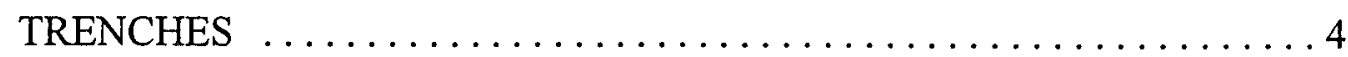

FIGURE 2. CLOSURE SITE, AREA 23 LANDFILL COVERS AND

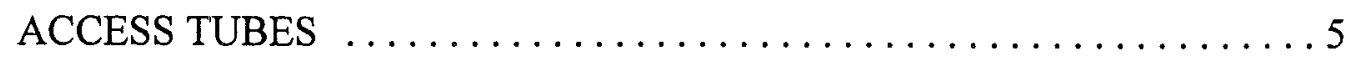

FIGURE 3. PRECIPITATION AREA 23 META STATION $\ldots \ldots \ldots \ldots \ldots \ldots \ldots 24$ FIGURE 4. ROW A CUMULATIVE RESIDUAL MOISTURE CONTENT . . . . . . 26 FIGURE 5. ROW B CUMULATIVE RESIDUAL MOISTURE CONTENT ...... . 27 FIGURE 6. ROW C CUMULATIVE RESIDUAL MOISTURE CONTENT . . . . . . 28 FIGURE 7. ROW S1 CUMULATIVE RESIDUAL MOISTURE CONTENT _.. . . . 29 FIGURE 8. ROW S2, V1 CUMULATIVE RESIDUAL MOISTURE CONTENT _.. 30

\section{TABLES}

TABLE 1. CHRONOLOGY OF SIGNIFICANT EVENTS-AREA 23 HAZARDOUS

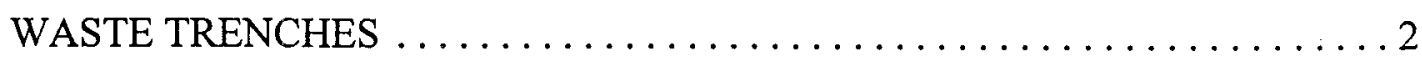

TABLE 2. NEUTRON ACCESS TUBES MONITORED AT THE AREA 23 HAZARDOUS WASTE LANDFILL RCRA UNIT $\ldots \ldots \ldots \ldots \ldots \ldots 11$

TABLE 3. SUBSIDENCE MONUMENT COORDINATES AND ELEVATIONS $\ldots . . . .17$

TABLE 4. PRECIPITATION DATA FOR THE MERCURY NEVADA, METEOROLOGICAL STATION, MER, FOR THE PERIOD NOVEMBER 1, 1997 THROUGH OCTOBER 31, 1998 


\section{LIST OF ABBREVIATIONS AND ACRONYMS}

$\mathrm{BN}$

Bechtel Nevada

CAU

Corrective Action Unit

CFR

Code of Federal Regulations

$\mathrm{cm}$

centimeter(s)

CRMC

Cumulative Residual Moisture Content

DOE

U.S. Department of Energy

$\mathrm{ET}_{\mathrm{POT}}$

Estimates of Potential Evapotranspiration

$\mathrm{ft}$

foot (feet)

gal

gallon

hr

hour

in

inch

$\mathrm{km}$

kilometer

$\mathrm{L}$

liter

$\mathrm{m}$

meter(s)

$\mathrm{mi}$

mile

NDEP

Nevada Division of Environmental Protection

NTS

Nevada Test Site

RCRA

Resource Conservation and Recovery Act

REECo

Reynolds Electrical and Engineering Company, Inc.

RVMC

Residual Volumetric Moisture Content

$\sec$

seconds

VMC

Volumetric Moisture Content 


\section{ABSTRACT}

This annual Neutron Soil Moisture Monitoring report provides an analysis and summary for site inspections, meteorological information, and neutron soil moisture monitoring data obtained at the Area 23 Hazardous Waste Trenches Resource Conservation and Recovery Act (RCRA) unit, located in Area 23 of the Nevada Test Site, Nye County, Nevada, during the October 1997 October 1998 period.

Inspections of the Area 23 Hazardous Waste Trenches RCRA unit are conducted to determine and document the physical condition of the covers, facilities, and any unusual conditions that could impact the proper operation of the waste unit closure.

Physical inspections of the closure were completed quarterly and indicated that the site is in good condition with no significant findings noted.

An annual subsidence survey of the elevation markers was conducted in July 1998. There has been no subsidence at any of the markers since monitoring began six years ago.

The objective of the neutron logging program is to monitor the soil moisture conditions along 30 neutron access tubes and detect changes that may be indicative of moisture movement at a point located directly beneath each trench.

Precipitation for the period October 1997 through October 1998 was 30.78 centimeters $(\mathrm{cm})$ (12.12 inches [in]). The annual rainfall (January 1998 through January 1999) was $27.66 \mathrm{~cm}$ (11.12 in) which set a new all time record. The highest 30 -day cumulative rainfall occurred on February 24, 1998, with a total of $11.87 \mathrm{~cm}$ (4.24 in). The heaviest daily precipitation occurred on February 23,1998 , with a total of $4.67 \mathrm{~cm}$ (1.84 in) falling in that 24 -hour period. The recorded average annual rainfall for this site from 1971 to January 1999 is $14.96 \mathrm{~cm}$ (5.89 in).

All monitored access tubes are within the compliance criteria of less than 5 percent residual volumetric moisture content at the compliance point directly beneath each respective trench. Soil conditions remain dry and stable underneath the trenches. 


\section{EXECUTIVE SUMMARY}

\section{INTRODUCTION}

The Area 23 Hazardous Waste Trenches were closed in-place in September 1993. Post-closure monitoring of the Area 23 Hazardous Waste Trenches began in October 1993. The post-closure monitoring program is used to verify that the Area 23 Hazardous Waste Trench covers are performing properly, and that there is no water infiltrating into or out of the waste trenches. The performance of the Area 23 Hazardous Waste Trenches is currently monitored using 30 neutron access tubes positioned on and along the margins of the covers. Soil moisture measurements are obtained in the soils directly beneath the trenches and compared to baseline conditions from the first year of post-closure operation. This report documents the post-closure activities between October 1997 and October 1998.

\section{REGULATORY CRITERIA}

A formal change of the compliance criteria for the Unit Nevada Test Site (NTS) Resource Conservation and Recovery Act Part B Permit was submitted to the Nevada Division of Environmental Protection (NDEP) in December 1996 and was approved on February 10, 1997. The changes were incorporated into the Part B Permit (NEV HW009) as a Class 1 Modification as per Appendix I to 40 Code of Federal Regulations $\$ 270.42$.

The level of concern, point of compliance, and schedule of actions are summarized below. Notification to NDEP is required if residual volumetric moisture contents (RVMC) above 5 percent (relative to baseline conditions) are observed and confirmed in two consecutive monitoring periods, at a point directly beneath each respective hazardous waste trench. The NDEP must be notified within seven days of determination of a valid trend. A preliminary written assessment detailing recommendations to determine the nature, cause, and action to be taken is to be submitted to NDEP for concurrence within 30 days of the notification.

\section{RESULTS OF INSPECTIONS AND THE MONITORING PROGRAM}

The unit was inspected quarterly. No significant concerns were observed.

As of February 23, 1998, 11.87 centimeters (cm) (4.24 inches [in]) of rain had fallen in a 30-day period. During a heavy rainfall on February 17, standing water was diverted away from some of the access tubes. Additional repair of the access was determined to be necessary. Preliminary 
Monitoring Report CAU 112

Section: SUMMARY

Revision: 0

Date: $2 / 4 / 1999$

review of the February soil moisture data for access tube S2-14 indicated that it may not have been thoroughly sealed during the previous fall maintenance on the covers.

Test Geoprobe ${ }^{\circledR}$ holes were placed along the B row near access Tube B-13 on September 8, 1998. Preliminary results indicated that void spaces underlie the ground surface. These voids are entrained within an old nonhazardous waste landfill and are found approximately 1.2 meters (m) (4 feet [ft]) below grade. This waste material is not associated with the hazardous waste trenches closed under the Environmental Restoration Project. Additional investigations will be scheduled to determine if these voids are providing a surface water transport pathway to the access tubes during high rainfall events.

\section{PRECIPITATION}

Precipitation for the period October 1997 through October 1998 was $30.78 \mathrm{~cm}$ (12.12 in) (U.S. National Weather Service, 1998). The annual rainfall (January 1998 through January 1999) was $27.66 \mathrm{~cm}$ (11.12 in) which set a new all time record. This record rainfall exceeded the previous record set in 1984 of 10.87 in. The highest 30-day cumulative rainfall occurred on February 24,1998 , with a total of $11.87 \mathrm{~cm}$ (4.24 in). The heaviest daily precipitation occurred on February 23, 1998, with a total of $4.67 \mathrm{~cm}$ (1.84 in) falling in that 24-hour (hr) period. The recorded average annual rainfall for this site from 1971 to January 1999 is $14.96 \mathrm{~cm}$ (5.89 in).

The Part B Permit (NDEP, 1995) specifies that rainfall events that exceed $1.0 \mathrm{in}$. in any 30-day period will require monthly monitoring for one quarter. The action level of $2.54 \mathrm{~cm}(1.0 \mathrm{in})$ in any 30-day period was exceeded on September 3,1997, with $3.43 \mathrm{~cm}$ accumulated (1.35 in). That action level has been exceeded in each quarter since, which has required continuous monthly monitoring through November 1998. The NTS has experienced the wettest year recorded on this and other monitored sites since rainfall monitoring station record keeping began at the NTS.

\section{SOIL MOISTURE MONITORING}

Graphs of Cumulative Residual Moisture Content (CRMC) relative to the regulatory level of concern ( 5 percent RVMC) are found for each trench in Figures ES-1 through ES-4.

The CRMC graph tracks changes over time from the baseline conditions at the point of compliance (directly beneath the hazardous waste trench) for each access tube. The residual moisture content is calculated by subtracting the first year average soil moisture content 
(baseline) from the soil moisture content for each monitoring period on a depth basis. The residual soil moisture is plotted as Residual Volumetric Moisture Content vs Logging Date for each access tube.

The soil moisture content point of compliance is located at a depth of $1 \mathrm{~m}$ ( $3 \mathrm{ft}$ ) from the bottom of each neutron access tube (the point directly beneath each hazardous waste trench). The monitored depth varies from tube to tube because the angled boreholes have varying stand-off distances to each respective trench.

The level of regulatory concern is indicated as the dark line at the 5 percent residual moisture level (Figures ES-1 though ES-4). Values exceeding this limit for two consecutive monitoring periods require notification to NDEP and the submittal of an Action Plan to investigate the cause.

\section{SUMMARY AND CONCLUSIONS}

1. Precipitation for the period October 1997 through October 1998 was $30.78 \mathrm{~cm}$ (12.12 in). The annual rainfall (January 1998 through January 1999) was $27.66 \mathrm{~cm}$ (11.12 in) which set a new all time record. The highest 30-day cumulative rainfall occurred on February 24,1998 , with a total of $11.87 \mathrm{~cm}$ (4.24 in). The heaviest daily precipitation occurred on February 23, 1998, with a total of $4.67 \mathrm{~cm}$ (1.84 in) falling in that 24-hr period. The recorded average annual rainfall for this site from 1971 to January 1999 is $14.96 \mathrm{~cm}(5.89 \mathrm{in})$.

2. The Part B Permit (NDEP, 1995) specifies that rainfall events that exceed 1.0 in. in any 30-day period will require monthly monitoring for one quarter. The action level of $2.54 \mathrm{~cm}(1.0 \mathrm{in})$ in any 30-day period was exceeded on September 3,1997, with $3.43 \mathrm{~cm}$ (1.35 in) accumulated and has been exceeded in each quarter since. This has required continuous monthly monitoring from September 1997 through November 1998. These weather conditions are the wettest recorded on this and other monitored NTS weather stations since record keeping had begun.

3. Inspections of the cover were done to identify any significant changes to the unit requiring action. No significant concerns were observed.

4. An elevation survey of the subsidence markers was conducted in July 1998. There has been no subsidence at any of the markers since monitoring began six years ago. 
5. Most access tubes located along the periphery of the cover (Tubes A, B, C-1 through C-4, and S-2) still show low levels of infiltration occurring down along the access tubes to depth. Access tubes located on, and penetrating the cover, indicate infiltration is limited to $1.83 \mathrm{~m}(6 \mathrm{ft})$ where the geomembrane liner is located, with the possible exception of Tube C-12 which shows some apparent wetting at the detection limit of the system at the 2.8-m (8-ft) level in the February and March monitoring period. It is not clear if this was due to an actual increase in moisture content or statistical noise. Tube C-12 returned to baseline conditions after the March 1998 monitoring period.

6. All monitored access tubes are within the compliance criteria of less than 5 percent RVMC at the compliance point directly beneath each respective trench. Soil conditions remain dry and stable underneath the trenches.

\section{INDIVIDUAL TRENCH SUMMARY}

No significant concerns were observed during the site inspections over the period October 1997 through October 1998 (Figures ES-1 through ES-5).

The annual subsidence survey of the two covers indicates that no subsidence has been detected to date.

Soil conditions remain dry and stable beneath the trenches through the October 1997 to October 1998 monitoring period. Due to the record February precipitation some near surface leakage beneath the well-head protection boxes is seen in the first $6.1 \mathrm{~m}(20 \mathrm{ft})$ of some access tubes located along the cover margins with small changes in moisture content detected to as deep as $18.3 \mathrm{~m}(60 \mathrm{ft})$ in some cases.

Maintenance and repair activities to the well-head protection boxes were completed in October 1997 in an effort to correct these effects. The continued observation of this wetting effect indicates that, at least under these record precipitation events, the maintenance activity was not completely successful, or that the source mechanism has not been adequately assessed.

Moisture contents at the point of compliance for all access tubes remain below the compliance criteria of 5 percent RVMC. Trench conditions are summarized on the next page: 


\section{Trench A}

CRMC at the point of compliance for all Row A tubes remains at less than 1 percent RVMC with no trends evident. The Row A access tubes remain stable, dry, and below the compliance criteria of 5 percent RVMC.

\section{Trench B}

CRMC at the point of compliance indicates that soils surrounding the Row B access tubes are below the compliance level of 5 percent RVMC with no trends evident.

\section{Trench C}

$\mathrm{CRMC}$ at the point of compliance for all Row $\mathrm{C}$ tubes remains at less than 1 percent $\mathrm{RVMC}$ with no trends evident. The Row $\mathrm{C}$ access tubes remain stable, dry, and below the compliance criteria of five percent RVMC.

\section{Trench S-1}

CRMC at the point of compliance for all Row S-1 tubes remains at less than 1 percent RVMC with no trends evident.

All access tubes remain dry, stable and below the compliance criteria of 5 percent RVMC.

\section{Trench S-2}

CRMC at the point of compliance for all Row S-2 tubes remains at less than 1 percent RVMC with no trends evident.

Row S-2 access tubes remain stable, dry, and below the compliance criteria of 5 percent RVMC.

\section{Control Well V-1}

The Vertical Control Tube V-1 is a $15.24-\mathrm{m}(50-\mathrm{ft})$ vertical neutron access tube located at the north margin of the cover. This tube was located in a slight depression that frequently filled with ponded water from runoff from the covers and from a catchment area located to the north. As a result, this "control" tube best represented a worse-case scenario rather 
than typical conditions. As a result of this ponding, the access tube has shown significantly more leakage than observed at any of the other access tubes. Corrective action to prevent future problems of this nature was completed in September 1997 by recontouring the surrounding soils. Some leakage is still evident during periods of high rainfall.

The CRMC for access Tube V-1, while noisier than other access tubes, remains below the Action Level of 5 percent RVMC.

\section{FINDINGS}

1. Most access tubes located along the periphery of the cover (Tubes A, B, C-1 through $\mathrm{C}-4$, and S-2) show low levels of infiltration occurring down along the access tubes to depth. Access tubes located on, and penetrating the cover, indicate

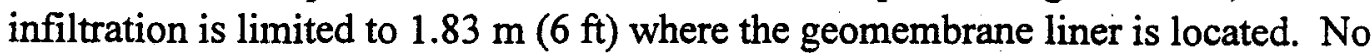
leakage across the liner has been observed.

2. Test core samples were obtained near Tube B-13 on September 8, 1998.

Preliminary results indicated that void spaces underlie the ground surface in that area. The voids are believed to be entrained within an old nonhazardous landfill

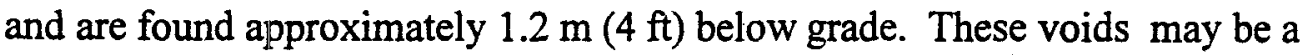
possible source and pathway for the infiltration noted along the access tubes.

3. The monthly monitoring criteria required for one quarter after precipitation events greater than 1.0 in any 30 -day period has been used to document the ability of the monitoring system to detect moisture changes over a short term and to insure that events would not be missed with a longer sampling period. Since the inception of the monitoring program, meteorologic conditions ranging from average to even. historic record precipitation conditions have been observed using this monthly monitoring criteria. The results have shown that the system can detect and report the same results whether using monthly, quarterly, or even a biannual sampling period.

4. No significant concerns were observed during the site inspections over the period October 1997 through October 1998.

5. The annual subsidence survey of the two covers indicates that there has been no subsidence detected to date. 
6. Soil conditions remain dry and stable beneath the trench through the October 1997 to October 1998 monitoring period.

7. Moisture contents at the point of compliance for all access tubes remain below the compliance criteria of 5 percent RVMC.

\section{RECOMMENDATIONS}

1. Further studies regarding the location, extent, and effects of subsurface voids should be conducted to determine if these features are related to the moisture infiltration along the access tubes. Additional soil probing along the periphery of the cover and an assessment of horizontal water transport within these pathways is recommended.

2. The continued use of monthly monitoring for one quarter after any rainfall event over 1.0 in in any 30-day period should be reevaluated as these events can be monitored and evaluated as effectively using a quarterly or biannual monitoring period. 


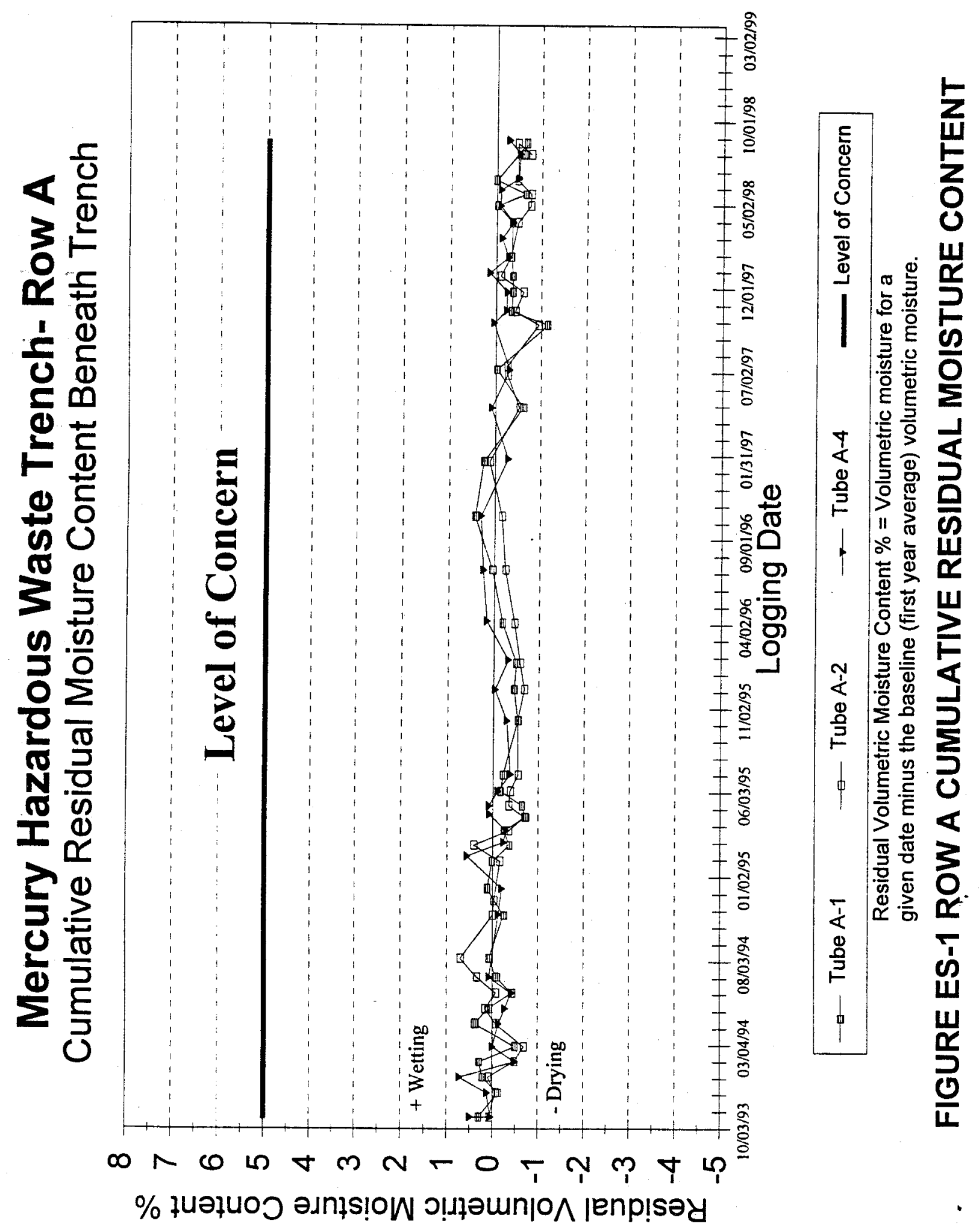

ES-8 


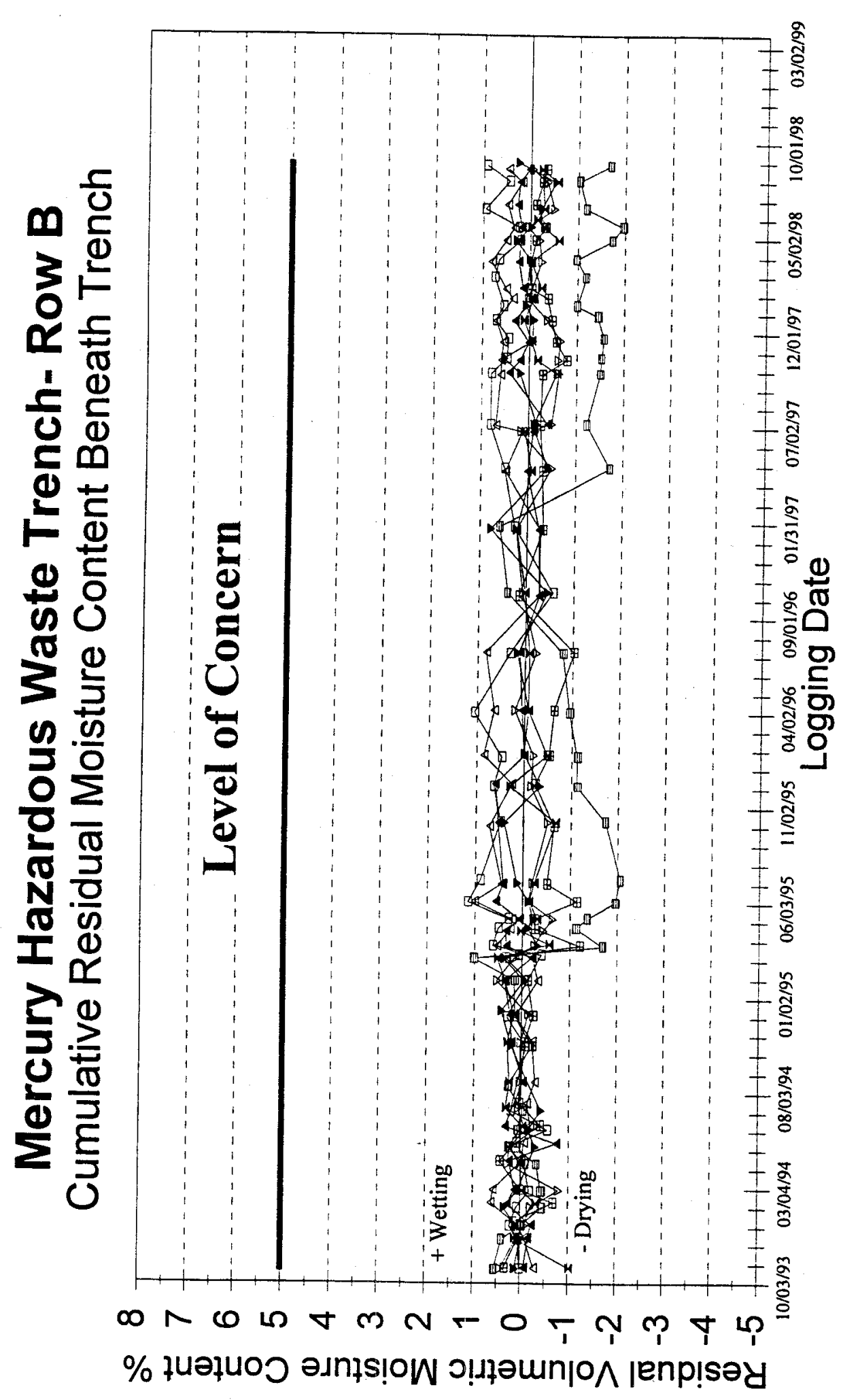

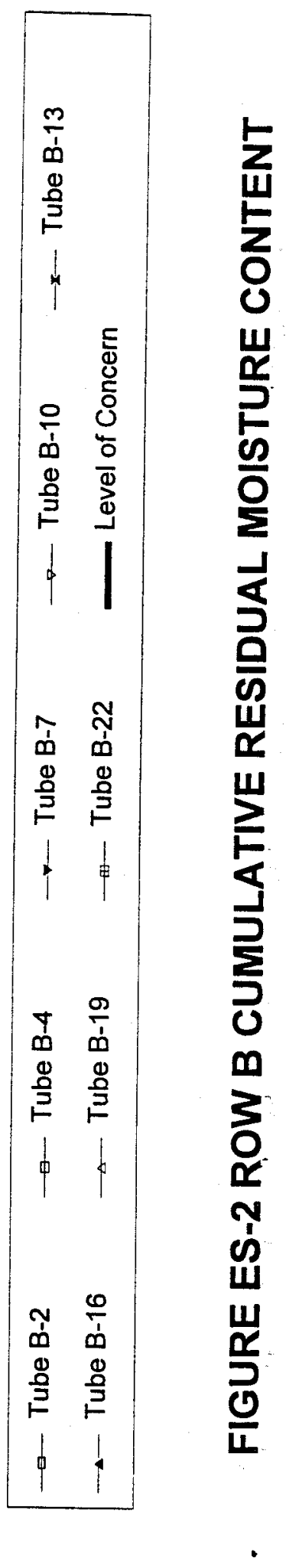

ES-9 


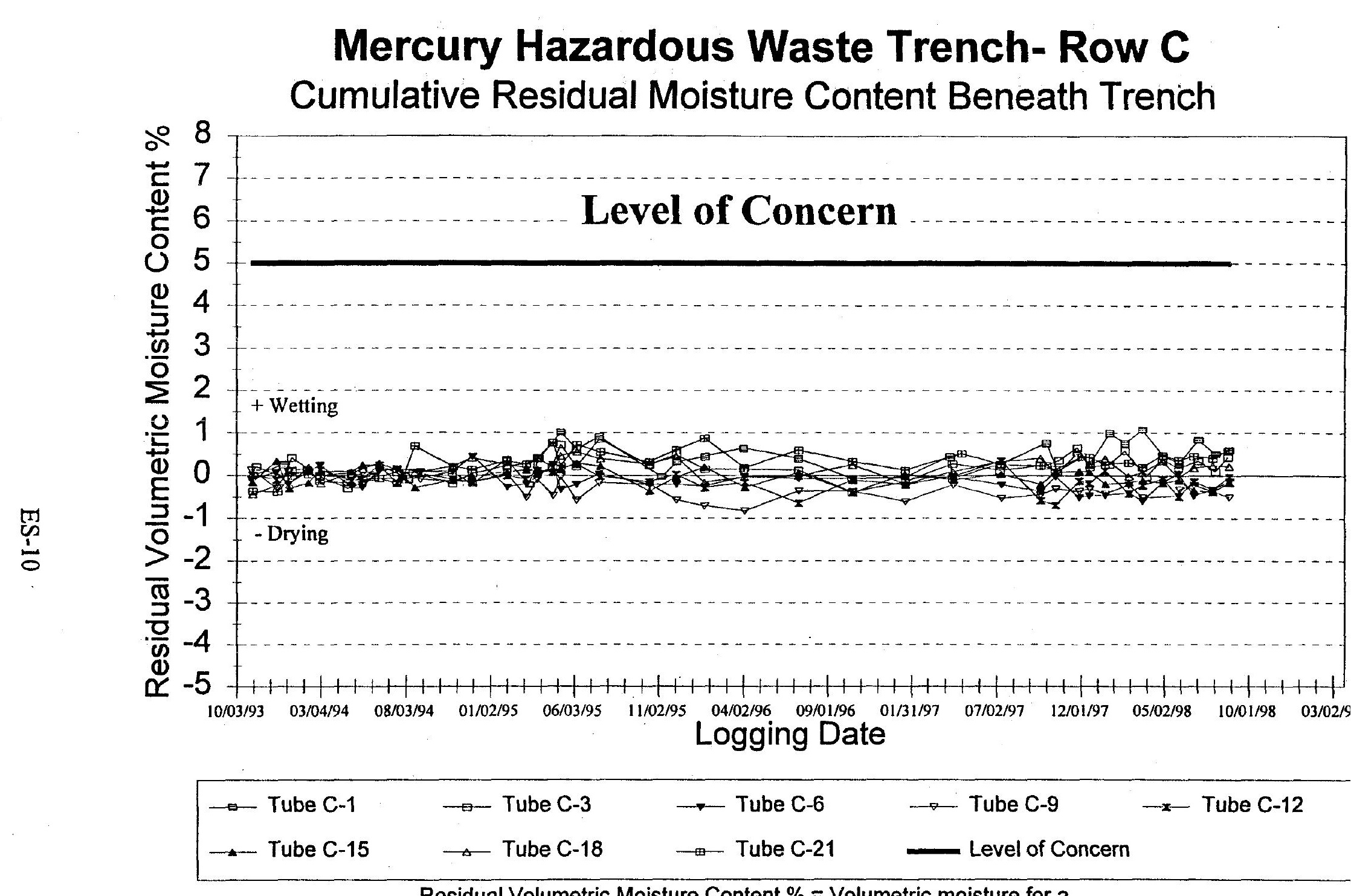

Residual Volumetric Moisture Content $\%=$ Volumetric moisture for a given date minus the baseline (first year average) volumetric moisture.

- FIGURE ES-3 ROW C CUMULATIVE RESIDUAL MOISTURE CONTENT 


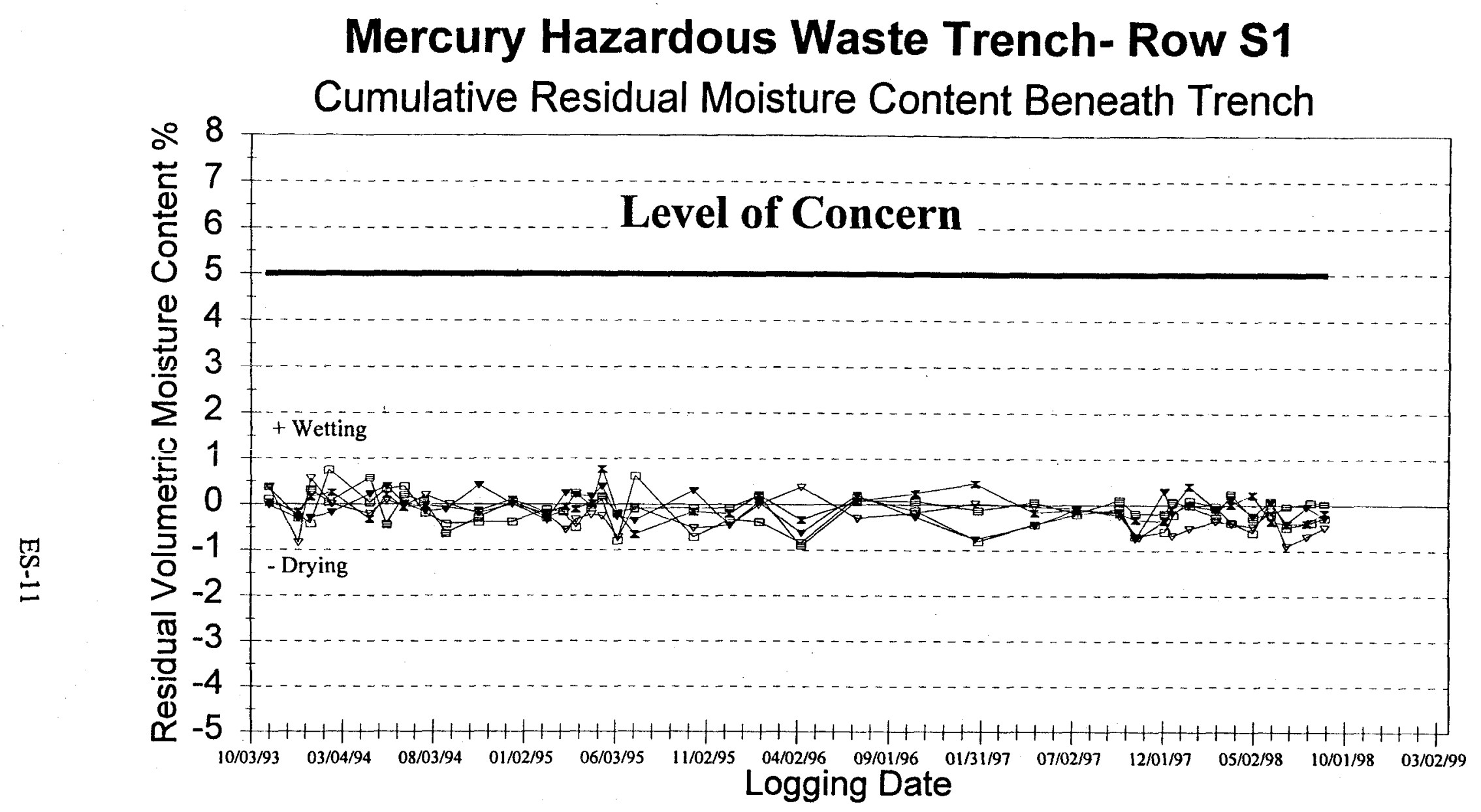

$\begin{array}{lll}\rightarrow \text { Tube S1-2 } & \rightarrow \text { Tube S1-5 } & \rightarrow \text { Tube S1-8 } \\ \rightarrow \text { Tube S1-11 } & \rightarrow \text { Tube S1-14 Level of Concern }\end{array}$

Residual Volumetric Moisture Content $\%=$ Volumetric moisture for a given date minus the baseline (first year average) volumetric moisture. 


\section{Mercury Hazardous Waste Trench- Row S2}

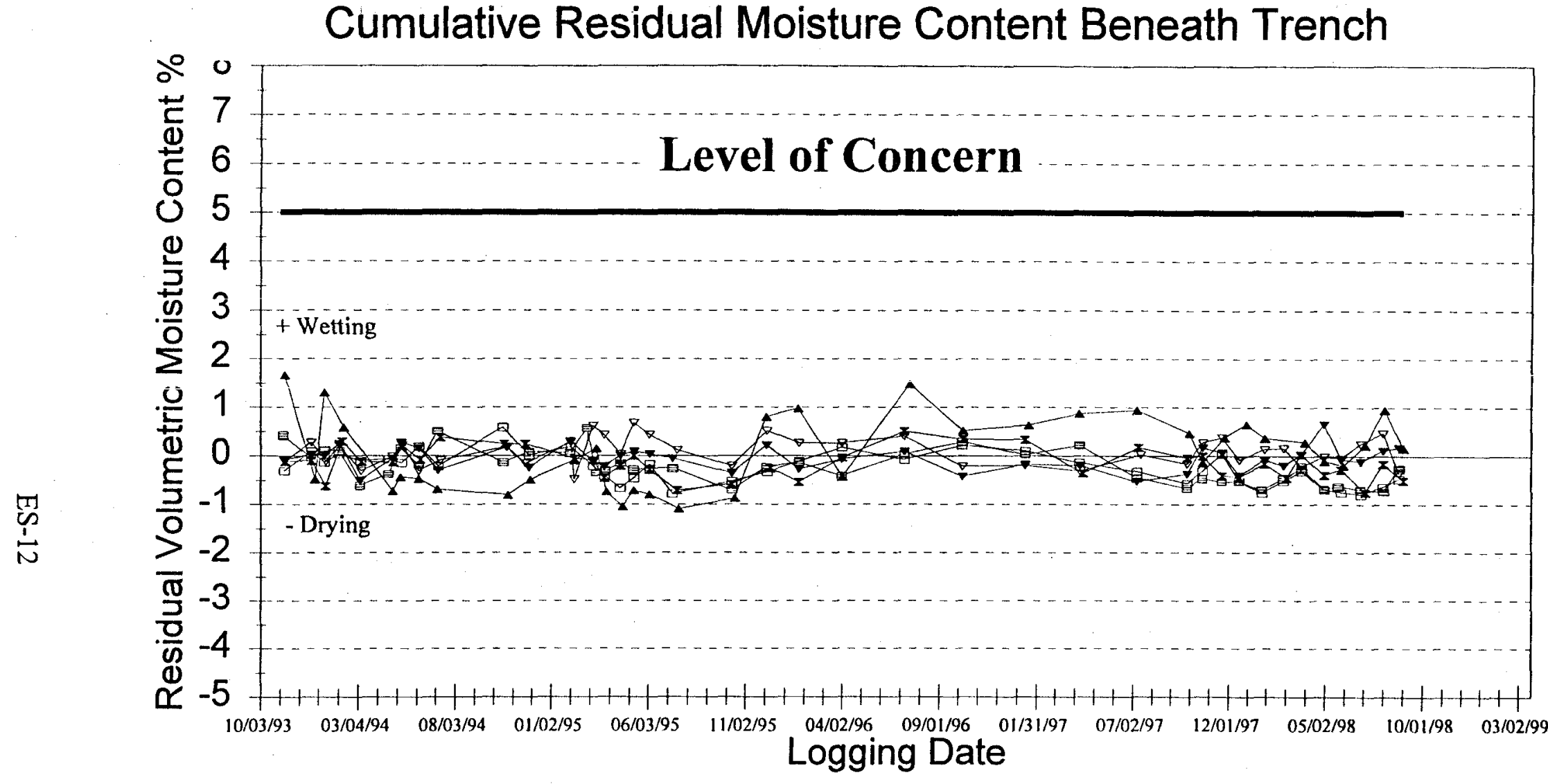

$\begin{array}{|lll|}\rightarrow-\text { Tube S2-2 } & \rightarrow-\text { Tube S2-5 } & \rightarrow \text { Tube S2-8 } \\ \rightarrow-\text { Tube S2-14 } & \rightarrow \text { Tube V-1 } & \rightarrow \text { Tube S2-11 }\end{array}$

Residual Volumetric Moisture Content $\%=$ Volumetric moisture for a given date minus the baseline (first year average) volumetric moisture.

- FIGURE ES-5 ROW S2,V1 CUMULATIVE RESIDUAL MOISTURE CONTENT 


\subsection{INTRODUCTION}

\subsection{SCOPE AND OBJECTTVE}

This annual Neutron Soil Moisture Monitoring report provides an analysis and summary for site inspections, meteorological information, and neutron soil moisture monitoring data obtained at the Area 23 Hazardous Waste Landfill, Corrective Action Unit (CAU) 112, located in Mercury, Nevada. This report covers the period October 1997 through October 1998.

Inspections of the Area 23 Hazardous Waste Landfill are conducted to determine and document the physical condition of the covers, facilities, and any unusual conditions that could impact the proper operation of the landfill closure.

The objective of the neutron logging program is to monitor the stability in soil moisture conditions beneath the trenches and detect changes that may be indicative of moisture entering through the landfill cover and therefore producing leachate movement beneath the landfill.

\subsection{SITE HISTORY}

A summary of significant events regarding the closure of the Area 23 Hazardous Waste Trenches can be found in Table 1 .

The Area 23 Landfill (Figure 1) has been in operation for approximately 25 years. During that time, various trenches were excavated and used for the disposal of sewage from portable toilets, sanitary waste, aerosol cans, wood waste, non-infectious medical waste, and hazardous wastes. All the trenches were originally covered with a soil cover. A portion of the landfill (Figure 2) was closed under the Resource Conservation and Recovery Act (RCRA) using an engineered soil/synthetic geomembrane cover. The cover was completed in August 1993. Soil moisture monitoring began in October 1993.

The unit consists of two covers, a smaller cover for Trench $\mathrm{A}$, and a larger, separate cover for Trenches B, C, S-1, and S-2. Hazardous Waste Trench A is greater than 51.8 meters (m)

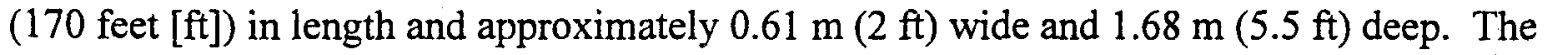
northern portion of this trench was identified as containing hazardous waste and is approximately $16.76 \mathrm{~m}(55 \mathrm{ft})$ in length, with the rernaining portions filled with sanitary wastes. The southern extent of the trench (containing sanitary waste) is not known (U.S. Department of Energy [DOE], 1992). 


\section{TABLE 1. CHRONOLOGY OF SIGNIFICANT EVENTS - AREA 23 HAZARDOUS WASTE TRENCHES}

\begin{tabular}{|c|c|}
\hline DATE & SIGNIFICANT EVENTS \\
\hline 1988 & Closure Plan for the Nevada Test Site; Earth Technology Corporation, 1988 \\
\hline \multirow[t]{2}{*}{1990} & $\begin{array}{l}\text { Letter to DOE/NV from the Nevada Division of Environmental Protection (NDEP), Effective Date of } \\
\text { Closure for Area } 23 \text { Landfill, May 17, } 1990\end{array}$ \\
\hline & Exploratory Excavation at the Area 23 Landfill, Nevada Test Site, Mercury, Nevada; Issued 1990 \\
\hline 1991 & $\begin{array}{l}\text { Excavation activities occurred during the period October } 14,1991 \text { to November } 21,1991 \text {. Four } \\
\text { exploratory trenches and potholes were used to identify waste materials and locations. }\end{array}$ \\
\hline \multirow{2}{*}{1992} & $\begin{array}{l}\text { Area } 23 \text { Exploratory Excavation Activities to Identify the Location of Hazardous Waste Trenches (Phase } 1 \\
\text { Report) Vols } 1 \text { and 2; issued April } 1992\end{array}$ \\
\hline & $\begin{array}{l}\text { Four small exploratory trenches excavated for sampling. Activities occurred between June } 29 \text {, through } \\
\text { July } 1,1992 \text {. }\end{array}$ \\
\hline \multirow{6}{*}{1993} & Amended Closure Plan Area 23 Landfill Hazardous Waste Trenches (Phase 2 Report); issued April 1993. \\
\hline & Closure of the hazardous waste trenches March 25 through August 26, 1993 \\
\hline & $\begin{array}{l}79 \text { neutron access tubes were installed along the periphery and through the cover of the two landfills } \\
\text { between March } 25 \text { to May 18, 1993. Approximately 5,200 feet of casing was installed. }\end{array}$ \\
\hline & Post-closure monitoring began in October 1993. \\
\hline & Certification and Closure Report Area 23 Landfill Hazardous Waste Trenches; issued October 1993. \\
\hline & $\begin{array}{l}\text { First Quarterly Report RCRA Post Closure Monitoring and Inspection, Mercury Hazardous Waste } \\
\text { Trenches; report issued April } 1993 .\end{array}$ \\
\hline \multirow{3}{*}{1994} & $\begin{array}{l}\text { Second Quarterly Report RCRA Post Closure Monitoring and Inspection, Mercury Hazardous Waste } \\
\text { Trenches; report issued May } 1994 .\end{array}$ \\
\hline & $\begin{array}{l}\text { Third Ouarterly Report RCRA Post Closure Monitoring and Inspection, Mercury Hazardous Waste } \\
\text { Trenches; report issued August } 1994 .\end{array}$ \\
\hline & $\begin{array}{l}\text { Revised Post-Closure Soil Moisture Monitoring Schedule for Closed Area } 23 \text { Landfill Hazardous Waste } \\
\text { Trenches; December 21, } 1994 \text { Letter from P. J. Liebendorfer to D. R. Elle. }\end{array}$ \\
\hline
\end{tabular}




\begin{tabular}{|c|c|}
\hline DATE & SIGNIFICANT EVENTS \\
\hline \multirow[b]{3}{*}{1995} & RCRA Part B permit number NEV HW009 became effective May 1, 1995 \\
\hline & $\begin{array}{l}\text { Fourth Quarterly Report RCRA Post Closure Monitoring and Inspection. Mercury Hazardous Waste } \\
\text { Trenches; report issued January } 1995 .\end{array}$ \\
\hline & $\begin{array}{l}\text { In September 1995, NDEP requested that a uniform reporting format and specific changes in the } \\
\text { presentation of the soil moisture data be developed. In subsequent meetings between DOE, NDEP, and } \\
\text { Reynolds Electrical \& Engineering Co., Inc. (REECo) (now Bechtel Nevada [BN]), the compliance } \\
\text { criteria was modified placing the point of compliance beneath each respective hazardous waste trench. }\end{array}$ \\
\hline \multirow{2}{*}{1996} & $\begin{array}{l}\text { Annual Report RCRA Post-Closure Monitoring and Inspection, Mercury Hazardous Waste Trenches } \\
\text { Volume I and II December } 1994 \text { - December 1995; report issued March } 1996 .\end{array}$ \\
\hline & $\begin{array}{l}\text { A request was submitted to NDEP in December } 1996 \text { requesting that the interim monitoring criteria be } \\
\text { formally adopted. }\end{array}$ \\
\hline \multirow{3}{*}{1997} & $\begin{array}{l}\text { Annual Report RCRA Post-Closure Monitoring and Inspection. Mercury Hazardous Waste Trenches } \\
\text { Volume I and II; for the Period October 1995 - October 1996; report issued January } 1997 .\end{array}$ \\
\hline & $\begin{array}{l}\text { NDEP approved the request to adopt the proposed monitoring criteria on February } 10,1997 \text {. The changes } \\
\text { were incorporated into the Permit (NEV HW009) as a Class } 1 \text { modification as per Appendix I to } 40 \text { Code } \\
\text { of Federal Regulations (CFR) } \$ 270.42\end{array}$ \\
\hline & $\begin{array}{l}\text { Maintenance and corrective actions to address the ponding and leakage problems associated with the } \\
\text { access tubes located along the margins of the cover was started September } 18 \text { and completed October } 2 \text {, } \\
\text { 1997. Soils were excavated around the well-head protection blocks, a bentonite layer was emplaced, and } \\
\text { the soils recompacted and graded to prevent run-on and ponded water from infiltrating down along the } \\
\text { access tubes. The soils along the toe of the closure cover were regraded to provide improved drainage. }\end{array}$ \\
\hline $1993-1998$ & No infiltration has been detected through the covers and the waste remains dry and stable. \\
\hline
\end{tabular}




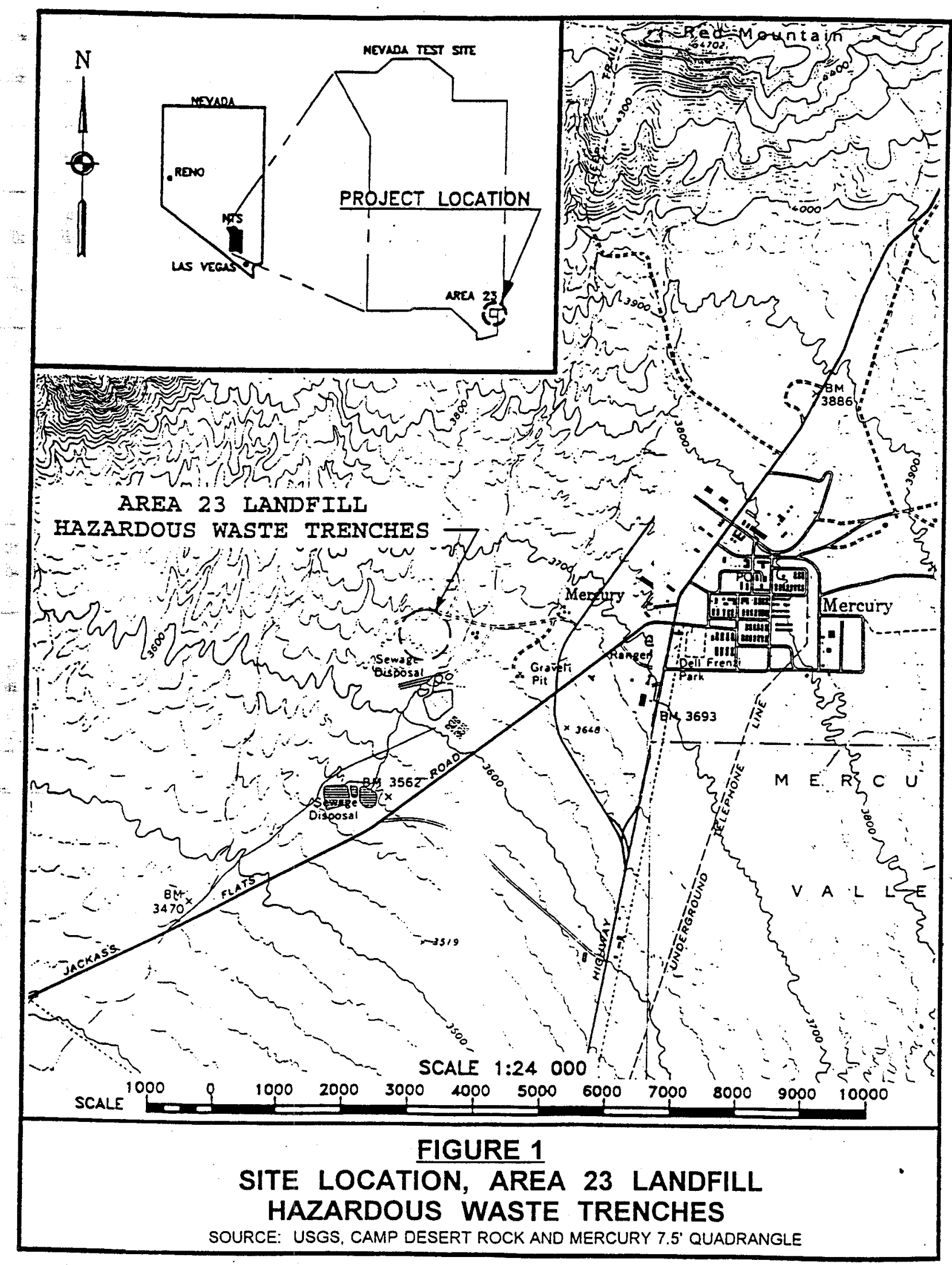




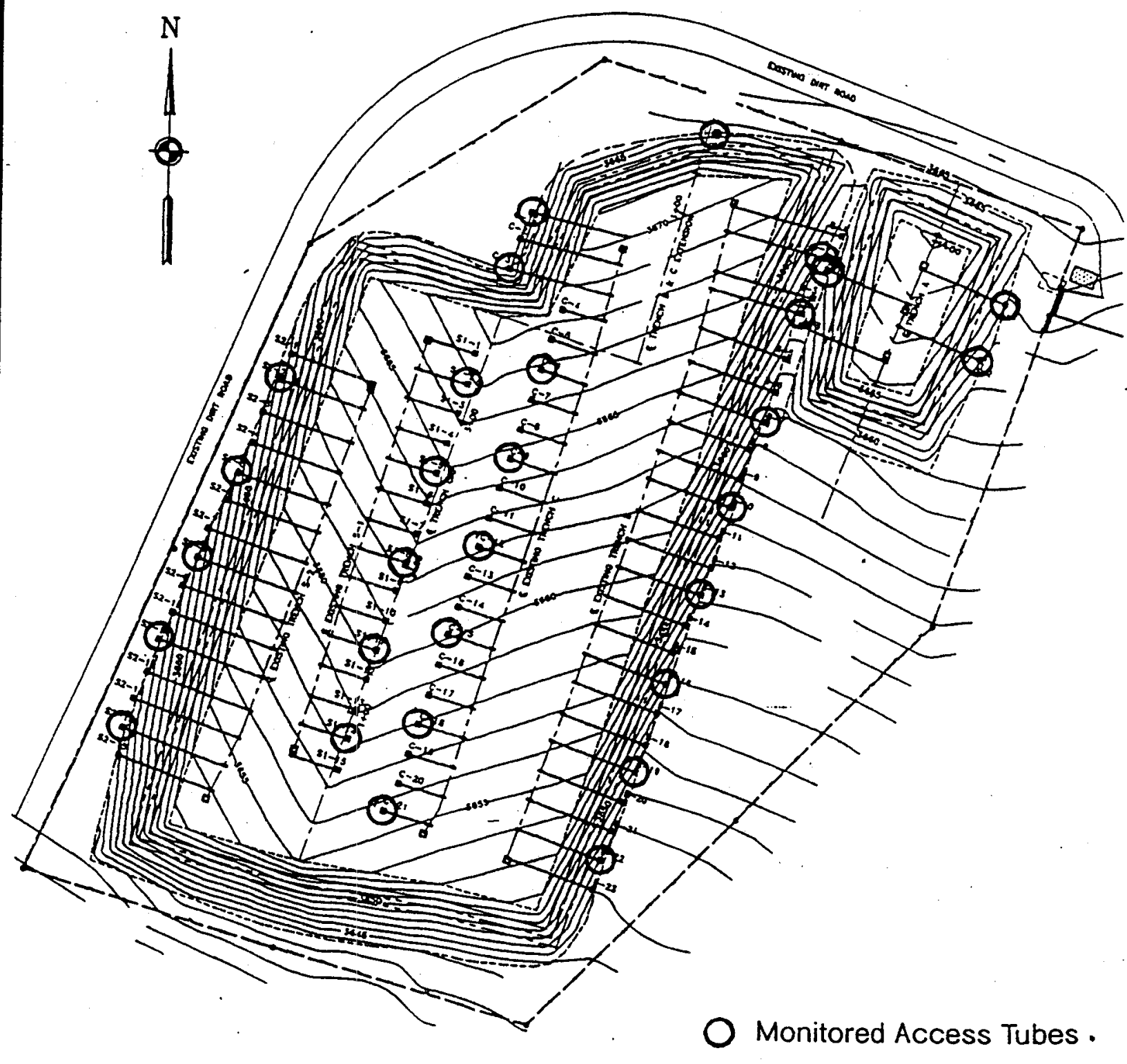


Trench B is $135 \mathrm{~m}$ ( $442 \mathrm{ft}$ ) long, 0.61 to $0.91 \mathrm{~m}$ ( 2 to $3 \mathrm{ft}$ ) wide, and 1.68 to $2.13 \mathrm{~m}$ ( 5.5 to $7 \mathrm{ft}$ ) deep. Monuments for Trench B were labeled "Medical Waste" and "Sanitary Waste" on the north end of the trench. Medical waste was found overlying hazardous waste on the north end of the trench during characterization studies (DOE, 1992).

Trench $\mathrm{C}$ is $114.6 \mathrm{~m}$ ( $376 \mathrm{ft})$ long, to $0.91 \mathrm{~m} \mathrm{(2} \mathrm{to} 3 \mathrm{ft})$ wide and 0.15 to $2.44 \mathrm{~m}(0.5$ to $8 \mathrm{ft})$ deep. Concrete monuments on the north end of Trench C were labeled "Sanitary Waste," "Aerosol Cans," and "Hazardous Waste" (DOE, 1992).

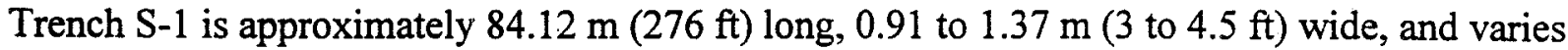
from 1.52 to $3.96 \mathrm{~m}$ ( 5 to $13 \mathrm{ft}$ ) deep. Trench S-1 was marked with a concrete monument labeled "Sewage" on the north end of the trench and unmarked on the south end (DOE, 1992).

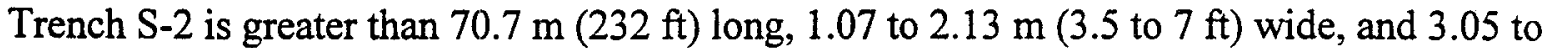
$4.27 \mathrm{~m}$ (10 to $14 \mathrm{ft})$ in depth. Trench S-2 was marked with a concrete monument as "Sewage" on the north end, but unmarked on the southern end. The southern end was not determined in exploratory excavations (DOE, 1992).

Waste inventories (Earth Technology, 1988) indicate that approximately 62,459 liters (L) (16,500 gallons [gal]) of hazardous wastes were disposed of in trenches $\mathrm{A}, \mathrm{B}$, and $\mathrm{C}$ at the Area 23 Landfill. This waste includes $37,854 \mathrm{~L}(10,000 \mathrm{gal})$ of corrosive material and 20,820 L (5,500 gal) of ignitable materials. Approximately 13,249 L (3,500 gal) of miscellaneous nonhazardous chemicals were also disposed of in the trenches. Waste inventory data are not available for Trenches S-1 and S-2. Waste oil was observed in both trenches during exploratory excavation of these trenches (DOE, 1992).

\subsection{SITE GEOLOGY AND HYDROLOGY}

The Area 23 Hazardous Waste Landfill is located approximately 1.21 kilometers $(\mathrm{km})$ (3/4 mile [mi]) west of Mercury, Nevada, on the Nevada Test Site (NTS), Nye County, Nevada (Figure 1). The site lies within the Mercury Valley and is underlain by unconsolidated alluvium derived from the Specter Range, Red Mountain, and Mercury Ranges. These ranges consist of Paleozoic carbonates and quartzites. The near surface alluvium is composed of silty sands containing abundant gravel and cobbles. Some boulders, up to $0.91 \mathrm{~m}(3 \mathrm{ft})$ in diameter, have been noted. Localized caliche development is present in the near surface and is observed in the boreholes used to emplace the neutron access tubes. 
The NTS is underlain by the Ash Meadows Aquifer. It is an interbasin flow system above a carbonate basement rock and is relatively independent of the topographic boundaries. The Ash Meadows Aquifer beneath the Area 23 Landfill occupies the lower Cenozoic alluvial fill with the ground water table estimated at about 244 to $335 \mathrm{~m}$ ( 800 to $1,100 \mathrm{ft}$ ) below the ground surface with flow to the southwest (Winograd et al, 1975). The nearest water well is located approximately $5.63 \mathrm{~km}(3.5 \mathrm{mi})$ to the southwest at Army Well Number 1. A ground water monitoring well for the Area 23 Sewage Lagoons was drilled approximately $0.4 \mathrm{~km}(0.25 \mathrm{mi})$ south of the trenches. This well was completed in March 1996 to a depth about $350 \mathrm{~m}(1,300 \mathrm{ft})$. Groundwater was intercepted at approximately $396 \mathrm{~m}(1,300 \mathrm{ft})$ under $45 \mathrm{~m}(150 \mathrm{ft})$ of head. Groundwater level in the well is currently in equilibrium at approximately $350 \mathrm{~m}(1,150 \mathrm{ft})$.

The longest continuous rainfall records available for the NTS were recorded in Area 5 over a 31-year period. The average rainfall was 12.45 centimeters $(\mathrm{cm})$ (4.9 inches [in]), while the annual total ranged between a minimum of $2.79 \mathrm{~cm}(1.1 \mathrm{in})$ to a maximum of $23.42 \mathrm{~cm}(9.22 \mathrm{in})$. Estimates of Potential Evapotranspiration $\left(\mathrm{ET}_{\mathrm{POT}}\right)$ obtained from characterization studies in Area 5 indicate an $\mathrm{ET}_{\mathrm{POT}}$ of about 157.5 centimeters/year (62 inches/year), which is significantly higher than the mean annual precipitation (DOE, 1995b). 


\subsection{REGULATORY CRITERIA}

\subsection{BACKGROUND}

The Amended Closure Plan (DOE, 1993) included a proposal that the level of concern triggering notification to the NDEP would be based on the hydraulic conductivity of the soils beneath the trenches. A hydraulic conductivity vs. saturation curve was proposed to determine the moisture content at which the soils had a hydraulic conductivity of $1 \times 10^{-7} \mathrm{~cm} / \mathrm{second}(\mathrm{sec})$ $\left(3.94 \times 10^{-8} \mathrm{in} / \mathrm{sec}\right)$, which is the U.S. Environmental Protection Agency criteria for clay liners. For soils in Area 5, this value was reached for a measured water content of 14 percent. This value was chosen for the Area 23 Hazardous Waste Trenches as the action threshold above which water movement may occur. The reporting criteria to NDEP as stated in the Amended Closure Plan (DOE, 1993) was:

- "If the measured water content of 14 percent is exceeded in two consecutive monthly measurements, or obvious damage occurs to the cover....action would be taken."

Once the closure drilling and construction program was completed and the first neutron logs were obtained, it was found that the fundamental assumption of homogeneous soils similar to those in Area 5 was incorrect. The soils beneath the site are heterogeneous and inter-fingered with caliche lenses producing an environment that is not hydrologically similar to that of Area 5 . Drill logs and neutron logs indicate that it would be extremely difficult, if not impossible, to use the hydraulic conductivity method originally proposed due to lithologic variability of the alluvium. Doing so would lead to numerous false positives and negatives.

Instead, it was proposed in the first quarterly neutron logging report (DOE, 1994a) to use the traditional method of a time series analysis to monitor and report wetting and drying changes over time. For the first year (baseline), Residual Volumetric Moisture Content (RVMC) was calculated monthly by the difference between the current month and the previous month's moisture content at each depth interval. The observation of a progressive wetting front (one that continues for two consecutive monthly measurements) and is greater than 5 percent RVMC would be tracked and reported to NDEP in the quarterly reports. Positioning errors of the neutron probe (tool), which could incorrectly infer changes in moisture content, are excluded. A further set of actions is necessary to determine the cause for progressive wetting fronts if observed in two consecutive months and infiltrating deeper than $4.27 \mathrm{~m}(14 \mathrm{ft})$. 
Monitoring Report CAU 112

Section:REGULATORY

Revision: 0

Date: $2 / 4 / 1999$

The 5 percent RVMC criteria was based on data observed on other neutron logs and infiltration studies conducted at comparable sites on the NTS. Changes of up to 15 percent RVMC over an interval of 0.9 to $1.5 \mathrm{~m} \mathrm{(} 3$ to $5 \mathrm{ft}$ ) have been observed in soil covers from rainfall events in the lower elevations of Area 5. Considering that the neutron probe has a repeatability of \pm 1 percent RVMC due to system noise, a level of concern of 5 percent RVMC was chosen as a conservative initial action level for compliance reporting.

The first-year data set (1994) was conducted on a monthly basis to obtain baseline data (DOE, $1994 a, b, c$ and 1995a).

Based on the data collected over the first year, the monitoring program was modified by the NDEP and DOE in late 1994 (NDEP, 1994). The following changes were made:

- Conduct moisture monitoring and liner inspections quarterly;

- Monitor only 30 neutron access tubes rather than 72 tubes. Table 2 provides the tubes selected for monitoring;

- Report monthly precipitation data to NDEP annually;

- If precipitation exceeds $2.54 \mathrm{~cm}$ (1.0 in) in any 30-day period, or $2.54 \mathrm{~cm}(1.0 \mathrm{in})$ in any 6-hour (hr) period, then monitoring will be conducted within two weeks of the end of the 30-day period and monthly, thereafter, for one quarter;

- After two years of post-closure monitoring, during which time the annual precipitation was average or above average, the DOE may submit a request to NDEP to reevaluate the monitoring/inspection schedule for further reductions.

The NDEP requested that a uniform reporting format and specific changes in the presentation of the soil moisture data be developed in September 1995. The emphasis is to produce a simplified presentation of trends to observe whether the compliance level is being exceeded. The compliance criteria was modified in subsequent meetings between DOE, NDEP, and REECo (now BN) placing the "point of compliance" beneath each respective hazardous waste trench. The neutron access tubes were installed with the bottom of the access tube at a point directly beneath each respective trench. The depth from the original grade of the landfill (before the installation of the cover) to this point is provided in Appendix A. To avoid measurement errors associated with geometry problems at the end of the access tube, a point $0.91 \mathrm{~m}(3 \mathrm{ft})$ from the bottom of the access tube was selected as the measurement point. 
A formal change of the compliance criteria for the Unit NTS RCRA Part B Permit was submitted to NDEP in December 1996 requesting adoptation of the interim monitoring criteria. This request was approved on Feburary 10,1997. The changes were incorporated into the Part $B$ Permit (NEV HW009) as a Class 1 Modification as per Appendix I to 40 CFR $\$ 270.42$.

TABLE 2. NEUTRON ACCESS TUBES MONITORED AT THE AREA 23 HAZARDOUS WASTE LANDFILL RCRA UNIT ${ }^{A}$

\begin{tabular}{|l|l|l|l|l|}
\hline TRENCH A & TRENCH B & TRENCH C & TRENCH S-1 & TRENCH S-2 \\
\hline \hline A-1 & B-2 & C-1 & S1-2 & S2-2 \\
\hline A-2 & B-4 & C-3 & S1-5 & S2-5 \\
\hline A-4 & B-7 & C-6 & S1-8 & S2-8 \\
\hline & B-10 & C-9 & S1-11 & S2-11 \\
\hline & B-13 & C-12 & S1-14 & S2-14 \\
\hline & B-16 & C-15 & & \\
\hline & B-19 & C-18 & & \\
\hline & B-22 & C-21 & & \\
\hline
\end{tabular}

${ }^{\text {A }}$ Background control well V-1 is also monitored

\subsection{SITE INSPECTION COMPLIANCE CRITERIA}

Visual inspections and photographs of the Area 23 Hazardous Waste Landfill RCRA Trenches are done on a quarterly basis and are reported in the annual report. Monthly inspections are done if Precipitation Action Levels are exceeded (see Section 2.3). Inspections consist of the following observations:

- Condition of the gate (locked, open);

- Condition of signs (faded, missing, detached); 
- Problems with fencing (breaks, needed repairs);

- Erosion of two overland flow diversion trenches;

- Condition of two covers (subsidence, erosion, excessive vegetation);

- Deterioration of the neutron access tube concrete pads, covers; and

- Unusual activity that could impact the proper operation of the covers.

\subsection{SOIL MOISTURE MONITORING COMPLIANCE CRITERIA}

A formal change of the compliance criteria for the Unit NTS RCRA Part B Permit was submitted to NDEP in December 1996 and was approved on Feburary 10, 1997. The changes were incorporated into the Part B Permit (NEV HW009) as a Class 1 Modification as per Appendix I to 40 CFR $\$ 270.42$.

Notification to NDEP is required if RVMC above 5 percent (relative to baseline conditions) are observed and confirmed in two consecutive monitoring periods, at a point directly beneath each respective hazardous waste trench. The NDEP must be notified within seven days of determination of a valid trend. A preliminary written assessment detailing recommendations to determine the nature, cause, and action to be taken is to be submitted to NDEP for concurrence within 30 days of the notification.

Soil moisture monitoring is accomplished using a calibrated neutron tool. Thirty neutron access tubes are logged at $1 \mathrm{ft}$ intervals. The data are collected based on the calendar year and analyzed quarterly (January, April, July, and October), with an annual report issued by January $31^{\text {st }}$ of the following year. Data analysis is based on the calculated residual moisture content obtained by subtracting the first-year average soil moisture content (baseline) from the soil moisture content for each monitoring period on a depth basis.

Neutron logging operations will be according to the following guidance and notification criteria based on discussions with the DOE and NDEP:

- Report monthly precipitation data to NDEP annually;

- If precipitation exceeds $2.54 \mathrm{~cm}$ (1.0 in) in any 30-day period, or $2.54 \mathrm{~cm}(1.0 \mathrm{in})$ in any 6-hr period, then monitoring will be conducted within two weeks of the end of the 30-day 
period and monthly, thereafter, for one quarter;

- Wetting events with greater than 5 percent RVMC, showing a progressive change in either moisture content or movement, will be tracked and reported on a quarterly basis. Events that occur as single point anomalies (at one depth) that are attributable to logging tool positioning errors will be excluded.

- The NDEP is to be notified if the RVMC is confirmed to be above 5 percent relative to baseline conditions for two consecutive monitoring periods. The point of compliance is the point directly beneath each respective hazardous waste trench. Notification of NDEP will be within seven days of the confirmation. Within 30 days of the notification, a preliminary written assessment detailing recommendations to determine the nature, cause, and action to be taken will be submitted to NDEP for concurrence. 
THIS PAGE INTENTIONALLY LEFT BLANK 


\subsection{SITE INSPECTIONS AND ANNUAL SUBSIDENCE SURVEY}

\subsection{INTRODUCTION}

The two covers and the surrounding area are thoroughly examined each quarter. The inspection checklists for the reporting period are found in Appendix B. Inspections consist of criteria identified in Section 2.3.

\subsection{FINDINGS FROM THE QUARTERLY INSPECTIONS}

\subsubsection{Fourth Quarter Inspection (October-December 1997)}

Monthly inspections were completed on October 28, November 24, and December 22, 1997. Over $2.54 \mathrm{~cm}$ ( $1.0 \mathrm{in})$ of rain fell on the site in a 30-day period as of September 3. Therefore, monthly neutron logging was required at the site for this quarter. Two signs were down and damaged, but all others were in good condition. Even without the damaged signs, the site was well marked. Only minor vegetation was present on the landfill cover.

\subsubsection{First Quarter Inspection (January-March 1998)}

Monthly inspections were completed on January 21, February 19, and March 26, 1998. Over $2.54 \mathrm{~cm}$ (1.0 in) of rain fell on the site in a 30-day period as of December 6, 1997. Therefore, monthly neutron logging was required at the site for this quarter. Damaged signs were replaced on January 27,1998 . On January 29, 1998, it was discovered that the CAU number for the site was incorrect on the inspection forms. The forms were changed from CAU 114 to CAU 112 and were correct as of the February inspections.

As of February 23,1998, $10.8 \mathrm{~cm}^{-}$(4.24 in) of rain had fallen in a 30-day period. During a heavy rainfall on February 17, standing water was diverted away from some of the access tubes. Additional repair of the access was determined to be necessary. Preliminary review of the February soil moisture data for access tube S2-14 indicated that it may not have been thoroughly sealed during the previous summer's maintenance on the covers. It was determined that an additional evaluation of the situation was necessary.

Inspections during this quarter indicated that the signs, fencing, and the site in general, were in good condition. 


\subsubsection{Second Quarter Inspection (April-June 1998)}

Monthly inspections were completed on April 22, May 20, and June 30,1998. Over $10.2 \mathrm{~cm}$ ( 4 in) of rain fell on the site in February and over $2.54 \mathrm{~cm}(1.0 \mathrm{in})$ fell on the site in March. Therefore, monthly neutron logging was required at the site for this quarter. Maintenance of several neutron access tubes was done on April 28-29, 1998. The work was checked during the next heavy rainfall. During the June inspection, erosion was noted around several of the neutron access tubes. A follow-up inspection by the task manager determined that significant erosion had not taken place.

Inspections during this quarter indicated that the signs, fencing, and the site in general, were in good condition.

\subsubsection{Third Quarter Inspection (July-September 1998)}

Monthly inspections were completed on July 30, August 19, and September 17, 1998. The total rainfall as of June 16, 1998 was 1.84 in. Therefore, monthly neutron logging was required at the site for this quarter.

A damaged sign was noted during the August inspections. However, even with the damaged sign, the site was still well marked. Test Geoprobe ${ }^{\otimes}$ holes were placed near access tube B-13 on September 8, 1998. Preliminary results indicated that void spaces underlie the ground surface in that area. The voids are believed to be entrained within an old nonhazardous landfill and are found approximately $1.2 \mathrm{~m}(4 \mathrm{ft})$ below grade. These waste trenches are not the hazardous waste trenches closed under the Environmental Restoration Project. Additional investigations will be done.

Inspections during this quarter indicated that the signs, fencing, and the site in general, were in good condition.

\subsubsection{Fourth Quarter Inspection (October 1998)}

The monthly inspection was completed on October 21, 1998. The 30-day cumulative rainfall was $2.87 \mathrm{~cm}$ (1.13 in) in August. Therefore, monthly neutron logging was required at the site for this quarter. A few signs were loose and were repaired the week following the inspection. The rest of the site was in good condition. 
Monitoring Report CAU 112

Section: SITE SURVEY

Revision: 0

Date: $2 / 4 / 1999$

\subsection{ANNUAL SUBSIDENCE SURVEY}

The elevation of the subsidence markers were confirmed with an elevation survey conducted August 1998. There has been no subsidence at any of the markers since monitoring began in August 1993. The survey results are found in Table 3 and the survey plat is located in Appendix C.

TABLE 3. SUBSIDENCE MONUMENT COORDINATES AND ELEVATIONS

\begin{tabular}{|c|c|c|c|c|c|c|c|c|}
\hline \multirow{2}{*}{ \% } & \multicolumn{2}{|c|}{ 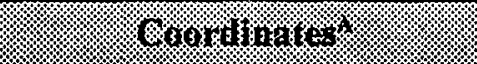 } & \multicolumn{5}{|c|}{ 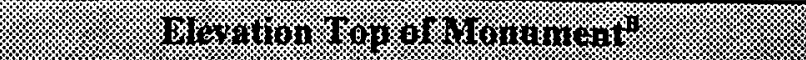 } & \\
\hline & (6) & 6. & 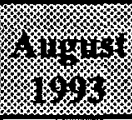 & 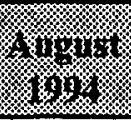 & 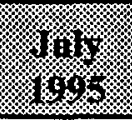 & 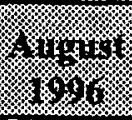 & \% & 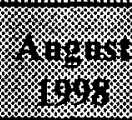 \\
\hline SM-1 & 20380836.722 & 1832371.6774 & 3669.17 & 3669.17 & 3669.17 & 3669.17 & 3669.17 & 3669.174 \\
\hline SM-2 & 20380756.583 & 1832342.1769 & 3666.41 & 3666.41 & 3666.41 & 3666.41 & 3666.41 & 3666.415 \\
\hline SM-3 & 20380845.802 & 1832220.1677 & 3669.31 & 3669.31 & 3669.31 & 3669.31 & 3669.31 & 3669.310 \\
\hline SM-4 & 20380638.070 & 1832176.9730 & 3660.61 & 3660.61 & 3660.61 & 3660.61 & 3660.61 & 3660.617 \\
\hline SM-5 & 20380443.800 & 1832094.8852 & 3653.32 & 3653.32 & 3653.32 & 3653.32 & 3653.32 & 3653.332 \\
\hline SM-6 & 20380539.981 & 1832035.1841 & 3658.52 & 3658.52 & 3658.52 & 3658.52 & 3658.52 & 3658.526 \\
\hline SM-7 & 20380692.893 & 1832079.4908 & 3664.49 & 3664.49 & 3664.49 & 3664.49 & 3664.49 & 3664.499 \\
\hline SM-8 & 20380783.752 & 1832030.6240 & 3665.65 & 3665.65 & 3665.65 & 3665.65 & 3665.65 & 3665.652 \\
\hline SM-9 & 20380638.535 & 1831963.6795 & 3659.41 & 3659.41 & 3659.41 & 3659.41 & 3659.41 & 3659.412 \\
\hline SM-10 & 20380478.713 & 1831927.2693 & 3654.23 & 3654.23 & 3654.23 & 3654.23 & 3654.23 & 3654.235 \\
\hline
\end{tabular}

A All coordinates based on the Nevada State Plane Grid - Central Zone - North American Datum of 1983 in feet.

${ }^{B}$ All elevations based on the North American Vertical Datum of 1929 in feet. 
Monitoring Report CAU 112

Section: SITE SURVEY

Revision: 0

Date: $2 / 4 / 1999$

\section{THIS PAGE INTENTIONALLY LEFT BLANK}




\subsection{SOIL MOISTURE MONITORING}

\subsection{INTRODUCTION}

The objective of the Mercury Landfill Hazardous Waste Unit vadose zone monitoring system is to monitor the performance of the two landfill covers, and provide an early warning of the potential for leachate migration from the landfill into the subsurface.

The Area 23 Landfill Hazardous Waste Trenches monitoring system uses a portable neutron moisture logging tool to determine changes in the moisture content in soils surrounding neutron access tubes which extend beneath the landfill. By monitoring changes in soil moisture content it is possible to detect the movement of wetting and drying fronts in the soils beneath the two hazardous waste trenches. The detection of changes in soil moisture content beneath the landfill provides an early warning of the potential movement of leachate from the landfill to the surrounding environment, indicating possible failure of one or both covers.

A total of 79 neutron access tubes have been drilled at approximately 45 degree angles along the margins of the trenches (Figure 2). The access tubes extend to a point directly beneath the trenches and range in length from $11.6 \mathrm{~m}(8.2 \mathrm{~m}$ in vertical depth) to $31.1 \mathrm{~m}(21.9 \mathrm{~m}$ in vertical depth) (38 ft [ $27 \mathrm{ft}$ vertical depth] to $102 \mathrm{ft}$ [ $72 \mathrm{ft}$ vertical depth]). The average length of the tubes is $19.8 \mathrm{~m}$ (14.0 m vertical depth) (65 ft [46 ft vertical depth]).

Two Campbell Pacific Nuclear Hydroprobes (Model 503DR), each containing 50 millicurie ${ }^{241}$ Americium/Beryllium neutron sources, are used to obtain moisture logs in the access tubes. Each logging tool has a published range of $0-32$ percent volumetric moisture content (VMC), with a precision of 0.24 percent at 24 percent VMC at a one-minute count time (CPN, 1984).

Calibration of the neutron logging tools was done in soil pits constructed at the Area 23 Landfill. Six different soil moisture contents were used $(3.4,5.4,7.5,7.8,11.2$, and 12.0 percent VMC). The pits were carefully constructed to match typical near surface in-situ formation conditions and used the same neutron access tubes (approximately $12.7 \mathrm{~cm}$ [5 in] outside-diameter steel ODEX 115 drill casing) as installed beneath the waste trenches.

The calibration procedure and results are discussed in the first quarterly post-closure report (DOE 1994a). Based on the results of the field calibration, the best fit linear regression equation for moisture content of the soil surrounding the neutron access tubes (percent VMC) is given by:

Meter Serial No. 1304: $\% \mathrm{VMC}=3.15 \times 10^{-3} \times($ COUNTS $)-8.06$ 
Meter Serial No. $7074: \quad \% \mathrm{VMC}=4.68 \times 10^{-3} \times($ COUNTS $)-8.36$

where "COUNTS" refers to the raw output from the neutron logging tool.

A coefficient of determination $\left(\mathrm{r}^{2}\right)$ of 0.98 was obtained for both linear regression calibration curves, indicating that the calibration data set and calibration model are in excellent agreement over the range of volumetric water contents represented. These logging tools can provide accurate estimates of the moisture content in typical near-surface geologic materials found at the landfill site.

The repeatability (precision) of the logging tools based on counting statistics can be determined from the approximate 95 percent confidence interval:

Meter Serial No. $1304=\left[3.15 \times 10^{-3}(\right.$ COUNTS $\left.)-8.06\right] \pm 6.17 \times 10^{-3}(\text { COUNTS } / \mathrm{k})^{0.5}$

Meter Serial No. $7074=\left[4.68 \times 10^{-3}(\right.$ COUNTS $\left.)-8.36\right] \pm 9.17 \times 10^{-3}(\text { COUNTS } / \mathrm{k})^{0.5}$

Where:

COUNTS are the instrument recorded and displayed value (actual count normalized to $16 \mathrm{sec})$; and

$\mathrm{k}=$ count time in seconds divided by 16 .

A 16 -sec count time is used at the site resulting in a $\mathrm{k}=1$.

The calibration was conducted over the range of 3 percent to 12 percent VMC. It is valid (provides accurate moisture contents) over the range of moisture contents for soils with approximately the same mineralogy and density as the calibration soil.

Meter 7074 is no longer in use at the Area 23 Hazardous Waste Trenches after being irreparably damaged on January 28, 1997. Meter 1304 is now being used to log all Area 23 access tubes.

Soil moisture monitoring was initially done on a monthly basis for the 79 neutron access tubes over the first year of operation (DOE, 1994a,b,c and 1995a). This data set represents the baseline conditions to which all subsequent data (this report) are compared. After the first year of operation, permission was granted by the NDEP to reduce the number of monitored access tubes from 79 to 30, and begin quarterly monitoring (NDEP, 1994). 


\subsection{OPERATING PROCEDURES}

Neutron logging operations follow industry standard practices and proceedures (CPN, 1984). Logging operations are conducted without a centralizer on the downhole tool as the neutron access tubes are inclined at a 45 degree angle. Field quality control operations require a daily standard count test to be run at the start and end of the day. Failure to pass this statistical test requires stopping operations, notifying the supervisor, and determining the cause.

Neutron logs are obtained by lowering the neutron tool to within $0.61 \mathrm{~m}(2 \mathrm{ft})$ of the bottom of the access tube. A count is obtained using a $16-\mathrm{sec}$ count time at $0.3-\mathrm{m}(1-\mathrm{ft})$ intervals along the length of the access tube. The data are recorded on field log sheets and stored in the data logger of the neutron probe as raw counts. The data logger is then downloaded to an office personnel computer on a daily basis where it is converted into absolute moisture content. Once the data have been converted to absolute moisture contents, they are presented as two graphs: Cumulative Residual Moisture Content and Baseline Difference. These graphs are discussed in Section 4.4.1.

\subsection{PRECIPITATION DATA}

Precipitation data were collected from the National Weather Service Nuclear Support Office's CLINET station "MER" in Mercury, Nevada. This station was relocated from its former location, approximately $1.2 \mathrm{~km}(3 / 4 \mathrm{mi})$ east of the Area 23 Hazardous Waste Trenches, to a location approximately $30 \mathrm{~m}(100 \mathrm{ft})$ northeast of the entrance gate. Precipitation records for this station for the period October 1997 through October 1998 are found in Appendix D and are summarized in Table 4 and Figure 3.

Precipitation for the period October 1997 through October 1998 was $30.78 \mathrm{~cm}$ (12.12 in) (U.S. National Weather Service, 1997). The annual rainfall (January 1998 through January 1999) was $27.66 \mathrm{~cm}$ (11.12 in) which set a new all time record. This record rainfall exceeded the previous record set in 1984 of 10.87 inches. The highest 30 day cumulative rainfall occurred on February 24,1998 , with a total of $11.87 \mathrm{~cm}(4.24 \mathrm{in})$. The heaviest daily precipitation occurred on February 23, 1998, with a total of $4.67 \mathrm{~cm}$ (1.84 in) falling in that 24-hr period. The recorded average annual rainfall for this site from 1971 to January 1999 is $14.96 \mathrm{~cm}$ (5.89 in).

The Part B Permit (NDEP, 1995) specifies that rainfall events that exceed $2.54 \mathrm{~cm}$ (1.0 in) in any 30-day period will require monthly monitoring for one quarter. The action level of $2.54 \mathrm{~cm}$ (1.0 in) in any 30-day period was exceeded on September 3, 1997, with $3.43 \mathrm{~cm}$ (1.35 in) accumulated and has been exceeded in each quarter since. This has required continuous monthly monitoring from September 1997 through November 1998. These weather conditions are the wettest recorded on this and other monitored sites since record keeping had began. 
TABLE 4. PRECIPITATION DATA FOR THE MERCURY NEVADA, METEOROLOGICAL STATION, MER, FOR THE PERIOD NOVEMBER 1, 1997 THROUGH OCTOBER 31, 1998

\begin{tabular}{|c|c|c|c|}
\hline DATE & $\begin{array}{l}\text { PRECIPITATION } \\
\text { inches }\end{array}$ & $\begin{array}{l}\text { MONTHLY } \\
\text { ACCUMULATION } \\
\text { inches }\end{array}$ & $\begin{array}{l}\text { 30-DAY } \\
\text { ACCUMULATION } \\
\text { inches }\end{array}$ \\
\hline November 10,1997 & $\overline{\overline{0.41}}$ & $\overline{\overline{0.41}}$ & $\overline{\overline{0.41}}$ \\
\hline November 13,1997 & 0.13 & 0.54 & 0.54 \\
\hline November 14,1997 & 0.11 & 0.65 & 0.65 \\
\hline November 26,1997 & 0.13 & 0.78 & 0.78 \\
\hline December 6, 1997 & 0.26 & 0.26 & $\overline{1.04}$ \\
\hline December 7, 1997 & 0.10 & 0.36 & 1.14 \\
\hline December 8, 1997 & 0.05 & 0.41 & 1.19 \\
\hline January 4,1998 & 0.12 & 0.12 & 0.53 \\
\hline January 9,1998 & 0.10 & 0.22 & 0.22 \\
\hline January 10,1998 & 0.14 & 0.36 & 0.36 \\
\hline January 29,1998 & 0.13 & 0.49 & 0.49 \\
\hline January 30,1998 & 0.01 & 0.50 & 0.50 \\
\hline February 2,1998 & 0.18 & 0.18 & $\overline{0.68}$ \\
\hline February 3,1998 & 0.41 & 0.59 & 1.09 \\
\hline February 4,1998 & 0.04 & 0.63 & 1.01 \\
\hline February 6,1998 & 0.19 & 0.82 & 1.20 \\
\hline February 7, 1998 & 0.10 & 0.92 & 1.30 \\
\hline February 8,1998 & 0.01 & 0.93 & 1.31 \\
\hline February 14,1998 & 0.19 & 1.12 & 1.26 \\
\hline February 15,1998 & 0.01 & 1.13 & 1.27 \\
\hline February 17,1998 & 0.35 & 1.48 & 1.62 \\
\hline February 19,1998 & 0.17 & 1.65 & 1.79 \\
\hline February 20,1998 & 0.28 & 1.93 & 2.07 \\
\hline February 23,1998 & 1.84 & 3.77 & 3.91 \\
\hline February 24,1998 & 0.33 & 4.10 & 4.24 \\
\hline March 5, 1998 & $\overline{0.04}$ & $\overline{0.04}$ & $\overline{3.96}$ \\
\hline March 6, 1998 & 0.08 & 0.12 & 3.63 \\
\hline March 13,1998 & 0.05 & 0.17 & 3.34 \\
\hline March 14,1998 & 0.03 & 0.20 & 3.37 \\
\hline March 25,1998 & 0.22 & $\overline{0.42}$ & 2.59 \\
\hline March 26, 1998 & 0.50 & 0.92 & 1.25 \\
\hline March 28, 1998 & 0.20 & 1.12 & 1.12 \\
\hline April 1, 1998 & $\overline{0.13}$ & $\overline{0.13}$ & $\overline{1.25}$ \\
\hline April 3, 1998 & 0.11 & 0.24 & 1.36 \\
\hline April 6, 1998 & 0.07 & 0.31 & 1.31 \\
\hline
\end{tabular}




\begin{tabular}{|c|c|c|c|}
\hline DATE & $\begin{array}{l}\text { PRECIPITATION } \\
\text { inches }\end{array}$ & $\begin{array}{l}\text { MONTHLY } \\
\text { ACCUMULATION } \\
\text { inches }\end{array}$ & $\begin{array}{c}\text { 30-DAY } \\
\text { ACCUMULATION } \\
\text { inches }\end{array}$ \\
\hline April 12, 1998 & 0.05 & 0.36 & 1.36 \\
\hline April 15,1998 & 0.02 & 0.38 & 1.30 \\
\hline April 25, 1998 & 0.58 & 0.96 & 1.66 \\
\hline May 4,1998 & $\overline{0.04}$ & $\overline{0.04}$ & $\overline{0.76}$ \\
\hline May 12,1998 & 0.30 & 0.34 & 0.99 \\
\hline$\overline{\text { June } 3,1998}$ & 0.17 & $\overline{0.17}$ & $\overline{0.51}$ \\
\hline June 8, 1998 & 0.88 & 1.05 & 1.35 \\
\hline June 9, 1998 & 0.33 & 1.38 & 1.68 \\
\hline June 11,1998 & 0.03 & 1.41 & 1.71 \\
\hline June 12,1998 & 0.42 & 1.83 & 1.83 \\
\hline July 20, 1998 & $\overline{0.02}$ & $\overline{\overline{0.02}}$ & $\overline{0.02}$ \\
\hline July 21,1998 & 0.23 & 0.25 & 0.25 \\
\hline July 22,1998 & 0.02 & 0.27 & 0.27 \\
\hline July 23,1998 & 0.24 & 0.51 & 0.51 \\
\hline August 13,1998 & $\overline{0.62}$ & 0.62 & 1.13 \\
\hline August 30,1998 & 0.53 & 1.15 & 1.15 \\
\hline August 31, 1998 & 0.03 & 1.18 & 1.18 \\
\hline September 3, 1998 & $\overline{0.01}$ & $\overline{0.01}$ & 1.19 \\
\hline September 4, 1998 & 0.16 & 0.17 & 1.35 \\
\hline September 8, 1998 & 0.07 & 0.24 & $\overline{1.42}$ \\
\hline October 24,1998 & $0 . \overline{04}$ & $\overline{0.04}$ & 0.04 \\
\hline October 26,1998 & 0.04 & 0.04 & 0.08 \\
\hline October 29,1998 & 0.03 & 0.11 & 0.11 \\
\hline
\end{tabular}

Data from the U.S. National Weather Service Nuclear Support Office, 1997 and 1998

${ }^{A}$ To meet compliance requirements, the 30-day accumulation records the total integrated rainfall that has occurred over the previous 30-day period. Monthly monitoring, rather than quarterly, is required for one quarter when $2.54 \mathrm{~cm}$ (1.0 in) of rainfall has occurred over a 30-day period. 
Mercury Weather Station, MER

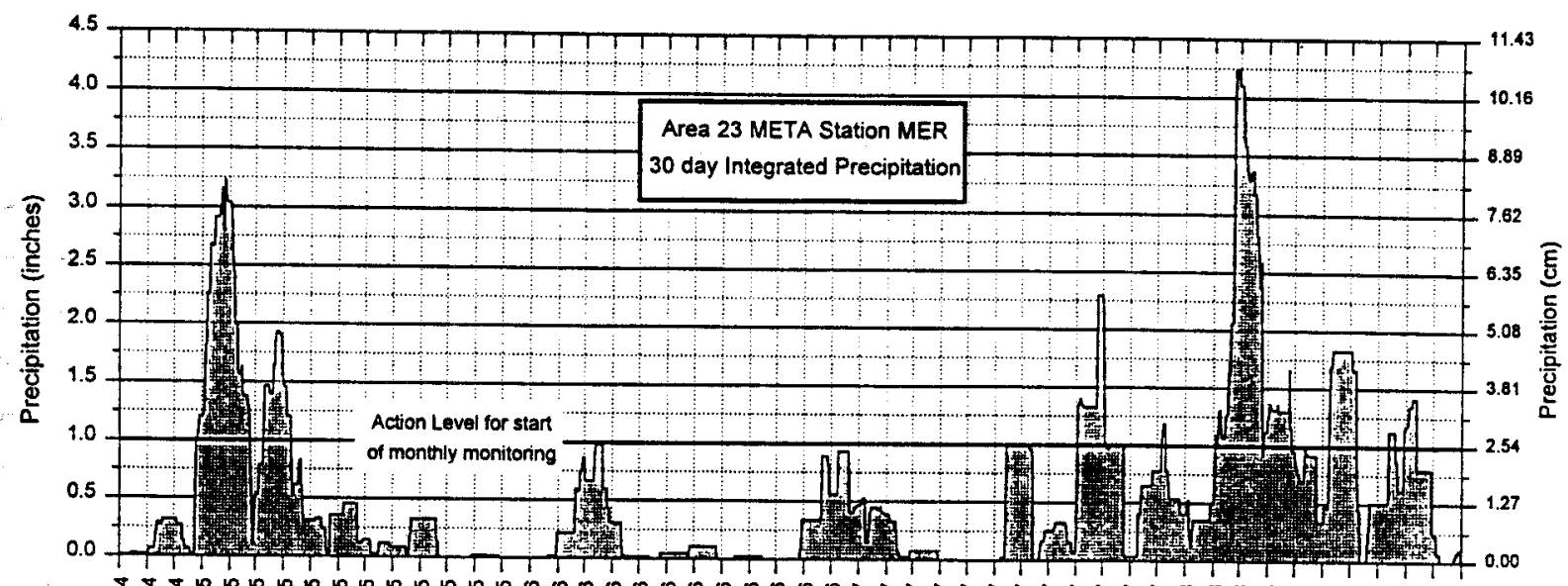

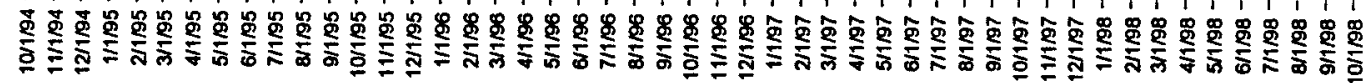
Date
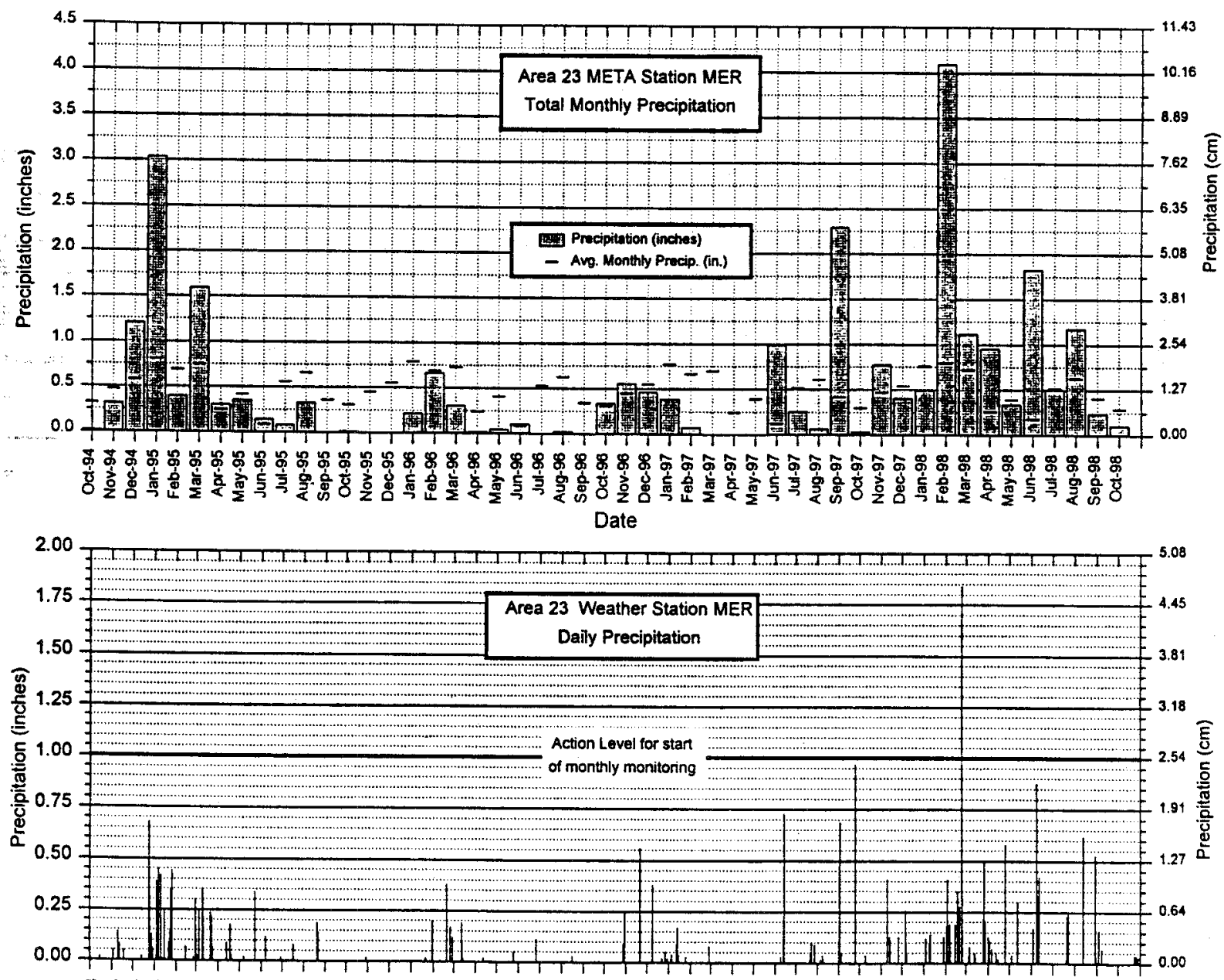

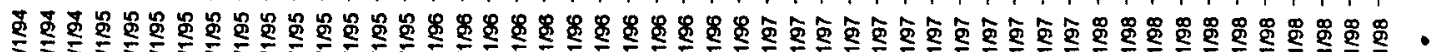

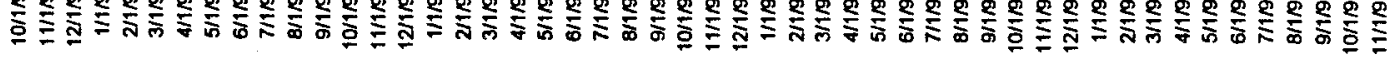
Date

Figure 3. Precipitation Area 23 META Station 


\subsection{SOIL MOISTURE MONITORING RESULTS}

\subsubsection{DATA PRESENTATION}

Due to the initial regulatory requirement to monitor underneath the trenches, and construction limitations in order to minimize the introduction of water through the Very Low Density Polyethylene cover, the depth at which a tube intersects the centerline of any specific trench varies with the stand-off distance to that trench. A listing of depths can be found in Appendix A. Unless specifically stated, all depths reported here are access tube length, not vertical depth.

The Cumulative Residual Moisture Content (CRMC) graph (Figures 4-8) tracks changes over time from baseline conditions relative to the regulatory level of concern. The residual moisture content is calculated by subtracting the first-year average soil moisture content (baseline) from the soil moisture content for each monitoring period on a depth basis. The depth used is approximately $0.91 \mathrm{~m}(3 \mathrm{ft})$ from the bottom of each neutron access tube. This corresponds to the point directly beneath each hazardous waste trench and avoids geometry problems associated with the end of the access tube. This residual value is plotted as Residual Volumetric Moisture Content vs Date for each access tube (Figures 4 through 8). The level of regulatory concern is indicated as a heavy line at the plus 5 percent residual moisture level. Values exceeding this limit for two consecutive monitoring periods require notifying the NDEP within seven days and the submittal of an Action Plan to investigate the cause within 30 days.

A second graph Baseline Difference (Appendix E) shows the changes occurring for one specific monitoring period along the entire length of a neutron access tube relative to baseline conditions. It is calculated by subtracting the first-year average soil moisture content (baseline) from the current soil moisture content for each monitoring period on a depth basis. The result of this subtraction is referred to as the Residual Soil Moisture Content (or Residual Moisture). The Residual Soil Moisture Content is plotted along with the actual Volumetric Soil Moisture Content of both the current and baseline data vs depth from the top of the casing. A positive residual moisture content indicates conditions at that depth and point in time that are wetter than baseline conditions, while negative values indicate dryer conditions. Repeatability and instrumentation noise is approximately \pm 1 percent RVMC. The Baseline Difference graph provides detailed information on the overall performance of the entire unit, while the Cumulative Residual graph focuses only on cumulative trends relative to the regulatory level of concern at a specific depth which are needed to make compliance decisions. 


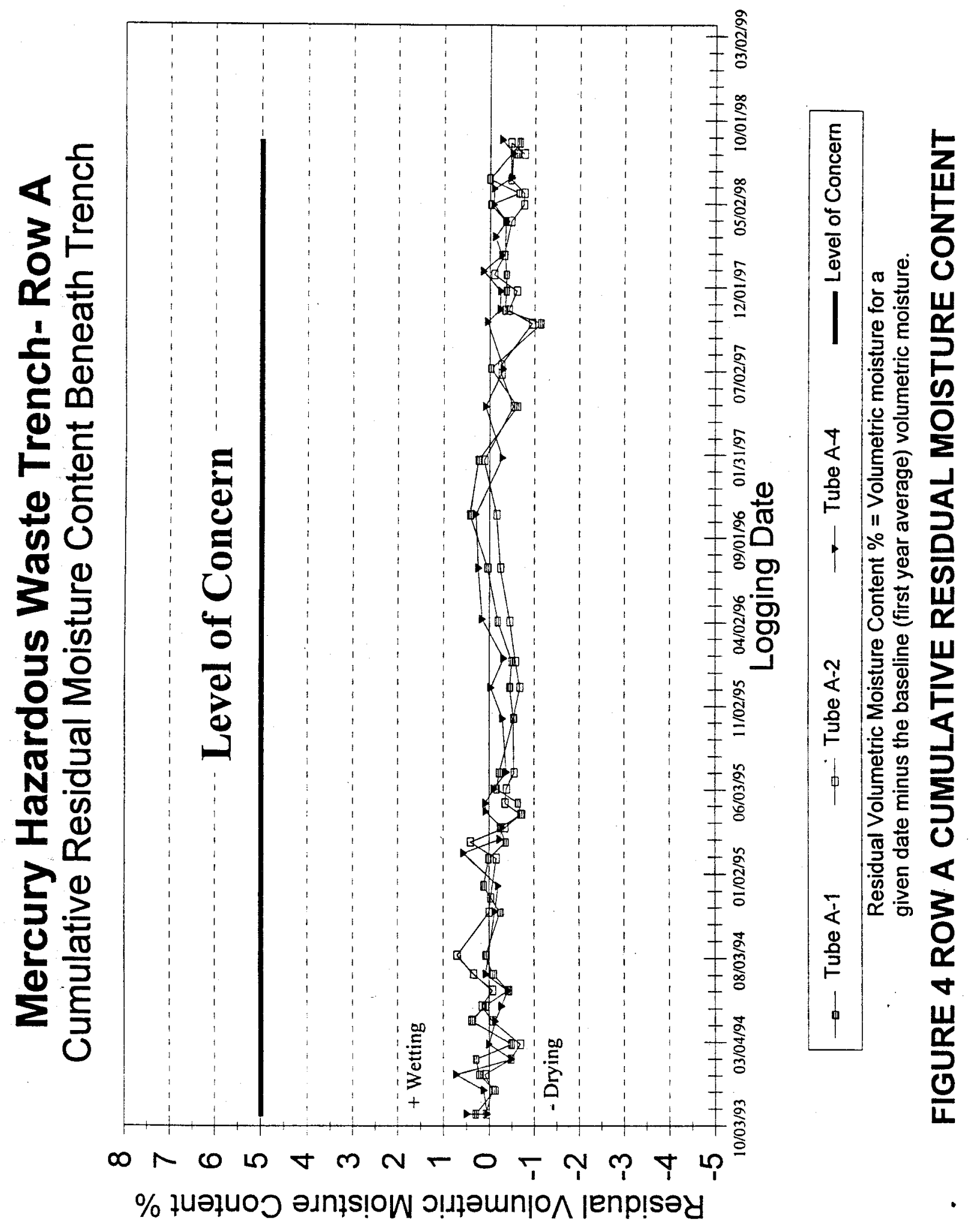




\section{Mercury Hazardous Waste Trench- Row B}

Cumulative Residual Moisture Content Beneath Trench

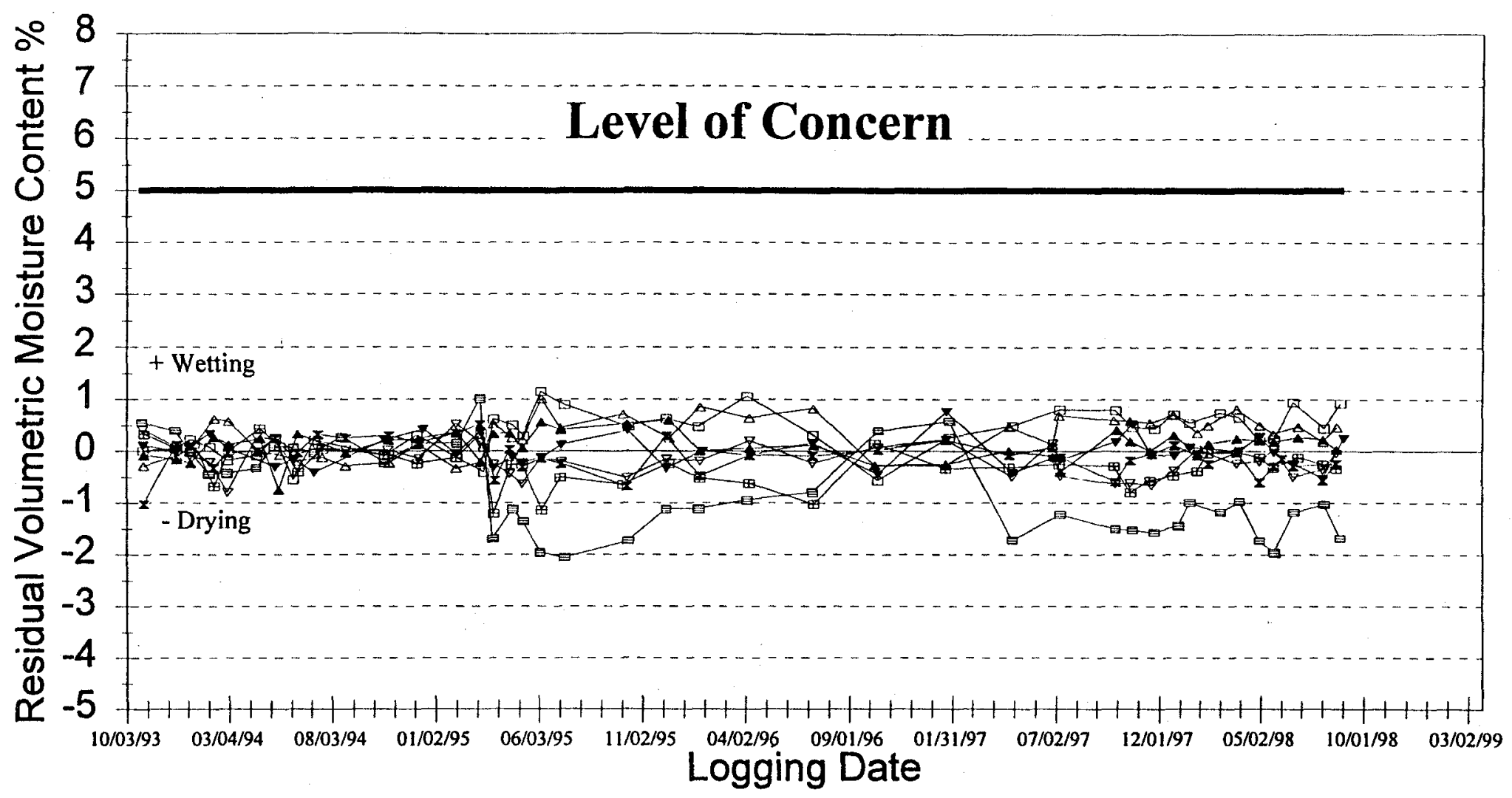

$\begin{array}{lllll}\rightarrow-\text { Tube B-2 } & \rightarrow \text { Tube B-4 } & \rightarrow \text { Tube B-7 } & \rightarrow \text { Tube B-10 } & \rightarrow \text { Tube B-13 } \\ - \text { Tube B-16 } & \rightarrow \text { Tube B-19 } & \rightarrow \text { Tube B-22 } & \text { Level of Concern }\end{array}$



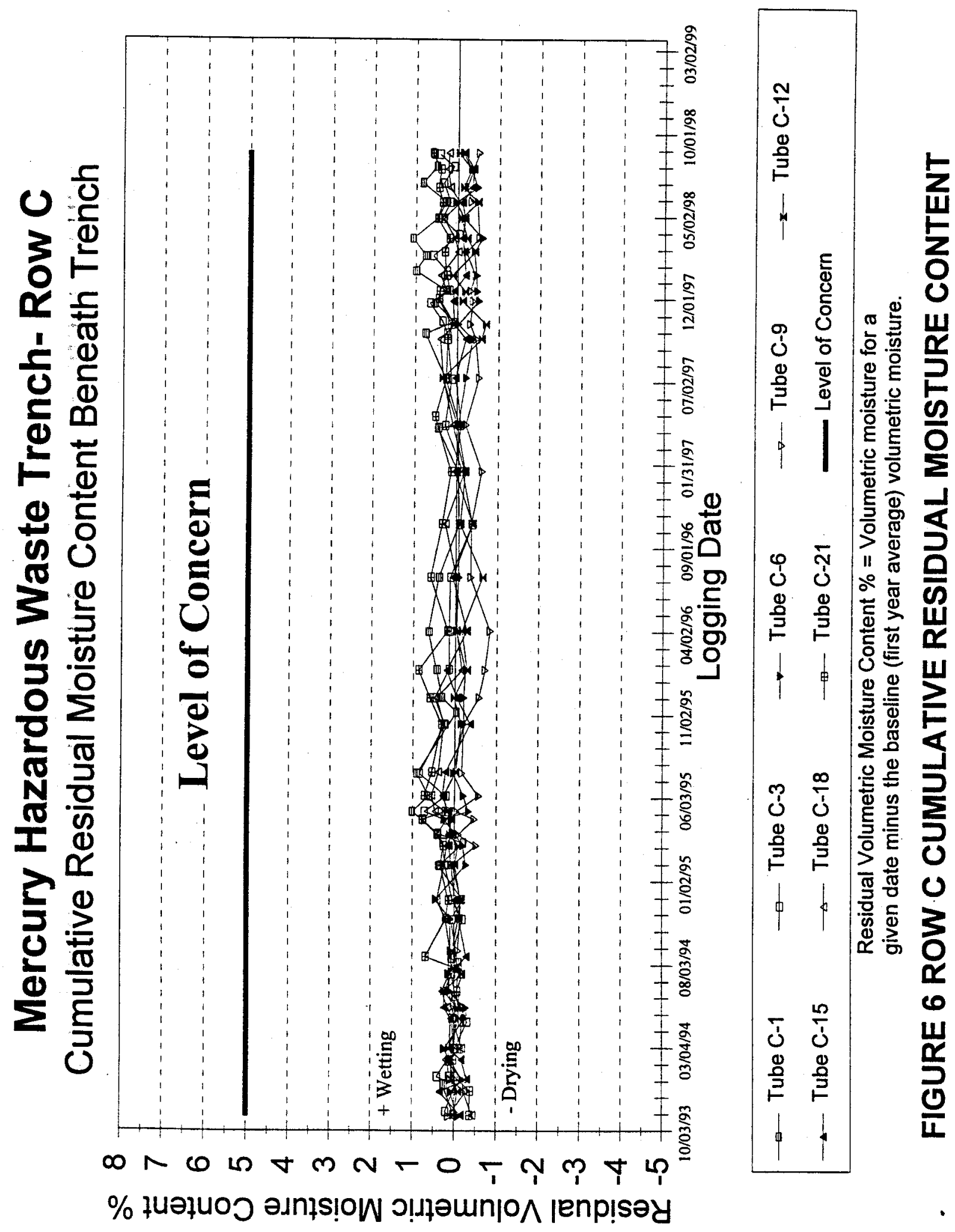


\section{Mercury Hazardous Waste Trench- Row S1}

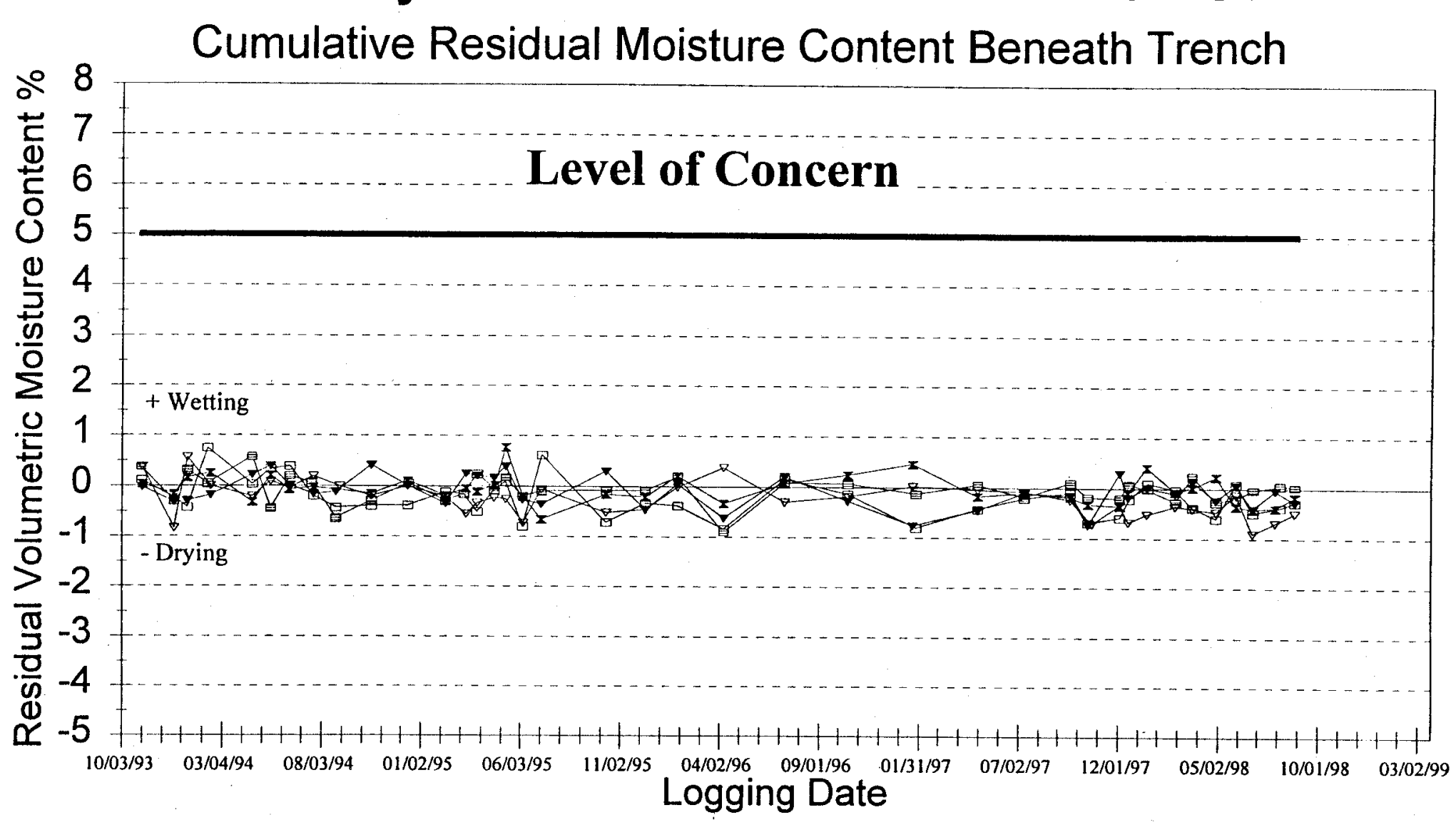

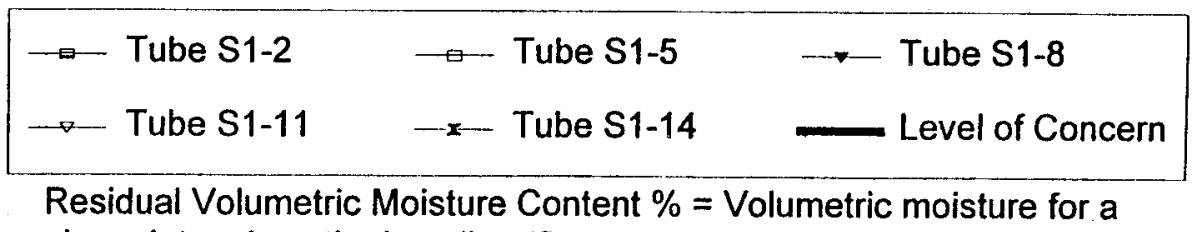
given date minus the baseline (first year average) volumetric moisture. 


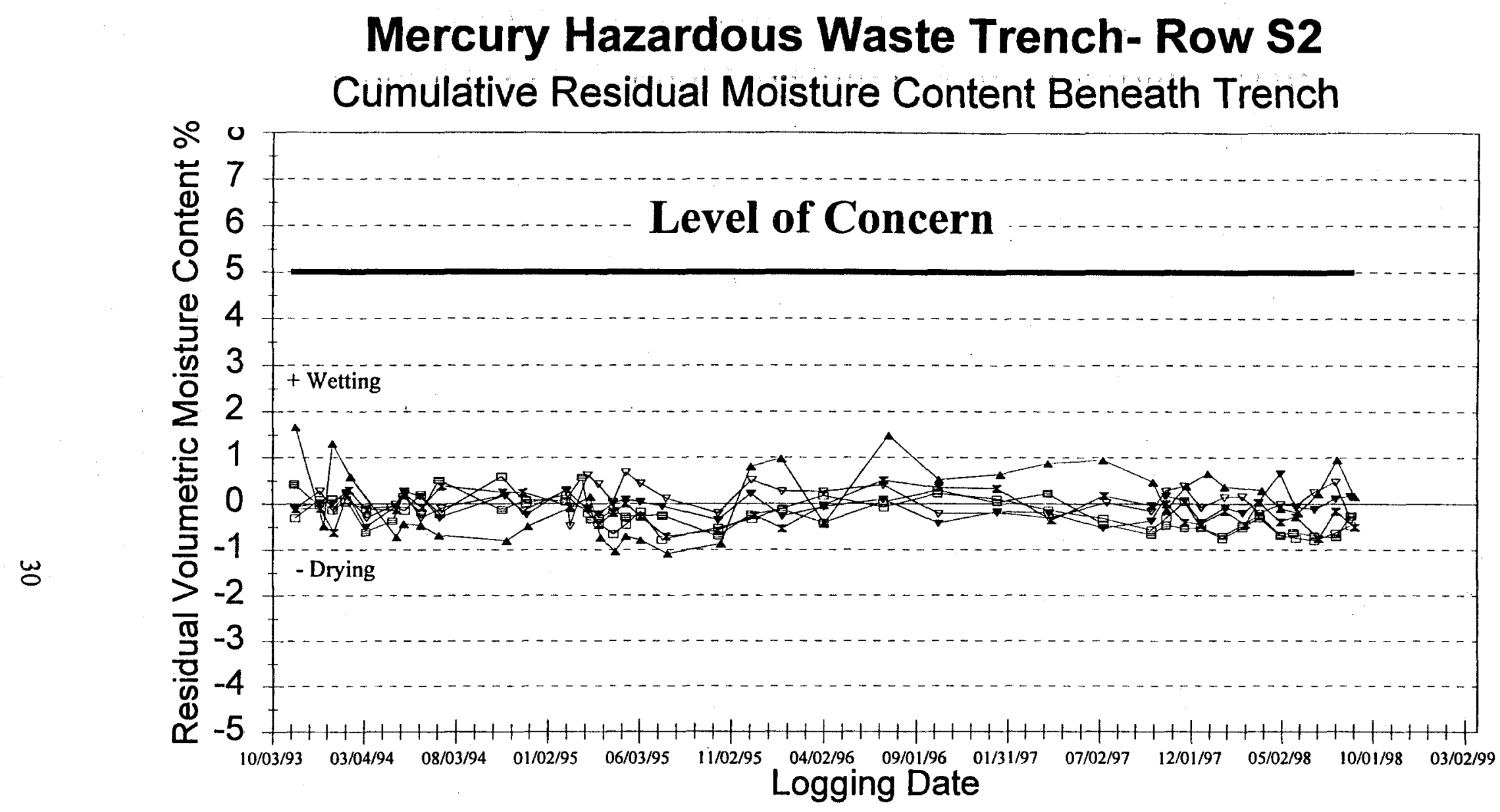

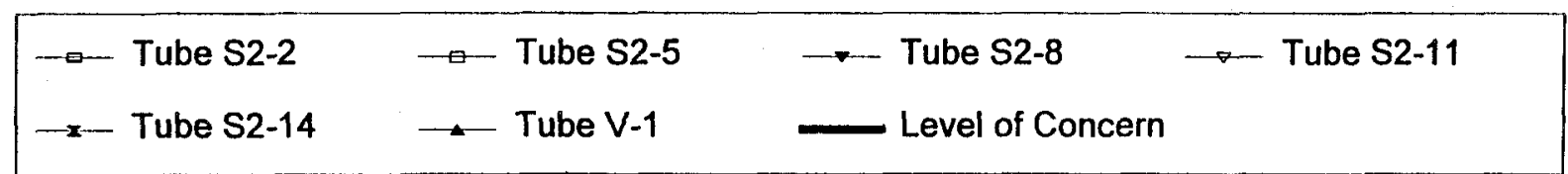

Residual Volumetric Moisture Content $\%=$ Volumetric moisture for a given date minus the baseline (first year average) volumetric moisture.

- FIGURE 8 ROW S2,V1 CUMULATIVE RESIDUAL MOISTURE CONTENT 


\subsubsection{DISCUSSION OF ANALYTICAL DATA TRENDS}

Figures 4 through 8 provide summary monitoring information with respect to the level of regulatory concern. Observations for each trench are provided below. As noted previously, monthly monitoring was started in September 1997 due to a 30-day integrated rainfall over $2.54 \mathrm{~cm}$ (1.0 in) and has operated continuously throughout the October 1997 - October 1998 monitoring period.

The rapid changes in near-surface moisture content that have been noted in previous monitoring reports are still apparent in this monitoring period. These effects are associated with near-surface water moving down along the neutron access tubes. Maintenance and repair activities to the well-head protection boxes were completed in October 1997 in an effort to correct these effects. The continued observation of this wetting effect indicates that, at least under these record precipitation events, the maintenance activity was not successful, or the source mechanism has not been adequately assessed. As noted previously in the third quarter inspection report (Section 3.3.3), subsurface voids have been noted while using a Geoprobe ${ }^{\circledR}$ core sampler in the soils in the area near the cover toe at Tube B-13. These voids are associated with a prior landfill operation and may be a possible source and pathway for the infiltration noted along the access tubes.

The behavior of the access tubes located along the periphery of the cover is a rapid near-surface change in moisture content in response to heavy rainfall events with subsequent drying immediately afterwards. Monitoring criteria require monthly monitoring after precipitation events greater than $2.54 \mathrm{~cm}$ (1.0 in) in any 30-day period. This has been used to document the ability of the monitoring system to detect changes over a short term and to verify that these changes would not be missed with a longer sampling period. Since the inception of the monitoring program, meteorologic conditions ranging from average to even historic record precipitation conditions have been observed using this monthly monitoring criteria. The results have shown that the system can detect and report the same results whether using monthly, quarterly, or even a biannual sampling period. Considering that there is no added benefit in the continued use of the monthly monitoring criteria, this requirement should be reevaluated.

\subsection{HAZARDOUS WASTE TRENCH A (ROW A)}

Baseline difference graphs for Tubes A-1, A-2, and A-4 in Trench A are found in Appendix E. Conditions remain dry and stable at depth for the period October 1997 through October of 1998.

Near-surface wetting events, associated with the record 10.41-cm (4.10-in) February rainfall, can be observed to extend to approximately $5.5 \mathrm{~m}(18 \mathrm{ft})$ in Tubes A-1, A-2, and A-4 by March 1998 with changes of up to 3 percent RVMC. By the following month, small changes of less than 1 percent RVMC can be detected at approximately $12.2 \mathrm{~m} \mathrm{(40} \mathrm{ft)} \mathrm{in} \mathrm{depth} \mathrm{for} \mathrm{Tubes} \mathrm{A-1} \mathrm{and}$

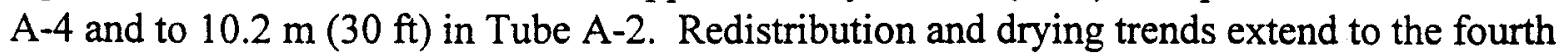


quarter monitoring period with Tube A-4 returning to baseline conditions and Tubes A-1 and A-4 at less than 1 percent RVMC. Beginning in September 1998, Tube A-2 indicates a negative RVMC which extends from just beneath the cement well-head protection plug to about $1.5 \mathrm{~m}$ $(5 \mathrm{ft})$ in depth. This characteristic is typical of an air gap forming between the neutron access tube and the soil interface. This effect may be due to soil shrinkage caused by wetting or settling within the annulus of the borehole.

CRMC graphs for Row A Tubes A-1, A-2, and A-4 are found in Figure 4. The vertical depth (from the original grade) beneath Trench A for Tubes A-1, A-2, and A-4 is approximately $16.8 \mathrm{~m}$ $(55 \mathrm{ft})$.

The residual soil moisture content on Row A remains unchanged from the first-year baseline conditions at less than 1 percent RVMC. Maximum variation is \pm 1 percent which is within the range of instrumentation noise.

No trends are evident and conditions remain dry and stable and below the compliance criteria of 5 percent RVMC.

\subsection{HAZARDOUS WASTE TRENCH B (ROW B)}

Baseline difference graphs (Appendix E) indicate similar conditions as observed on Row A with near surface wetting events typically occurring in the first $1.5 \mathrm{~m}(5 \mathrm{ft})$ due to the heavy February rainfall. Most tubes peak at about $0.9 \mathrm{~m}(3 \mathrm{ft})$ in depth and range from between 5 to about 12 percent. Tube 13 shows a singular peak of 14 percent occurring and remaining stationary at the $1.5-\mathrm{m}(5-\mathrm{ft})$ level.

As noted in previous reports (DOE, 1996, 1997a), Tube B-13 (and to a lesser extent Tubes B-10 and B-16) was noted to show a progression of moisture moving down along the access tube to a depth of about $15.2 \mathrm{~m}(50 \mathrm{ft})$ where it was contained, probably due to a caliche layer. By October 1998, Tube B-13 shows an increase of about 2 percent RVMC at a depth of $18.3 \mathrm{~m}$ $(60 \mathrm{ft})$. Tubes B-10 and B-16 show an advance of $1 \mathrm{~m}(3 \mathrm{ft})$ from October 1997 to October 1998. Tube B-16 has shown the largest increase in moisture content at the boundary of a caliche layer at about $15.2 \mathrm{~m}(50 \mathrm{ft})$ with a peak RVMC of 4.5 percent in the October $1998 \mathrm{log}$.

The CRMC for Row B, Tubes B-2, B-4, B-7, B-10, B-13, B-16, B-19, and B-22 is found in Figure 5. The vertical depth (from the original grade) beneath Trench $B$ for Tubes $B-2$ through B-7 varies from approximately 21.3 to $18.3 \mathrm{~m}$ (70 to $60 \mathrm{ft}$ ), while tubes B-10 through B-22 vary between 16.8 to $15.8 \mathrm{~m}$ ( 55 to $52 \mathrm{ft}$ ). A listing of depths can be found in Appendix A.

Test core samples were obtained near Tube B-13 on September 8, 1998. Preliminary results indicated that void spaces underlie the ground surface in that area. The voids are believed to be associated with an old nonhazardous waste landfill and are found approximately $1.2 \mathrm{~m} \mathrm{(4ft)}$ 
below grade. This landfill wastes are not part of the hazardous waste trenches closed under the Environmental Restoration Project. These voids may be a possible source and pathway for the infiltration noted along the access tubes. Additional studies will be scheduled to assess this mechanism.

At the compliance depth, all Row B access tubes remain at less than 1 percent RVMC and are well within the compliance criteria of 5 percent RVMC.

\subsection{HAZARDOUS WASTE TRENCH C (ROW C)}

Access Tubes C-1 and C-3 are located along the northwest periphery of the cap. The remaining access Tubes C- 6 through C-21 are located on and penetrate the cover. The depth of Tubes C-1 and $\mathrm{C}-3$ is approximately $18.3 \mathrm{~m}(60 \mathrm{ft})$ beneath the original grade, while Tubes C-6 through C-21 are approximately $6.1 \mathrm{~m}(20 \mathrm{ft})$ beneath the original grade.

Baseline difference graphs (Appendix E) for Tubes C- 1 and C-3 are similar to those of Row A and $\mathrm{B}$ and other access tubes located along the periphery of the cover and show some nearsurface wetting along the access tube. Tube C-1 has an 8 percent RVMC peak at $0.61 \mathrm{~m}(2 \mathrm{ft})$ in

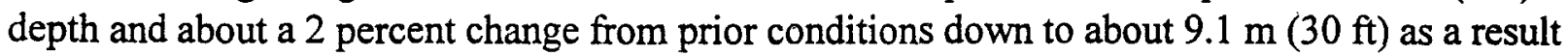
of the February precipitation. In a similar manner, Tube C- 3 has a peak of 5 percent at $0.6 \mathrm{~m}$ $(2 \mathrm{ft})$ and a 1 percent change in RVMC at $9.1 \mathrm{~m}(30 \mathrm{ft})$.

Access Tubes C- 6 through C-21 are installed through the cover and are very similar in the character of their soil moisture content profiles. The February precipitation can be seen as a peak of up 11 percent RVMC (Tube C-9) in the 1.5- to $1.8-\mathrm{m}$ (5- to 6-ft) levels. The geomembrane liner, located at approximately $1.8 \mathrm{~m}(6 \mathrm{ft})$, provides a barrier to infiltration. Below this depth, the residual moisture contents remain at less than 1 percent with the possible exception of Tube $\mathrm{C}-12$. Tube $\mathrm{C}-12$ shows some apparent wetting at the $2.4-\mathrm{m}(8-\mathrm{ft})$ level in the February and March monitoring periods. Because these changes are at the detection level of the instrument, it is not clear if this represents a valid response or statistical noise. In either case, baseline conditions were observed after March 1998.

CRMC graphs for Row C, Tubes C-1, C-3, C-6, C-9, C-12, C-15, C-18, and C-21 are found in Figure 6. The vertical depth (from original ground surface) beneath Trench $\mathrm{C}$ for Tubes $\mathrm{C}-1$ and

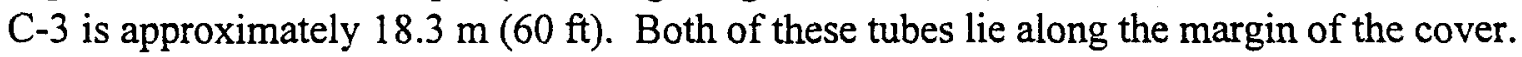
Tubes C- 6 through C-21 are installed on the cover and extend through it to a vertical depth (from the original ground surface) of approximately $6.1 \mathrm{~m}(20 \mathrm{ft})$.

CRMC (Figure 6) at the point of compliance for all Row $C$ tubes remains at less than 1 percent $\mathrm{RVMC}$ with no trends evident. Row $\mathrm{C}$ access tubes remain stable, dry, and below the compliance criteria of 5 percent RVMC. 


\subsection{HAZARDOUS WASTE TRENCH S-1 (ROW S-1)}

Access tubes for Row S-1 are installed on top of the cover and penetrate through it to a depth of approximately $6.1 \mathrm{~m}(20 \mathrm{ft})$ below the original ground surface.

Baseline difference graphs (Appendix E) for tubes on Row S-1 are very similar to those of Row C. Wetting can be observed in the first 0.3 to $0.6 \mathrm{~m}$ ( 1 to $2 \mathrm{ft}$ ) with infiltration down to $1.8 \mathrm{~m}(6 \mathrm{ft})$ where the geomembrane liner prevents any further movement. In the February logging period, Tube S1-2 indicated a 9 percent RVMC at the geomembrane liner located $1.8 \mathrm{~m}$ $(6 \mathrm{ft})$ in depth. This residual moisture content returns to 3 percent RVMC by March and to 2 percent RVMC in October. Below the liner the tubes, remain stable and dry with the residual moisture contents remaining at less than 1 percent.

CRMC graphs for Row S-1, Tubes S1-2, S1-5, S1-8, S1-11, and S1-14 are found in Figure 7. All tubes are installed on the cover and extend through it to a vertical depth of approximately $6.1 \mathrm{~m}(20 \mathrm{ft})$ from the original ground surface.

CRMC at the point of compliance for all Row S-1 tubes (Figure 7) remains at less than 1 percent RVMC with no trends evident. Row S-1 access tubes remain stable, dry, and below the compliance criteria of 5 percent RVMC.

\subsection{HAZARDOUS WASTE TRENCH S-2 (ROW S-2)}

Access tubes on Row S2 are located along the northwest periphery of the cover. Baseline difference graphs (Appendix E) indicate similar conditions as observed on Rows A and B with some near-surface ( 0 to $2.1 \mathrm{~m}$ [0 to $7 \mathrm{ft}]$ ) wetting beneath all the cement well-head protection boxes immediately after the February precipitation event and then showing movement down to about 12 to $18 \mathrm{~m} \mathrm{(40} \mathrm{to} 60 \mathrm{ft}$ ) at a residual moisture content of about 1 percent.

An increase in moisture content (approximately 3 percent RVMC) is still noted at the bottom of Access Tube S2-14. As discussed in the previous reports (DOE 1995a, 1996, 1997a), it is still not clear if this represents a positioning error in the steep gradient in moisture content associated with the change in lithology at this point or if it may also reflect a change in moisture content due to water or condensate that has moved down inside of the access tube.

The CRMC for Row S-2, Tubes S2-2, S2-5, S2-8, S2-11, and S2-14, are found in Figure 8. The vertical depths (from the original surface) beneath Trench S-2 for Tubes S2-1 through S2-5 is approximately $16.8 \mathrm{~m}(55 \mathrm{ft})$. For Tubes S2-8 to S2-14, the depth varies from 19.8 to $21.9 \mathrm{~m}$ ( 65 to $72 \mathrm{ft}$ ). A listing of access tube depths can be found in Appendix A. 
CRMC at the point of compliance for all Row S-2 tubes remains at less than 1 percent RVMC with no trends evident. Row S-2 access tubes remain stable, dry and below the compliance criteria of 5 percent RVMC.

\subsection{VERTICAL CONTROL TUBE V-1}

The Vertical Control Tube V-1 is a $15.2-\mathrm{m}(50-\mathrm{ft})$ vertical neutron access tube located at the north margin of the cover. Its purpose was to provide information on infiltration and evaporation sequences of the soils immediately surrounding the RCRA closure. It is used for background comparative purposes. Unfortunately, the tube was located in a slight depression that frequently filled with ponded water from runoff from the covers and a catchment area located to the north. As a result, this "control" tube represents a worse case scenario in terms of the amount and degree of water infiltration rather than typical conditions.

The record February rainfall can be seen as a wetting event extending to approximately $5.5 \mathrm{~m}$ (18 ft) by the end of April 1998. By October 1998, the moisture has redistributed and equilibrated and the overall profile has returned to pre-February conditions. Although the soils have been re-contoured to remove the depression within which this access tube is located, the changes in moisture content indicates that there is still some leakage down along the access tube.

The CRMC for access Tube V-1 remains below 5 percent RVMC. 
Monitoring Report CAU 112

Section:MONITORING

Revision: 0

Date: $2 / 4 / 1999$

\section{THIS PAGE INTENTIONALLY LEFT BLANK}




\subsection{SUMMARY, CONCLUSIONS, AND RECOMMENDATIONS}

\subsection{SUMMARY AND CONCLUSIONS}

1. Precipitation for the period October 1997 through October 1998 was $30.78 \mathrm{~cm}$ (12.12 in). The annual rainfall (January 1998 through January 1999) was $27.66 \mathrm{~cm}$ (11.12 in) which set a new all time record. The highest 30-day cumulative rainfall occurred on February 24, 1998 with a total of $11.87 \mathrm{~cm}$ (4.24 in). The heaviest daily precipitation occurred on February 23, 1998 , with a total of $4.67 \mathrm{~cm}$ (1.84 in) falling in that $24-\mathrm{hr}$ period. The recorded average annual rainfall for this site from 1971 to January 1999 is $14.96 \mathrm{~cm}$ (5.89 in).

2. The Part B Permit (NDEP, 1995) specifies that rainfall events that exceed 1.0 inch in any 30-day period will require monthly monitoring for one quarter. The action level of $2.54 \mathrm{~cm}$ (1.0 in) in any 30-day period was exceeded on September 3,1997, with $3.43 \mathrm{~cm}$ (1.35 in) accumulated and has been exceeded in each quarter since. This has required continuous monthly monitoring from September 1997 through November 1998. These weather conditions are the wettest recorded on this and other monitored sites at the NTS since record keeping had begun.

3. Inspections of the cover were done to identify any significant changes to the unit requiring action. No significant concerns were observed.

4. An elevation survey of the subsidence markers was conducted in July 1998 . There has been no subsidence at any of the markers since monitoring began six years ago.

5. Most access tubes located along the periphery of the cover (Tubes A, B, C-1 through C-4, and S-2) show low levels of infiltration occurring down along the access tubes to depth. Access tubes located on, and penetrating the cover, indicate infiltration is limited to $1.83 \mathrm{~m}$ $(6 \mathrm{ft})$ where the geomembrane liner is located, with the possible exception of Tube C-12 which shows some apparent wetting at the detection limit of the system at the $2.8-\mathrm{m}(8-\mathrm{ft})$ level in the February and March monitoring period. It is not clear if this was due to an actual increase in moisture content or statistical noise. Baseline conditions are observed after the March 1998 monitoring period. 
6. All monitored access tubes are within the compliance criteria of less than 5 percent residual volumetric moisture content at the compliance point directly beneath each respective trench. Soil conditions remain dry and stable underneath the trenches.

Summary of trench conditions:

\section{Trench A}

CRMC at the point of compliance indicates that soil surrounding the access tubes are stable, dry, and below the compliance level of 5 percent RVMC.

\section{Trench B}

CRMC at the point of compliance for all Row B access tubes remains stable and dry, and are within the compliance criteria.

\section{Trench C}

CRMC at the point of compliance for all Row $C$ tubes remains at less than 1 percent $R V M C$ with no trends evident.

The Row $\mathrm{C}$ access tubes remain stable, dry, and below the compliance criteria of 5 percent RVMC.

\section{Trench S-1}

CRMC at the point of compliance for all Row S-1 tubes remains at less than 1 percent RVMC with no trends evident.

The Row S-1 access tubes remain stable, dry, and below the compliance criteria of 5 percent RVMC.

\section{Trench S-2}

CRMC at the point of compliance for all Row S-2 tubes remains at less than 1 percent RVMC with no trends evident.

The Row S-2 access tubes indicates that the soil remains stable, dry, and below the compliance criteria of 5 percent RVMC. 


\section{Control Well V-1}

The Vertical Control Tube $\mathrm{V}-1$ is a $15.24-\mathrm{m}(50-\mathrm{ft})$ vertical neutron access tube located at the north margin of the cover. This tube was located in a slight depression that frequently filled with ponded water from runoff from the covers and from a catchment area located to the north. As a result, this "control" tube best represented a worse-case scenario rather than typical conditions. Evidence of ponded water, as well as cracks and erosion in the soils surrounding the concrete access box have been noted in the past. As result of this ponding, this access tube has shown significantly more leakage than observed on any of the other access tubes. Regrading and repairs were finished in October 1997, but changes observed in moisture content along this tube indicate that some leakage is still occurring.

The CRMC for access Tube V-1 remains below the compliance level of 5 percent RVMC.

\subsection{FINDINGS}

1. Most access tubes located along the periphery of the cover (Tubes A, B, C-1 through C-4, and S-2) show low levels of infiltration occurring down along the access tubes to depth. Access tubes located on, and penetrating the cover, indicate infiltration is limited to

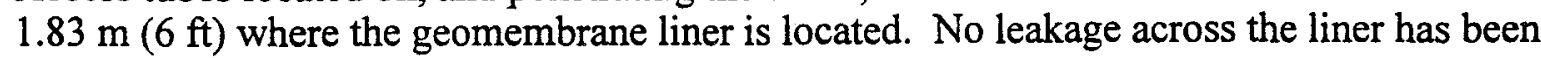
observed.

2. Test core samples were obtained near Tube B-13 on September 8, 1998. Preliminary results indicated that void spaces underlie the ground surface in that area. The voids are believed to be entrained within an old nonhazardous landfill and are found approximately $1.2 \mathrm{~m} \mathrm{(4ft)}$ below grade. These voids may be a possible source and pathway for the infiltration noted along the access tubes.

3. The monthly monitoring criteria required after precipitation events greater than $1.0 \mathrm{in}$. in any 30-day period has been used to document the ability of the monitoring system to detect changes over a short term and to verify that the changes would not be missed with a longer sampling period. Since the inception of the monitoring program, meteorologic conditions ranging from average to even historic record precipitation conditions have been observed using this monthly monitoring criteria. The results have shown that the system can detect and report the same results wether using monthly, quarterly, or even a biannual sampling period.

4. No significant concerns were observed during the site inspections over the period October 1997 through October 1998.

5. The annual subsidence survey of the two covers indicates that there has been no subsidence detected to date.

6. Soil conditions remain dry and stable beneath the trench through the October 1996 to October 1997 monitoring period. 
7. Moisture contents at the point of compliance for all access tubes remain below the compliance criteria of 5 percent RVMC.

\subsection{RECOMMENDATIONS}

1. Further studies regarding the location, extent, and effects of subsurface voids should be conducted to determine if these features are related to the moisture infiltration along the access tubes. Additional soil probing along the periphery of the cover and an assessment of the horizontal water transport pathway is recommended.

2. The continued use of monthly monitoring for one quarter after any rainfall event over $1.0 \mathrm{in}$. in any 30-day period should be reevaluated as these events can be monitored and evaluated as effectively using a quarterly or biannual monitoring period. 


\subsection{REFERENCES}

Code of Federal Regulations. 40 CFR §270.42. July, 1998

CPN, 1984, 503DR Hydroprobe Operating Manual, CPN Corporation.

Earth Technology Corporation, 1988, Closure Plan for the Nevada Test Site.

Nevada Division of Environmental Protection, 1994, Letter From P. J. Liebendorfer to D. R.

Elle, Revised Post-Closure Soil Moisture Monitoring Schedule For Closed Area 23 Landfill Hazardous Waste Trenches, December 21, 1994.

Nevada Division of Environmental Protection, 1995, Nevada Division of Environmental Protection Permit for a Hazardous Waste Management Facility, U.S. DOE, Nevada Test Site, Permit Number NEV HW009.

U.S. Department of Energy, 1992, Area 23 Exploratory Excavation Activities to Identify the Location of Hazardous Waste Trenches (Phase 1 Report), Vols. 1 and 2.

U.S. Department of Energy, 1993, Amended Closure Plan, Area 23 Landfill, Hazardous Waste Trenches, Phase 2 Report.

U.S. Department of Energy, 1994a, First Quarterly Report RCRA Post Closure Monitoring and Inspection. Mercury Landfill Hazardous Waste Trenches, April 1994.

U.S. Department of Energy, 1994b, Second Quarterly Report Post Closure Monitoring and Inspection. Mercury Landfill Hazardous Waste Trenches, May 1994.

U.S. Department of Energy, 1994c, Third Quarterly Report Post Closure Monitoring and Inspection. Mercury Landfill Hazardous Waste Trenches, August 1994.

U.S. Department of Energy, 1995a, Fourth Quarterly Report Post Closure Monitoring and Inspection. Mercury Landfill Hazardous Waste Trenches, January 1995.

U.S. Department of Energy, 1995b, Performance Assessment for the Area 5 Radioactive Waste Management Site at the Nevada Test Site, Nye County, Nevada; DOE/NV/11432-196. 
U.S. Department of Energy, 1996, Annual Report RCRA Post-Closure Monitoring and Inspection, Mercury Landfill Hazardous Waste Trenches, March 1996; DOE/NV/11718-011.

U.S. Department of Energy, 1997a, Annual Report RCRA Post-Closure Monitoring and Inspection, Mercury Landfill Hazardous. Waste Trenches for the Period October 1995 October 1996, January 1997; DOE/NV/11718-092.

U.S. Department of Energy, 1997b, Letter from S. A. Mellington to P. J. Liebendorfer, Request for Formal Approval in Changing the Area 23 Neutron Logging Action Criteria. CAU $\underline{112}$, January 15, 1997.

U.S. National Weather Service Nuclear Support Office, 1997, Meteorological Data for the MER Station.

U.S. National Weather Service Nuclear Support Office, 1998, Meteorological Data for the MER Station.

Winograd, I. J., W. Thordarson, and R. A. Young, 1975, Hydrology of the Nevada Test Site and Vicinity, South Eastern Nevada, United States Department of the Interior, Geological Survey. 
Monitoring Report CAU 112

Section: APPENDIX A

Revision: 0

Date: $2 / 4 / 1999$

\section{APPENDIX A}

\section{NEUTRON ACCESS TUBE INSTALLATION SUMMARY}


Monitoring Report CAU 112

Section: APPENDIX B

Revision: 0

Date: 2/4/1999

\section{APPENDIX B}

\section{MONTHLY INSPECTION CHECKLISTS}


APPENDIX A -- NEUTRON ACCESS TUBE INSTALLATION SUMMARY

\begin{tabular}{|c|c|c|c|c|c|c|c|}
\hline \multirow{2}{*}{$\begin{array}{l}\text { NEUTRON } \\
\text { ACCESS } \\
\text { TUBE } \\
\text { NUMBER }\end{array}$} & \multirow{2}{*}{$\begin{array}{l}\text { DRMLLING } \\
\text { COMPLETION } \\
\text { DATE }\end{array}$} & \multicolumn{2}{|c|}{ PLANNED } & \multicolumn{2}{|c|}{ AS BUILT } & \multirow{2}{*}{$\begin{array}{l}\text { CALCULATED } \\
\text { VERTICAL } \\
\text { DEPTH'(FEET) }\end{array}$} & \multirow{2}{*}{$\begin{array}{l}\text { VERTICAL } \\
\text { POINT OF } \\
\text { COMPLIANCE } \\
\text { DEPTHI FEET }\end{array}$} \\
\hline & & $\begin{array}{l}\text { LENGTH } \\
\text { (FEET) }\end{array}$ & ANGLE & $\begin{array}{l}\text { LENGTH } \\
\text { (FEET) }\end{array}$ & ANGLE & & \\
\hline $\mathrm{V}-1$ & $5-28-93$ & 50.0 & 90 & 50.0 & 90 & 50.0 & 48 \\
\hline$A-1$ & $5-18-93$ & 78.0 & 45 & 78.0 & 45 & 55.1 & 53.0 \\
\hline$A-2$ & $5-19-93$ & 80.0 & 45 & 71.5 & 45 & 50.6 & 48.8 \\
\hline$A-3$ & $5-19-93$ & 84.0 & 45 & 84.0 & 45 & 59.4 & $\mathrm{NM}^{2}$ \\
\hline$\overline{A-4}$ & $5-20-93$ & 84.0 & 45 & 84.0 & 45 & 59.4 & 56.6 \\
\hline B-1 & $4-29-93$ & 104.0 & 45 & 104.0 & 45 & 73.5 & $\mathrm{NM}^{2}$ \\
\hline$\overline{B-2}$ & $4-30-93$ & 98.0 & 45 & 98.0 & 45 & 69.3 & 67.2 \\
\hline B-3 & $4-30-93$ & 92.0 & 45 & 92.0 & 45 & 65.0 & $\mathrm{NM}^{2}$ \\
\hline B-4 & $5-3-93$ & 88.3 & 45 & 88.3 & 45 & 62.4 & 60.1 \\
\hline B-5 & $5-4-93$ & 84.2 & 45 & 84.2 & 45 & 59.5 & $\mathrm{NM}^{2}$ \\
\hline$\overline{B-6}$ & $5-4-93$ & 84.0 & 45 & 84.0 & 45 & 59.4 & $\overline{\mathrm{NM}^{2}}$ \\
\hline B-7 & $5-5-93$ & 84.1 & 45 & 84.1 & 45 & 59.4 & 56.6 \\
\hline$\overline{B-8}$ & $5-6-93$ & 84.0 & 45 & 84.0 & 45 & 59.4 & $\overline{N^{2}}$ \\
\hline B-9 & $5-7-93$ & 79.5 & 45 & 79.5 & 45 & 56.2 & $\overline{\mathrm{NM}^{2}}$ \\
\hline B-10 & $5-10=93$ & 78.0 & 45 & 78.0 & 45 & 55.1 & 53.0 \\
\hline B-11 & $5-10-93$ & 78.0 & 45 & 78.0 & 45 & 55.1 & $\mathrm{NM}^{2}$ \\
\hline B-12 & $5-11-93$ & 79.0 & 45 & 79.0 & 45 & 55.8 & $\overline{\mathrm{NM}^{2}}$ \\
\hline$\overline{B-13}$ & $5-11-93$ & 79.0 & 45 & 79.0 & 45 & 55.8 & 53.7 \\
\hline B-14 & $5-11-93$ & 74.0 & 45 & 74.0 & 45 & 52.3 & $\mathrm{NM}^{2}$ \\
\hline B-15 & $5-12-93$ & 74.0 & 45 & 74.0 & 45 & 52.3 & $\mathrm{NM}^{2}$ \\
\hline B-16 & $5-12-93$ & 74.0 & 45 & 77.0 & 45 & 54.4 & 53.0 \\
\hline B-17 & $5-13-93$ & 79.0 & 45 & 79.0 & 45 & 55.8 & $\overline{\mathrm{NM}^{2}}$ \\
\hline B-18 & $5-13-93$ & 79.5 & 45 & 79.5 & 45 & 56.2 & $\mathrm{NM}^{2}$ \\
\hline B-19 & $5-13-93$ & 78.0 & 45 & 78.0 & 45 & 55.1 & 537 \\
\hline B-20 & $5-14-93$ & 78.0 & 45 & 78.0 & 45 & 55.1 & $\mathrm{NM}^{2}$ \\
\hline B-21 & $5-14-93$ & 79.0 & 45 & 79.0 & 45 & 55.8 & $\overline{\mathrm{NM}^{2}}$ \\
\hline B-22 & $5-17-93$ & 78.0 & 45 & 78.0 & 45 & 55.1 & 53.0 \\
\hline B-23 & $5-17-93$ & 79.5 & 45 & 79.5 & 45 & 56.2 & $\mathrm{NM}^{2}$ \\
\hline $\mathrm{C}-1$ & $5-26-93$ & 88.0 & 45 & 88.0 & 45 & 62.2 & 60.1 \\
\hline$\overline{C-2}$ & $5-27-93$ & 92.0 & 45 & 75.0 & 45 & 53.0 & $\overline{\mathrm{NM}^{2}}$ \\
\hline $\mathrm{C}-3$ & $5-21-93$ & 94.0 & 45 & $85: 0$ & 45 & 60.1 & 55.2 \\
\hline $\mathrm{C}-4$ & $4-12-93$ & 41.0 & 45 & 41.0 & 45 & 29.0 & $\mathrm{NM}^{2}$ \\
\hline $\mathrm{C}-5$ & $4-12-93$ & 41.0 & 45 & 41.0 & 45 & 29.0 & $\overline{\mathrm{NM}^{2}}$ \\
\hline$c-6$ & 4-9-93 & $41 \%$ & 45 & 41.0 & 45 & 29.0 & 26.2 \\
\hline $\mathrm{C}-7$ & $4-9-93$ & 41.0 & 45 & 41.0 & 45 & 29.0 & $\mathrm{NM}^{2}$ \\
\hline $\mathrm{C}-8$ & $4-7-93$ & 41.0 & 45 & 41.0 & 45 & 29.0 & $\overline{N^{2}}$ \\
\hline C-9 & $4-7-93$ & 41.0 & 45 & 41.0 & 45 & 29.0 & 25.5 \\
\hline $\mathrm{C}-10$ & $4-7-93$ & 41.0 & 45 & 41.0 & 45 & 29.0 & $\mathrm{NM}^{2}$ \\
\hline$C-11$ & $4-7-93$ & 41.0 & 45 & 41.0 & 45 & 29.0 & $\mathrm{NM}^{2}$ \\
\hline$C-12$ & $4-6-93$ & 41.0 & 45 & 41.0 & 45 & 29.0 & $26: 2$ \\
\hline $\mathrm{C}-13$ & $4-6-93$ & 41.0 & 45 & 41.0 & 45 & 29.0 & $\mathrm{NM}^{2}$ \\
\hline
\end{tabular}


APPENDIX A -- NEUTRON ACCESS TUBE INSTALLATION SUMMARY

\begin{tabular}{|c|c|c|c|c|c|c|c|}
\hline \multirow{2}{*}{$\begin{array}{l}\text { NEUTRON } \\
\text { ACCESS } \\
\text { TUBE } \\
\text { NUMBER }\end{array}$} & \multirow{2}{*}{$\begin{array}{l}\text { DRILING } \\
\text { COMPLETION } \\
\text { DATE }\end{array}$} & \multicolumn{2}{|c|}{ PLANNED } & \multicolumn{2}{|c|}{ AS BUILT } & \multirow{2}{*}{$\begin{array}{l}\text { CALCULATED } \\
\text { VERTICAL } \\
\text { DEPTH'(FEET) }\end{array}$} & \multirow{2}{*}{$\begin{array}{l}\text { VERTICAL } \\
\text { POINT OF } \\
\text { COMPLIANCE } \\
\text { DEPTH (FEET) }\end{array}$} \\
\hline & & $\begin{array}{l}\text { LENGTH } \\
\text { (FEET) }\end{array}$ & ANGLE & $\begin{array}{l}\text { LENGTH } \\
\text { (FEET) }\end{array}$ & ANGLE & & \\
\hline $\mathrm{C}-14$ & $4-6-93$ & 41.0 & 45 & 41.0 & 45 & 29.0 & $\mathrm{NM}^{2}$ \\
\hline $\mathrm{C}-15$ & 4-5-93 & 41.0 & 45 & 41.0 & 45 & 29.0 & 26.9 \\
\hline$C-16$ & $4-5-93$ & 41.0 & 45 & 41.0 & 45 & 29.0 & $\mathrm{NM}^{2}$ \\
\hline C-17 & $4-5-93$ & 41.0 & 45 & 41.0 & 45 & 29.0 & $\mathrm{NM}^{2}$ \\
\hline $\mathrm{C}-18$ & $4-5-93$ & 41.0 & 45 & 41.0 & 45 & 29.0 & 276 \\
\hline $\mathrm{C}-19$ & $4-2-93$ & 41.0 & 45 & 41.0 & 45 & 29.0 & $\mathrm{NM}^{2}$ \\
\hline C-20 & $4-2-93$ & 41.0 & 45 & 41.0 & 45 & 29.0 & $\mathrm{NM}^{2}$ \\
\hline $\mathrm{C}-21$ & $4-2-93$ & 41.0 & 45 & 41.0 & 45 & 29.0 & 27.6 \\
\hline S1-1 & $3-25-93$ & 41.0 & 45 & 41.0 & 45 & 29.0 & $\mathrm{NM}^{2}$ \\
\hline Sl-2 & $3-25-93$ & 41.0 & 45 & 41.0 & 45 & 29.0 & 27.6 \\
\hline S1-3 & $3-26-93$ & 41.0 & 45 & 41.0 & 45 & 29.0 & $\overline{N^{2}}$ \\
\hline S1-4 & $3-26-93$ & 41.0 & 45 & 41.0 & 45 & 29.0 & $\overline{N^{2}}$ \\
\hline S1-5 & 3-30-93 & 410 & 45 & 41.0 & 45 & 29.0 & 26.9 \\
\hline S1-6 & $3-30-93$ & 41.0 & 45 & 41.0 & 45 & 29.0 & $\mathrm{NM}^{2}$ \\
\hline S1-7 & $3-31-93$ & 41.0 & 45 & 41.0 & 45 & 29.0 & $\mathrm{NM}^{2}$ \\
\hline $\mathrm{S1-8}$ & $3-31-93$ & 41.0 & 45 & $\overline{41.0}$ & 45 & 29.0 & 27.6 \\
\hline S1-9 & 3-31-93 & 41.0 & 45 & 41.0 & 45 & 29.0 & $\mathrm{NM}^{2}$ \\
\hline S1-10 & $3-31-93$ & 41.0 & $\overline{45}$ & 41.0 & 45 & 29.0 & $\overline{\mathrm{NM}^{2}}$ \\
\hline S1-11 & $4-1-93$ & 410 & 45 & $41 \%$ & 45 & 29.0 & 276 \\
\hline S1-12 & $4-1-93$ & 41.0 & 45 & 41.0 & 45 & 29.0 & $\mathrm{NM}^{2}$ \\
\hline S1-13 & $4-1-93$ & 41.0 & 45 & 41.0 & 45 & 29.0 & $\mathrm{NM}^{2}$ \\
\hline $\mathrm{S} 1-14$ & 41193 & 41.0 & 45 & 41.0 & 45 & 29.0 & 26.9 \\
\hline S1-15 & $4-2-93$ & 41.0 & 45 & 41.0 & $\overline{45}$ & 29.0 & $\mathrm{NM}^{2}$ \\
\hline S2-1 & $4-13-93$ & 74.2 & 45 & 74.2 & 45 & 52.4 & $\overline{\mathrm{NM}^{2}}$ \\
\hline $\mathrm{S} 2-2$ & $5-18-93$ & 78.0 & 45 & 78.0 & 45 & 55.1 & 53.0 \\
\hline S2-3 & $4-14-93$ & 78.0 & 45 & 78.0 & 45 & 55.1 & $\mathrm{NM}^{2}$ \\
\hline S2-4 & $4-15-93$ & 79.0 & 45 & 79.0 & 45 & 55.8 & $\mathrm{NM}^{2}$ \\
\hline $\mathrm{S} 2-5$ & $4-16-93$ & 82.2 & 45 & 82.2 & 45 & 58.1 & 55.2 \\
\hline S2-6 & $4-19-93$ & 82.2 & 45 & 82.2 & 45 & 58.1 & $\mathrm{NM}^{2}$ \\
\hline S2-7 & $4-19-93$ & 92.0 & 45 & 92.0 & 45 & 65.0 & $\mathrm{NM}^{2}$ \\
\hline $\mathrm{S} 2-8$ & $4-21-93$ & 92.0 & 45 & 92.0 & 45 & 65.0 & 63.6 \\
\hline S2-9 & $4-21-93$ & 93.5 & 45 & 93.5 & 45 & 66.1 & $\mathrm{NM}^{2}$ \\
\hline S2-10 & $4-22-93$ & 96.0 & 45 & 96.0 & 45 & 67.9 & $\overline{\mathrm{NM}^{2}}$ \\
\hline $\mathrm{S} 2 \mathrm{-11}$ & $4-22-93$ & 97.4 & 45 & 974 & 45 & 68.9 & 66.5 \\
\hline $\mathrm{S} 2-12$ & 4-23-93 & 99.0 & 45 & 99.0 & 45 & 70.0 & $\mathrm{NM}^{2}$ \\
\hline $\mathrm{S} 2-13$ & $4-26-93$ & 103.6 & 45 & 103.6 & 45 & 73.2 & $\mathrm{NM}^{2}$ \\
\hline $\mathrm{S} 2-14$ & $4-27-93$ & 101.9 & 45 & 101.9 & 45 & 72.0 & 69.3 \\
\hline$S 2-15$ & $4-28-93$ & 98.2 & 45 & 98.2 & 45 & 69.4 & $\mathrm{NM}^{2}$ \\
\hline
\end{tabular}

Note 1: Calculated depth is from existing grade prior to construction of the cover and is based upon the As-Built length of casing and angle

Note 2: NM - Not Monitored 


\section{AREA 23 HAZARDOUS WASTE TRENCHES (CAU 114) INSPECTION CHECKLIST}

Inspect the landfill and surrounding area. Look for any unusual changes such as water accumulation, chemical odors, deterioration of adjacent structures, etc. Refer to the previous inspection checklist in order to identify any changes. Do not rely on your memory. An inspection should be completed after a problem is reported by contractor, DOE, or Nevada Division of Environmental Protection personnel. At a minimum, routine inspections are to be completed at a frequency negotiated with the State of Nevada.

\section{GENERAL INFORMATION}

1. Date of inspection: $10 / 28 / 97$

2. Facility Manager (name and organization):

3. Reason for inspection: Monthly: $X$ Quarterly: Problem Reported: $N_{0}$ Unúsual Weather or other condition: $\Lambda^{\prime} \lambda$ Provide any necessary details:

4. Name, organization and telephone number of person reporting problem:

5. Describe weather conditions over the past few weeks (high winds, precipitation, local flooding):

$$
\text { cool; sunin, }
$$

\section{LANDFILL AREA}

6. Is the landfill area gate closed:

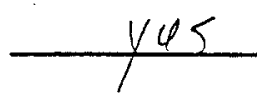
Locked:

7. Describe the condition of the fencing (i.e., are repairs required?):

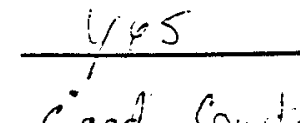
Cood Contition

8. Describe the condition of the signs (missing, fading damaged, etc.): down and damaged - all of hers good

9. Is there excessive erosion of the two overland flow diversion trenches: If yes, describe: 


\section{AREA 23 HAZARDOUS WASTE TRENCHES (Continued)}

10. Describe any subsidence, erosion, excessive vegetation, etc., on the landfill covers: Only mincr vegptatica

11. Describe any unusual deterioration of the neutron-access tube concrete pads: Mlone

12. Are all neutron access tube covers closed: Y0,5

13. Describe any unusual activity or condition which could impact the proper operation of the covers: None

\section{AREA SURROUNDING THE LANDFILL}

14. Describe any significant changes within several hundred feet of the unit. Changes can include construction, change in land use, storage of materials nearby, soil piles, change in use of the facility, etc.: None

15. Describe the effect (or possible effect) of any changes noted above:

16. Describe any other discharges into the landfill or along the top of the landfill: Nouse

17. Additional comments, observations, or recommendations: No che

\section{FOLLOW UP}

18. Based on the findings indicated above, is an additional inspection required before the next scheduled inspection: No If yes, when will this inspection be completed:

Any significant changes must be reported to the appropriate supervisor immediately. inspected by: Shana on Parsons Signed: 1 hamm M. Mrint) Date: $10 / 28 / 97$

Names of other persons present during inspection (print): 


\section{AREA 23 HAZARDOUS WASTE TRENCHES (CAU 114)}

INSPECTION CHECKLIST

Inspect the landfill and surrounding area. Look for any unusual changes such as water accumulation, chemical odors, deterioration of adjacent structures, etc. Refer to the - previous inspection checklist in order to identify any changes. Do not rely on your memory. An inspection should be completed after a problem is reported by contractor, DOE, or Nevada Division of Environmental Protection personnel. At a minimum, routine inspections are to be completed at a frequency negotiated with the State of Nevada.

\section{GENERAL INFORMATION}

1. Date of inspection: 1/124/97

2. Facility Manager (name and organization):

3. Reason for inspection: Monthly: $X$ Quarterly:

Problem Reported: Noul Unusual Weather or other condition: N/A Provide any necessary details:

4. Name, organization and telephone number of person reporting problem:

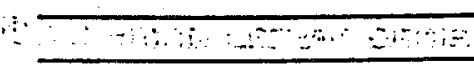

5. Describe weather conditions over the past few weeks (high winds, precipitation, local flooding):

$$
\text { Cod, sunny to clovdy, }
$$

\section{LANDFILL AREA}

6. Is the landfill area gate closed: $\frac{N_{0}-M o n+h y \text { logging }}{\text { taking place }}$ Locked: $\frac{10-M o n+h l y}{. \log g i n g}$

7. Describe the condition of the fencing (i.e., are repairs required?): Good

8. Describe the condition of the signs (missing, fading, damaged, etc.): focd

9. Is there excessive erosion of the two overland flow diversion trenches: No If yes, describe: 
10. Describe any subsidence, erosion, excessive vegetation, etc., on the landfill covers: None

11. Describe any unusual deterioration of the neutron-access fube concrete pads: None 12. Are all neutron access tube covers closed: No-A Fia' opin for logging-
all others Closed

13. Describe any unusual activity or condition which could impact the proper operation of the covers: licup

\section{AREA SURROUNDING THE LANDFILL}

14. Describe any significant changes within several hundred feet of the unit. Changes can include construction, change in land use, storage of materials nearby, soil piles, change in use of the facility, etc.: Aloue

15. Describe the effect (or possible effect) of any changes noted above:

16. Describe any other discharges into the landfill or along the top of the landfill: Noue

17. Additional comments, observations, or recommendations: None

\section{FOLLOW UP}

18. Based on the findings indicated abgve, is an additional inspection required before the next scheduled inspection: No If yes, when will this inspection be completed:

Any significant changes must be reported to the appropriate supervisor immediately.

Inspected by: Shaunon Parsons

Signed:

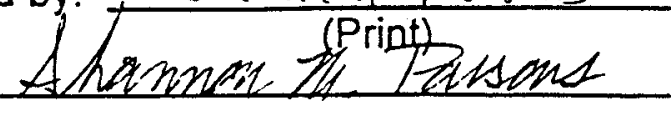

Date: $11 / 24 / 97$

Names of other persons present during inspection (print): 


\section{AREA 23 HAZARDOUS WASTE TRENCHES (CAU 114) INSPECTION CHECKLIST}

Inspect the landfill and surrounding area. Look for any unusual changes such as water accumulation, chemical odors, deterioration of adjacent structures, etc. Refer to the previous inspection checklist in order to identify any changes. Do not rely on your memory. An inspection should be completed after a problem is reported by contractor, DOE, or Nevada Division of Environmental Protection personnel. At a minimum, routine inspections are to be completed at a frequency negotiated with the State of Nevada.

\section{GENERAL INFORMATION}

1. Date of inspection: $12 / 22 / 97$

2. Facility Manager (name and organization):

3. Reason for inspection: Monthly: $X$ Quarterly:

Problem Reported: Unusual Weather or other condition:

Provide any necessary details:

4. Name, organization and telephone number of person reporting problem:

5. Describe weather conditions over the past few weeks (high winds, precipitation, local flooding): cold, windy, liglot precip.

\section{LANDFILL AREA}

6. Is the landfill area gate closed: $\frac{N_{0}-\operatorname{loggins} \text { in }}{\text { pogress }}$ Locked: No- logging in

7. Describe the condition of the fencing (i.e., are repairs required?): cood

8. Describe the condition of the signs (missing, fading, damaged, etc.): Cood

9. Is there excessive erosion of the two overland flow diversion trenches: $N_{0}$ e If yes, describe: 


\section{AREA 23 HAZARDOUS WASTE TRENCHES (Continued)}

10. Describe any subsidence, erosion, excessive vegetation, etc., on the landfill covers: 11. Describe any unusual deterioration of the neutron-access tube concrete pads:

12. Are all neutron access tube covers closed: No- some open for log ging

13. Describe any unusual activity or condition which could impact the proper operation of the covers: None

\section{AREA SURROUNDING THE LANDFILL}

14. Describe any significant changes within several hundred feet of the unit. Changes can include construction, change in land use, storage of materials nearby, soil piles, change in use of the facility, etc.:

15. Describe the effect (or possible effect) of any changes noted above: $V / A$

16. Describe any other discharges into the landfill or along the top of the landfill: Ne ue

17. Additional comments, observations, or recommendations:_None

\section{FOLLOW UP}

18. Based on the findings indicated above, is an additional inspection required before the next scheduled inspection: No If yes, when will this inspection be completed:

Any significant changes must be reported to the appropriate supervisor immediately. Inspected by: Shannon Parsons

Signed:

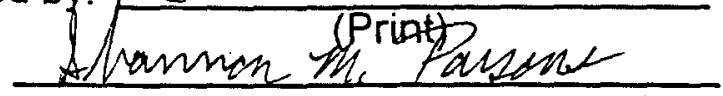

Date: $12 / 22 / 97$

Names of other persons present during inspection (print):

Fim MiCloskey 


\section{AREA 23 HAZARDOUS WASTE TRENCHES (CAU 114) INSPECTION CHECKLIST}

Inspect the landfill and surrounding area. Look for any unusual changes such as water accumulation, chemical odors, deterioration of adjacent structures, etc. Refer to the previous inspection checklist in order to identify any changes. Do not rely on your memory. An inspection should be completed after a problem is reported by contractor, DOE, or Nevada Division of Environmental Protection personnel. At a minimum, routine inspections are to be completed at a frequency negotiated with the State of Nevada.

\section{GENERAL INFORMATION}

1. Date of inspection: $\operatorname{Tan} 21,1998$

2. Facility Manager (name and organization):

3. Reason for inspection: Monthly: $\not$ Quarterly: Problem Reported: Provide any necessary details: 4. Name, organization and telephone number of person reporting problem:

5. Describe weather conditions over the past few weeks (high winds, precipitation, local flooding): Unusual Weather or other condition:

\section{LANDFILL AREA}

6. Is the landfill area gate closed:

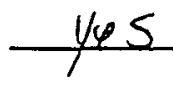
Locked: yes

7. Describe the condition of the fencing (i.e., are repairs required?): Good

8. Describe the condition of the signs (missing, fading, damaged, etc.): A frew sigus down andlor damaged, Site still wril marked.

9. Is there excessive erosion of the two overland flow diversion trenches: No: If yes, describe: 


\section{AREA 23 HAZARDOUS WASTE TRENCHES (Continued)}

10. Describe any subsidence, erosion, excessive vegetation, etc., on the landfill covers: None

11. Describe any unusual deterioration of the neutron-access tube concrete pads: vine

12. Are all neutron access tube covers closed: Yes

13. Describe any unusual activity or condition which could impact the proper operation of the covers: None

\section{AREA SURROUNDING THE LANDFILL}

14. Describe any significant changes within several hundred feet of the unit. Changes can include construction, change in land use, storage of materials nearby, soil piles, change in use of the facility, etc.: Nouk

15. Describe the effect (or possible effect) of any changes noted above: $\mathrm{N} / \mathrm{A}$

16. Describe any other discharges into the landfill or along the top of the landfill: None

17. Additional comments, observations, or recommendations: Repair SigHS.

\section{FOLLOW UP}

18. Based on the findings indicated abpve, is an additional inspection required before the next scheduled inspection: No If yes, when will this inspection be completed:

Any significant changes must be reported to the appropriate supenisor immediately. inspected by Shannon Parsons

Signed: Ahamon (Print) Dasene

Date: $1 / 21 / 98$

Names of other persons present during inspection (print): 


\section{AREA 23 HAZARDOUS WASTE TRENCHES (CAU 112) INSPECTION CHECKLIST}

Inspect the landfill and surrounding area. Look for any unusual changes such as water accumulation, chemical odors, deterioration of adjacent structures, etc. Refer to the previous inspection checklist in order to identify any changes. Do not rely on your memory. An inspection should be completed after a problem is reported by contractor, $D O E$, or Nevada Division of Environmental Protection personnel. At a minimum, routine inspections are to be completed at a frequency negotiated with the State of Nevada.

\section{GENERAL INFORMATION}

1. Date of inspection: $\bar{z} / 19 / 98$

2. Facility Manager (name and organization):

3. Reason for inspection: Monthly: $\not$ Quarterly: Problem Reported: : Unusual Weather or other condition:

Provide any necessary details:

4. Name, organization and telephone number of person reporting problem:

5. Describe weather conditions over the past few weeks (high winds, precipitation, local flooding): rain, el niao sterins, cold fo mild

\section{LANDFILL AREA}

6. Is the landfill area gate closed: Yys Locked:

7. Describe the condition of the fencing (i.e., are repairs required?): bood

8. Describe the condition of the signs (missing, fading, damaged, etc.): hood

9. Is there excessive erosion of the two overland flow diversion trenches: If yes, describe:

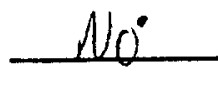




\section{AREA 23 HAZARDOUS WASTE TRENCHES (Continued)}

10. Describe any subsidence, erosion, excessive vegetation, etc., on the landfill covers: None

11. Describe any unusual deterioration of the neutron-access tube concrete pads: Nony

12. Are all neutron access tube covers closed:

yes

13. Describe any unusual activity or condition which could impact the proper operation of the covers: Nonle

\section{AREA SURROUNDING THE LANDFILL}

14. Describe any significant changes within several hundred feet of the unit. Changes can include construction, change in land use, storage of materials nearby, soil piles, change in use of the facility, etc.:

15. Describe the effect (or possible effect) of any changes noted above: None

16. Describe any other discharges into the landfill or along the top of the landfill: Standing Water was dieleted a earlier in the wed following a

17. Additional comments, observations, or recommendations: Is of this month the CAU number has been correted on the iuspretion shepts from CAVII4 to (AVIIZ.

\section{FOLLOW UP}

18. Based on the findings indicated above, is an additional inspection required before the next scheduled inspection: $N_{0}$ If yes, when will this inspection be completed:

Any significant changes must be reported to the appropriate supervisor immediately. Inspected by: Shannox Parjonj Signed: Ahumon (Print) Tausere Date: $2 / 19 / 98$ Names of other persons present during inspection (print): 


\section{AREA 23 HAZARDOUS WASTE TRENCHES (CAU 112) INSPECTION CHECKLIST}

Inspect the landfill and surrounding area. Look for any unusual changes such as water accumulation, chemical odors, deterioration of adjacent structures, etc. Refer to the. previous inspection checklist in order to identify any changes. Do not rely on your memory. An inspection should be completed after a problem is reported by contractor, DOE, or Nevada Division of Environmental Protection personnel. At a minimum, routine inspections are to be completed at a frequency negotiated with the State of Nevada.

\section{GENERAL INFORMATION}

1. Date of inspection:

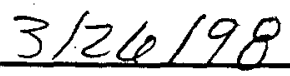

2. Facility Manager (name and organization):

3. Reason for inspection: Monthly: $\not \mathcal{X}$ Quarterly:

Problem Reported Unusual Weather or other condition:

- Provide any necessary details:

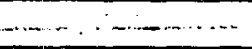

-

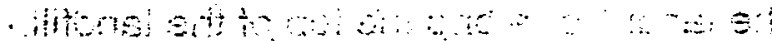

4. Name, organization and telephone number of person reporting problem:

5. Describe weather conditions over the past few weeks (high winds, precipitation, local flooding): rainy to sunky, wirm

\section{LANDFILL AREA}

6. Is the landfill area gate closed:

Locked: $\frac{\text { yes }}{1}$

7. Describe the condition of the fencing (i.e., are repairs required?): Go od

8. Describe the condition of the signs (missing, fading, damaged, etc.): leood

9. Is there excessive erosion of the two overland flow diversion trenches: $N_{0}$ ' If yes, describe: 


\section{AREA 23 HAZARDOUS WASTE TRENCHES (Continued)}

10. Describe any subsidence, erosion, excessive vegetation, etc., on the landfill covers:

11. Describe any unusual deterioration of the neutron-access tube concrete pads: Nione

12. Are all neutron access tube covers closed: $y \notin S$

13. Describe any unusual activity or condition which could impact the proper operation of the covers: Noae

\section{AREA SURROUNDING THE LANDFILL}

14. Describe any significant changes within several hundred feet of the unit. Changes can include construction, change in land use, storage of materials nearby, soil piles, change in use of the facility, etc.:

15. Describe the effect (or possible effect) of any changes noted above:

NIA

16. Describe any other discharges into the landfill or along the top of the landfill: None

17. Additional comments, observations, or recommendations: Nuqe

\section{FOLLOW UP}

18. Based on the findings indicated above, is an additional inspection required before. the next scheduled inspection: $N_{0}$ If yes, when will this inspection be completed:

Any significant changes must be reported to the appropriate supervisor immediately. Inspected by Shannon Pärsons

Signed:

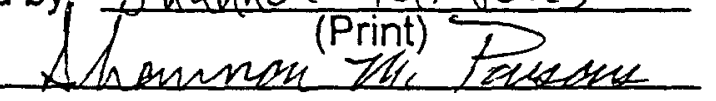

Date: $3 / 26 / 98$

Names of other persons present during inspection (print): 


\section{AREA 23 HAZARDOUS WASTE TRENCHES (CAU 112) INSPECTION CHECKLIST}

Inspect the landfill and surrounding area. Look for any unusual changes such as water accumulation, chemical odors, deterioration of adjacent structures, etc. Refer to the previous inspection checklist in order to identify any changes. Do not rely on your memory. An inspection should be completed after a problem is reported by contractor, DOE, or Nevada Division of Environmental Protection personnel. At a minimum, routine inspections are to be completed at a frequency negotiated with the State of Nevada.

\section{GENERAL INFORMATION}

1. Date of inspection:

$4 / 22 / 98$

2. Facility Mànàger (name and organization):

3. Reason for inspection: ... Monthly: “ $X$ Quarterly:

Problem Reported: ___ Unusual Weather or other condition:

Provide any necessary details:

4. Name, organization and telephone number of person reporting problem:

5. Describe weather conditions over the past few weeks (high winds, precipitation, local flooding): warm and windy

\section{LANDFILL AREA}

6. Is the landfill area gate closed: Locked: $y 45$

7. Describe the condition of the fencing (i.e., are repairs required?): Cood

8. Describe the condition of the signs (missing, fading, damaged, etc.): Cood

9. Is there excessive erosion of the two overland flow diversion trenches: NO If yes, describe: 


\section{AREA 23 HAZARDOUS WASTE TRENCHES (Continued)}

10. Describe any subsidence, erosion, excessive vegetation, etc., on the landfill covers:

None

11. Describe any unusual deterioration of the neutron-access tube concrete pads: None

12. Are all neutron access tube covers closed:

Y4s

13. Describe any unusual activity or condition which could impact the proper operation of the covers: None

\section{AREA SURROUNDING THE LANDFILL}

14. Describe any significant changes within several hundred feet of the unit. Changes can include construction, change in land use, storage of materials nearby, soil piles, change in use of the facility, etc.:

Woney.

15. Describe the effect (or possible effect) of any changes noted above: Non $\varphi$

16. Describe any other discharges into the landfill or along the top of the landfill: Noue

17. Additional comments; observations, or recornmendations: None

\section{FOLLOW UP}

18.- Based on the findings indicated above, is an additional inspection required before the next scheduled inspection: completed: If yes, when will this inspection be.

Any significant changes must be reported to the appropriate supervisor immediately. inspected by: Shannon Parsons

Signed:

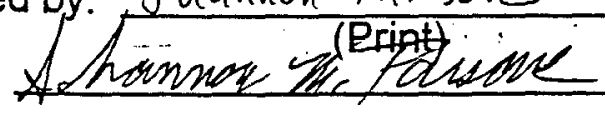

Date: $4 / 22 / 98$

Names of other persons present during inspection (print): 


\section{AREA 23 HAZARDOUS WASTE TRENCHES (CAU 112) INSPECTION CHECKLIST}

Inspect the landfill and surrounding area. Look for any unusual changes such as water accumulation, chemical odors, deterioration of adjacent structures, etc. Refer to the previous inspection checklist in order to identify any changes. Do not rely on your memory. An inspection should be completed after a problem is reported by contractor, $D O E$, or Nevada Division of Environmental Protection personnel. At a minimum, routine inspections are to be completed at a frequency negotiated with the State of Nevada.

\section{GENERAL INFORMATION}

1. Date of inspection: $5 / 20 / 98$

2. Facility Manager (name and organization):

3. Reason for inspection: Monthly: $\not$ Quarterly: Problem Reported: Unusual Weather or other condition: Provide any necessary details:

4. Name, organization and telephone number of person reporting problem:

5. Describe weather conditions over the past few weeks (high winds; precipitation, local flooding): windy and warm

\section{LANDFILL AREA}

6. Is the landfill area gate closed:

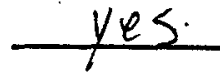
Locked: yes.

7. Describe the condition of the fencing (i.e., are repairs required?): $G_{00 d}$

8. Describe the condition of the signs (missing, fading, damaged, etc.): Good

9. Is there excessive erosion of the two overland flow diversion trenches: $\mathrm{No}$ If yes, describe: 
10. Describe any subsidence, erosion, excessive vegetation, etc., on the landfill covers: None

11. Describe any unusual deterioration of the neutron-access tube concrete pads: Noine

12. Are all neutron access tube covers closed:

$$
\text { Yes }
$$

13. Describe any unusual activity or condition which could impact the proper operation of the covers: None

\section{AREA SURROUNDING THE LANDFILL}

14. Describe any significant changes within several hundred feet of the unit. Changes can include construction, change in land use, storage of materials nearby, soil piles, change in use of the facility, etc.:

15. Describe the effect (or possible effect) of any changes noted above: $N / A$

16. Describe any other discharges into the landfill or along the top of the landfill: Nowe vepairs seem to be workikg

17. Additional comments, observations, or recommendations: None

\section{FOLLOW UP}

18. Based on the findings indicated above, is an additional inspection required before the next scheduled inspection: 0 lf yes, when will this inspection be completed:

Any significant changes must be reported to the appropriate supervisor immediately. Inspected by: Shannon Parsoas Signed: (Print)

Names of other persons present during inspection (print): Ruchard Filemyr 


\section{AREA 23 HAZARDOUS WASTE TRENCHES (CAU 112) INSPECTION CHECKLIST}

Inspect the landfill and surrounding area. Look for any unusual changes such as water accumulation, chemical odors, deterioration of adjacent structures, etc. Refer to the previous inspection checklist in order to identify any changes. Do not rely on your memory. An inspection should be completed after a problem is reported by contractor, DOE, or Nevada Division of Environmental Protection personnel. At a minimum, routine inspections are to be completed at a frequency negotiated with the State of Nevada.

\section{GENERAL INFORMATION}

1. Date of inspection:

$$
6-30-98
$$

2. Facility Manager (name and organization):

3. Reason for inspection: Monthly:

Problem Reported: Unusual Weather or other condition:

Provide any necessary details:

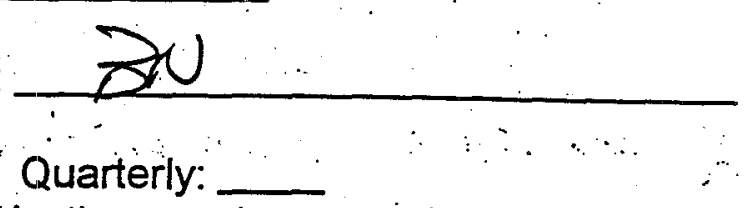
.............

4. Name, organization and telephone number of person reporting problem:

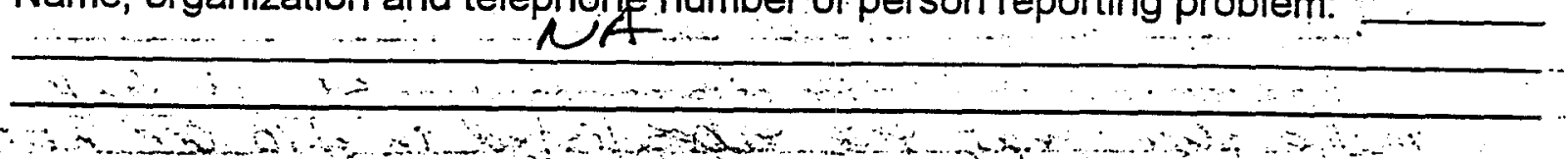

5. Describe weather conditions over the past few weeks (high winds, precipitation, local flooding): hot

\section{LANDFILL AREA}

6. Is the landfill area gate closed:

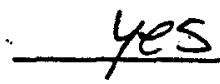
Locked:

yes

7. Describe the condition of the fencing (i.e., are repairs required?):

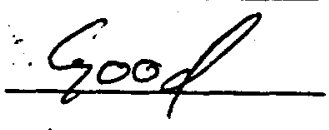

8. Describe the condition of the signs (missing, fading, damaged, etc.):

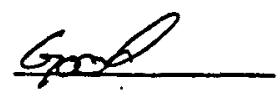

9. Is there excessive erosion of the two overland flow diversion trenches: If yes, describe: See $\$ 10$ 


\section{AREA 23 HAZARDOUS WASTE TRENCHES (Continued)}

10. Describe any subsidence, erosion, excessiye vegetation, gtc. on the landfill covers: Erosion from runoff has veated channels

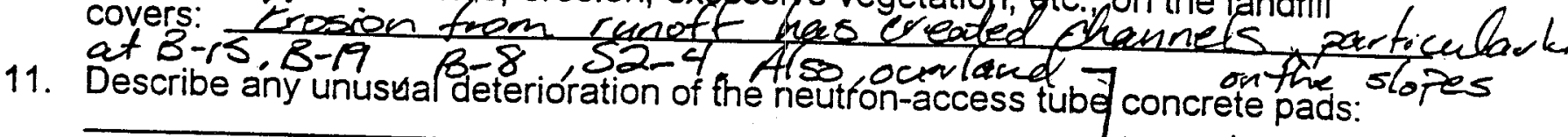

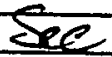

12. Are all neutron access tube covers closed: yes 13. Describe any unusual activity or condition which could impact the proper operation
of the covers:

\section{AREA SURROUNDING THE LANDFILL}

14. Describe any significant changes within several hundred feet of the unit. Changes can include construction, change in land usa, storage of materials nearby, soil 58. piles, change in use of the facility, etc.: fow is apporent at the south

15. Describe the effect (or possible effegt) of any changes noted above: Unknown -

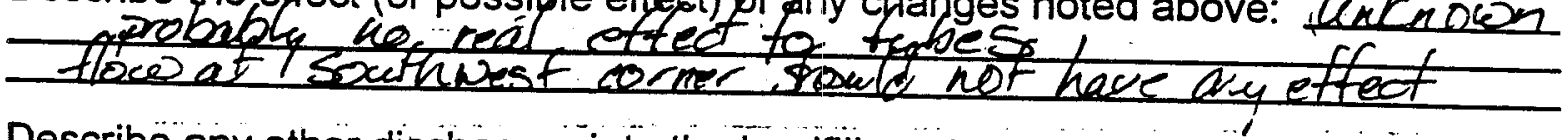

16. Describe any other discharges into the landfill or along the top of the landfill:

17. Additional comments observations, or recommendations: Shoceld check

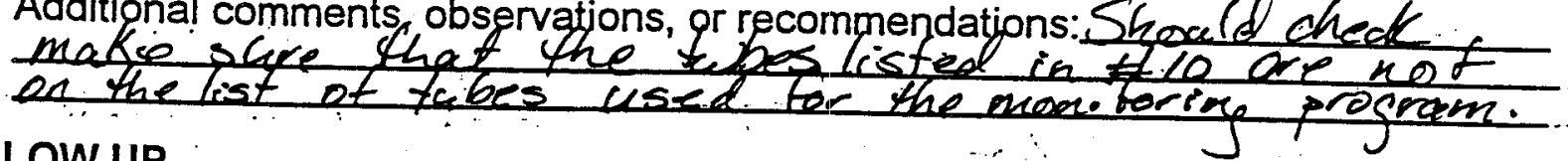

\section{FOLLOW UP}

18. Based on the findings indicated aboye, is an additional inspection required before the next scheduled inspection: 20 if yes, when will this inspection be
completed:

Any significant changes must be reported to the appropriate supervisor immediately. inspected by. Angefa Otson

Signed:

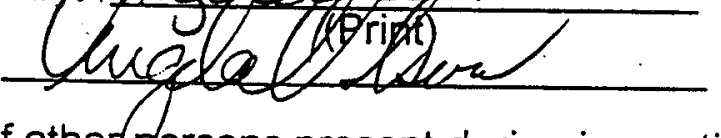

Date: $630-98$

Names of other(Dersons present during inspection (print): 


\section{AREA 23 HAZARDOUS WASTE TRENCHES (CAU 112) INSPECTION CHECKLIST}

Inspect the landfill and surrounding area. Look for any unusual changes such as water accumulation, chemical odors, deterioration of adjacent structures, etc. Refer to the previous inspection checklist in order to identify any changes. Do not rely on your memory. An inspection should be completed after a problem is reported by contractor, DOE, or Nevada Division of Environmental Protection personnel. At a minimum, routine inspections are to be completed at a frequency negotiated with the State of Nevada.

\section{GENERAL INFORMATION}

1. Date of inspection: $7-30-98$

2. Facility Manager (name and organizätion):

3. - Reason for inspection: Monthly: = Quarterly:

Problem Reported: Unusual Weather or other condition:

Provide any necessary details:

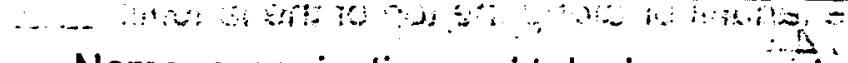

4. Name, organization and telephone number of person reporting problem:

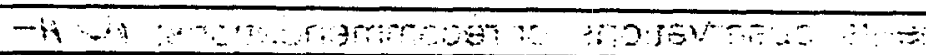

5.- Describe weather conditions over the past few weeks (high winds, precipitation, local flooding): windy raica

\section{LANDFILL AREA}

6. Is the landfill area gate closed: $y$ es Locked:

7. Describe the condition of the fencing (i.e., are repairs required? : in.

8. Describe the condition of the signs (missing, fading, damaged, etc.):

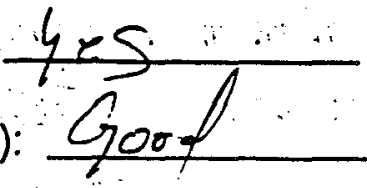

9. Is there excessive erosion of the two overland flow diversion trenches: ( $f^{\circ}$ If yes, describe: 
10. Describe any subsidence, erosion, excessive vegetation, etc., on the landfill covers: Noats

11. Describe any unusual deterioration of the nqutron-access tube concrete pads: Desceng

12. Are all neutron access tube covers closed: yes 13. Describe any unusual activity or condition which could impact the proper operation
of the covers:

\section{AREA SURROUNDING THE LANDFILL}

14. Describe any significant changes within several hundred feet of the unit. Changes can include construction, change in land use, storage of materials nearby, soil piles, change in use of the facility, etc.: NONE

15. Describe the effect (or possible effect) of any changes noted above: $N A$

16. Describe any other discharges into the landfill or along the top of the landfill: WA

17. Additional comments, observations, or recommendations: $N \mathbb{A}$

\section{FOLLOW UP}

18. Based on the findings indicated above, is an additional inspection required before the next scheduled inspection: No If yes, when will this inspection be completed:

Any significant changes mustbe reported to the appropriate supervisor immediately.

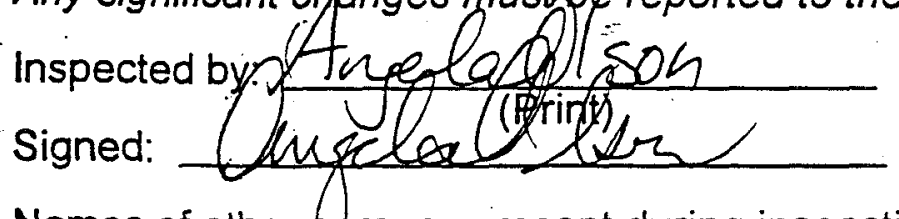

Date:

Names of other persons present during inspection (print): 


\section{Bechtel Nevada}

\section{AREA 23 HAZARDOUS WASTE TRENCHES (CAU 112) INSPECTION CHECKLIST}

Inspect the landfill and surrounding area. Look for any unusual changes such as water accumulation, chemical odors, deterioration of adjacent structures, etc. Refer to the previous inspection checklist in order to identify any changes. Do not rely on your memory. An inspection should be completed after a problem is reported by contractor, DOE, or Nevada Division of Environmental Protection personnel. At a minimum, routine inspections are to be completed at a frequency negotiated with the State of Nevada.

\section{GENERAL INFORMATION}

1. Date of inspection: $8 / 19 / 98$

2. Facility Manager (name and organization): $B N E R$

3. Reasoñ for inspection: "Monthly: $\chi$. Quarterly:

Problem Reported: ___ Unusual Weather or other condition:

Provide any necessary details:

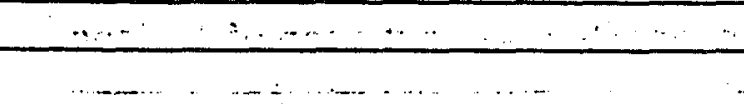

4. Name, organization and telephone number of person reporting problem:

5. Describe weather conditions over the past few weeks (high winds, precipitation, local flooding): Hof, windy, raing

\section{LANDFILL AREA}

6. Is the landfill area gate closed:

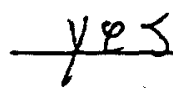

Locked:

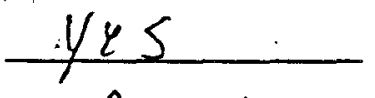

7. Describe the condition of the fencing (i.e., are repairs required?):

Good

8. Describe the condition of the signs (missing, fading, damaged, etc.): 1 s:ga appds repair - All others good.

9. Is there excessive erosion of the two overland flow diversion trenches: If yes, describe:

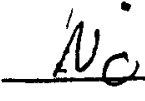


10. Describe any subsidence, erosion, excessive vegetation, etc., on the landfill covers: None

11. Describe any unusual deterioration of the neutron-access tube concrete pads: None

12. Are all neutron access tube covers closed: $y_{\ell} \leq$

13. Describe any unusual activity or condition which could impact the proper operation of the covers: Noun

\section{AREA SURROUNDING THE LANDFILL}

14. Describe any significant changes within several hundred feet of the unit. Changes can include construction, change in land use, storage of materials nearby, soil piles, change in use of the facility, etc.:

15. Describe the effect (or possible effect) of any changes noted above: $N / A$

16. Describe any other discharges into the landfill or along the top of the landfill: Noure 17. Additional comments, observations, or recommendations: Repair sign -
not eritical as many other Sighs in place.

\section{FOLLOW UP}

18. Based on the findings indicated above, is an additional inspection required before the next scheduled inspection: No If yes, when will this inspection be completed:

Significant changes noted must be notified to the ER Project Manager and Task Manager upon return to the office.

Inspected py; Shannon Parsons-Dyfuy

Date:

Names of other persons present during inspection (print):

Jerrel Ne/son 


\section{AREA 23 HAZARDOUS WASTE TRENCHES (CAU 112) INSPECTION CHECKLIST}

Inspect the landfill and surrounding area. Look for any unusual changes such as water accumulation, chemical odors, deterioration of adjacent structures, etc. Refer to the previous inspection checklist in order to identify any changes. Do not rely on your memory. An inspection should be completed after a problem is reported by contractor, $D O E$, or Nevada Division of Environmental Protection personnel. At a minimum, routine inspections are to be completed at a frequency negotiated with the State of Nevada.

\section{GENERAL INFORMATION}

1. Date of inspection:

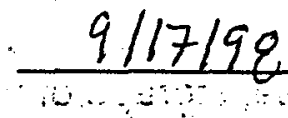

2. Facility Manager (name and organization):

3. Reason for inspection: Monthly: $K$ Quarterly:

Problem Reported: Unusual Weather or other condition:

Provide any necessary details:

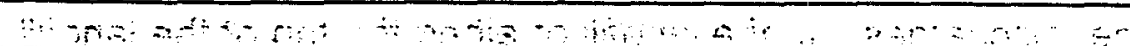
$\therefore \quad \therefore \therefore \therefore-1 ;$

4. - Name--organization and telephone number of person reporting problem:

5. Describe weather conditions over the past few weeks (high winds, precipitation, local flooding): Rainy to sunay and warn

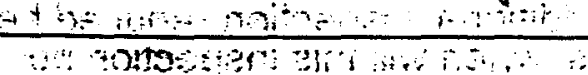

\section{LANDFILL AREA}

6. Is the landfill area gate closed:

$\frac{1}{1} 5$ Locked:

1. 25

7. Describe the condition of the fencing (i.e., are repairs required?): Qood

8. Describe the condition of the signs (missing, fading, damaged, etc.): cood

9. Is there excessive erosion of the two overland flow diversion trenches: $N_{0}$ If yes, describe: 
10. Describe any subsidence, erosion, excessive vegetation, etc., on the landfill covers: None

11. Describe any unusual deterioration of the neutron-access tube concrete pads: Abu

12. Are all neutron access tube covers closed: Yes

13. Describe any unusual activity or condition which could impact the proper operation. of the covers:

\section{AREA SURROUNDING THE LANDFILL}

14. Describe any significant changes within several hundred feet of the unit. Changes can include construction, change in land use, storage of materials nearby, soil piles, change in use of the facility, etc.: None

15. Describe the effect (or possible effect) of any changes noted above: $N / A$

16. Describe any other discharges into the landfill or along the top of the landfill: Neue

17. Additional comments, observations, or recommendations: Nou 4

\section{FOLLOW UP}

18. Based on the findings indicated above, is an additional inspection required before the next scheduled inspection: NC, If yes, when will this inspection be completed:

Significant changes noted must be notified to the ER Project Manager and Task Manager upon return to the office.

Inspected by: Shannon Parsons-Defry

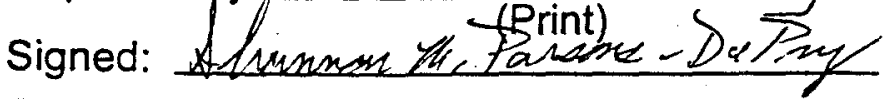

Date: $91 / 7 / 98$

Names of other persons present during inspection (print): 


\section{Bechtel Nevada}

AREA 23 HAZARDOUS WASTE: TRENCHES (CAU 112) INSPECTION CHECKLIST

Inspect the landfill and surrounding area. Look for any unusual changes such as water accumulation, chemical odors, deterioration of adjacent structures, etc. Refer to the previous inspection checklist in order to identify any changes. Do not rely on your memory. An inspection should be completed after a problem is reported by contractor, DOE, or Nevada Division of Environmental Protection personnel. At a minimum, routine inspections are to be completed at a frequency negotiated with the State of Nevada.

\section{GENERAL INFORMATION}

1. Date of inspection:

$10 / 21 / 98$

2. Facility Manager (name and organization):

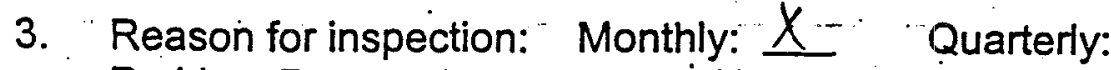

Problem Reported:

Provide any necessary details:

Unusual Weather or other condition:

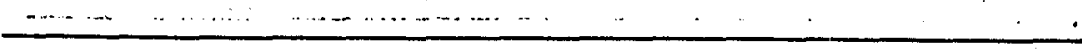

4. Name, organization and telephone number of person reporting problem:

5. Describe weather conditions over the past few weeks (high winds, precipitation, local flooding): sunny o mild -

\section{LANDFILL AREA}

6. Is the landfill area gate closed:

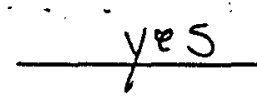

Locked: "yes

7. Describe the condition of the fencing (i.e., are repairs required?): $\mathrm{G} 60 \mathrm{~d}$

8. Describe the condition of the signs (missing, fading, damaged, etc.): A fe $w$ are loose. Repirs scheduled for noxt weel

9. Is there excessive erosion of the two overland flow diversion trenches: $N_{0}$ If yes, describe: 
10. Describe any subsidence, erosion, excessive vegetation, etc., on the landfill covers: None

11. Describe any unusual deterioration of the neutron-access tube concrete pads: None

12. Are all neutron access tube covers closed: yes

13. Describe any unusual activity or condition which could impact the proper operation of the covers: Noae

\section{AREA SURROUNDING THE LANDFILL}

14. Describe any significant changes within several hundred feet of the unit. Changes can include construction, change in land use, storage of materials nearby, soil piles, change in use of the facility, etc.: Nonce

15. Describe the effect (or possible effect) of any changes noted above: N/A

16. Describe any other discharges into the landfill or along the top of the landfill:

17. Additional comments, observations, or recommendations: …....Non $\varphi$

\section{FOLLOW UP}

18. Based on the findings indicated above, is an additional inspection required before the next scheduled inspection: $N_{0}$. If yes, when will this inspection be completed:

Significant changes.noted must be notified to the ER Project Manager and Task Manager upon retum to the office.

Inspected by:

Signed:

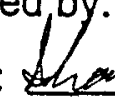

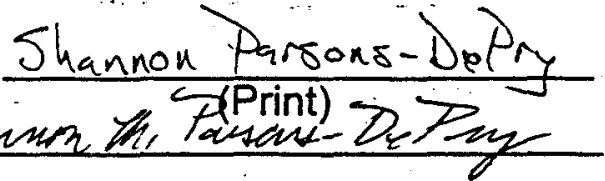

Date:

$10 / 21 / 98$

Names of other persons present during inspection (print): 
Monitoring Report CAU 112

Section: APPENDIX C

Revision: 0

Date: 2/4/1999

\section{APPENDIX C}

\section{SUBSIDENCE SURVEY PLAT}




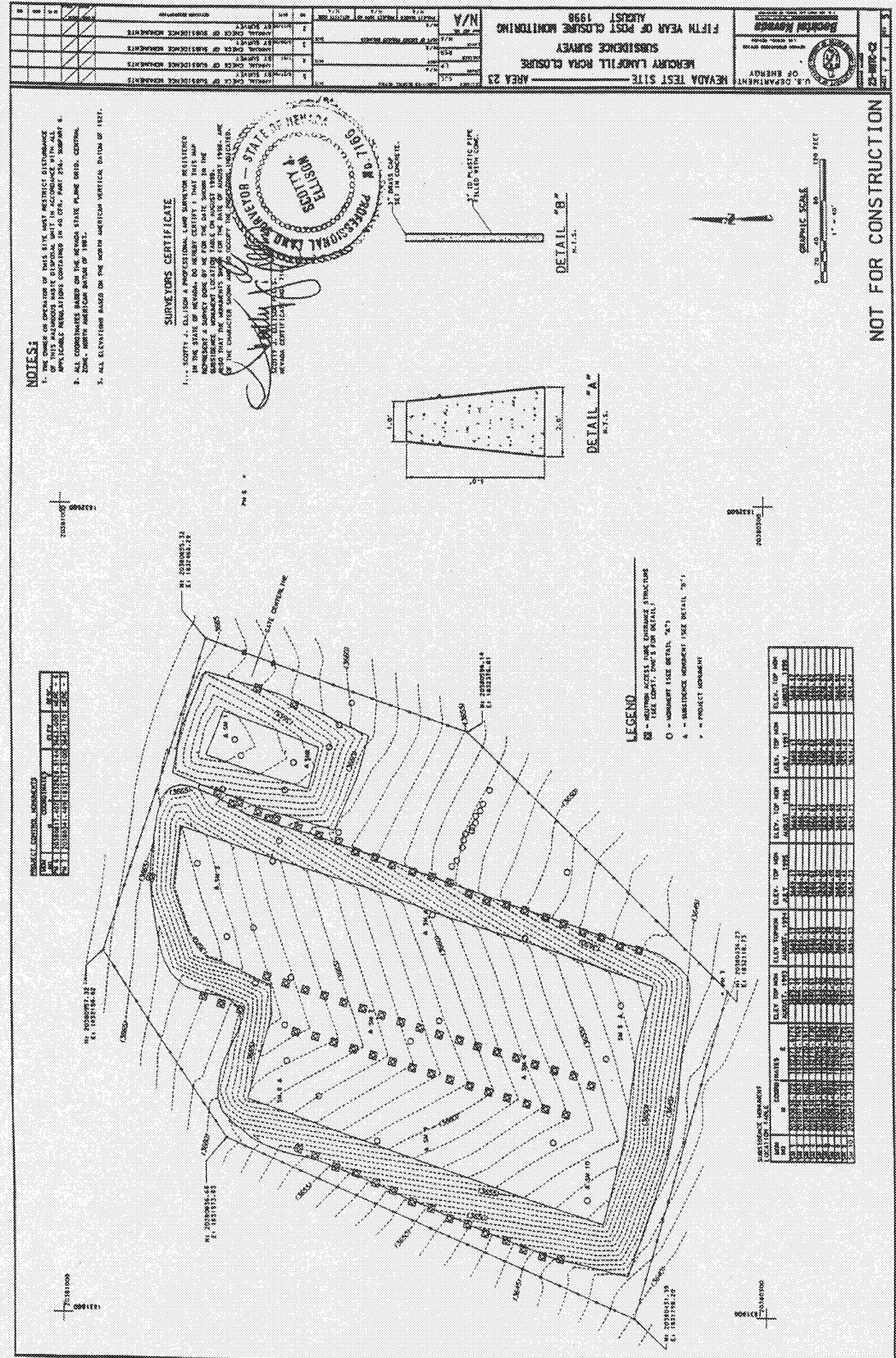


Monitoring Report CAU 112

Section: APPENDIX D

Revision: 0

Date: $2 / 4 / 1999$

APPENDIX D

PRECIPITATION RECORDS 


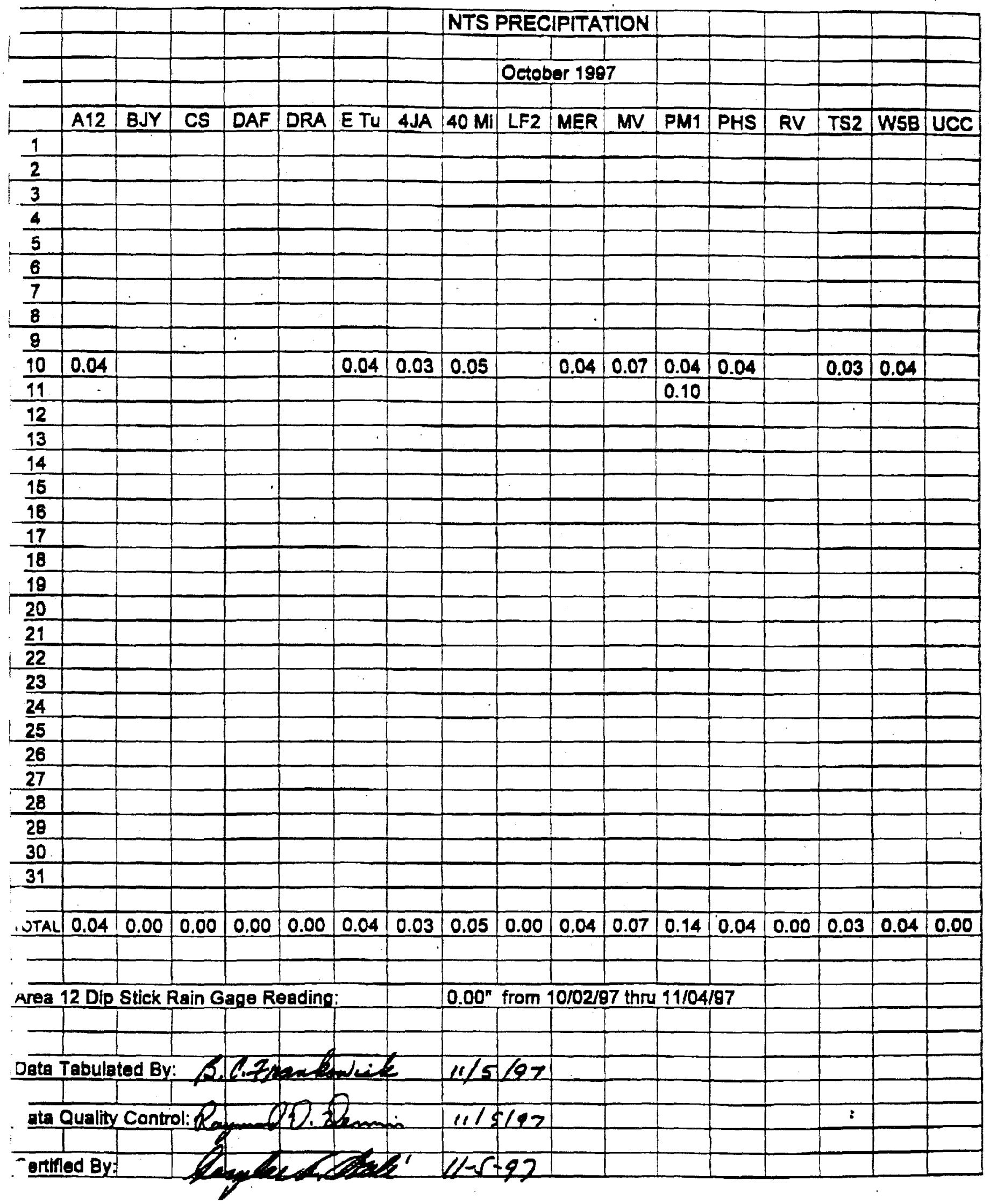




\begin{tabular}{|c|c|c|c|c|c|c|c|c|c|c|c|c|c|c|c|c|c|}
\hline & & & & & & & & \multicolumn{4}{|c|}{ NTS PRECIPITATION } & & & & & & \\
\hline & & & & & & & & & & & & & & & & & \\
\hline & & & & & & & & & \multicolumn{3}{|c|}{ November 1997} & & & & & 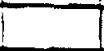 & \\
\hline & & & & & & & & & & & & & & & & & \\
\hline & A12 & BJY & $\mathrm{CS}$ & DAF & DRA & ETu & 4JA & $40 \mathrm{Mi}$ & LF2 & MER & MV & PM1 & PHS & RV & TS2 & W5B & UCC \\
\hline 1 & & & & & & & & & & & & & & & & & \\
\hline 2 & & & & & & & & & & & & & & & & & \\
\hline 3 & & & & & & & & & & & & & & & & & \\
\hline 4 & & & & & & & & & & & & & & & & & \\
\hline 5 & & & & & & & & & & & & & & & & & \\
\hline 6 & & & & $\therefore$ & & & & & & & & & & & & & \\
\hline 7 & & & & & & & & & & & & & & & & & \\
\hline 8 & & & & & & & & & & & & & & & 0.02 & & \\
\hline 9 & & & & & & & & & & & & & & & & & \\
\hline 10 & 0.47 & 0.23 & 0.35 & 0.07 & 0.43 & 0.37 & 0.24 & 0.32 & 0.44 & 0.41 & 0.46 & 0.15 & 0.23 & 0.26 & 0.27 & 0.37 & 0.28 \\
\hline 11 & 0.14 & & & 0.03 & & 0.18 & & 0.08 & 0.11 & & & 0.30 & 0,18 & & 0.07 & & \\
\hline 12 & & & & 0.02 & & & 0.08 & & 0.01 & & 0.04 & & & 0.10 & & 0.04 & \\
\hline 13 & 0.28 & 0.08 & & 0.18 & 0.08 & 0.28 & 0.10 & 0.22 & 0.19 & 0.13 & 0.07 & 0.25 & 0.22 & 0.34 & 0.09 & 0.01 & 0.27 \\
\hline 14 & 0.03 & & 0.11 & 0.05 & 0.03 & & & & 0.03 & 0.11 & & 0.08 & & 0.01 & & & 0.01 \\
\hline 15 & & & 0.01 & & & & & & & & & & & & & & \\
\hline 16 & & & & & & & & & & & & & & & & & \\
\hline 17 & & & & & & & & & & & & & & & & & \\
\hline 18 & & & & & & & & & & & & & & & & . & \\
\hline 19 & & & & & & & & & & & & & & & & & \\
\hline 20 & & & & & & & & & & & & & & & & & \\
\hline 21 & & & & & & & & & & & & & & & & & \\
\hline 22 & & & & & & & & & & & & & & & & & \\
\hline 23 & & & & & & & & & & & & & & & & & \\
\hline 24 & & & & & & & & & & & & & & & & & \\
\hline 25 & & & & & & & & & & & & & & & & & \\
\hline 28 & 0.35 & 0.12 & 0.15 & 0.02 & 0.10 & 0.52 & 0.30 & 0.44 & 0.38 & 0.13 & 0.32 & 0.24 & 0.21 & 0.07 & 0.18 & 0.12 & 0.13 \\
\hline 27 & 0.07 & & & & & & & & 0.02 & & & & & & & & \\
\hline 28 & 0.04 & & & & & & & & & & & & & & & & \\
\hline 29 & & & & & & & & & & & & & & & & & \\
\hline 30 & & & & & & & & & & & & & & & & & \\
\hline & & & & & & & & & & & & & & & & & \\
\hline & & & & & & & & & & & & & & & $\therefore$ & & \\
\hline TOTAL & 1.36 & 0.44 & 0.82 & 0.37 & 0.64 & 1.34 & 0.70 & 1.06 & 4.18 & 0.78 & 0.89 & 1.02 & 0.84 & \begin{tabular}{|l|}
0.78 \\
\end{tabular} & 0.63 & 0.54 & 0.7 \\
\hline & & & & & & & & & & & & & & & & & \\
\hline & & & & & & & & & & & & & & & & & \\
\hline Area & 12 Dip & Stlek & Rain $G$ & gge $R$ & ading & & 1.07 & $11 / 04$ & $97 \mathrm{thr}$ & 41210 & $2 / 97$ & & & & & & \\
\hline & & & & & & & & & & & & & & & & & \\
\hline & & & & & & & & & & & & & & & & & \\
\hline Data 7 & Tabule & $\operatorname{tod}$ By & & & & & 3 & 12 & $4 \angle 9$ & 2 & & & & & & & \\
\hline & & & & & & & & & & & $L$ & & & & & & \\
\hline Data & Qualit & Contr & ol: 2 & & (2) & 2 & ن & 12 & $\mathrm{IHC}$ & 27 & & & & & & & \\
\hline & & & & & & & & & & & & 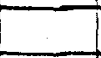 & & & $:$ & & E \\
\hline Centlif & $\operatorname{ed} B y$ & & & & $6 E$ & 2 & & 12 & $4 / 9$ & 7 & & & & & & & \\
\hline
\end{tabular}




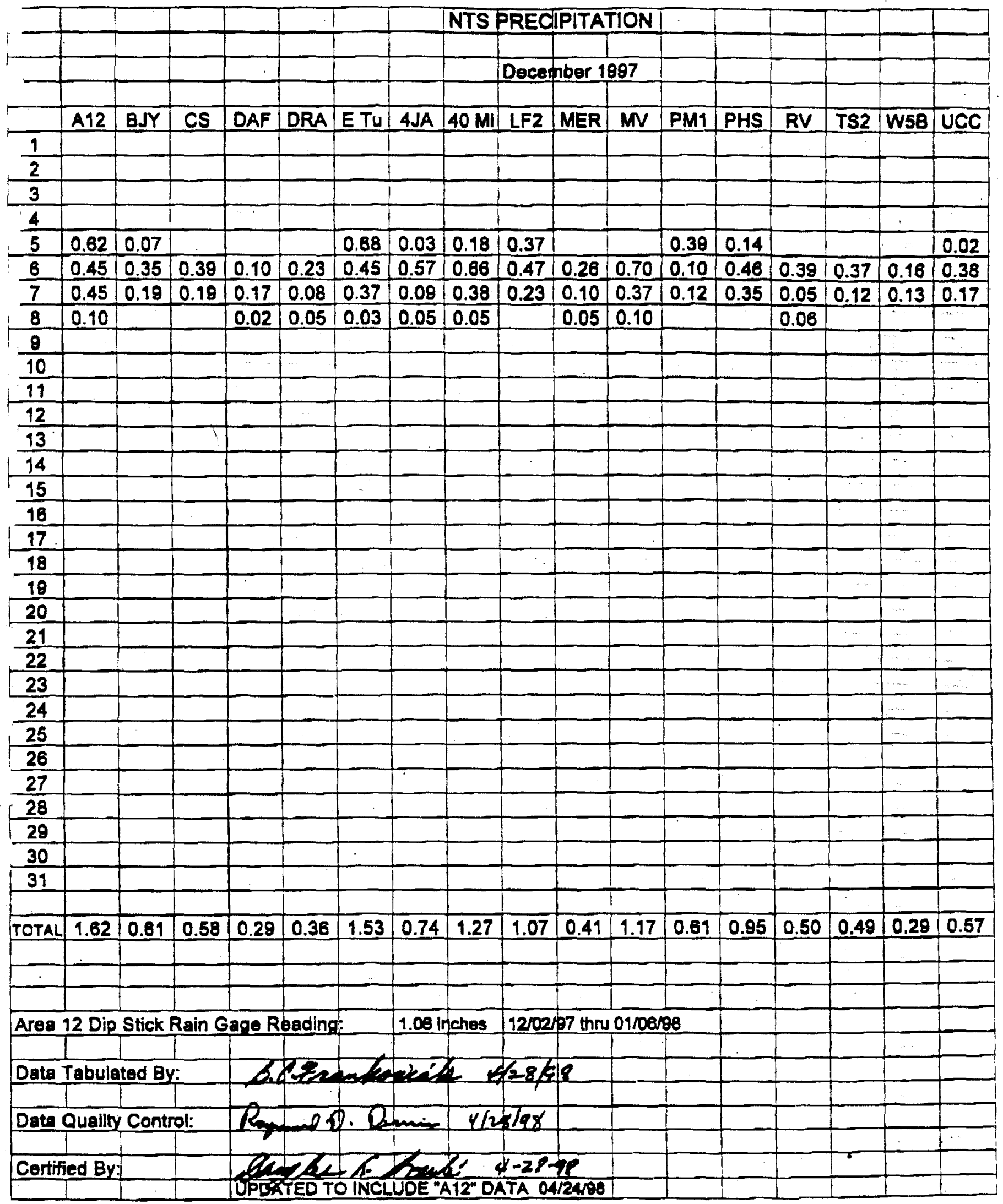




\begin{tabular}{|c|c|c|c|c|c|c|c|c|c|c|c|c|c|c|c|c|c|}
\hline & & & & & & & & NTS & PREC & DPITAT & TION & & & & & & \\
\hline & & & & & & & & & & & & & & & & & \\
\hline & & & & & & & & & Janue & by 1998 & & & & & & & \\
\hline & & & & & & & & & & & & & & & & & \\
\hline & A12 & BJY & CS & DAF & DRA & ETu & 4JA & $40 \mathrm{MI}$ & LF2 & MER & $M V$ & $P M 1$ & PHS & RV & TS2 & W5B & $\mathrm{UC}$ \\
\hline 1 & & & & & & & & &. & & & & & & : & & \\
\hline 2 & & & & & & & & & & &. & & & & & & \\
\hline 3 & & & & & & & & & & & & & & & & & \\
\hline 4 & 0.21 & 0.03 & 0.14 & 0.04 & 0.14 & 0.20 & 0.03 & 0.15 & 0.07 & 0.12 & 0.15 & 0.22 & 0.10 & 0.25 & 0.02 & 0.10 & 0.15 \\
\hline 5 & 0.03 & & & 0.02 & & 0.02 & & 0.08 & 0.03 & & 0.04 & 0.02 & 0.01 & 0.02 & 0.05 & & 0.0 \\
\hline 6 & & & & & & & & & & & & & & & & & \\
\hline 7 & & & & & & & & & & & & & & & & & \\
\hline 8 & & & & & & & & & & & & & 0.03 & & & & \\
\hline 9 & 0.05 & 0.15 & 0.08 & & 0.12 & 0.13 & 0.18 & 0.08 & 0.10 & 0.10 & 0.10 & 0.10 & 0.03 & 0.17 & 0.07 & & $0.0 y$ \\
\hline 10 & 0.12 & 0.05 & 0.14 & 0.03 & 0.14 & 0.07 & 0.07 & 0.08 & 0.03 & 0.14 & 0.17 & 0.07 & 0.01 & 0.04 & 0.03 & & 0.1 .7 \\
\hline 11 & 0.05 & & & 0.02 & & & & & & & 0.06 & & & & & & \\
\hline 12 & 0.10 & 0.05 & & & & 0.07 & & & & & & .10 & & & & & \\
\hline 13 & & & & 0.03 & & & & & & & & & & & & & \\
\hline 14 & & & & & & & & & & & 0.03 & & & & & & \\
\hline 15 & & & & & & & & & & & & & & & & & \\
\hline 16 & & & & & & & & & & & & & & & & & \\
\hline 17 & & & & & & & & & & & & & & & & & \\
\hline 18 & & & & & & & & & & & & & & & & & \\
\hline 19 & & & & & & & & & & & & & & & & & \\
\hline 20 & & & & & & & & & & 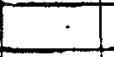 & & & & 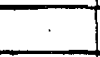 & & & \\
\hline 21 & & & & & & & & & & & & & & & & & \\
\hline 22 & & & & & & & & & & & & & & & & & \\
\hline 23 & & & & & & & & & & & & & & & & & \\
\hline 24 & & & & & & & & & & & & & & & & & \\
\hline 25 & & & & & & & & & & & & & & & & & \\
\hline 28 & & & & & & & & & & & & & & & & & \\
\hline 27 & & & & & & & & & & & & & & & & & \\
\hline 28 & & & & & & & & & & & & & & & & & \\
\hline 29 & 0.15 & 0.15 & 0.07 & 0.29 & 0.07 & 0.23 & 0.18 & 0.08 & 0.13 & 0.13 & 0.10 & 0.20 & 0.22 & 0.07 & 0.28 & 0.05 & $0.2 \mathrm{~B}^{-1}$ \\
\hline 30 & 0.05 & & & 0.05 & & & & 0.05 & & 0.01 & 0.05 & & 0.03 & & & 0.07 & \\
\hline 31 & & & & & & & & & & & & & & & & 0.07 & 0.1 \\
\hline & & & & & & & & & & & & & & & & & \\
\hline TOTAL & 0.78 & 0.43 & 0.41 & 0.48 & 0.47 & 0.72 & 0.46 & 0.48 & 0.36 & 0.50 & 0.70 & 0.71 & 0.43 & 0.55 & 0.45 & 0.29 & 0.5 \\
\hline & & & & & & & & & & & & & & & & & \\
\hline & & & & & & - & & & & & & & & & & & \\
\hline & & & & & & & & & & & & & & & & & 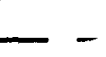 \\
\hline Area 1 & 12 Dio & Stick & Rain G & $9 g 0 R$ & gadlng & & $.70 \mathrm{lnd}$ & heg & $01 / 03$ & 88 thru & $02102 \pi$ & & & & & & \\
\hline & & & & & & & & & & & & & & & & & \\
\hline Data T & Tabule & $\operatorname{ted} B y$ & & & & & & & 46: & $34 \sqrt{9}$ & & & & & & & L- \\
\hline & & & & & & & & & & & & & & & & & \\
\hline Data & Quality & Contn & & & & & & & 04 & $24 / 68$ & & & & & & & \\
\hline Cortifin & $\operatorname{lod} 8 y$ & & & $y$ & & & & & 106 & 60479 & & & & & & & \\
\hline & & & & UPDA & TED T & OINCL & UDE $A$ & $\frac{1}{122^{n}}$ & TTA OA & 12498 & & & & & & & \\
\hline
\end{tabular}




\begin{tabular}{|c|c|c|c|c|c|c|c|c|c|c|c|c|c|c|c|c|c|}
\hline & & & & 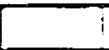 & & & & NTS & PREC & IPITA & TION & & & & & $\ldots$ & $\cdots$ \\
\hline & & & & & & & & & & & & & & & & $\cdots$ & \\
\hline & & & & & & & & & Febru & an 19 & & & & & & - & \\
\hline & & & & & & & & & & & & & & & & & - \\
\hline & A12 & BJY & CS & DAF & DRA & E Tu & 4JA & $40 \mathrm{MI}$ & LF2 & MER & MV & $P M 1$ & PHS & RV & TS2 & W6B & UCC \\
\hline 1 & & & & 0.02 & & & & & & & 0.05 & 0.02 & & 0.05 & & 0.03 & 0.02 \\
\hline 2 & 0.25 & 0.10 & 0.25 & 0.05 & 0.18 & 0.21 & 0.20 & 0.01 & 0.15 & 0.18 & 0.02 & 0.08 & 0.16 & 0.20 & 0.08 & $\cdots$ & 0.18 \\
\hline 3 & 0.82 & 0.23 & 0.86 & 0.37 & 0.44 & 0.48 & 0.88 & 0.68 & 0.87 & 0.41 & 0.70 & 0.13 & 0.24 & 0.48 & 0.42 & 0.17 & 0.70 \\
\hline 4 & 0.07 & 0.05 & 0.08 & 0.10 & 0.03 & 0.17 & 0.07 & 0.19 & 0.18 & 0.04 & & 0.20 & 0.09 & & 0.18 & 0.13 & 0.03 \\
\hline 5 & & & & 1 & & & & & & & & & & & & 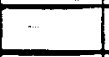 & $\cdots$ \\
\hline 6 & 0.81 & 0.58 & 0.54 & 0.45 & 0.16 & 0.59 & 0.48 & 0.49 & 0.49 & 0.18 & 0.74 & 0.08 & 0.58 & 0.40 & 0.38 & 0.37 & 0.53 \\
\hline 7 & 0.30 & 0.11 & 0.50 & 0.13 & 0.08 & 0.30 & 0.41 & 0.14 & 0.13 & 0.10 & 0.56 & 0.02 & 0.11 & 0.47 & 0.20 & 0.05 & 0.05 \\
\hline 8 & 0.23 & 0.04 & 0.07 & 0.20 & & 0.08 & 0.01 & \begin{tabular}{|l|}
0.11 \\
\end{tabular} & 0.11 & 0.01 & & 0.30 & 0.22 & & 0.20 & 0.07 & 0.02 \\
\hline 9 & 0.02 & & & & 0.02 & & & & & & & & & & $\cdots$ & & $\cdots$ \\
\hline 10 & & & & & & & & & & & & & & & & $-\infty$ & - \\
\hline 11 & & & & & & & & & & & & & & & & $=$ & $-\cdots$ \\
\hline 12 & 0.10 & 0.02 & 0.01 & 0.04 & 0.01 & 0.08 & & 0.02 & 0.02 & & 0.01 & 0.09 & 0.04 & & 0.03 & & \\
\hline 13 & 0.03 & 0.01 & 0.03 & 0.04 & & 0.02 & 0.01 & 0.03 & 0.03 & & 0.01 & & 0.02 & & 0.05 & & 0.01 \\
\hline 14 & 0.96 & 0.88 & 0.58 & 0.20 & 0.12 & 0.85 & 0.78 & 0.63 & 0.61 & 0.19 & 1.60 & 0.49 & 1.17 & 0.48 & 0.40 & 0.20 & 0.87 \\
\hline-15 & 0.07 & 0.04 & 0.05 & 0.10 & 0.05 & 0.07 & 0.03 & 0.14 & 0.16 & 0.01 & 0.25 & 0.05 & 0.10 & 0.02 & 0.14 & 0.02 & 0.03 \\
\hline 16 & 0.16 & & & & & 0.32 & 0.08 & & & & & 0.01 & & 0.10 & -1 & - & $\ldots$ \\
\hline 17 & 0.36 & 0.44 & 0.53 & 0.35 & 0.46 & 0.30 & 0.52 & 0.18 & 0.16 & 0.35 & 0.51 & 0.17 & 0.22 & 0.44 & 0.13 & 0.30 & 0.55 \\
\hline 18 & & 0.02 & 0.05 & 0.10 & & 0.08 & 0.05 & 0.03 & 0.04 & & 0.08 & & 0.05 & 0.03 & 0.02 & 0.03 & 0.05 \\
\hline 18 & 0.23 & 0.12 & 0.23 & 0.13 & 0.20 & \begin{tabular}{|l|}
0.51 \\
\end{tabular} & 0.33 & 0.16 & 0.08 & 0.17 & 0.35 & & 0.05 & 0.43 & 0.05 & 0.04 & 0.19 \\
\hline 20 & 0.20 & 0.33 & 0.20 & 0.33 & 0.41 & 0.04 & $0.25 \mathrm{e}$ & 0.2 & 0.14 & 0.28 & 0.25 & 0.11 & 0.25 & 0.05 & 0.12 & 0.30 & 0.24 \\
\hline 21 & 0.03 & 0.04 & 0.06 & 0.05 & & 0.03 & 0.050 & 0.04 & 0.03 & & 0.07 & & & 0.03 & 0.02 & 0.03 & \\
\hline 22 & & & & & & & & & & & 0.08 & & & & & $2 \ldots$ & $\cdots$ \\
\hline 23 & 2.98 & 2.300 & $1.68 \mathrm{a}$ & $1.63 \mathrm{e}$ & 2.18 & 2.45 & $1.70 \mathrm{e}$ & 1.65 & $1.81 \mathrm{e}$ & 1.84 & 2.410 & 0.66 & 2.33 & 2.51 & $1.58 \mathrm{\theta}$ & 1.60 & 2.100 \\
\hline 24 & 0.35 & 0.280 & 0.520 & $0.49 \mathrm{el}$ & 0.34 & 0.38 & $0.40 \mathrm{e}$ & 0.45 & 0.480 & 0.33 & $0.27 \mathrm{e}$ & 0.15 & 0.29 & 0.30 & $46 \theta$ & 0.45 & 0.200 \\
\hline 25 & & & & & & & & & & & & & & & & $\cdots$ & \\
\hline 28 & & & & & & & & & & & & & & & & & $\ldots$ \\
\hline 27 & & & & & & & & & & & & & & & & & \\
\hline 28 & & & & & & & & & & & & & & & & $=$ & \\
\hline & & & & & & & & & & & & & & & & & 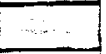 \\
\hline & & & & & & & & & & & & & & & & - & $-\ldots$ \\
\hline & & & & & & & & & & & & & & & & - & $\therefore$ \\
\hline & & & & & & & & & & & & & & & & $E$ & $\cdots$ \\
\hline OTAL & 7.77 & $5.68 \mathrm{~g}$ & 6.040 & $4.71 \mathrm{e}$ & 4.64 & 6.88 & $6.26 \theta$ & 5.15 & 5.080 & 4.10 & $7.98 \mathrm{e}$ & 2.57 & 5.92 & 5.97 & 4.430 & 3.79 & 5.570 \\
\hline & & & & & & & & & & & & & & & & $E$ & $\infty$ \\
\hline & & & & & & & & & & & & & & & 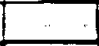 & $\ldots$ & \\
\hline 0 & Estime & ted val & lues. & & & & & & & & & & & & $\dot{-}$ & $+\infty$ & \\
\hline & & & & & & & & & & & & & & & & $\ldots$ & \\
\hline & & & & & & & & & & & & & & & & & 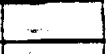 \\
\hline$\overline{\text { Area }}$ & 12 Dip & Stick & Rain G & $\overline{81}$ & ding & & 8.1010 & Dethen & $02 / 02 /$ & 88 thru & $03102 / 8$ & & & & & & \\
\hline & & & & & & & & & & & & & & & & & \\
\hline Dats & bul & d 1 & & & & & & & 472 & 142 & 1 & & & & & & \\
\hline & & & & & & & & & & & & & & & & & +6 \\
\hline Data & Qualls & Contr & & & & $\pi$ & & & 0412 & $24 / 9$ & & & & & & & \\
\hline & & & & & & & & & & & & & 1. & & & & \\
\hline Cortff & $\operatorname{lod} B y$ & & & $+2<6$ & & & & & 04 & $24 / 9$ & & & & & & & \\
\hline & & & & UUPDA & TED TS & $O$ INCL & UDE & $12^{-1}$ & ITAOA & 12408 & & & & & & & \\
\hline
\end{tabular}




\begin{tabular}{|c|c|c|c|c|c|c|c|c|c|c|c|c|c|c|c|c|c|}
\hline & & & & & & & & \multicolumn{4}{|c|}{ NTS PRECIPITATION } & & & & & & \\
\hline & & & & & & & & & & & & & & & & & \\
\hline & & & & & & & & & March & 1998 & & & & & & & \\
\hline & & & & & & & & & & & & & & & & & \\
\hline & A12 & BJY & $\mathrm{CS}$ & DAF & DRA & ETu & $4 \mathrm{JA}$ & $40 \mathrm{MI}$ & LF2 & MER & MV & PM1 & PHS & RV & TS2 & W5B & $\overline{U C C}$ \\
\hline 1 & & & & & & & & & . & & & & & & & & \\
\hline 2 & & & & & & & & & & & & & & & & & \\
\hline 3 & & & & & & & & & & & & & & & & & \\
\hline 4 & & & & & & & & & & & & & & & & & \\
\hline 5 & 0.05 & & & & 0.07 & 0.08 & & 0.04 & 0.02 & 0.04 & 0.10 & & 0.03 & 0.03 & & 0.05 & 0.02 \\
\hline 8 & 0.18 & 0.12 & 0.09 & & 0.08 & 0.12 & 0.08 & 0.10 & 0.07 & 0.08 & 0.12 & 0.11 & 0.15 & 0.17 & & 0.07 & 0.08 \\
\hline 7 & 0.03 & & & 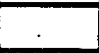 & & & 0.15 & & & & & & & & & & \\
\hline 8 & & & & & & & & & & & & & & & & & \\
\hline 9 & & & & & & & & & & & & & & & & & \\
\hline 10 & & & & & & & & & & & & & & & & & \\
\hline 11 & & & & & & & & & & & & & & & & & \\
\hline 12 & & & & & & & & & & & & & & & & & \\
\hline 13 & 0.23 & 0.07 & 0.10 & 0.02 & 0.03 & 0.20 & 0.48 & 0.18 & 0.12 & 0.05 & 0.02 & 0.18 & 0.40 & 0.27 & 0.07 & 0.08 & 0.11 \\
\hline 14 & 0.25 & & & & 0.03 & 0.10 & & & 0.07 & 0.03 & & 0.04 & & & 0.03 & & \\
\hline 15 & & & & 0.02 & & & & & & & & 0.01 & & & & & \\
\hline 18 & & 0.05 & 0.02 & 0.01 & & & 0.02 & 0.58 & & & & 0.03 & 0.04 & 0.08 & & & \\
\hline 17 & & & & & & & & & & & & & & & & & \\
\hline 18 & & & & & & & & & & & & & & & & & \\
\hline 19 & & & & & & & & & & & & & & & & & \\
\hline 20 & & & & & & & & & & & & & & & & & \\
\hline 21 & & & & & & & & & & & & & & & & & \\
\hline 22 & & & & & & & & & & & & & & & & & \\
\hline 23 & & & & & & & & & & & & & & & & & \\
\hline 24 & & & & & & & & & & & & & & & & & 0.02 \\
\hline 25 & 0.13 & 0.79 & 0.65 & 0.40 & 0.11 & 0.77 & 1.05 & 0.85 & 0.85 & 0.22 & 0.80 & 0.81 & 0.85 & 0.87 & 0.84 & 0.50 & 0.68 \\
\hline 26 & 0.03 & 0.03 & 0.02 & 0.05 & 0.58 & 0.36 & & 0.38 & 0.23 & 0.50 & 0.12 & 0.27 & 0.28 & & 0.23 & 0.02 & \\
\hline 27 & 0.02 & 0.08 & 0.18 & 0.10 & & 0.18 & & 0.03 & 0.03 & & 0.32 & 0.11 & \begin{tabular}{|l|}
0.10 \\
\end{tabular} & 0.07 & 0.08 & 0.07 & $0.1 \overline{1}$ \\
\hline 28 & 0.15 & 0.30 & 0.00 & 0.08 & 0.18 & 0.34 & 0.08 & 0.28 & 0.19 & 0.20 & 0.50 & 0.29 & 0.30 & 0.09 & 0.27 & 0.10 & 0.26 \\
\hline 29 & 0.09 & 0.08 & & 0.09 & & 0.08 & 0.05 & 0.02 & 0.05 & & 0.08 & 0.10 & 0.15 & & 0.03 & & 0.05 \\
\hline 30 & & & & 0.03 & & & & & & & & & 0.02 & & & & \\
\hline 31 & 0.30 & 0.18 & 0.29 & 0.07 & & 0.22 & 0.37 & 0.23 & 0.20 & & 0.28 & 0.12 & 0.03 & 0.40 & 0.25 & 0.12 & $0.2 i$ \\
\hline & & & & & & & & & & & & & & & & & \\
\hline TOTAL & 1.44 & 1.67 & 1.44 & 0.87 & 1.10 & 2.45 & 2.26 & 2.50 & 1.83 & 1.12 & 2.32 & 2.07 & 2.35 & 1.98 & 1.60 & 1.01 & $1.5 !$ \\
\hline & & & & & & & & & & & & & & & & & \\
\hline & & & & & & & & & & & & & & & & & \\
\hline & & & & & & & & & & & & & & & & & \\
\hline & & & & & & & & & & & & & & & & & \\
\hline Area & 2Dlp & Stick & Raln $Q$ & $990 . F$ & gadingt & & $3.25 \mathrm{kr}$ & ches & $03 / 02$ & 88 thru & $04 / 021$ & & & & & & \\
\hline & & & & & & & & & & & & & & & & & \\
\hline Data & Tabu & $=$ & & & & & & & $4 / 2$ & $\sqrt{98}$ & & & & & & & \\
\hline & & & & & & & & & & & & & & & & & \\
\hline Data & 2uallyy & Contr & & & & 0.0 & & 0 & $4 / 24$ & $\sqrt{18}$ & & & & & $\div$ & & \\
\hline & 7 & & & & & & & & 7 & & & & & & & & \\
\hline Certifi & ed. By: & & & & $=-7$ & $5 \mathrm{NC}$ & 6 & & $6 / 28$ & 879 & & & - & & & & \\
\hline
\end{tabular}




\begin{tabular}{|c|c|c|c|c|c|c|c|c|c|c|c|c|c|c|c|c|c|}
\hline & & & & & & T & & \multicolumn{5}{|c|}{ NTS PRECIPITATIONI } & 1 & & \multirow{2}{*}{ 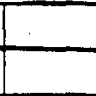 } & \multirow{2}{*}{$\frac{1}{t}$} & \\
\hline & & & & & & & & & & & & & & & & & \\
\hline & & & & & & & & & April & 1898 & & & & & & & \\
\hline & & & & & & & & & & & & 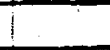 & & & & & \\
\hline & A12 & BJY & $\mathrm{CS}$ & DAF & DRA & ETU & $4 J A$ & $40 \mathrm{MI}$ & LF2 & MER & MV & PM1 & PHS & RV & TS2 & W5B & UCC \\
\hline 1 & 0.37 & 0.24 & 0.10 & 0.17 & 0.26 & 0.35 & 0.02 & 0.15 & 0.28 & 0.13 & 0.23 & 0.10 & 0.34 & 0.02 & 0.20 & 0.12 & 0.37 \\
\hline 2 & 0.01 & & & & & 0.01 & & 0.01 & 0.02 & & & & & & & & \\
\hline 3 & & & 0.03 & & 0.08 & 0.09 & & & & 0.11 & & 1 & & & & 0.11 & 0.05 \\
\hline 4 & & & & & & & & & & & & $T$ & & & & & \\
\hline 5 & & & & & & & & 1 & & & & 0.10 & & & & & \\
\hline 8 & 0.19 & 0.10 & 0.18 & 0.13 & 0.10 & 0.14 & 0.33 & 0.21 & 0.18 & 0.07 & 0.18 & 0.13 & 0.08 & 0.12 & 0.04 & 0.13 & 0.27 \\
\hline 7 & & & & 0.02 & & & & & & & & 1 & & & & 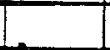 & \\
\hline 8 & & & & & & & & & & & & 1 & & & & & \\
\hline 8 & & & & & & & & & & & & 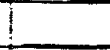 & & & & & \\
\hline 10 & & & & & & & & & & & & & & & & & \\
\hline 11 & & & & & & & & & & & & 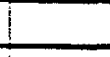 & & & & 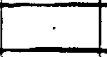 & \\
\hline 12 & 0.17 & 0.13 & 0.04 & 0.06 & 0.04 & 0.13 & 0.21 & 0.03 & 0.09 & 0.05 & 0.12 & 0.22 & 0.17 & 0.05 & 0.03 & 0.05 & 0.10 \\
\hline 13 & & & & & & & & & & & & & & & & & 0.02 \\
\hline 14 & 0.12 & 0.11 & & & & 0.10 & & 0.27 & 0.05 & & & 0.07 & 0.05 & 0.08 & 0.08 & & 0.02 \\
\hline 15 & & & & & 0.01 & & & & & 0.02 & . & & & & 0.02 & & 0.03 \\
\hline 16 & & & & & & & & & & & & & & & & & \\
\hline 17 & & & & & & & & & & & & & & & & & \\
\hline 18 & & & 2 & & & & & & & & & & & & & & \\
\hline 19 & & & & & & & & & & & & T & & & & & \\
\hline 20 & & & & & & & & & & & & & & & & & \\
\hline 21 & & & & & & & & & & & & & & & & & \\
\hline 22 & & & & & & & & & & & & & & & & & \\
\hline 23 & & & & & & & & & & & & & & & & & \\
\hline 24 & & & & & & & & & & & & & & & & & \\
\hline 25 & 0.23 & 0.08 & 0.20 & 0.31 & 0.44 & 0.25 & 0.25 & 0.21 & 0.04 & 0.58 & 0.25 & 0.35 & 0.24 & 0.28 & 0.25 & 0.16 & 0.23 \\
\hline 26 & & & & 0.02 & & & & & & & & & & & & & \\
\hline 27 & & & & & & & & & & & & 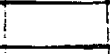 & & & & & \\
\hline 28 & & & & & & & & & & & & $\mathrm{i}$ & & & & & \\
\hline 29 & & & & & & & & & & & & & & & & & \\
\hline 30 & & & & & & & & & & & & & & & & & \\
\hline & & & & & & & & & & & & & & & & & \\
\hline & & & & & & & & & & & & & & & & & \\
\hline rOTAL & 1.08 & 0.86 & 0.55 & 0.71 & 0.93 & 1.07 & 0.89 & 0.88 & 0.66 & 0.96 & 0.78 & 0.87 & 0.88 & 0.53 & 0.62 & 0.57 & 1.09 \\
\hline & & & & & & & & & & & & & & & & & \\
\hline NOTE & & & & & & & & & & & & & & & & & \\
\hline & & & & & & & & & & & & $i$ & & & & & \\
\hline Area & $2 \mathrm{Dlo}$ & Stick f & $\operatorname{Ran} \mathrm{G}$ & $a g e R$ & eading & & $.70 \mathrm{lnc}$ & thes & 0402 & 88 thru & $05 / 05$ & & & & & & \\
\hline & & & & & & & & & & & & & & & & & \\
\hline Data & Tabule & $\operatorname{ted} B y$ & & & & 2) & & & & 05 & 261 & er & & & & & \\
\hline & & & & & & & & & & & & & & & & & \\
\hline Data & Quallh & Contr & & 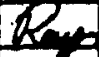 & & 2. & D. & $\min$ & & $5 / 0$ & $6 / 98$ & & & & $\cdot$ & & \\
\hline Certifi & od By & & & 9 & 7 & & & & & $5 / 0$ & 198 & & & & & & \\
\hline
\end{tabular}




\begin{tabular}{|c|c|c|c|c|c|c|c|c|c|c|c|c|c|c|c|c|c|}
\hline & & & & & & L & & \multicolumn{4}{|c|}{ NTS PRECIPITATION } & & & & & & \\
\hline & & & & & & & & & & & & & & & & & \\
\hline & & & & & & & & & May 1 & 898 & & & & & & & \\
\hline & & & & & & & & & & & & & & & & & \\
\hline & A12 & B.JY & $\mathrm{CS}$ & DAF & DRA & ETu & 4JA & $40 \mathrm{Mi}$ & LF2 & MER & MV & PM1 & PHS & RV & TS2 & W58 & UC. \\
\hline 1 & & & & & & & & & I & & & & & & & & \\
\hline 2 & 0.03 & & & & & & & 0.01 & 0.02 & & & 0.01 & & & & 0.01 & 0.0 \\
\hline 3 & & & & & & & & & & & & & & & & & $0.0_{1}$ \\
\hline 4 & 0.02 & & 0.02 & & & & 0.02 & & & 0.04 & 0.01 & 0.01 & 0.03 & & & 0.02 & $0.1^{n}$ \\
\hline 5 & 0.13 & 0.13 & 0.13 & 0.02 & 0.05 & 0.25 & 0.25 & 0.30 & 0.18 & & 0.48 & 0.23 & 0.37 & 0.10 & 0.05 & 0.03 & 0.0 \\
\hline 8 & 0.11 & 0.20 & & 0.02 & & & & & 0.02 & & 0.05 & & 0.07 & & 0.12 & & \\
\hline 7 & 0.10 & & 0.07 & 0.06 & & & & 0.20 & 0.08 & & & & 0.17 & 0.04 & 0.02 & & \\
\hline$B$ & & & & & & & & & & & & & & & & & \\
\hline 8 & & & & & & & & & & & & & & & & & \\
\hline 10 & & & & & & & & & & & & & & & & & \\
\hline 11 & & & & & & & & & & & & & & & & & \\
\hline 12 & 0.54 & 0.23 & 0.53 & 0.15 & 0.39 & 0.30 & 0.66 & 0.49 & 0.42 & 0.30 & 0.33 & 0.43 & 0.52 & 0.51 & 0.17 & 0.14 & 0.34 \\
\hline 13 & 0.40 & & & & & 0.30 & 0.02 & 0.11 & 0.26 & & & 0.03 & 0.02 & 0.02 & 0.06 & & \\
\hline 14 & & & & & & 0.02 & & & 0.01 & & & & & & & & \\
\hline 15 & & & & & & & & & & & & & & & & & \\
\hline 16 & & & & & & & & & & & & & & & & & \\
\hline 17 & & & & & & & & & & & & & & & & & \\
\hline 18 & & & & & & & & & & & & & & & & & \\
\hline 18 & & & & & & & & & & & & & & & & & \\
\hline 20 & & & & & & & & & & & & & & & & & \\
\hline 21 & & & & & & & & & & & & & & & & & \\
\hline 22 & & & & & & & & & & & & & & & & & \\
\hline 23 & & & & & & & & & & & & & & & & & \\
\hline 24 & & & & & & & & & & & & & & & & & \\
\hline 25 & & & & & & & & & & & & & & & & & \\
\hline 26 & & & & & & & & & & & & & & & & & \\
\hline 27 & & & & & & & & & & & & & & & & & \\
\hline 28 & & & & & & & & & & . & & & & & & & \\
\hline 28 & & & & & & & & & & & & & - & & & & \\
\hline 30 & & & & & & & & & & & & & 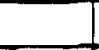 & & & & \\
\hline 31 & & & & & & & & & & & & & & & & & \\
\hline & & & & & & & & & & & & & & & & & \\
\hline TOTAL & 1.33 & 0.56 & 0.75 & 0.25 & 0.44 & 0.87 & 0.95 & 1.11 & 0.99 & 0.34 & 0.87 & 0.71 & 1.18 & 0.67 & 0.42 & 0.20 & 0.4 \\
\hline & & & & & & & & & & & & & & & & & \\
\hline NOTE & & & & & & & & & & & & & & & & & \\
\hline & & & & & & & & & $\therefore$ & & & & & & & & \\
\hline & & & & & & & & & NG/ & & & & & & & & \\
\hline Area 1 & 2 Dip & 8 tick f & $\operatorname{lain} G$ & $9 g e$ & ading: & & $.80 \mathrm{inc}$ & how & $06 / 00 / 8$ & 28 thru & DorD1/E & & & & & & \\
\hline Data 7 & abula & $\operatorname{ted} B y$ & & & 0 & & & & $\overline{01}$ & 102 & 198 & & & & & & \\
\hline Data C & 2uality & Contr & & & & 6) & & & 06 & 610 & 768 & & & & 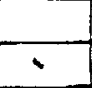 & & \\
\hline & & & & & & & & & & & 1 & & & & & & \\
\hline Centifin & ad By: & & & & & & & & & & $\mathrm{ELI}$ & & & & & & \\
\hline
\end{tabular}




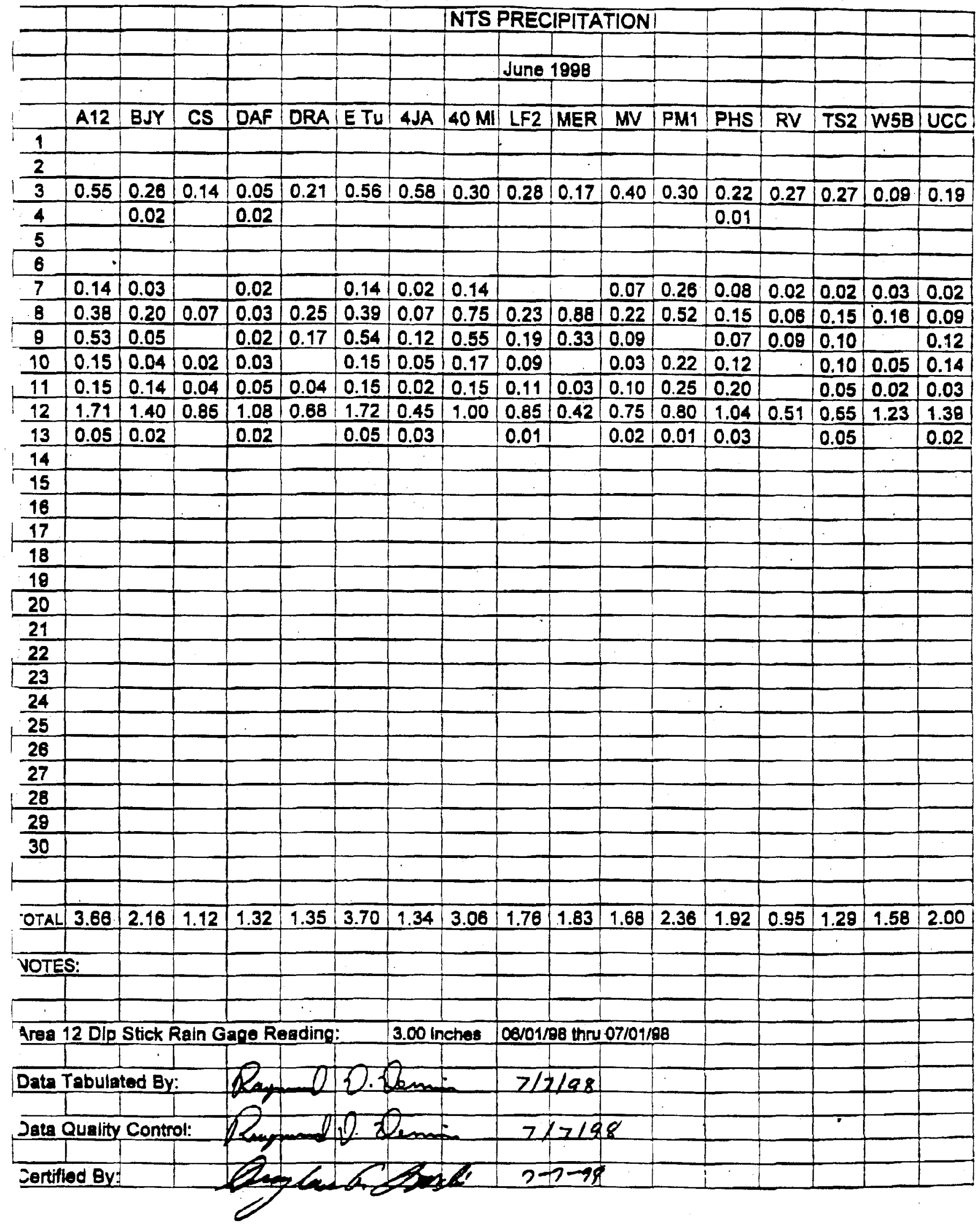




\begin{tabular}{|c|c|c|c|c|c|c|c|c|c|c|c|c|c|c|c|c|c|}
\hline & & & & & & & & \multicolumn{4}{|c|}{ NTS PRECIPITATION } & & & & & & \multirow[b]{2}{*}{ (2) } \\
\hline & & & & & & & & & & & & & & & & & \\
\hline & & & & & & & & & \multicolumn{2}{|c|}{ July 1088} & & & & & & & \\
\hline & & & & & & & & & & & & & & & & & \\
\hline & A12 & B.JY & CS & DAF & DRA & ETU & 4JA & $40 \mathrm{Mi}$ & LF2 & MER & $\mathrm{MN}$ & PM1 & PHS & RV & TS2 & W5B & U : \\
\hline 1 & & & & & & & & & & & & & $\cdot$ & & & & \\
\hline 2 & & & & & & & & & & & & & & & & & \\
\hline 3 & & & & & & & & & & & & & & & & & \\
\hline 4 & & & & & & & & & & & & & & & & & \\
\hline 5 & & & & & & & & & & & & & & & & & \\
\hline 8 & 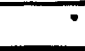 & & & & & & & & & & & & & & & & \\
\hline 7 & & & & & & & & & & & & & & & & & \\
\hline 8 & & & & & & & & & & & & & & & & & 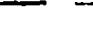 \\
\hline 8 & & & & & & & & & & & & & & & & & \\
\hline 10 & & & & & & & & & & & & & & & & & \\
\hline 11 & & & & & & & & & & & & & & & & & \\
\hline 12 & & & & & & & & & & & & & & & & & \\
\hline 13 & & & & & & & & & & & & & & & & & \\
\hline 14 & & & & & & & & & & & & & & & & & \\
\hline 15 & & & & & & & . & & & & & & & & & & \\
\hline 18 & & & & & & & & & & & & & & & & & \\
\hline 17 & & & & & & & & & & & & & & & & & \\
\hline 18 & & & & & & & & & & & & & & & & & \\
\hline 19 & & & & & & & & & & & & & & & & & . \\
\hline 20 & & & & & 0.02 & & & & & 0.02 & & & & & & & \\
\hline 21 & 0.12 & 0.05 & 0.14 & 0.10 & 0.02 & & 0.02 & 0.69 & 0.23 & 0.23 & 0.17 & 0.24 & 0.09 & 0.03 & 0.21 & 0.25 & 0.13 \\
\hline 22 & 0.01 & 0.37 & 0.08 & 0.02 & 0.06 & . & 0.03 & 0.01 & 0.02 & 0.02 & 0.01 & 0.02 & 0.20 & & 0.02 & 0.04 & 0.1 \\
\hline 23 & 1.78 & 1.00 & 0.23 & 0.96 & 0.16 & 1.55 & 0.38 & 0.34 & 0.25 & 0.24 & 0.30 & 0.82 & 0.94 & & 0.74 & 0.41 & 0.89 \\
\hline 24 & 0.01 & & & 0.02 & & & & 0.01 & & & & & & & 0.03 & & _ \\
\hline 25 & & & & & & & & & & & & & & & & & 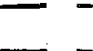 \\
\hline 26 & & & & & & & & & & & & & & & & & \\
\hline 27 & & & 0.02 & & & & 0.12 & 0.02 & & & & & 0.02 & & 0.18 & & \\
\hline 28 & & & & & & & & & & & & & & & & & . \\
\hline 29 & & & & & & & & & & & & & & & & & \\
\hline 30 & & & & & & & & & & & & & & & & & - \\
\hline 31 & & & & & & & & & & & & & & & & & \\
\hline & & & & & & & & & & & & & & & & & \\
\hline TOTAL & 1.92 & 1.42 & 0.47 & 1.10 & 0.26 & 1.55 & 0.55 & 1.07 & 0.50 & 0.51 & 0.48 & 1.18 & 1.25 & 0.03 & 1.18 & 0.70 & 1. \\
\hline & & & & & & & & & & & & & & & & & \\
\hline NOTES & & & & & & & & & & & & & & & & & - \\
\hline & & & & & & & & & & & & & & & & & - \\
\hline & & & & & & & & & & & & & & & & & $x$ \\
\hline Area 1 & $2 \mathrm{Dip}$ & Stick & $\operatorname{sein} C$ & gre $R$ & eading & & $2.1 \mathrm{lnc}$ & ches & 071018 & 98 thru & 08103 & & & & & & \\
\hline & & & & & & & & & & & & & & & & & - \\
\hline Data 1 & Eabuls & $\operatorname{tad} B y$ & & & & & & in & $8 \longdiv { 6 }$ & 298 & & & & & & & \\
\hline Data $C$ & Tualth & Contr & & & & & & & 81 & $6 / 98$ & & & & & $\cdot$ & & - \\
\hline & & ${ }^{\circ}$ & & & & & & & & & & & & & & & \\
\hline Cartifin & $\operatorname{ed~By}$ & & & & & & 7 & $q^{\prime}$ & 87 & $2-98$ & & & & & & & \\
\hline
\end{tabular}




\begin{tabular}{|c|c|c|c|c|c|c|c|c|c|c|c|c|c|c|c|c|c|}
\hline & & & & & & & & \multicolumn{4}{|c|}{ NTS PRECIPITATION } & & & & & & \\
\hline & & & & & & & & & & & & & & & & & \\
\hline & & & & & & & & & \multicolumn{3}{|c|}{ August 1998} & & & 1 & & & \\
\hline & & & & & & & & & & & & & & & & & \\
\hline & A12 & BNY & CS & DAF & DRA & ETu & $4 N A$ & $40 \mathrm{Mi}$ & LF2 & MER & MV & PM1 & PHS & RV & TS2 & W5B & UCC \\
\hline 1 & & & & & & & & & & & & & & & & & \\
\hline 2 & & & & & & & & & & & & & & & & & \\
\hline 3 & & & & & & & & & & & & & & & & & \\
\hline 4 & & & & & & & & & & & & & & & & & \\
\hline 5 & & & & & & & & & & & & & & & & & \\
\hline$\theta$ & & & & & & & & & & & & & & & & $\rightarrow$ & \\
\hline 7 & & & & & & & & & & & & & & & & & \\
\hline 8 & & & & & & & & & & & & & & & & & \\
\hline 8 & & & & & & & & & & & & & & & & & \\
\hline 10 & & & & & & & & & & & & 0.90 & & & & & \\
\hline 11 & & 0.28 & & & & & & & 0.85 & & & & & & & & \\
\hline 12 & & & & & & & & & & & & & & & & & \\
\hline 13 & 0.15 & & & & 1.03 & 0.18 & & & 0.03 & 0.62 & & & & & & & \\
\hline 14 & & & & & & 0.08 & & 0.05 & 0.19 & & & & 0.08 & & & & \\
\hline 15 & & & & & & & & & & & & & & & & & \\
\hline 18 & & & & & & & & & & & & & & & & & \\
\hline 17 & & & & & & & & & & & & & & & & & \\
\hline 18 & & & & & & & & & & & & & & & & & \\
\hline 19 & & & & & & & & & & & & & & & & & \\
\hline 20 & & & & & & & & & & & & & & & & & \\
\hline 21 & & & & & & & & & & & & & & & & & \\
\hline 22 & & & & & & & & & & & & & & & & & \\
\hline 23 & & & & & & & & & & & & & & & & & \\
\hline 24 & & & & & & & & & & & & & & & & & \\
\hline 25 & & & & & & & & & & & & & & & & & \\
\hline 26 & & & & & & & & & & & & & & & & & \\
\hline 27 & & & & & & & & & & & & & & & & & \\
\hline 28 & & & & & & & & & & & & & & & & & \\
\hline 29 & & & & & & & & & & & & & & & & & \\
\hline 30 & 0.25 & 0.25 & 0.55 & 0.50 & 0.48 & 0.37 & 0.22 & 0.18 & 0.26 & 0.53 & 0.65 & 0.30 & 0.25 & 0.34 & 0.14 & 0.37 & 0.73 \\
\hline 31 & 0.05 & 0.30 & 0.25 & 0.25 & & 0.07 & 0.25 & 0.13 & 0.03 & 0.03 & 0.02 & 0.01 & 0.03 & 0.05 & 0.04 & 0.20 & 0.03 \\
\hline & & & & & & & & & & & & & & & & & \\
\hline TOTAL & 0.45 & 0.81 & 0.80 & 0.75 & 1.51 & 0.68 & 0.47 & 0.38 & 1.08 & 1.18 & 0.67 & 1.21 & 0.34 & 0.39 & 0.18 & 0.57 & 0.78 \\
\hline NOTE & & & & & & & & & & & & & & & & & \\
\hline & & & & & & & & & & & & & & & & & \\
\hline Area & 2 Dlp & Stick & Rain G & $098 R$ & ending & & $.32 \ln c$ & & $\frac{11}{081030}$ & 1 & $\frac{1}{109071}$ & & & & & & \\
\hline & & & & & & & & & & & & & & & & & \\
\hline Data & Tabula & $\operatorname{ted} B y$ & & & $\bar{e}$ & 2 & & & 912 & 199 & & & & & & & \\
\hline & & & & & & & & & & & & & & & & & \\
\hline 는 & 2uality & Contr & & & 2 & & & & 912 & 148 & & & & & 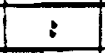 & & \\
\hline attiff & $\operatorname{cod} \mathrm{dy}$ & & & & 1 & 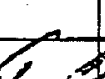 & 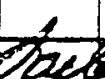 & & $4-3$ & $1-48$ & & & & & & & \\
\hline
\end{tabular}




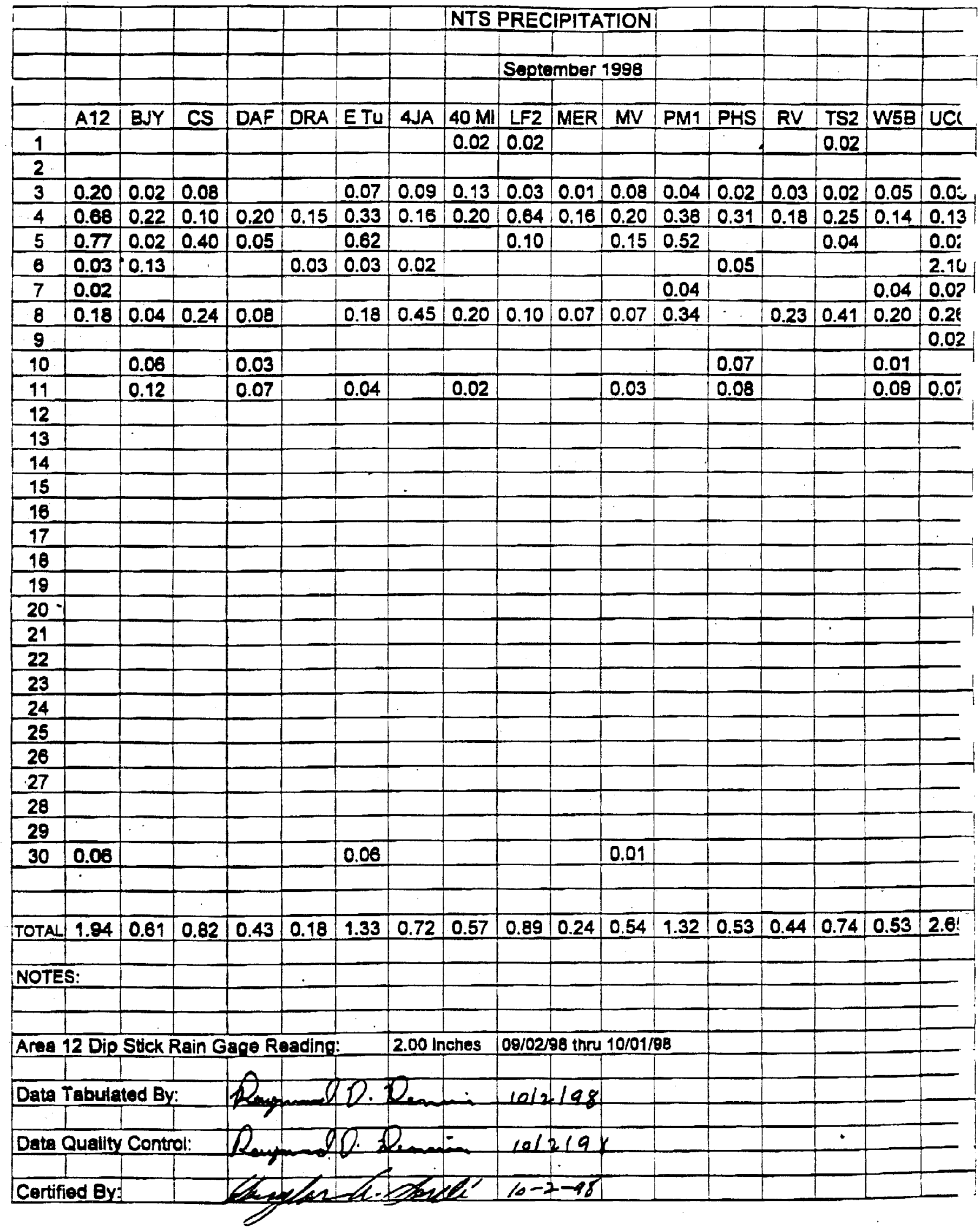




\begin{tabular}{|c|c|c|c|c|c|c|c|c|c|c|c|c|c|c|c|c|c|}
\hline & & & & & & & & \multicolumn{4}{|c|}{ NTS PRECIPITATION } & & & & & & \\
\hline & & & & & & & & & & & & & & & & & \\
\hline & & & & & & & & & \multicolumn{3}{|c|}{ October 1898} & & & & & & \\
\hline & & & & & & & & & & & & & & & & & \\
\hline & A12 & BJY & $\mathrm{CS}$ & DAF & DRA & ETu & 4JA & $40 \mathrm{Mi}$ & LF2 & MER & MV & PM1 & PHS & RV & TS2 & W5B & UCC \\
\hline 1 & & & & & & & & & & & & & & & & & \\
\hline 2 & & & & & & & & & & & & & & & & & \\
\hline 3 & & & & & & & & & & & & & & & & & \\
\hline 4 & & & & & & & & & & & & & & & & & \\
\hline 5 & & & & & & & & & & & & & & & & & \\
\hline 6 & & & & & & & & & & & & & & & & & \\
\hline 7 & & & & & & & & & & & & & & & & & \\
\hline 8 & & & & & & & & & & & & & & & & & \\
\hline 9 & & & & & & & & & & & & & & & & & \\
\hline 10 & & & & & & & & & & & & & & & & & \\
\hline 11 & & & & & & & & & & & & & & & & & \\
\hline 12 & & & & & & & & & & & & & & & & & \\
\hline 13 & & & & & & & & & & & & & & & & & \\
\hline 14 & & & & & & & & & & & & & & & & & \\
\hline 15 & & & & & & & & & & & & & & & & & \\
\hline 16 & & & & & & & & & & & & & & & & & \\
\hline 17 & & & & & & & & & & & & & & & & & \\
\hline 18 & & & & & & & & & & & & & & & & & \\
\hline 19 & & & & & & & & & & & & & & & & & \\
\hline 20 & & & & & & & & & & & & & & & & & \\
\hline 21 & 0.45 & 0.29 & & & & 0.68 & & 0.15 & 0.08 & & 0.03 & 0.54 & 0.18 & & 0.05 & & \\
\hline 22 & & & & & & & & & & & & & & & & & \\
\hline 23 & & & & & & & & & & & & & & & & & \\
\hline 24 & 0.31 & 0.05 & 0.10 & 0.13 & 0.03 & 0.50 & 0.14 & 0.55 & 0.15 & 0.04 & 0.14 & 0.25 & 0.35 & 0.07 & 0.34 & 0.05 & 0.12 \\
\hline 25 & & & & & & & & & & & & & & & & & \\
\hline 28 & 0.05 & 0.02 & & & 0.05 & 0.03 & 0.15 & & 0.01 & 0.04 & 0.02 & & 0.02 & 0.02 & 0.02 & \begin{tabular}{|c|}
0.09 \\
\end{tabular} & \\
\hline 27 & 0.03 & & & & & 0.05 & & & & & & & & & & & \\
\hline 28 & & & & & & & & & & & & . & & & & & \\
\hline 28 & 0.22 & 0.23 & & & 0.03 & 0.25 & 0.02 & & & 0.03 & & 0.33 & 0.10 & 0.08 & & 0.02 & 0.02 \\
\hline 30 & 0.02 & & & & & & & & & & & 0.08 & & & & & \\
\hline & & & & & & & & & & & & & & & & & \\
\hline & & & & & & & & & & & & & & & & & \\
\hline OTAL & 9.08 & 0.59 & 0.10 & 0.13 & 0.11 & 1.49 & 0.31 & 0.70 & 0.24 & 0.11 & 0.18 & 1.21 & 0.03 & 0.15 & 0.41 & 0.18 & 0.14 \\
\hline & & & & & & & & & & & & & & & & & \\
\hline VOTE & & & & & & & & & & & & & & & & & \\
\hline & & & & & & & & & & & & & & & & & \\
\hline & & & & & & & & & & & & & & & & & \\
\hline Area & 12 Dip & Stuck f & $\operatorname{Rain} G$ & $a g e n$ & ading & & $1.10 \mathrm{ir}$ & ches & 10018 & 88 ihru & $11 / 03 / 8$ & & & & & & \\
\hline & & & & & & & & & & & & & & & & & \\
\hline Data & Tabula & $\operatorname{tad} B y$ & & & 2 & 2. & & & 110 & $4 / 94$ & & & & & & & \\
\hline & & & & & & & & & & & & & & & & & \\
\hline 2 ata & Quality & Contr & & 72 & 2 & 0.1 & & & kles & $\angle 88$ & & & & & 1 & & \\
\hline & & & & 7 & & $\pi$ & 5 & & & & & & & & & & \\
\hline Certif & $\operatorname{ed} B y$ & & & & & $\Sigma$ & 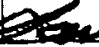 & 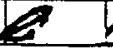 & $6+0$ & $4-9 d$ & & & & & & & \\
\hline
\end{tabular}




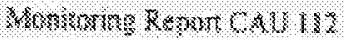

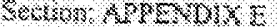

Rervisiner is

2020: 3361938

\section{APPENDIX E}

\section{BASELINE DIFFERENCE GRAPHS}


BASELINE DIFFERENCE

ROW A 


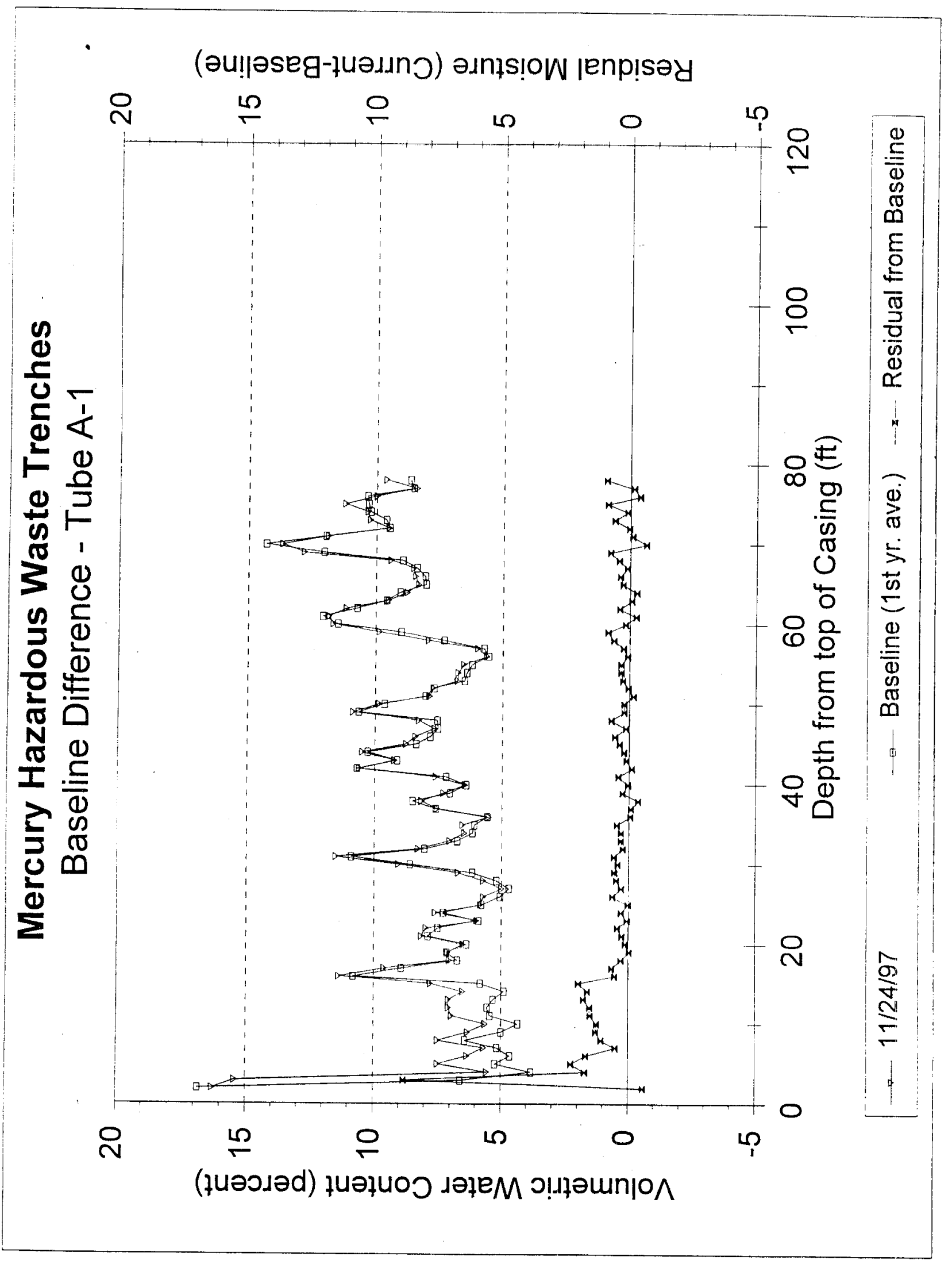




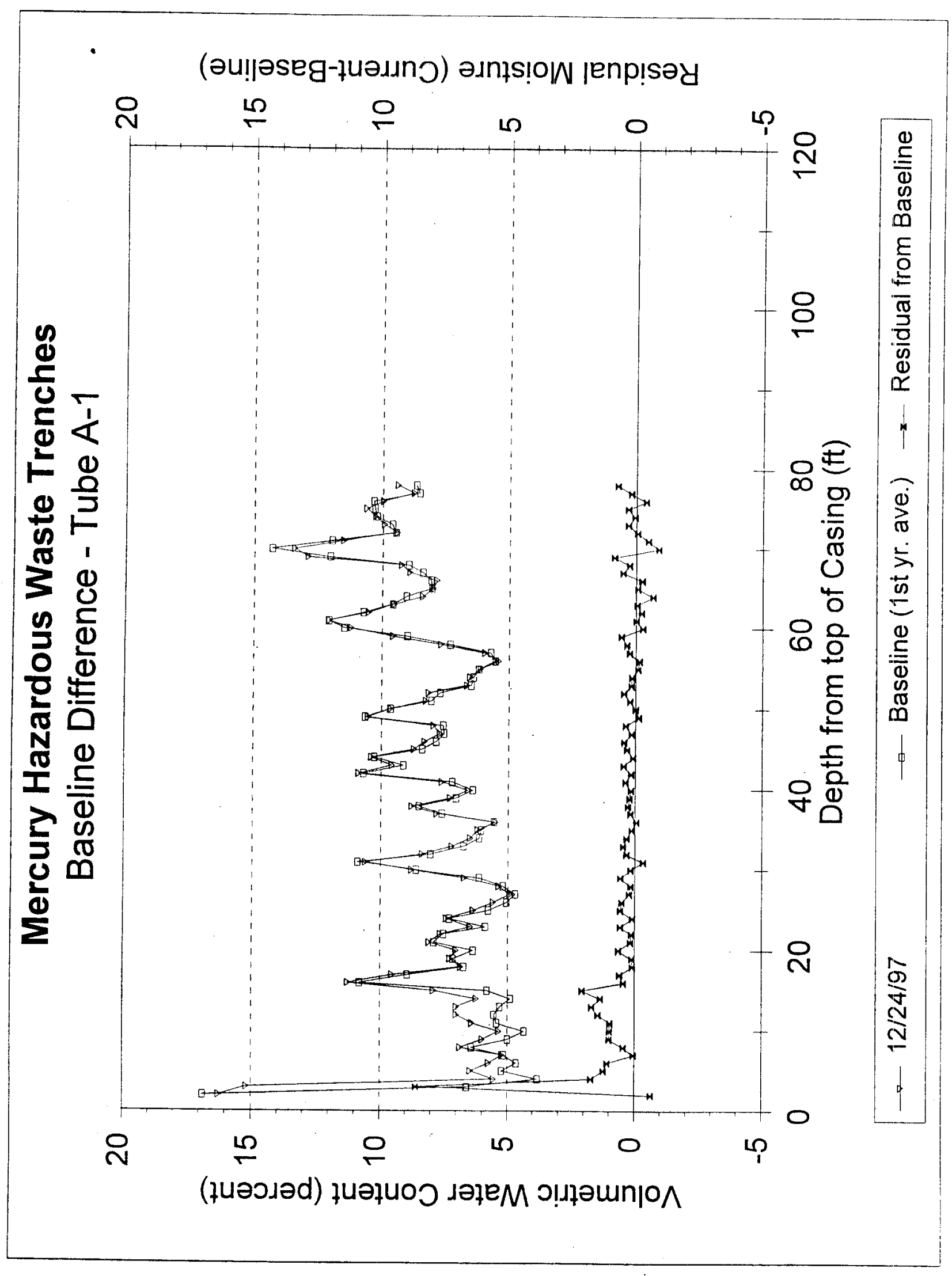




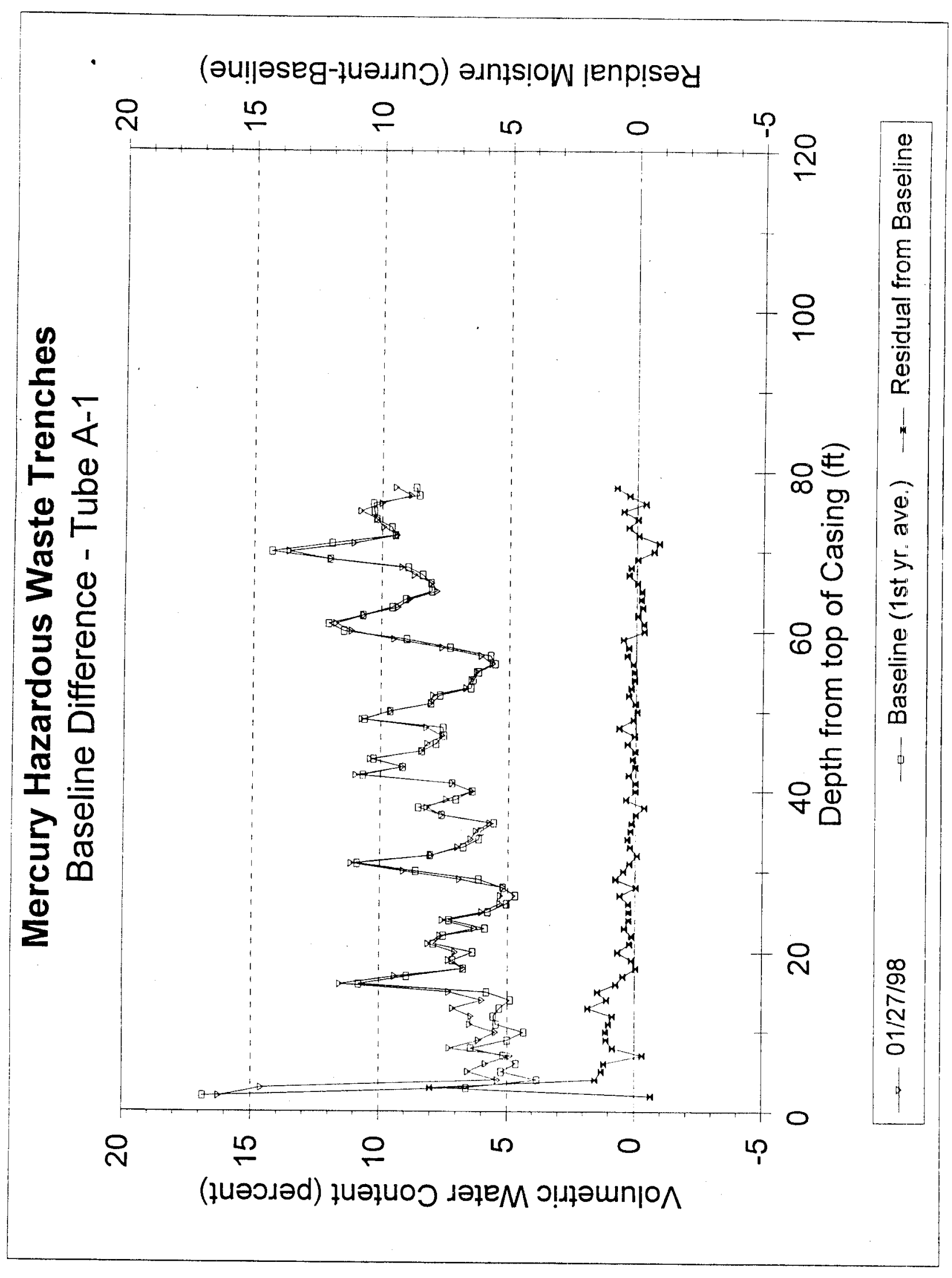




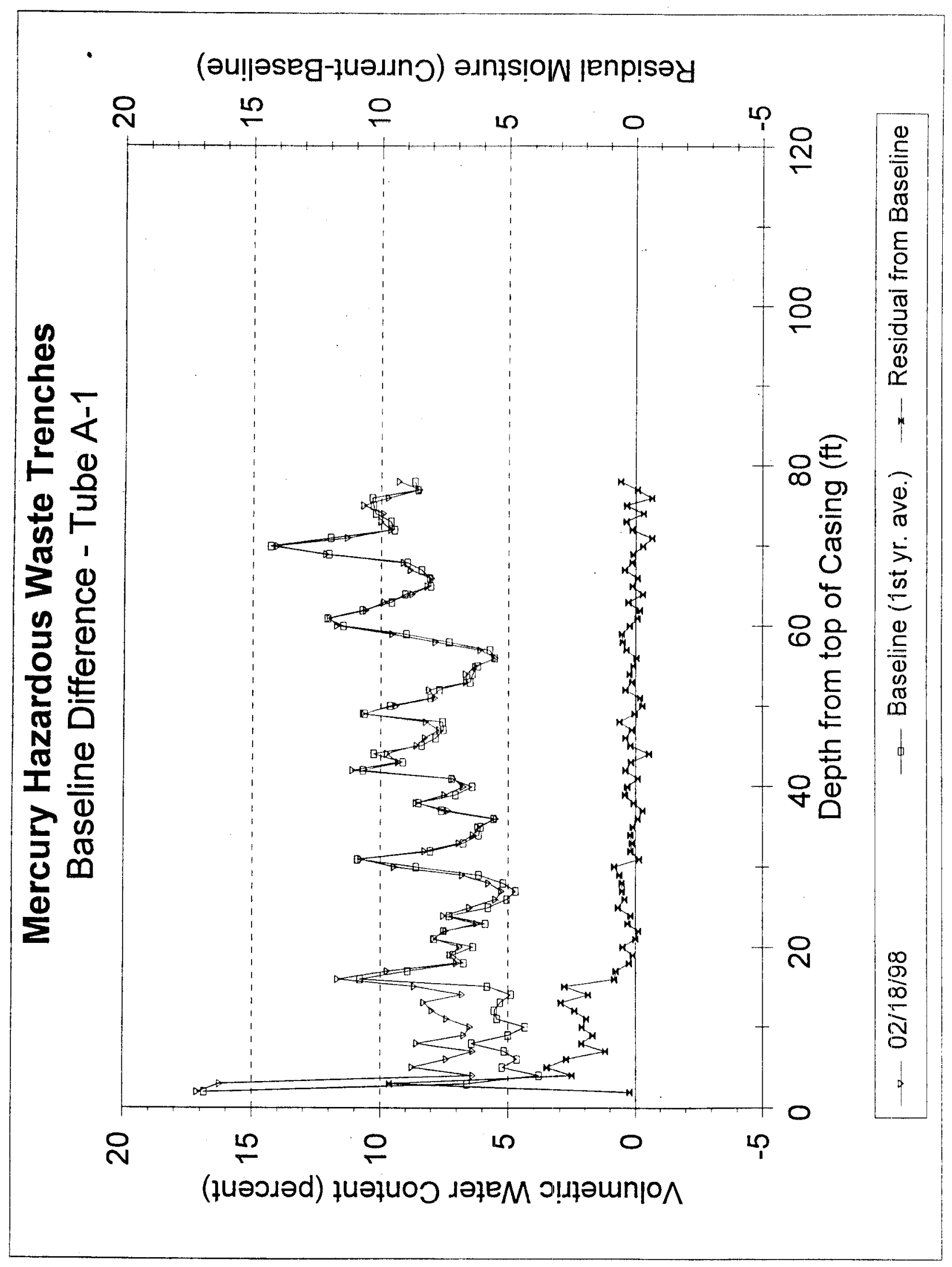




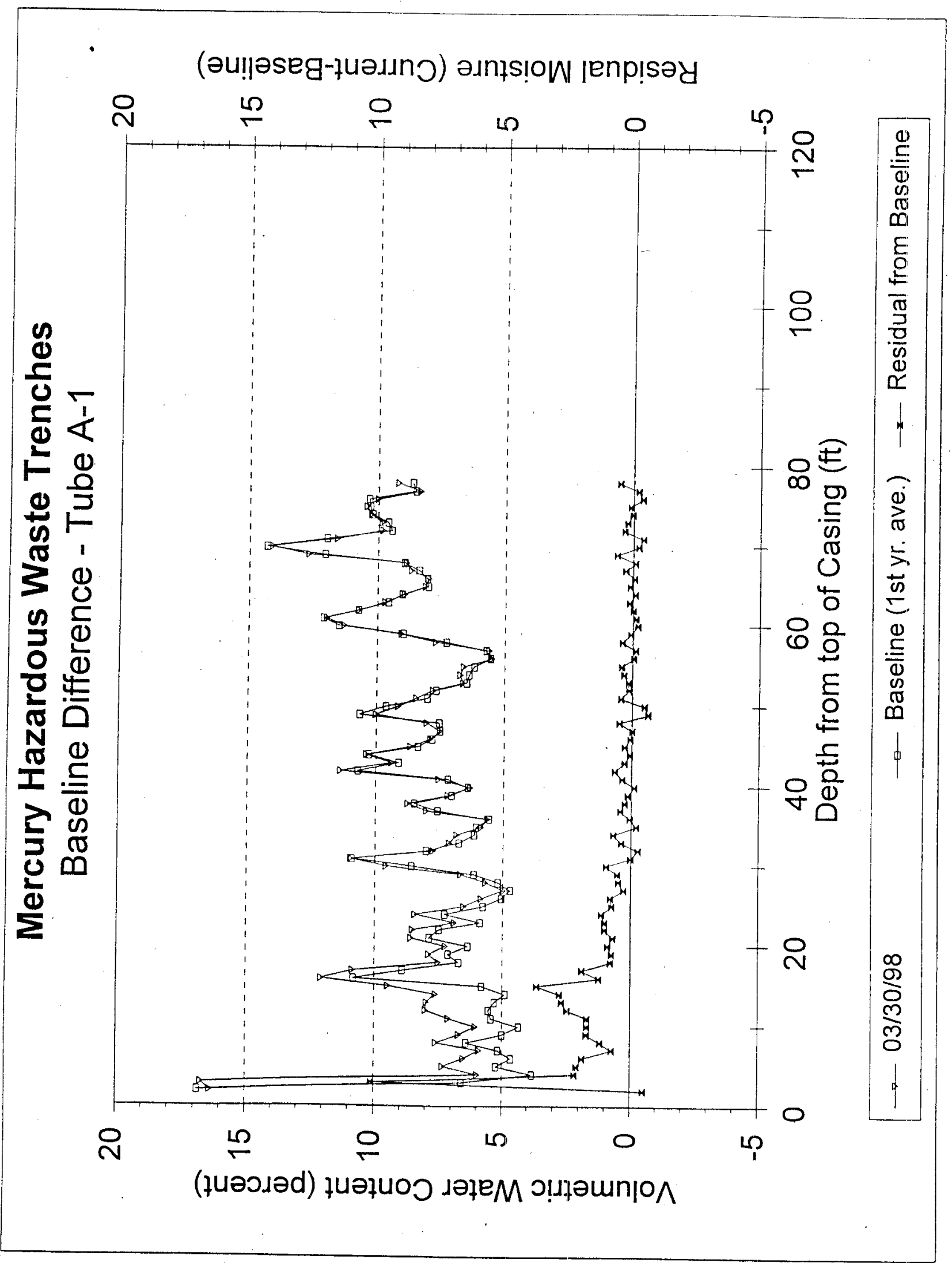




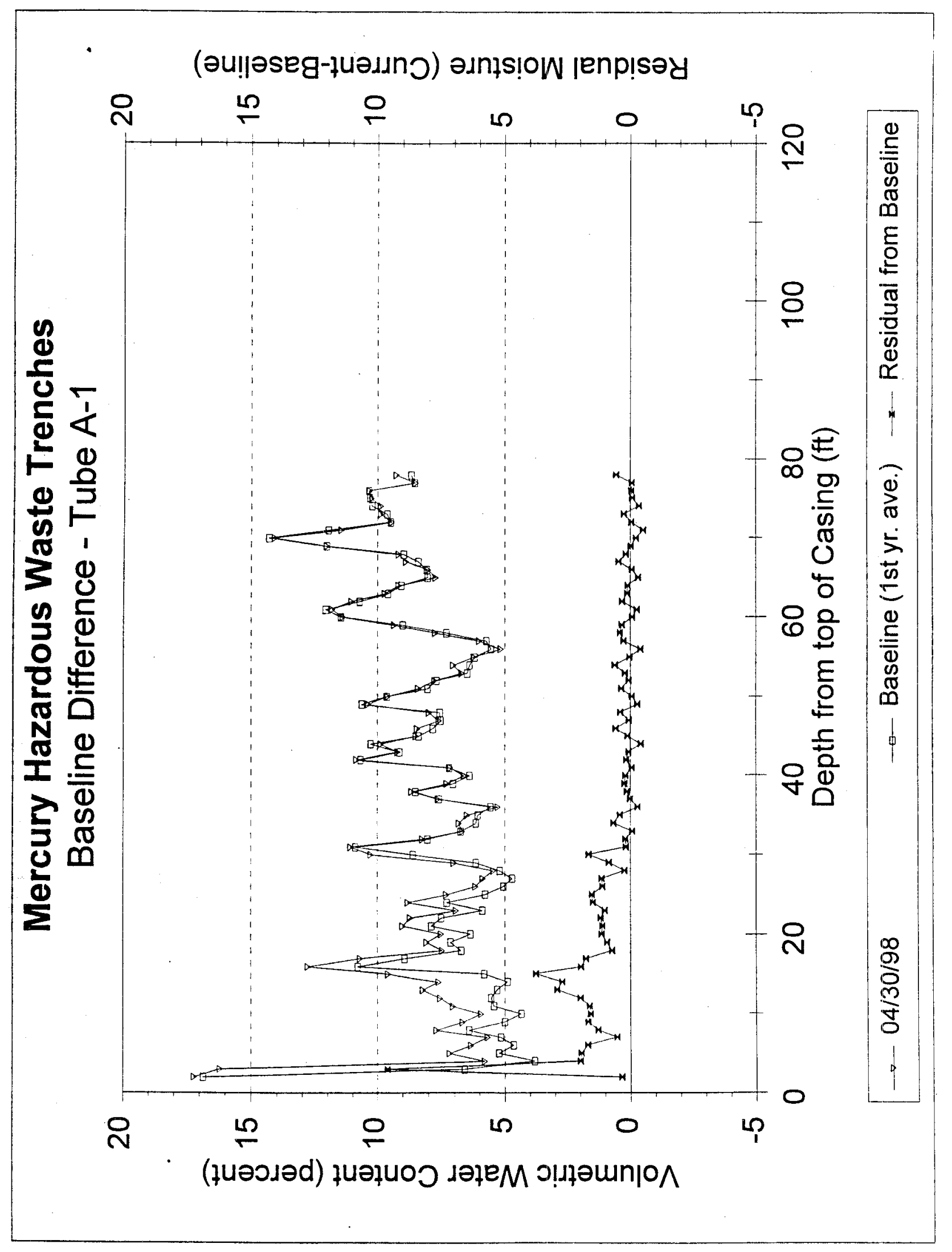




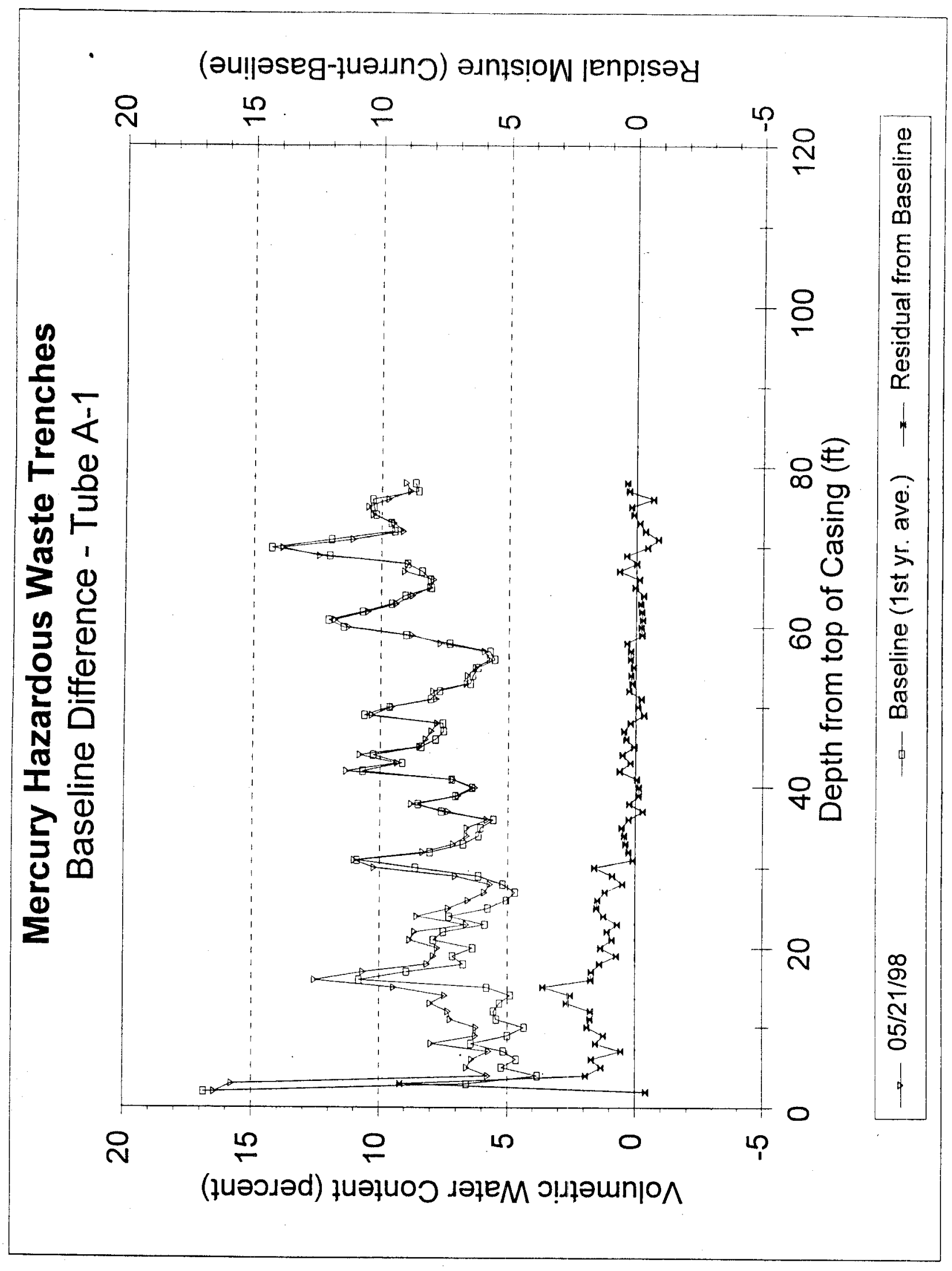




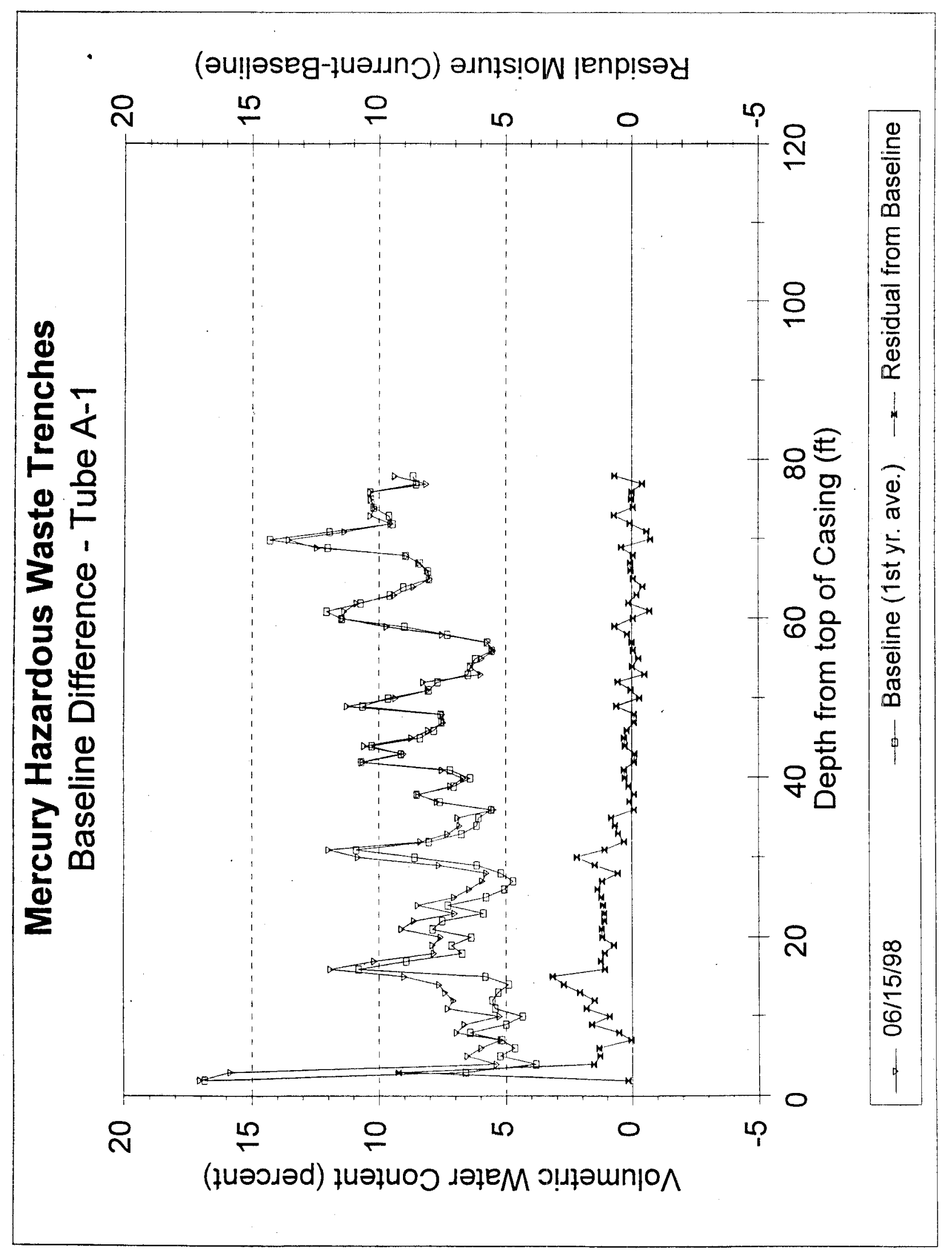




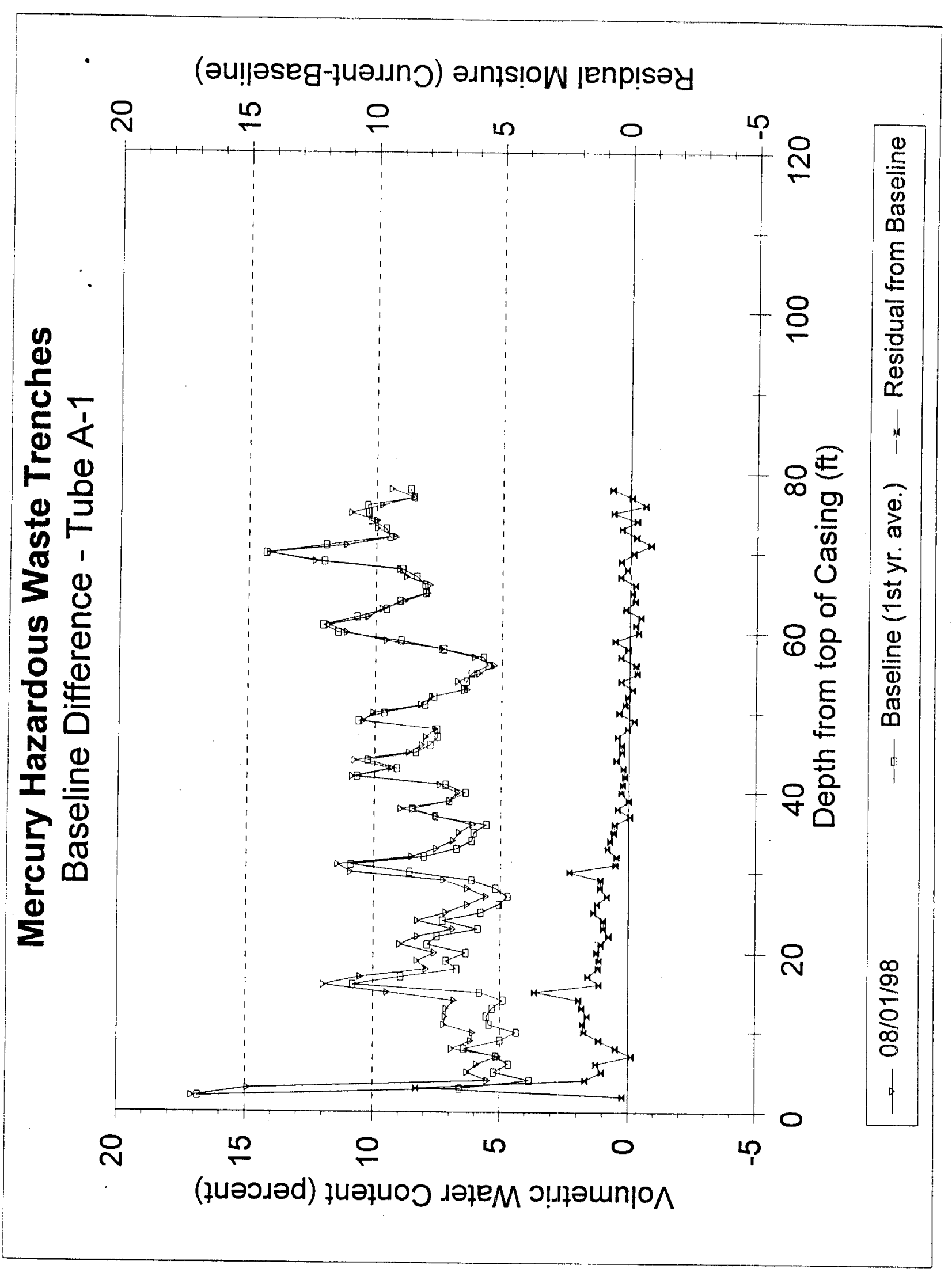




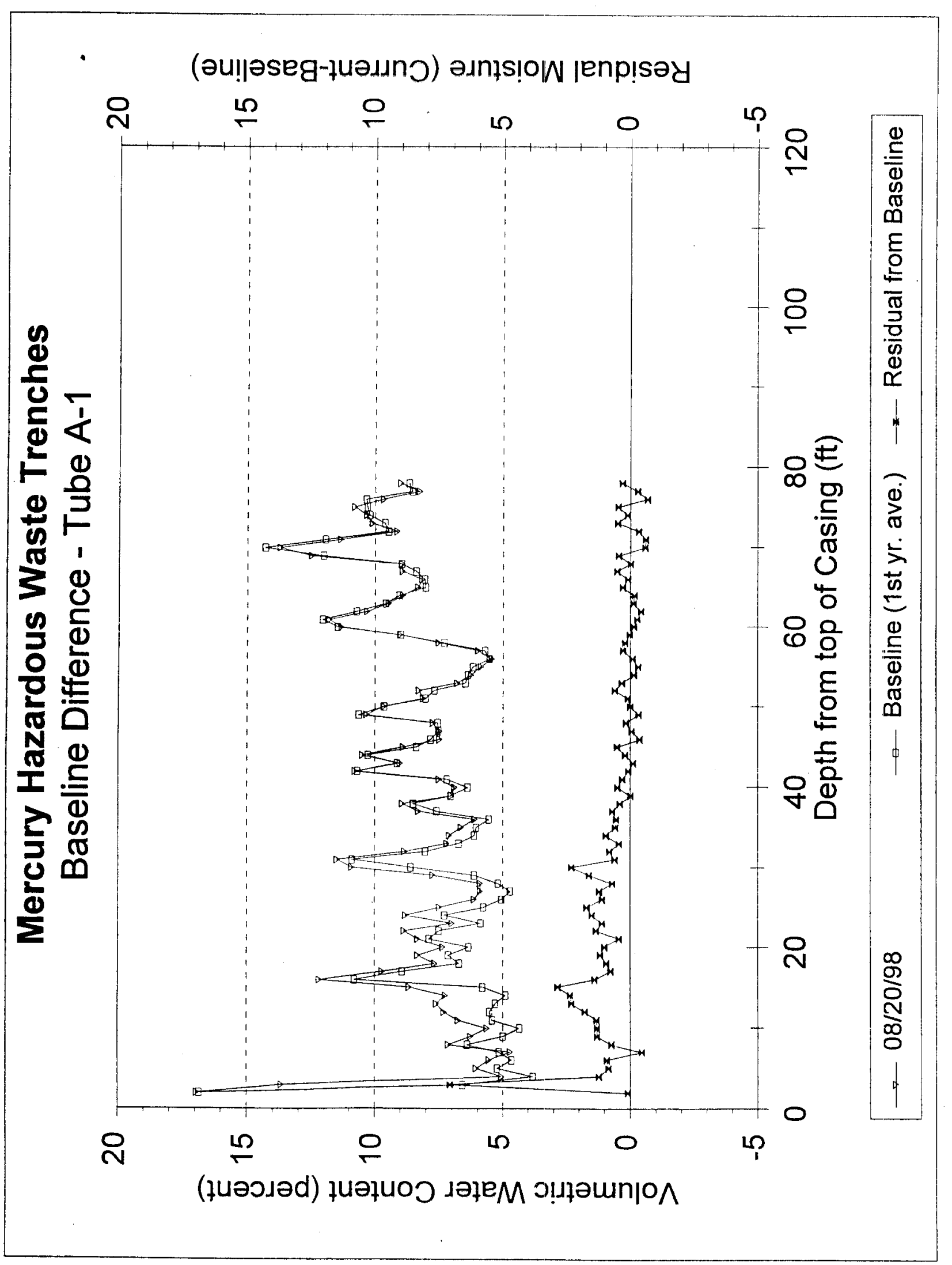




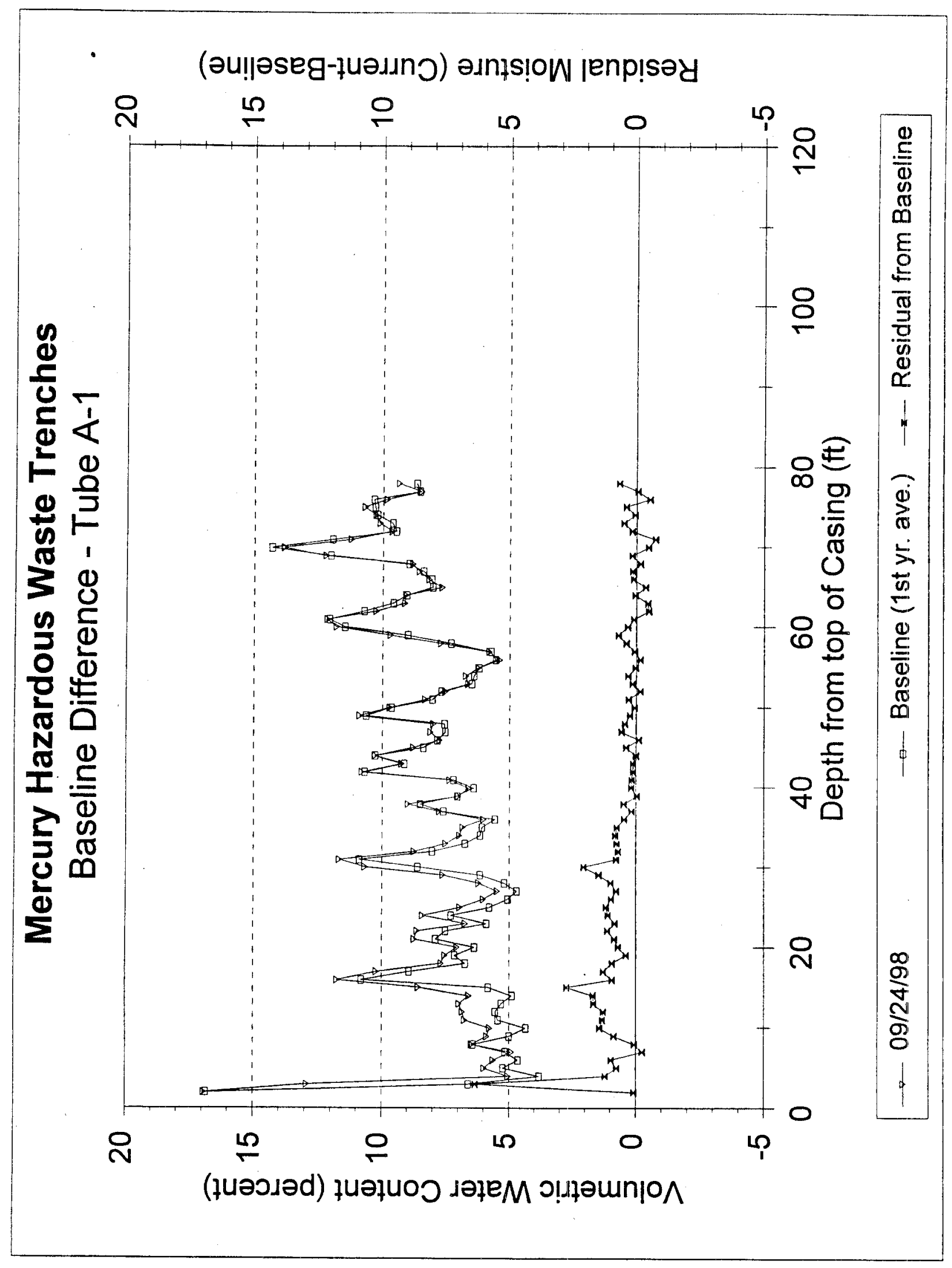




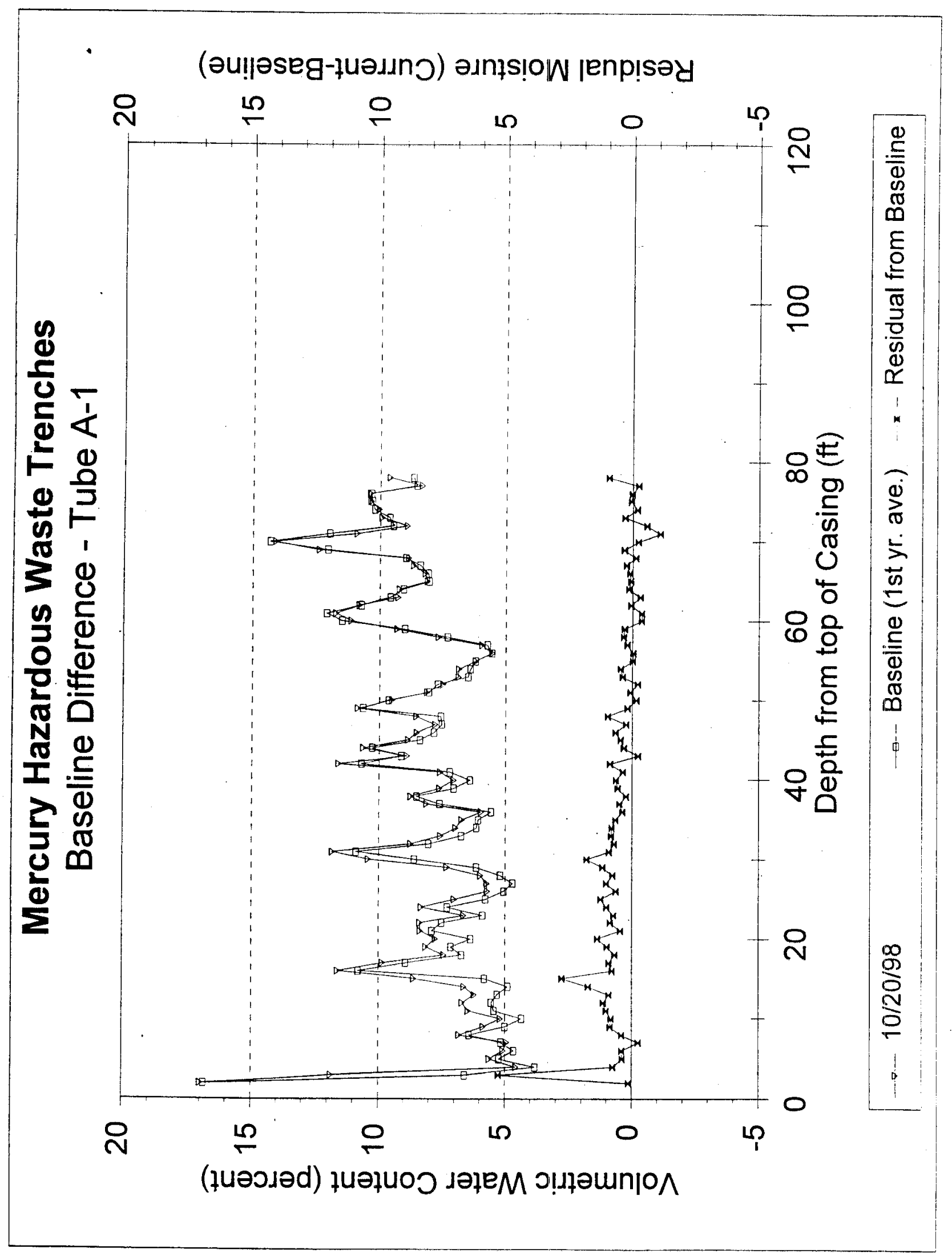




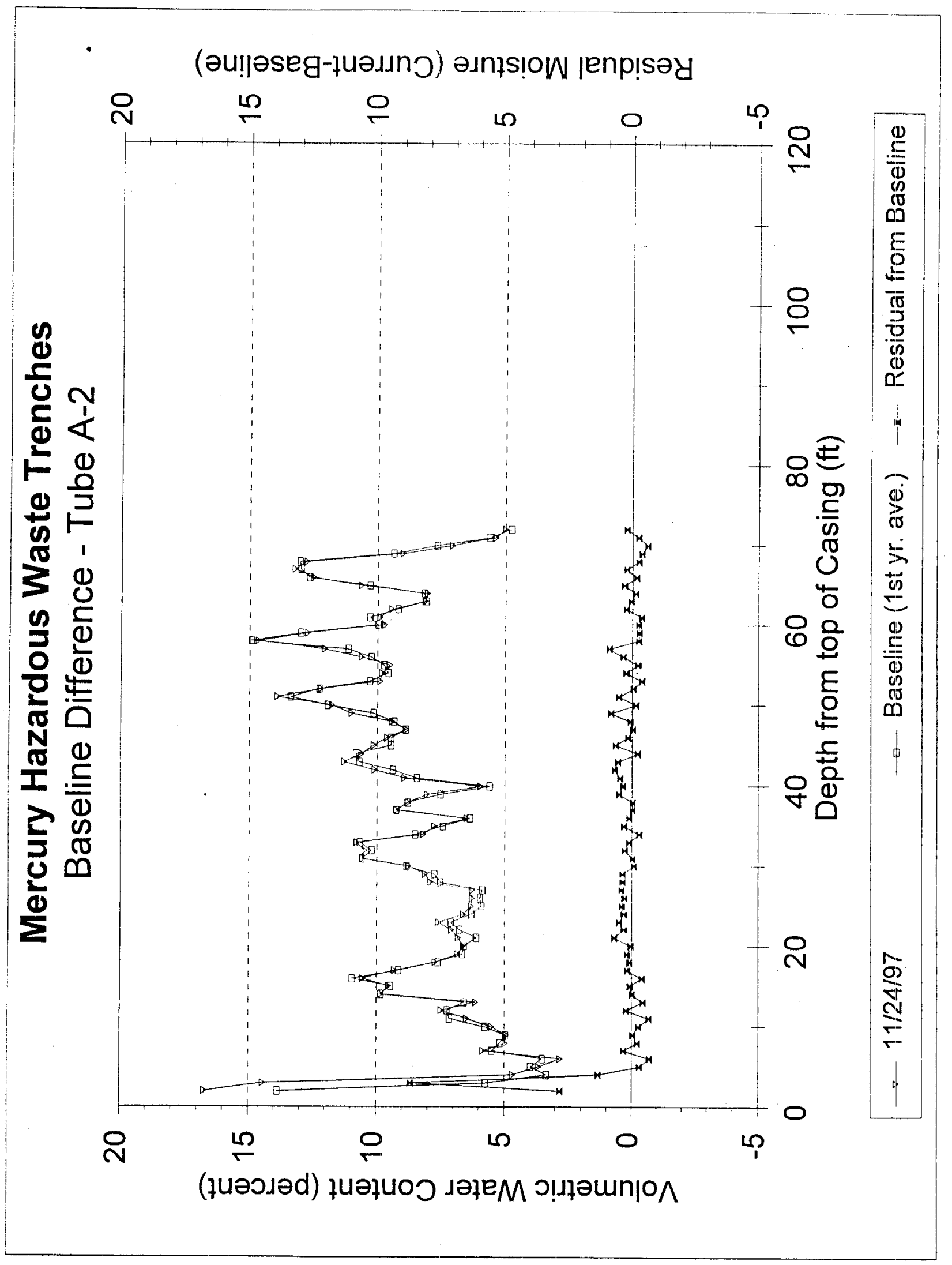




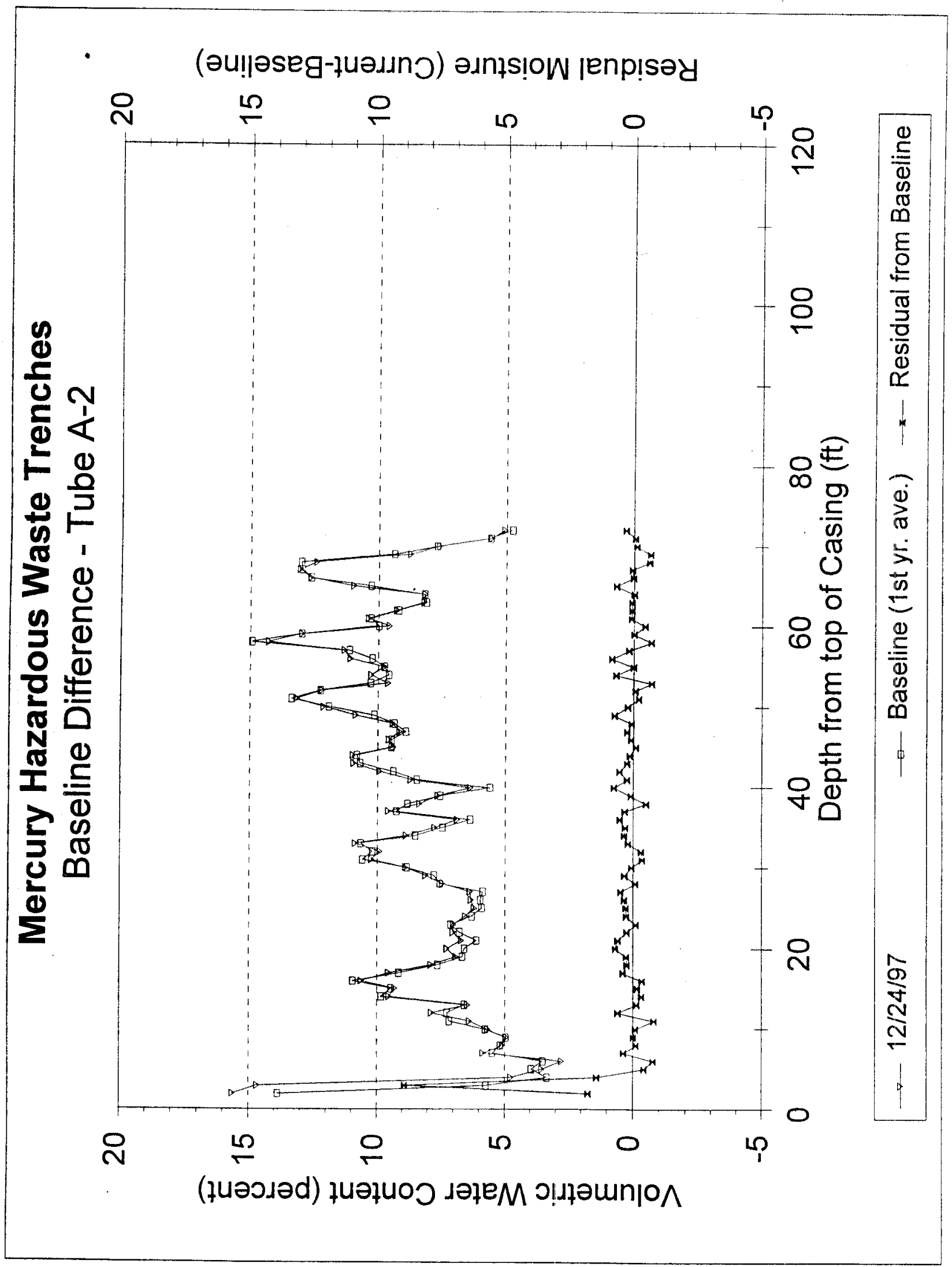




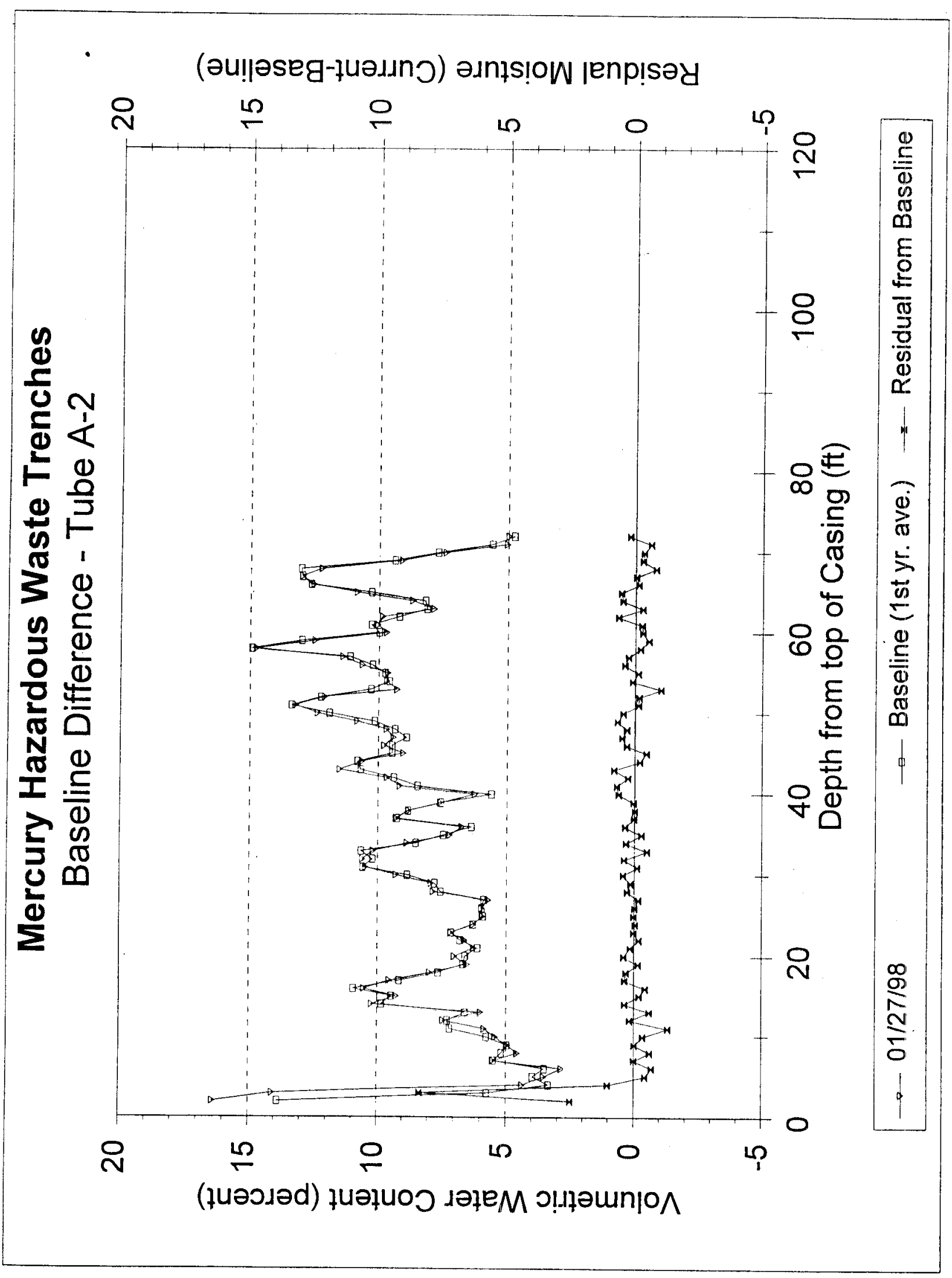




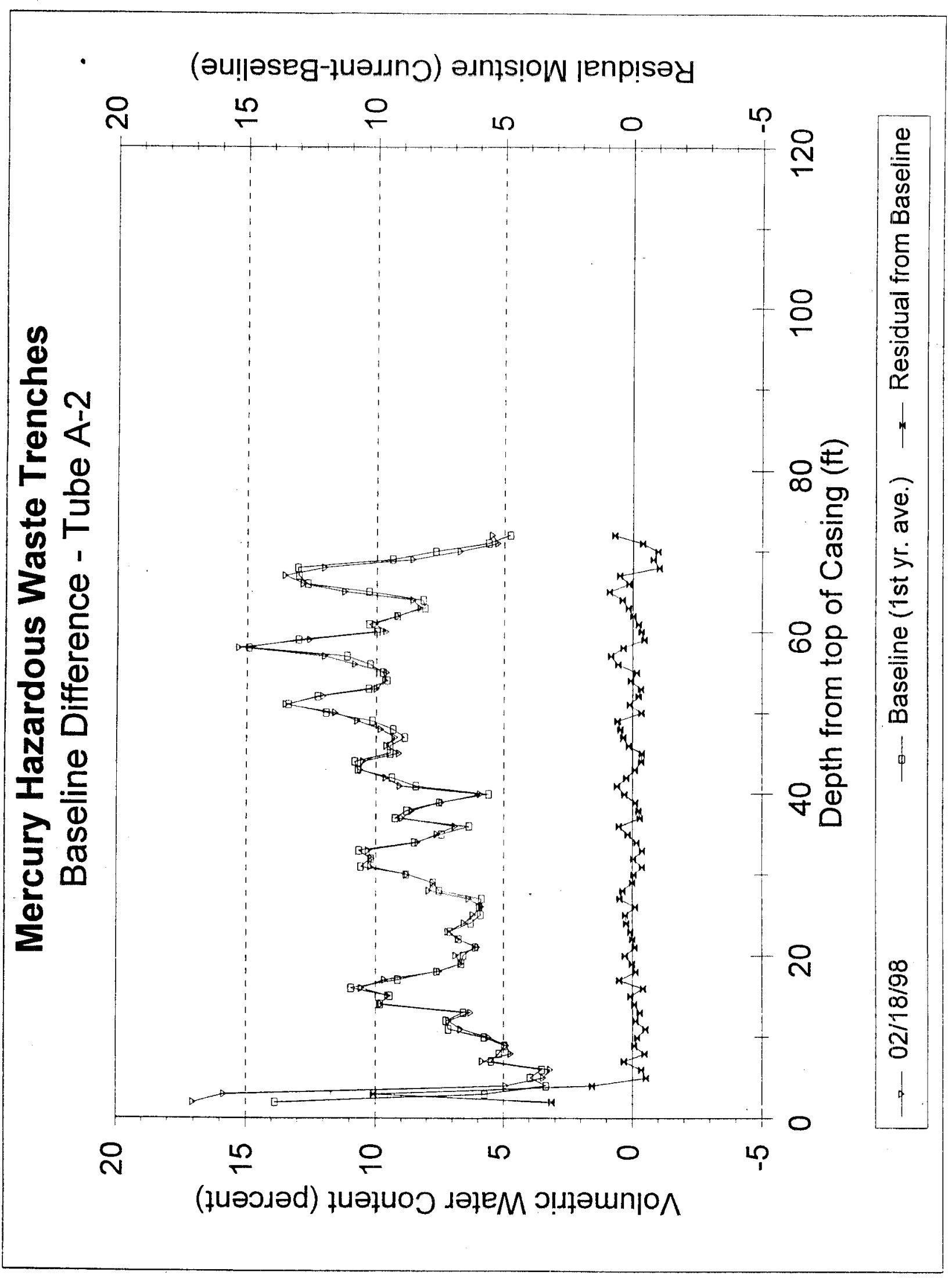




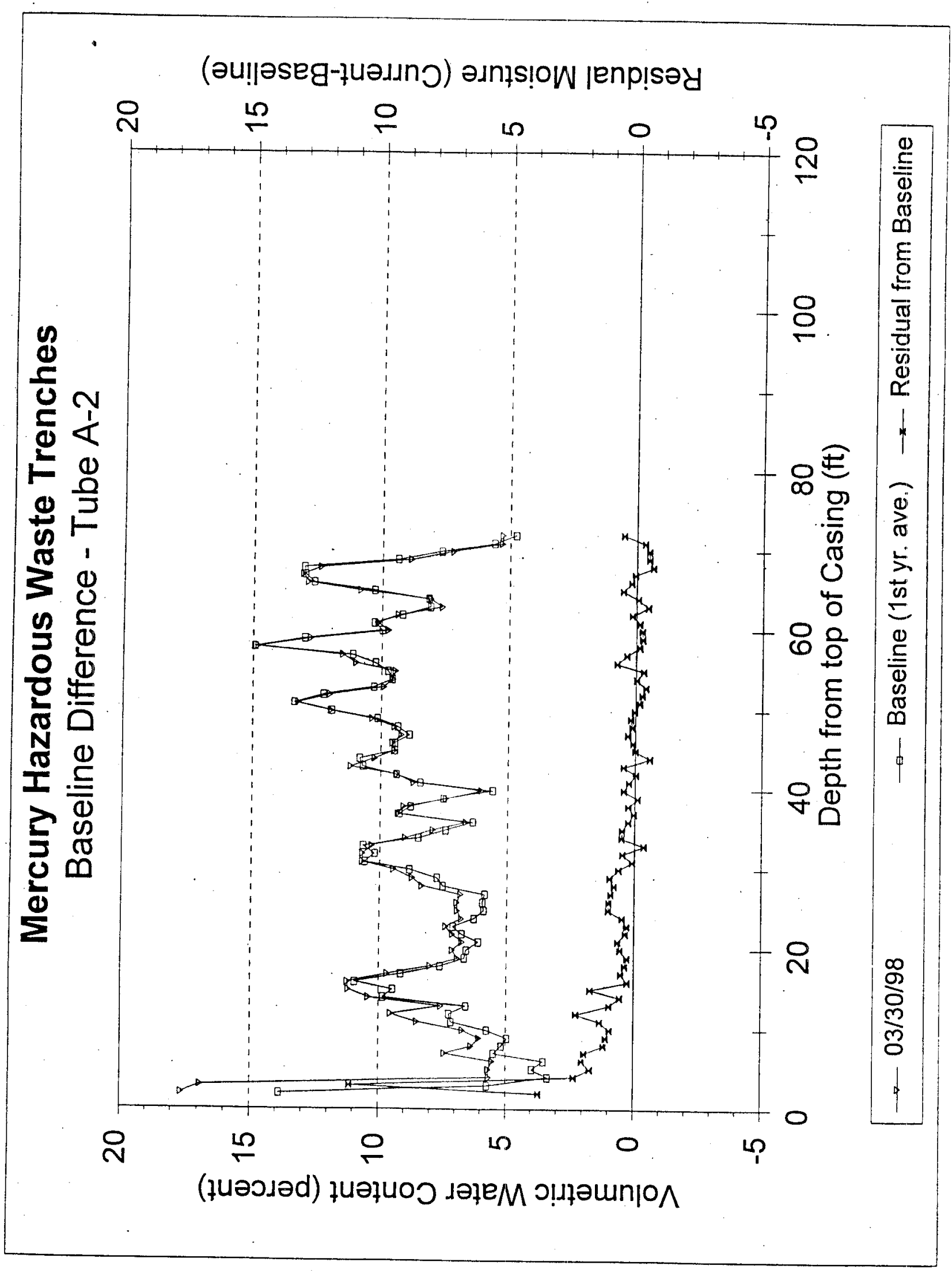




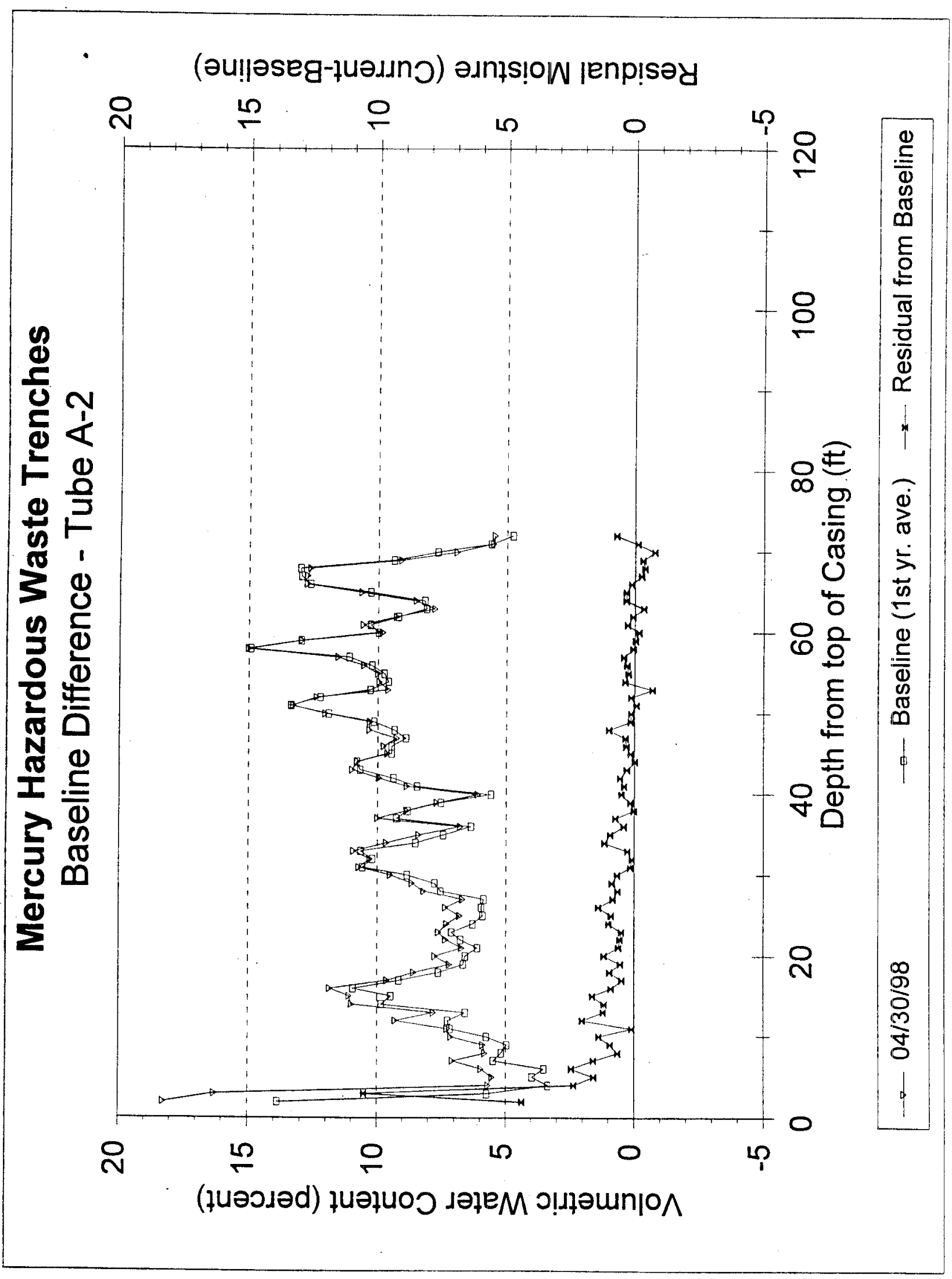




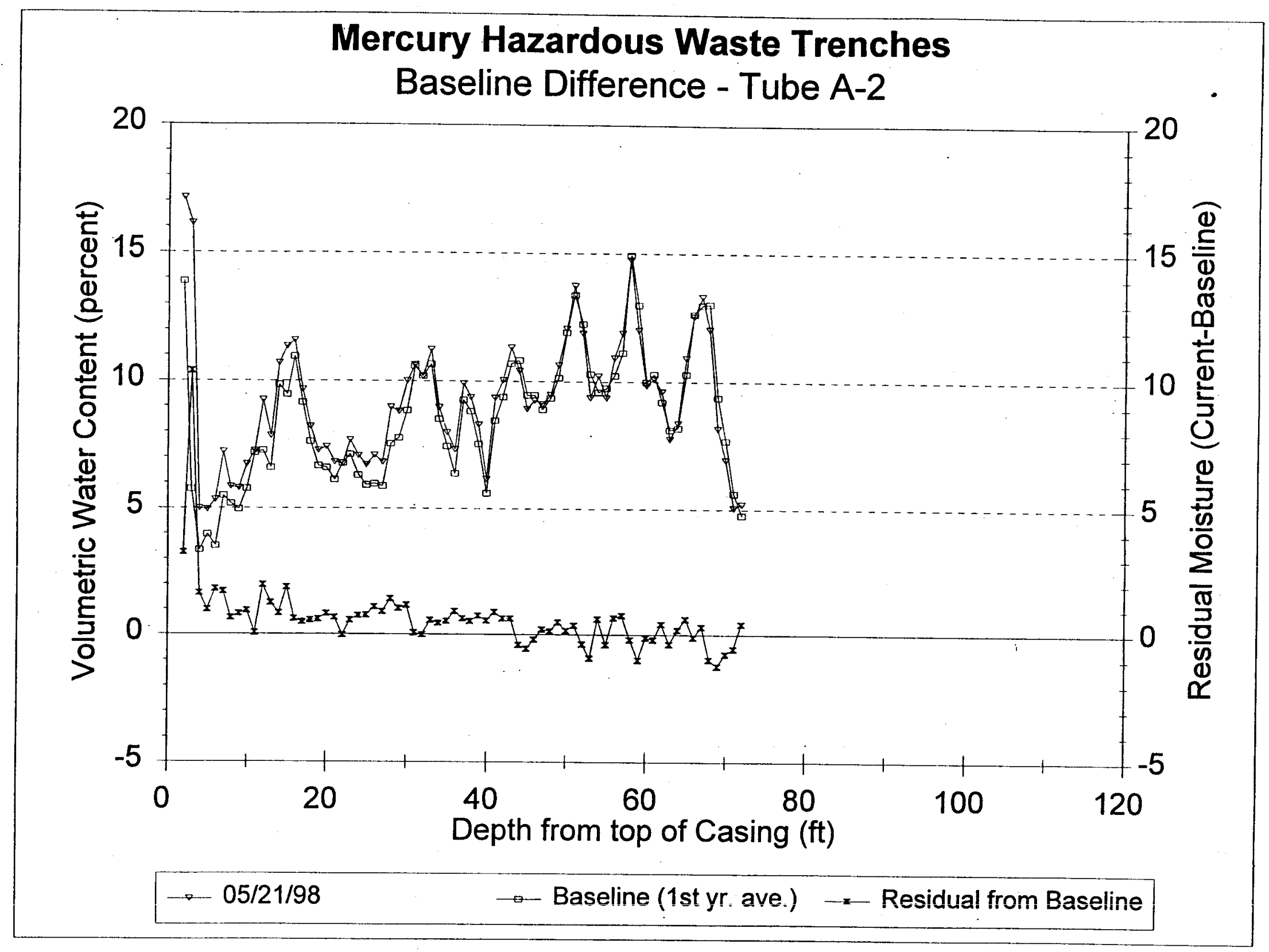




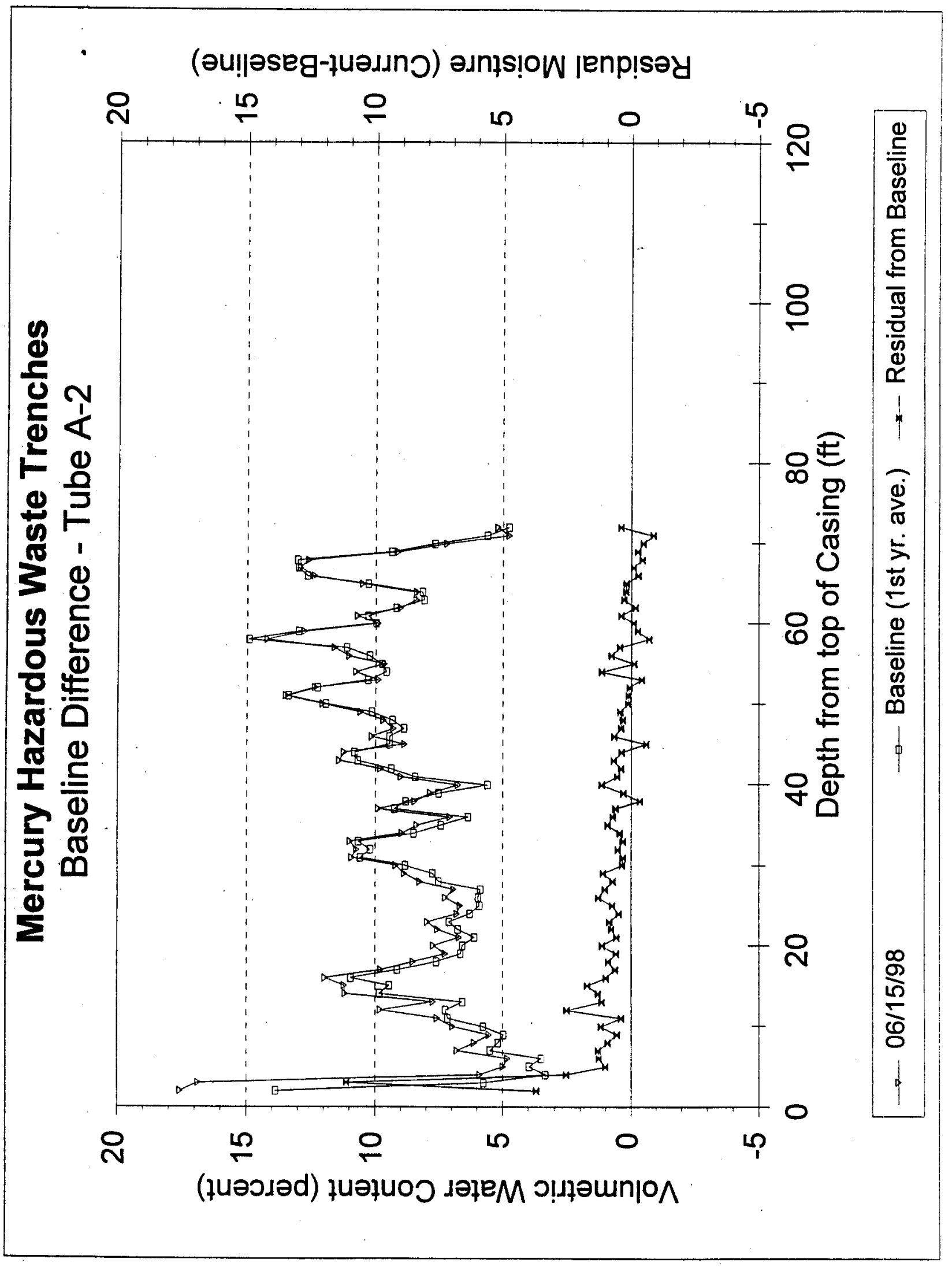




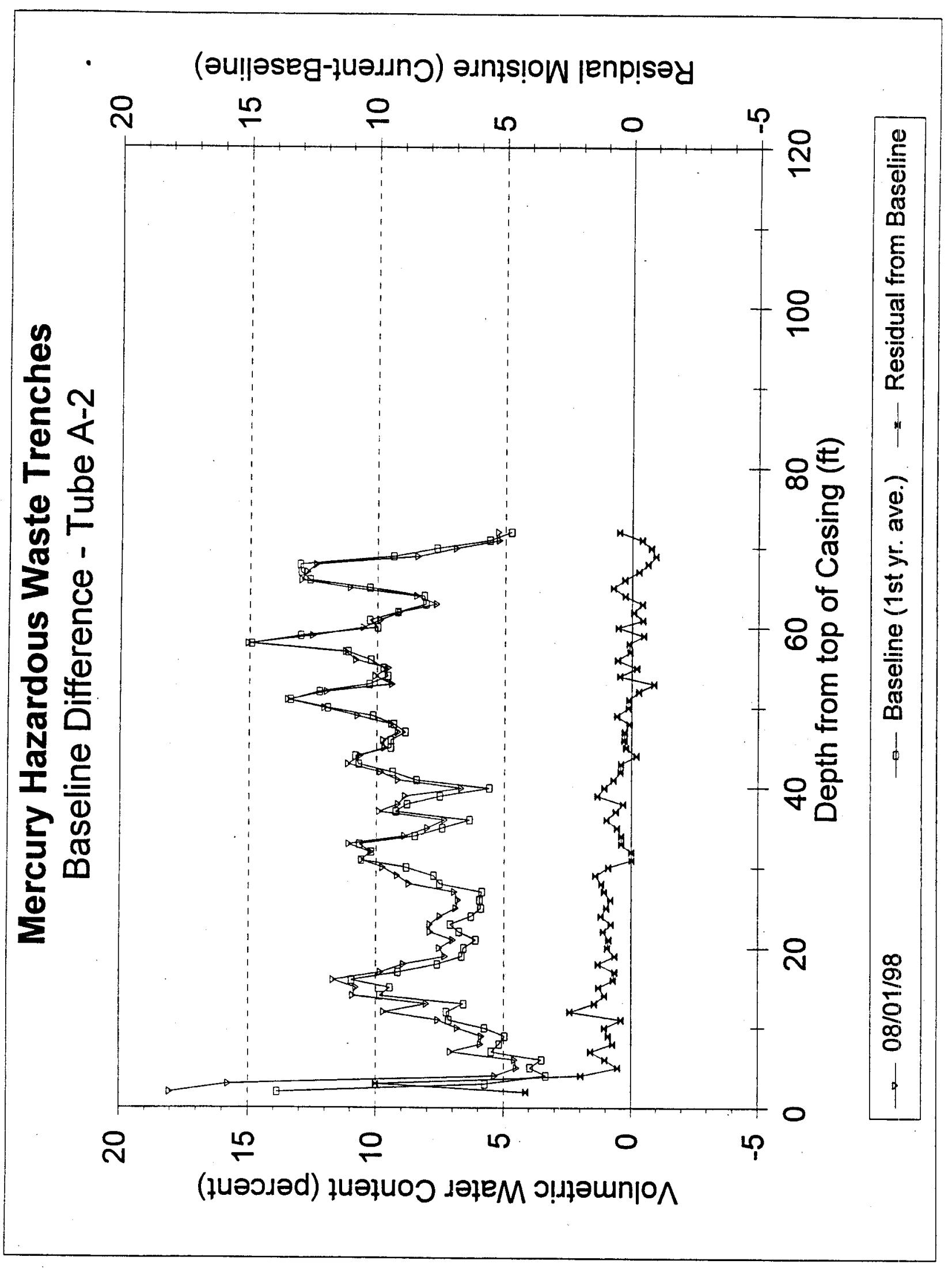




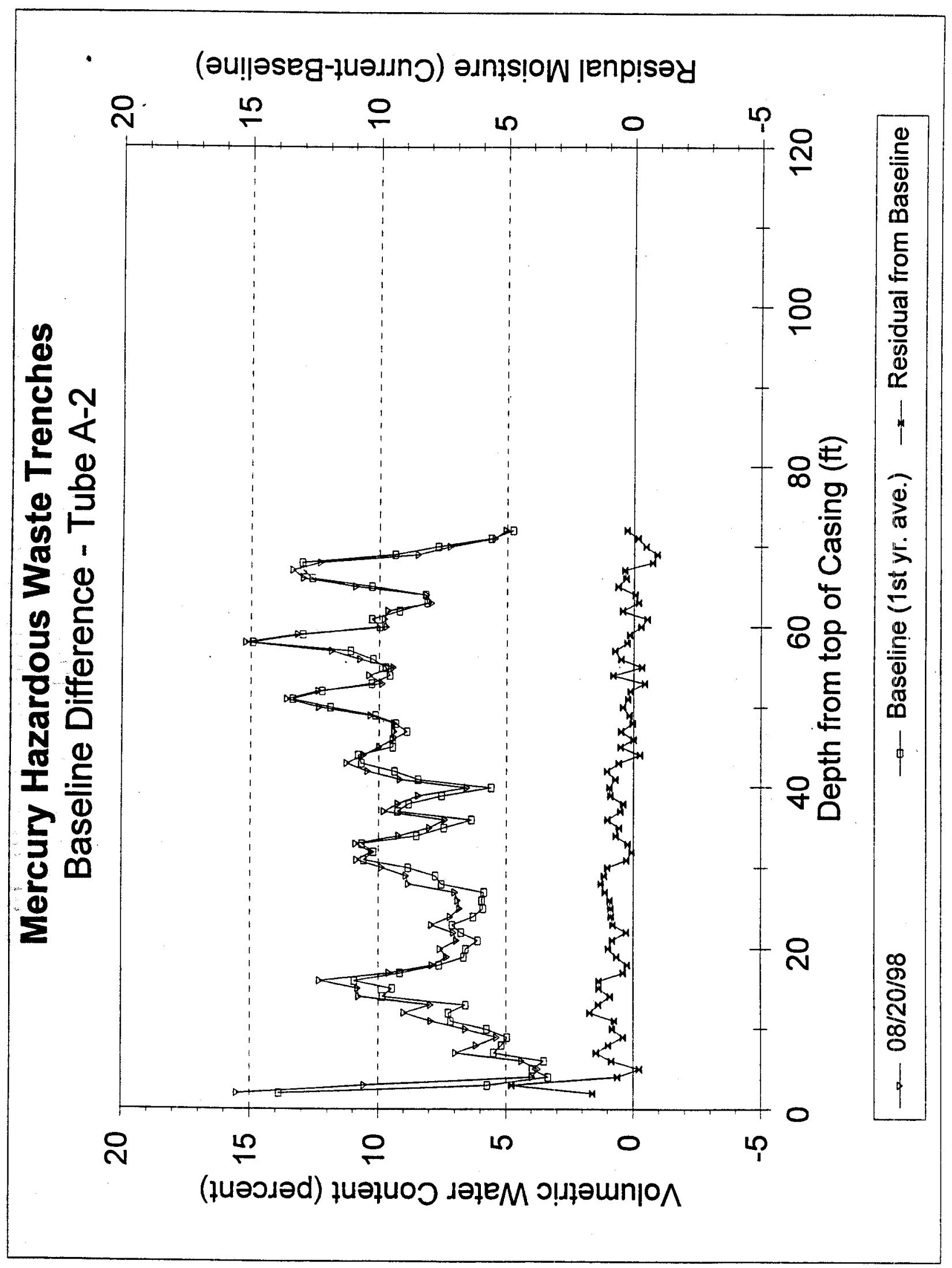




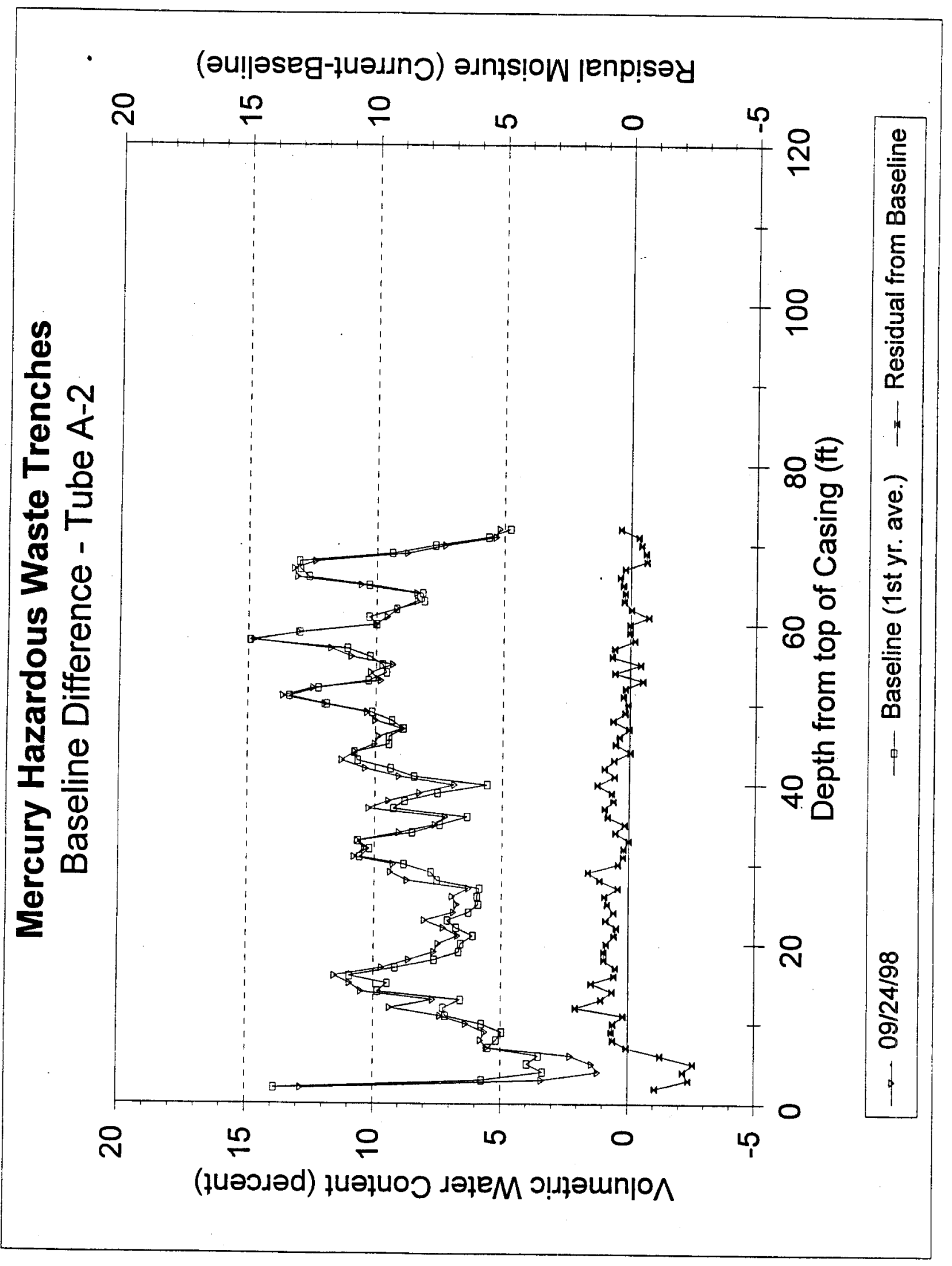




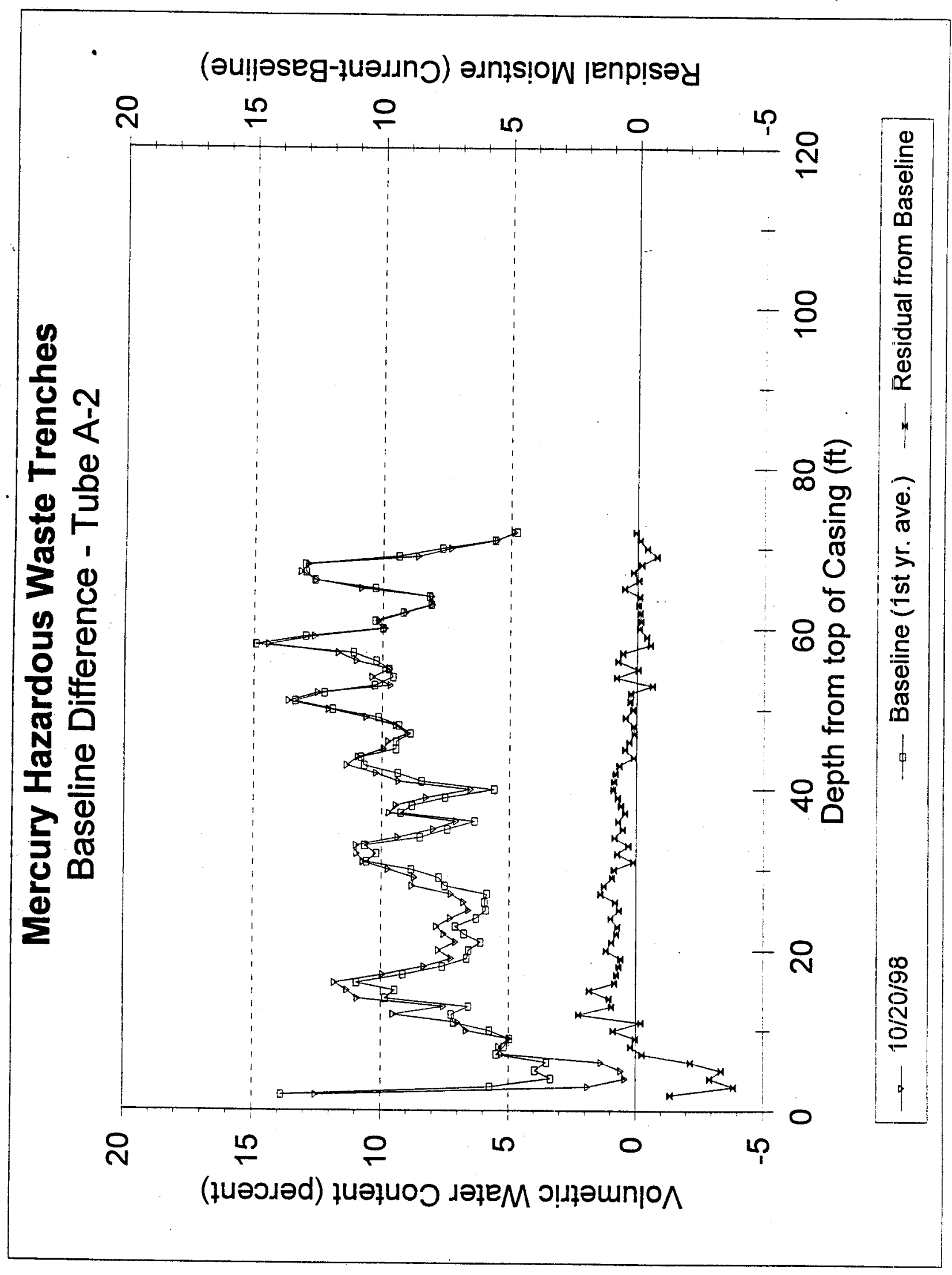




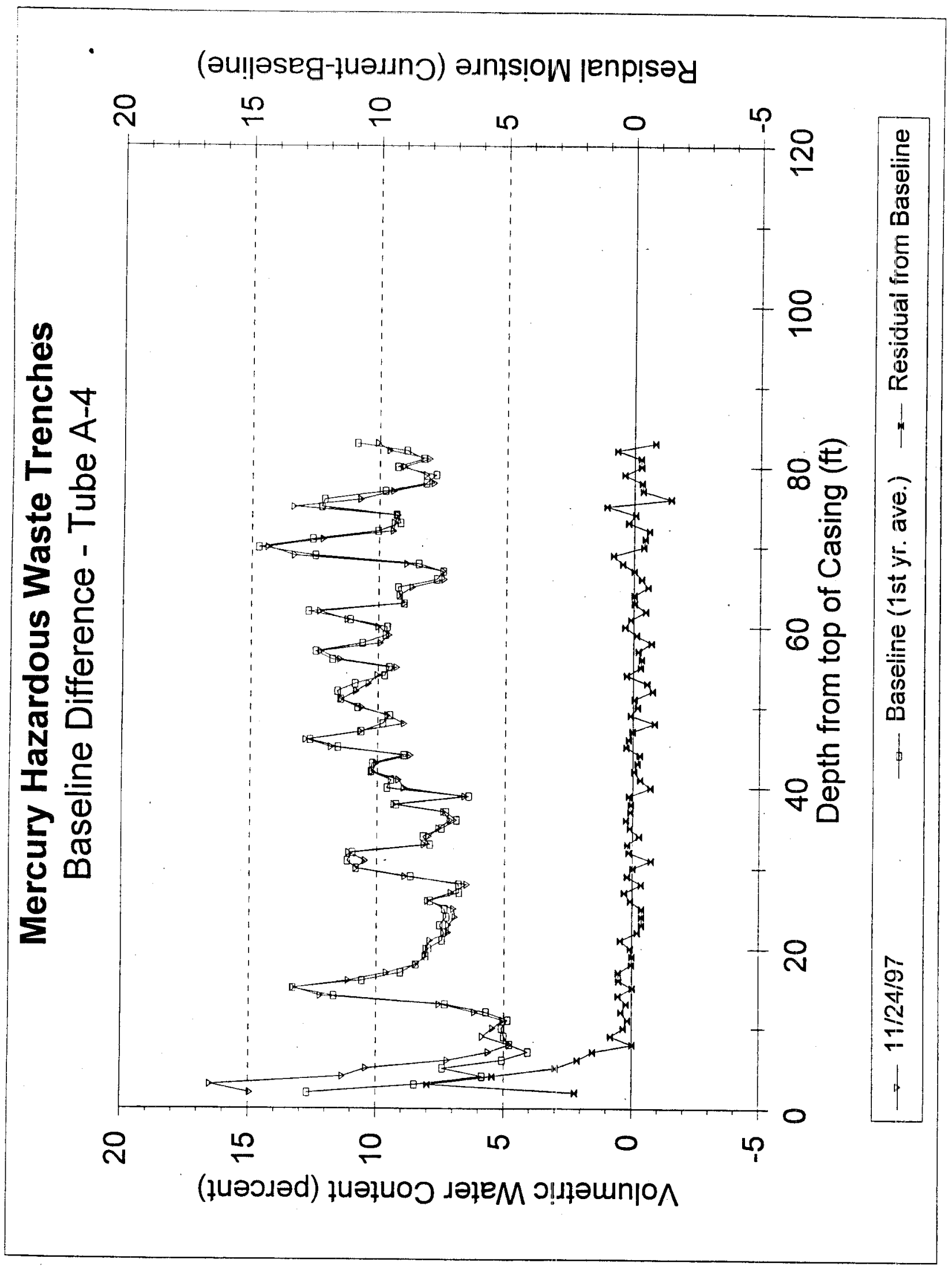




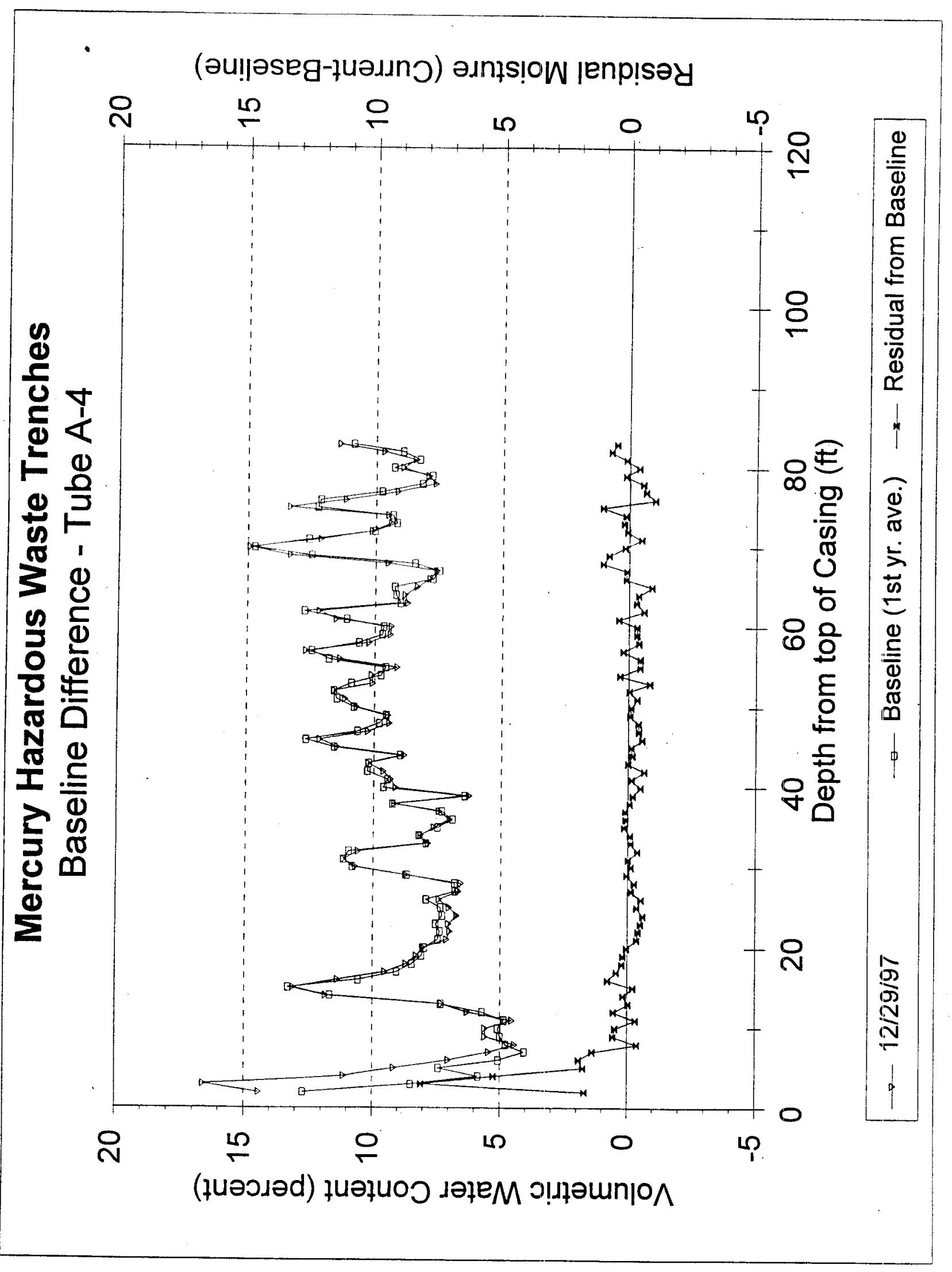




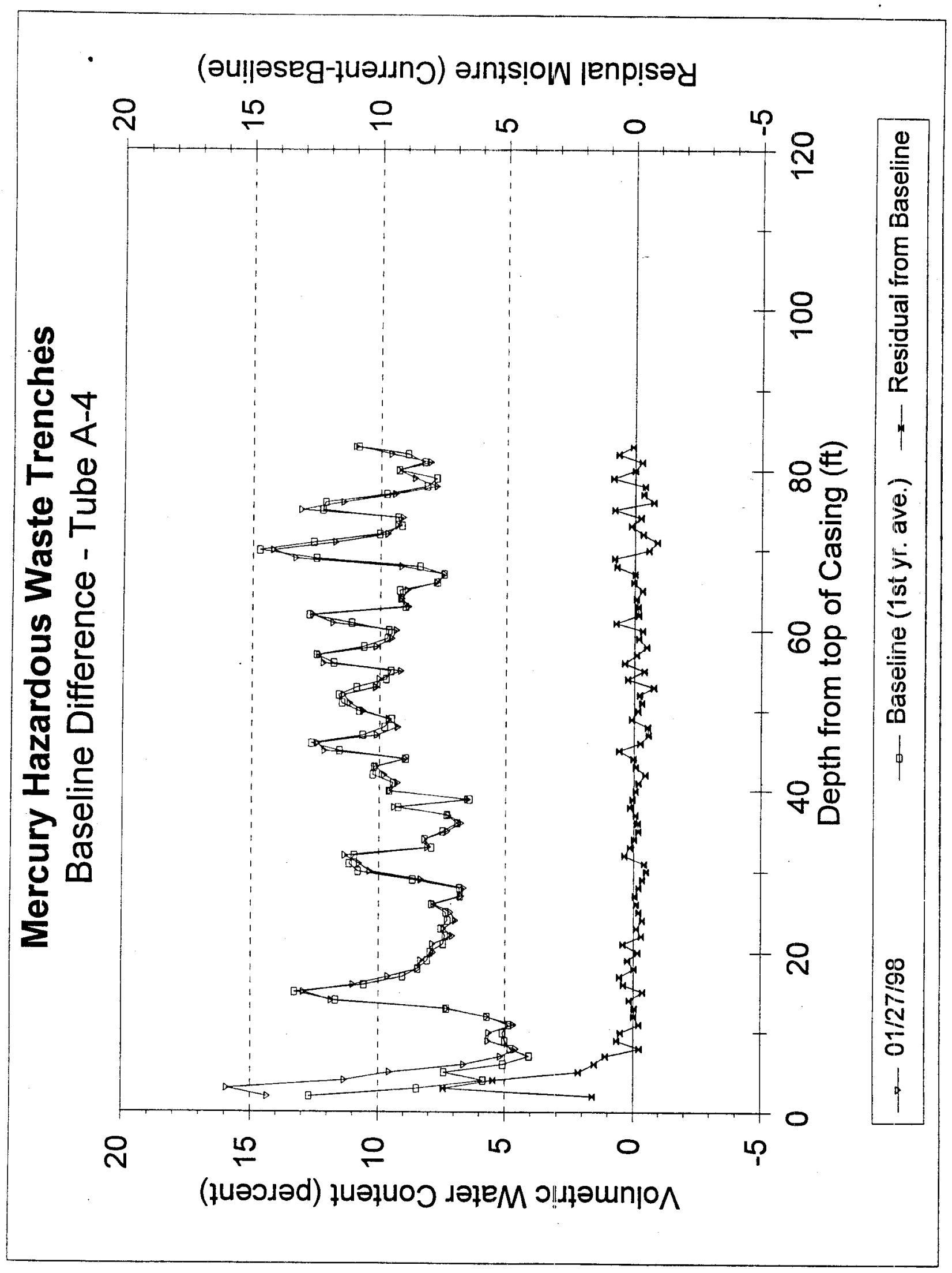




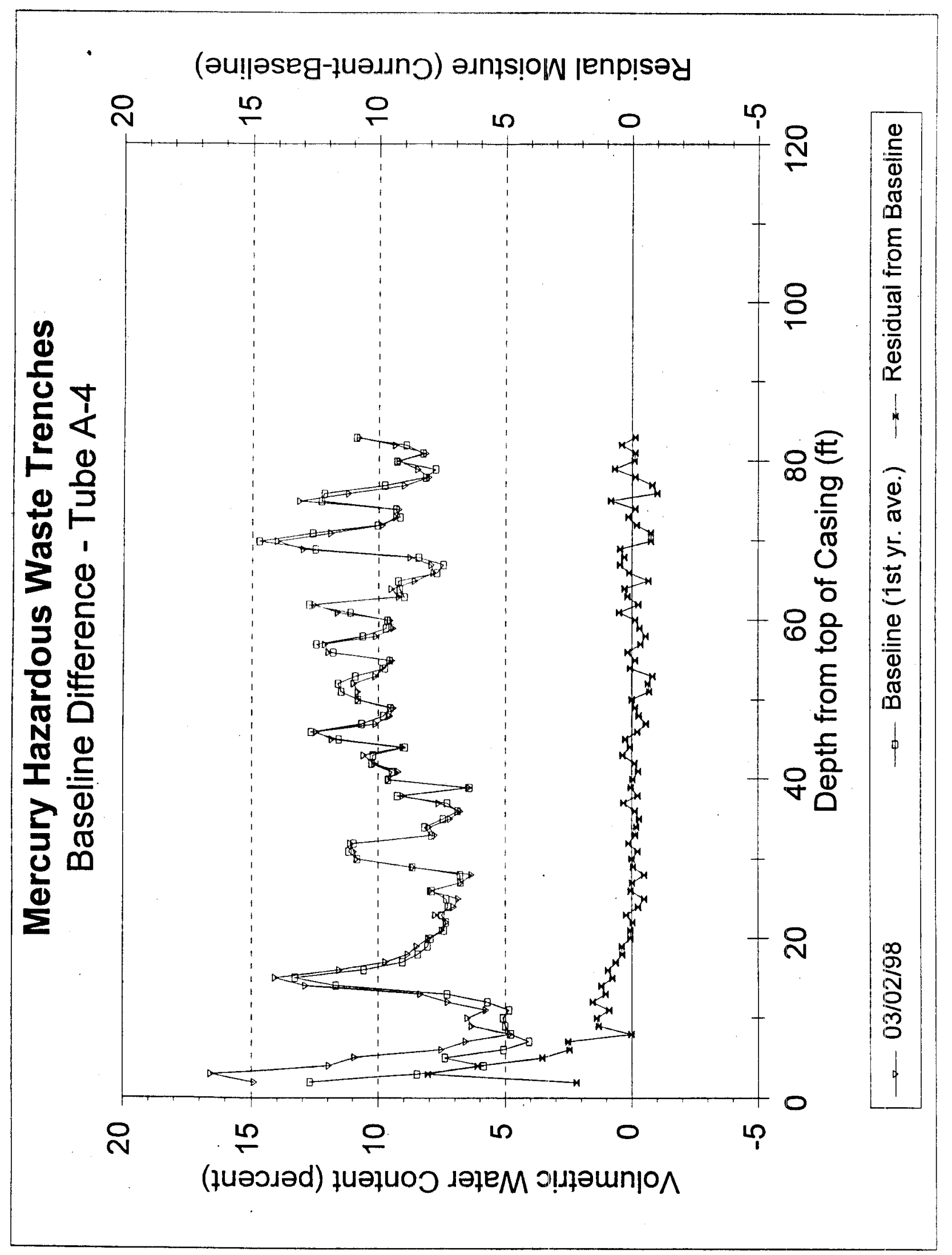




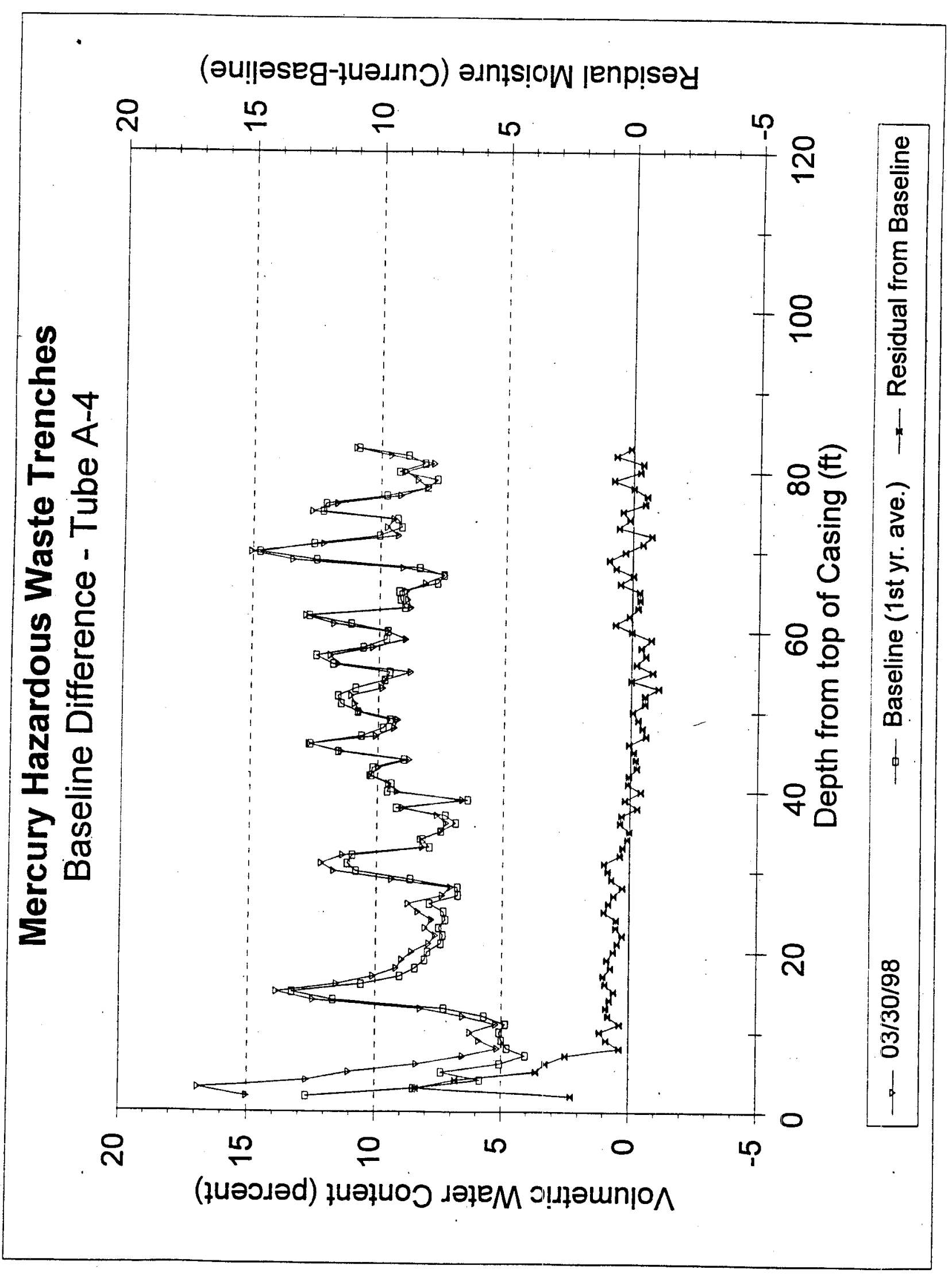




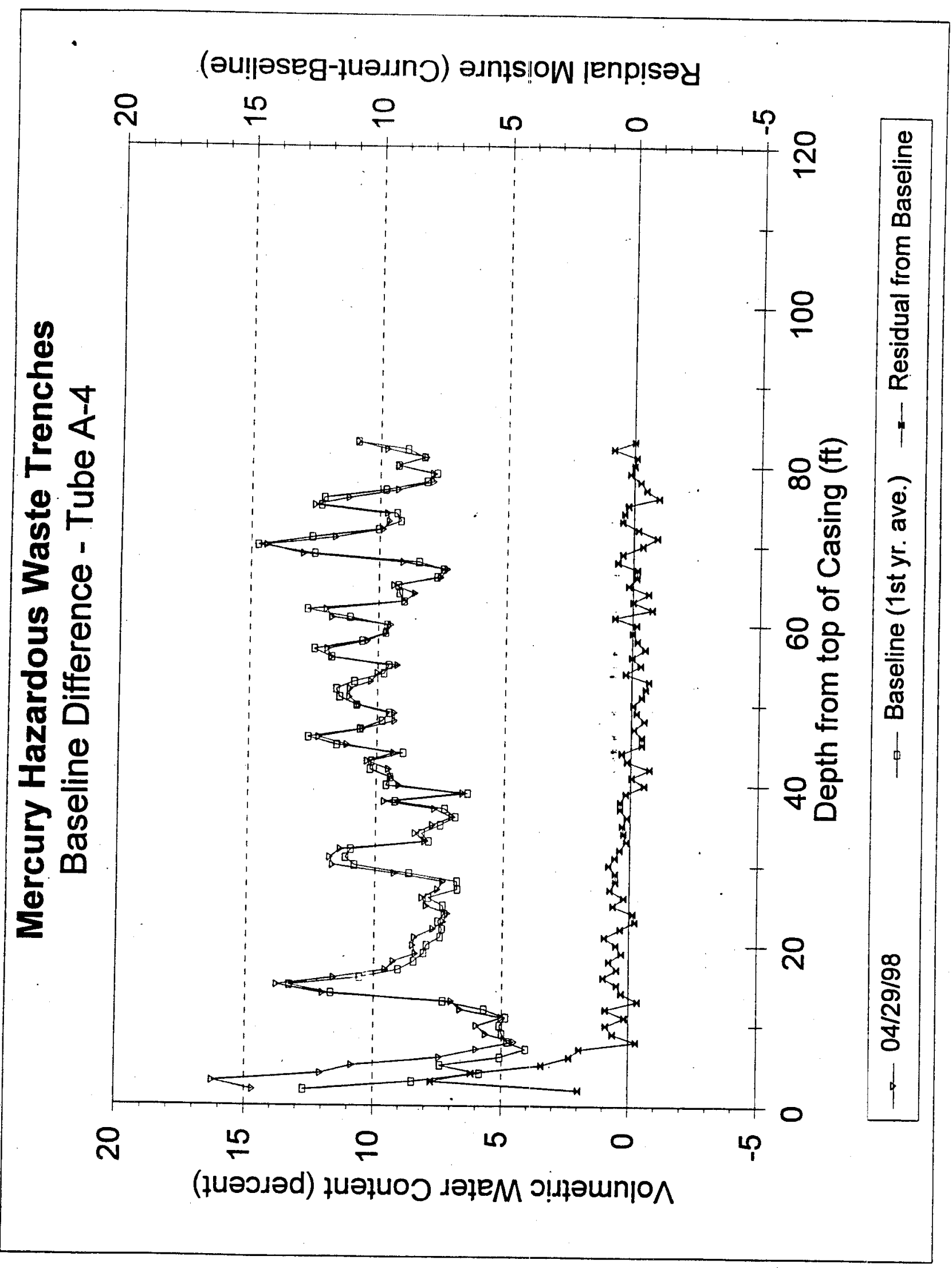




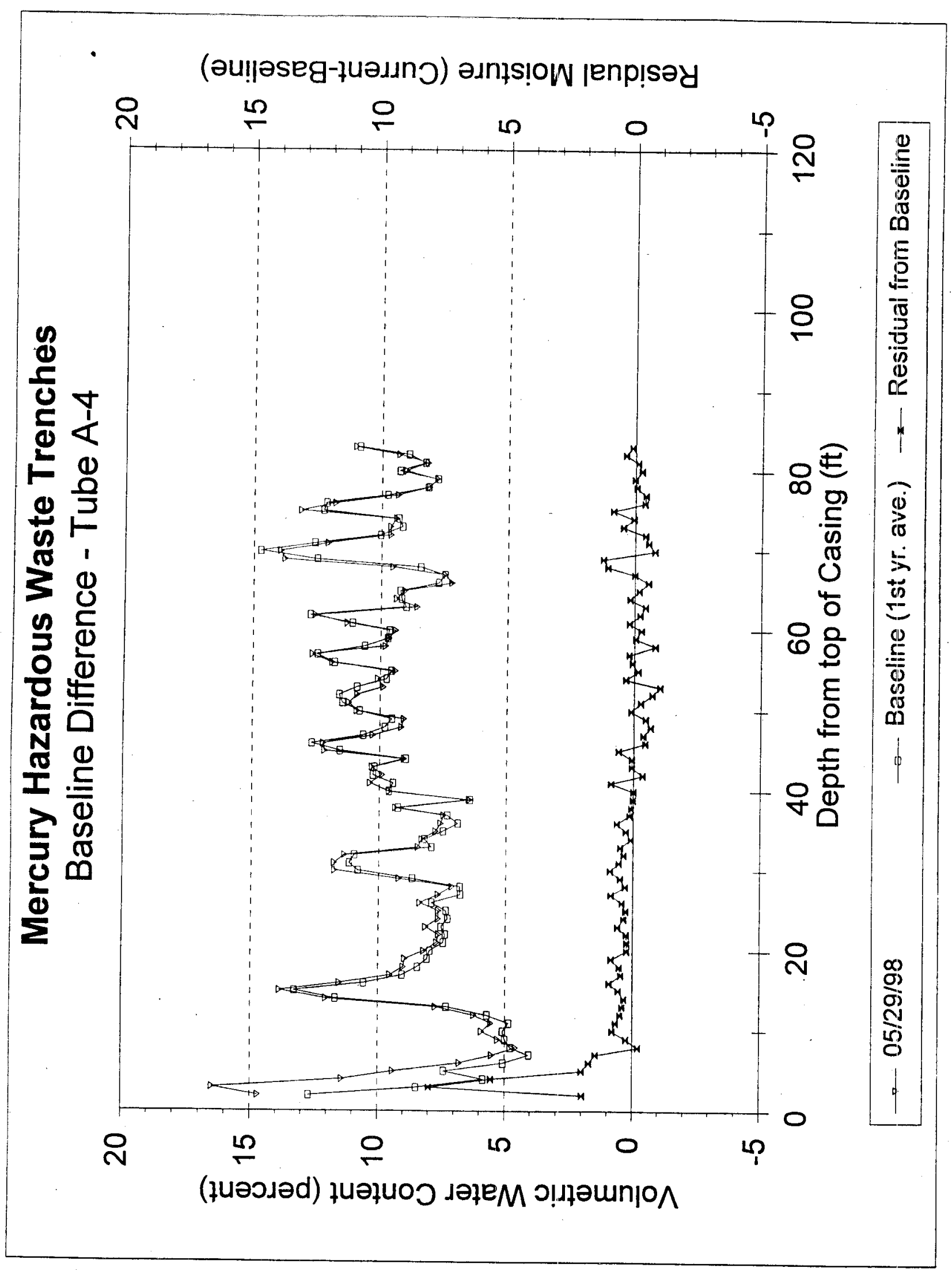




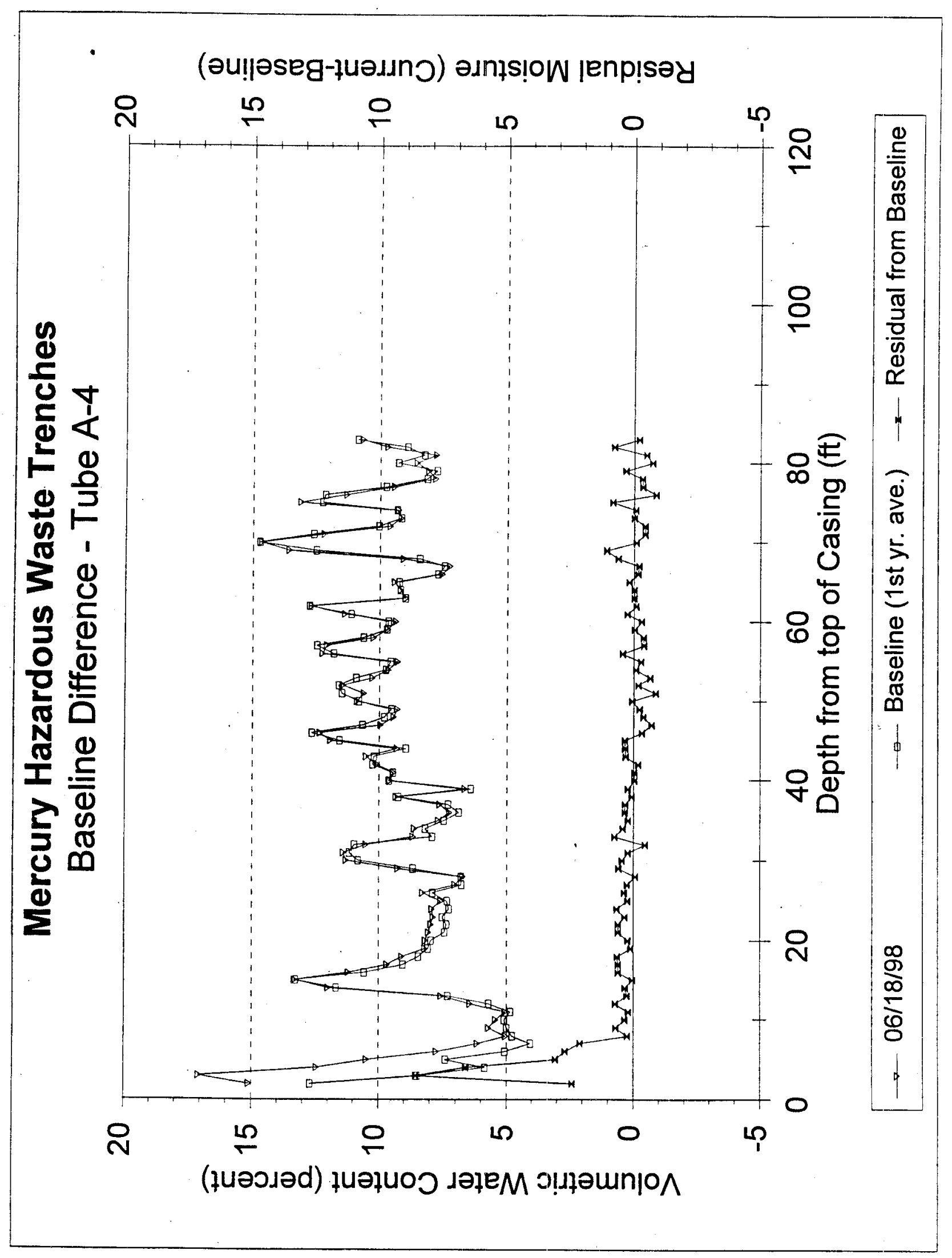




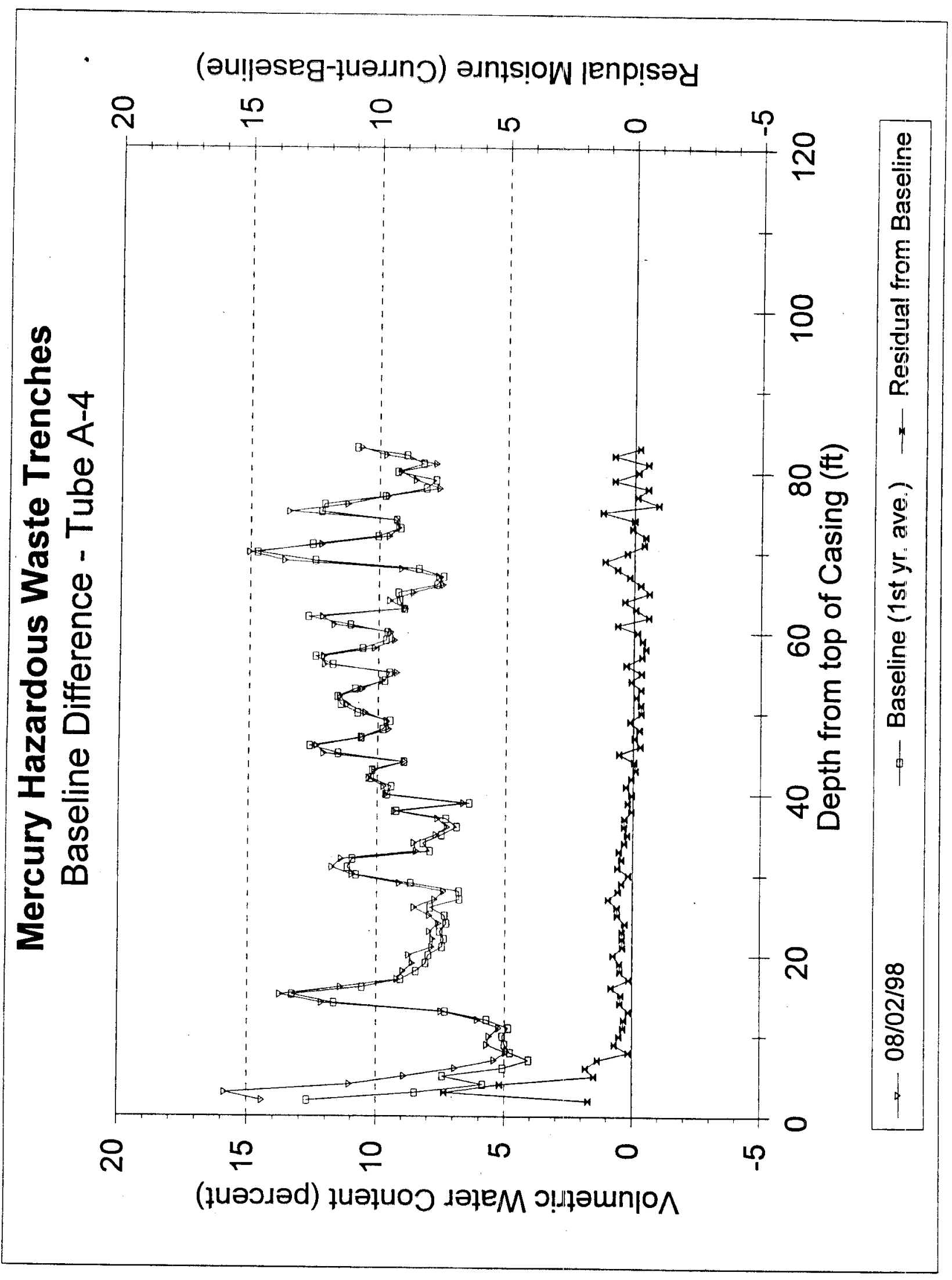




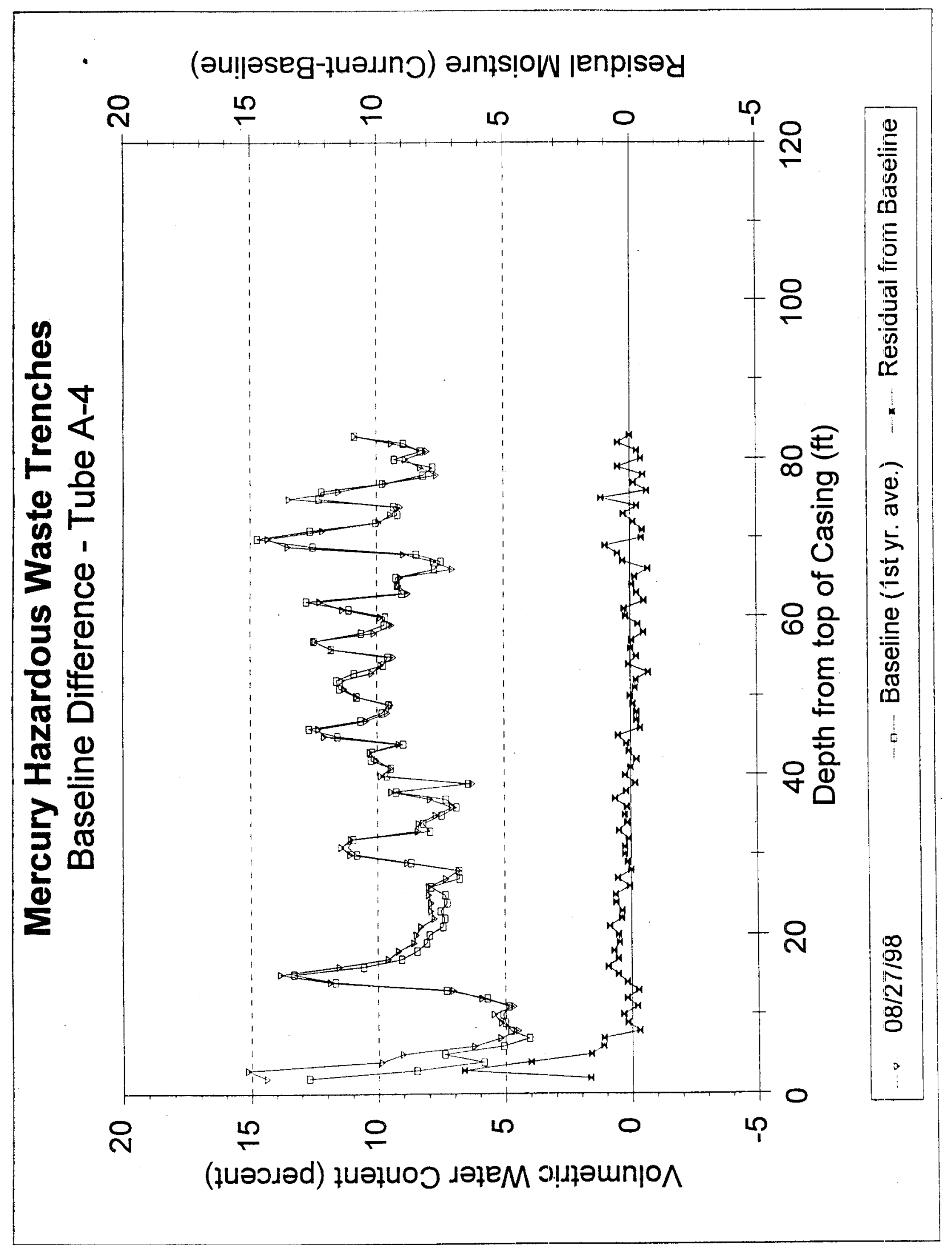




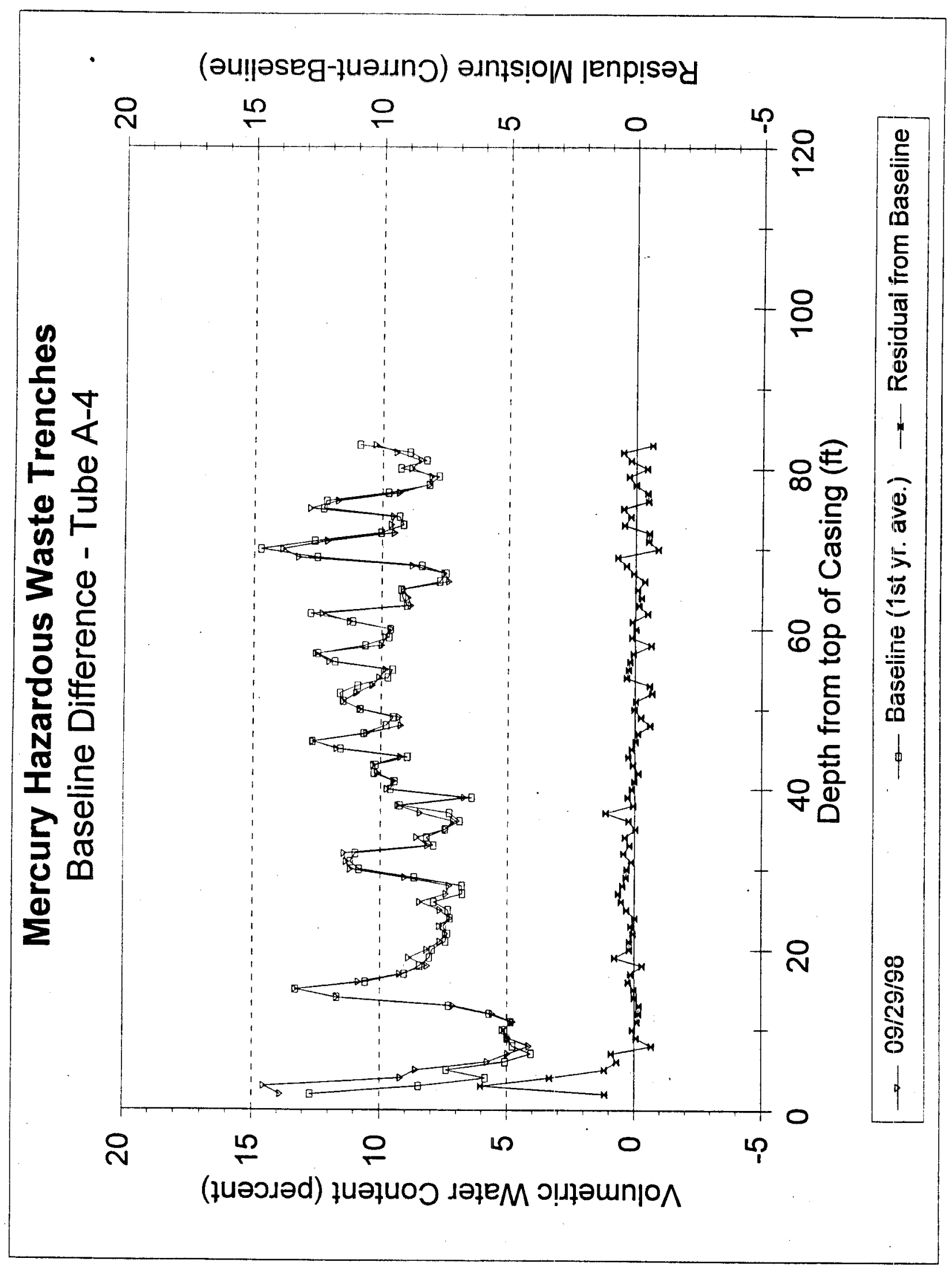




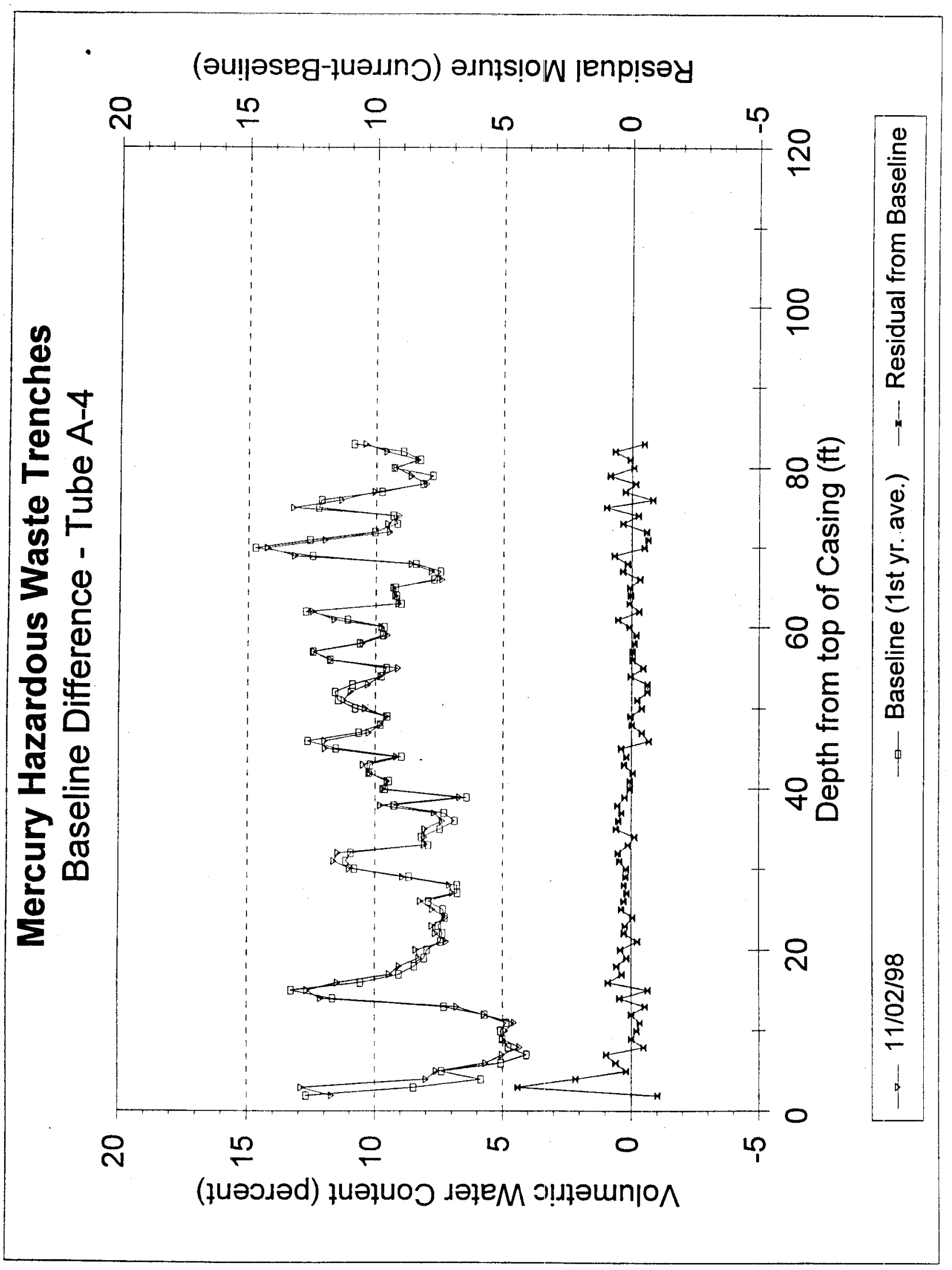


BASELINE DIFFERENCE

ROW B 


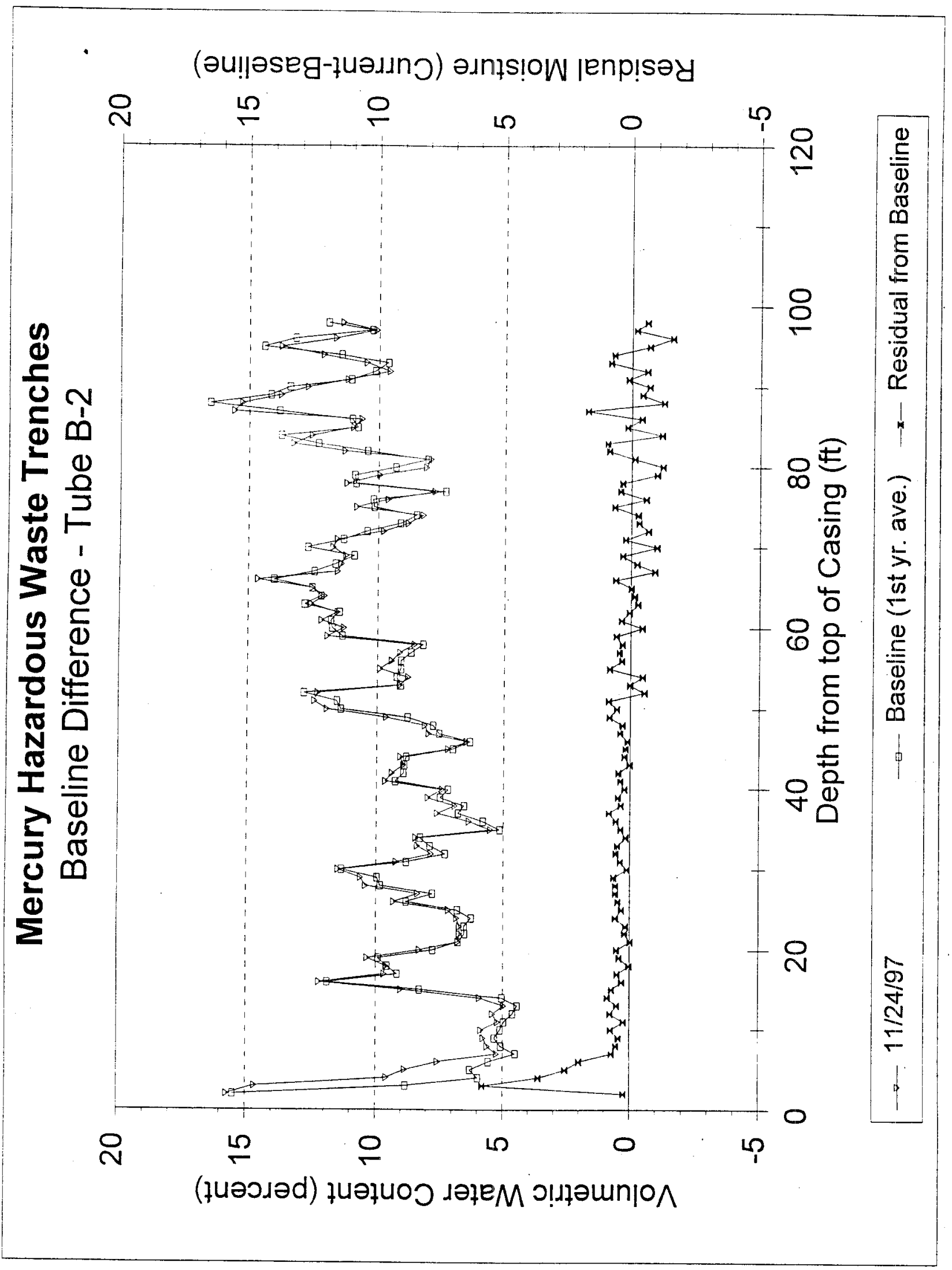




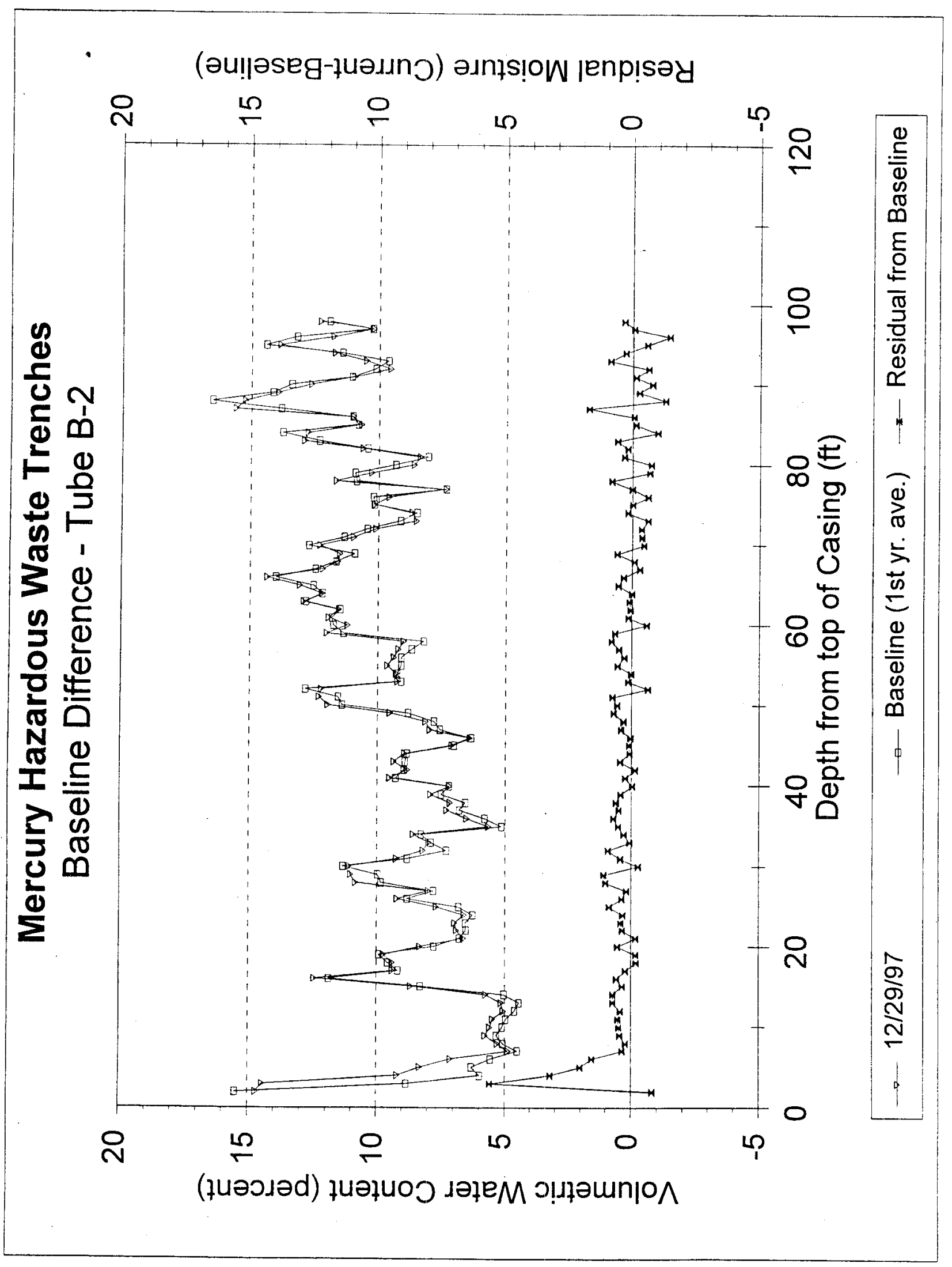




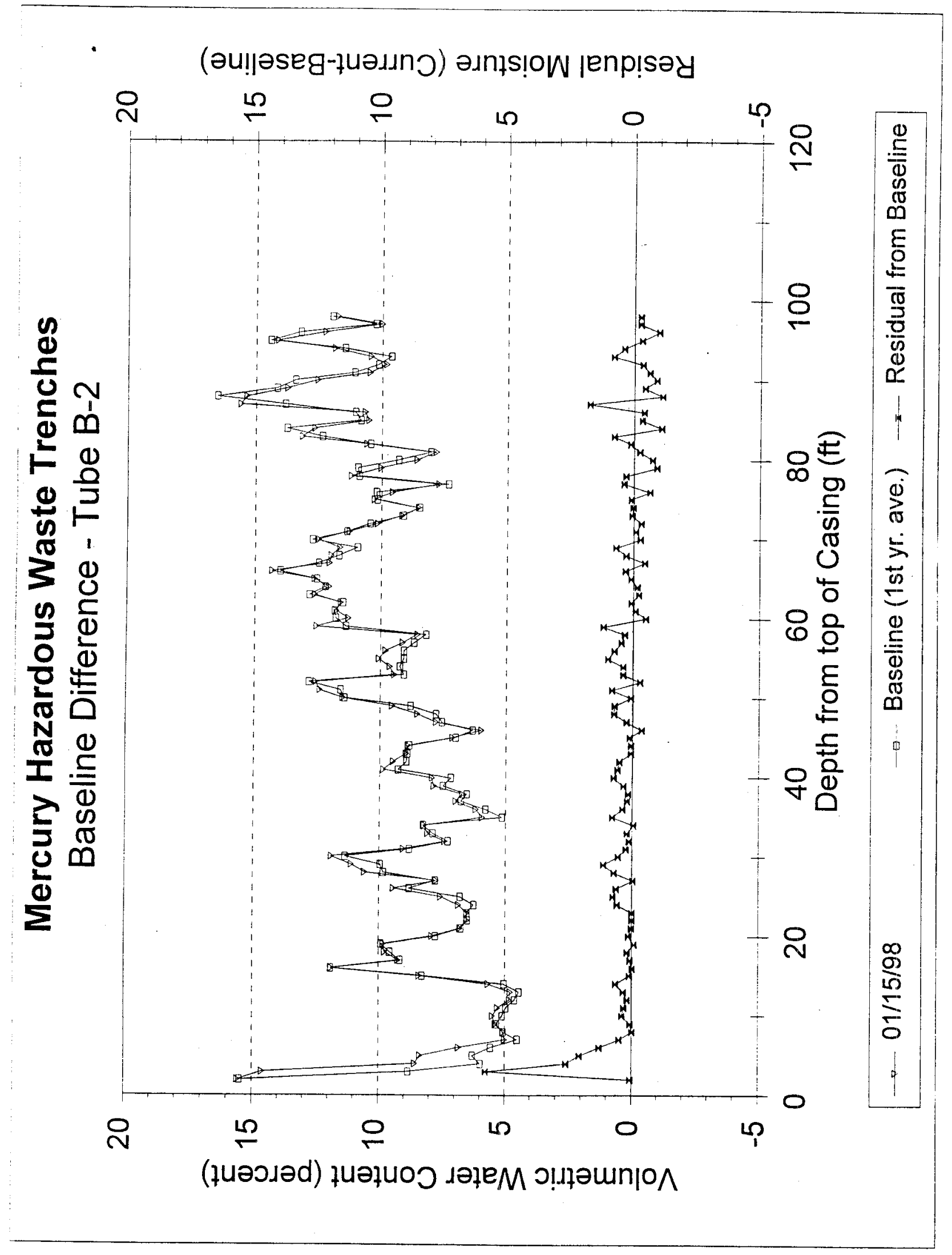




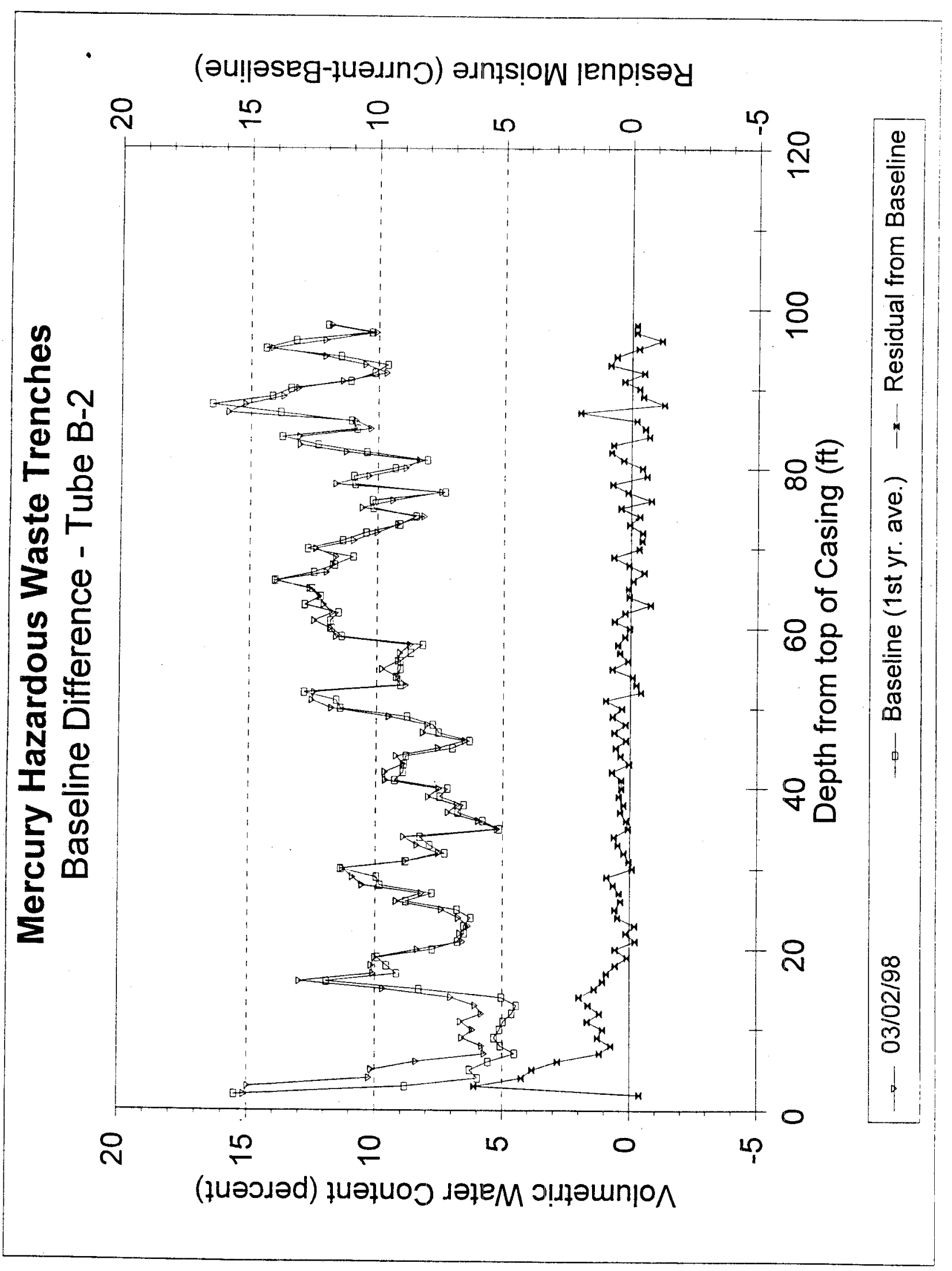




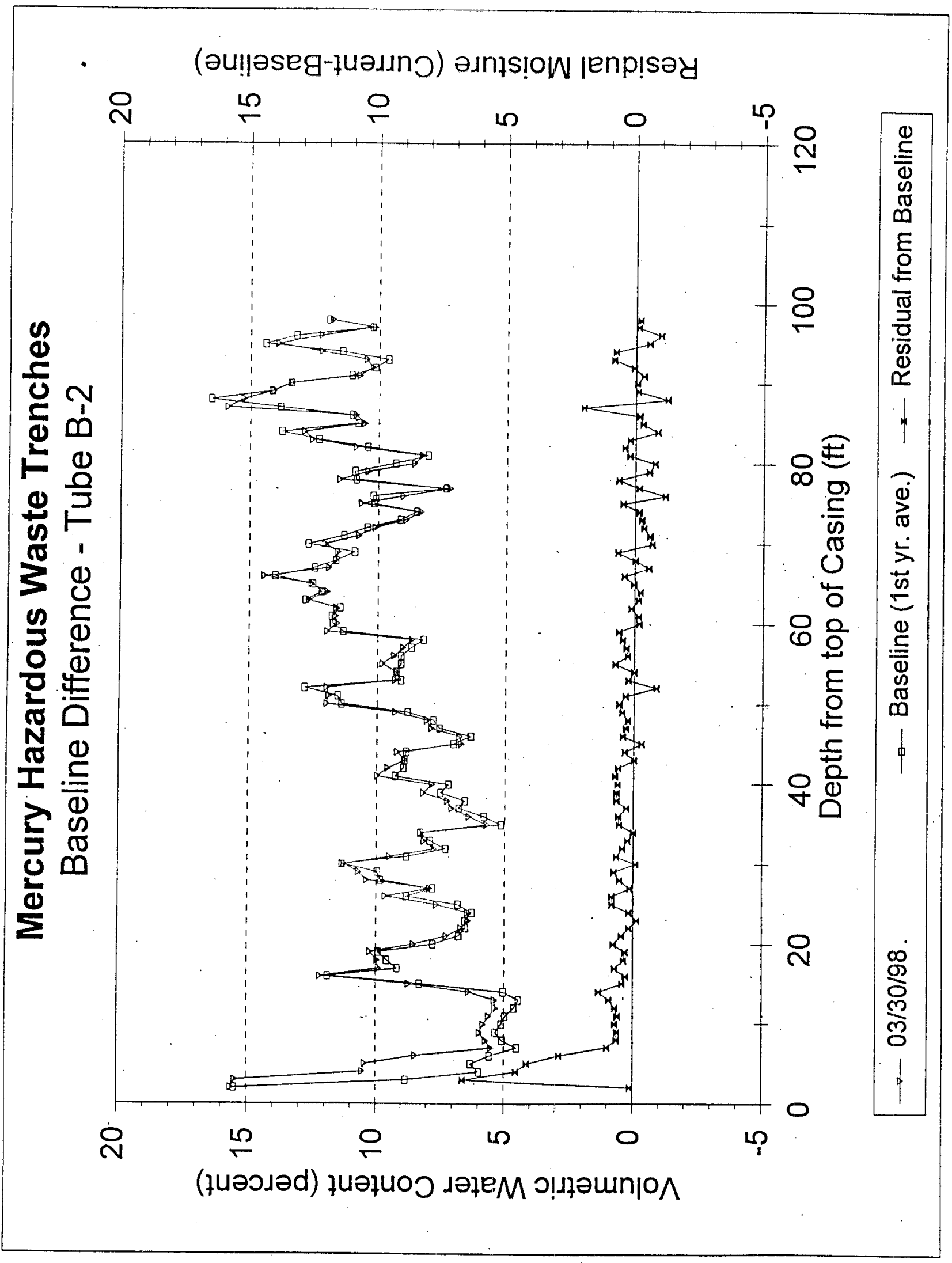




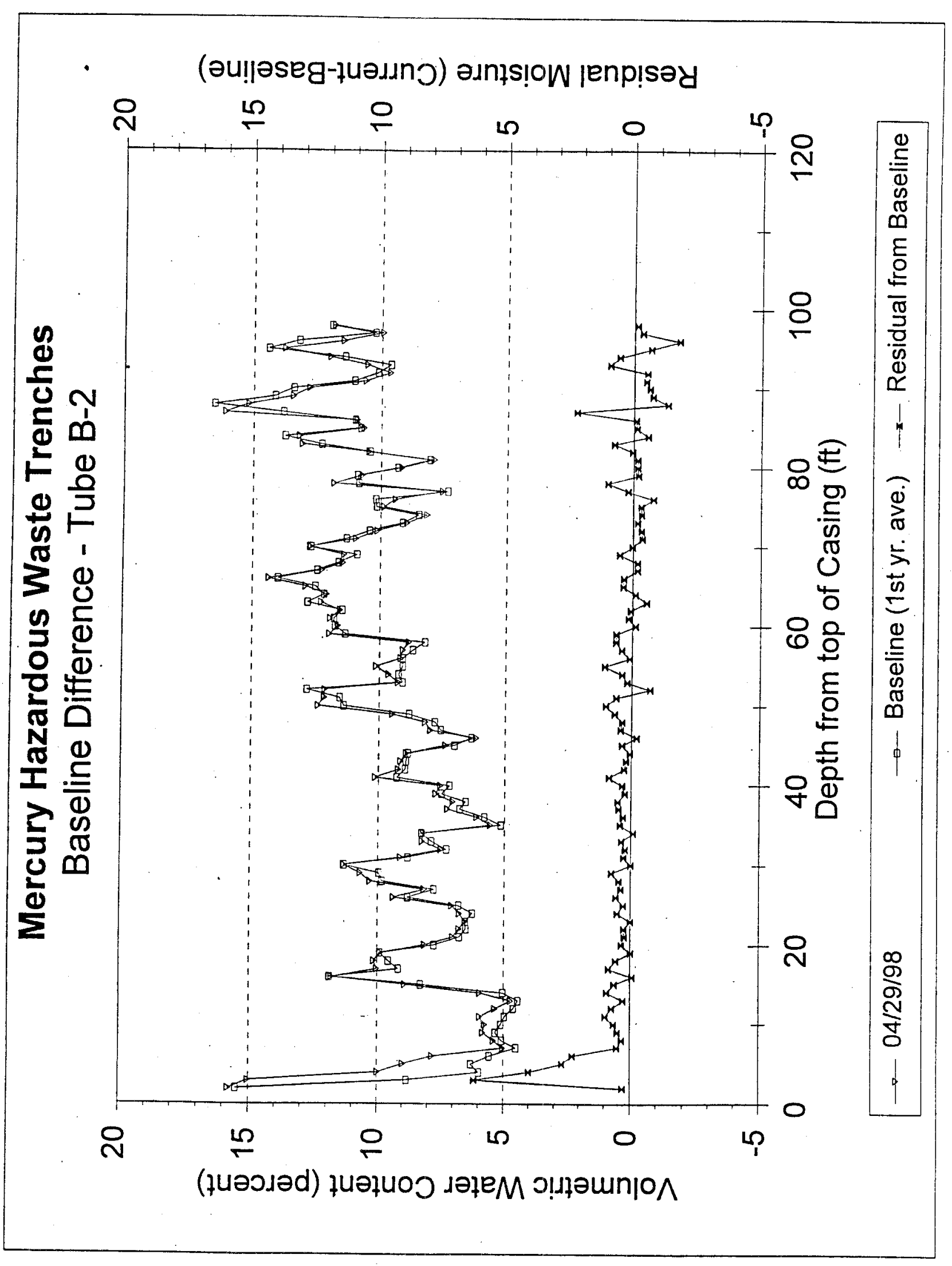




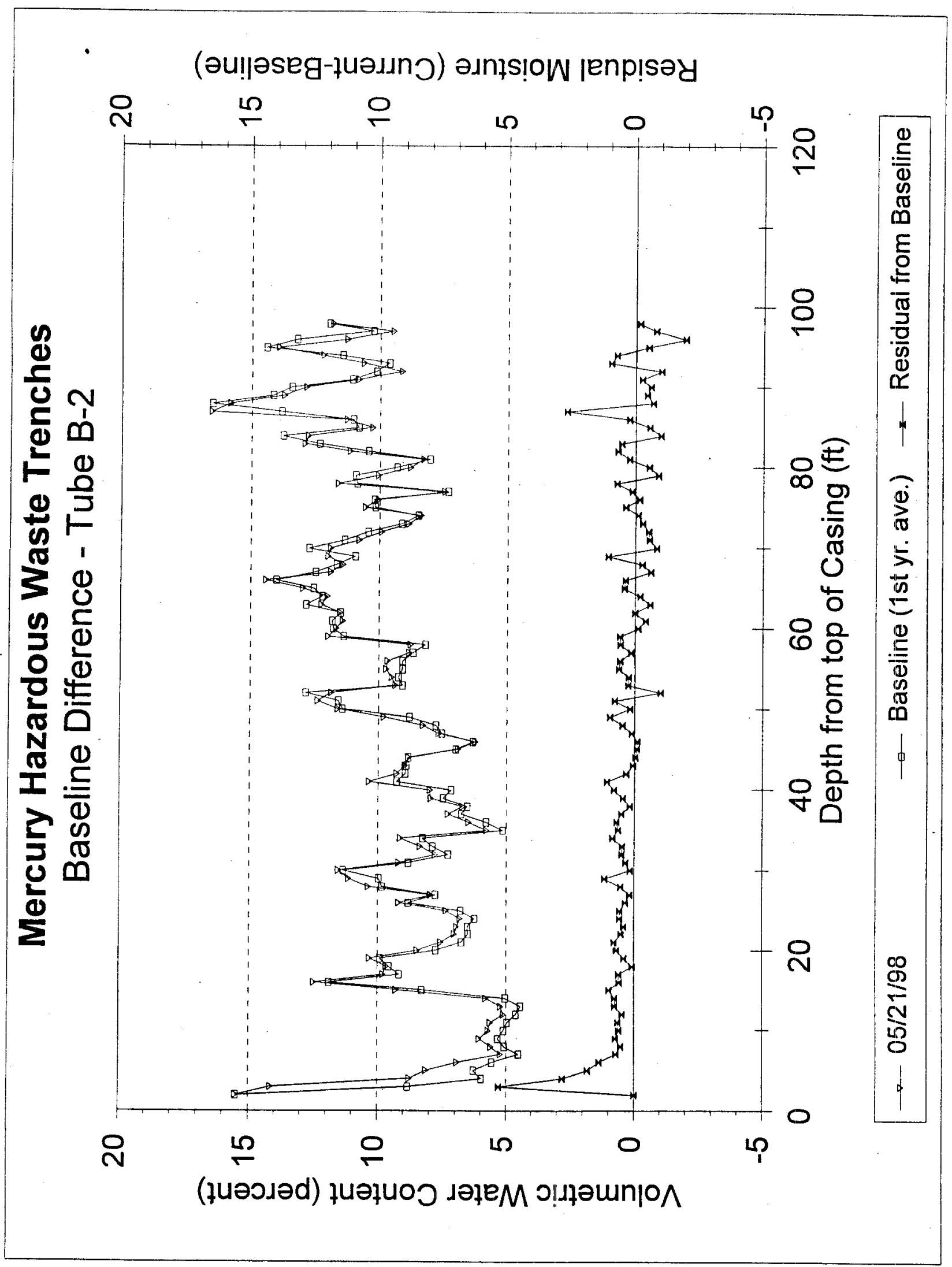




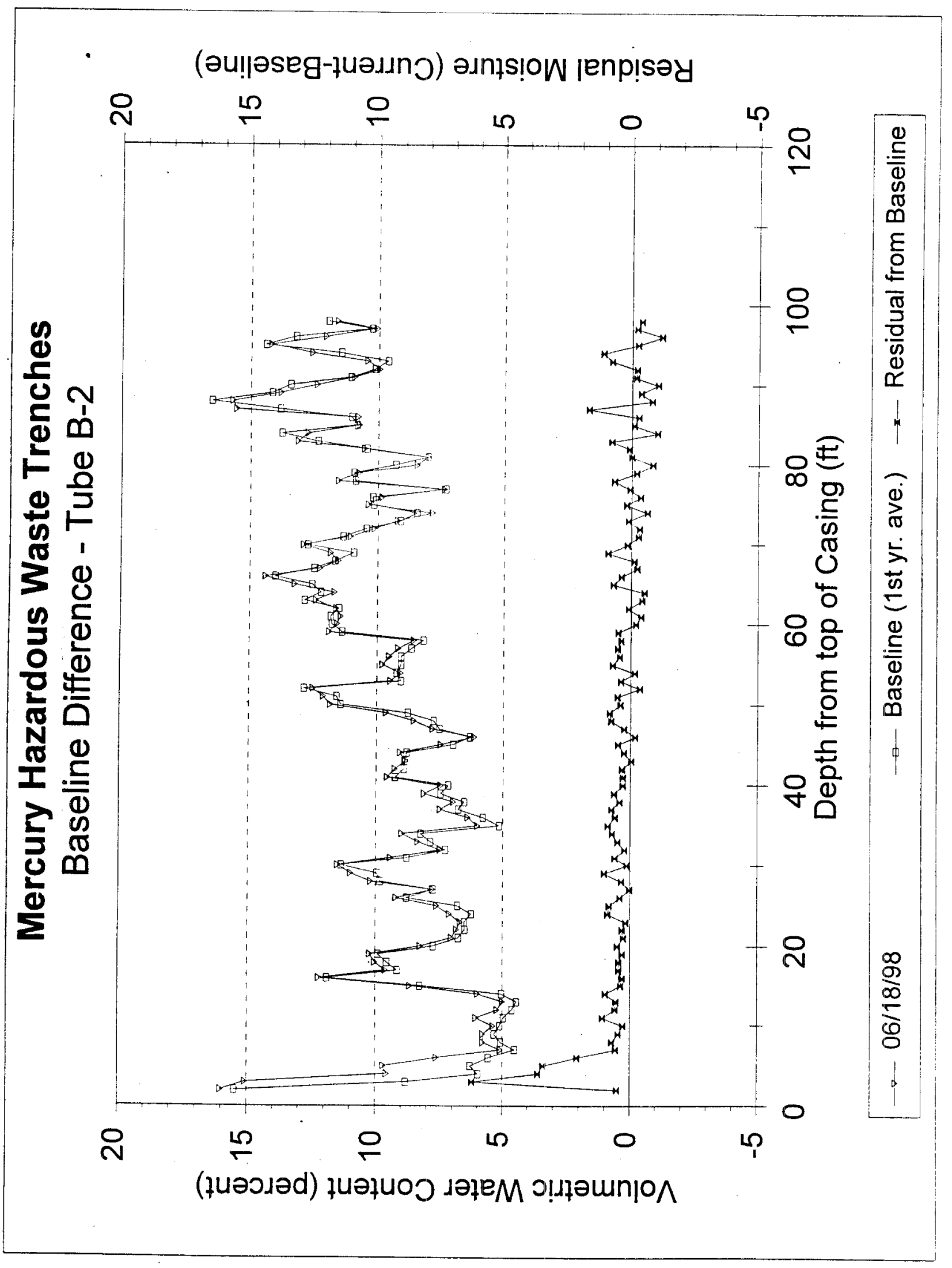




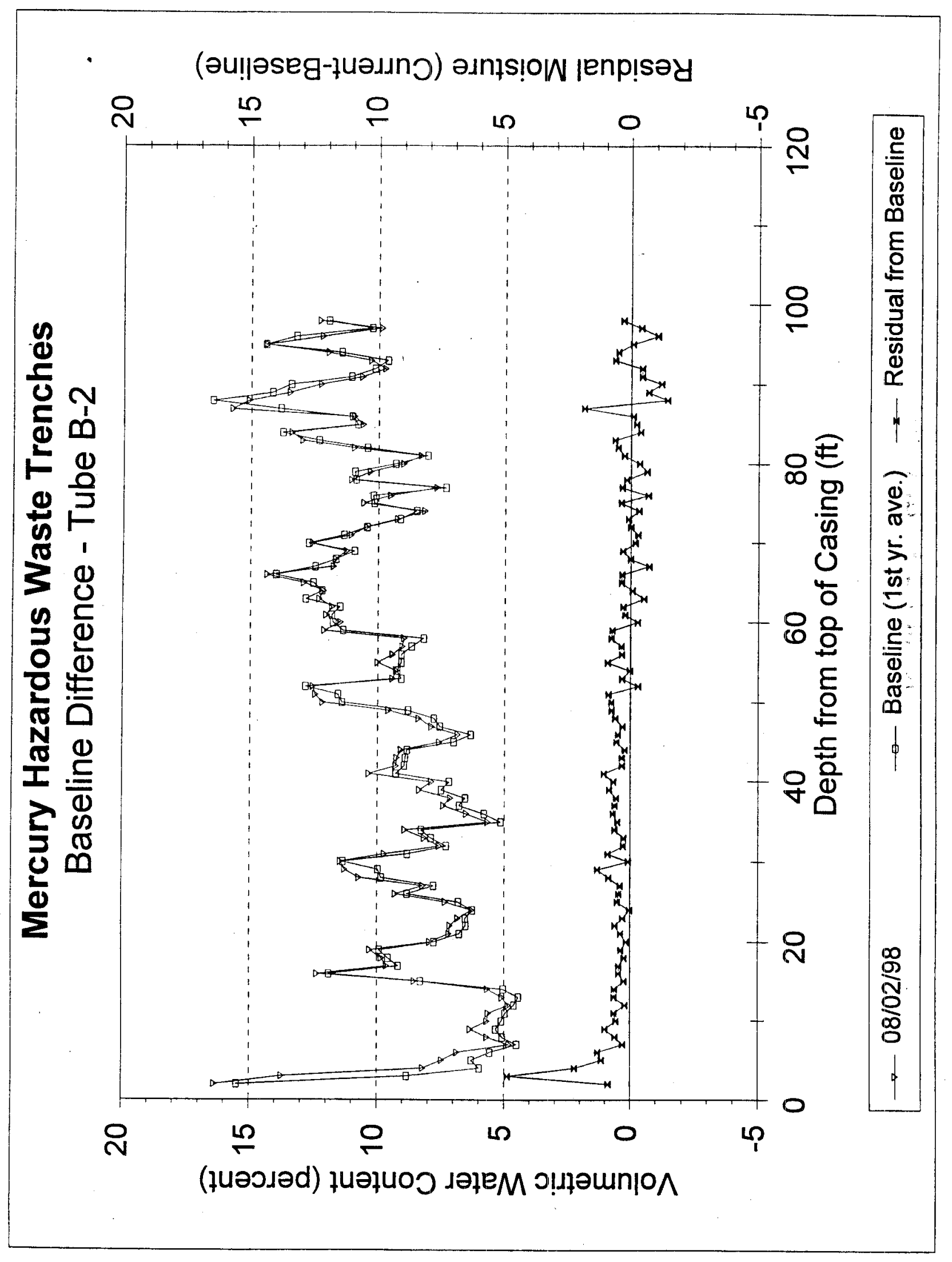




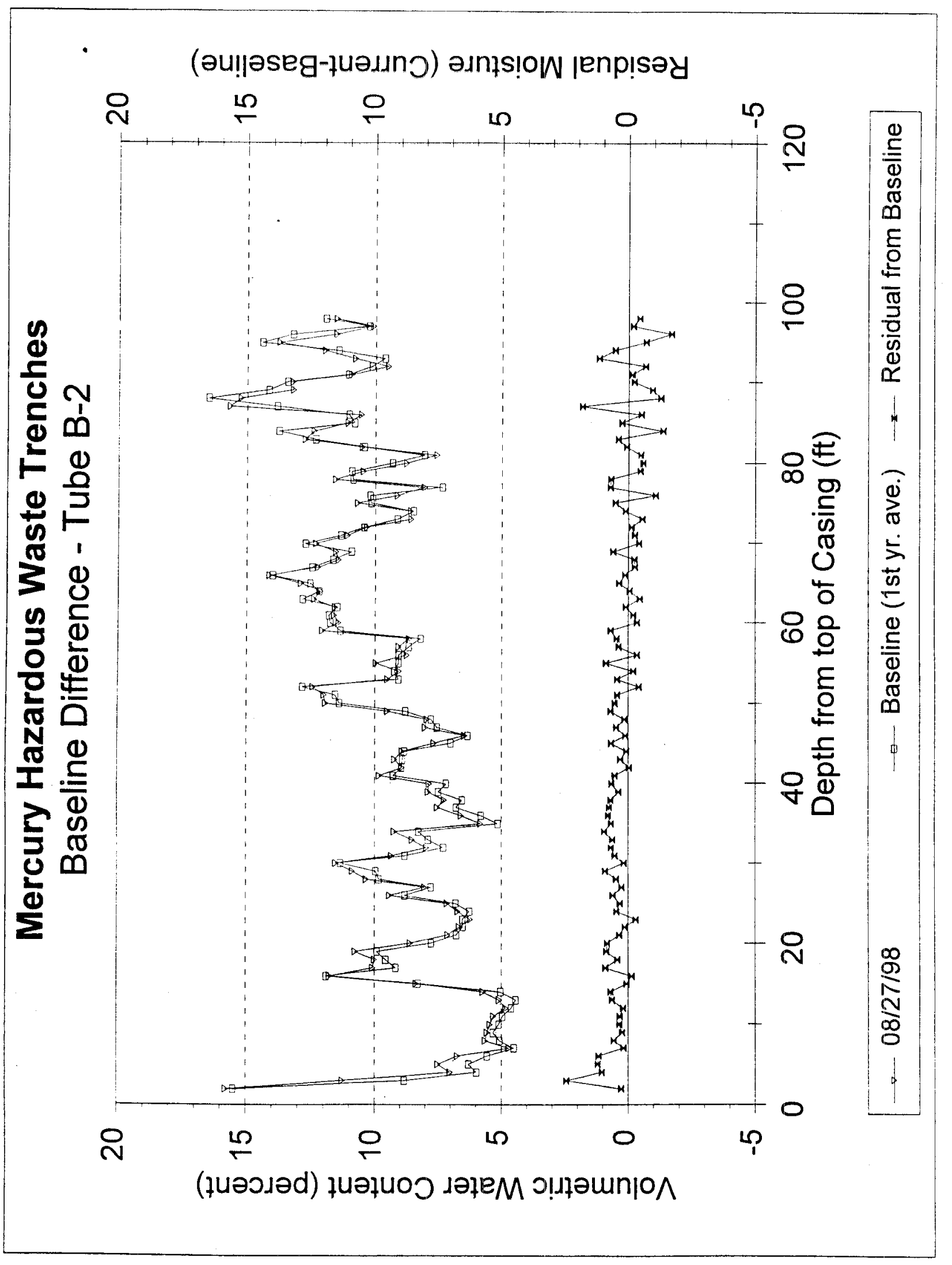




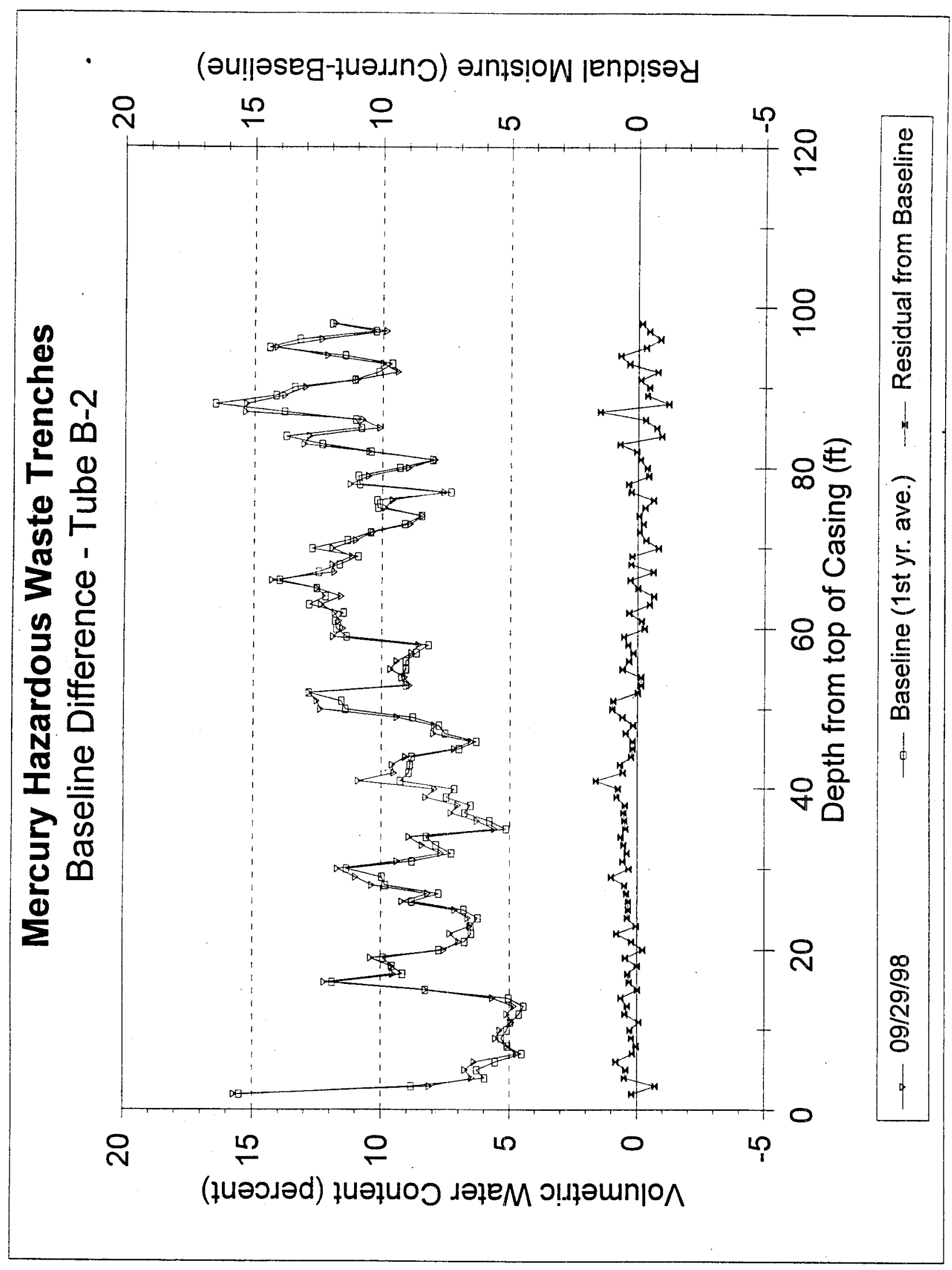




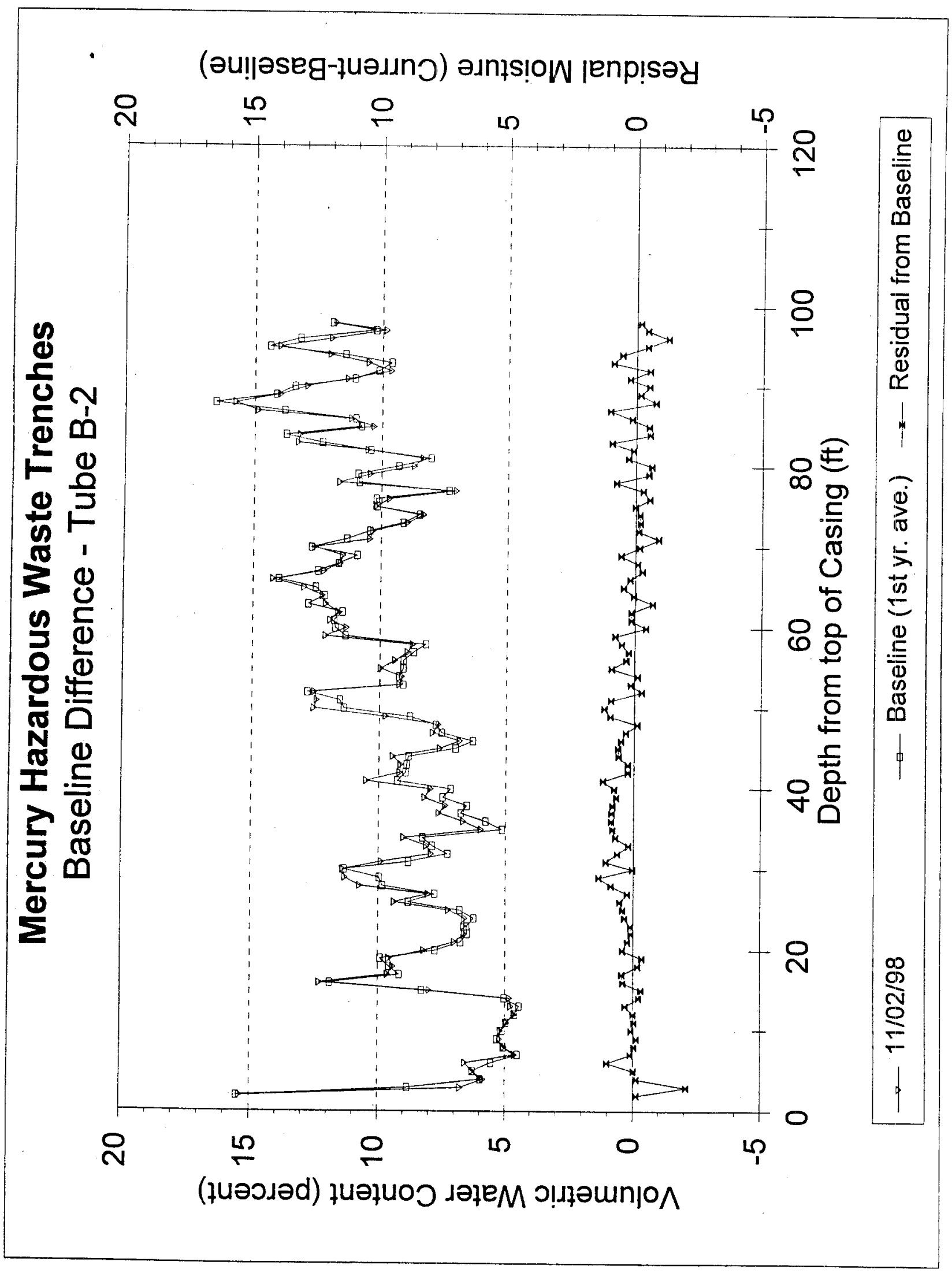




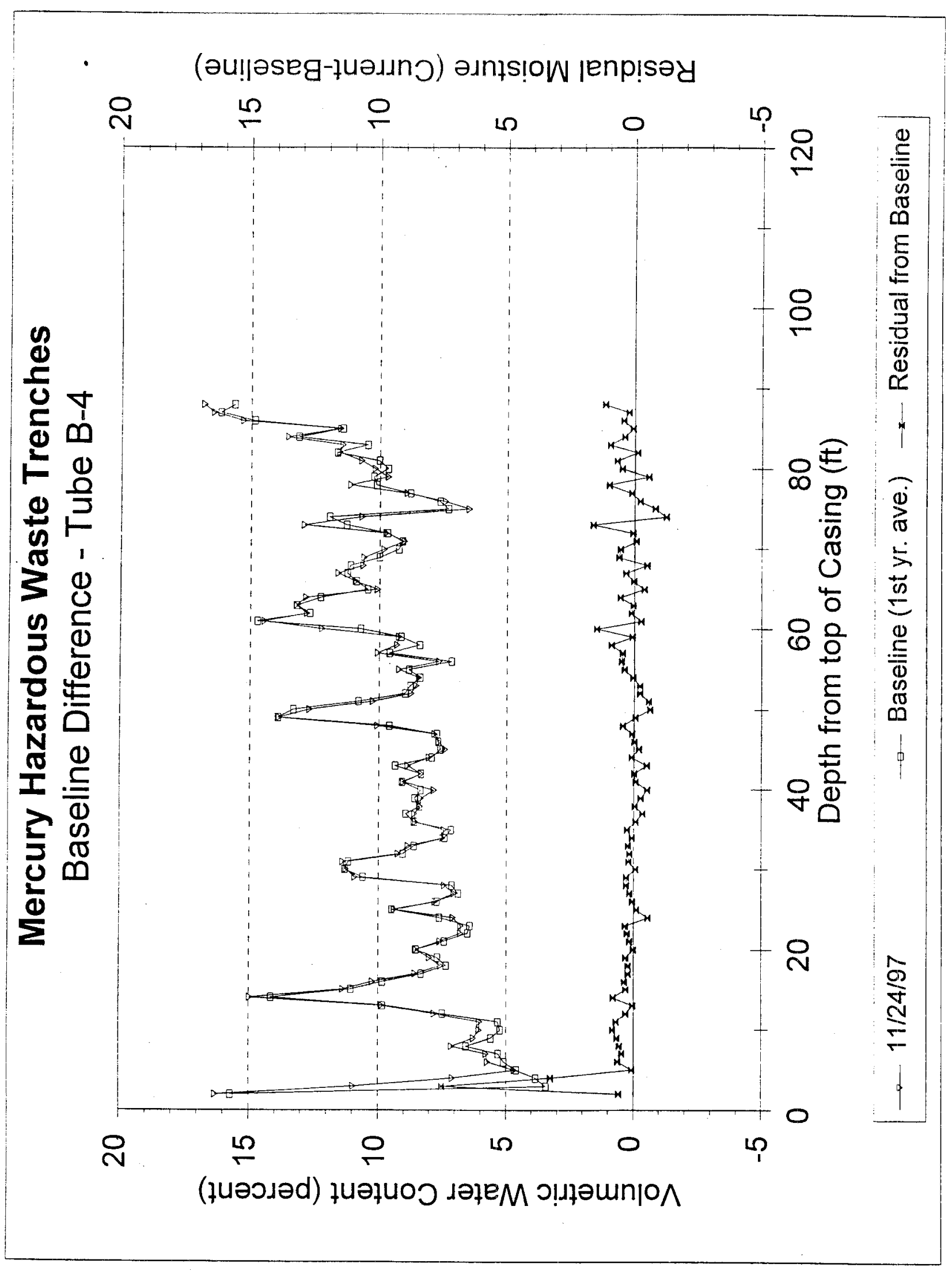




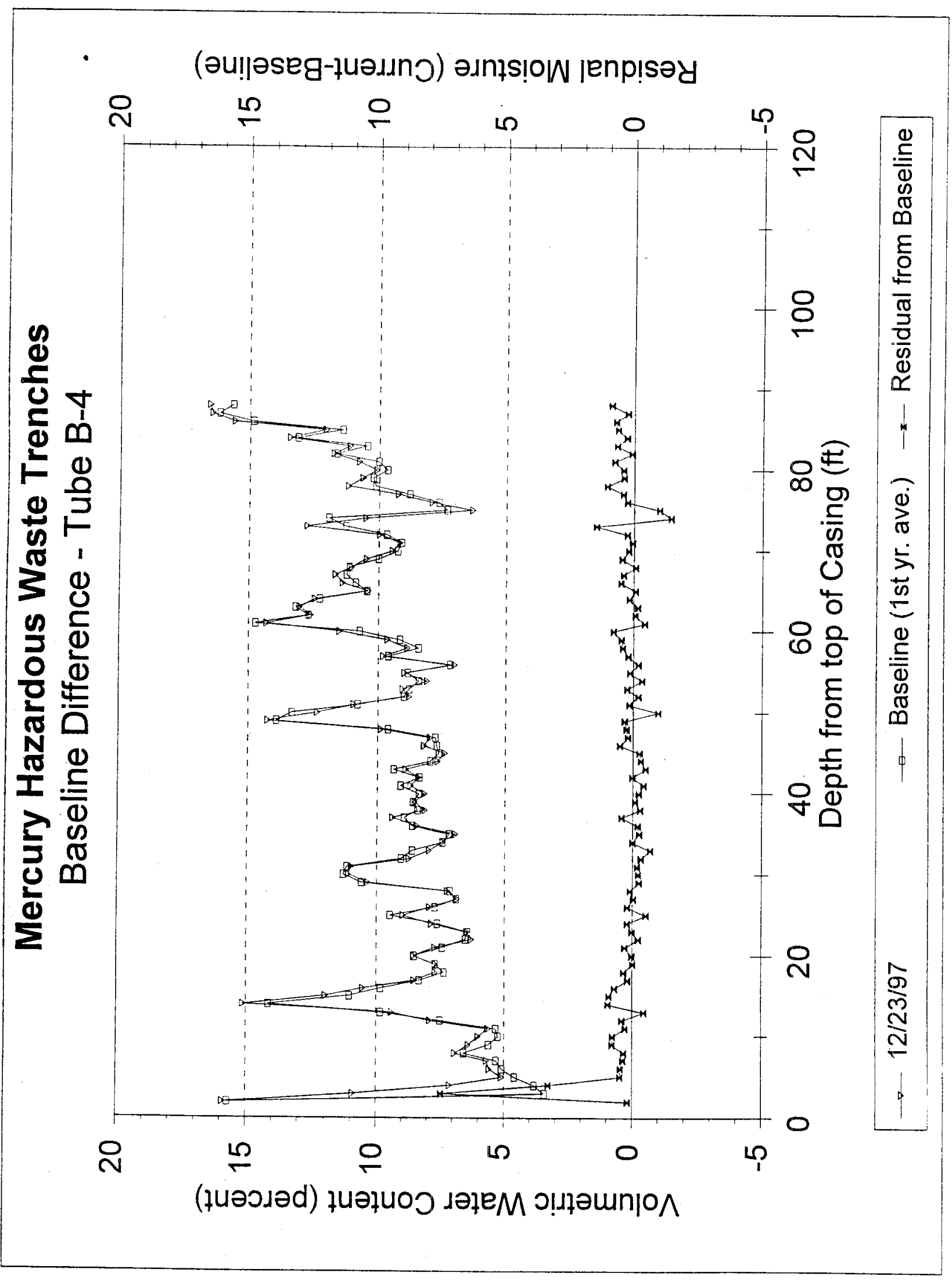




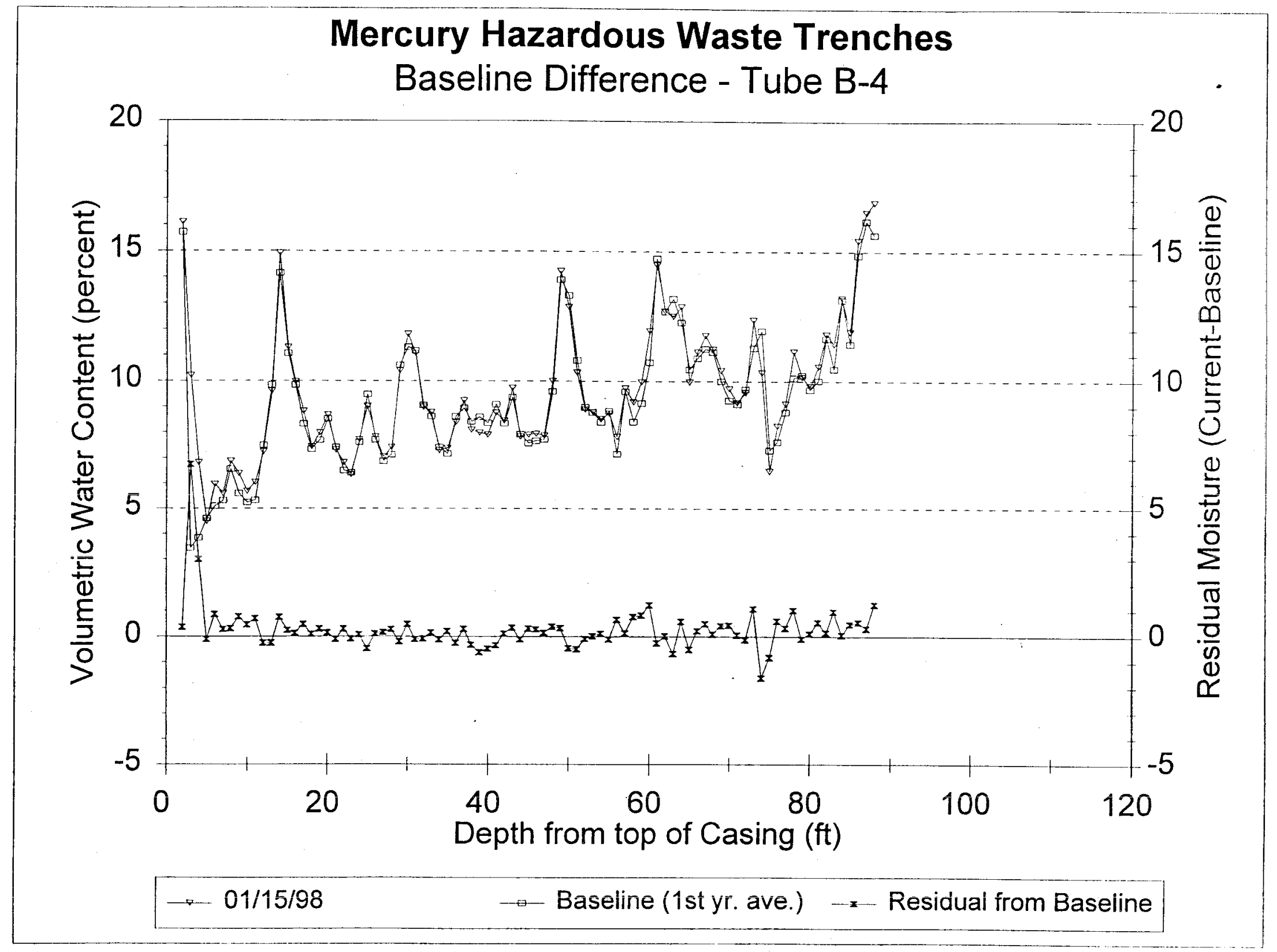




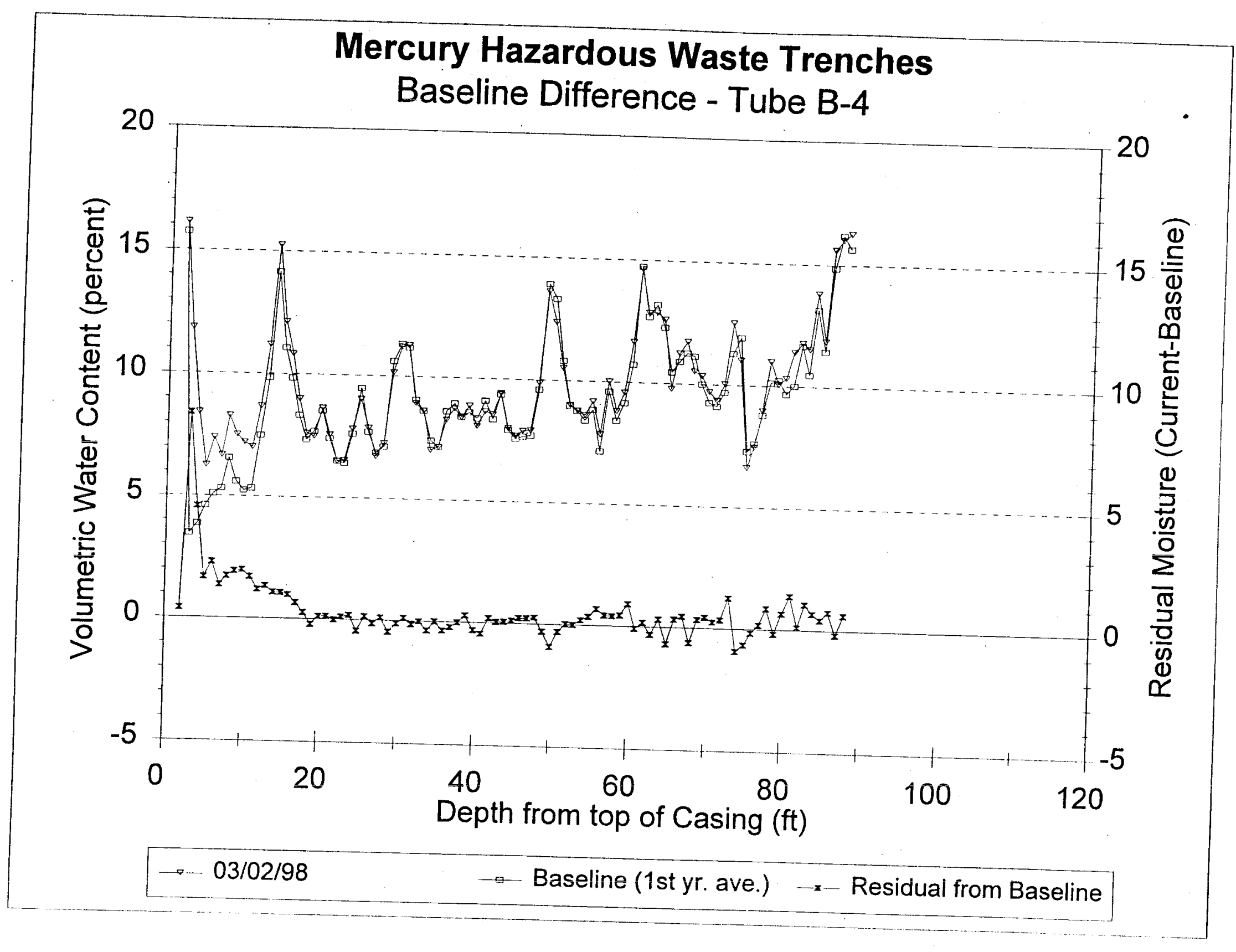




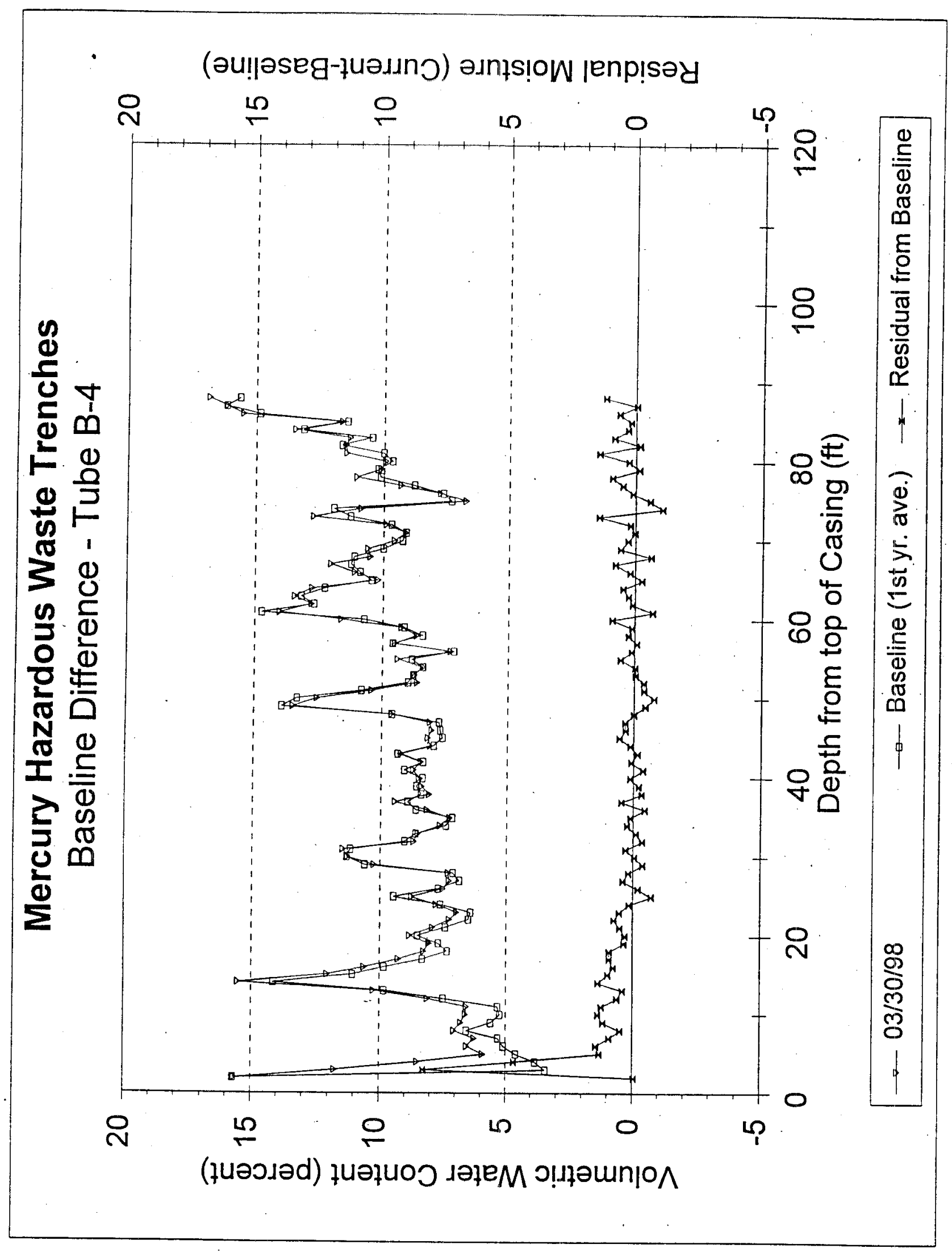




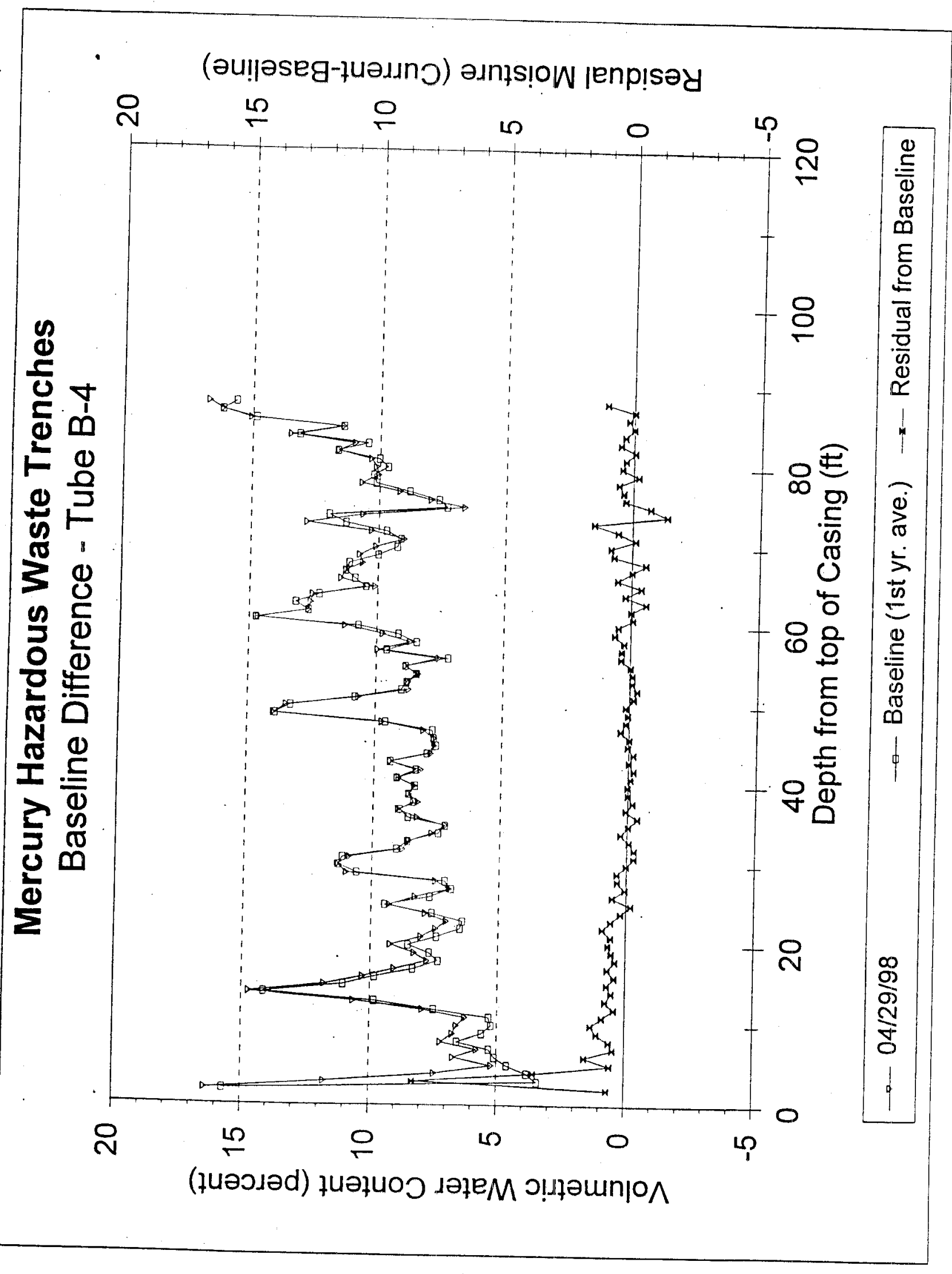




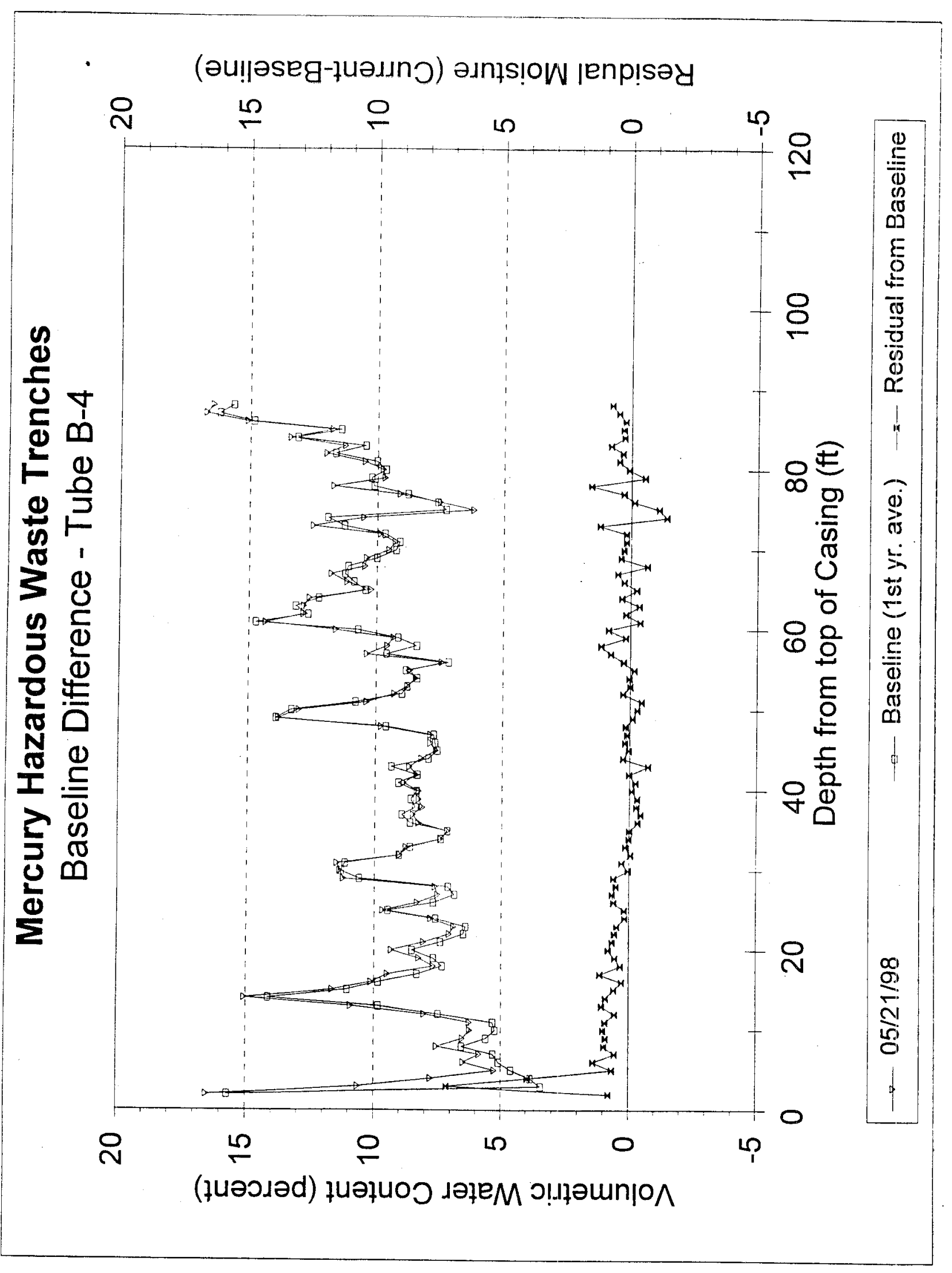




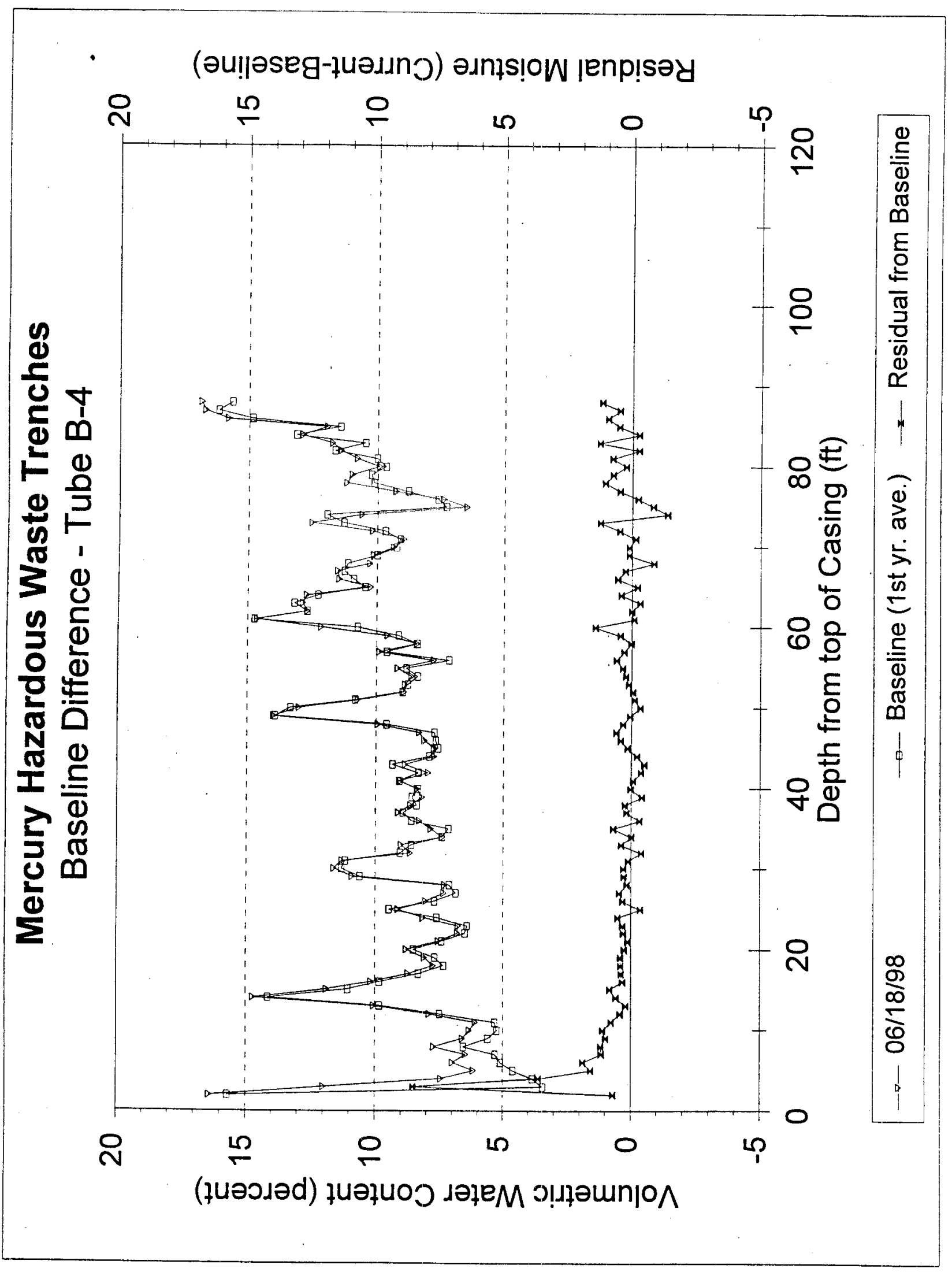




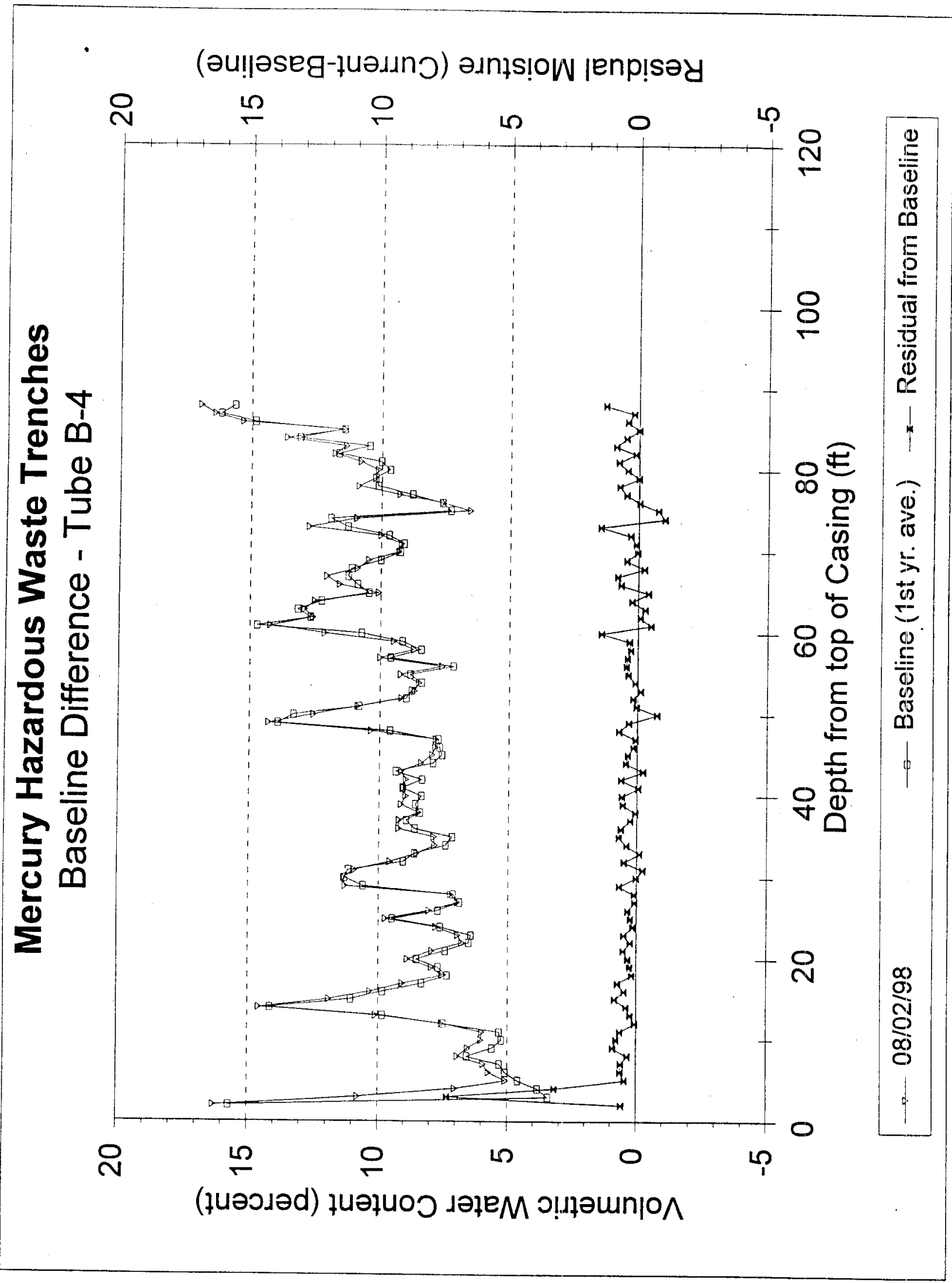




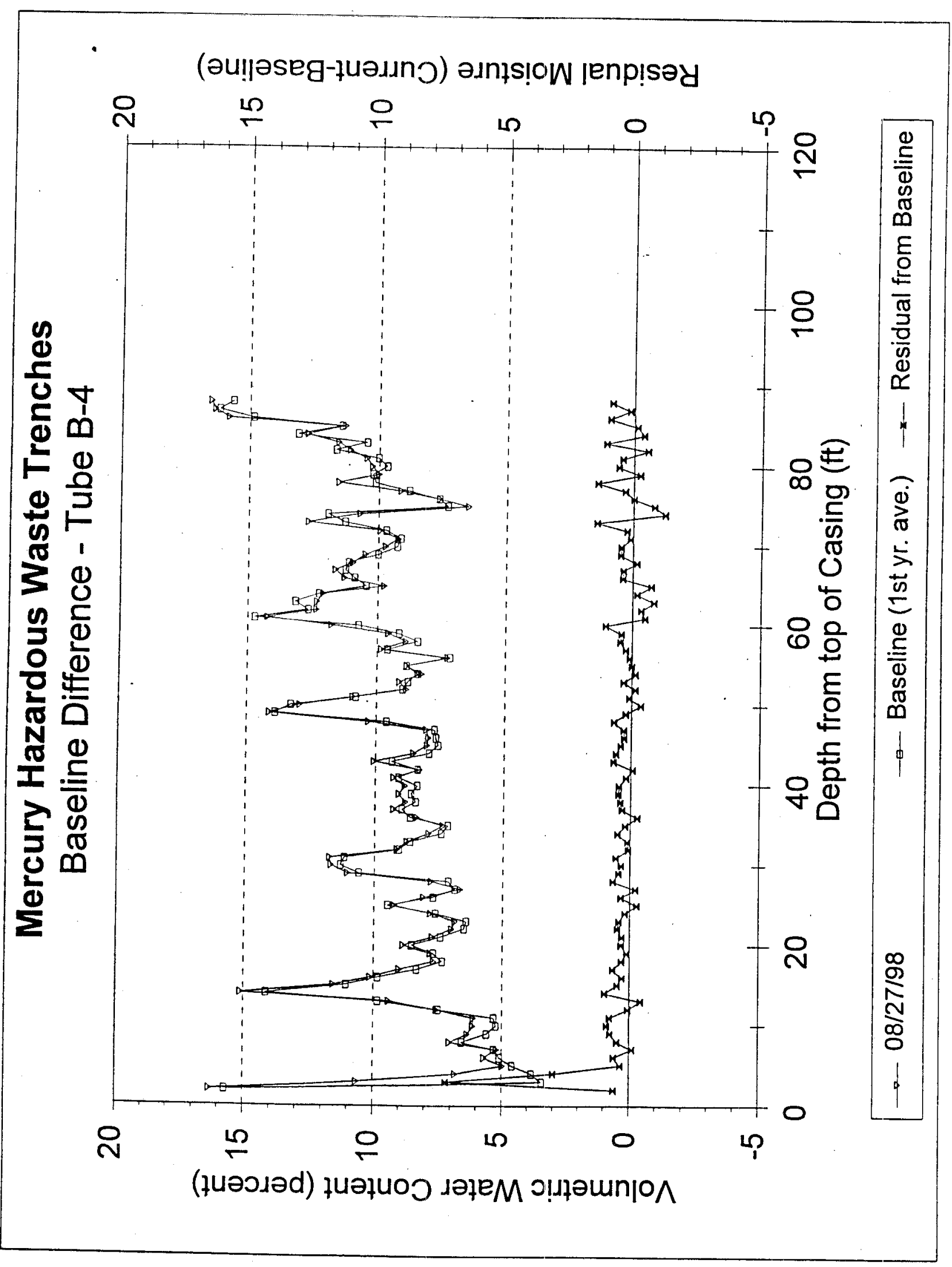




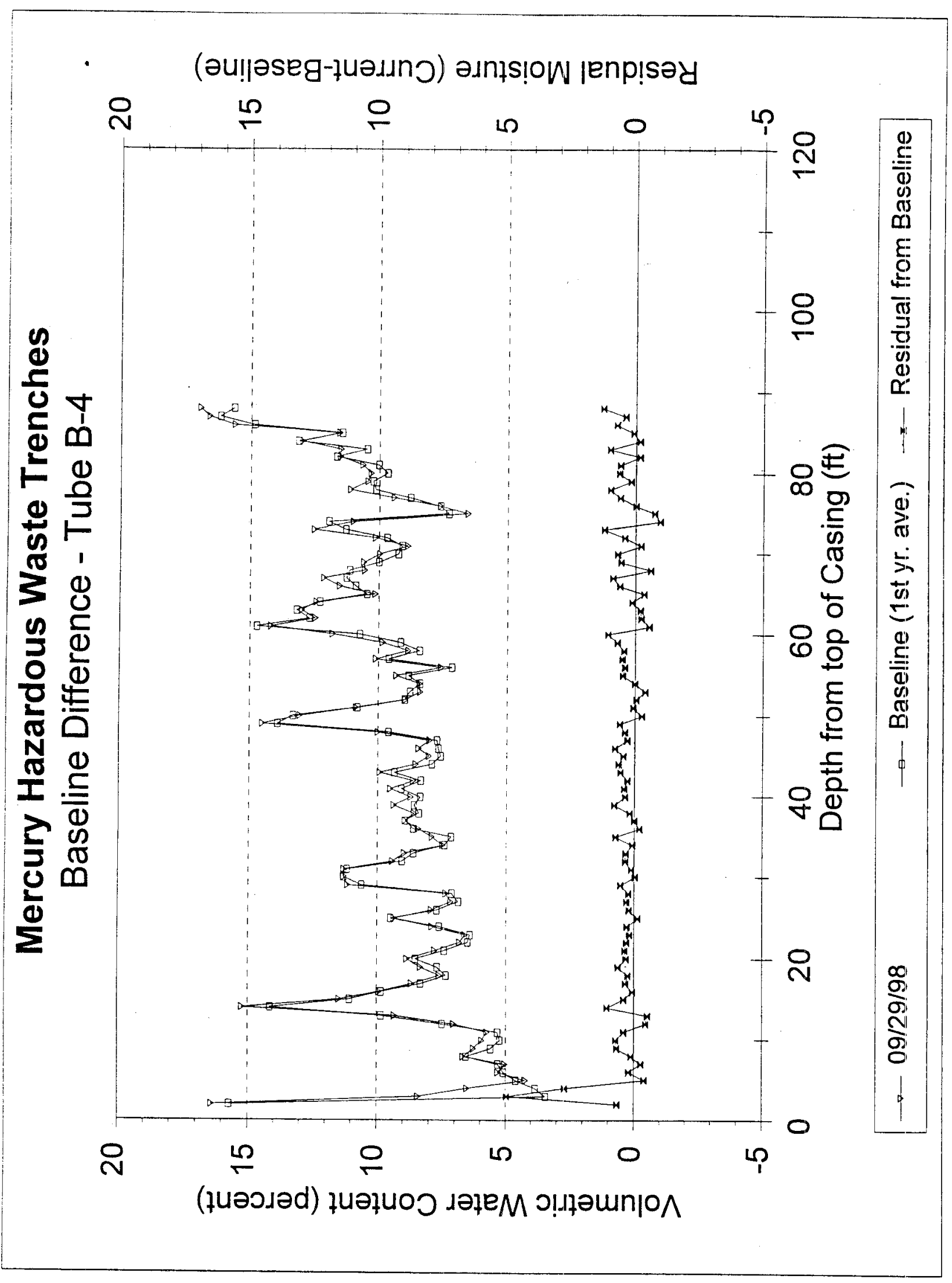




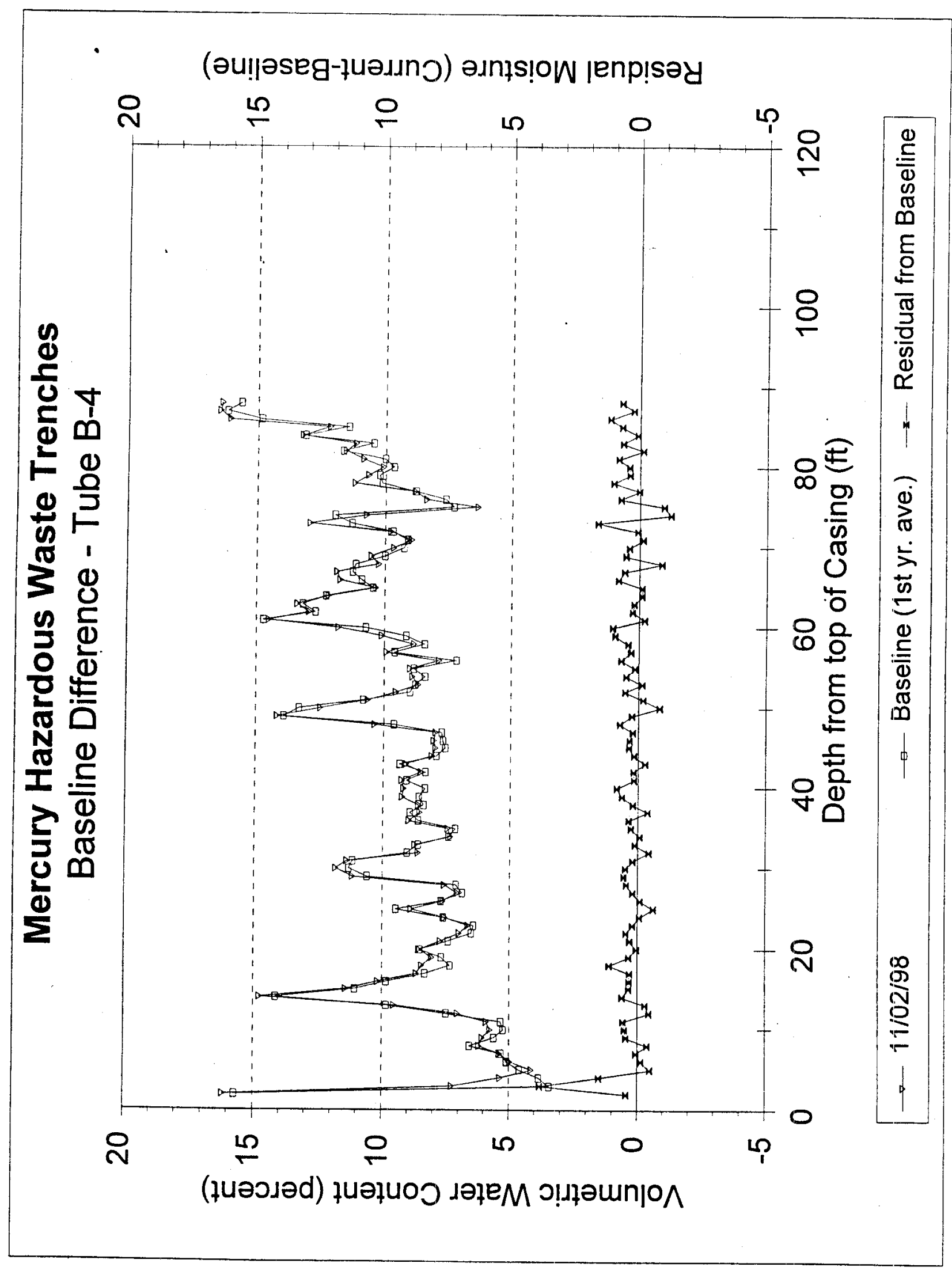




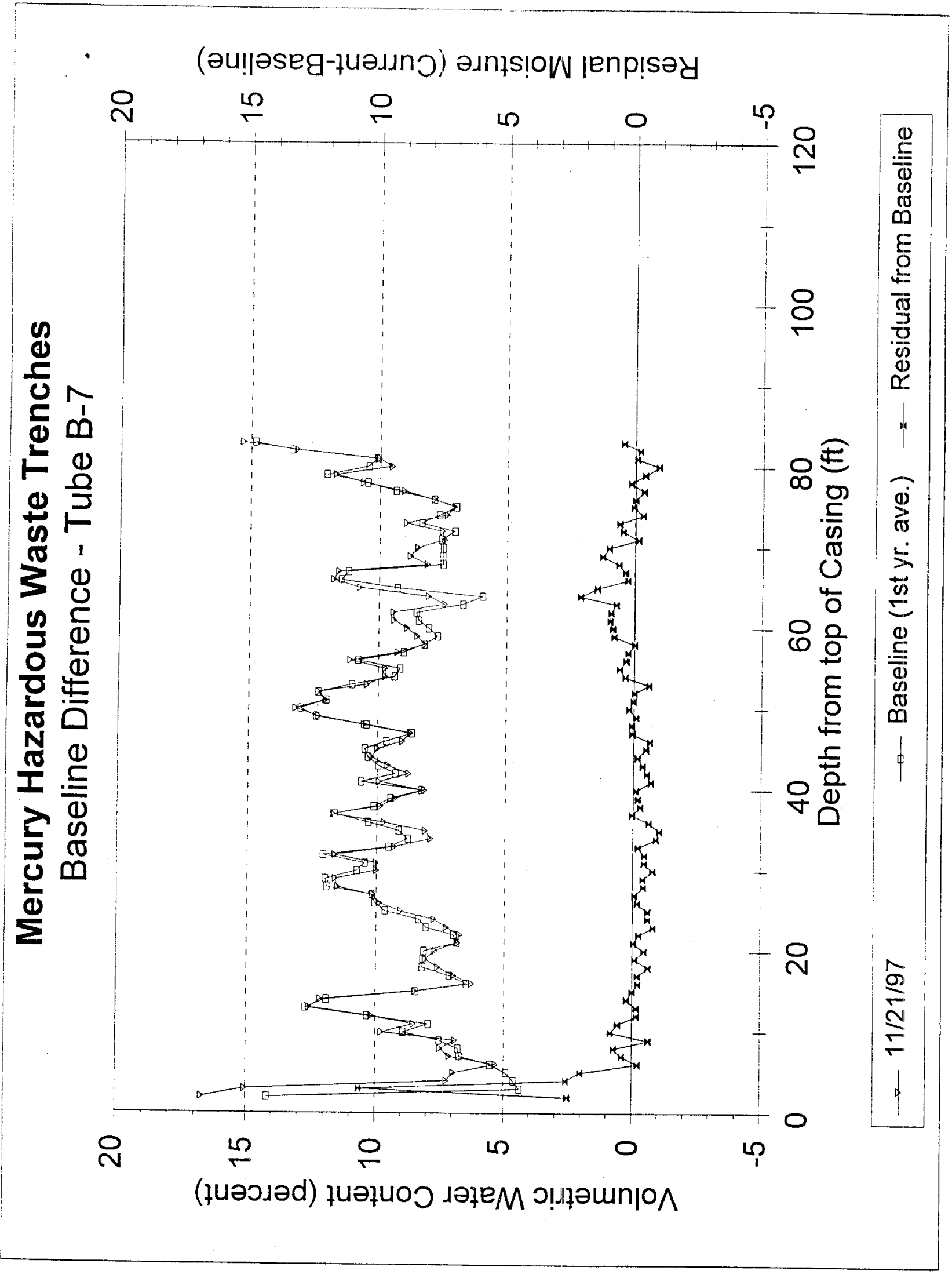




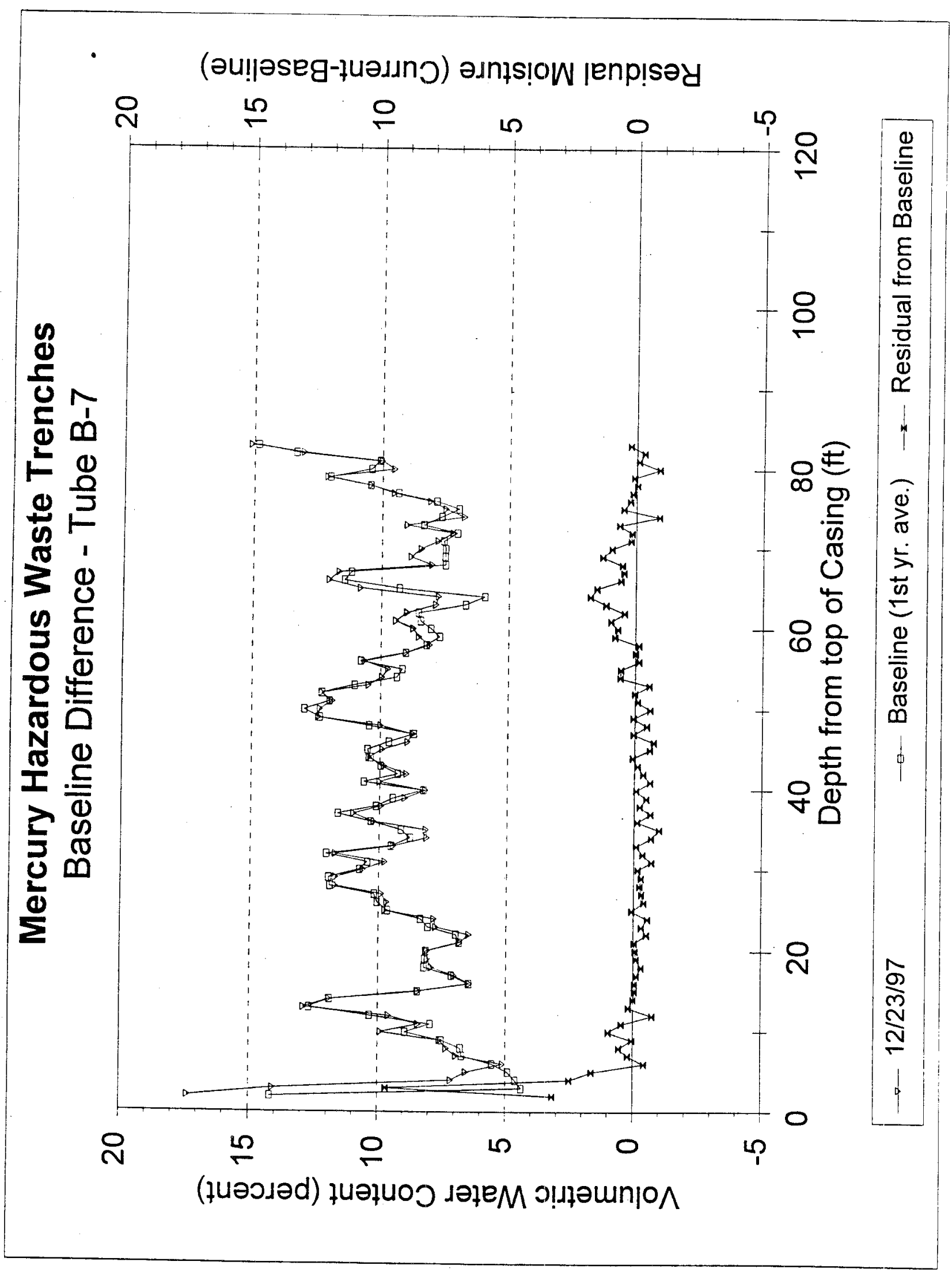




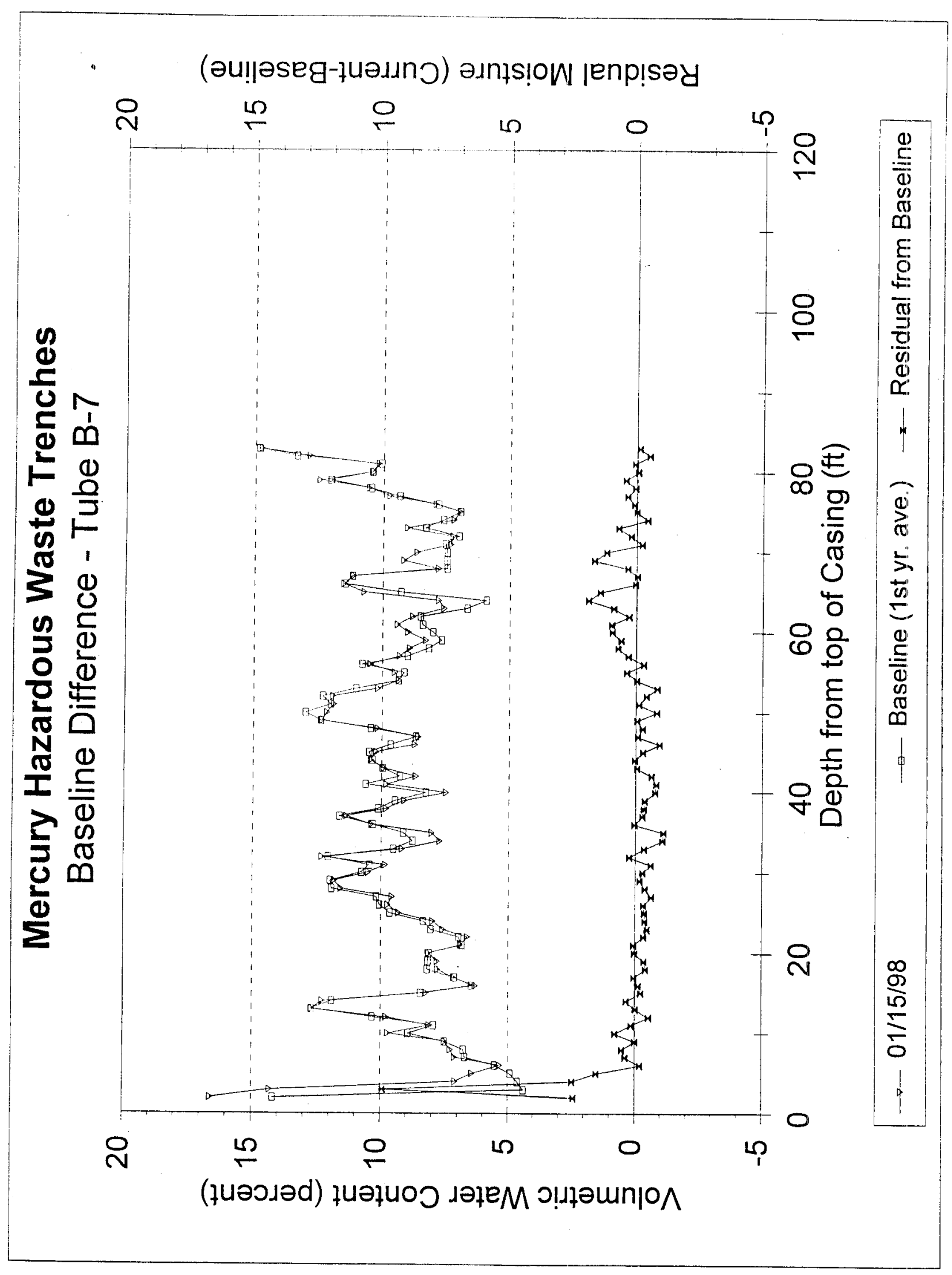




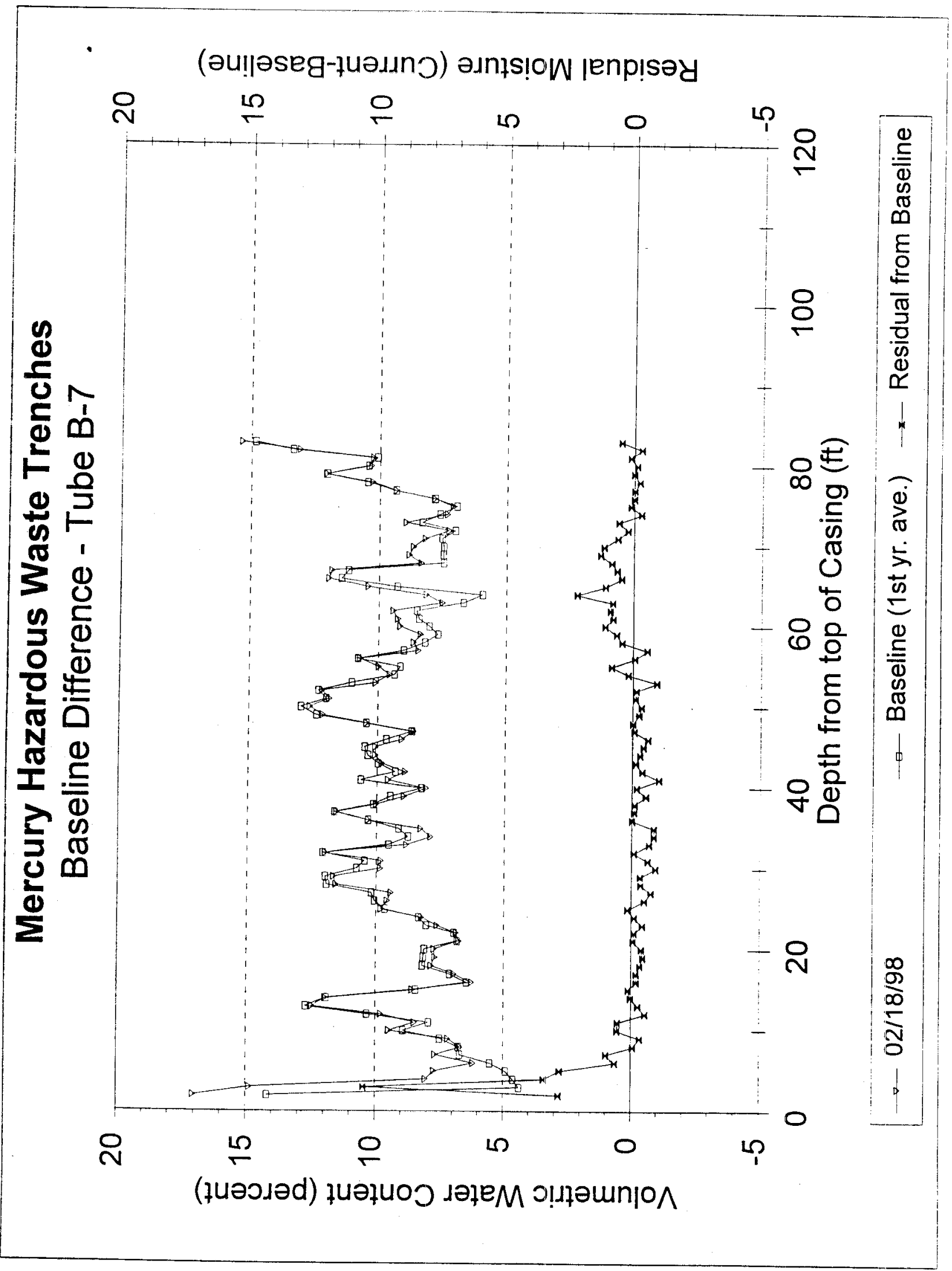




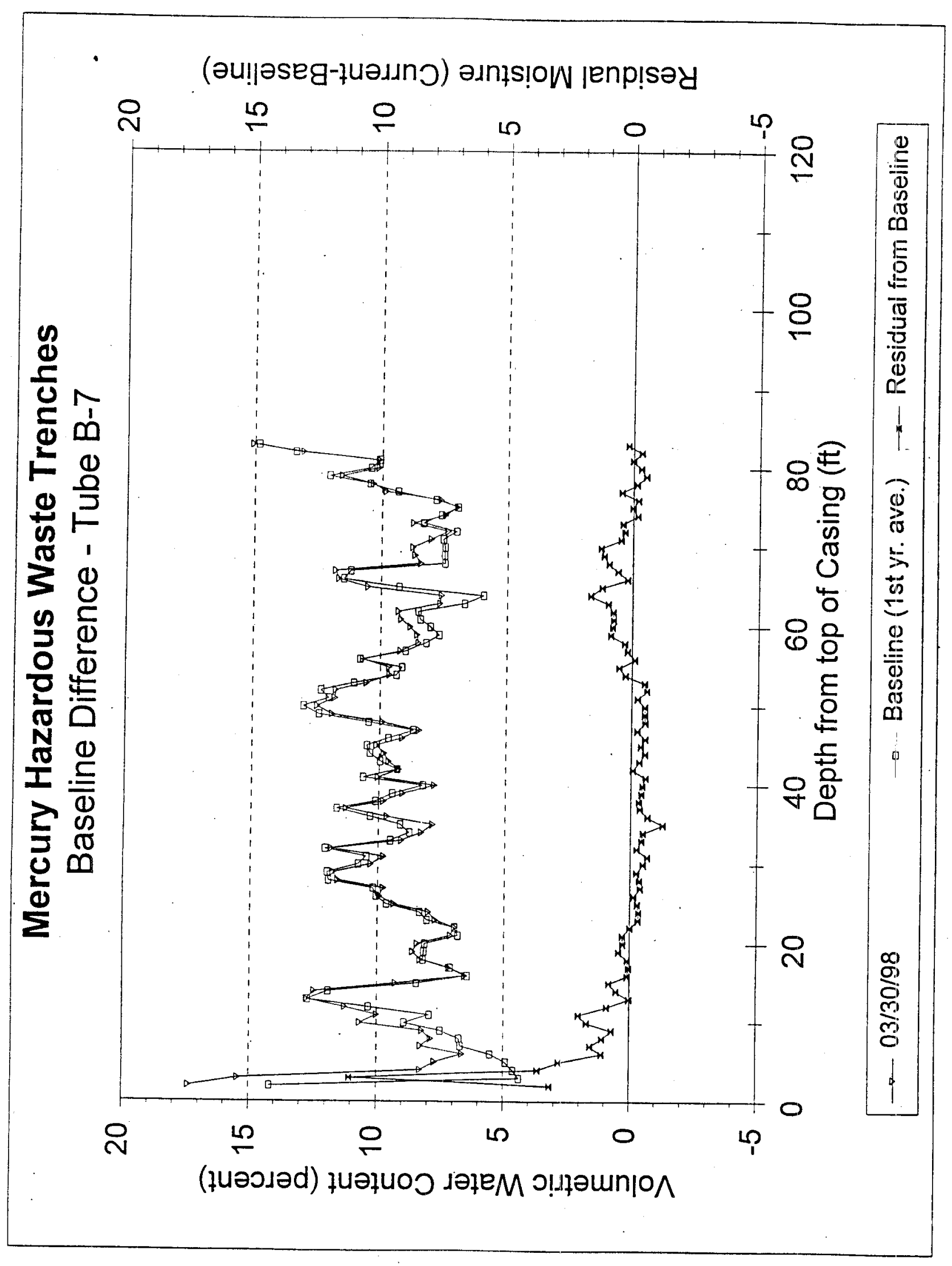




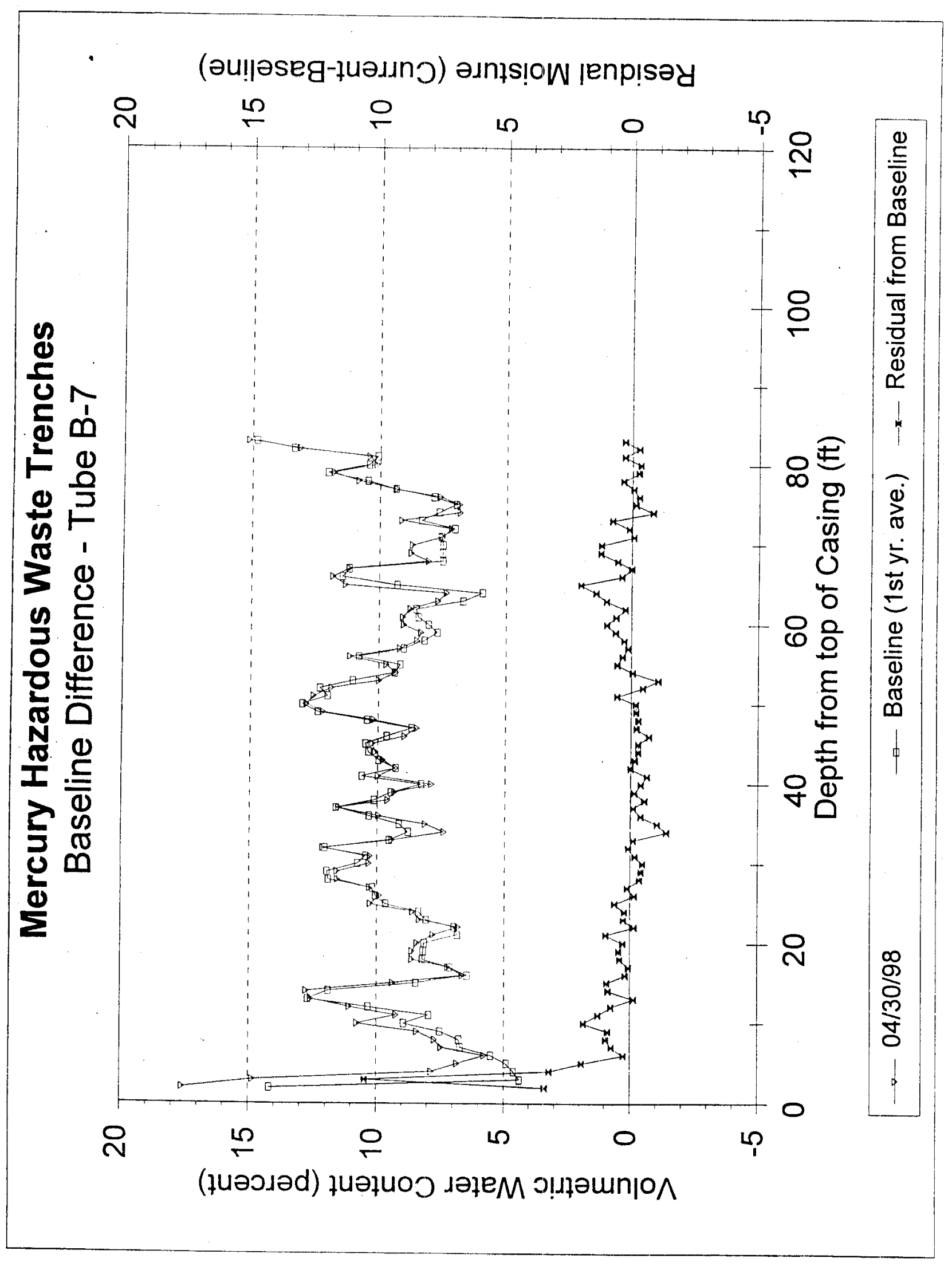




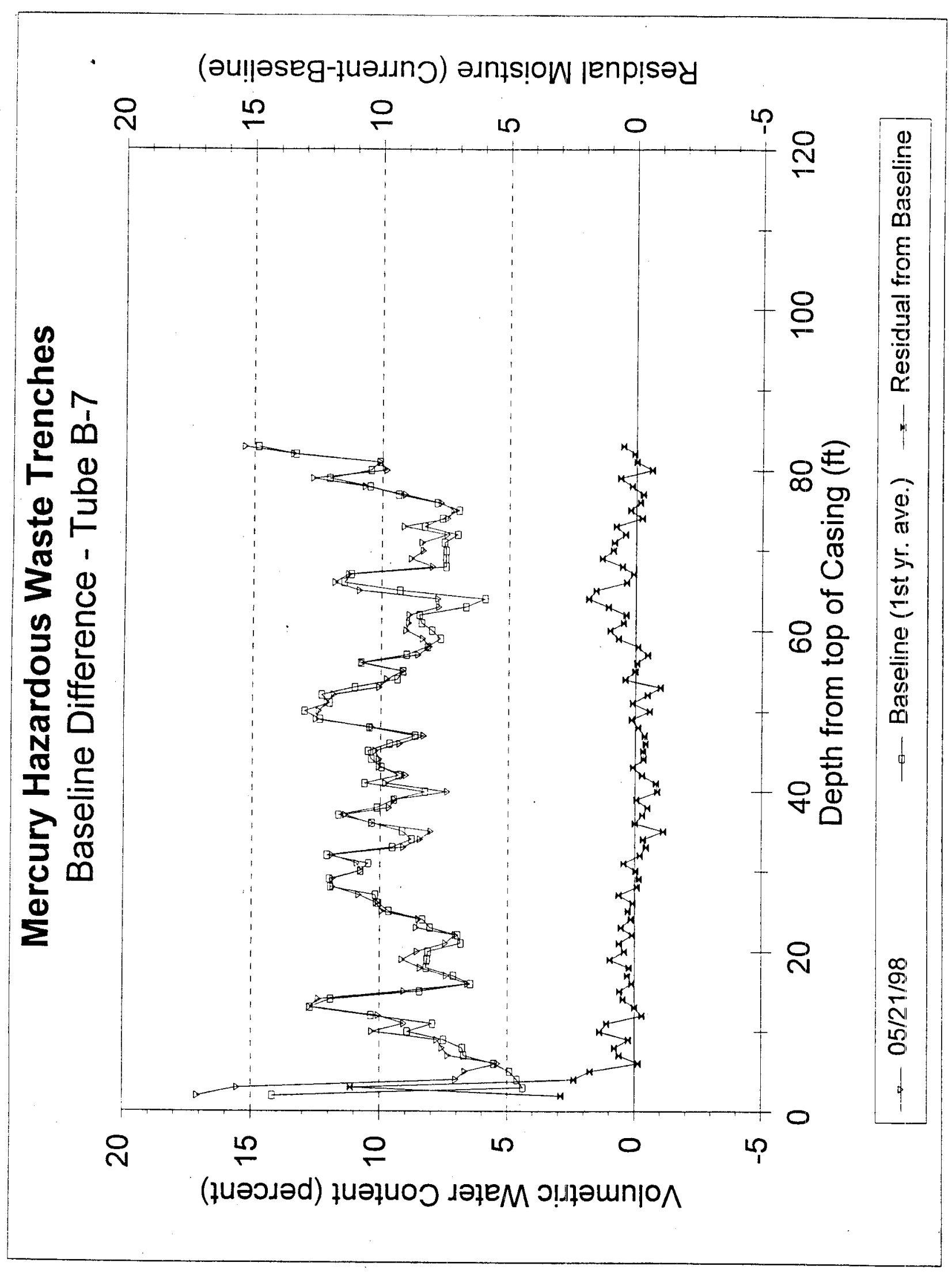




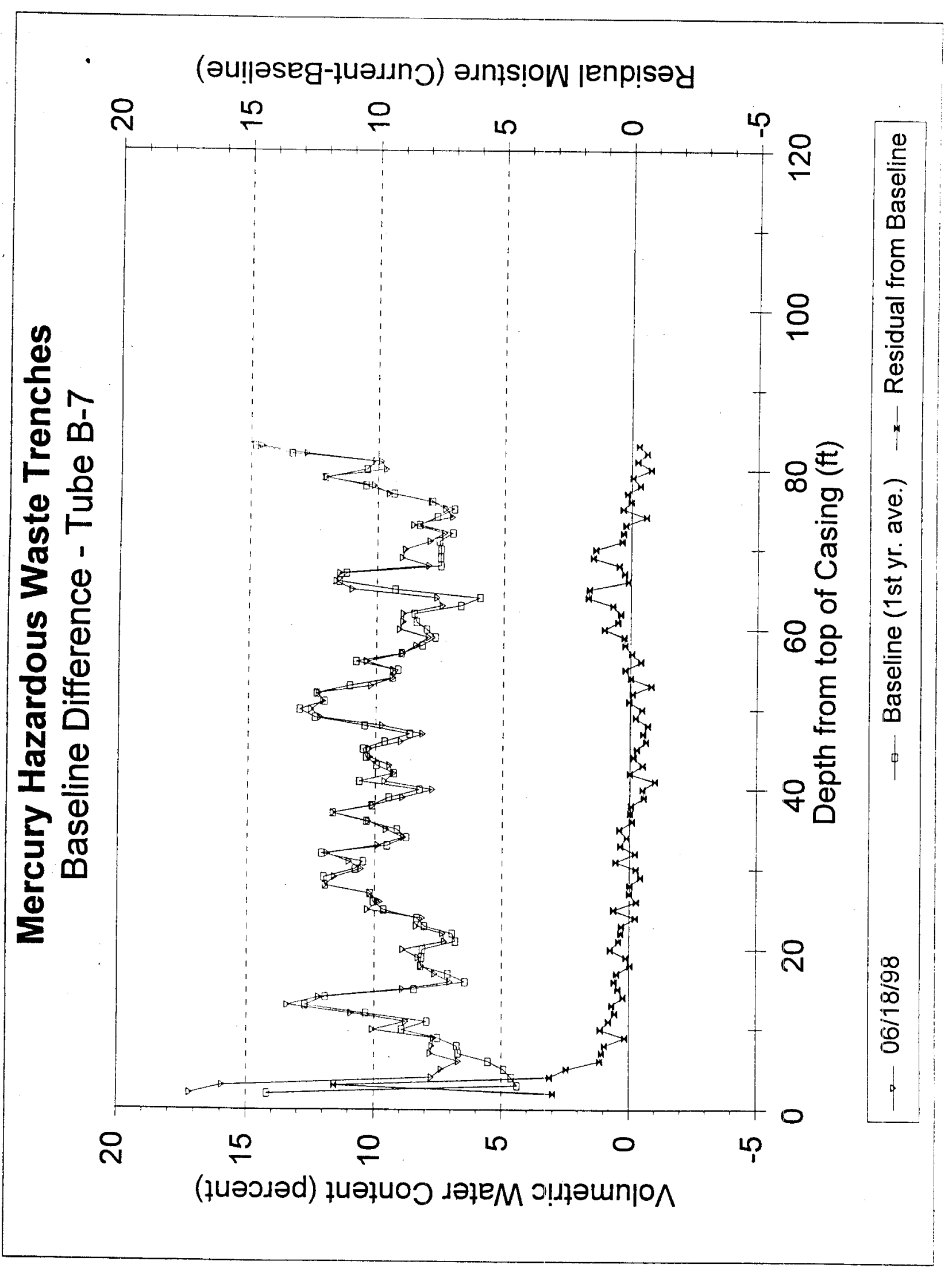




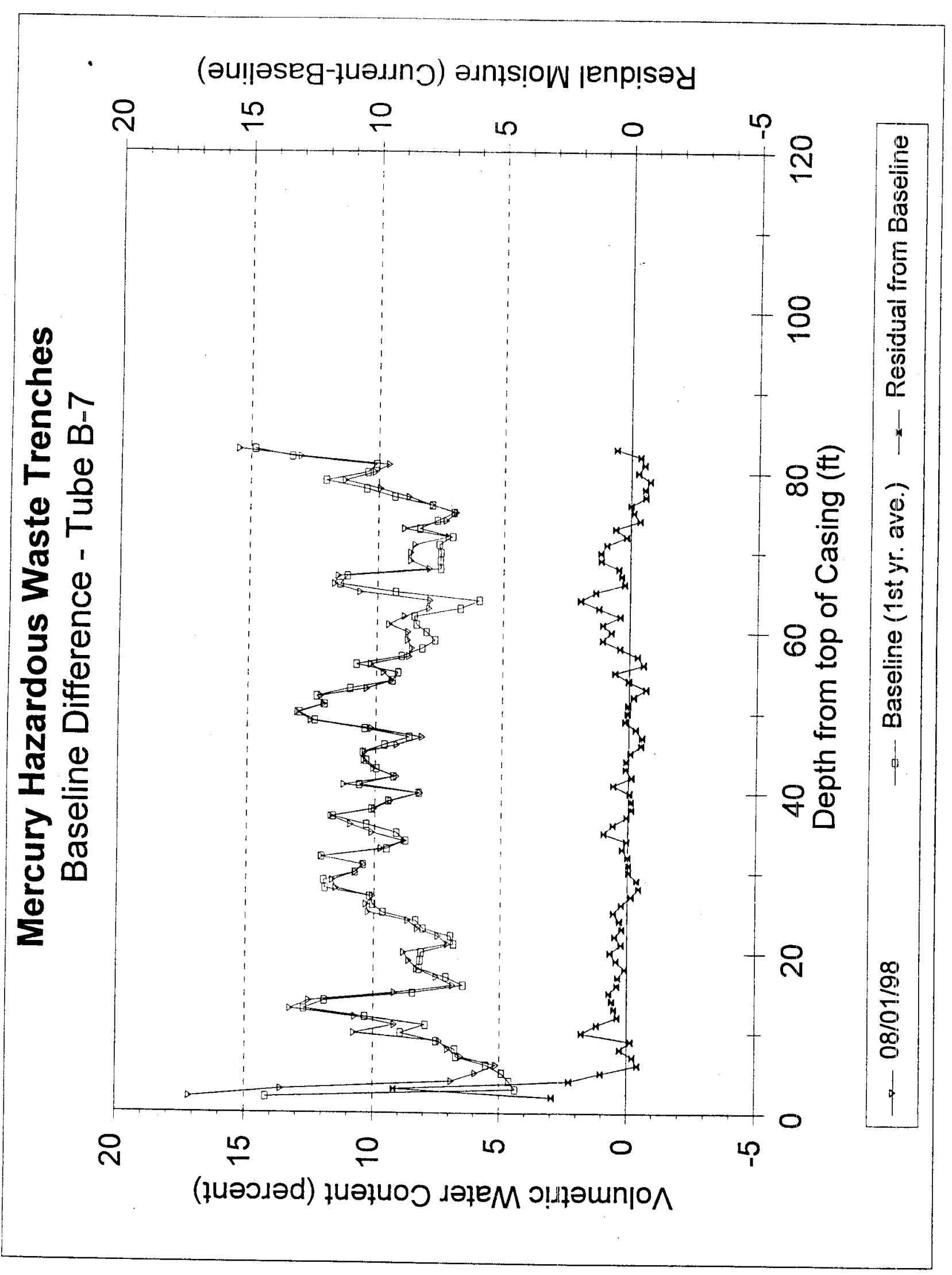




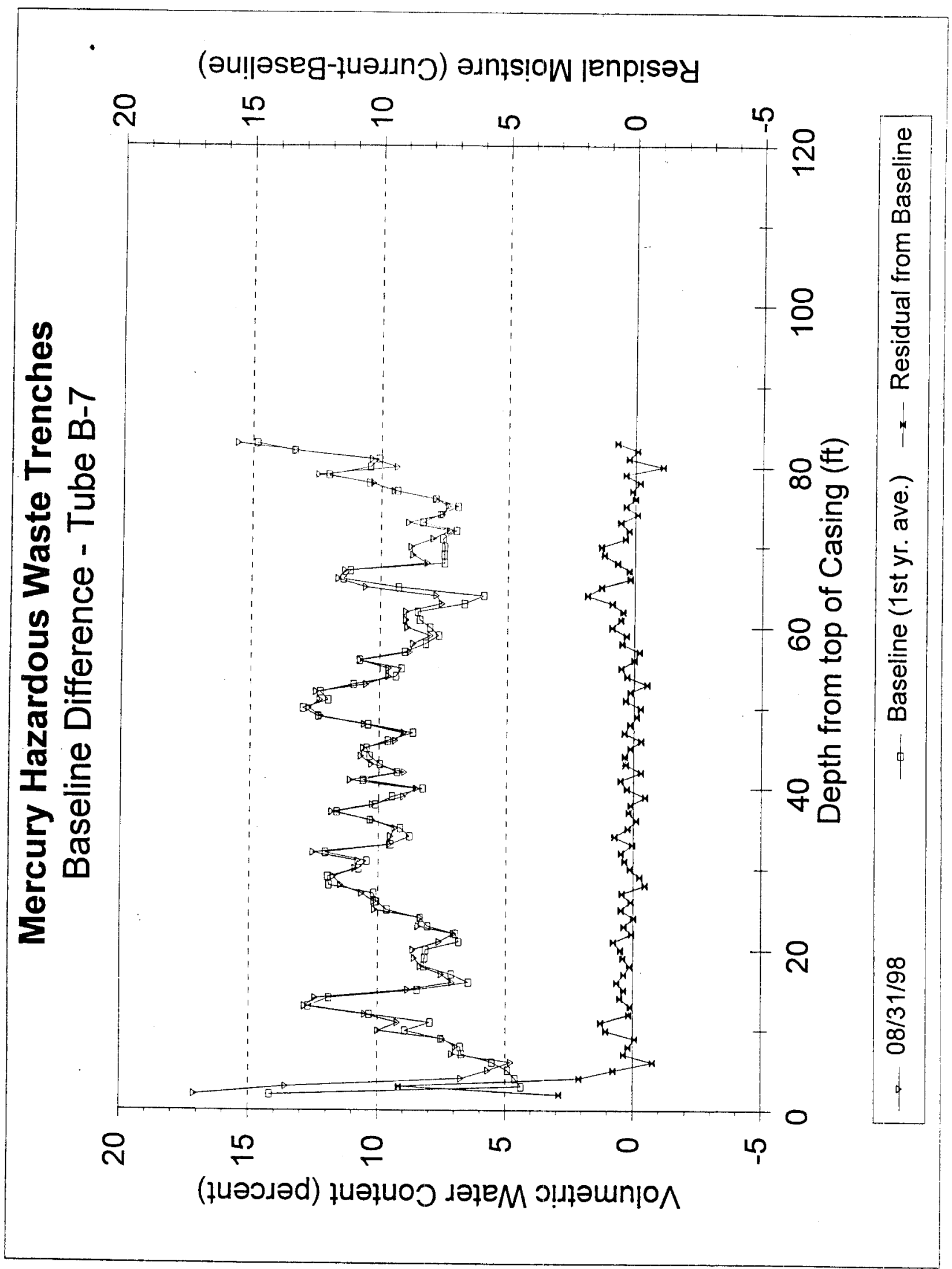




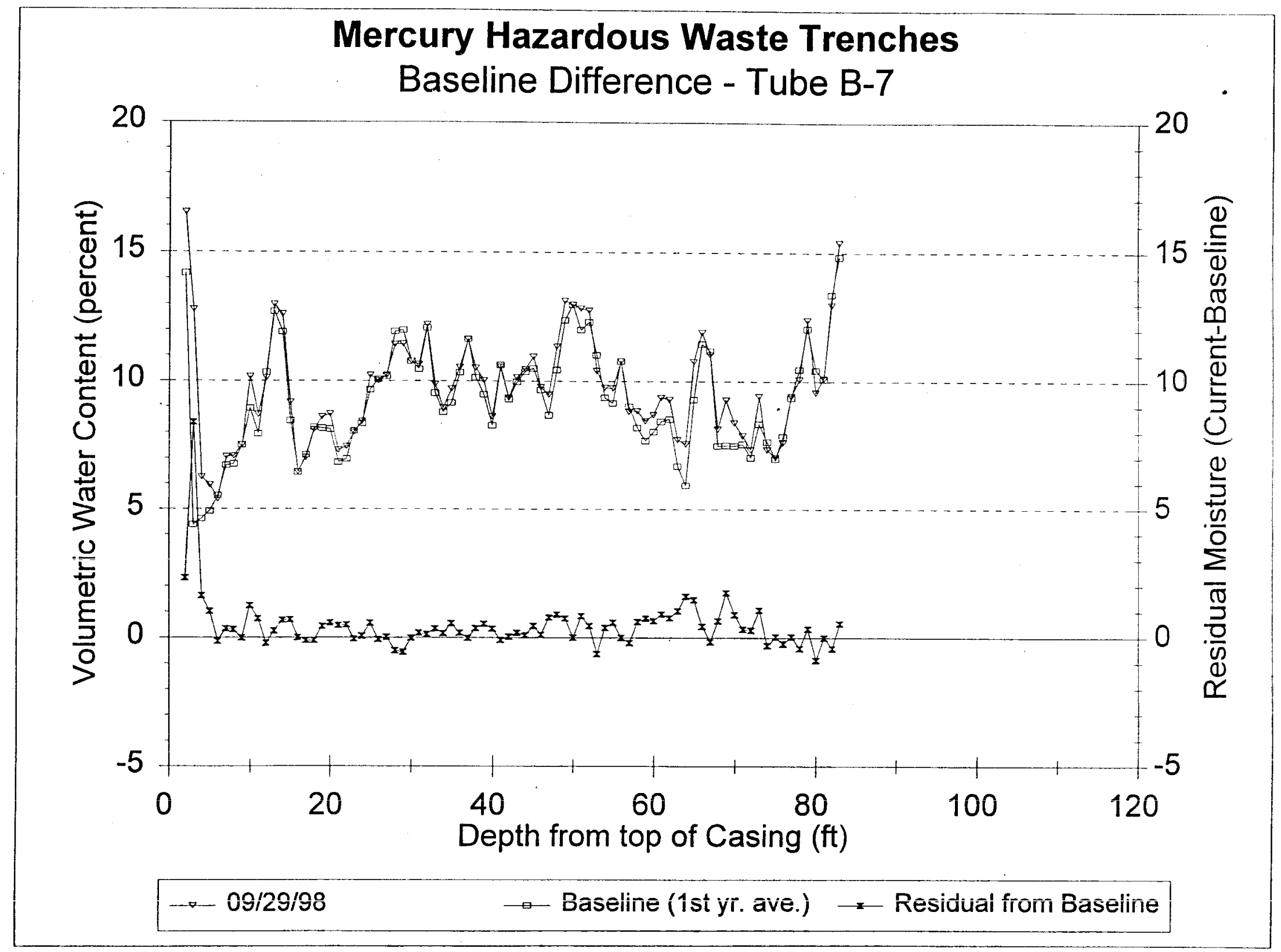




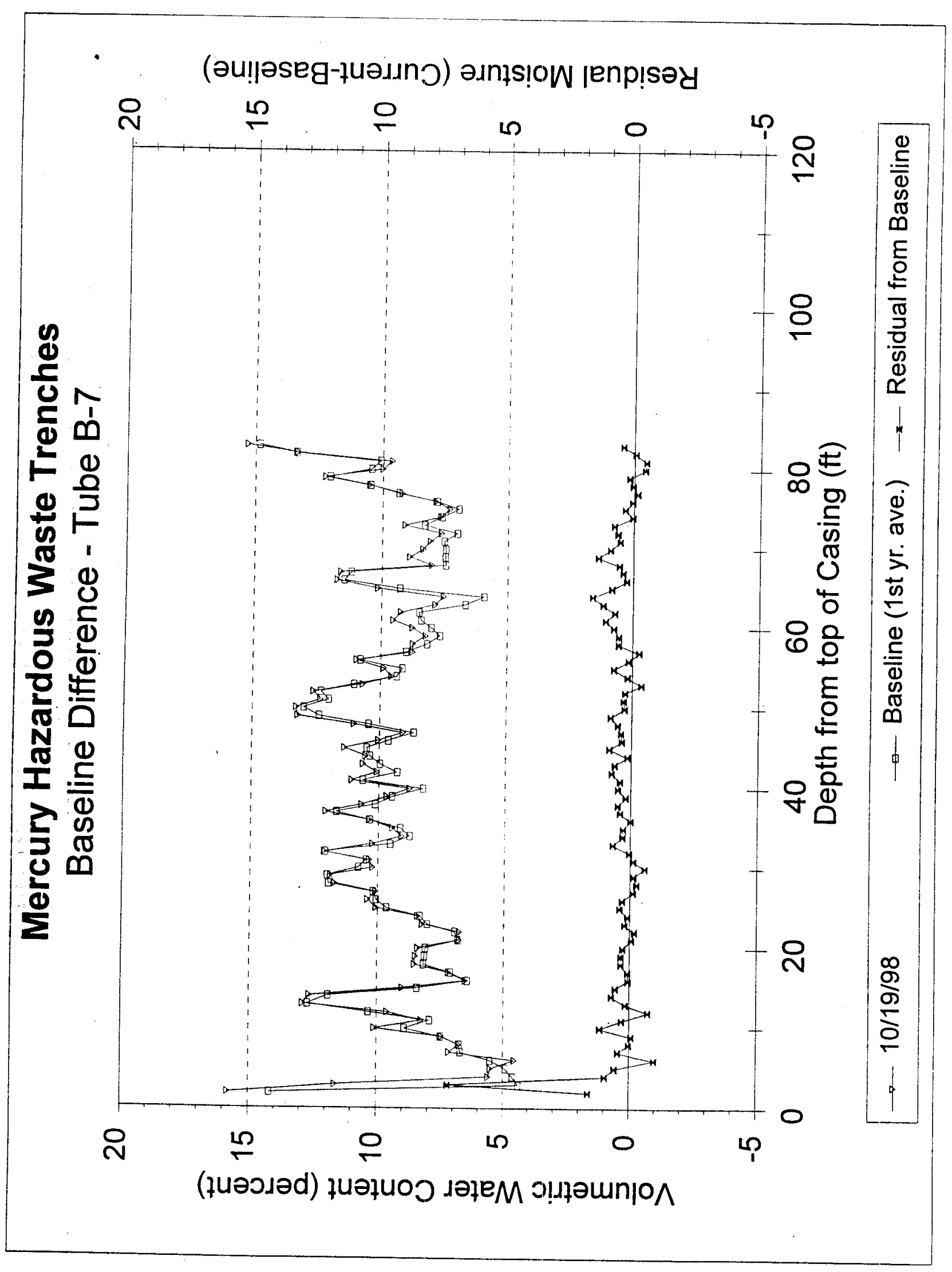




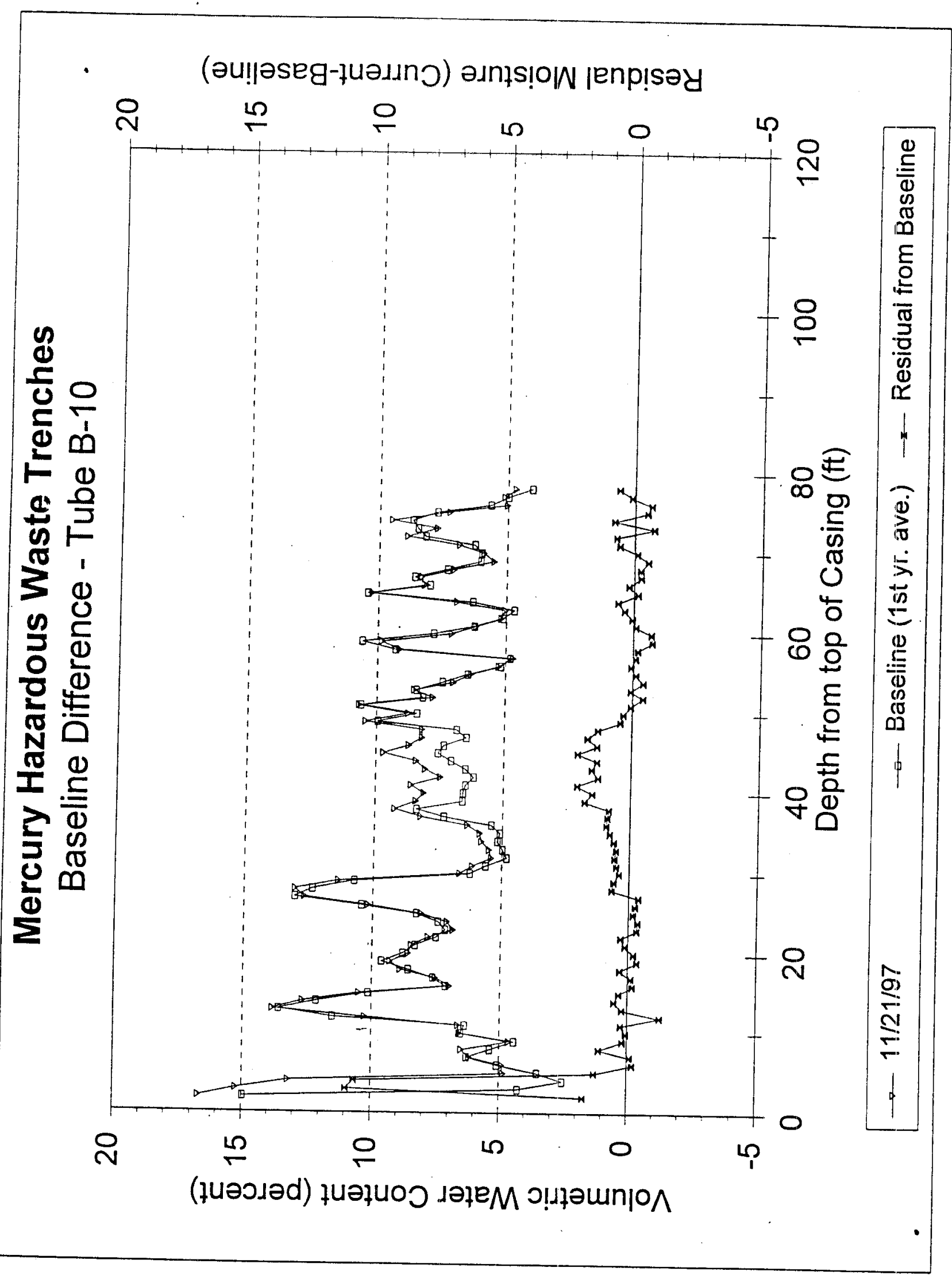




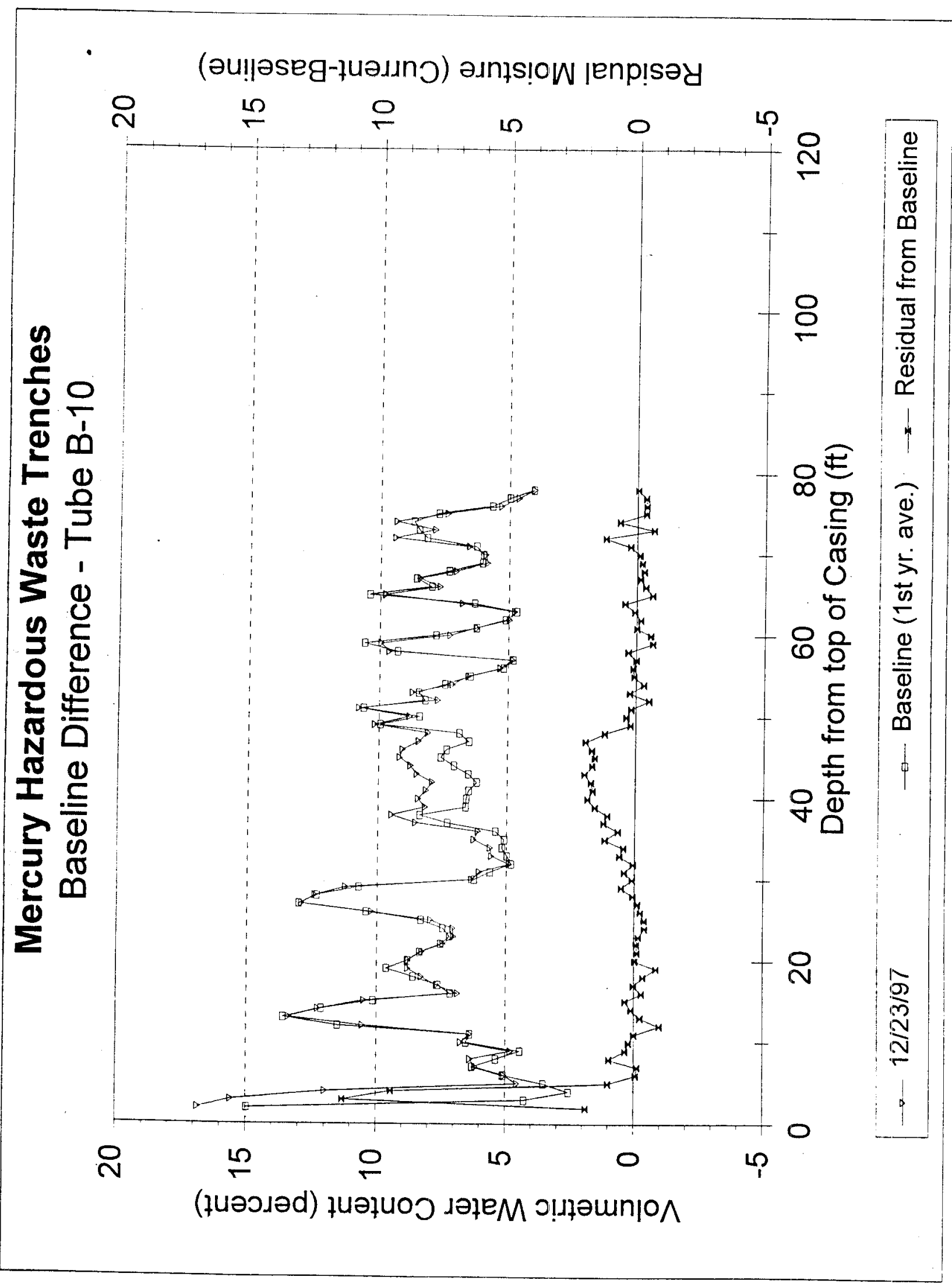




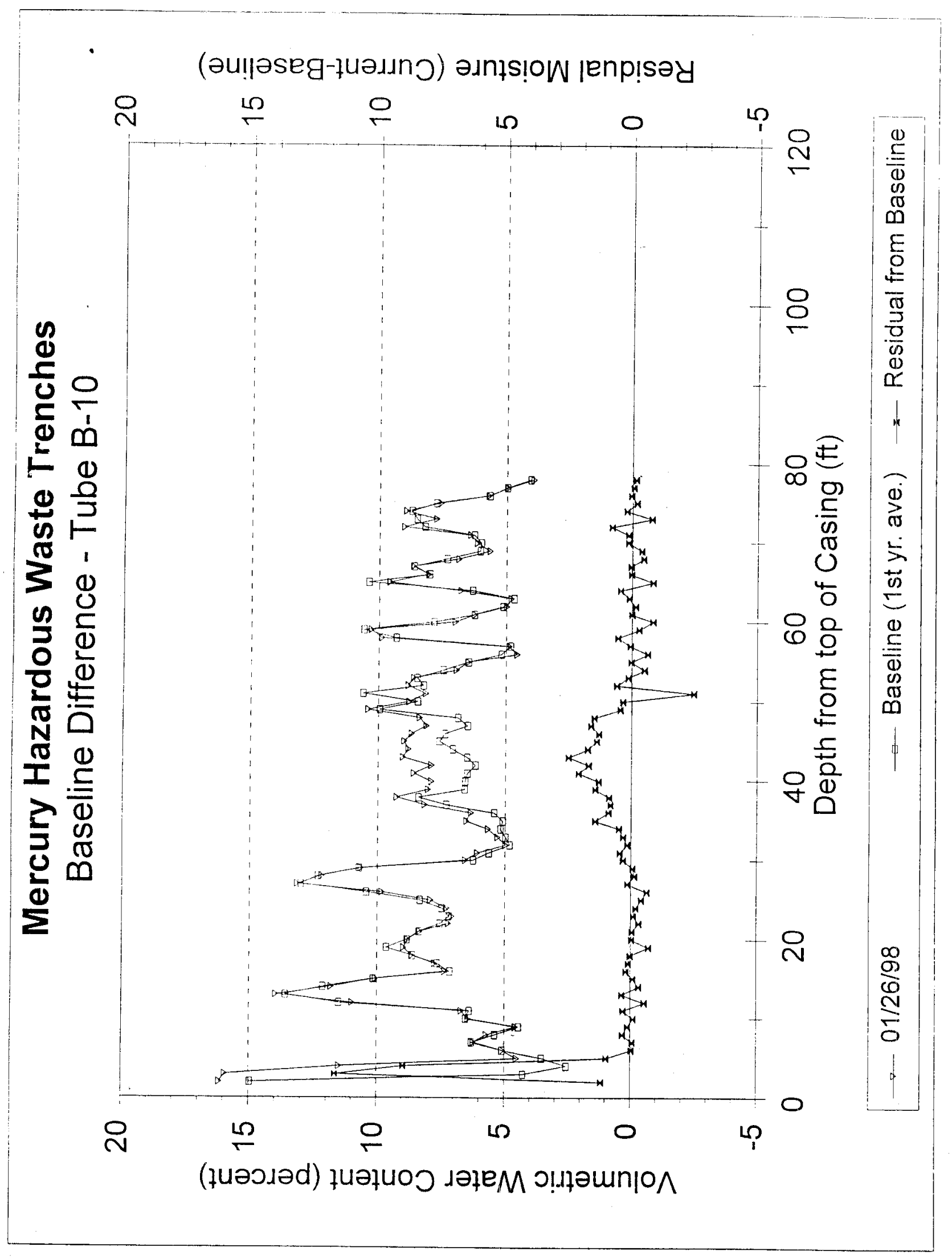




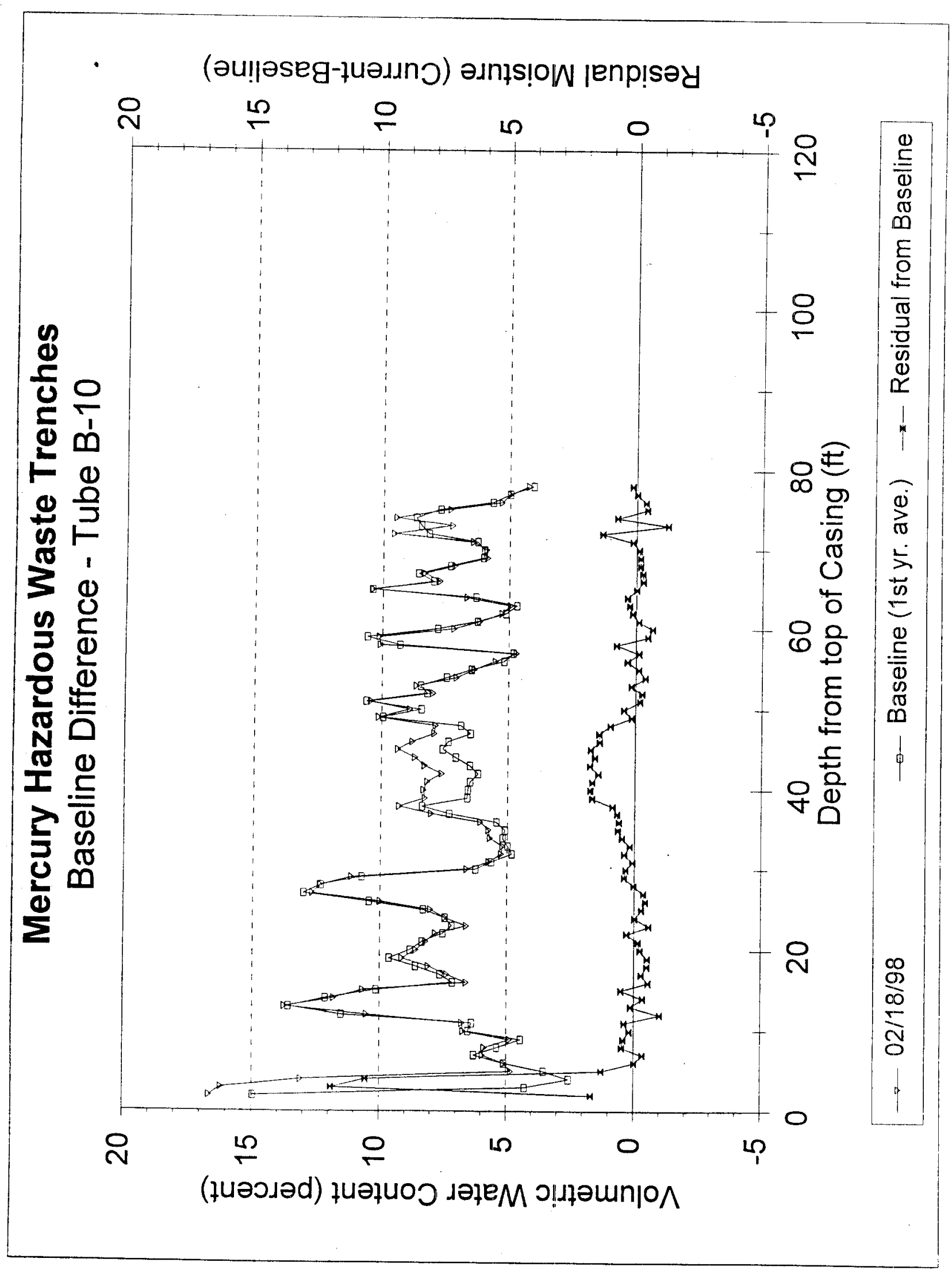




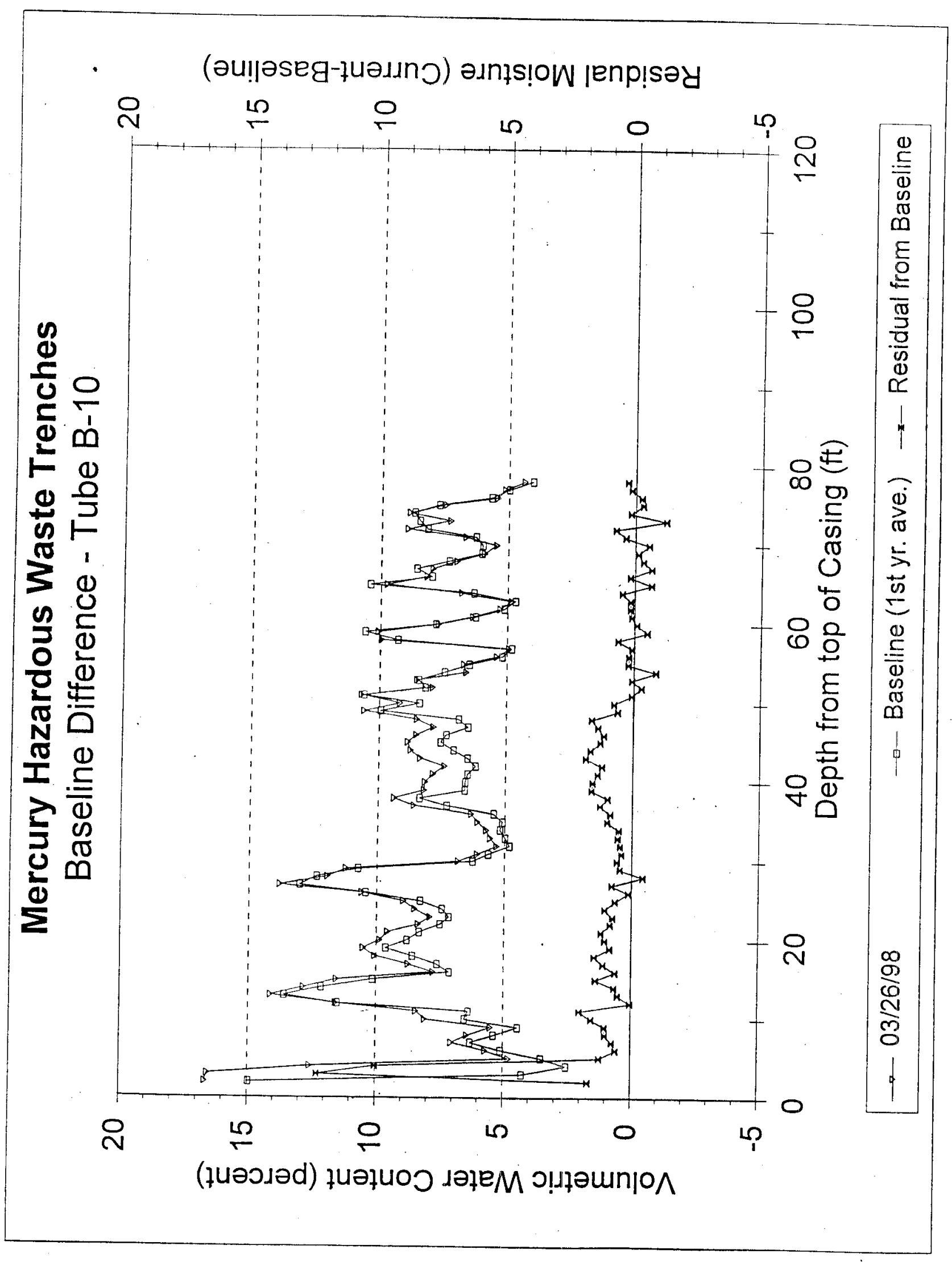




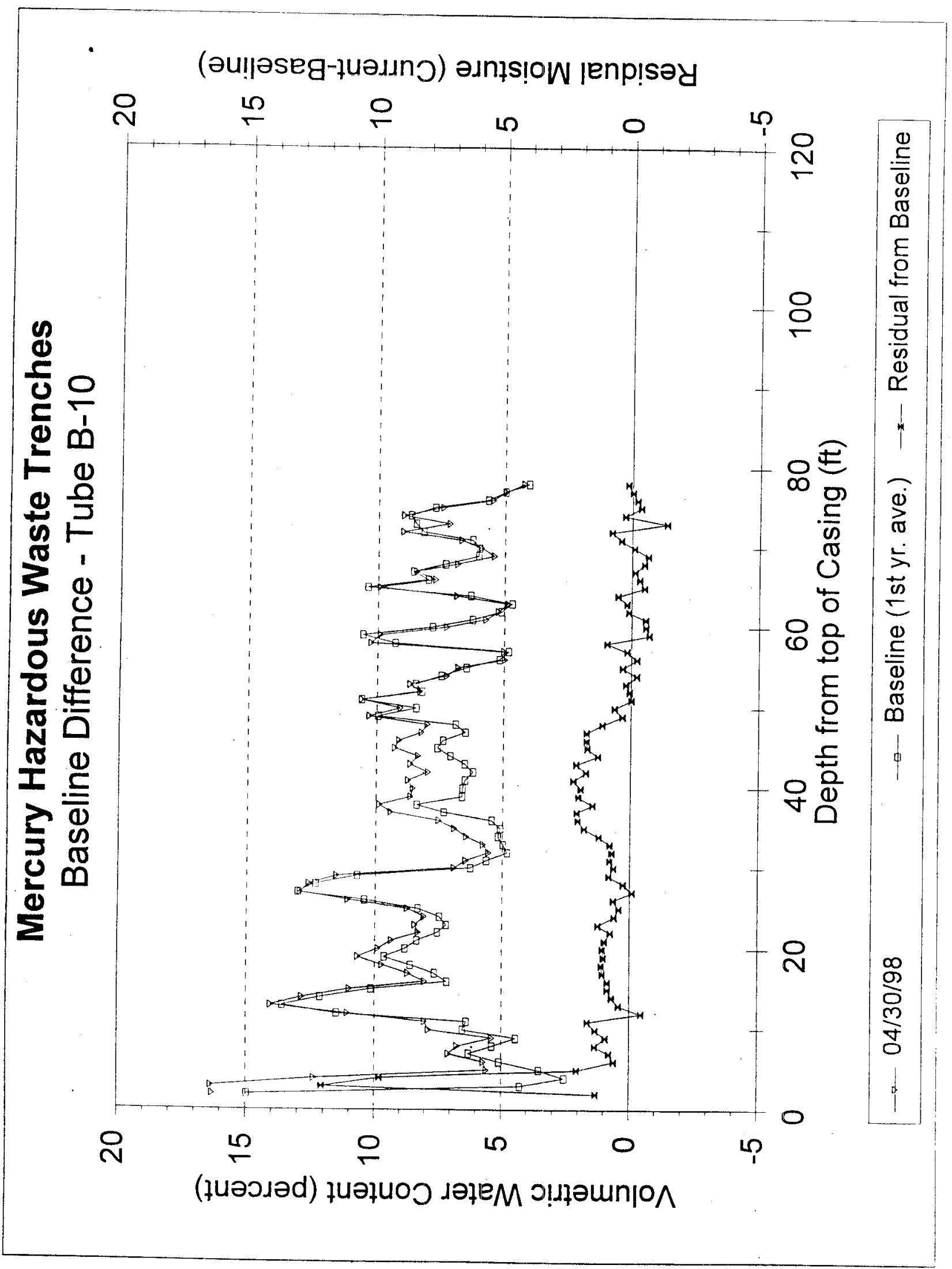




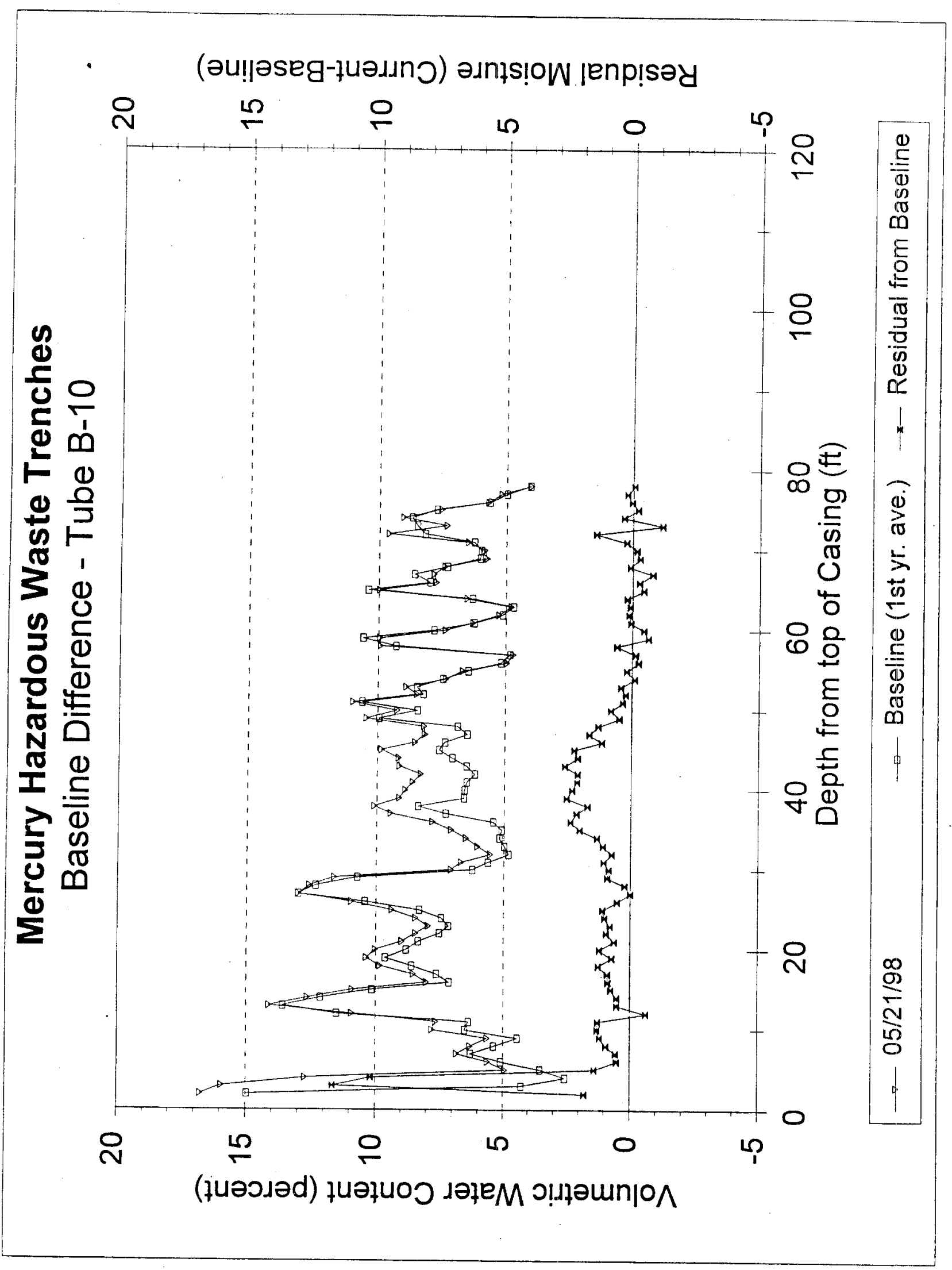




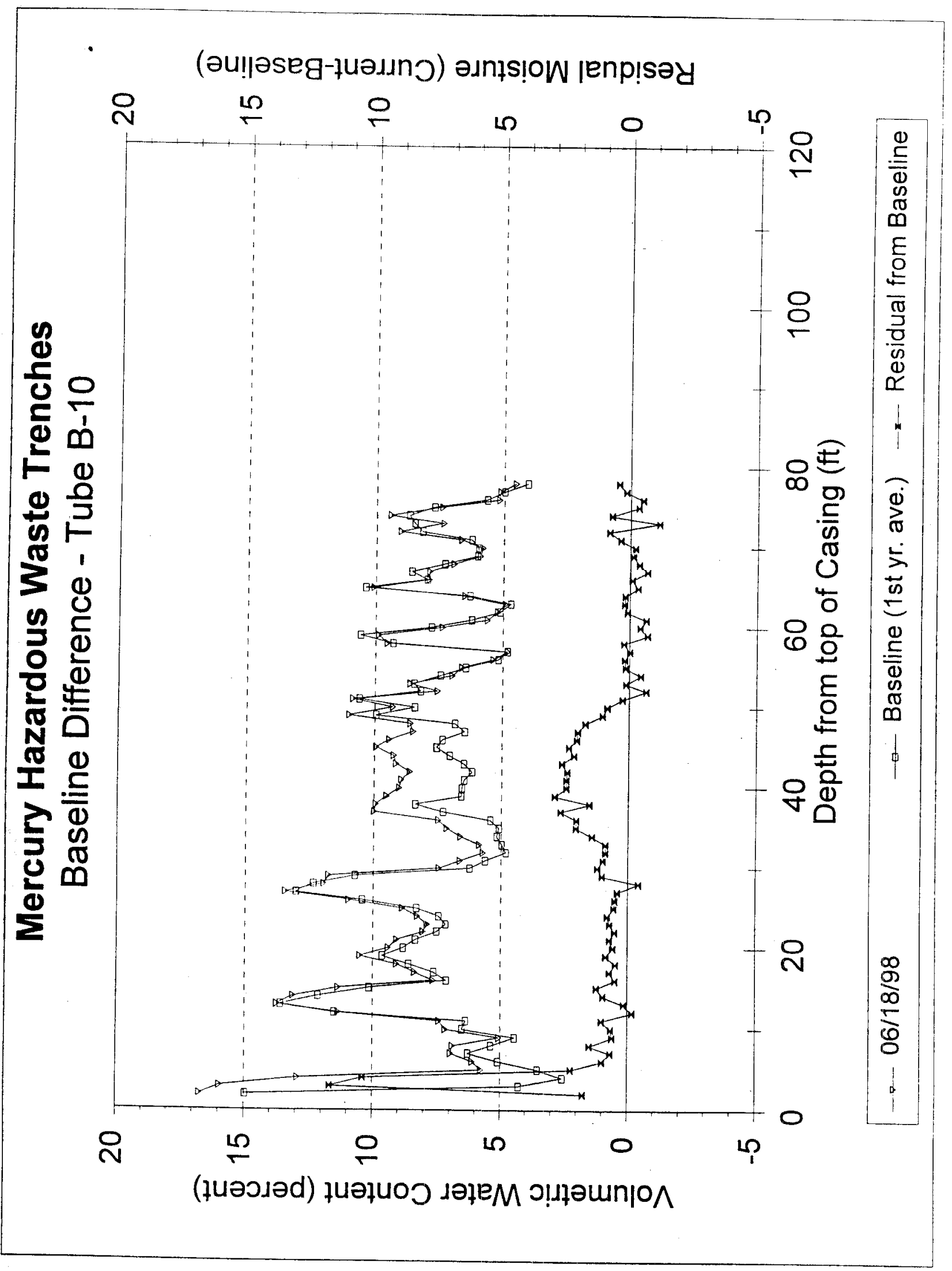




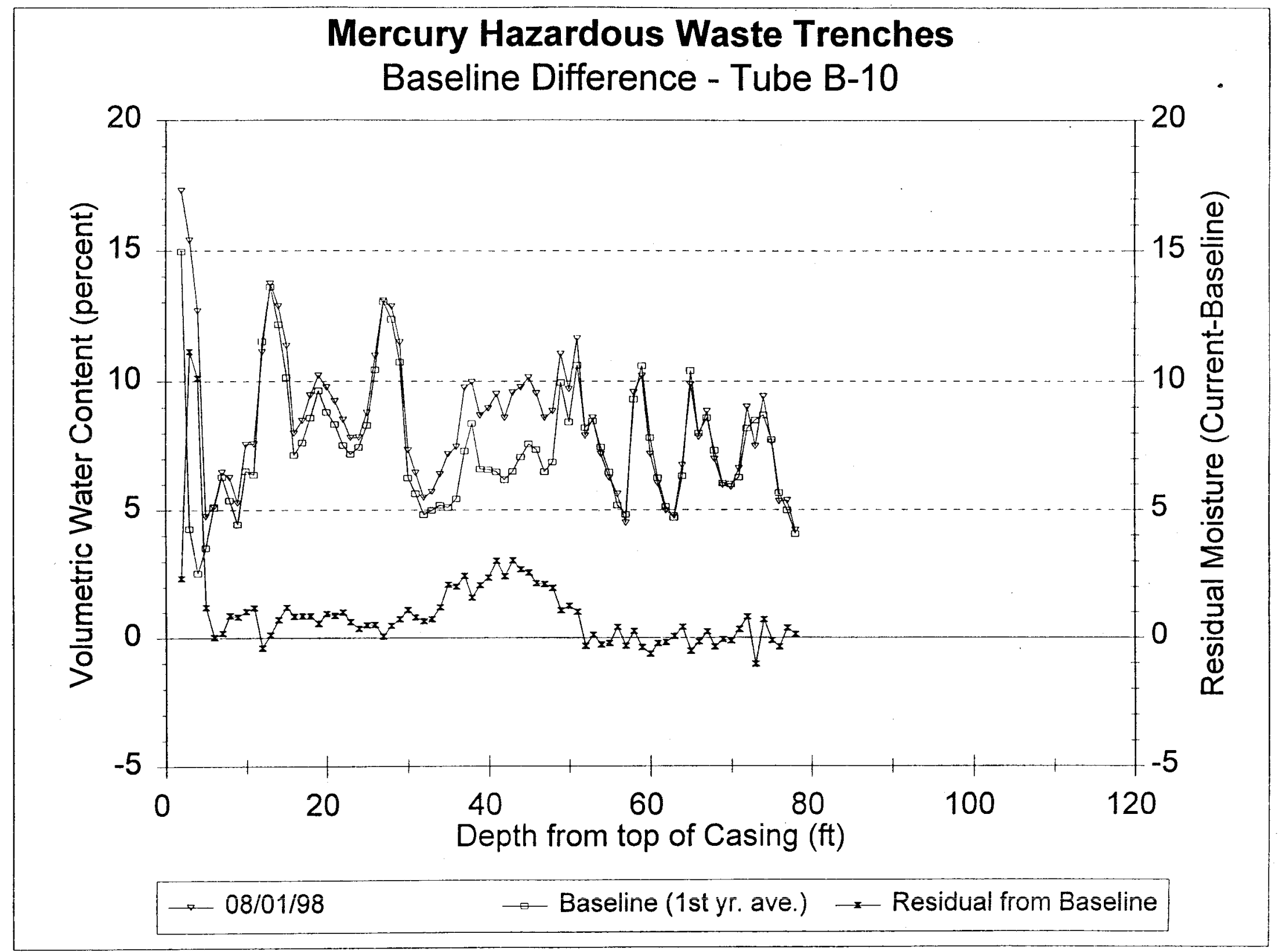




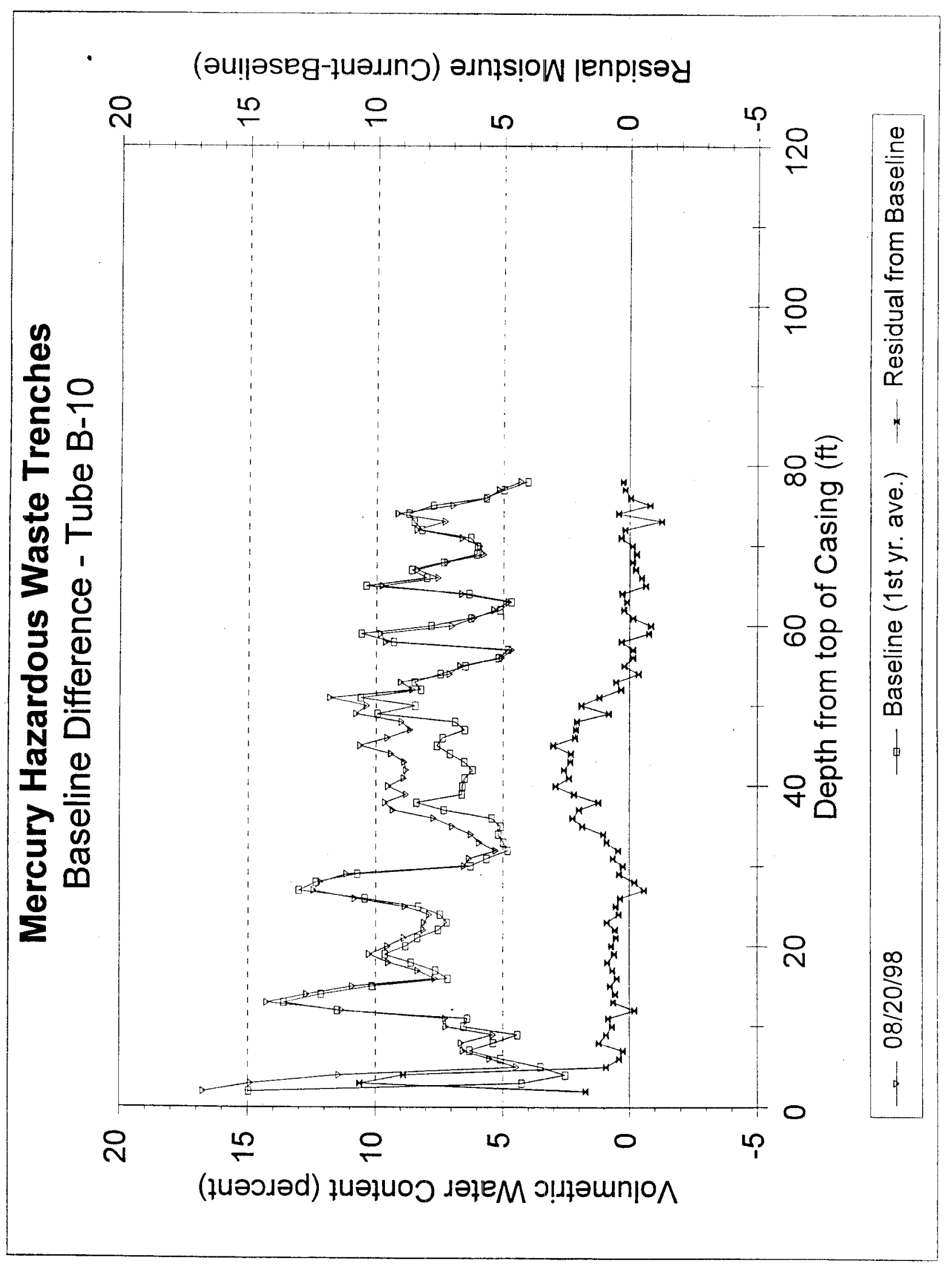




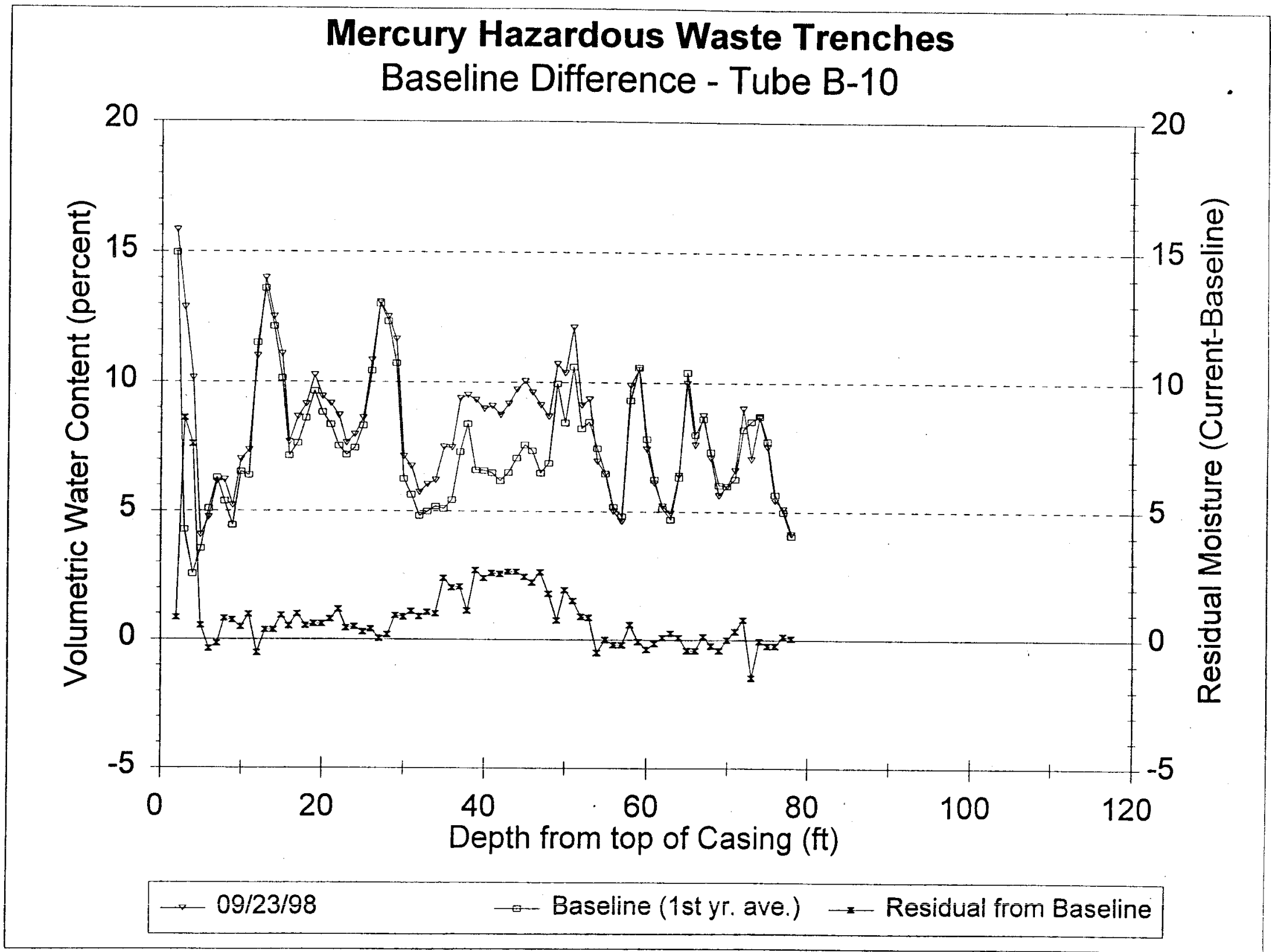




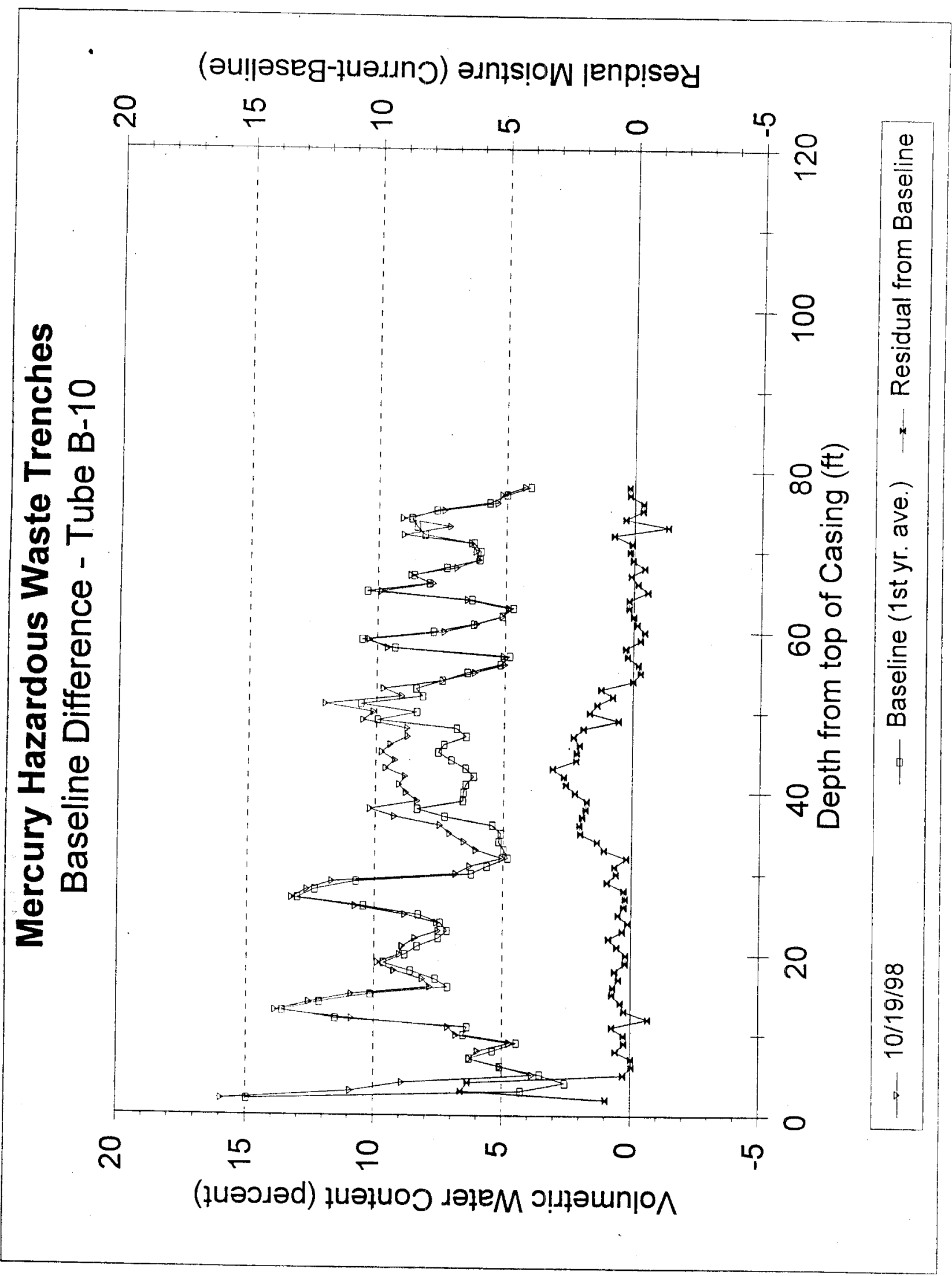




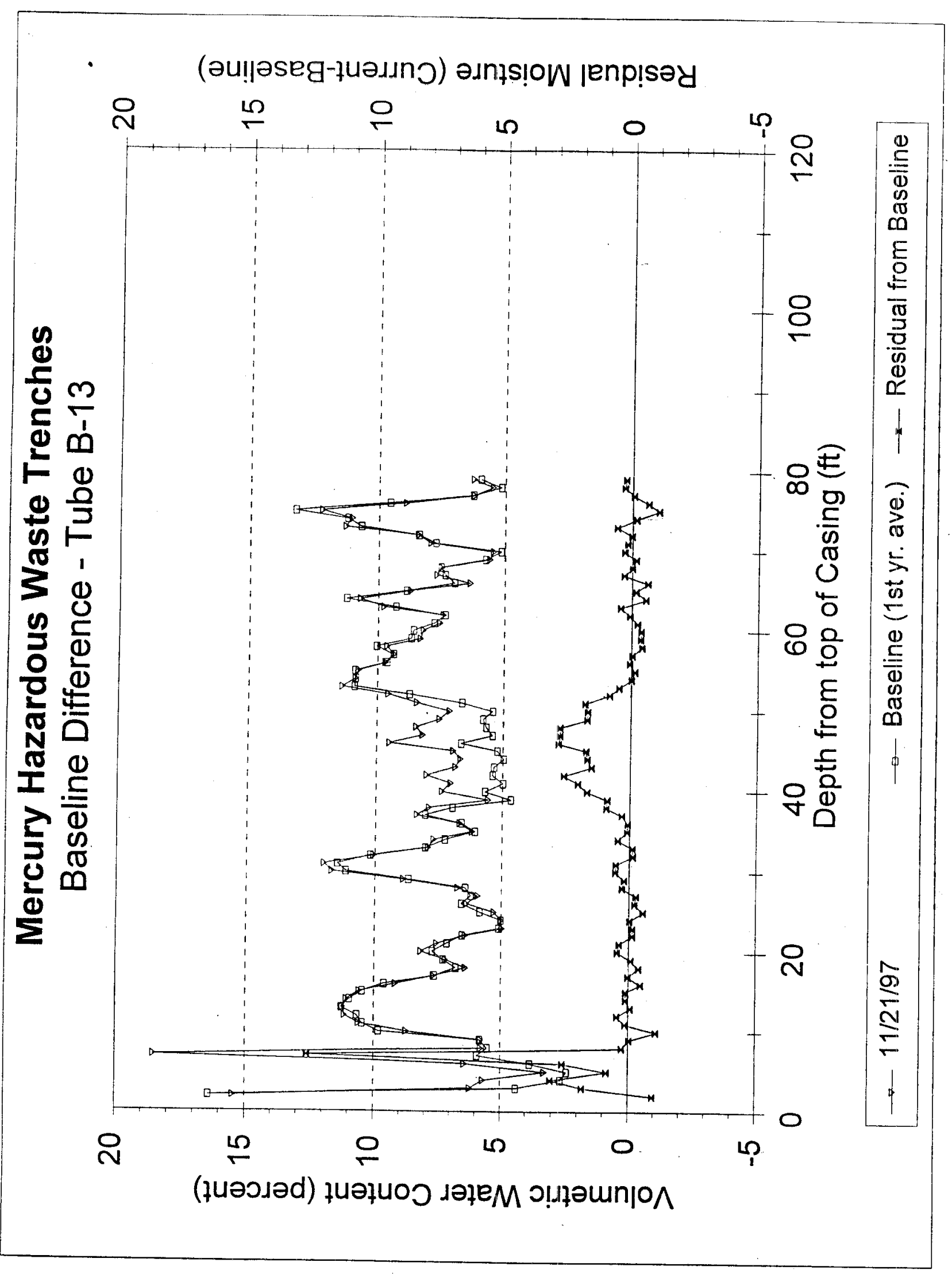




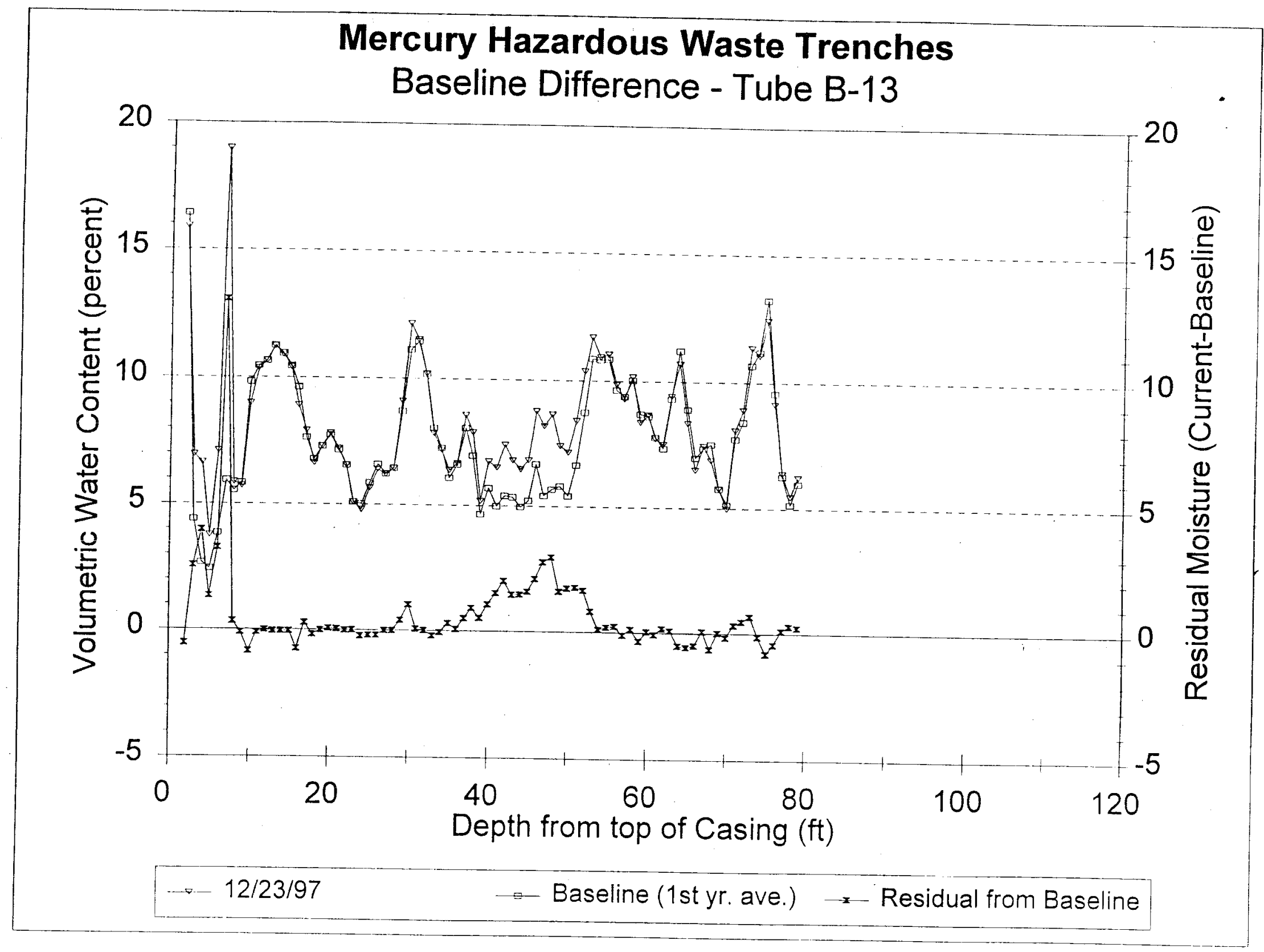




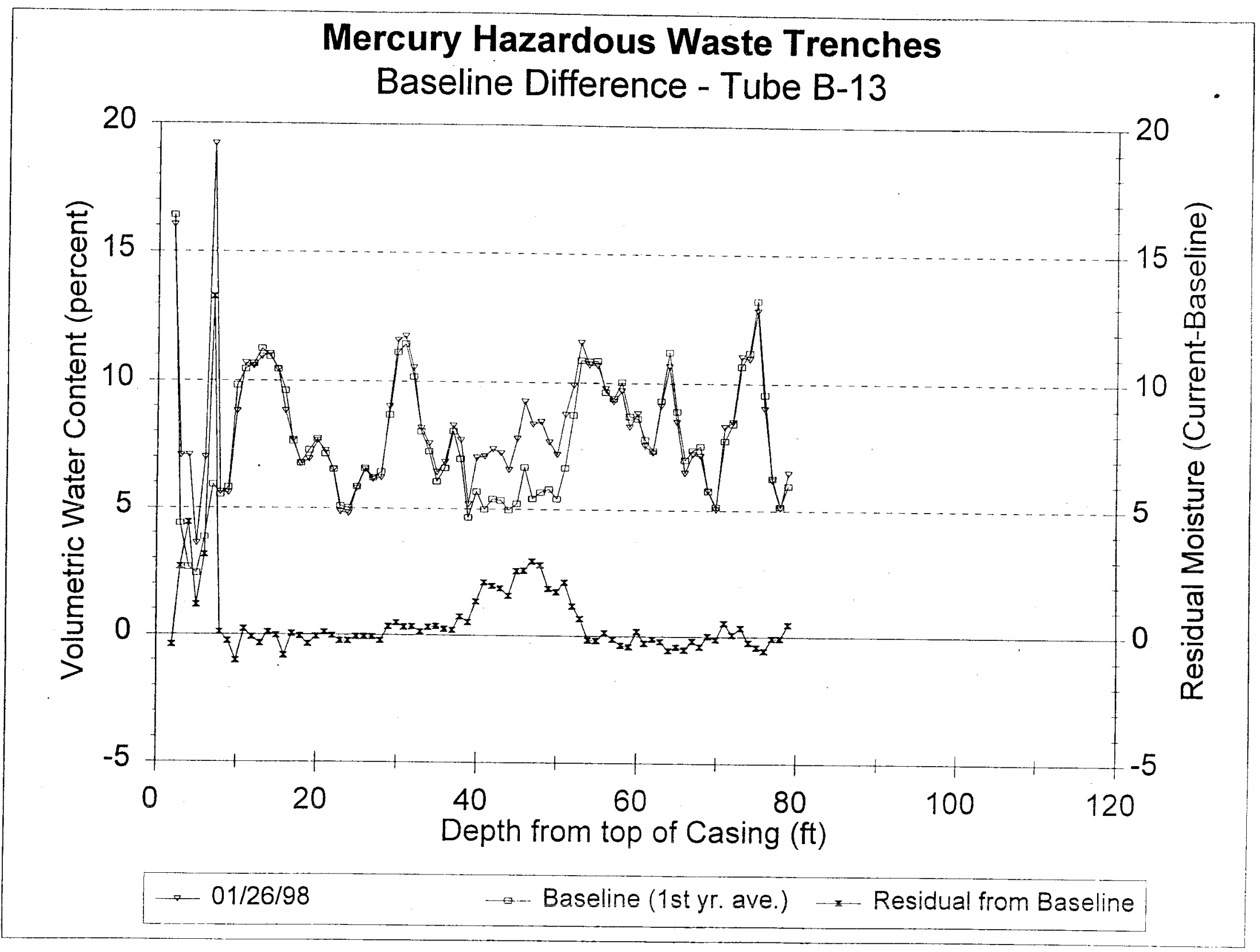




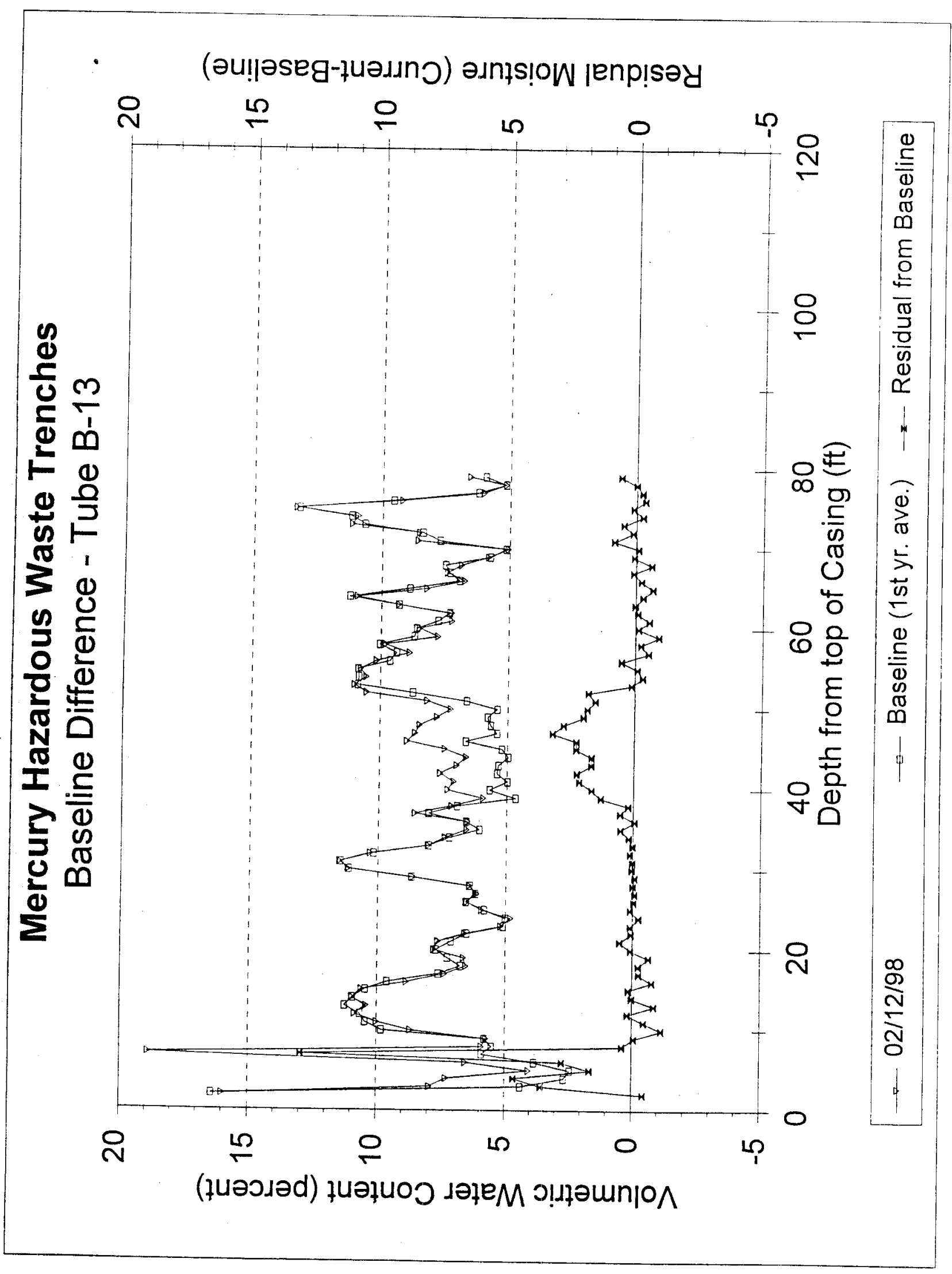




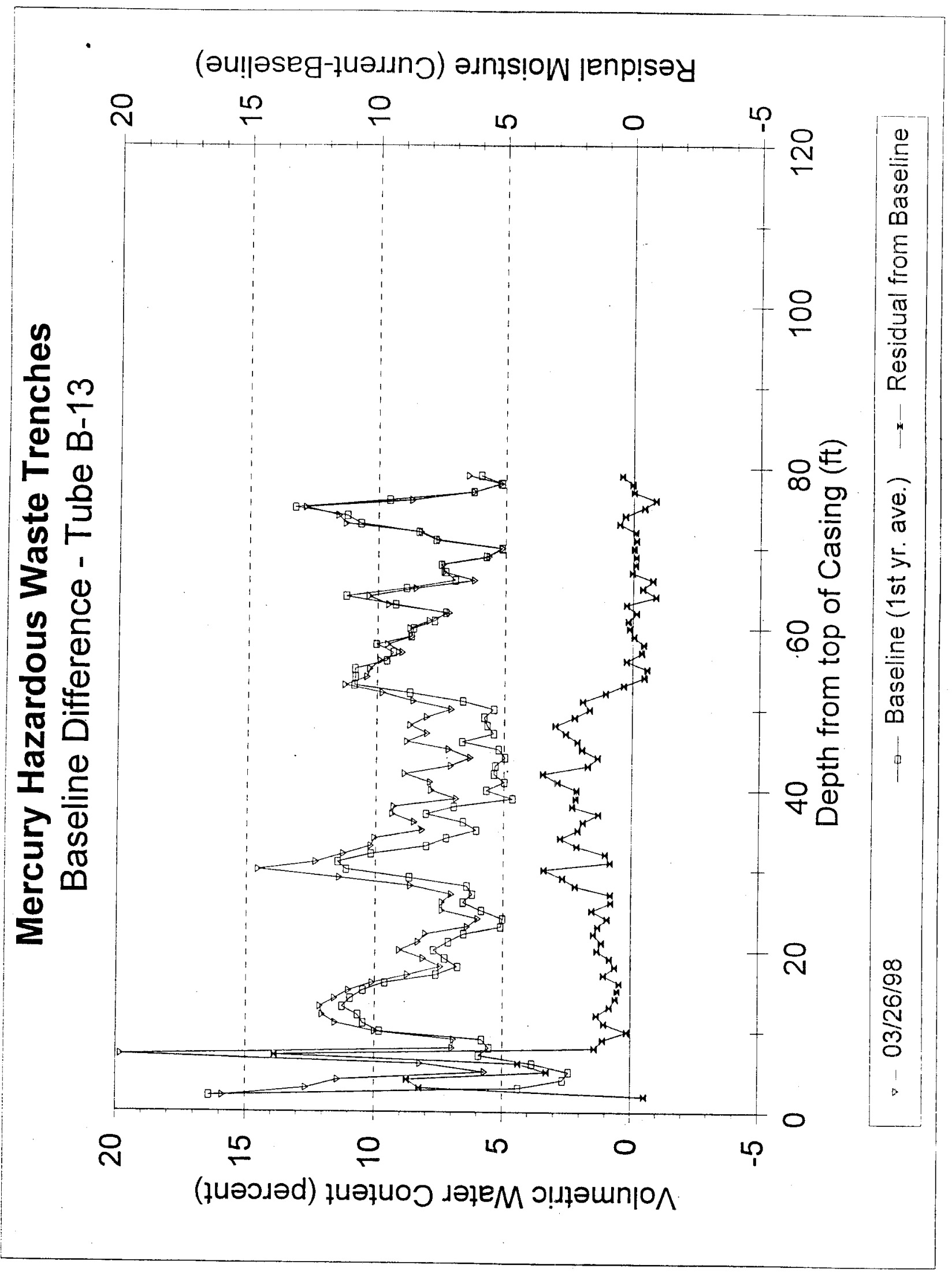




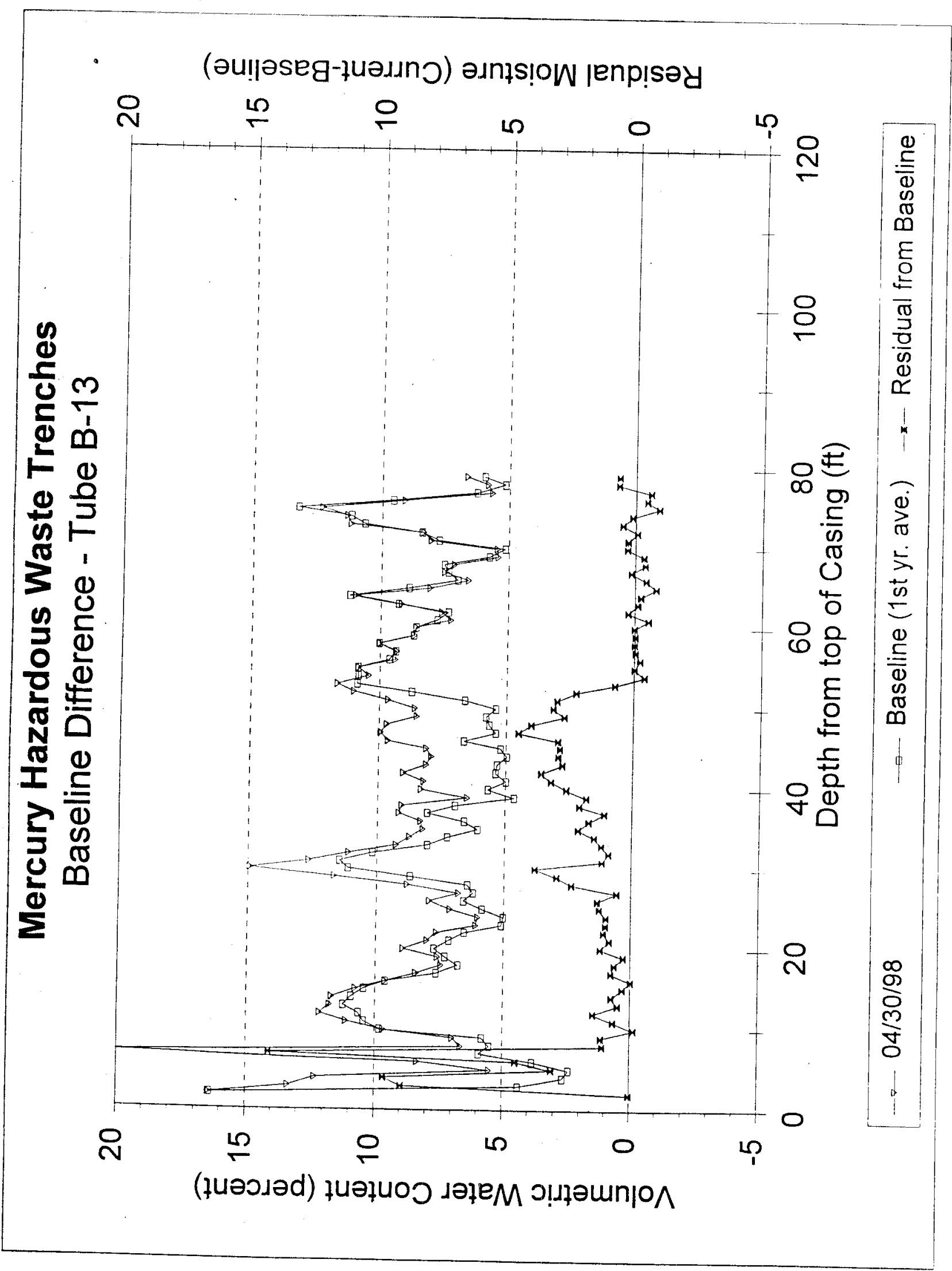




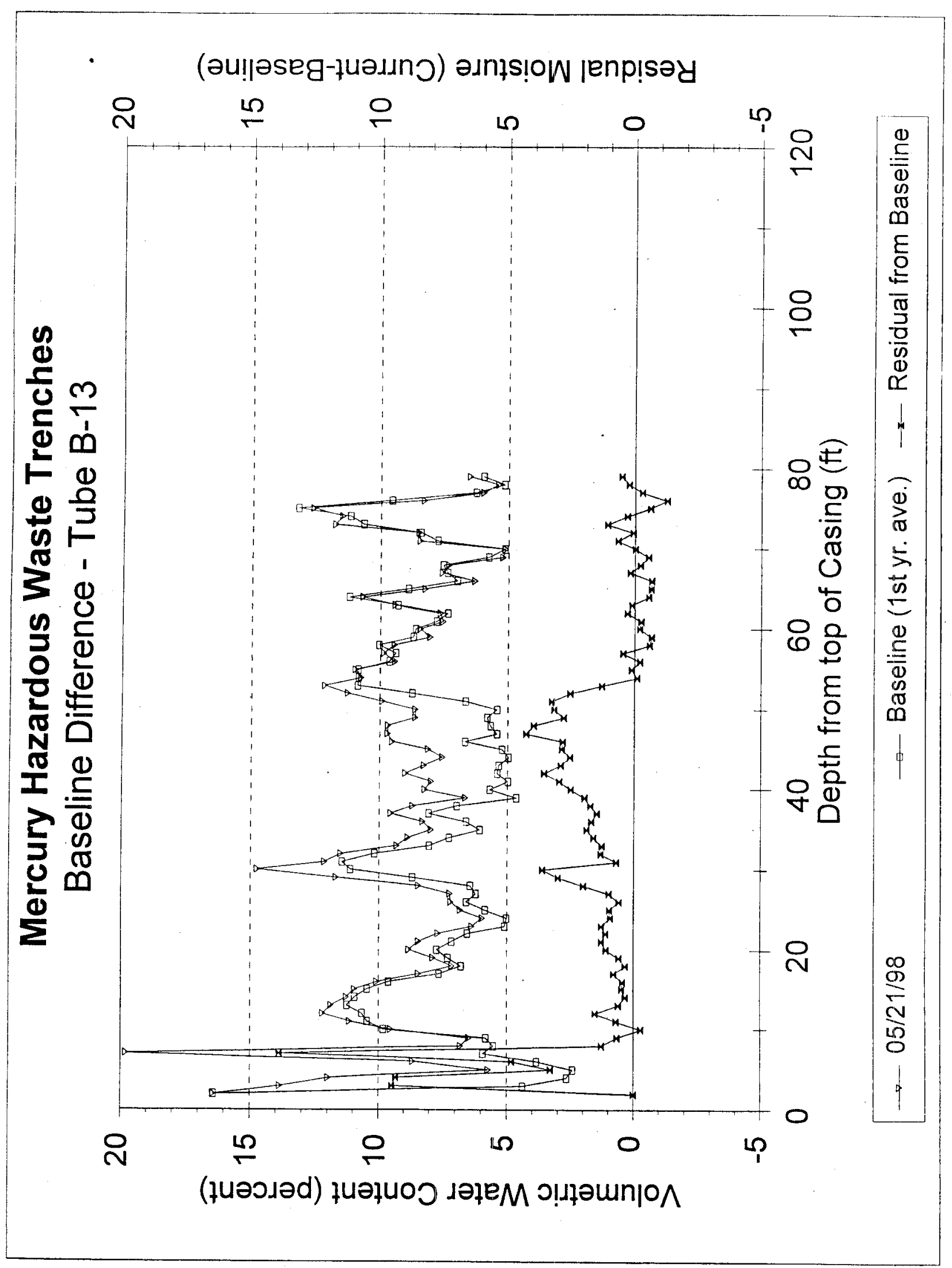




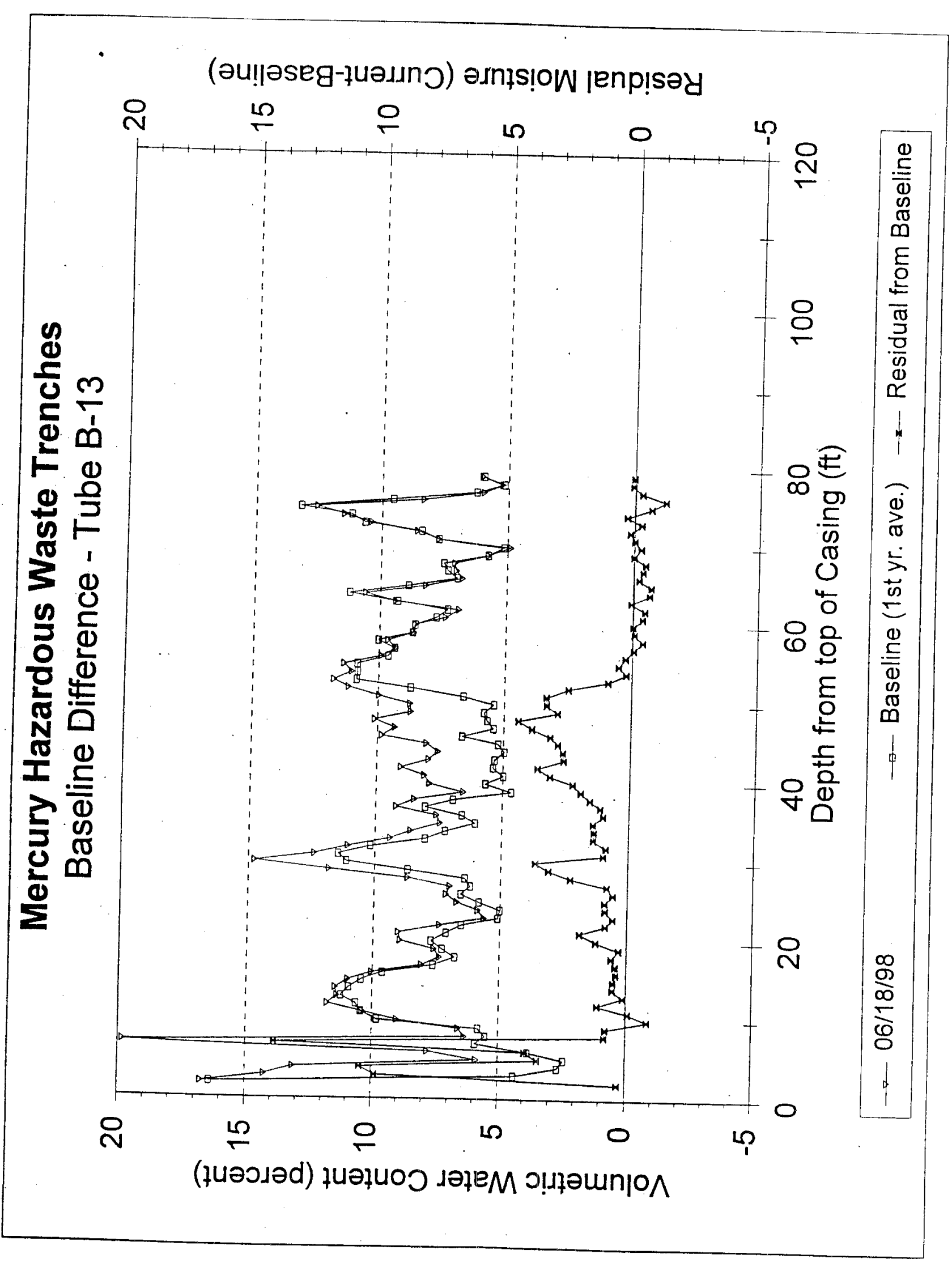




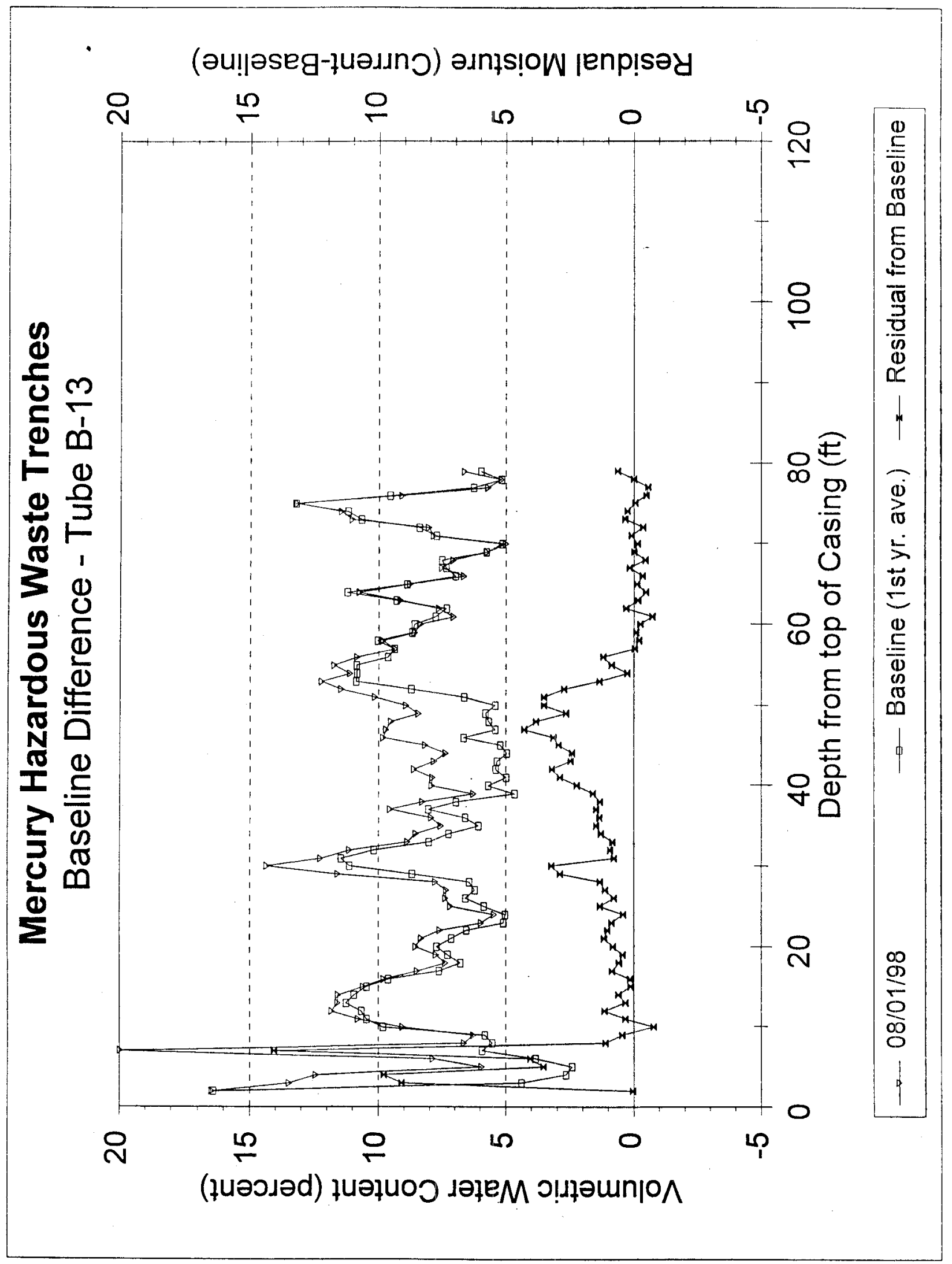




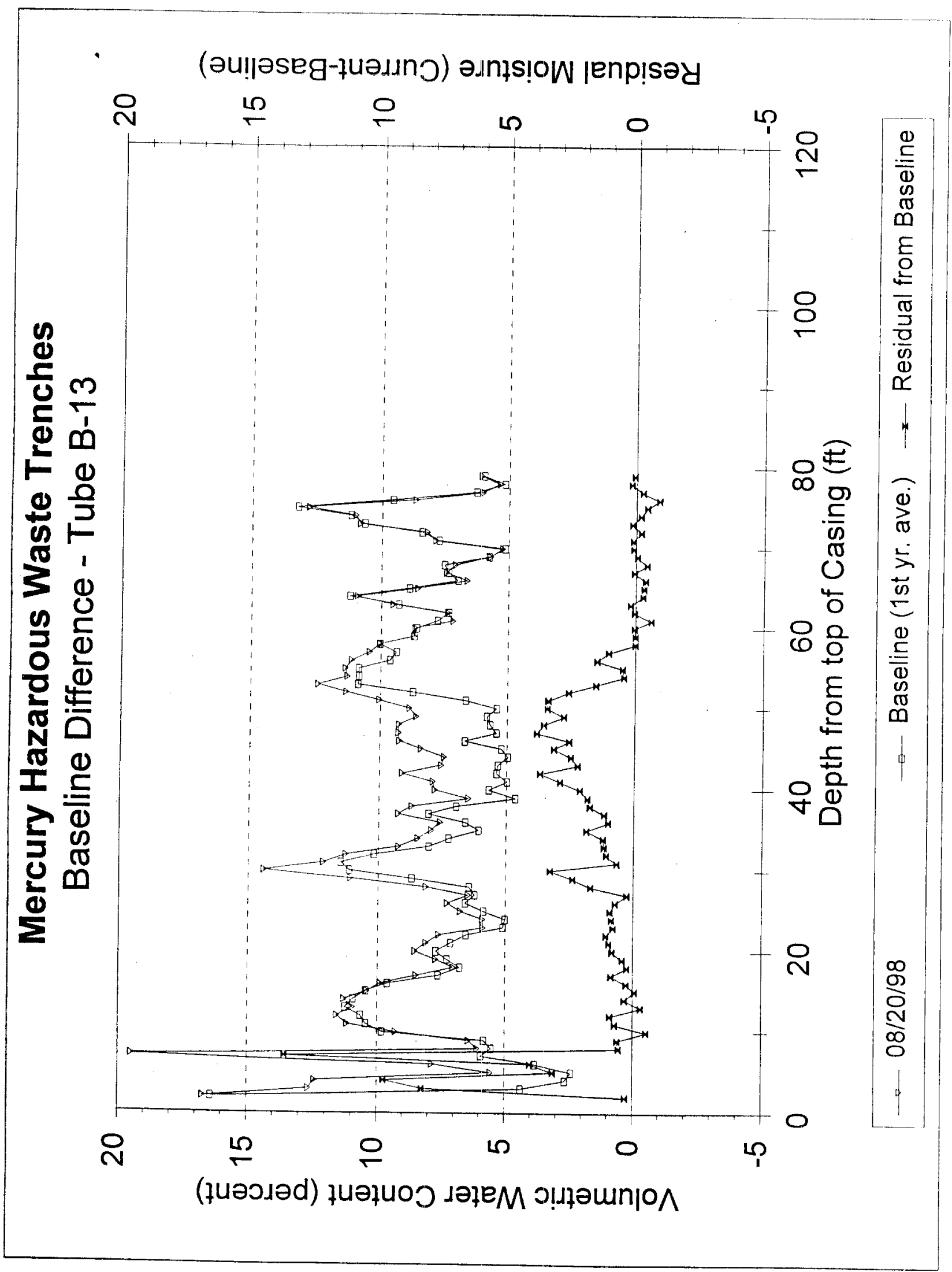




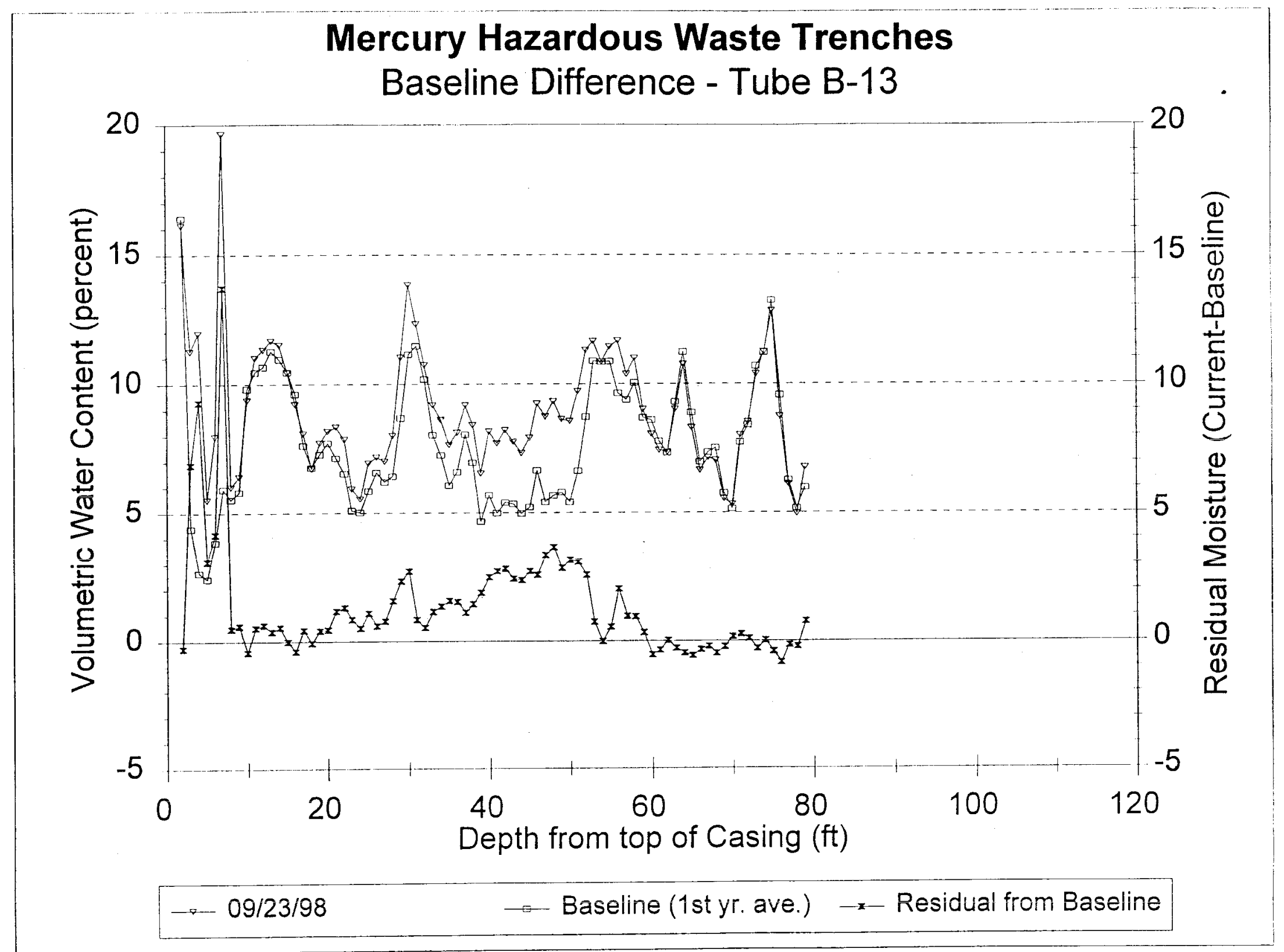




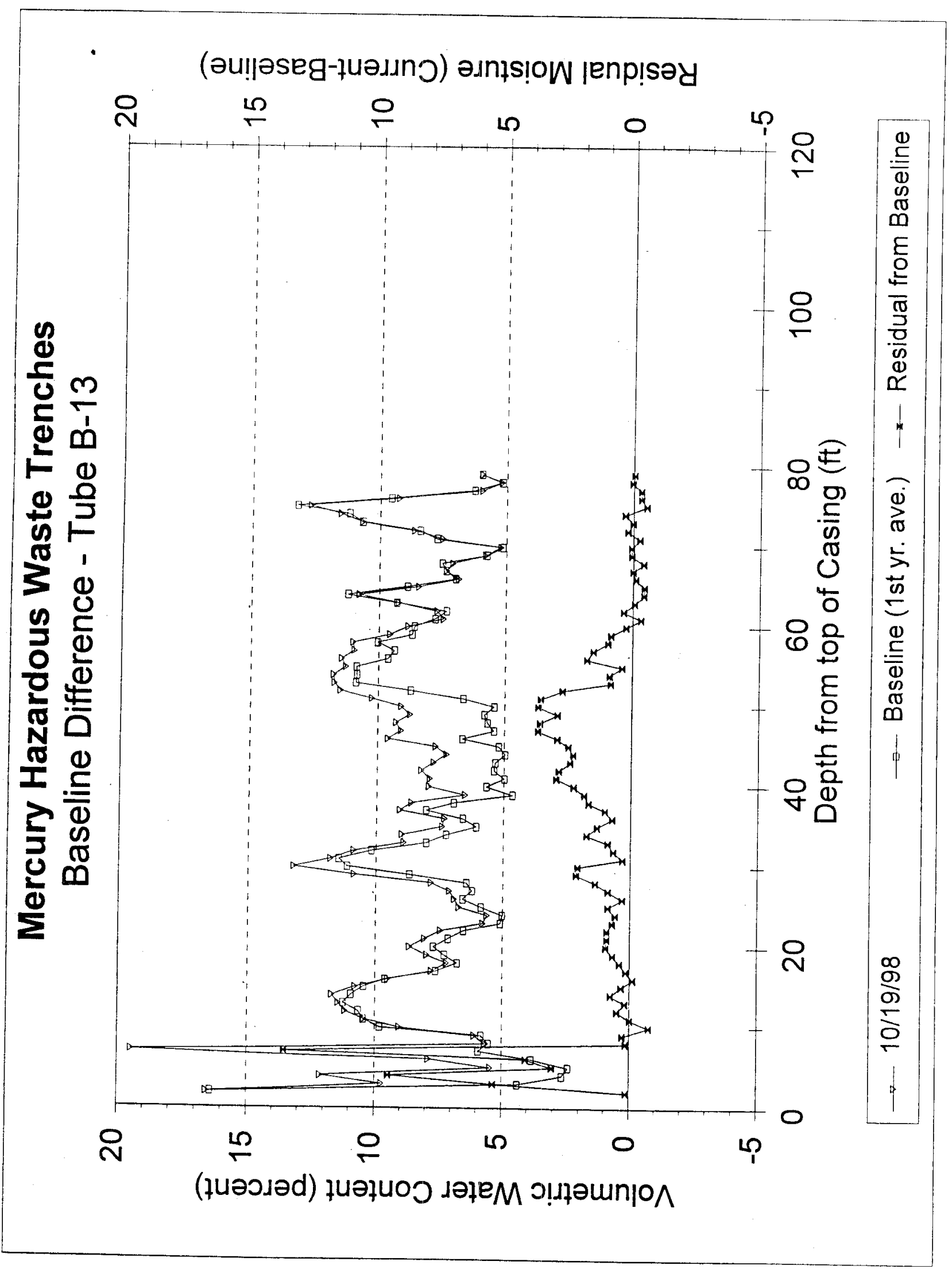




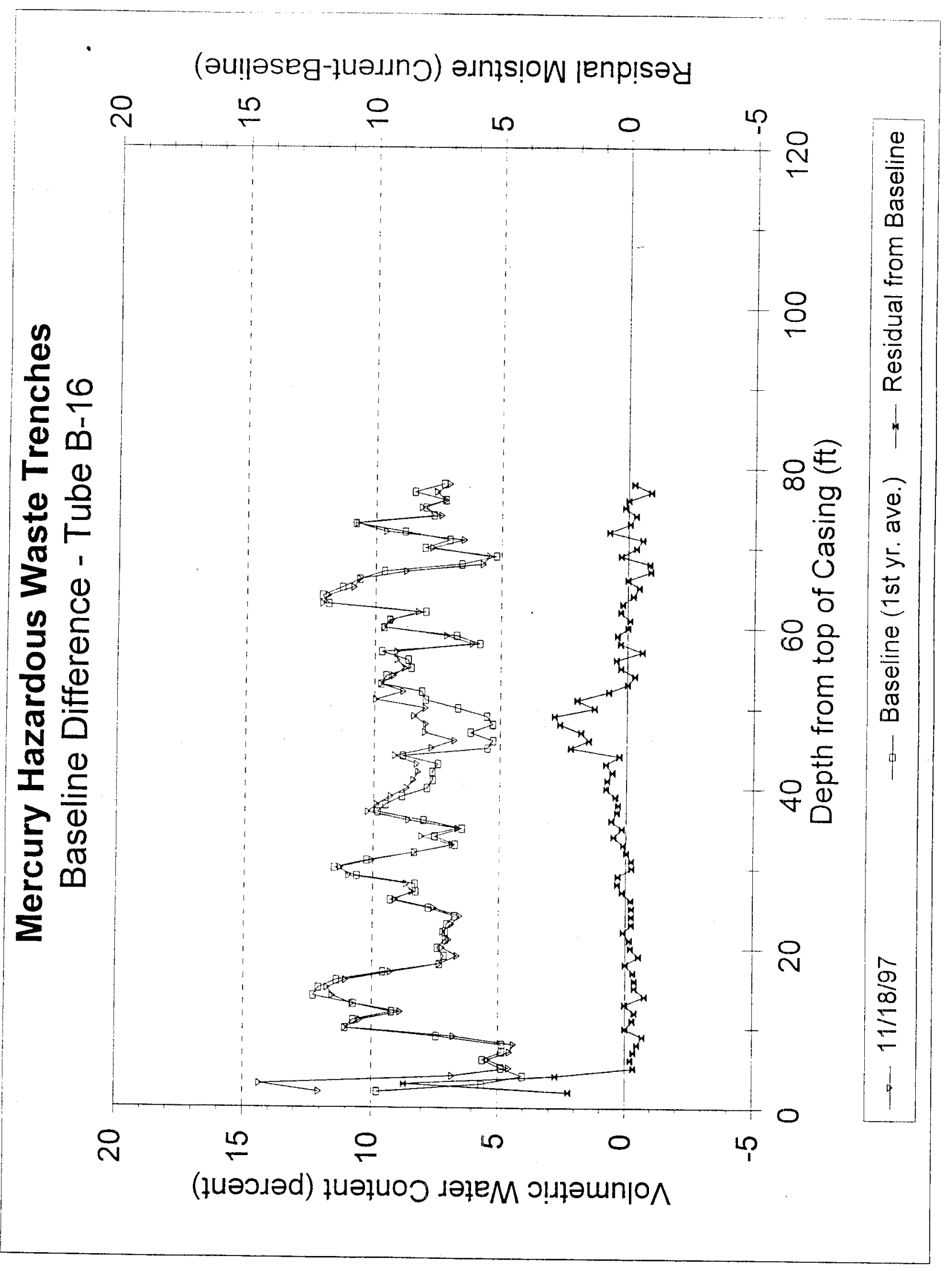




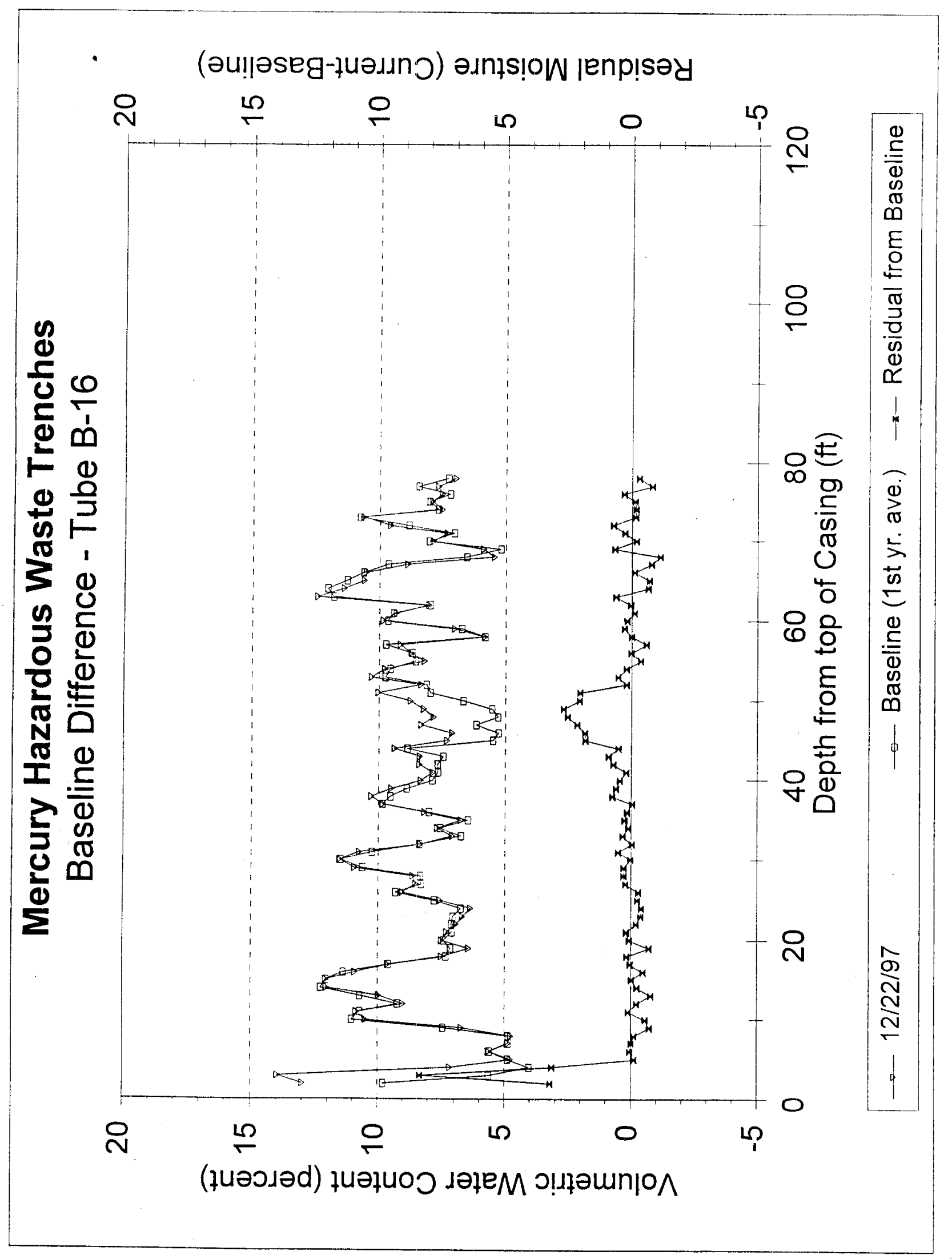




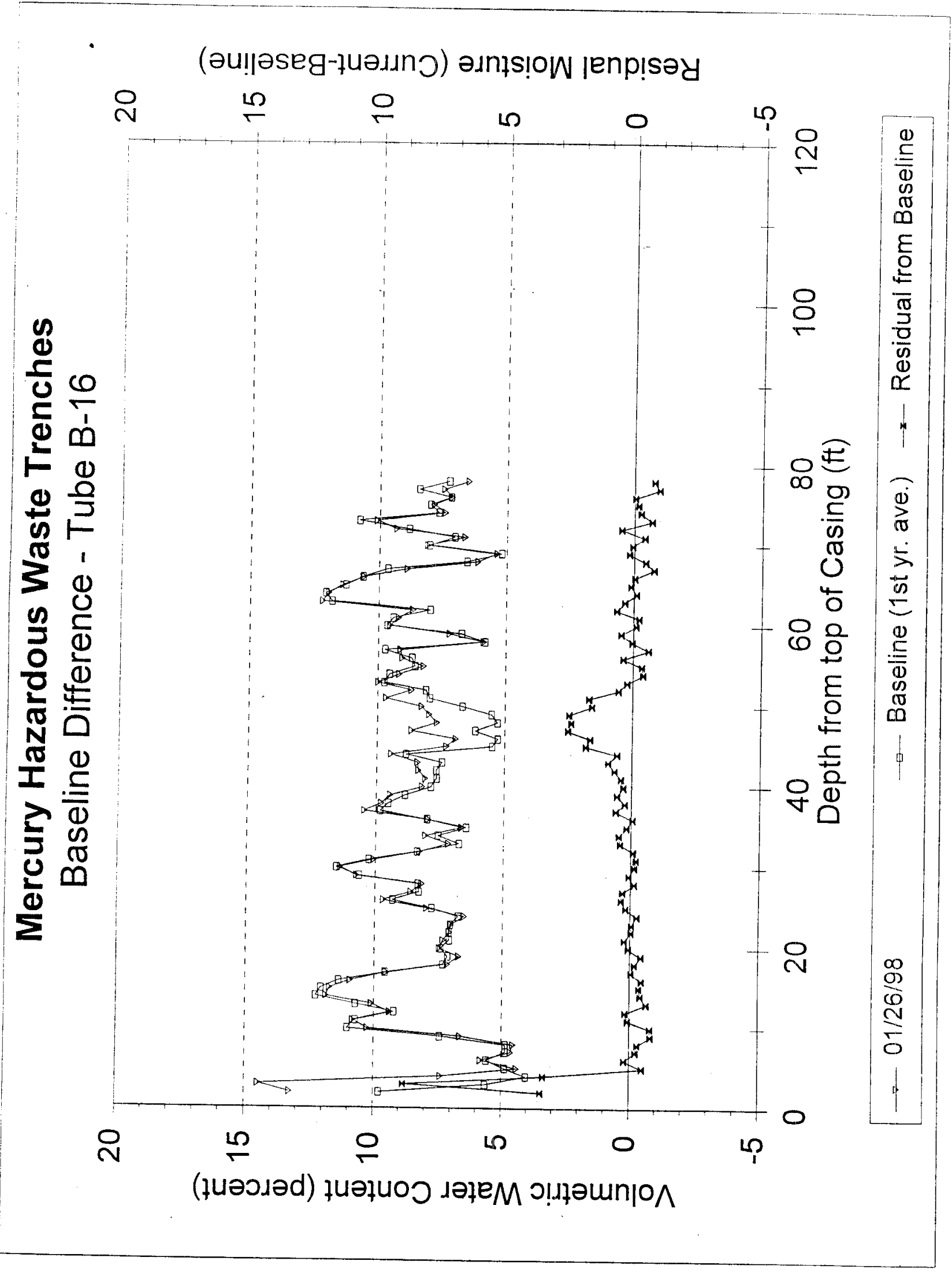




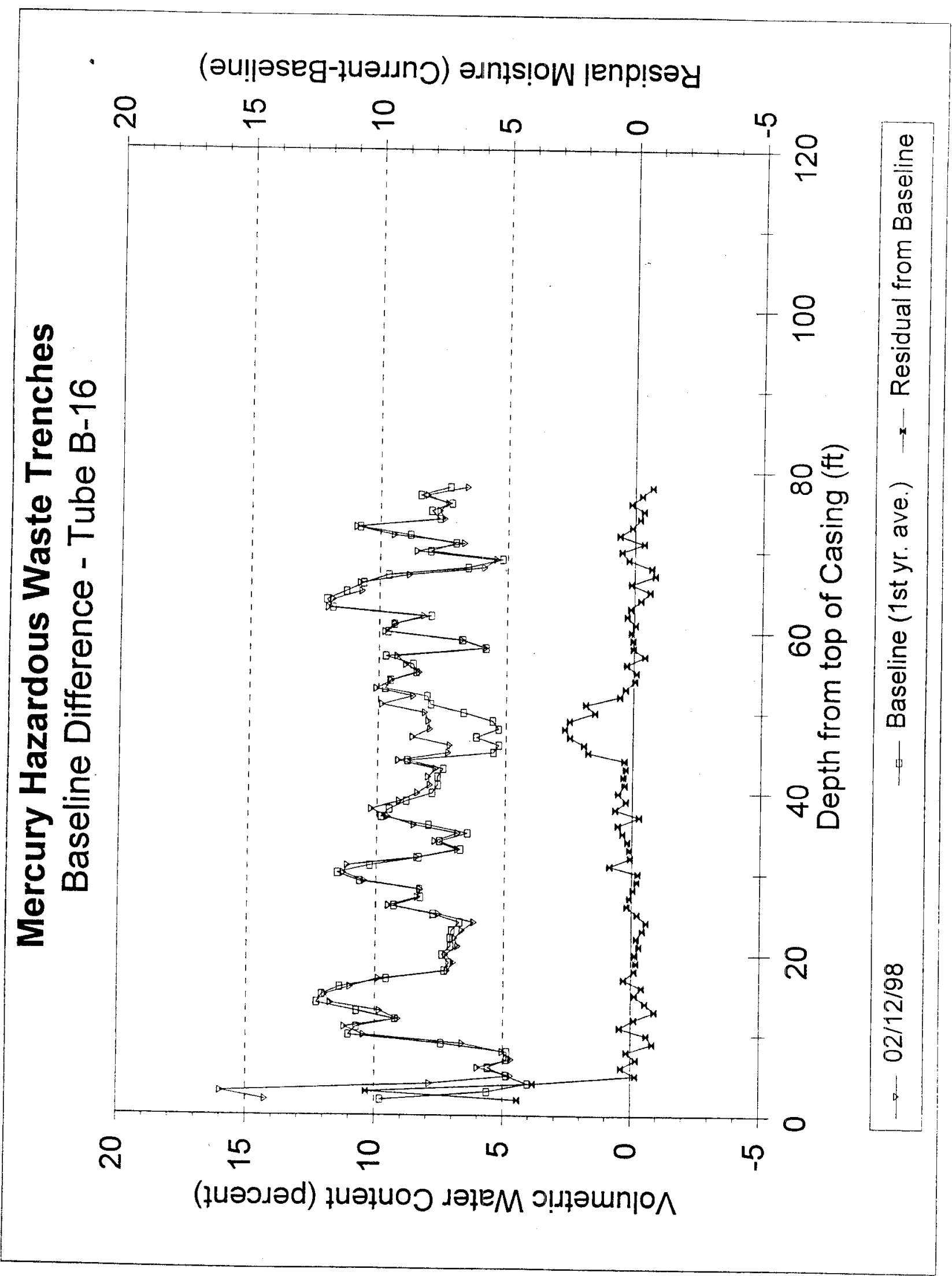




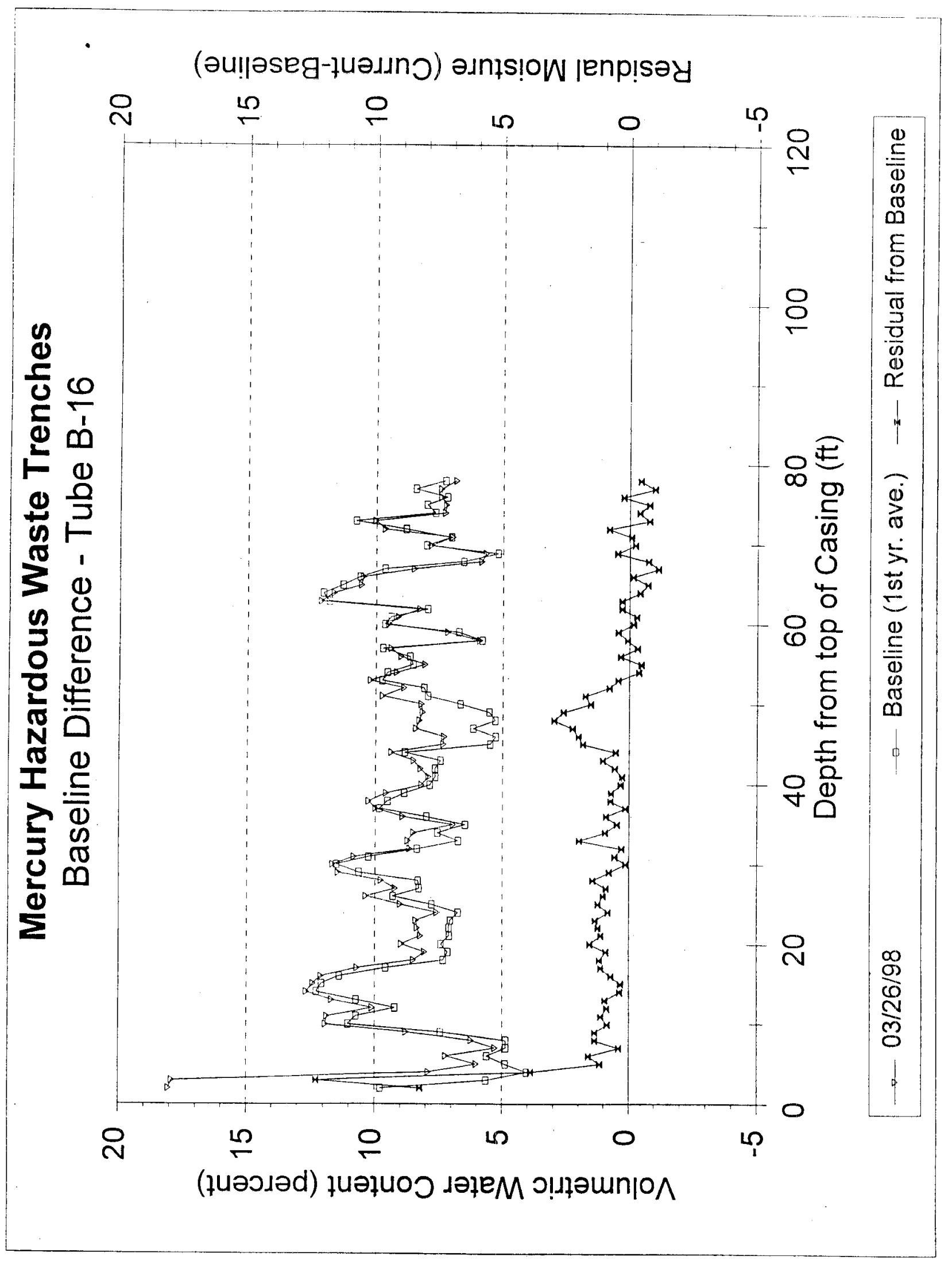




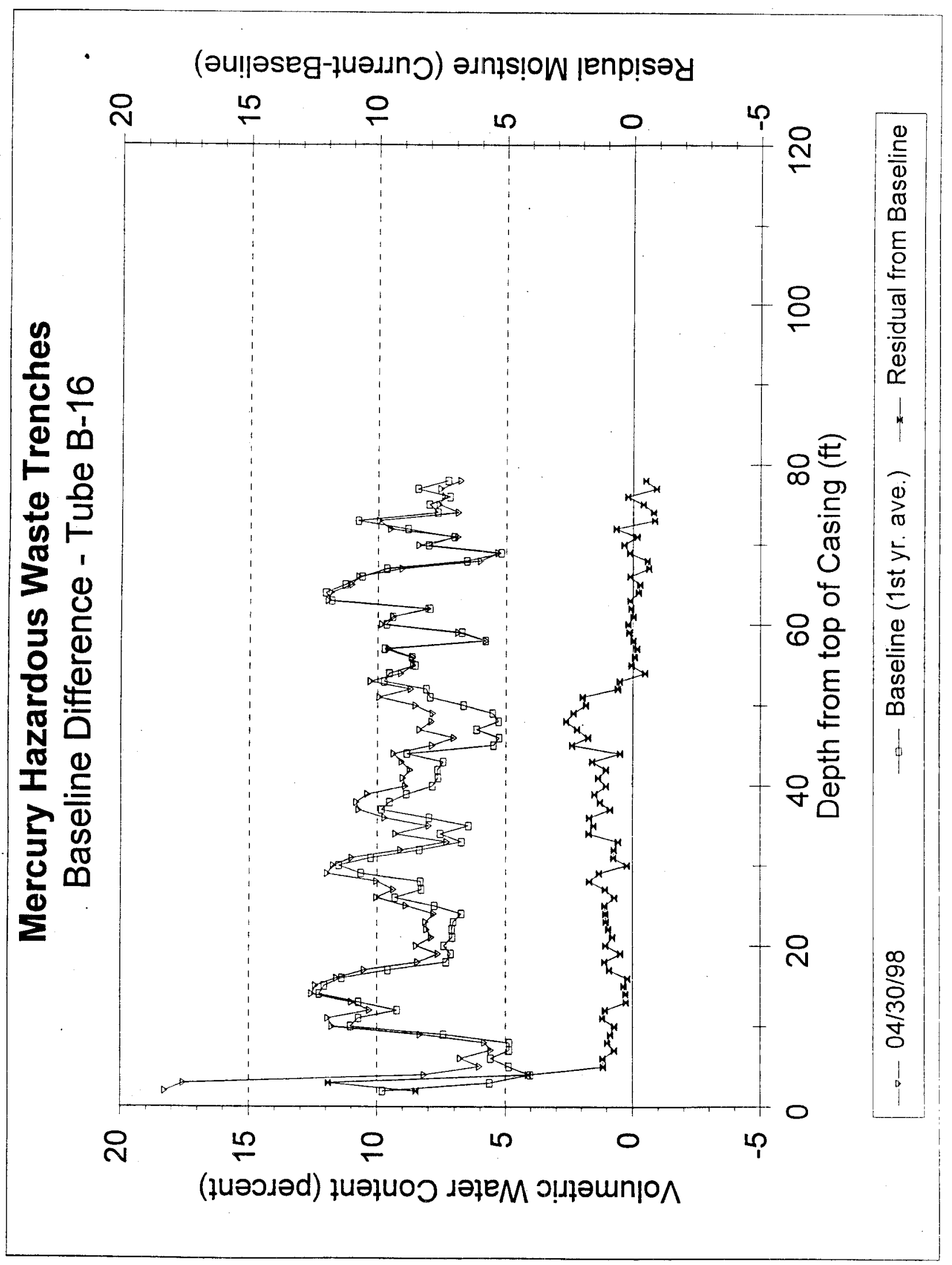




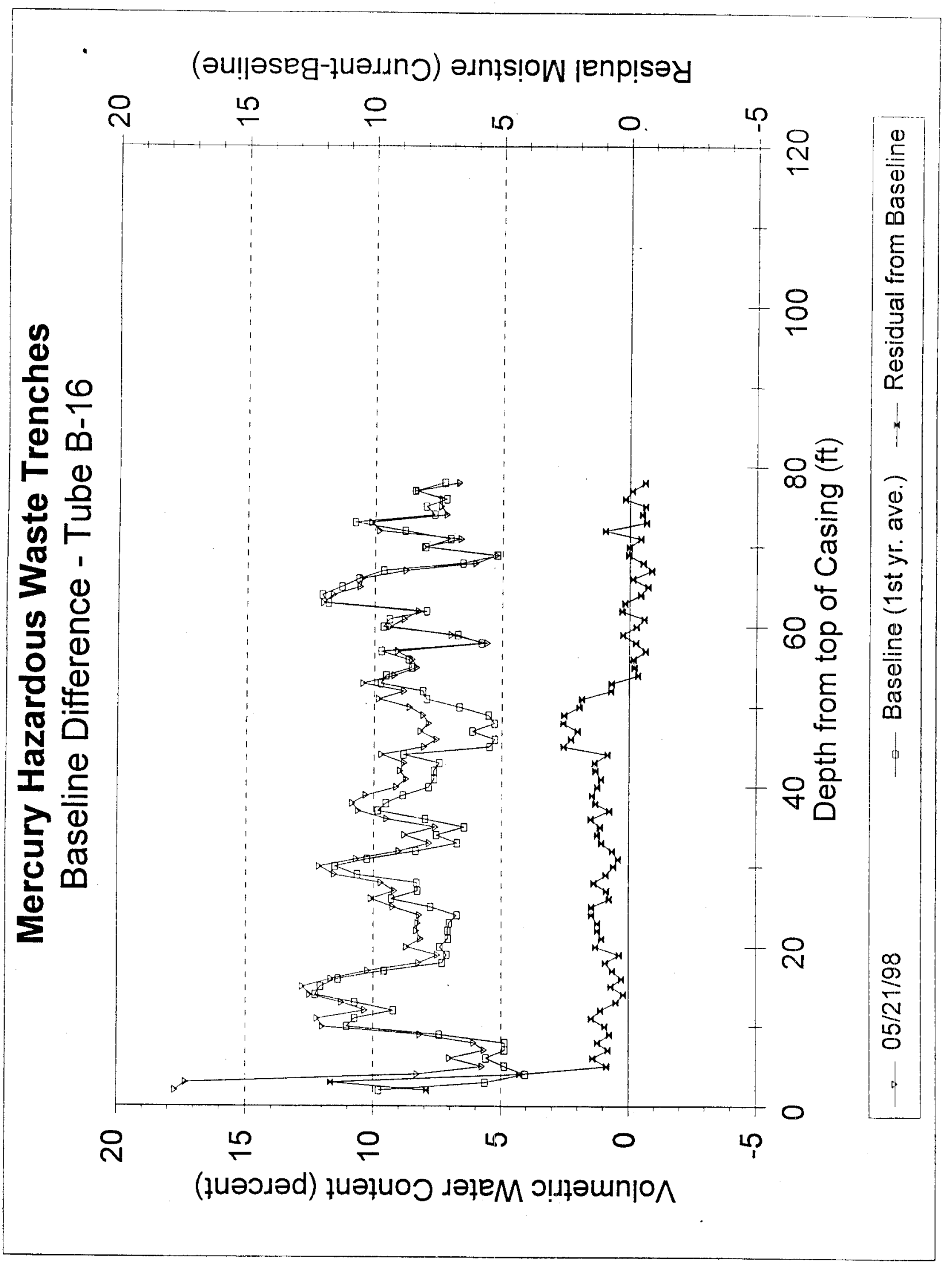




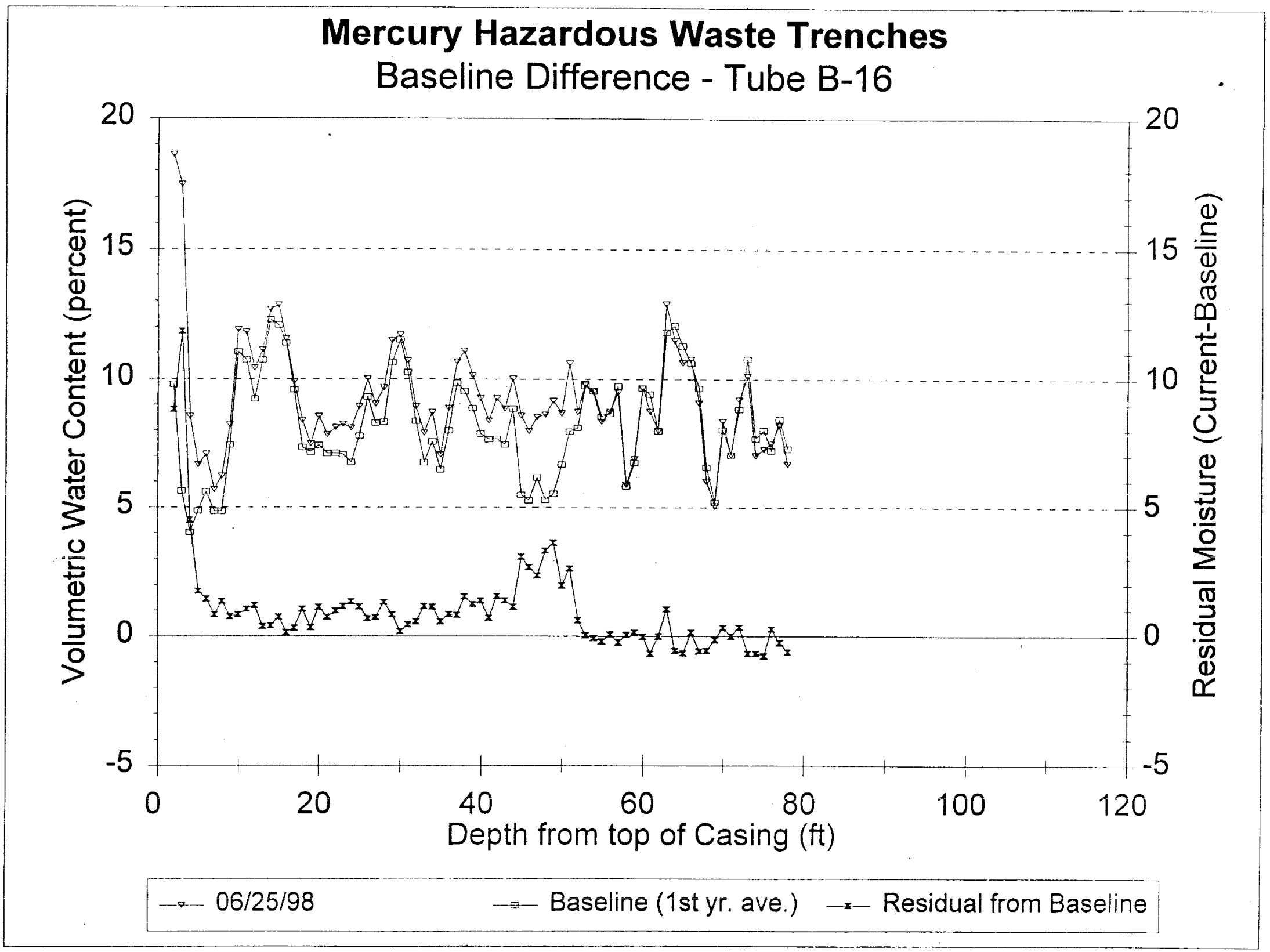




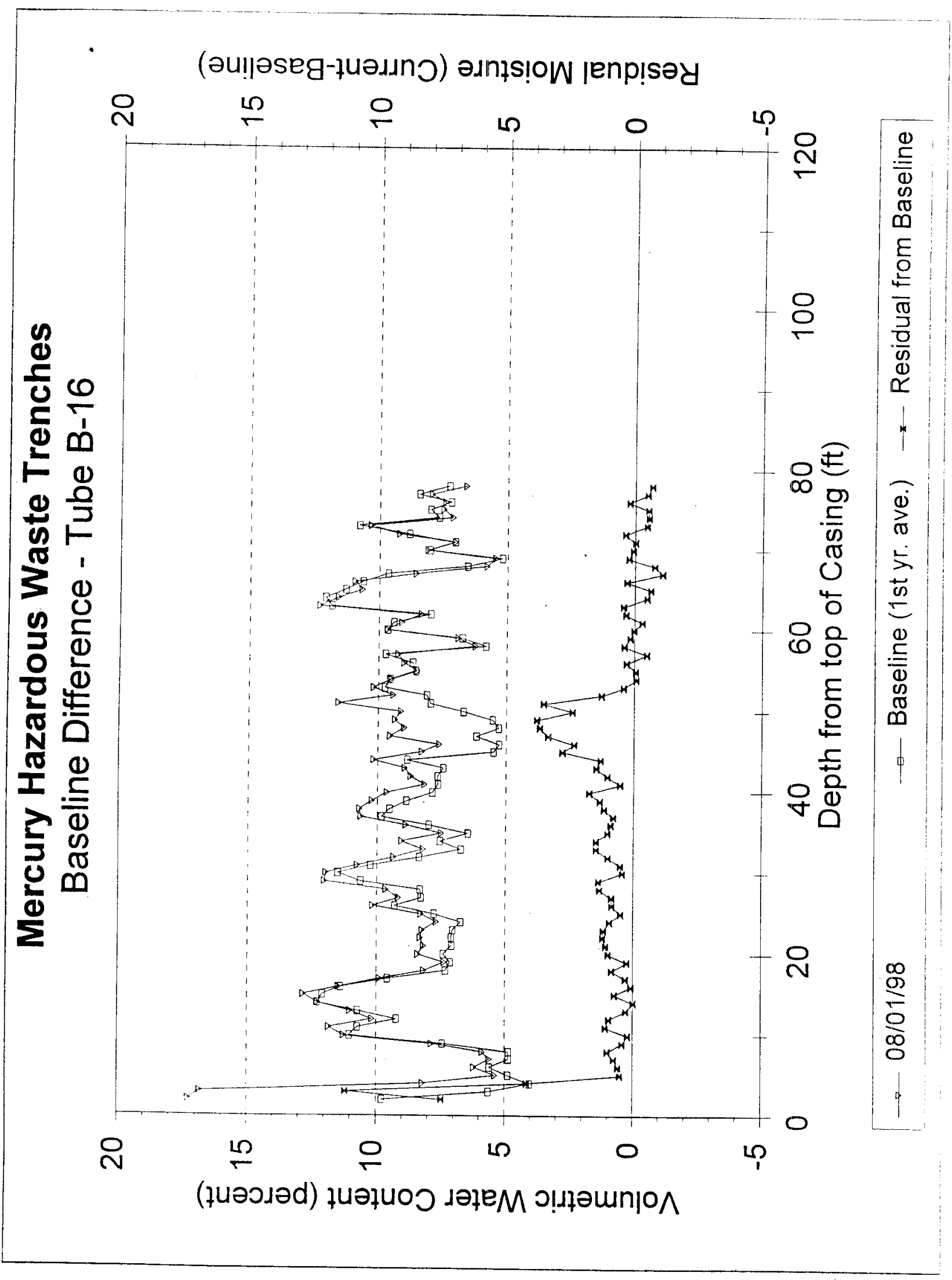




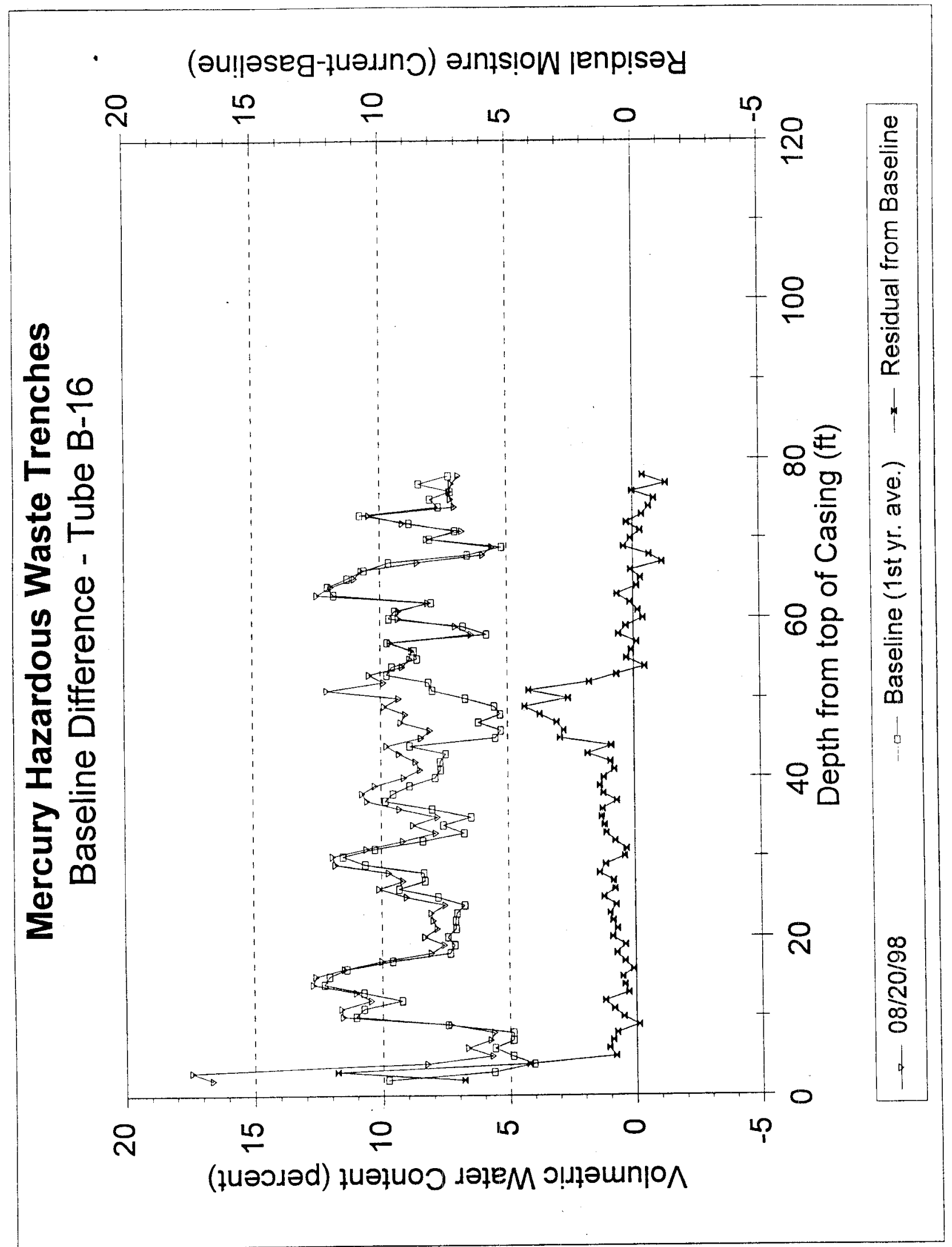




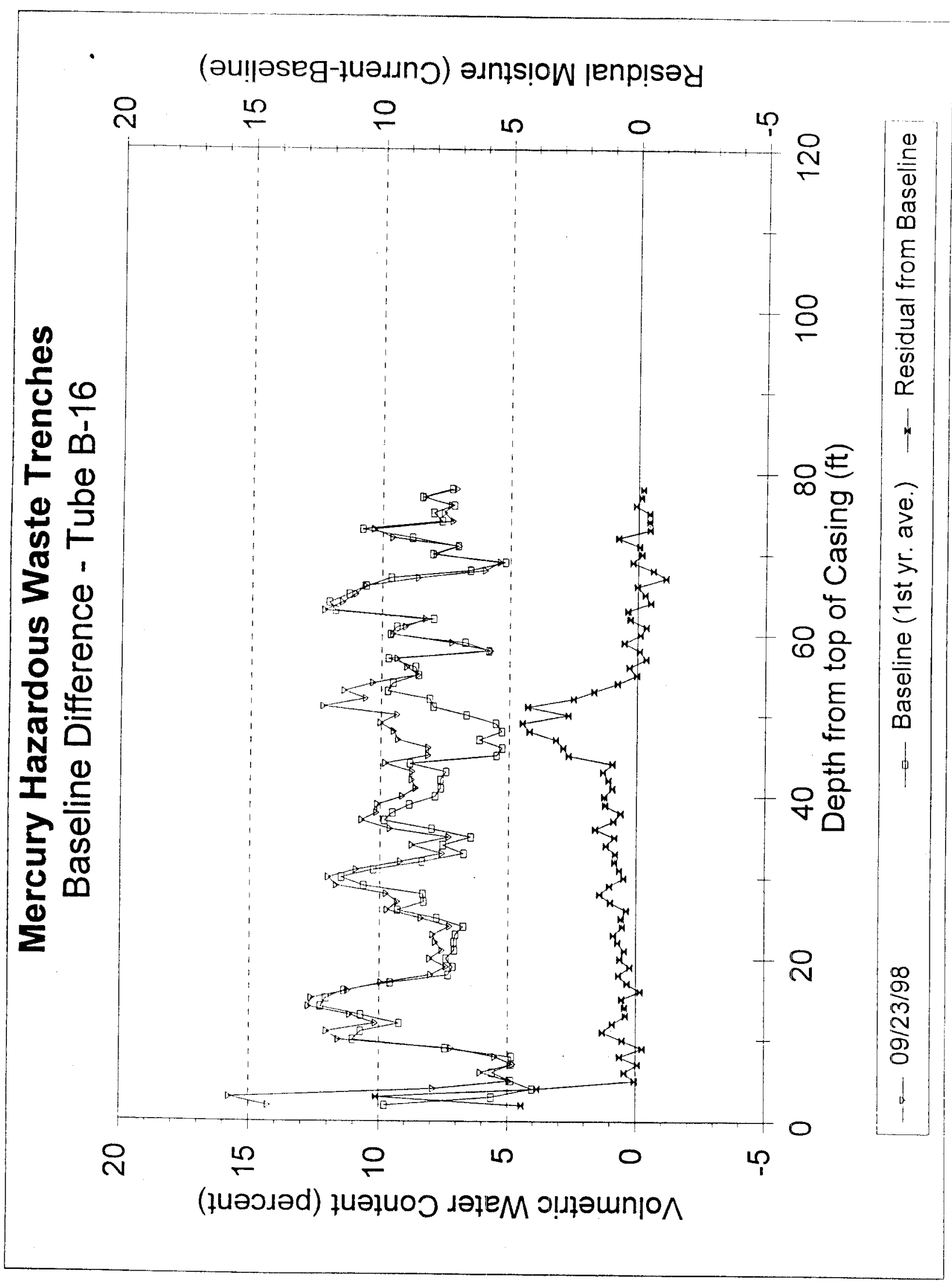




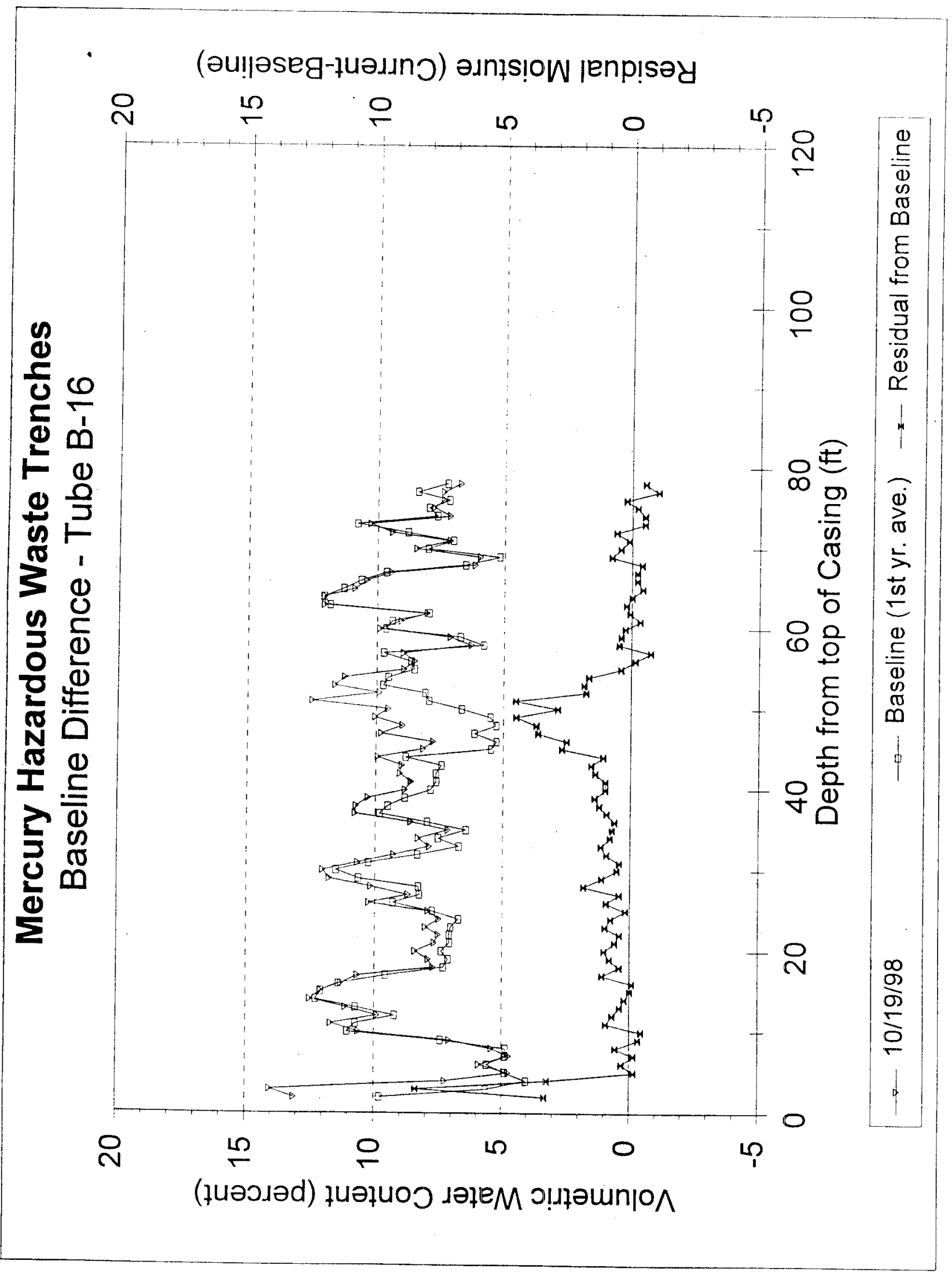




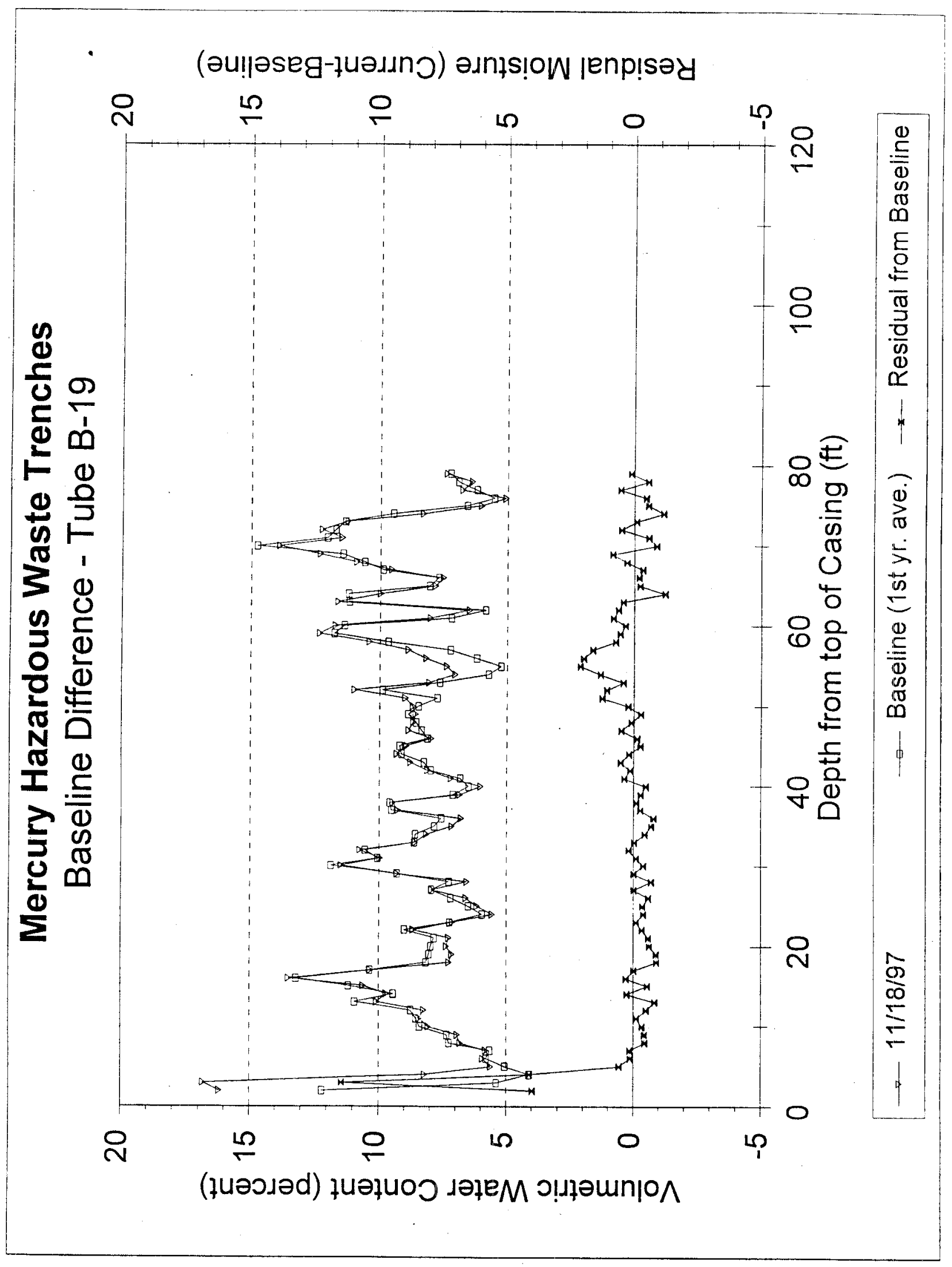




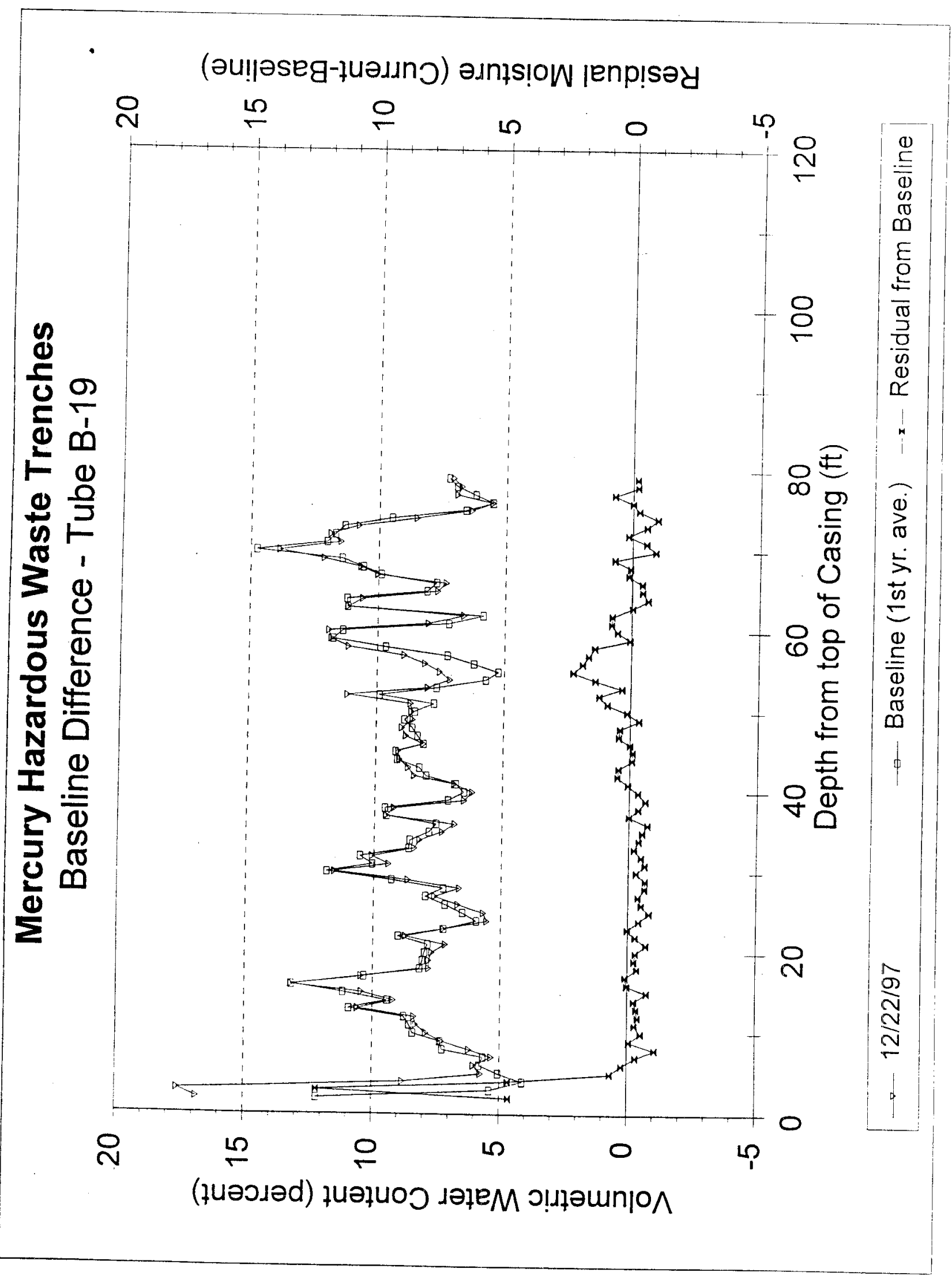




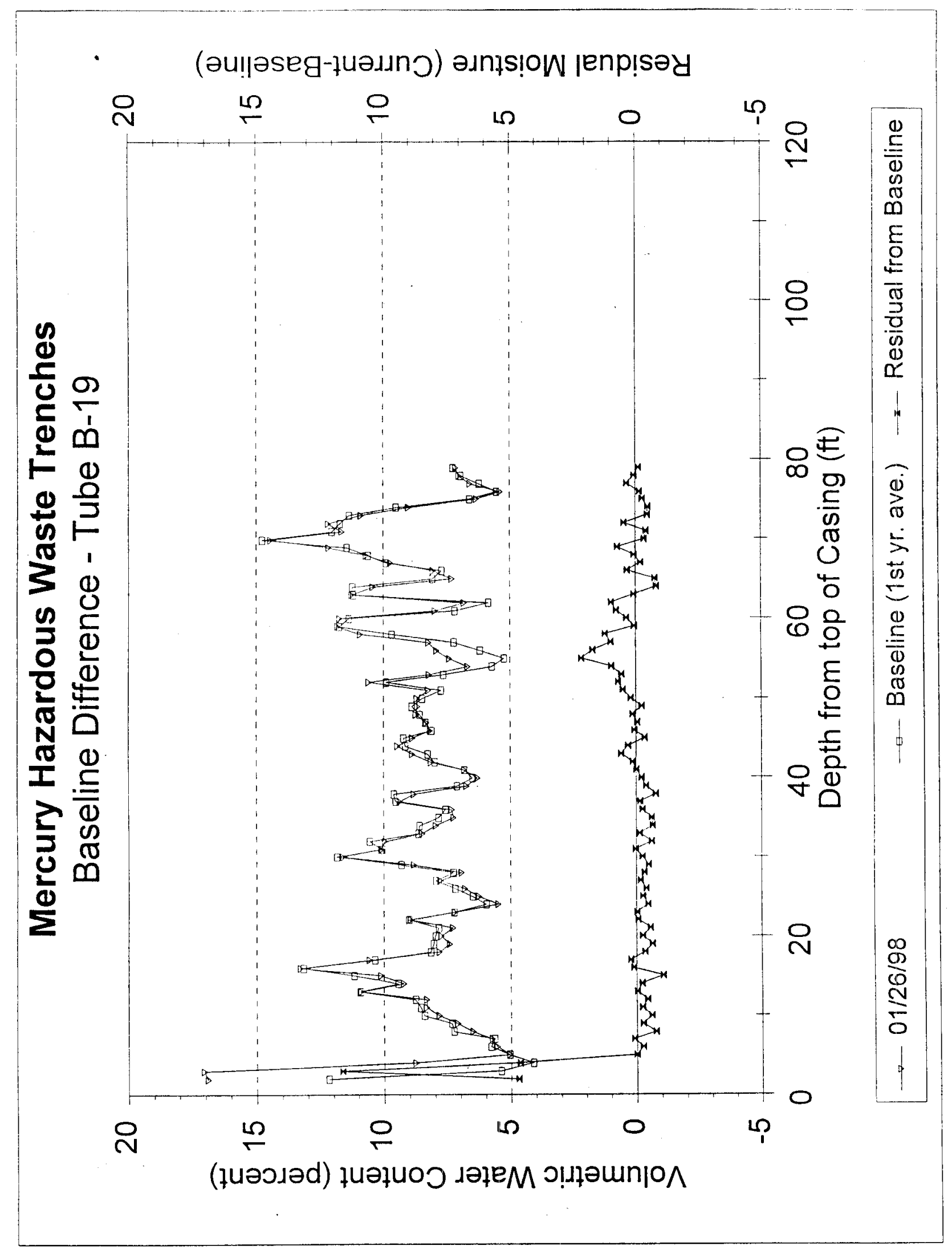




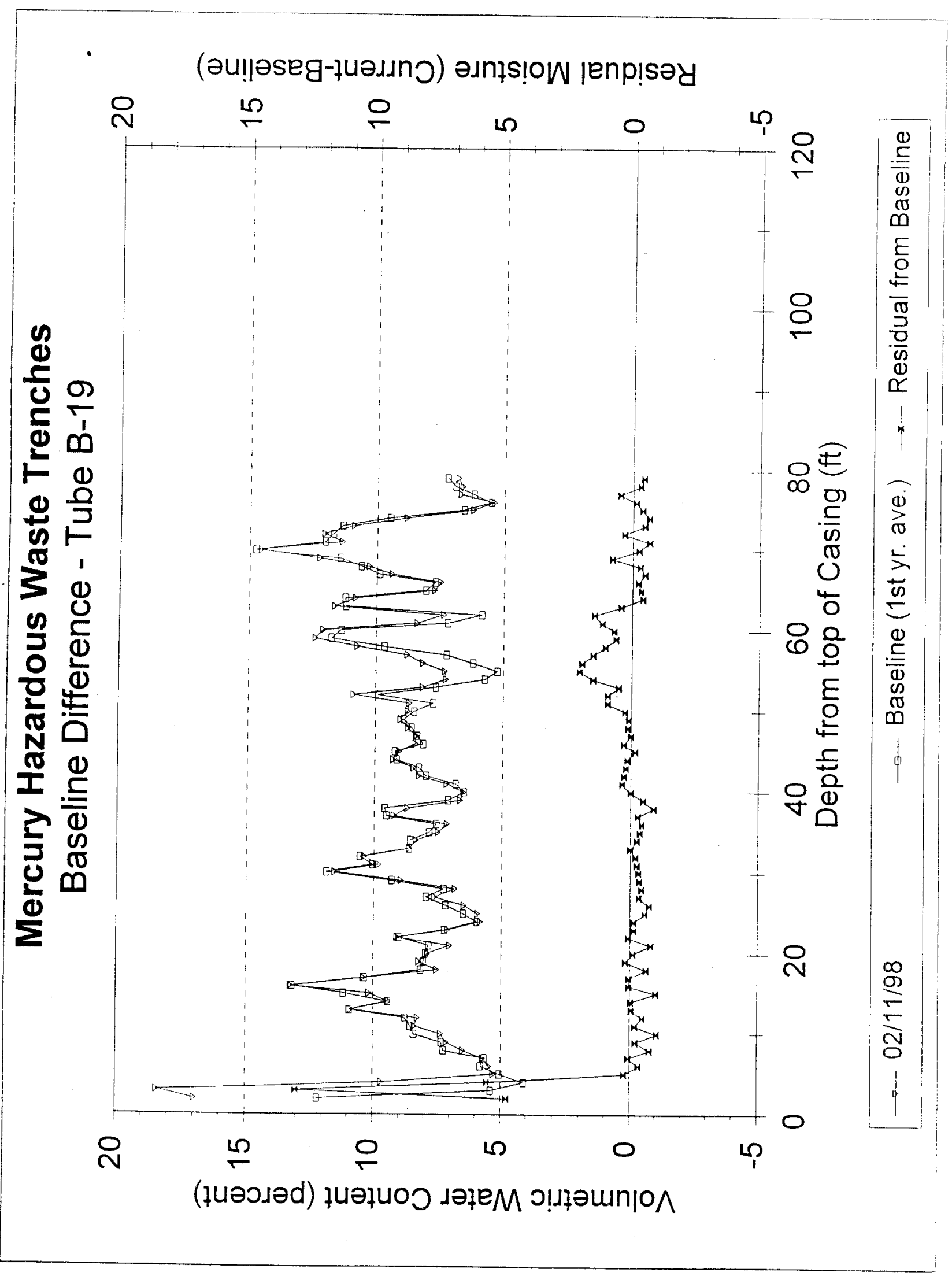




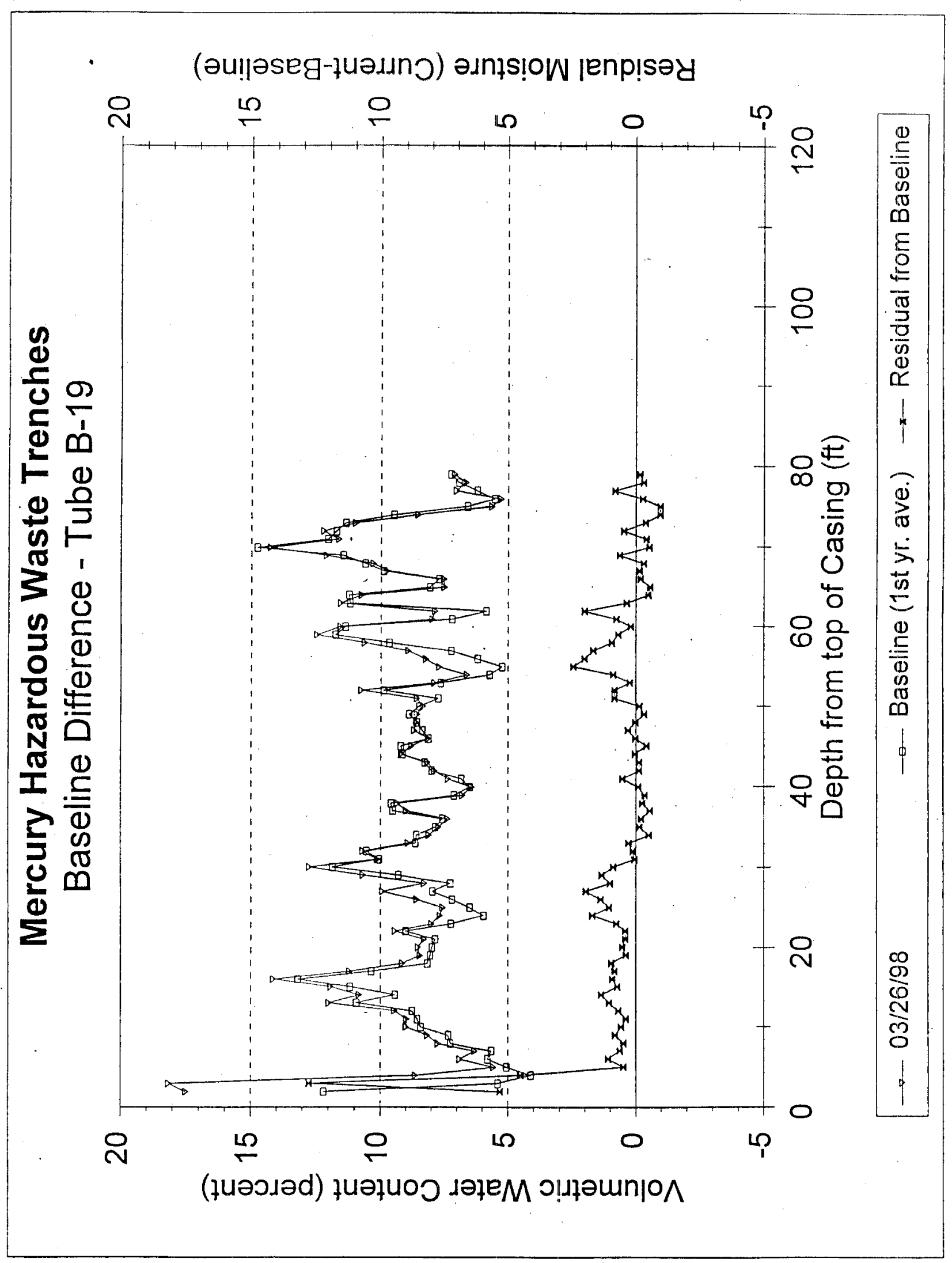




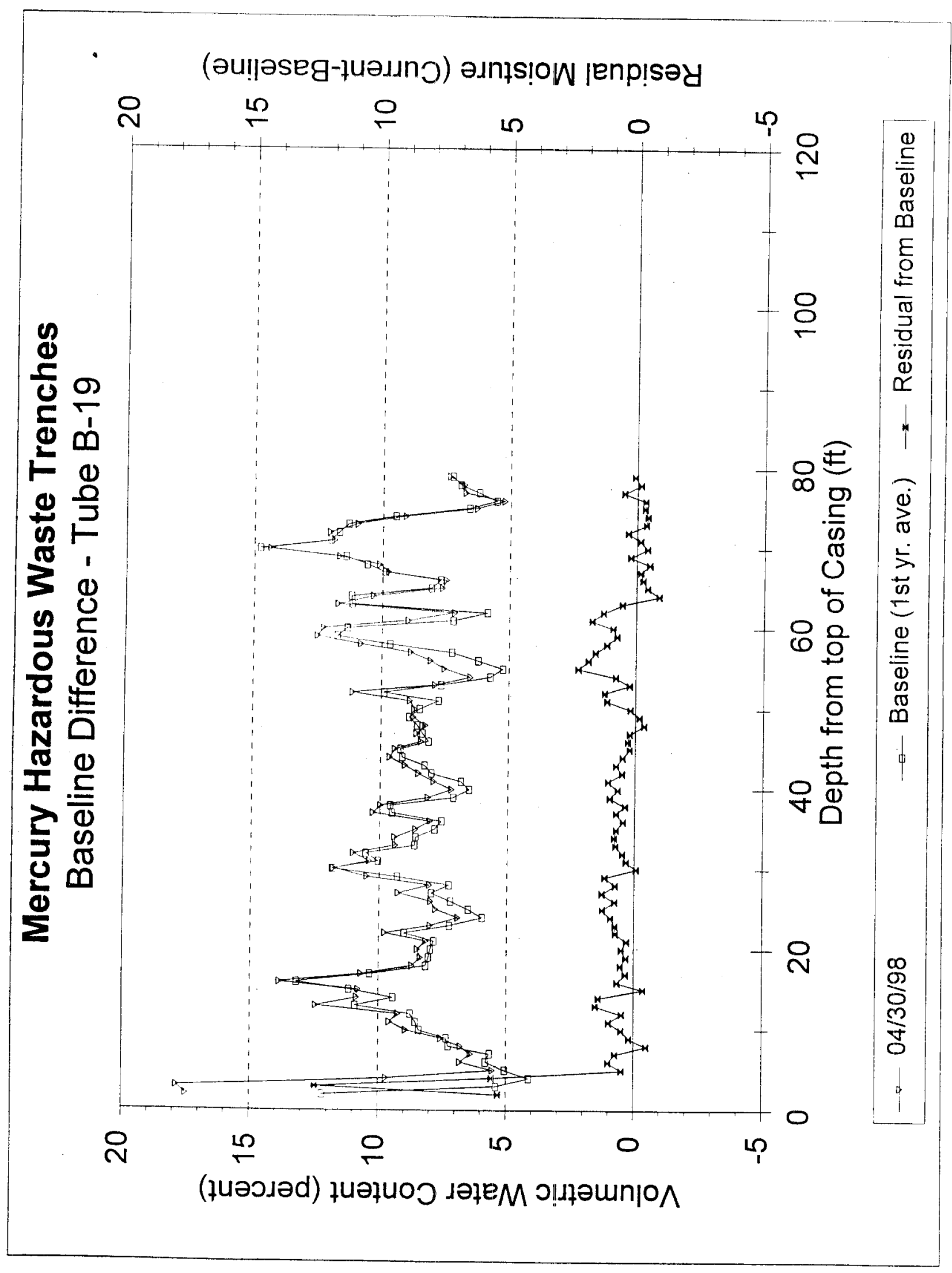




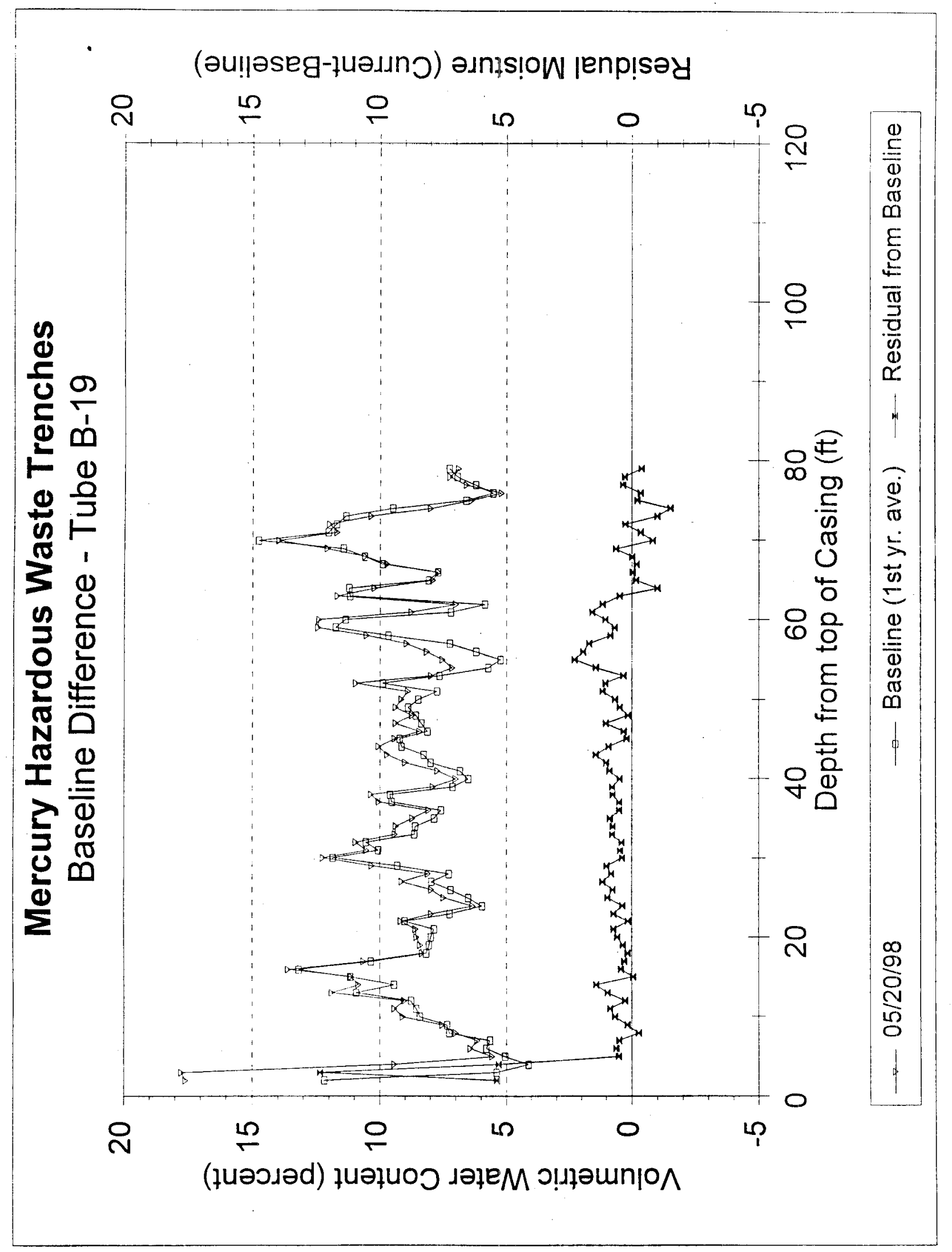




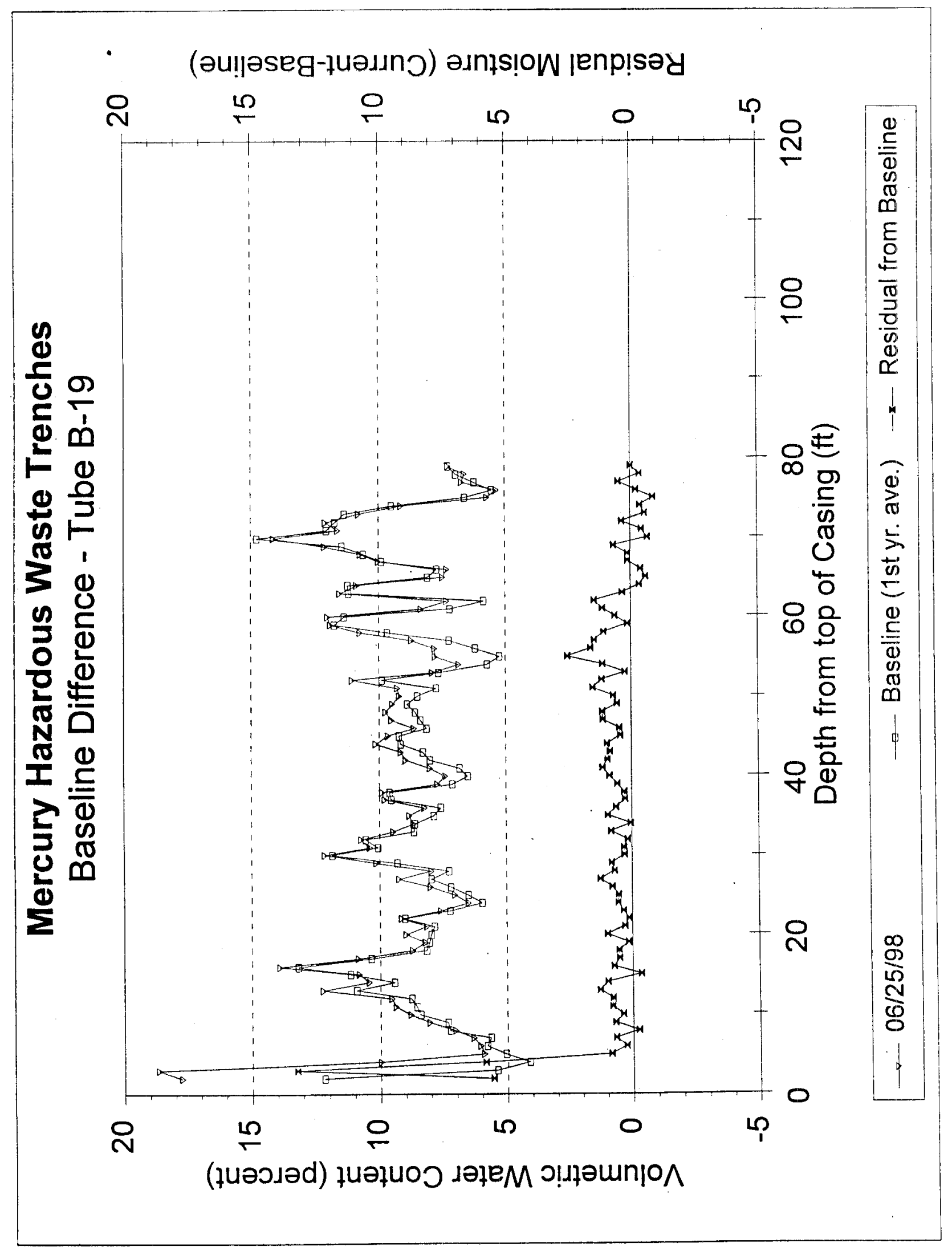




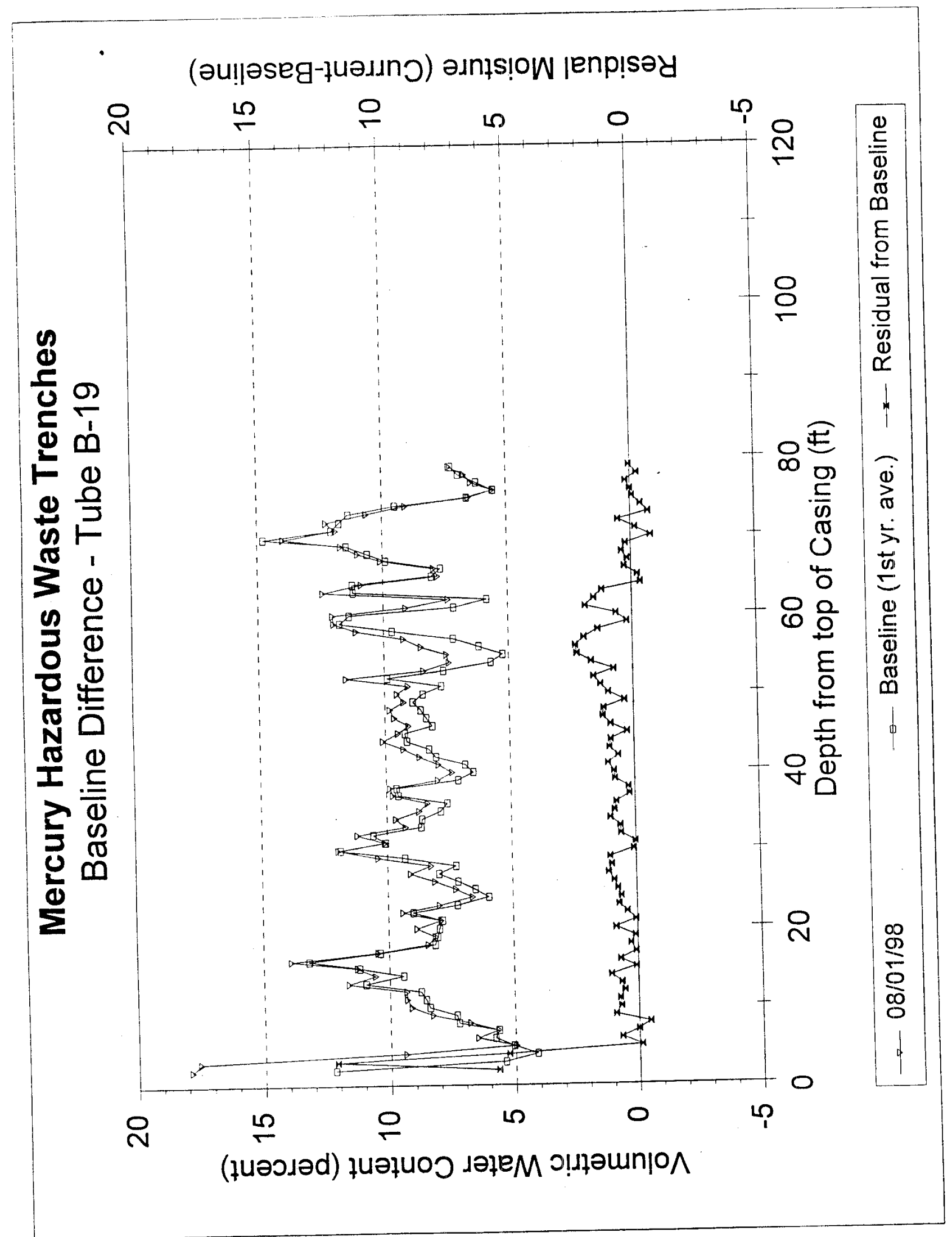




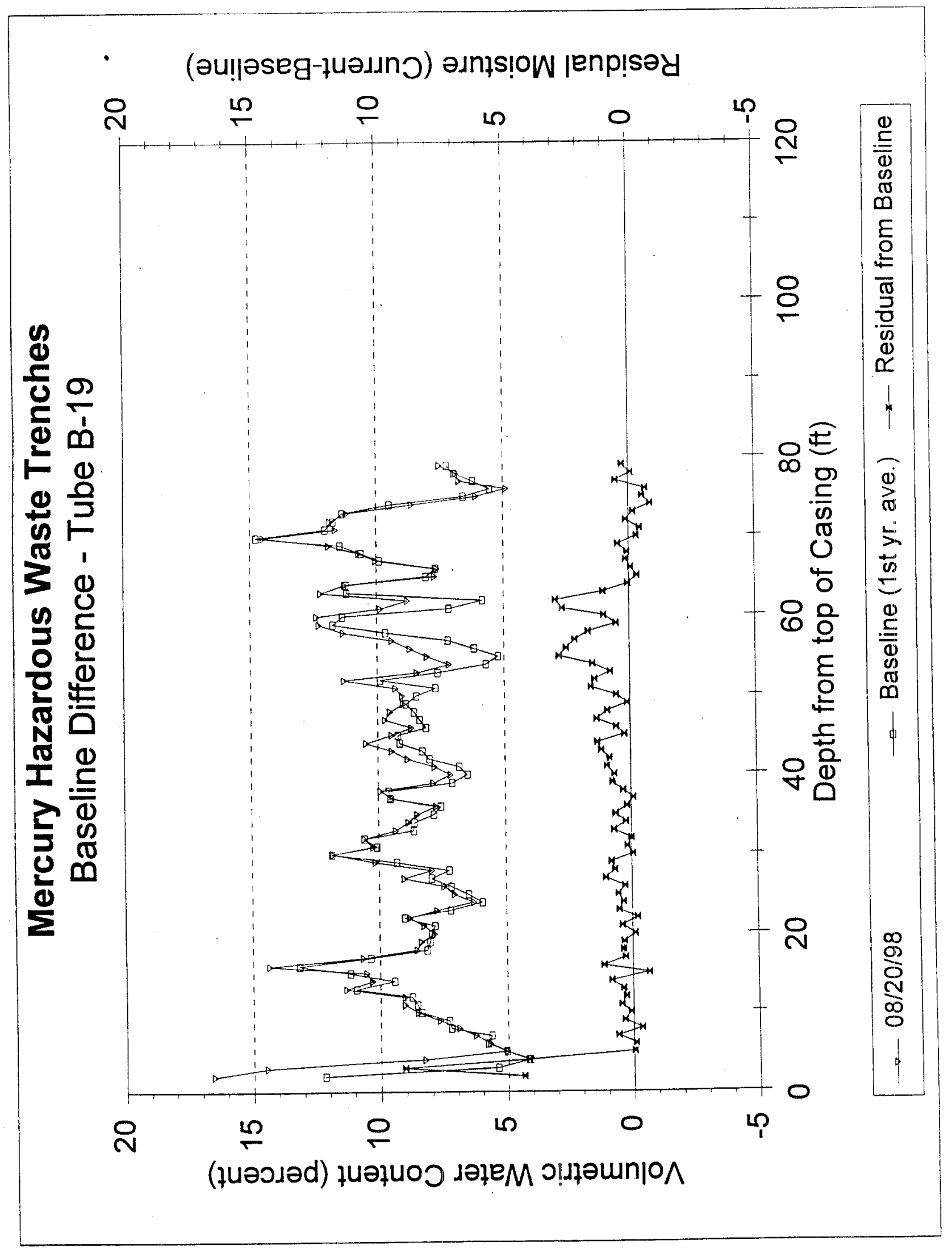




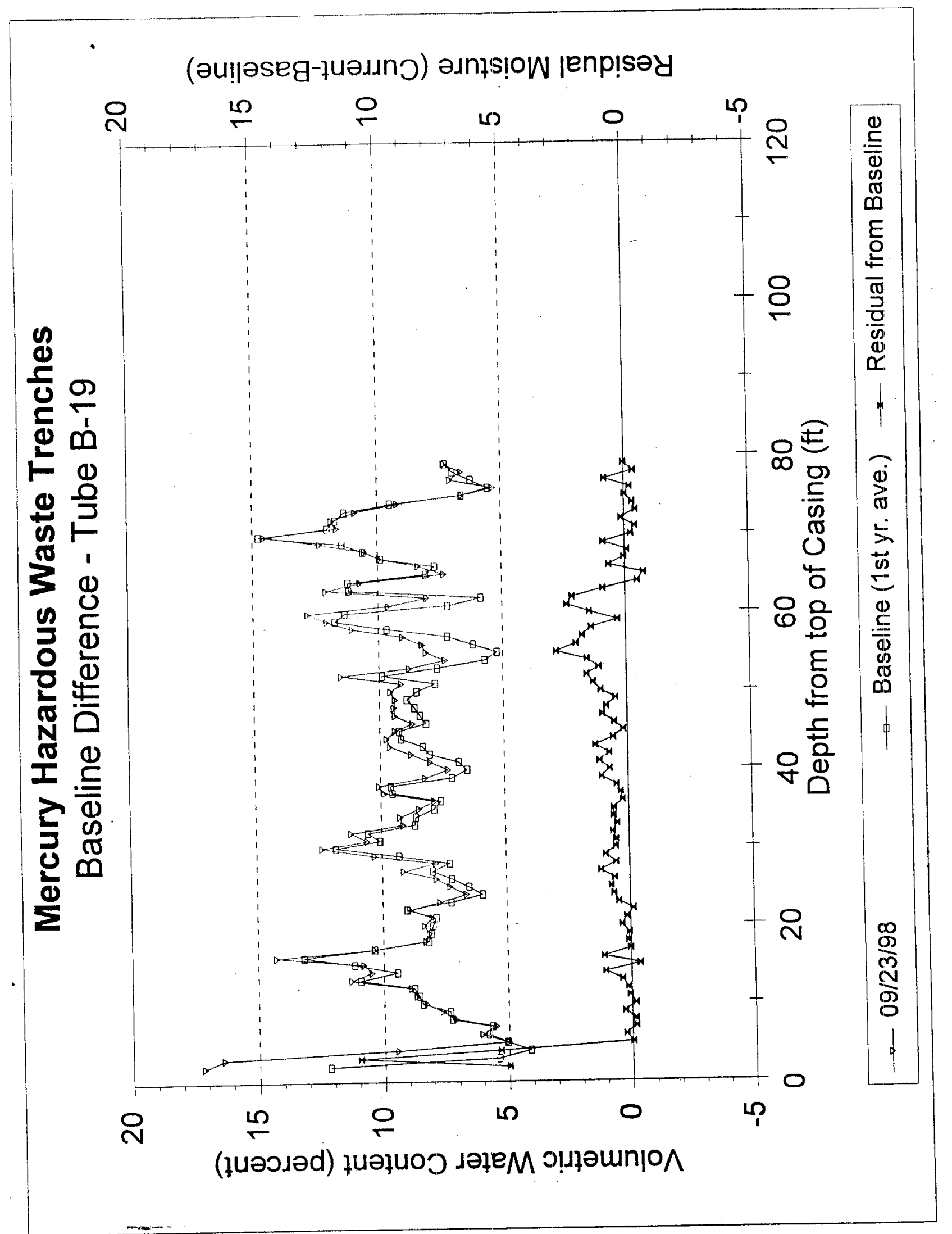




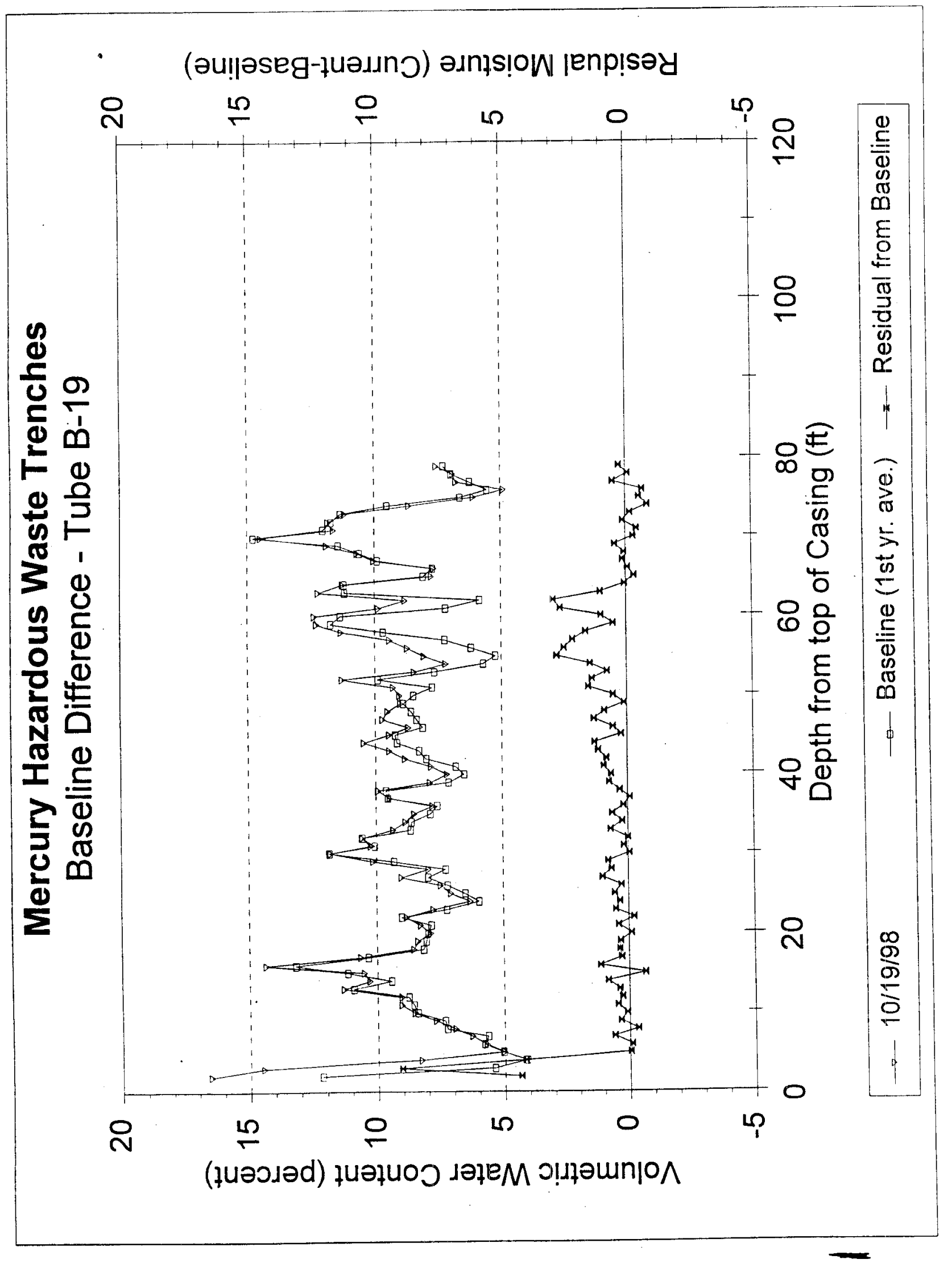




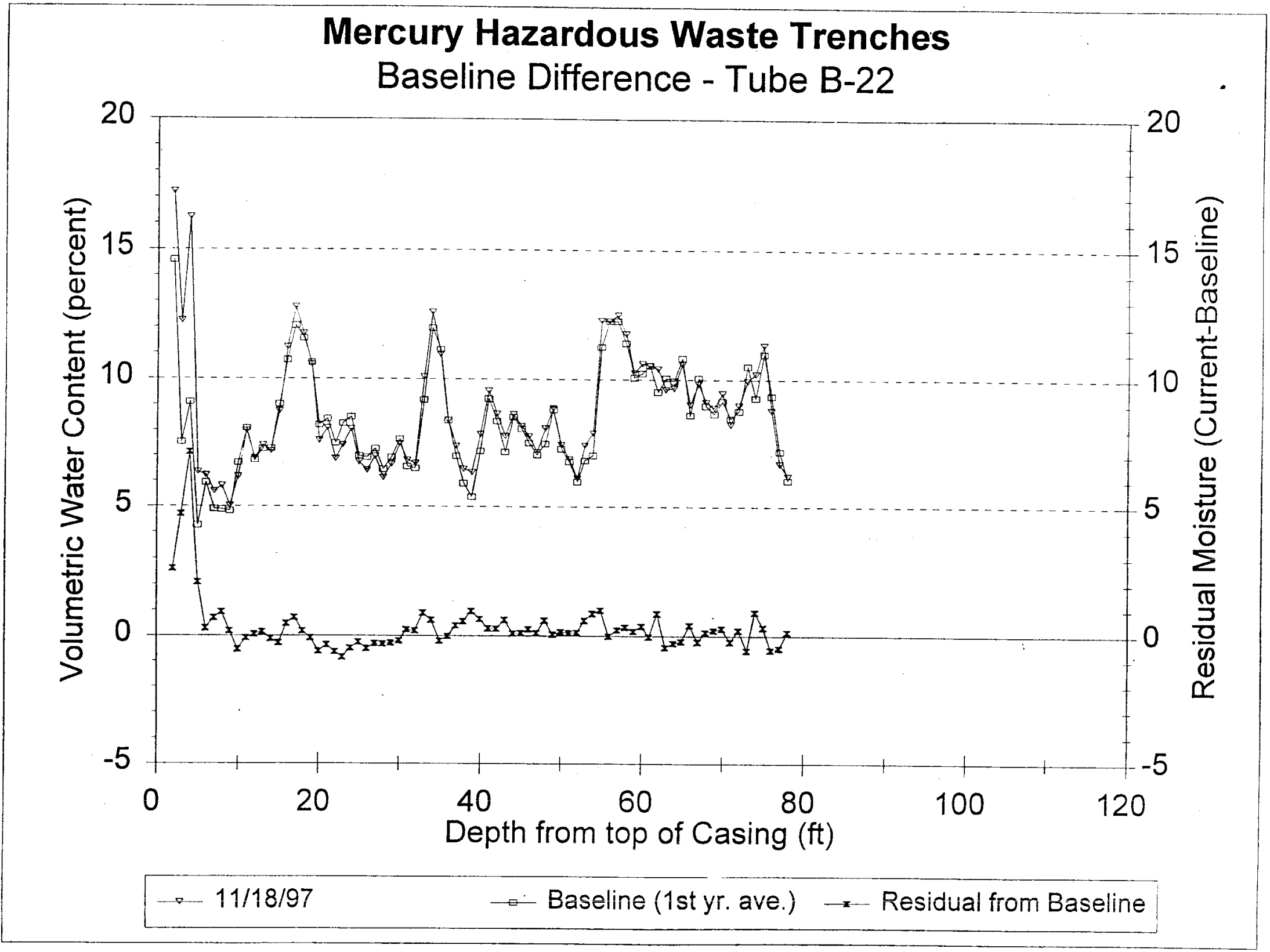




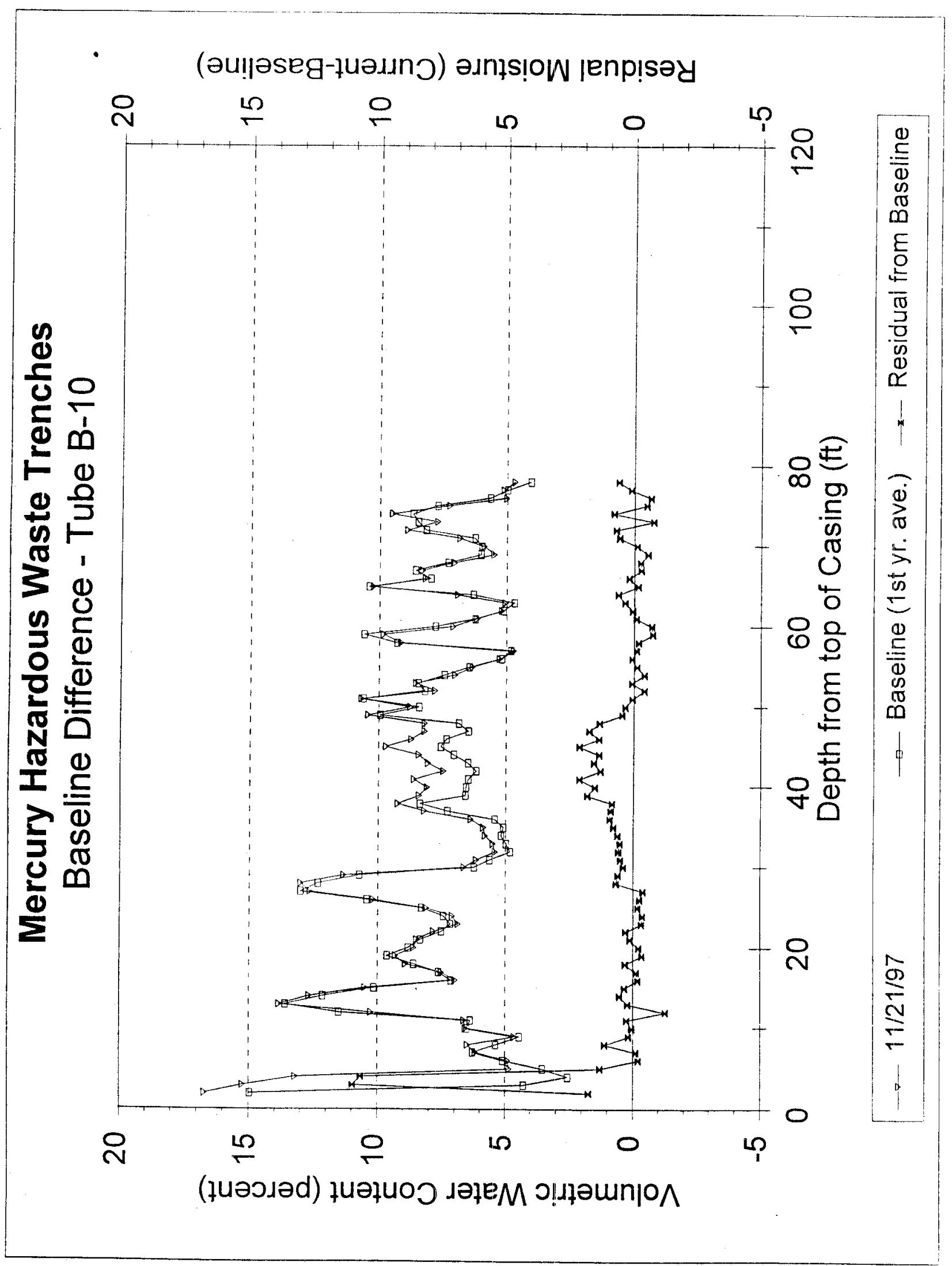




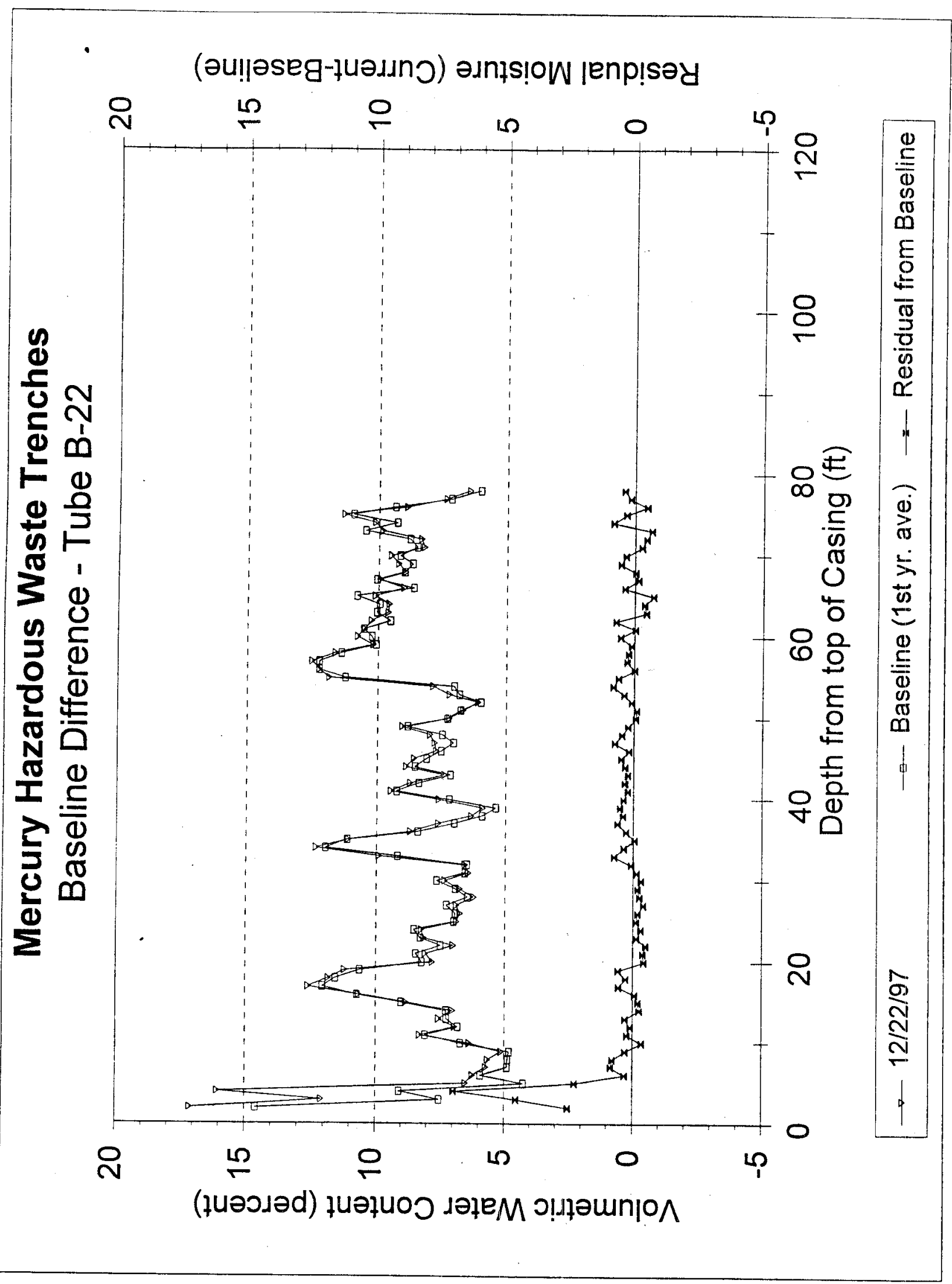




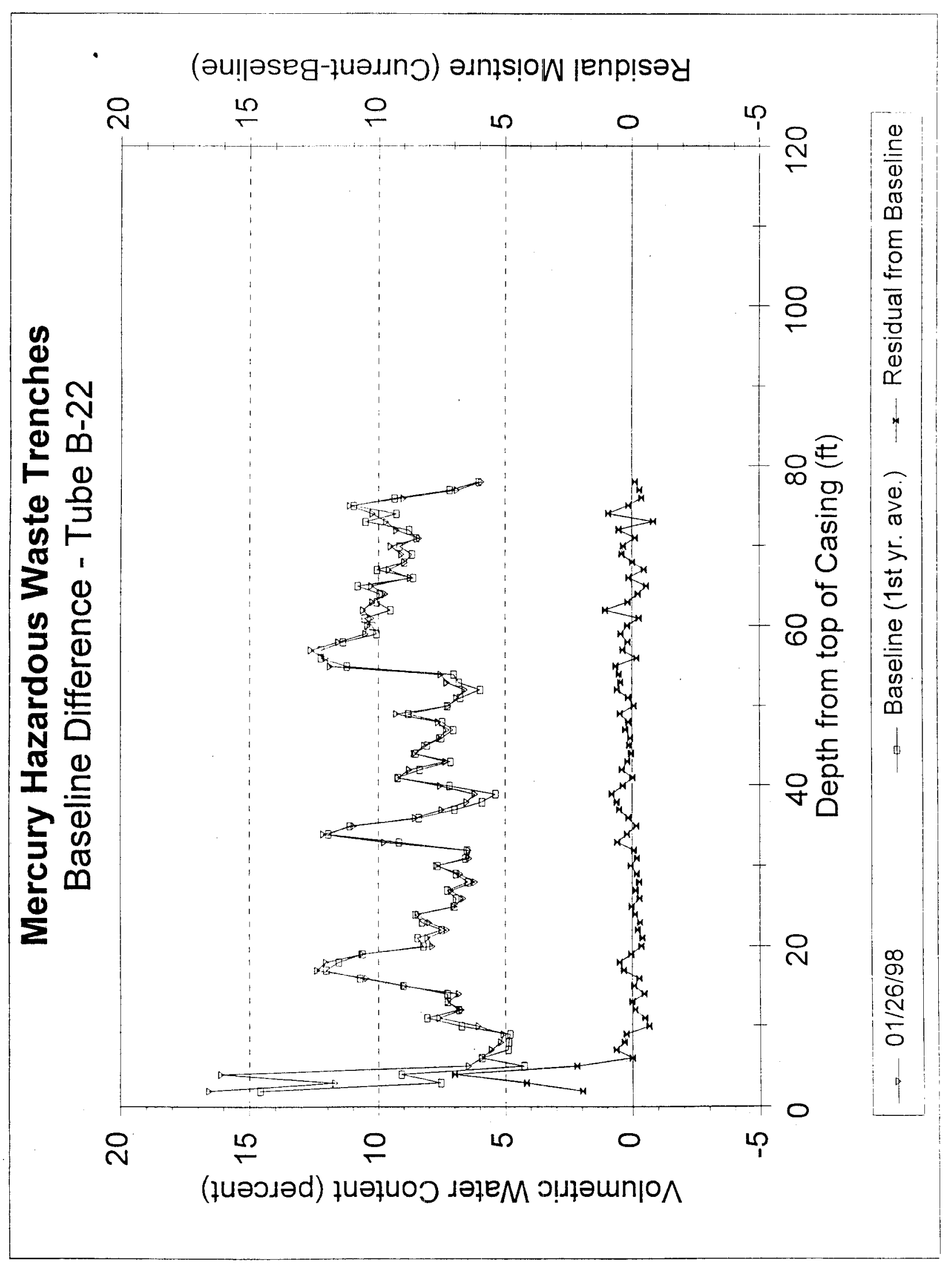




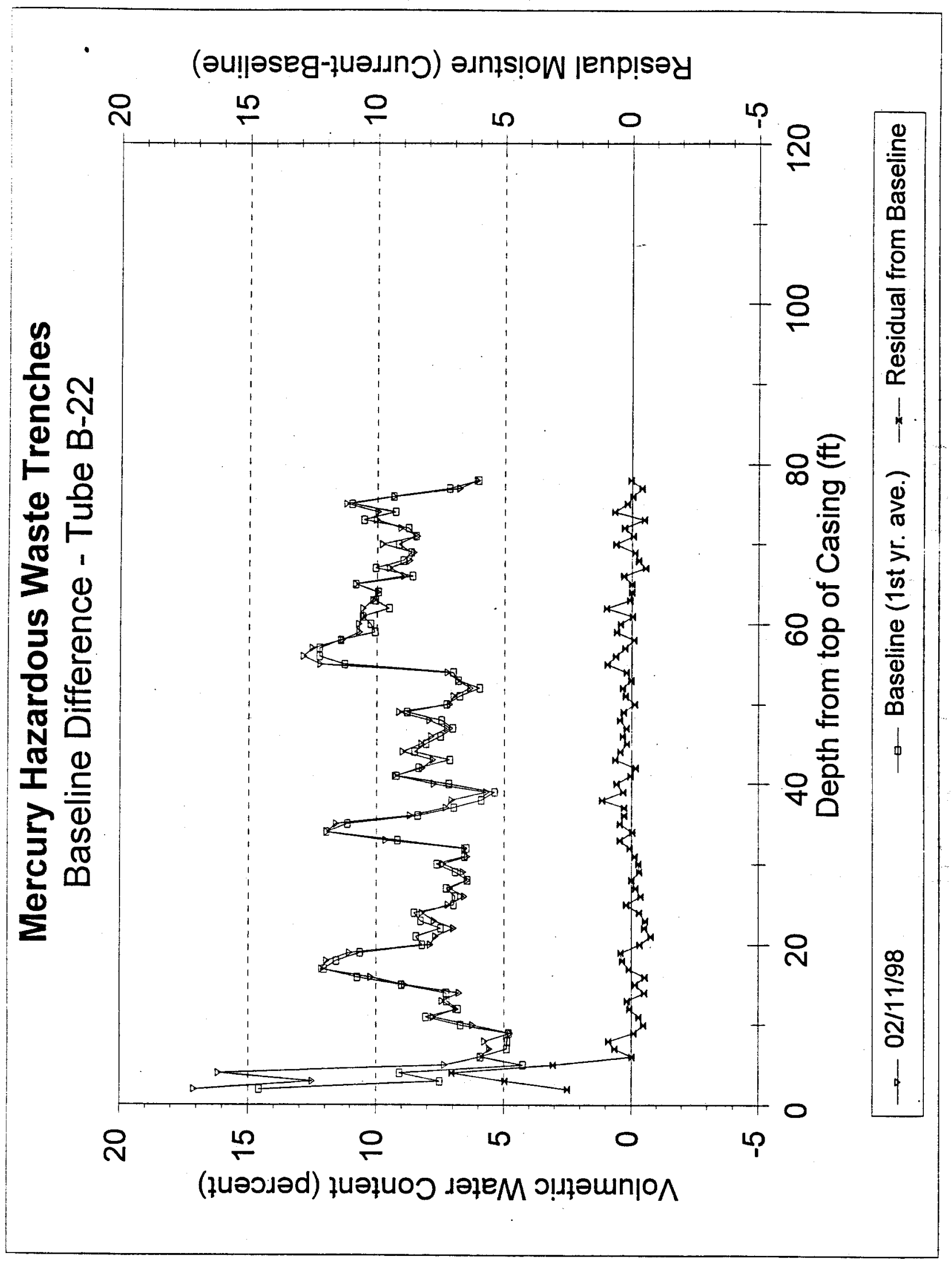




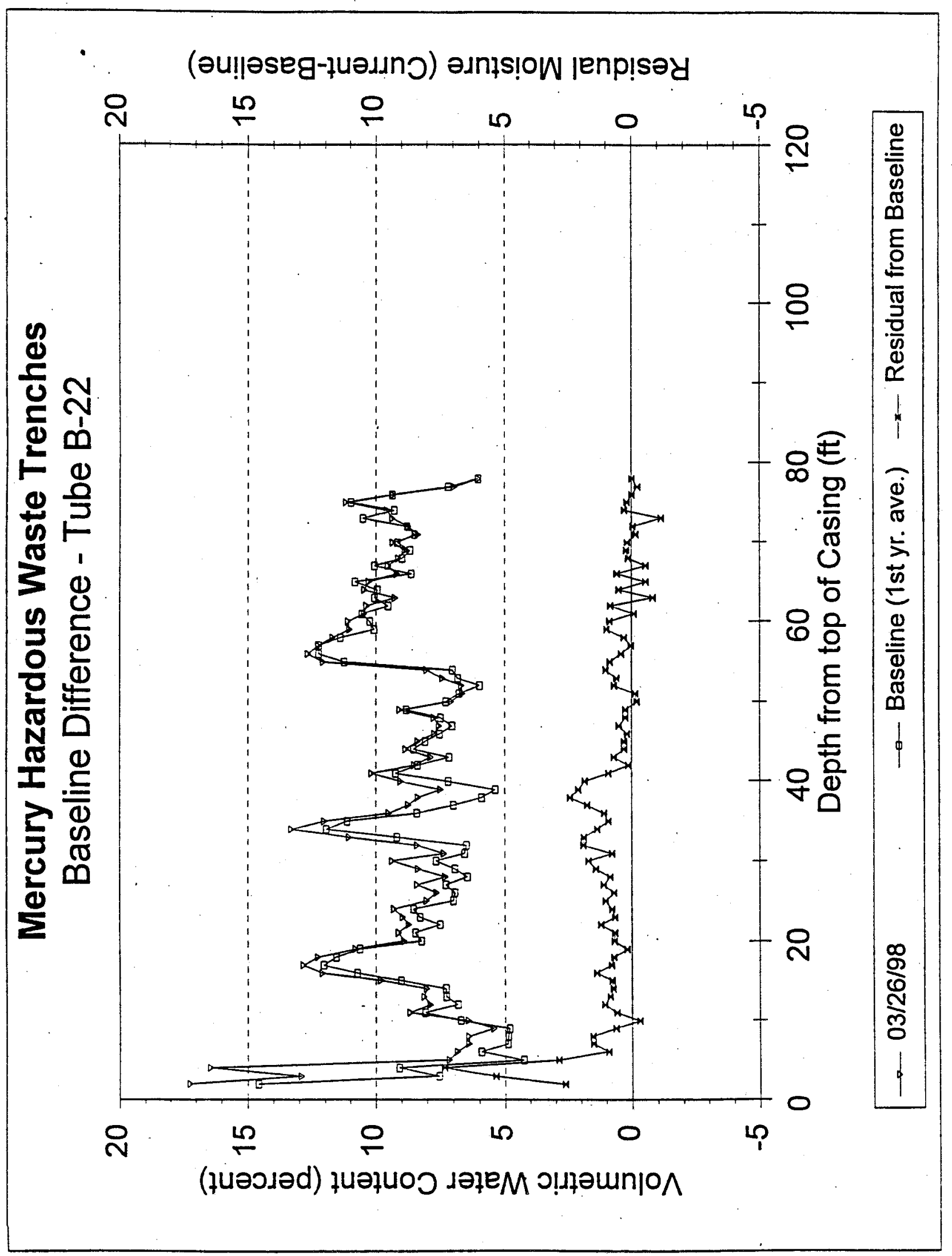




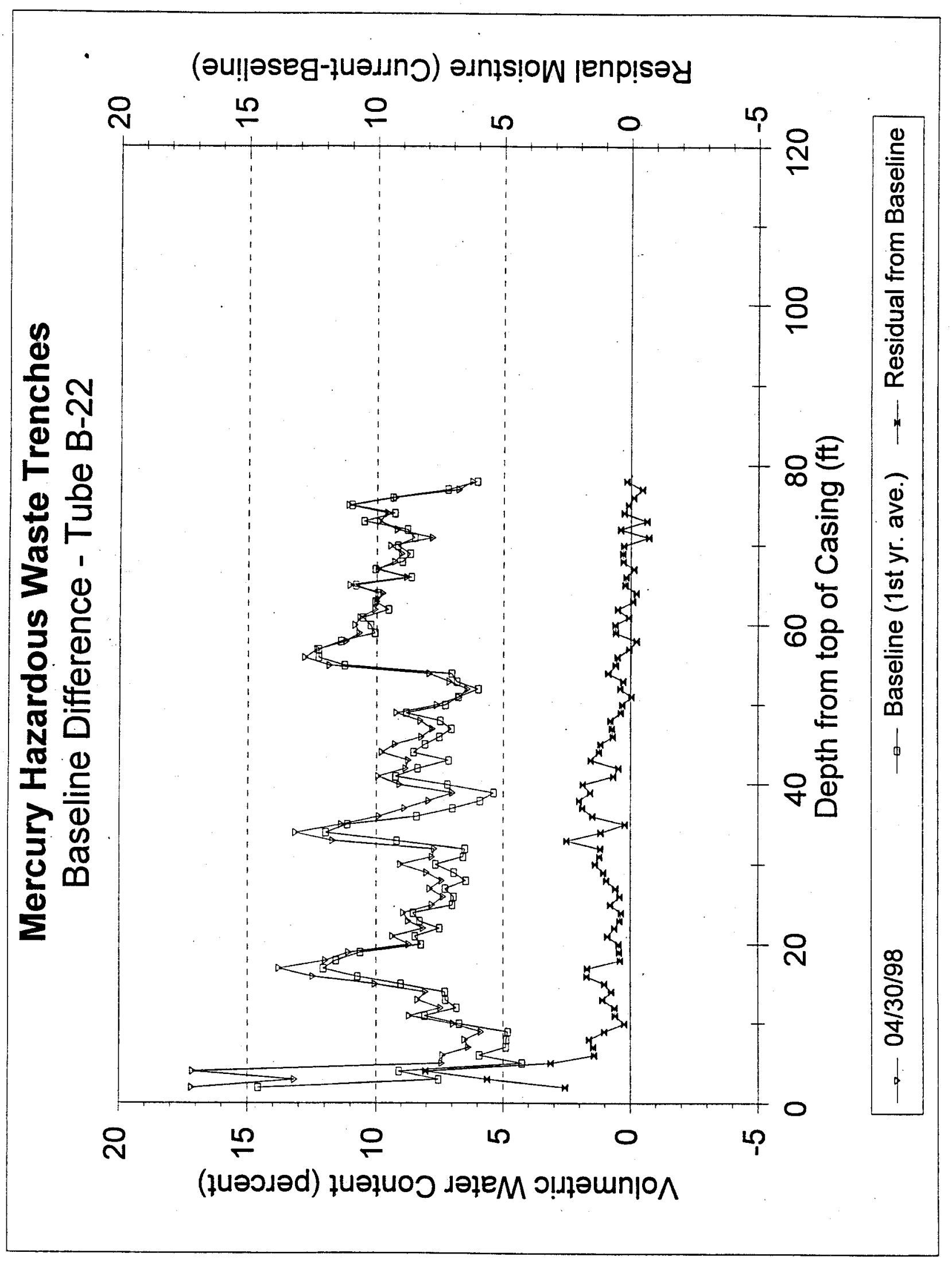




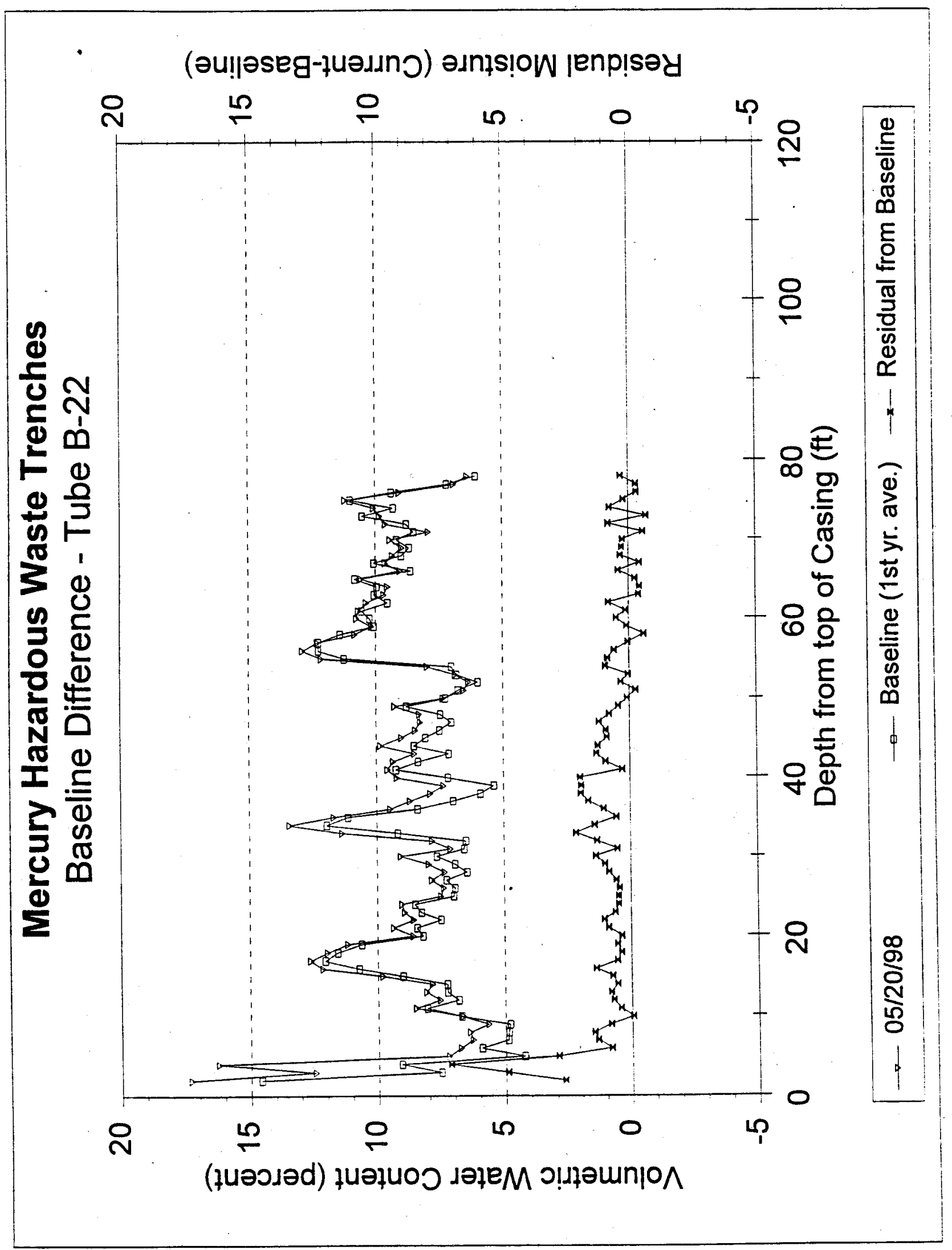




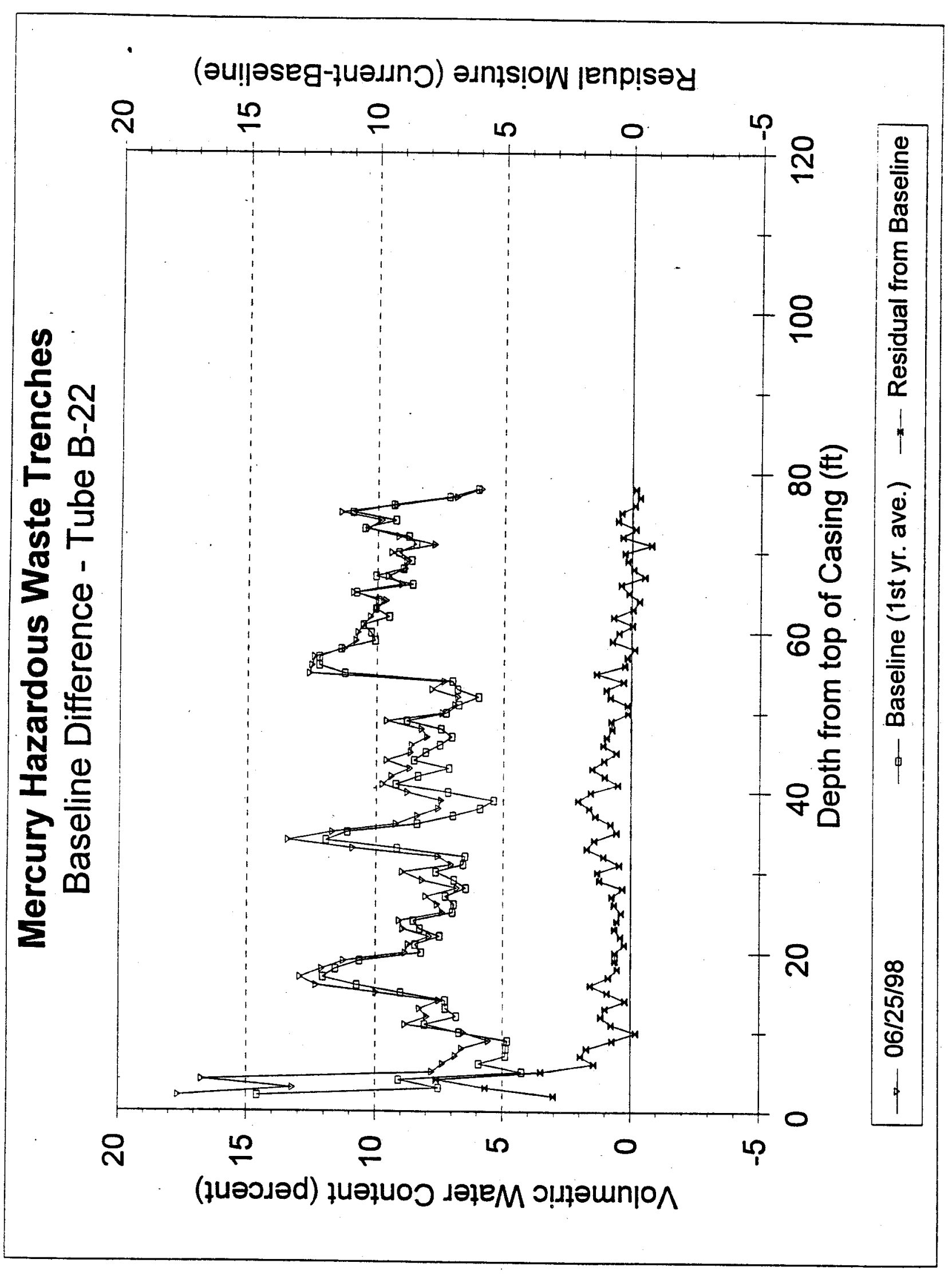




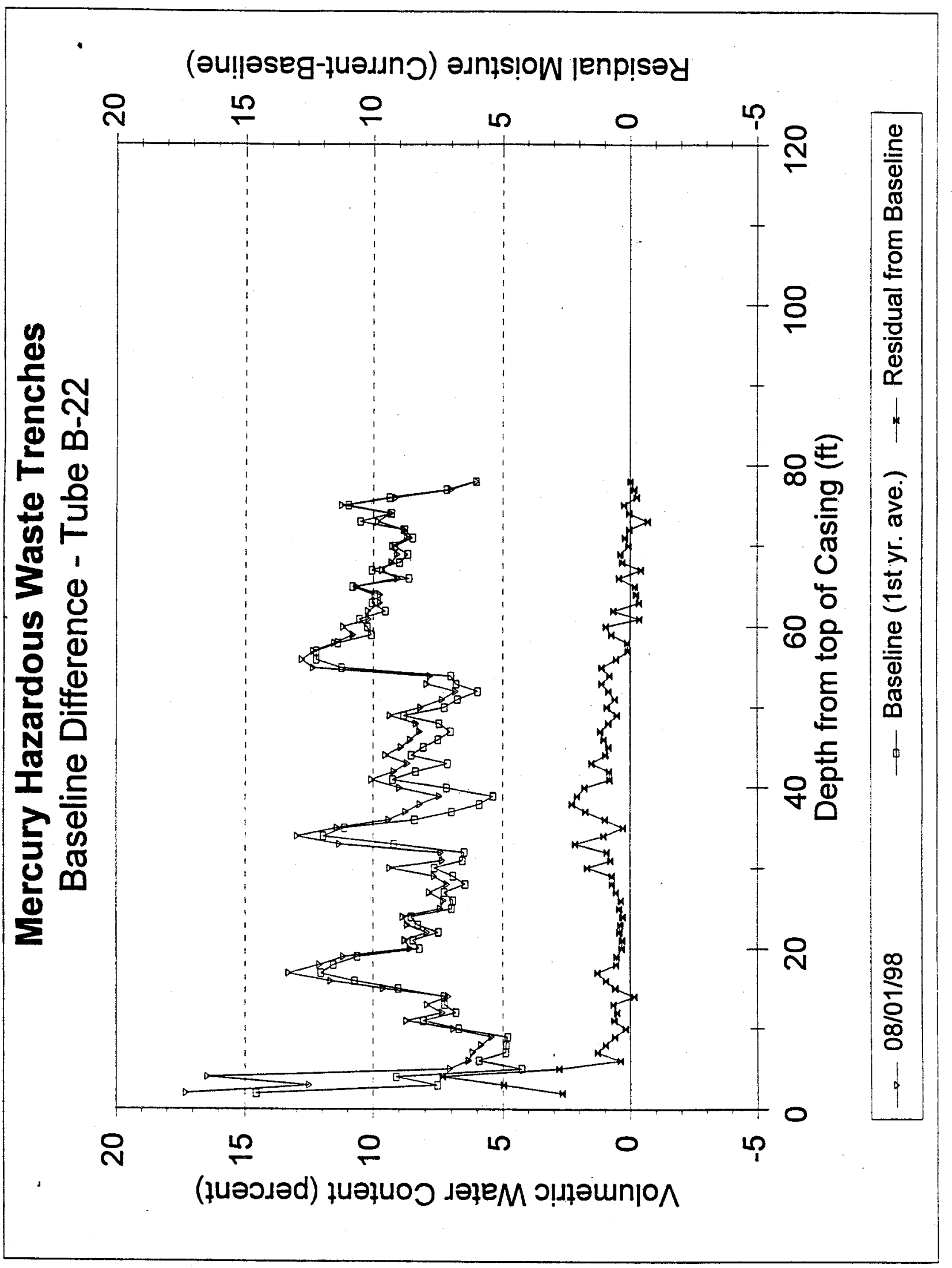




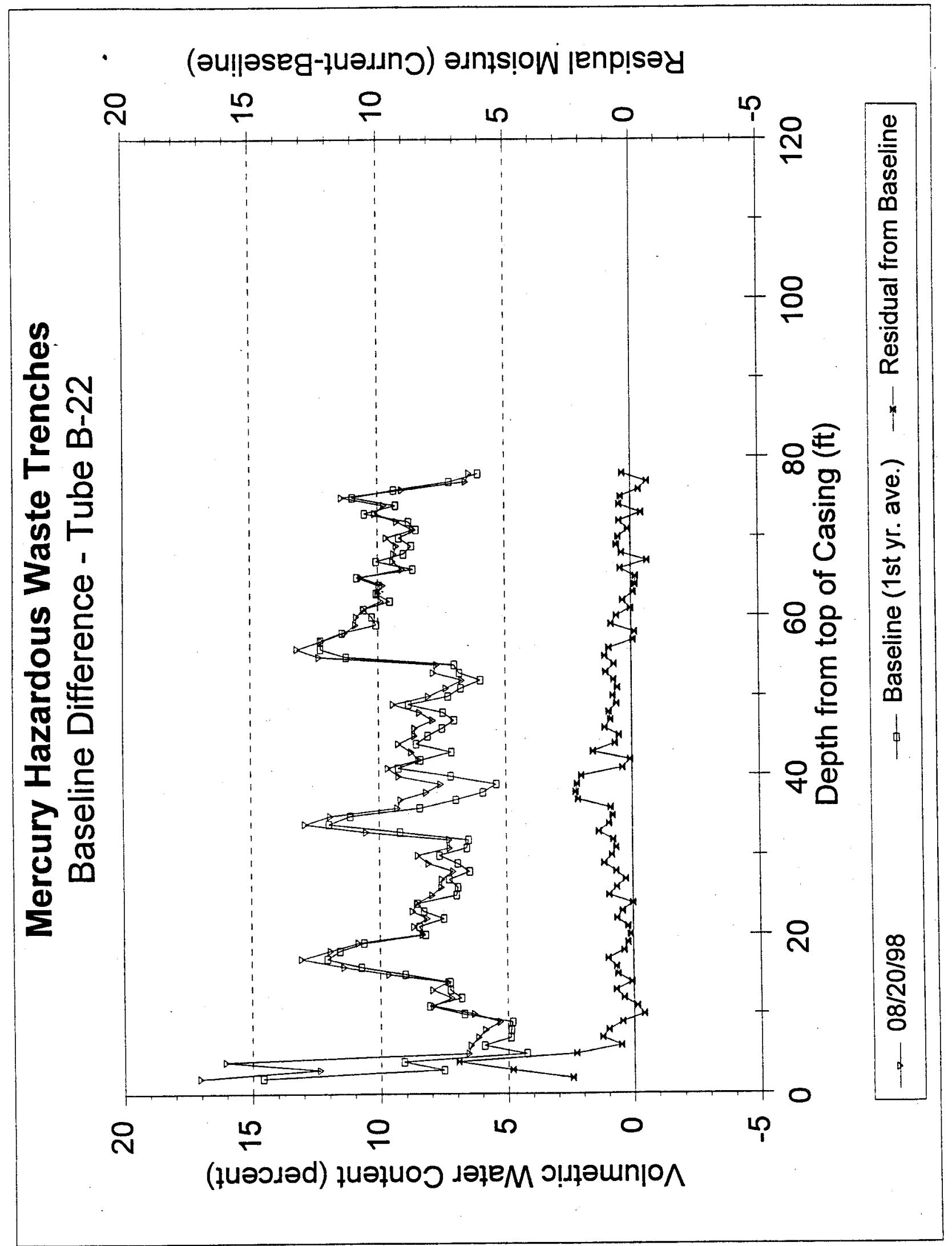




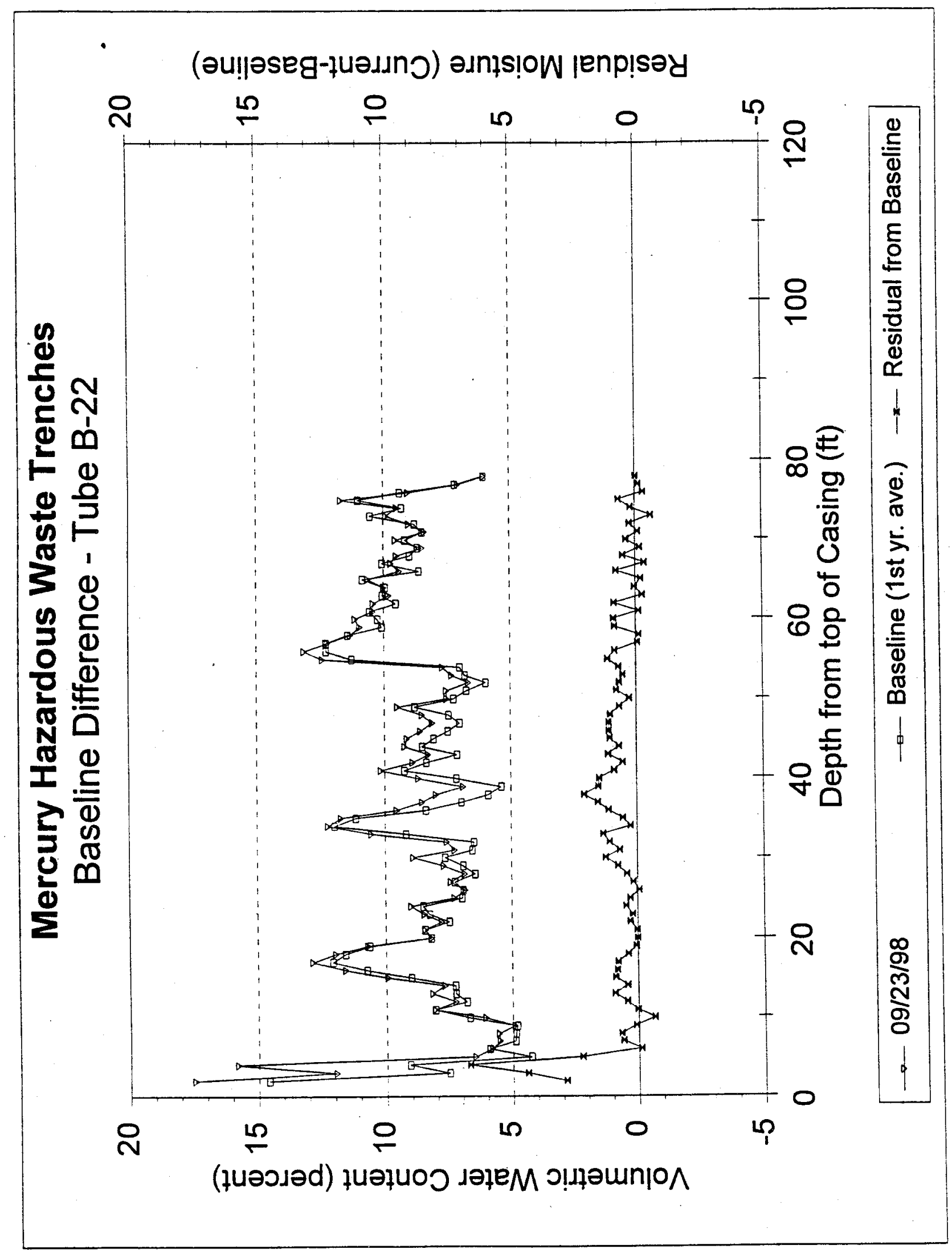




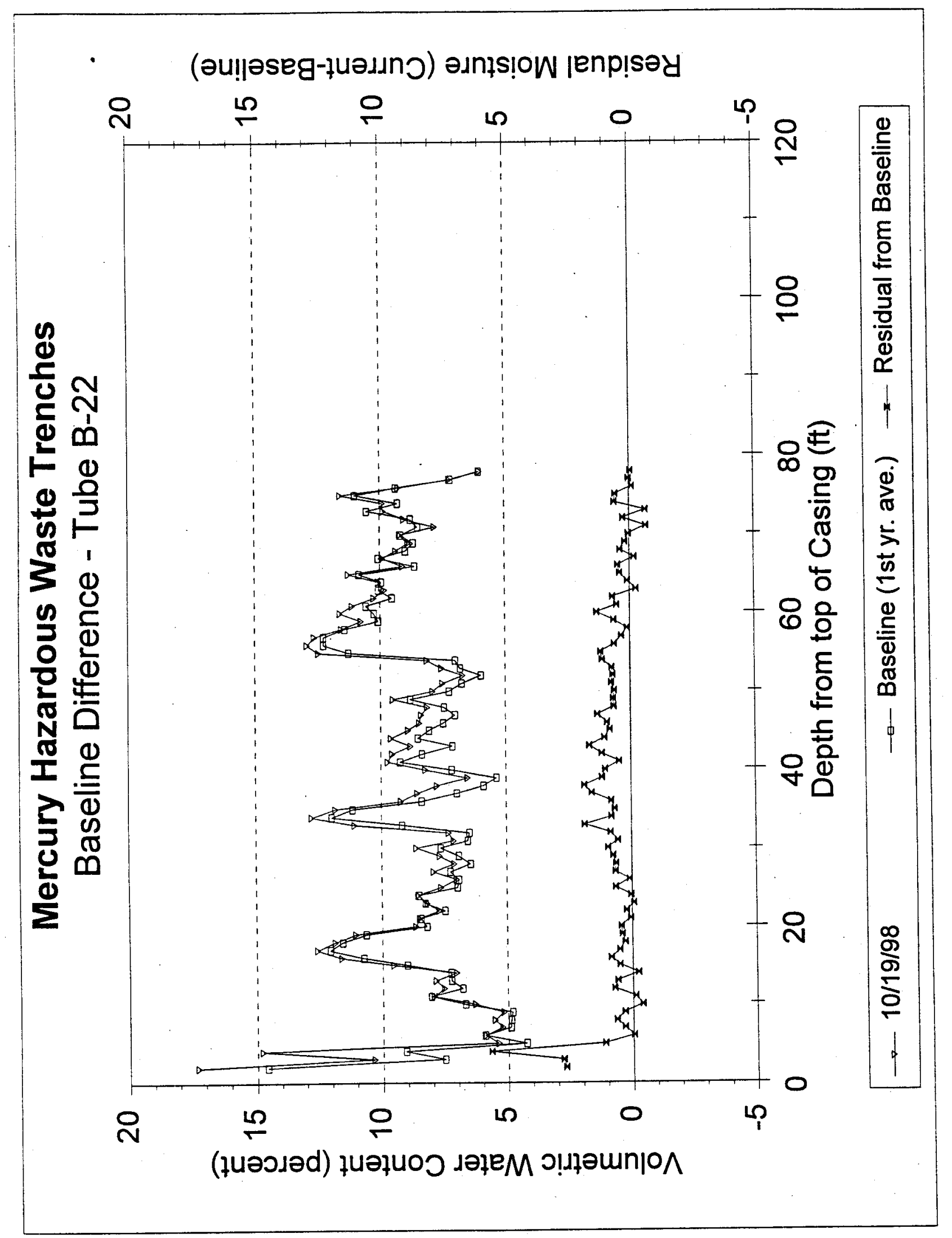




\section{BASELINE DIFFERENCE}

\section{ROW C}




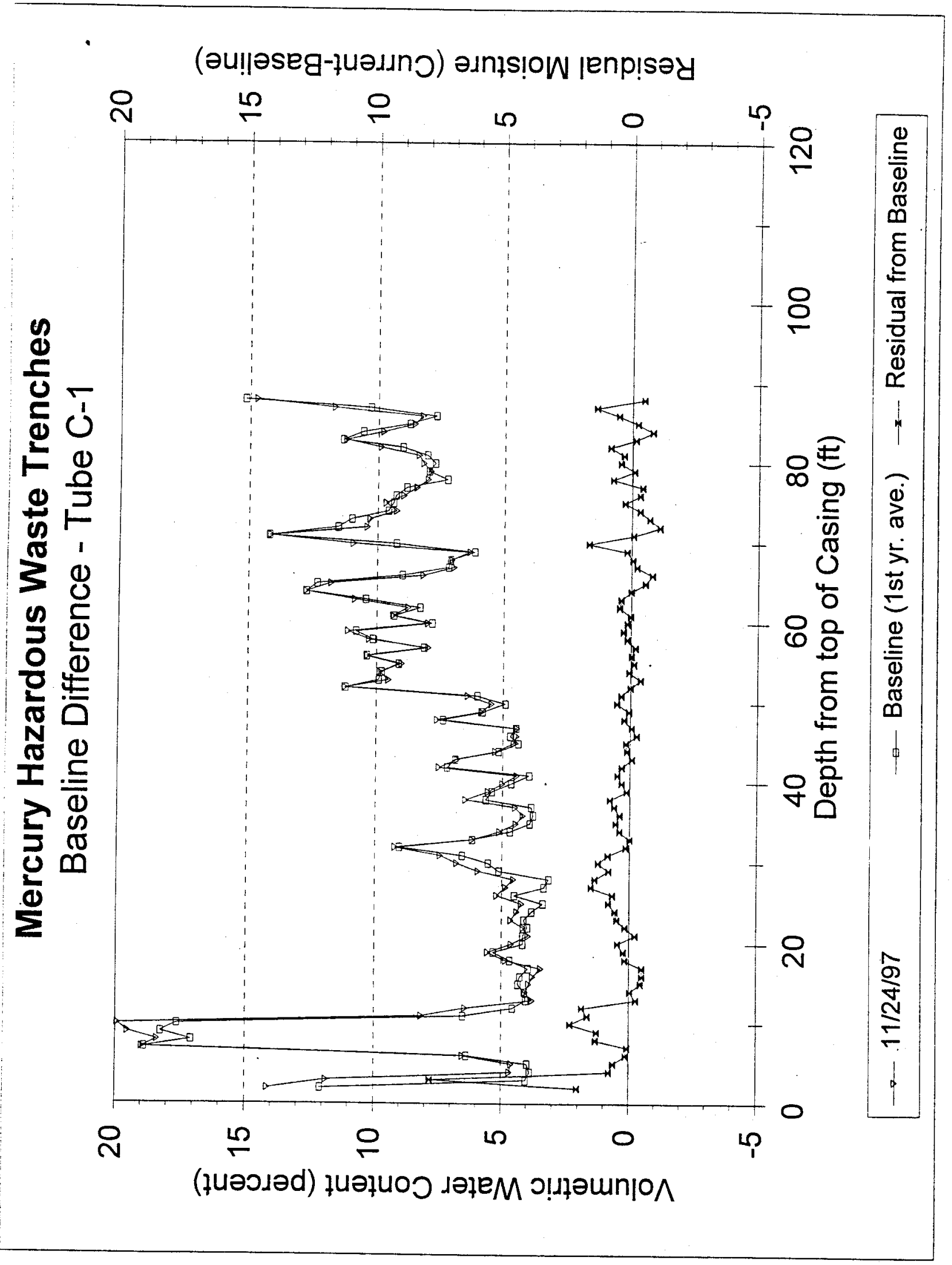




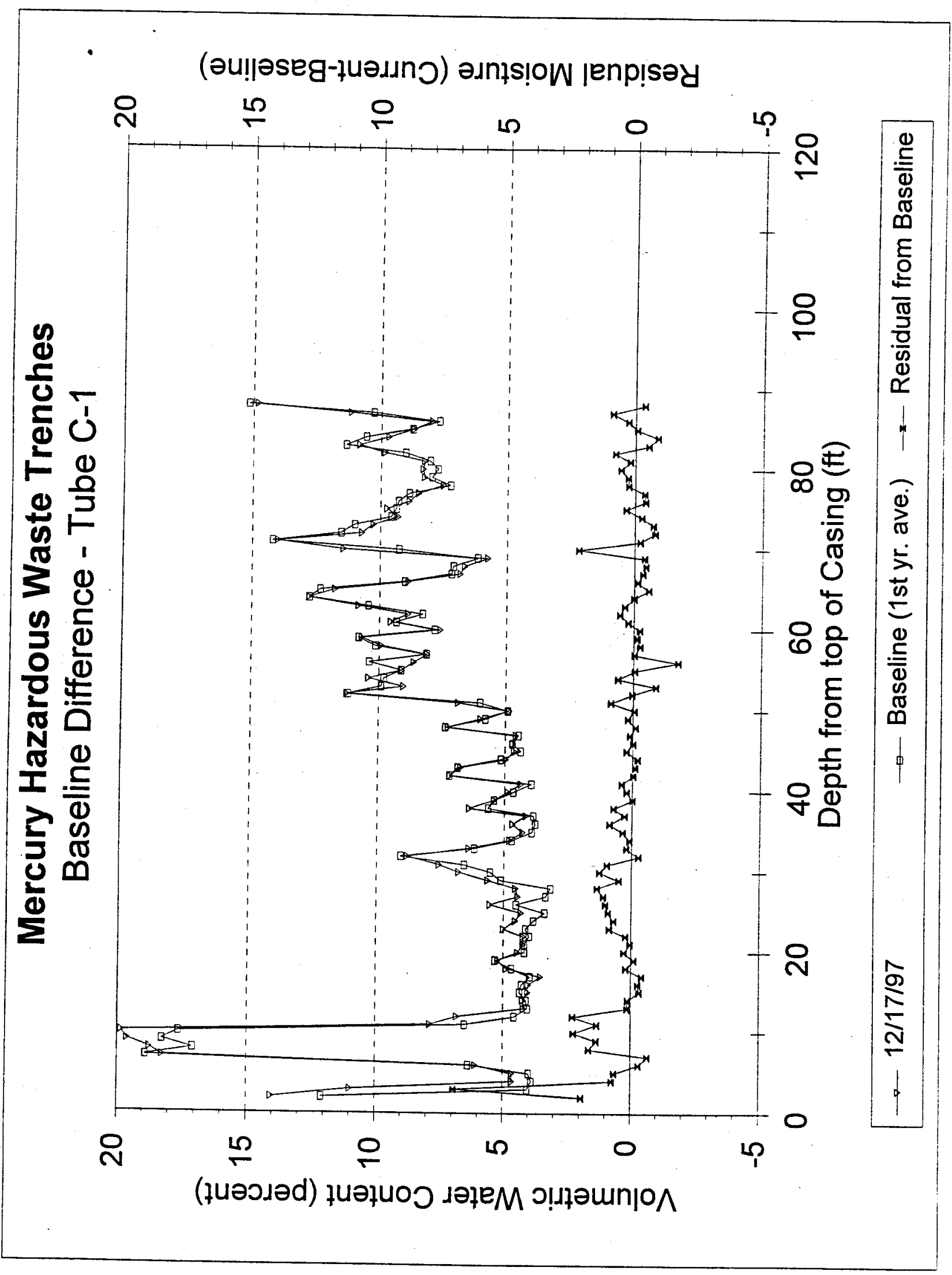




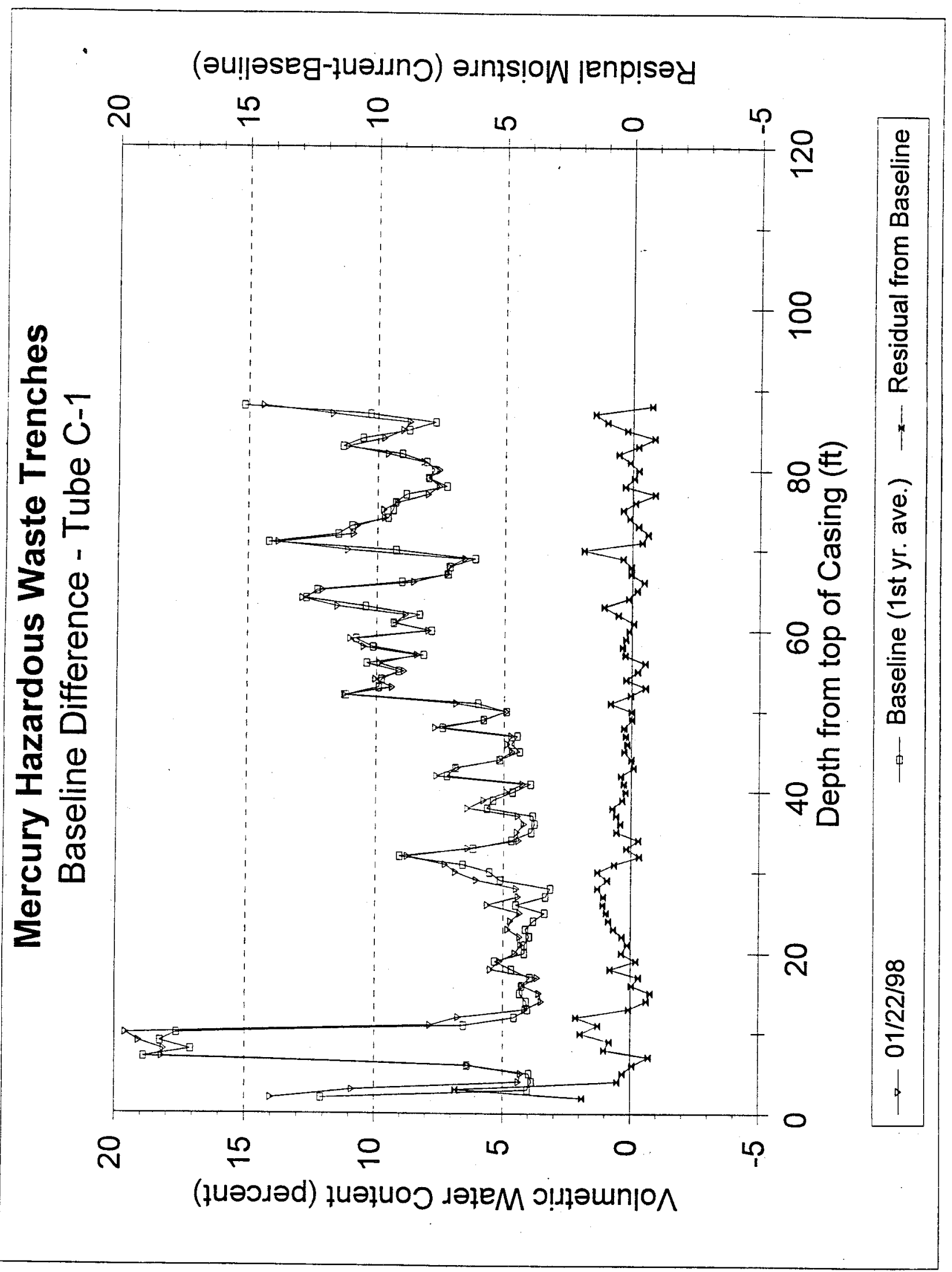




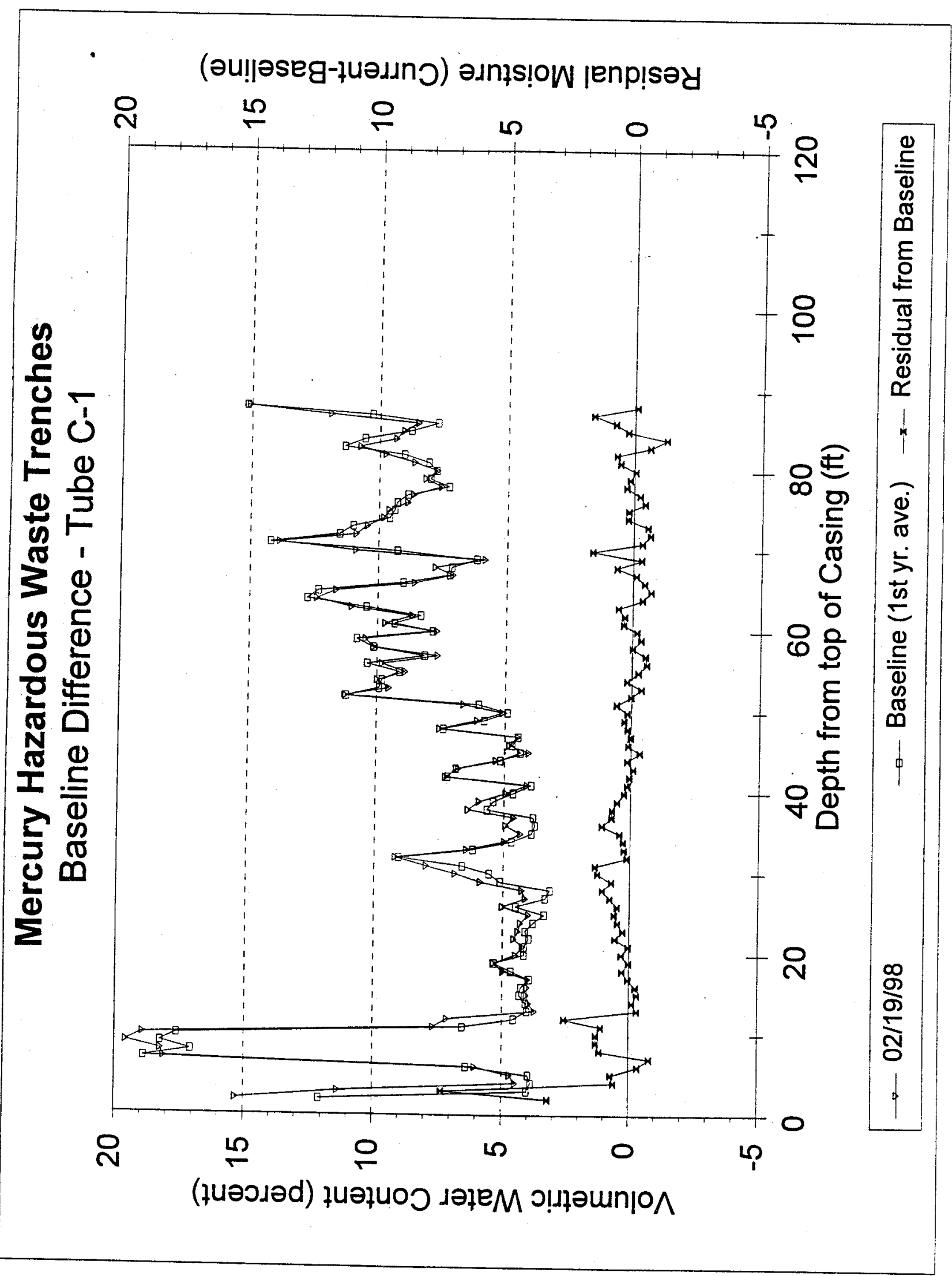




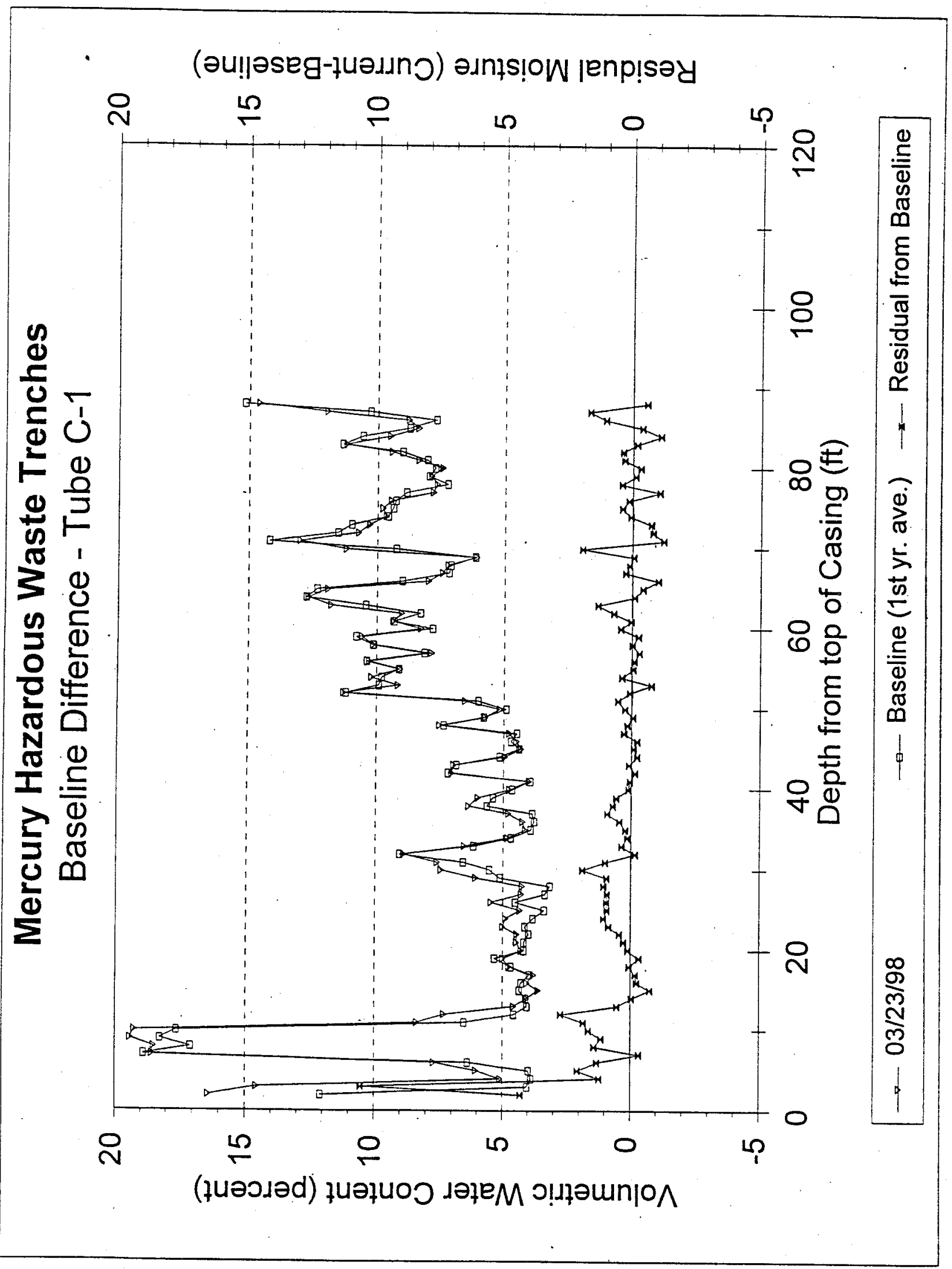




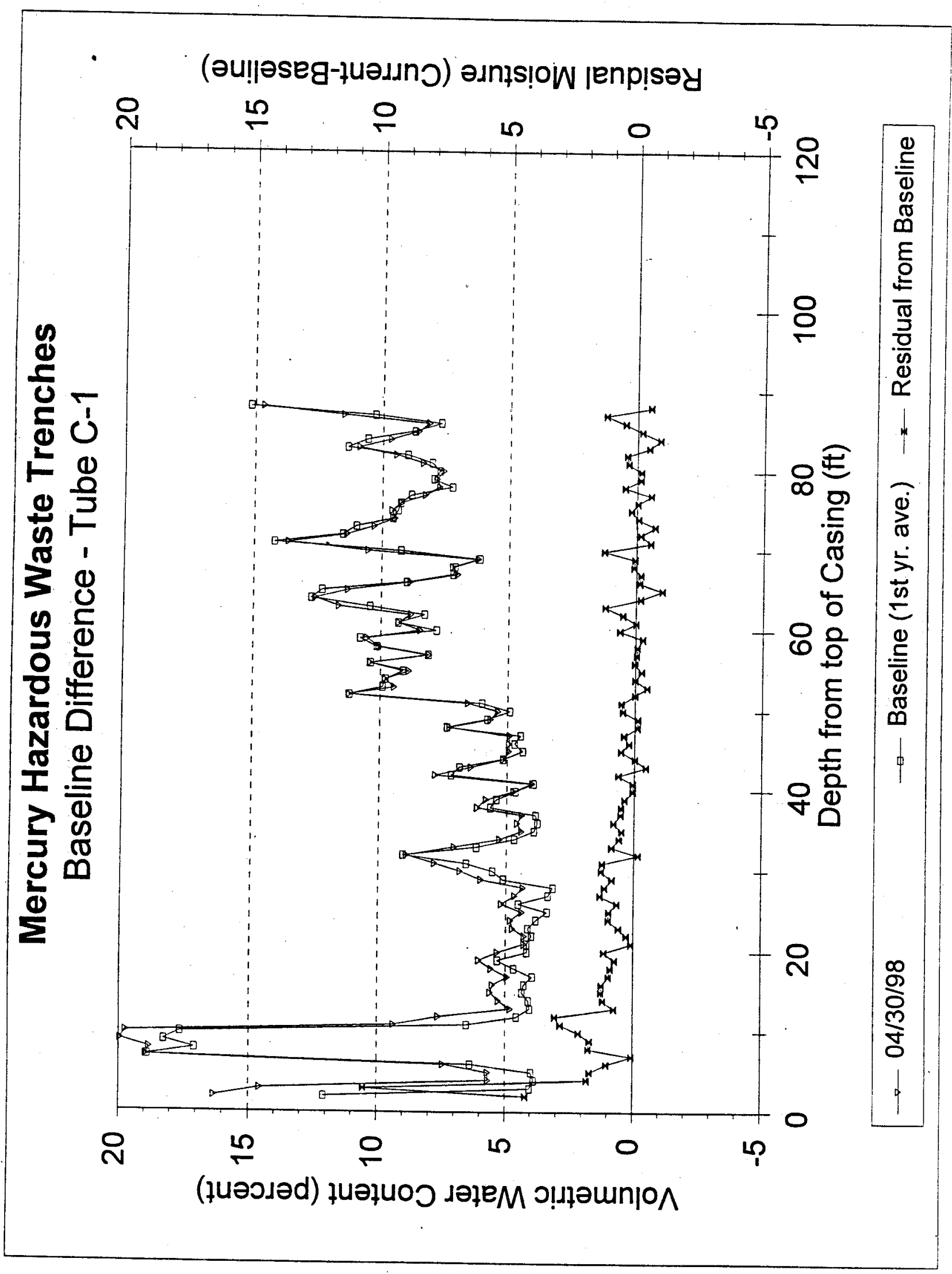




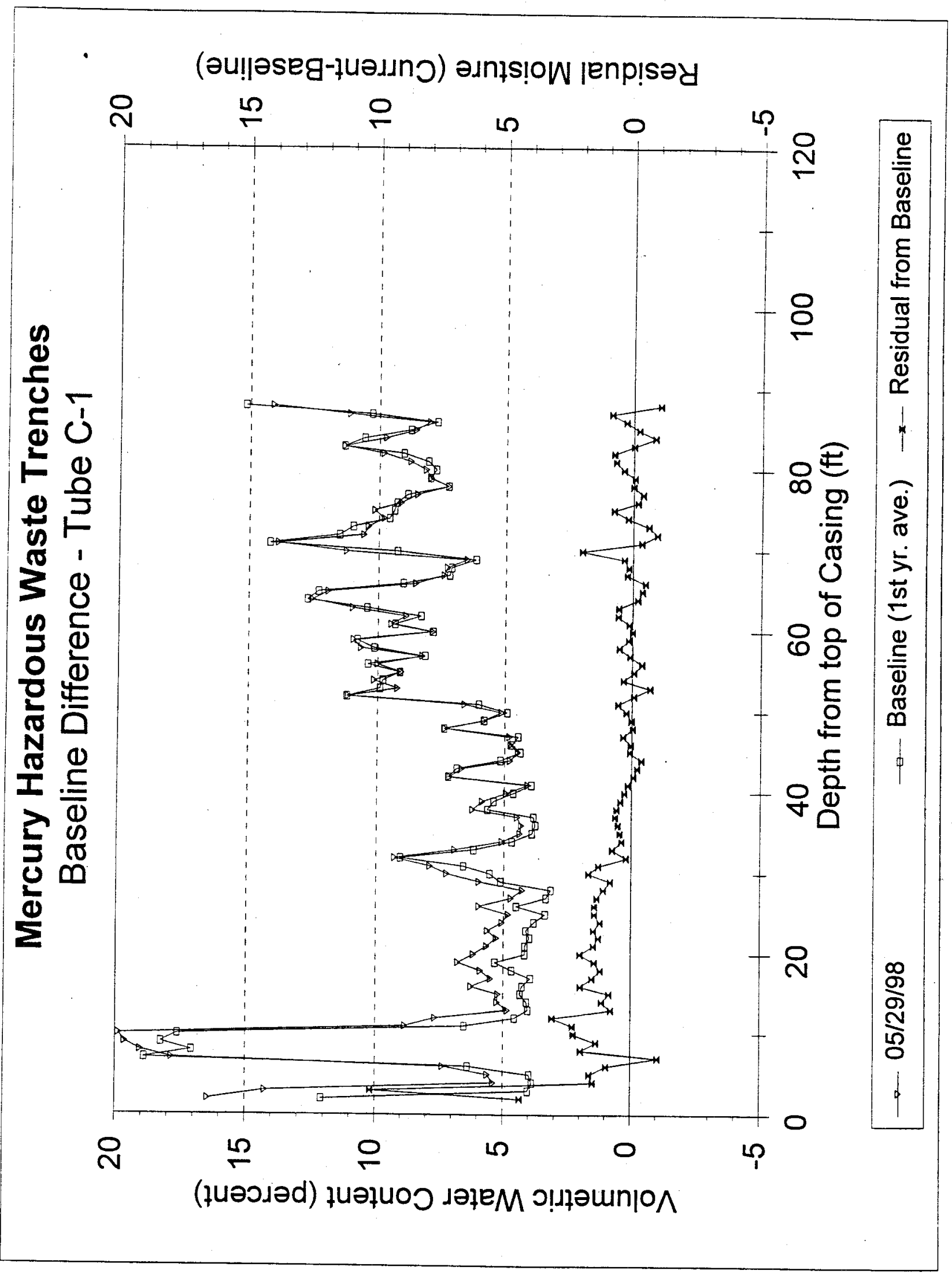




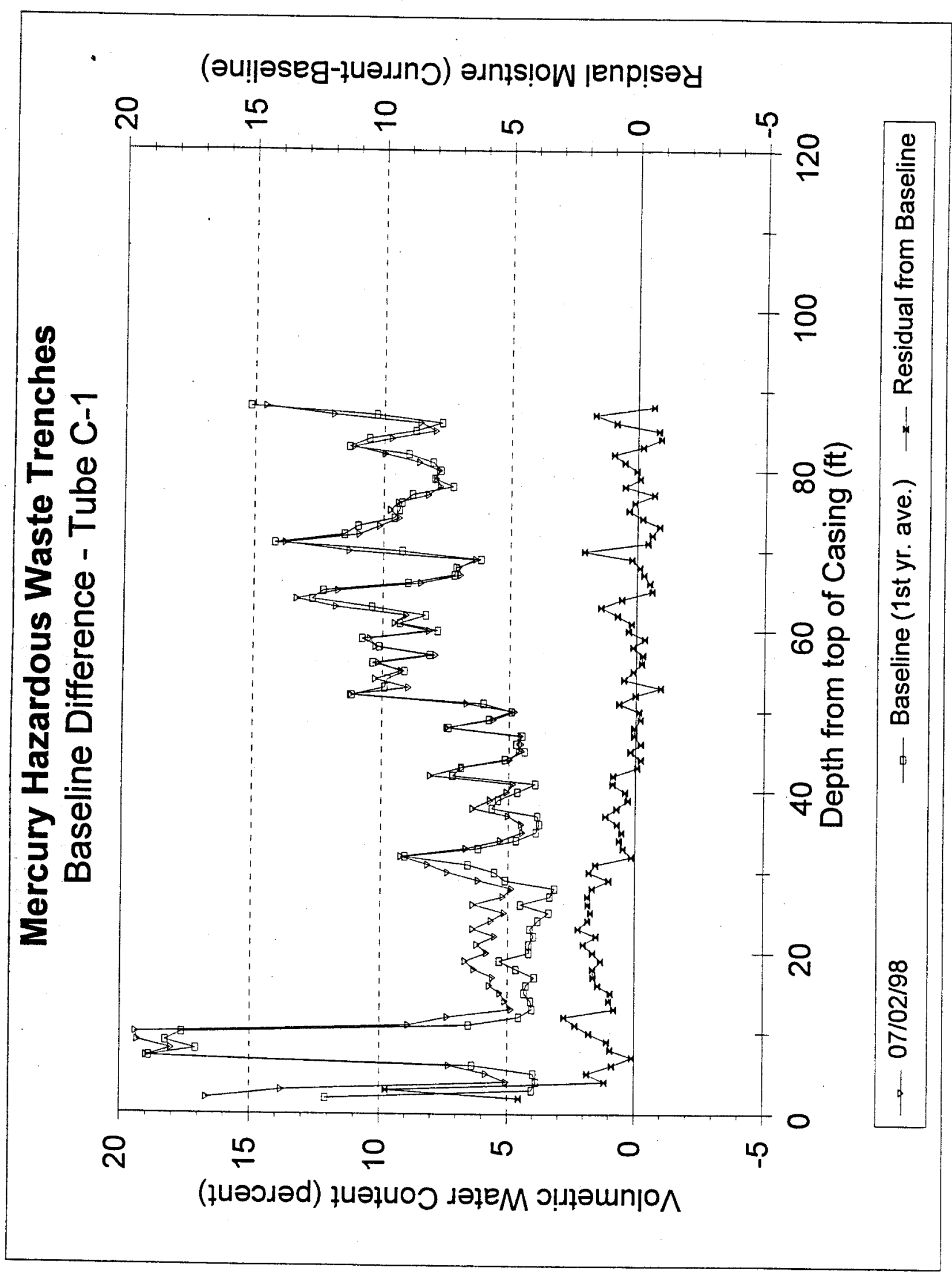




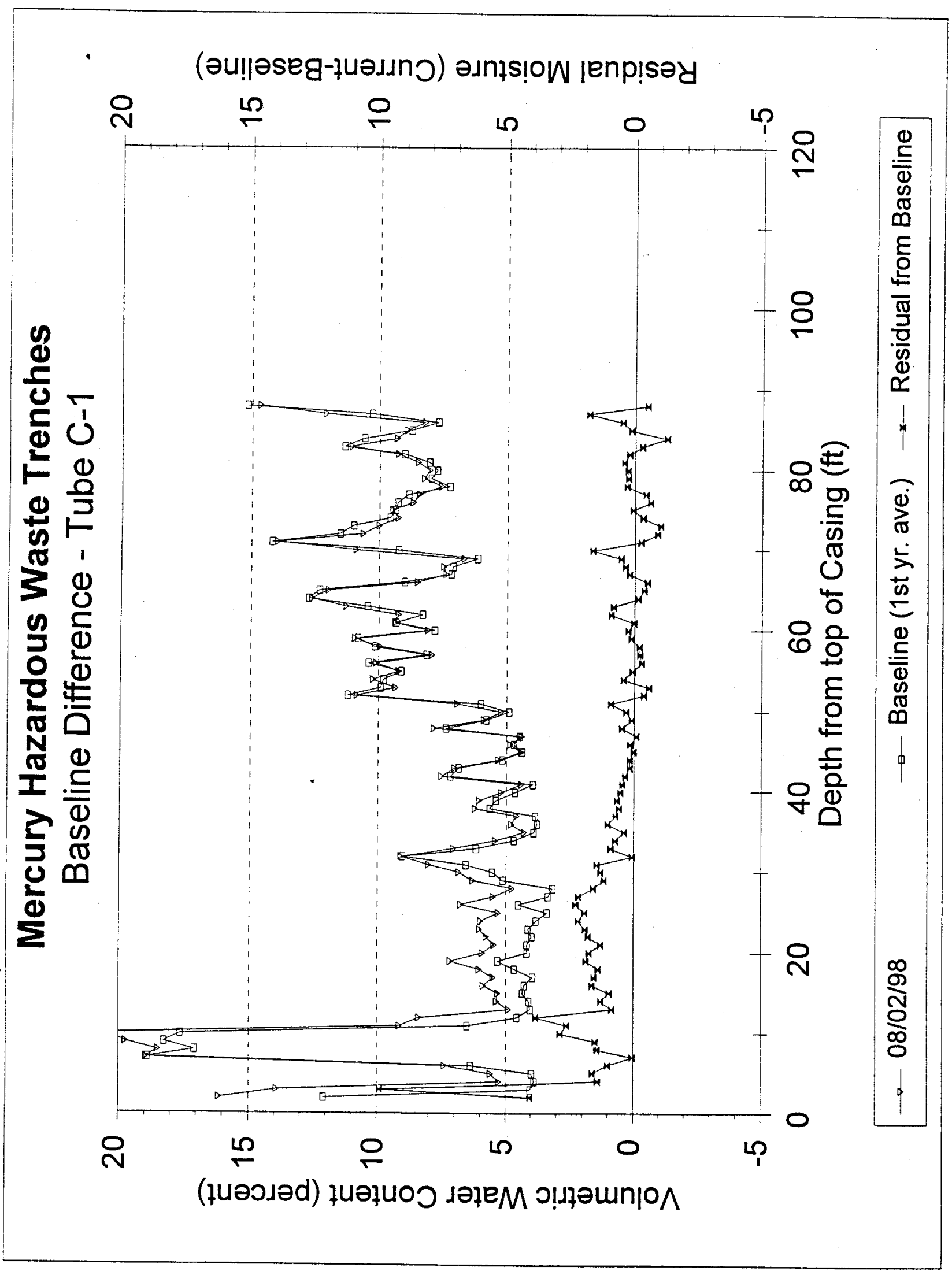




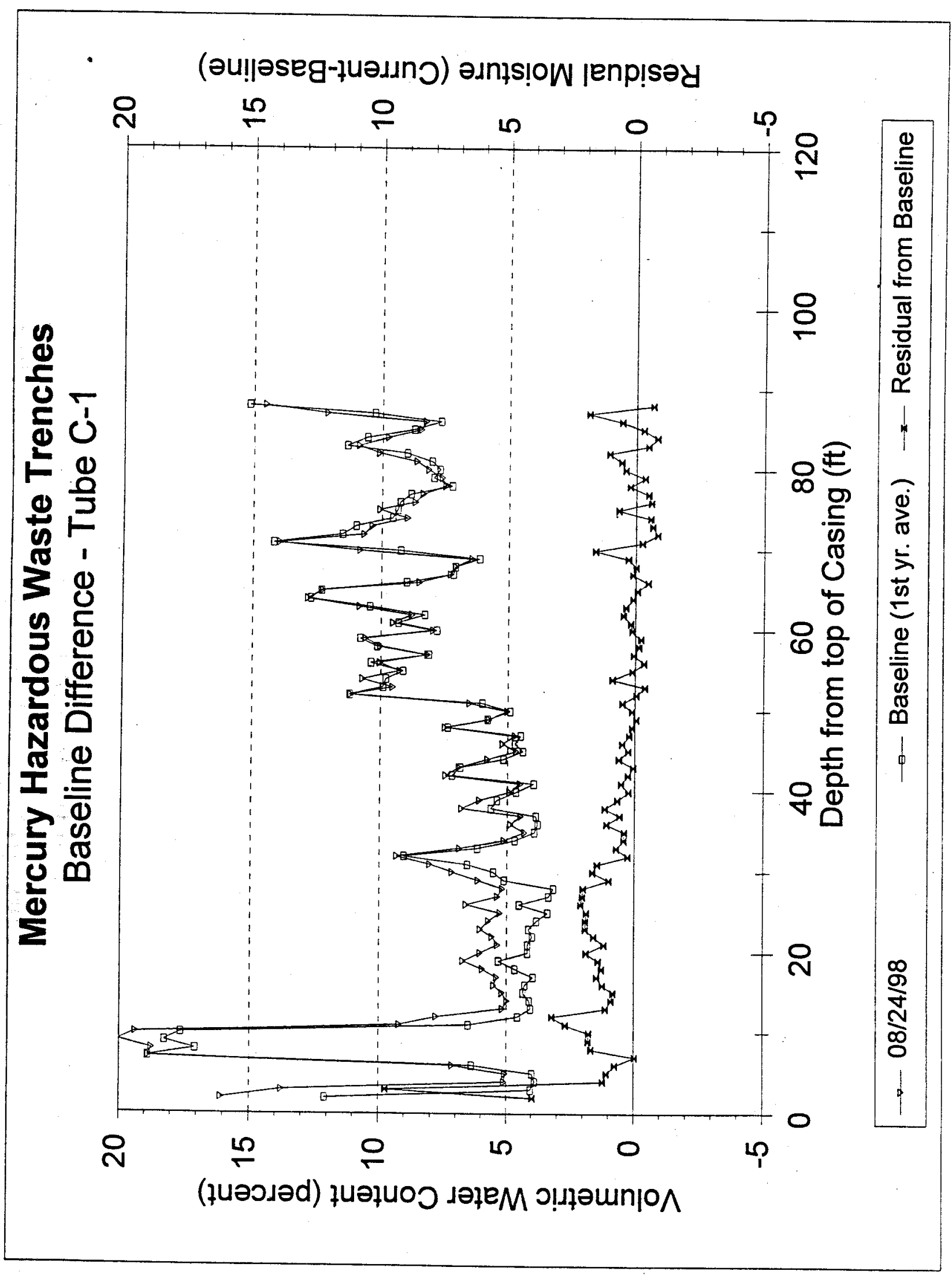




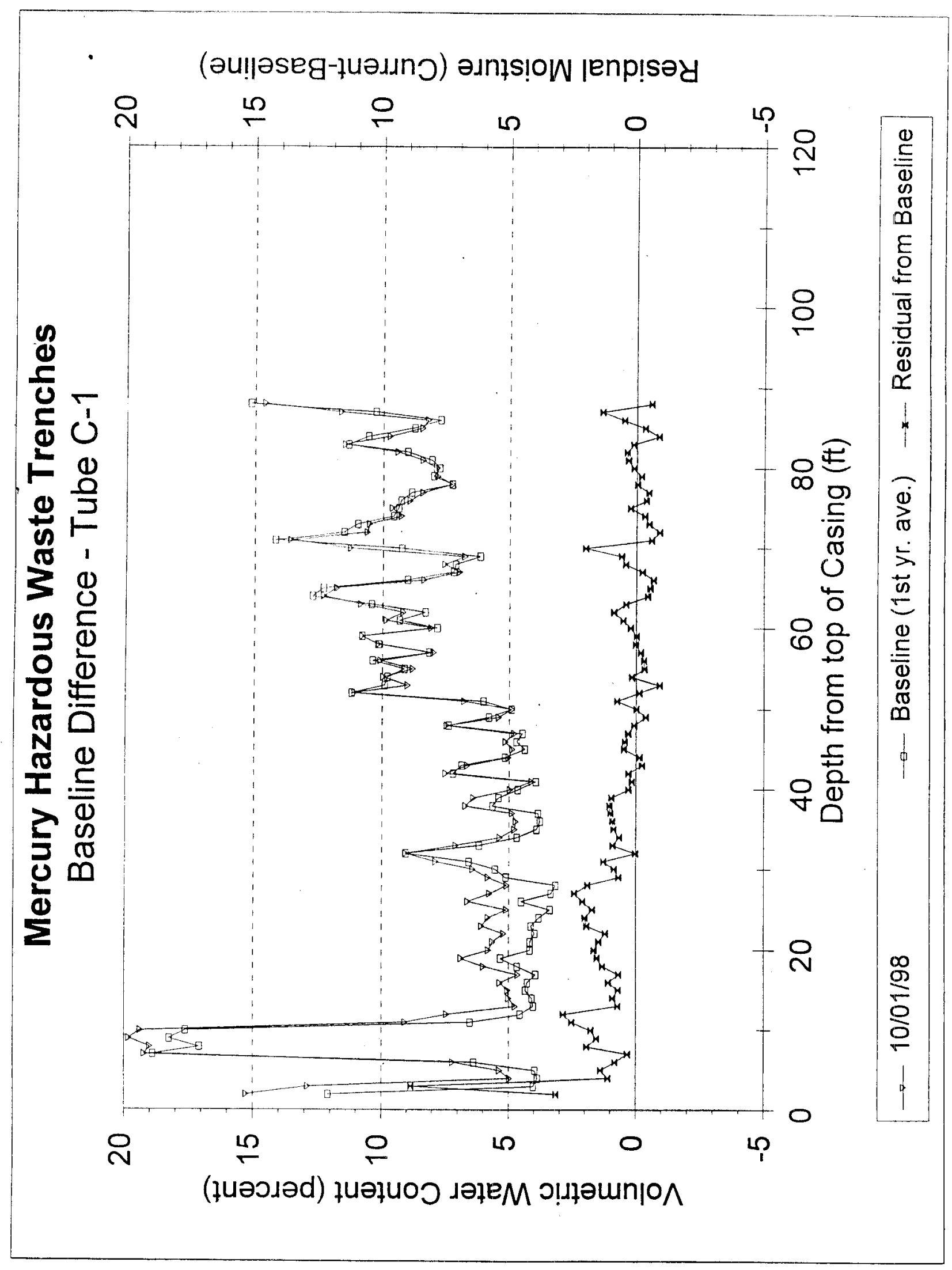




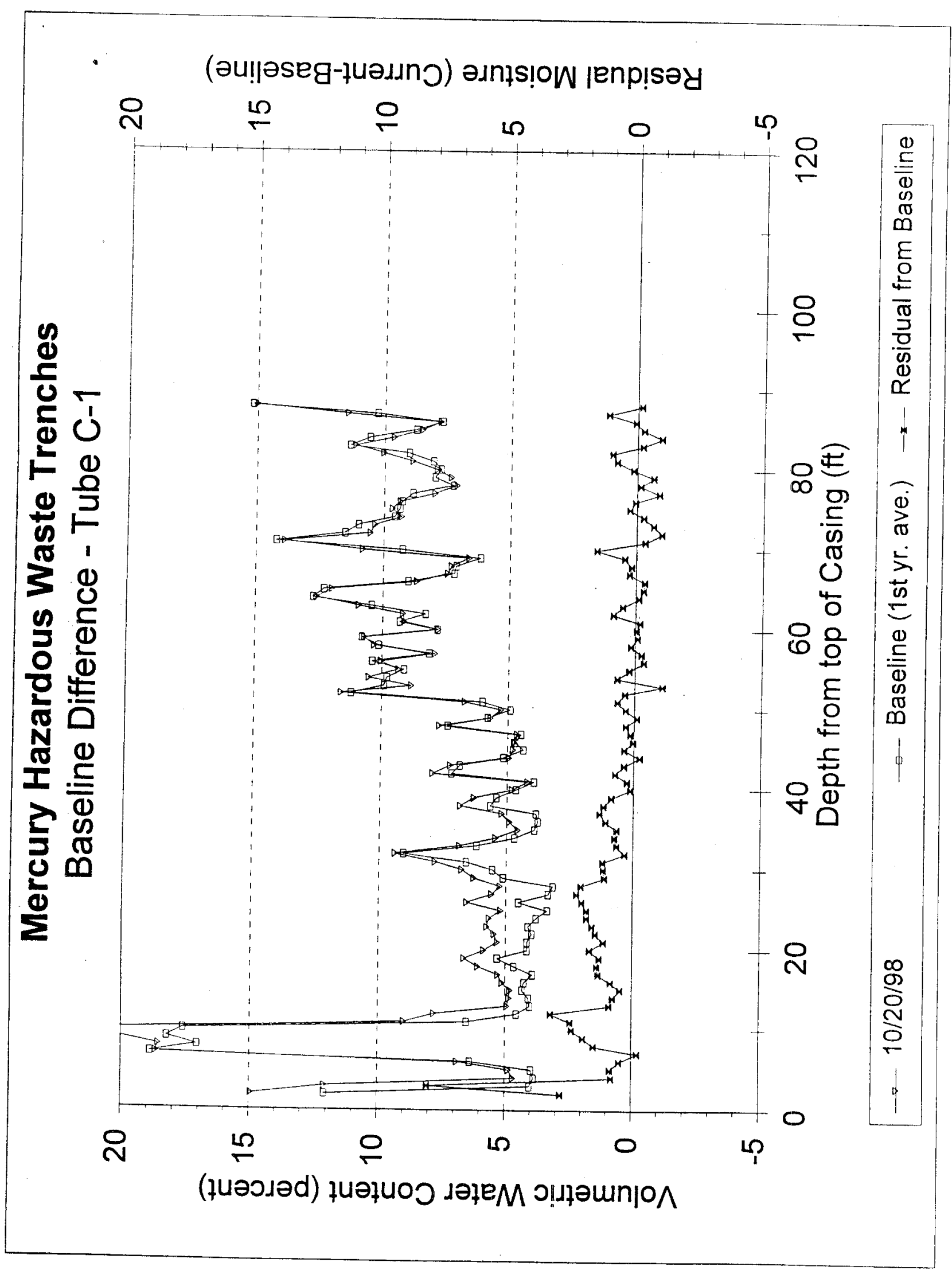




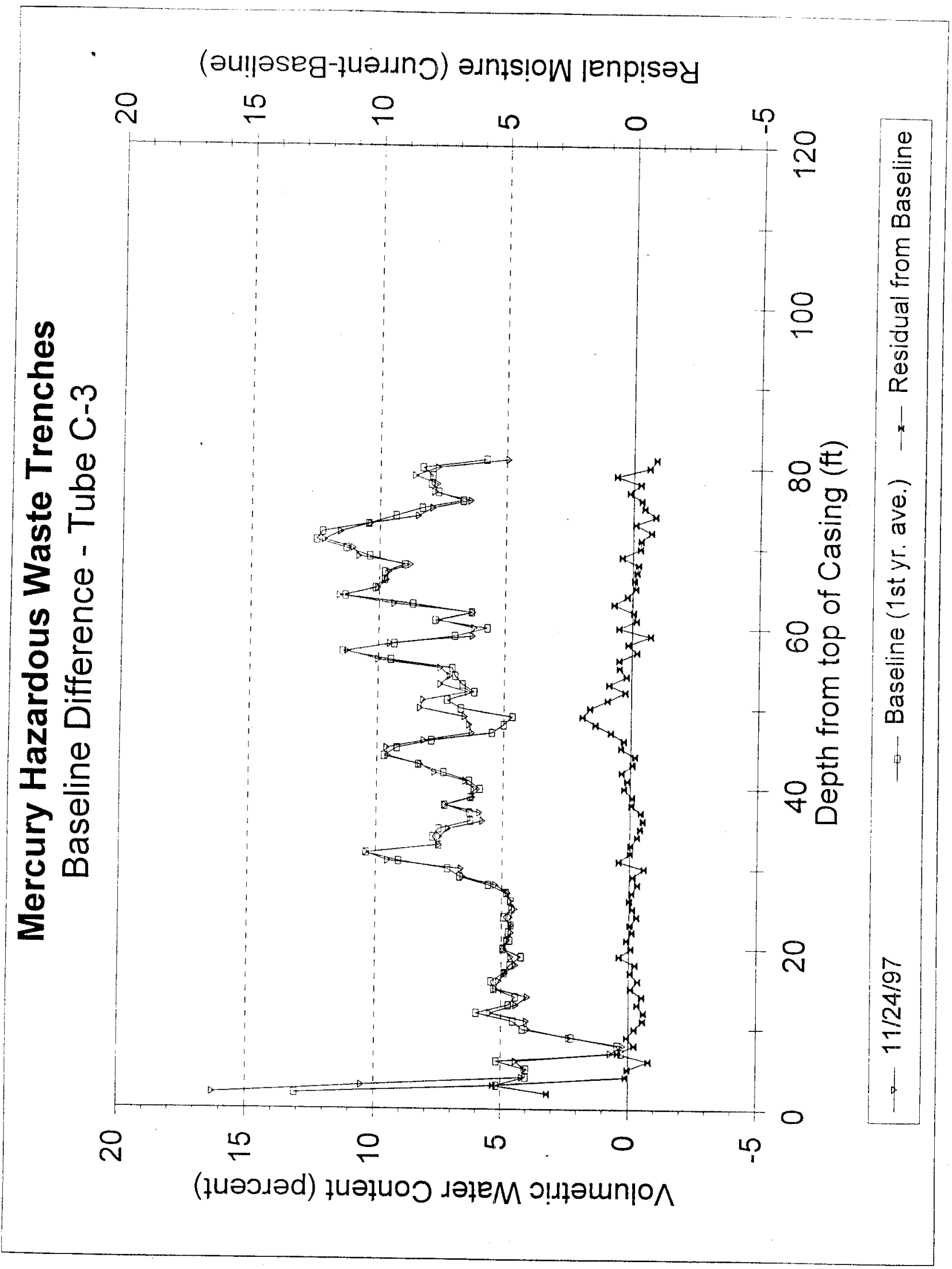




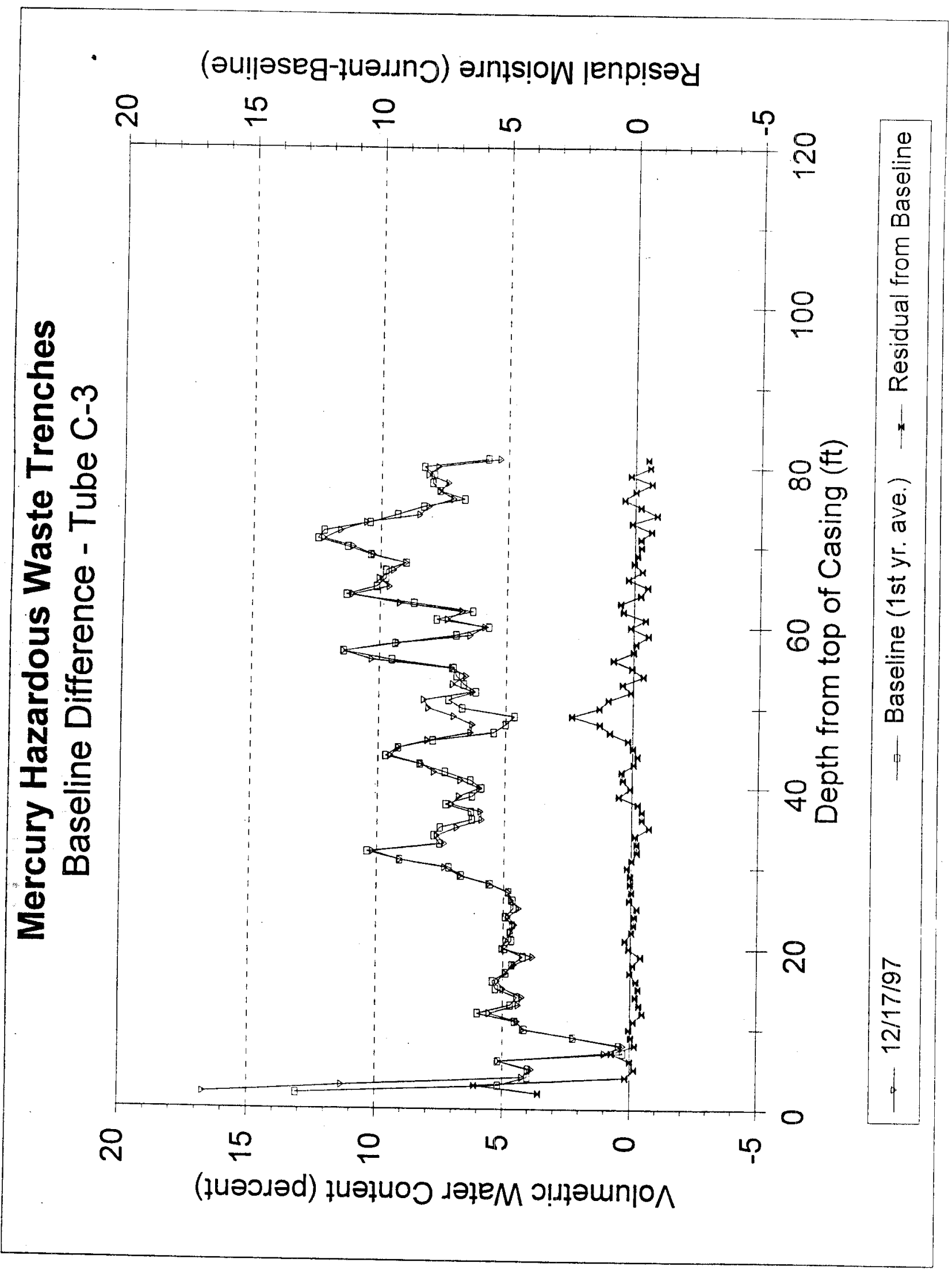




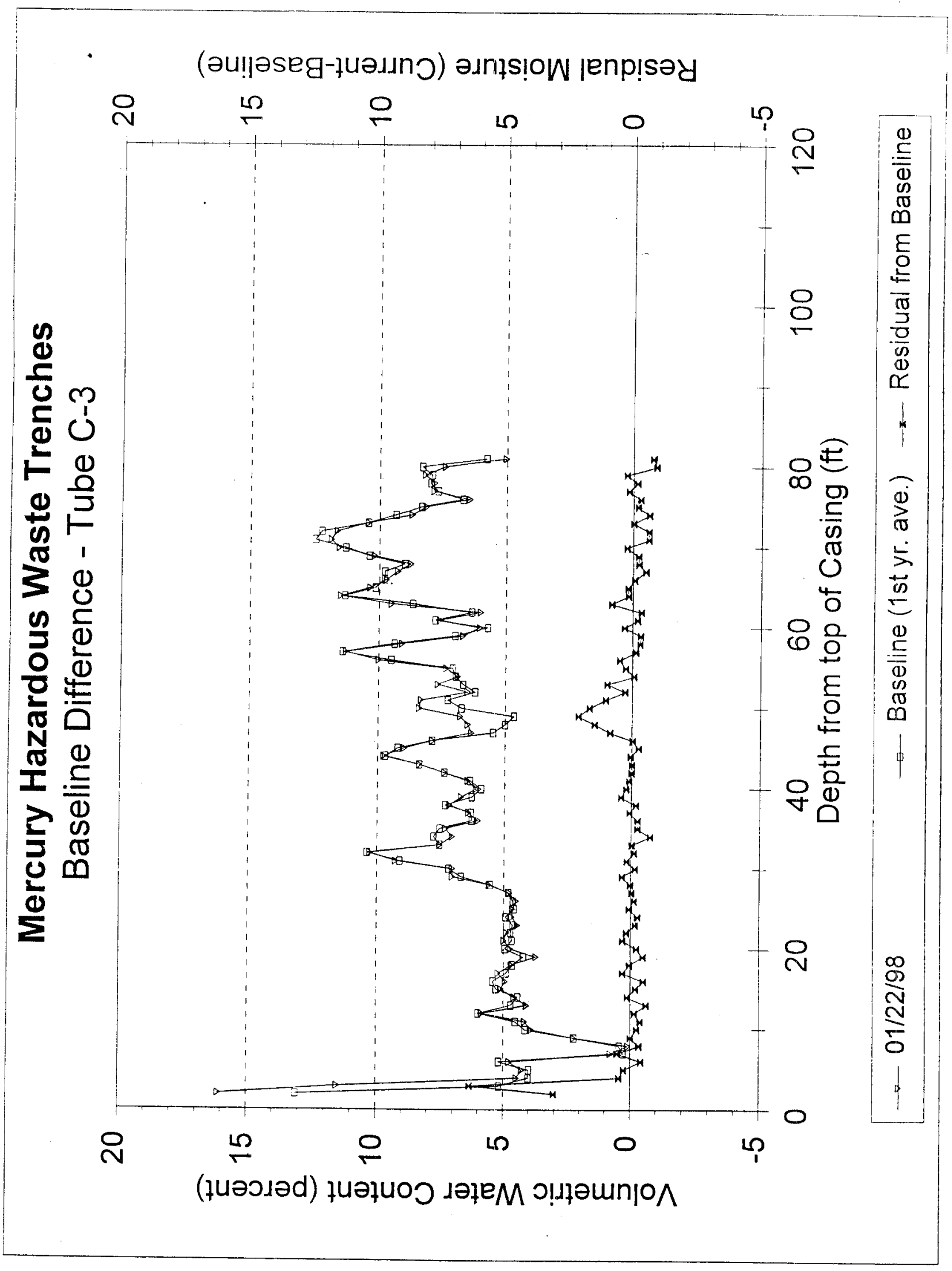




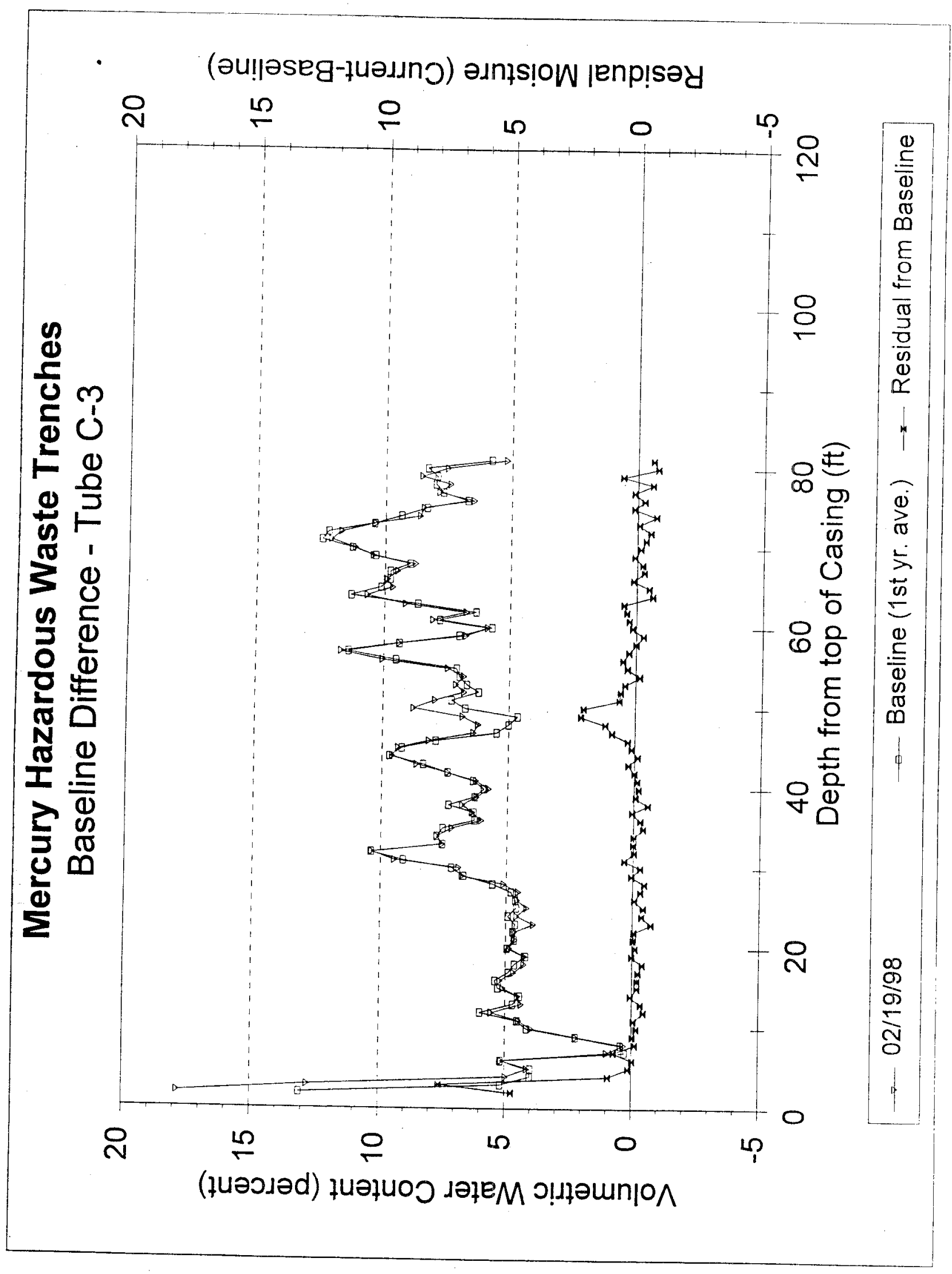




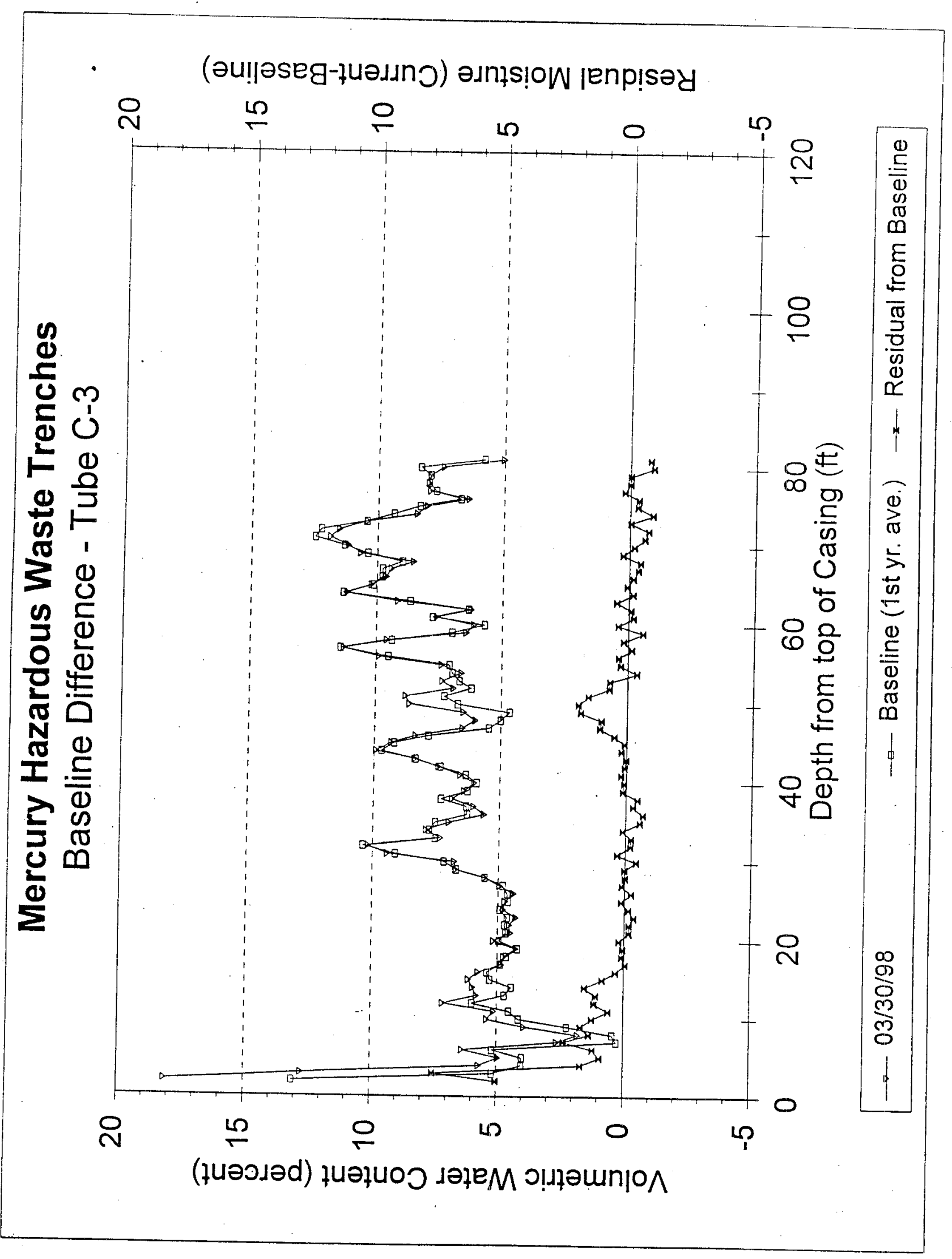




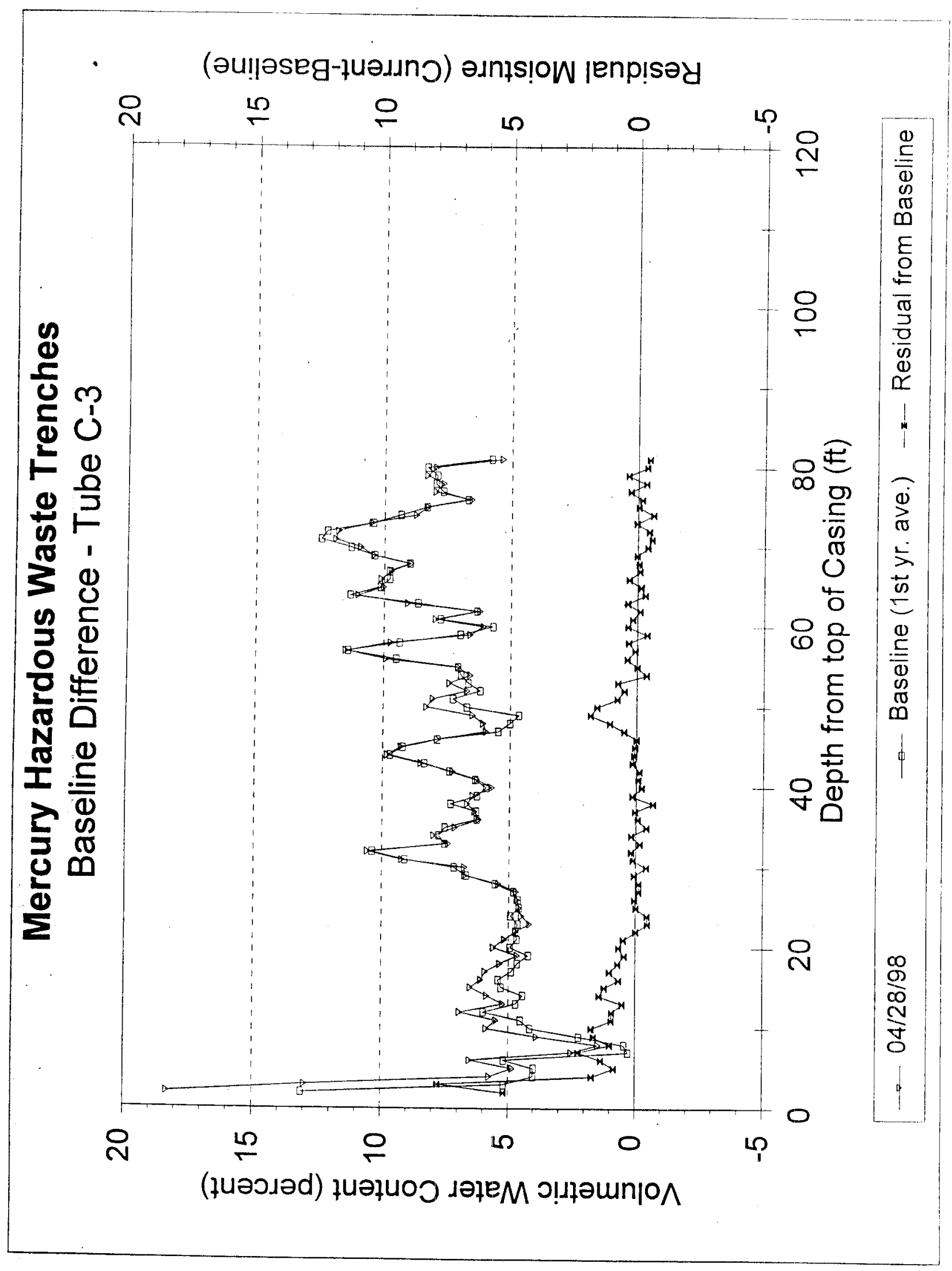




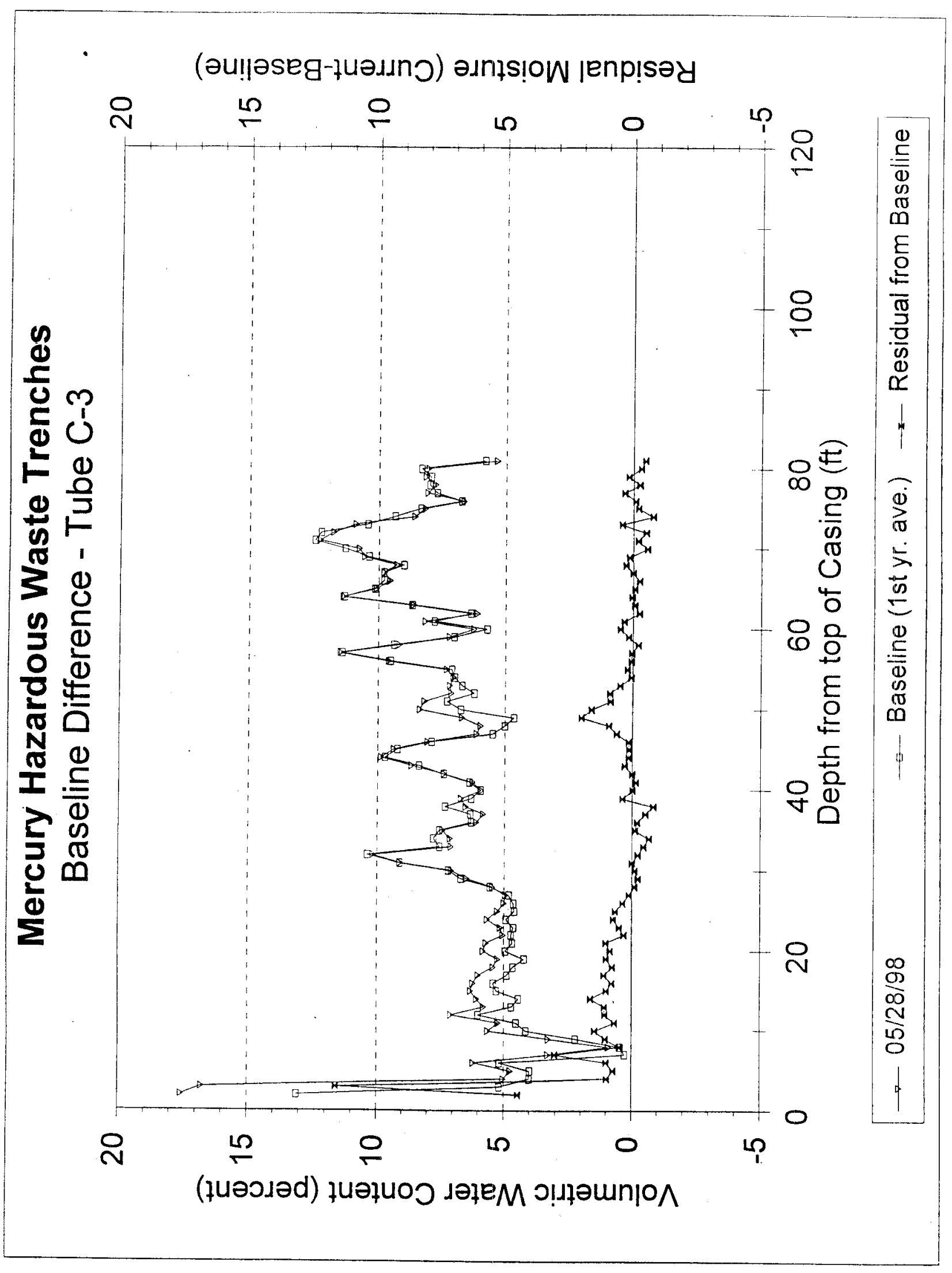




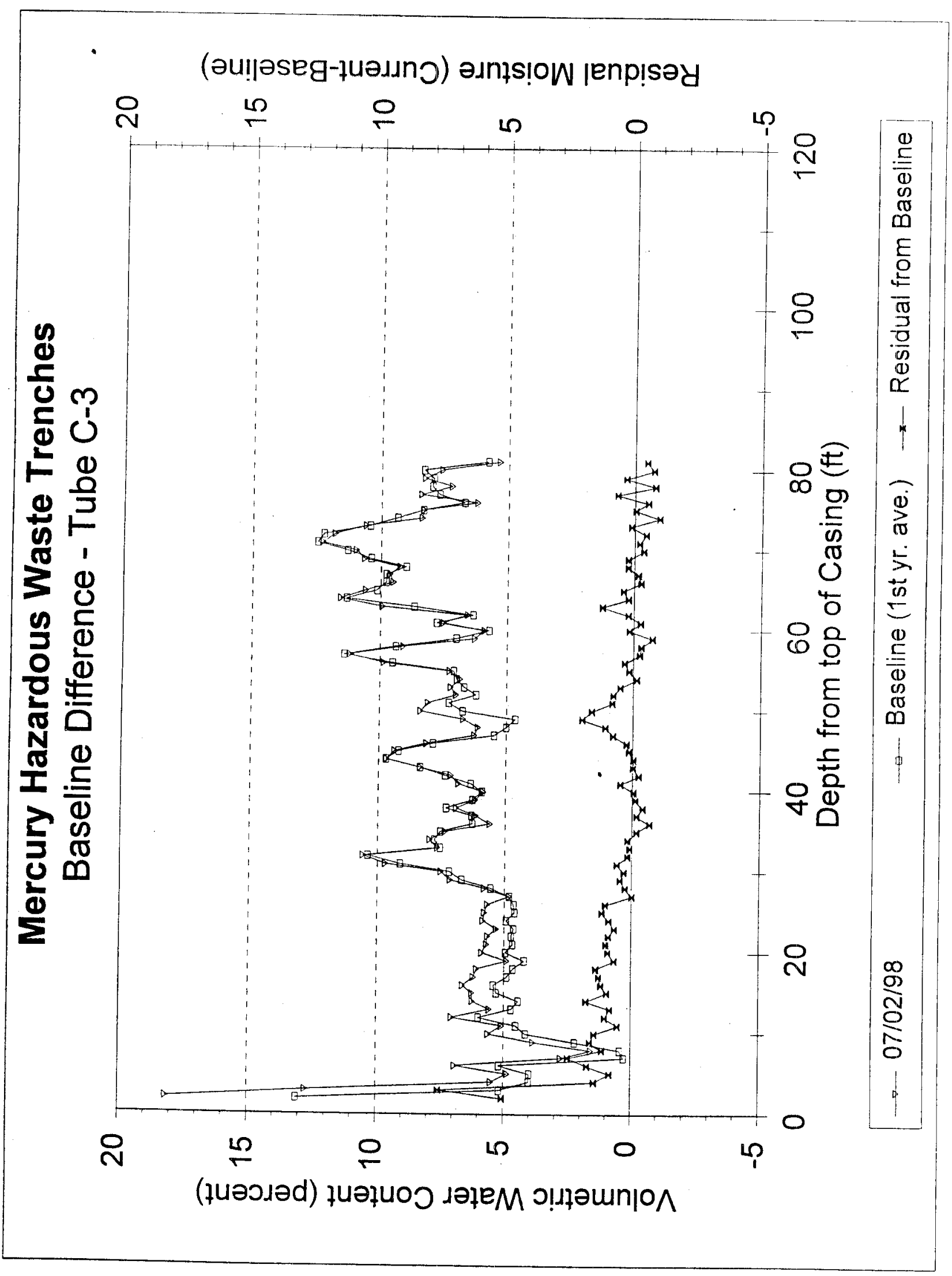




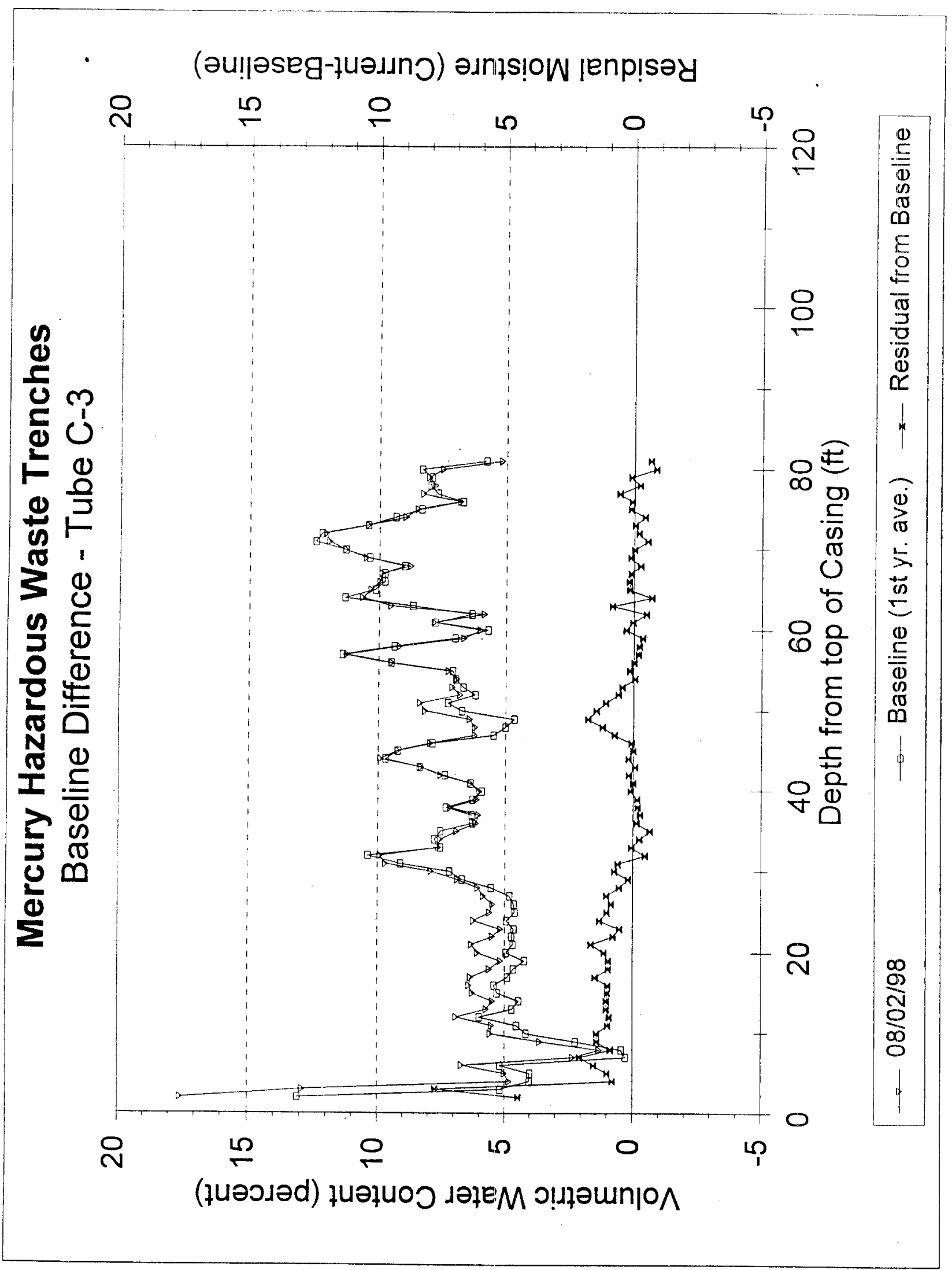




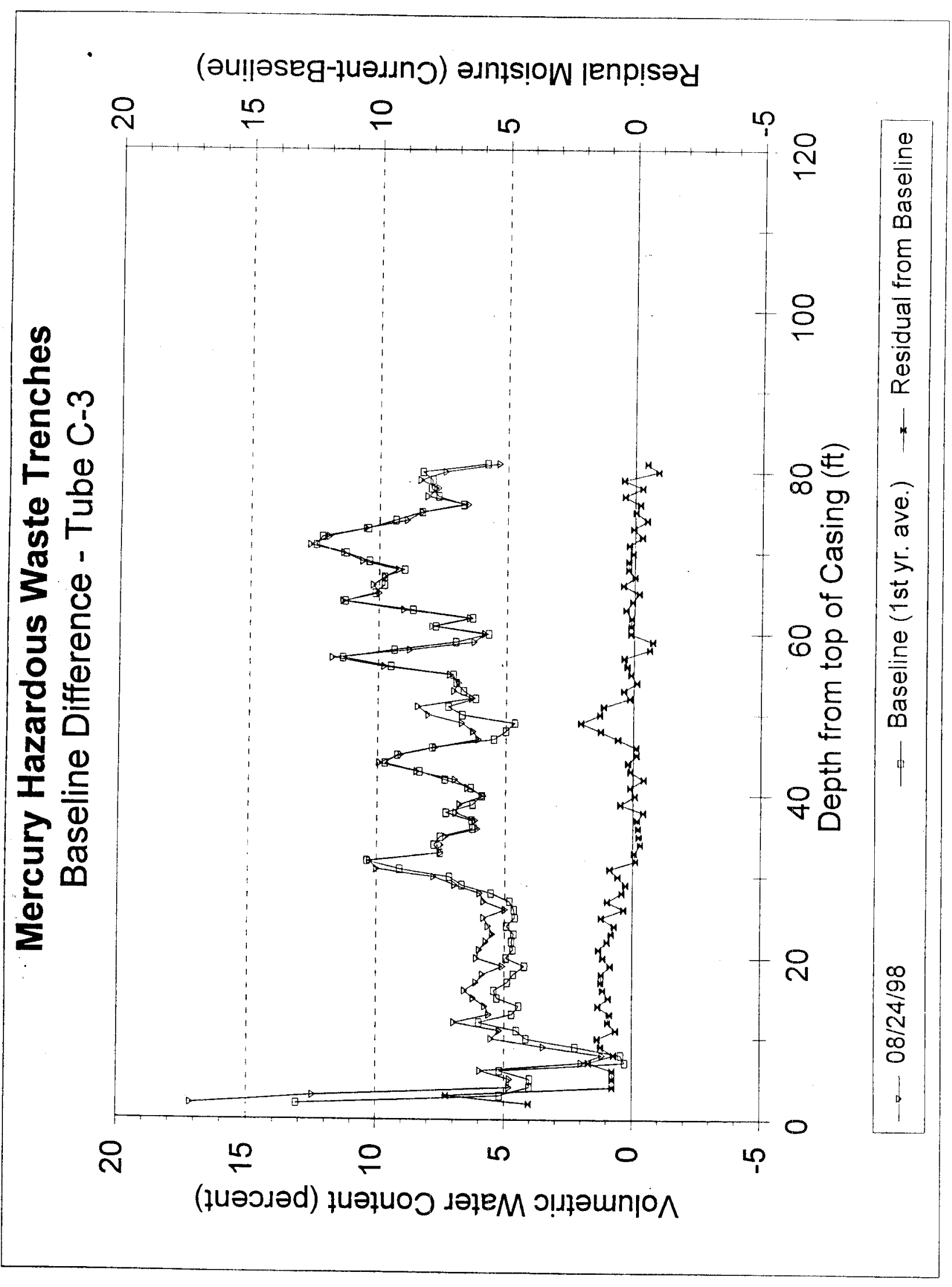




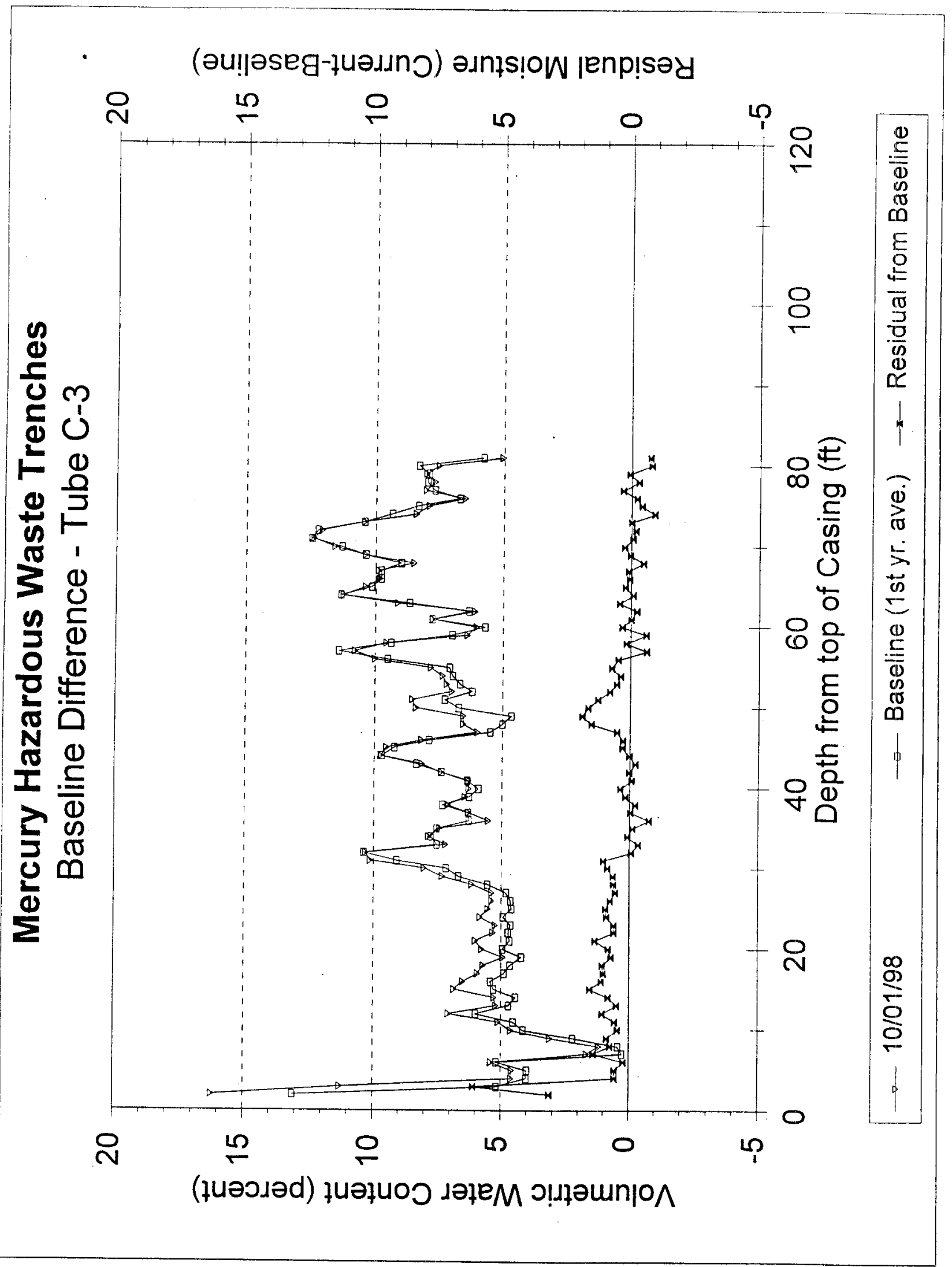




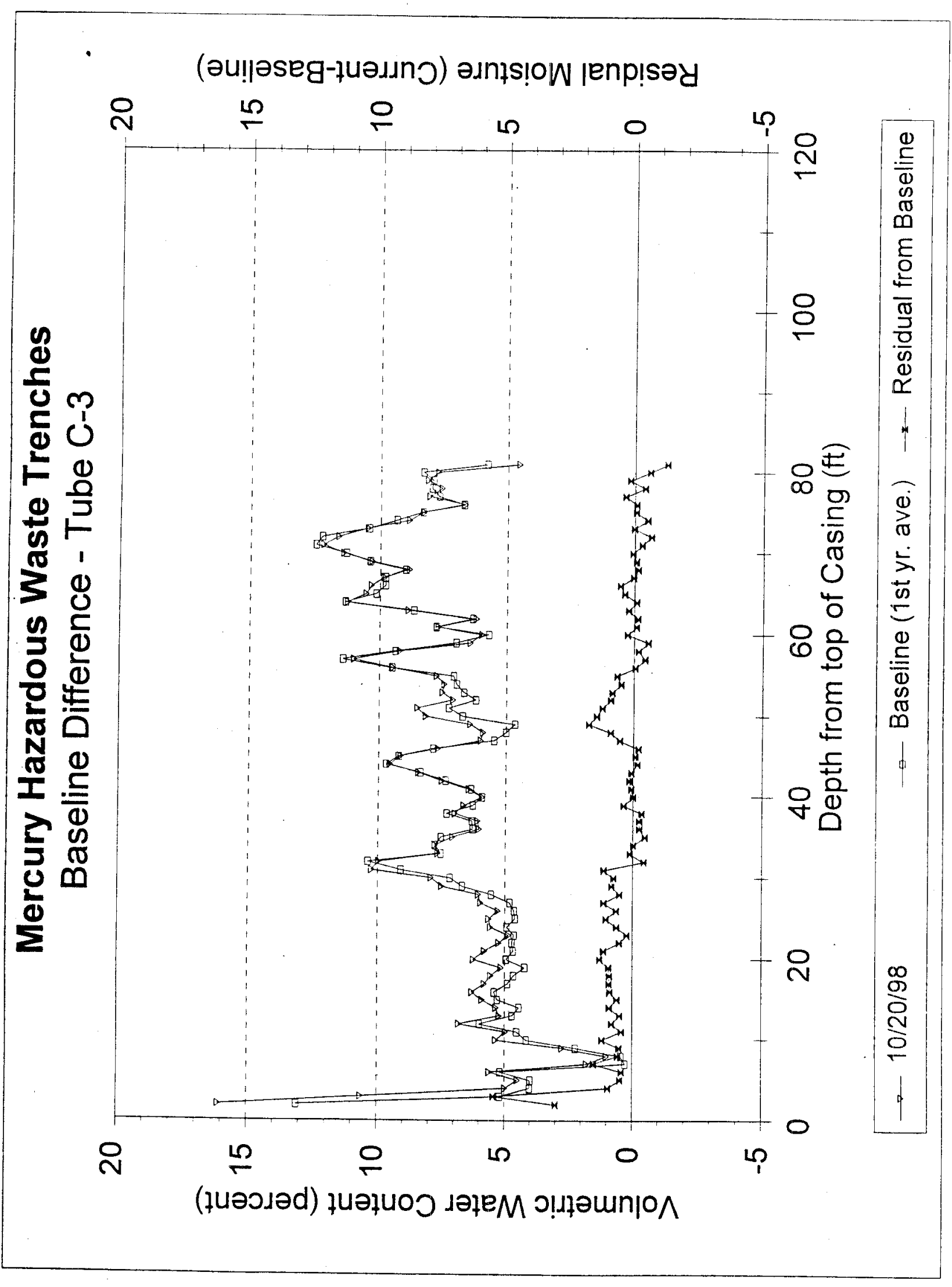




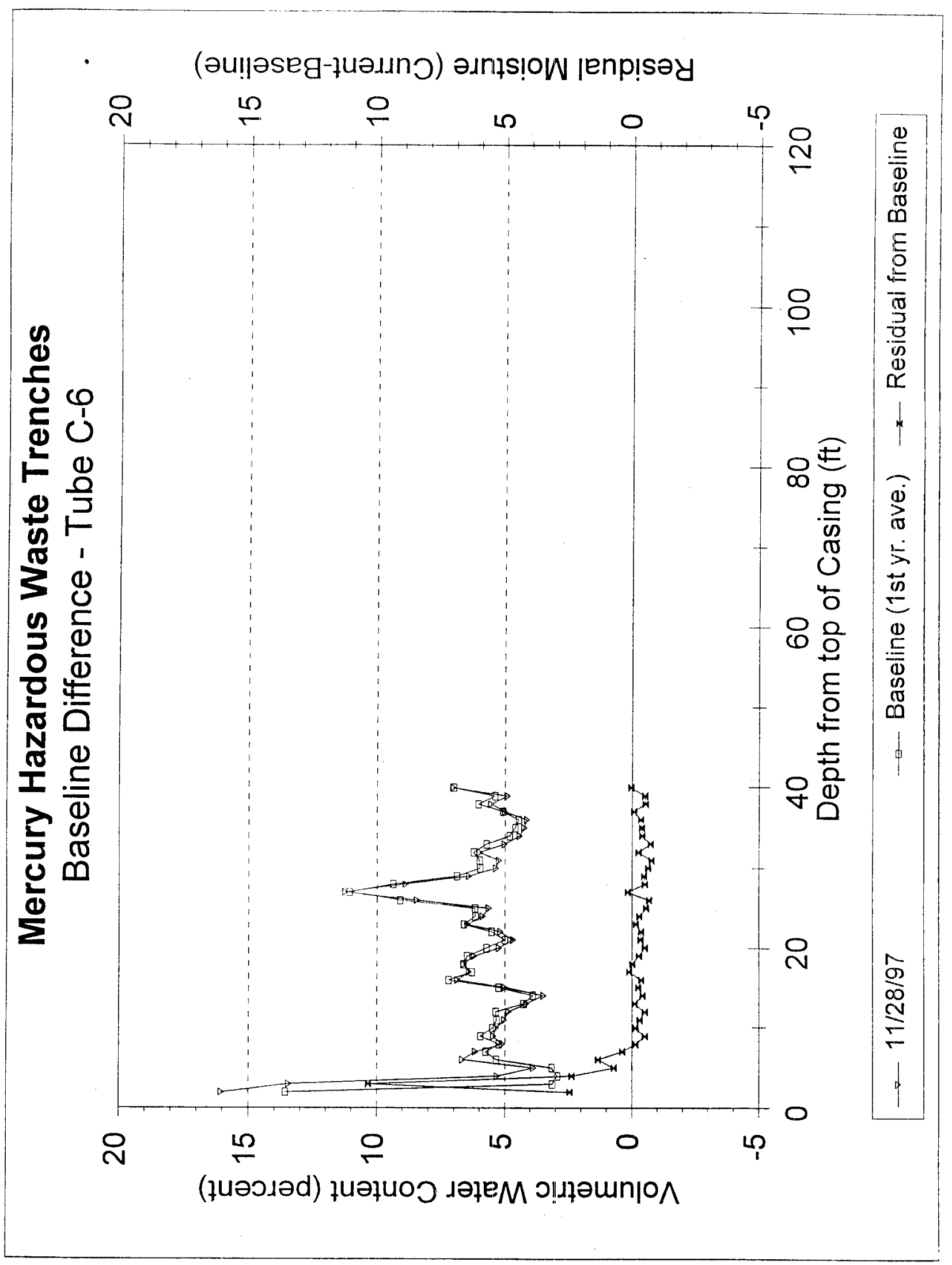




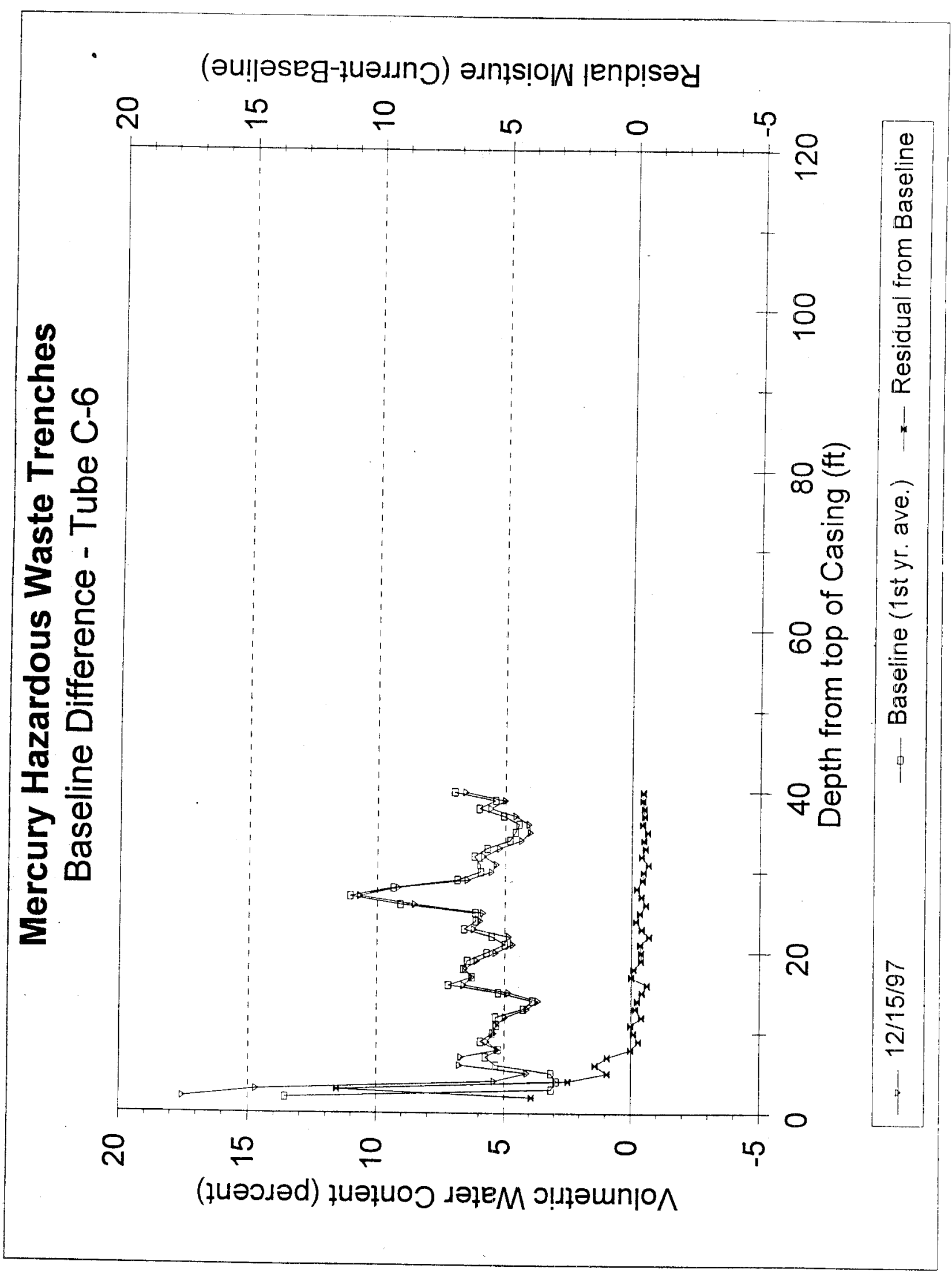




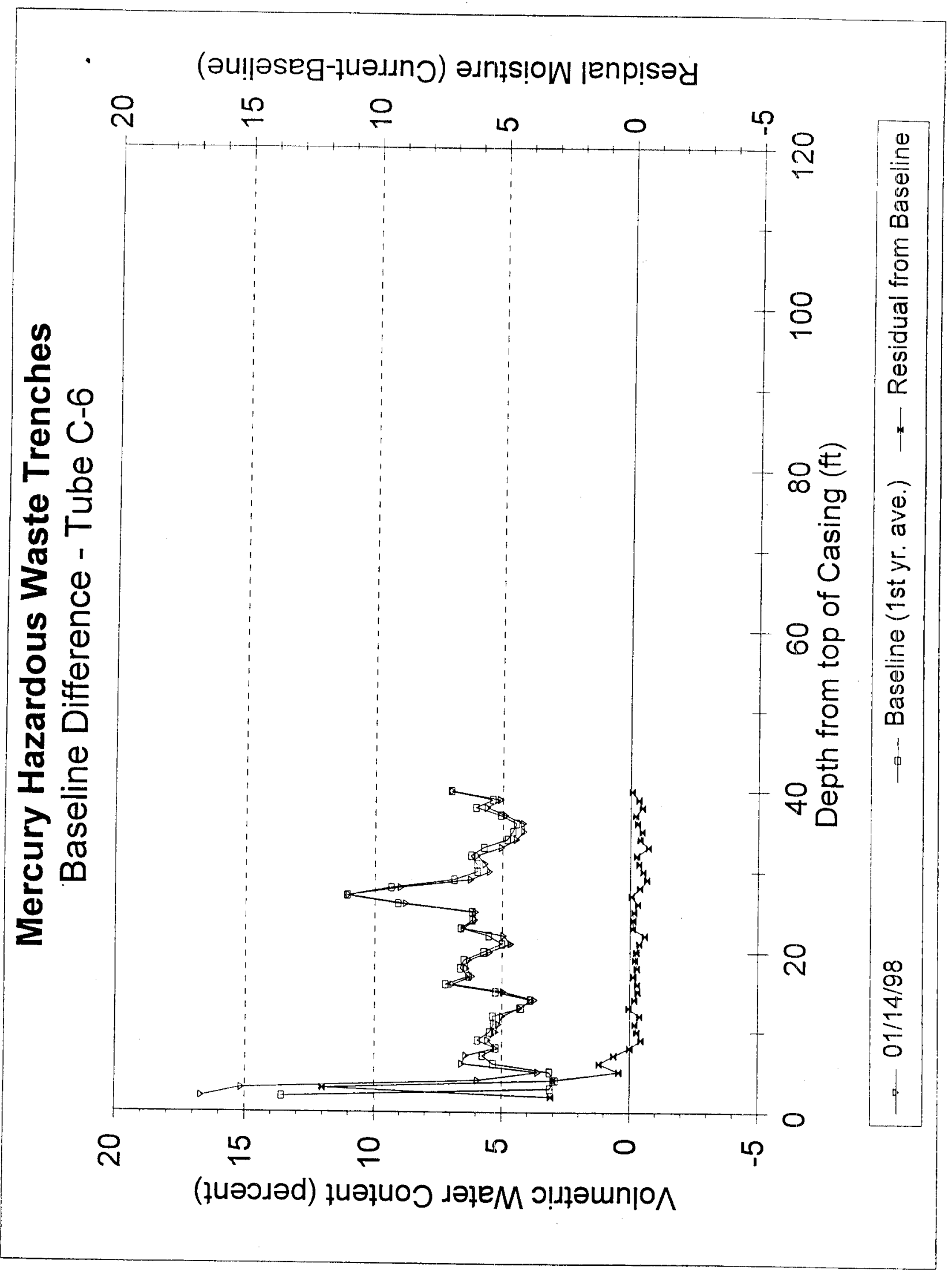




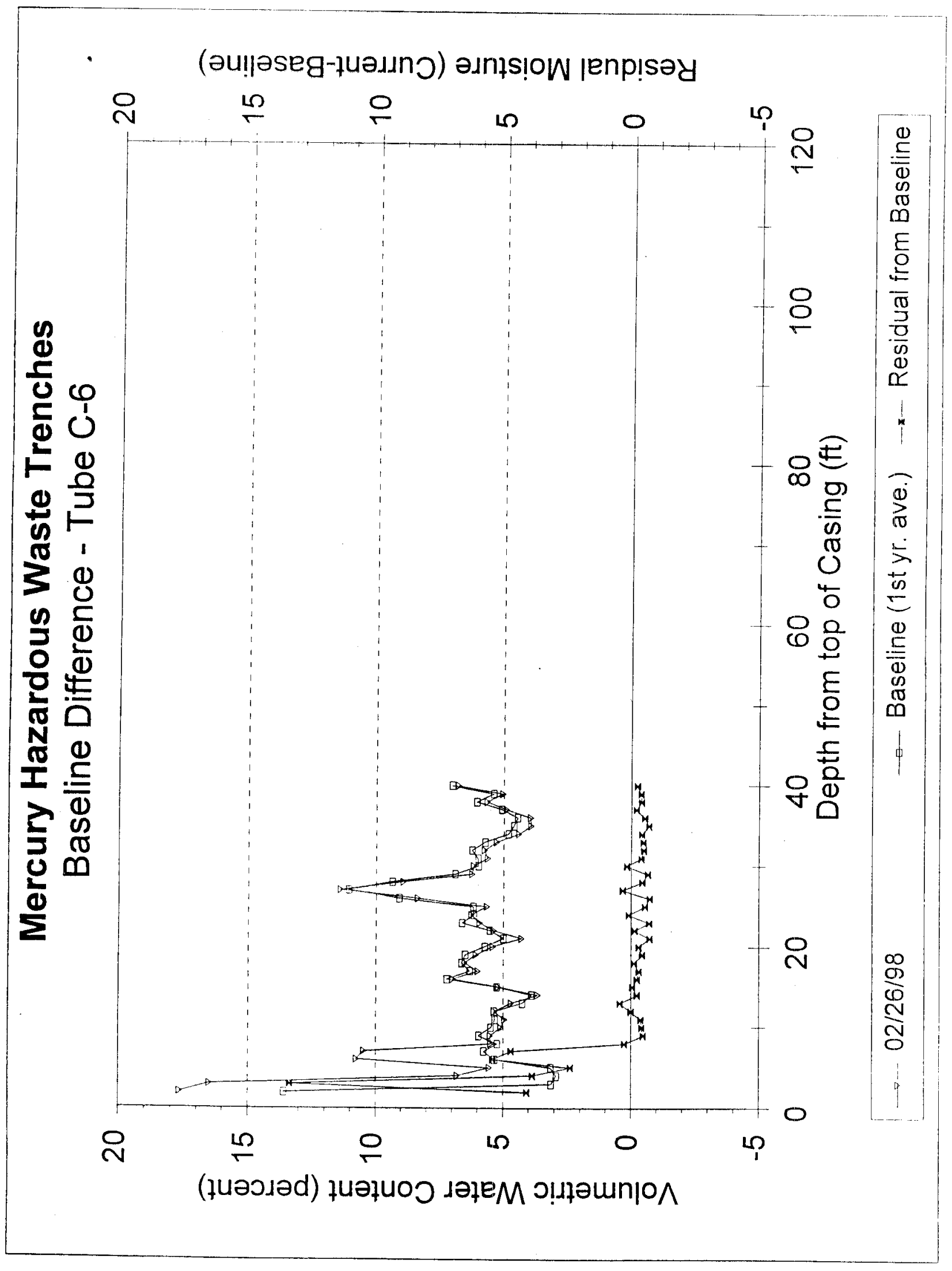




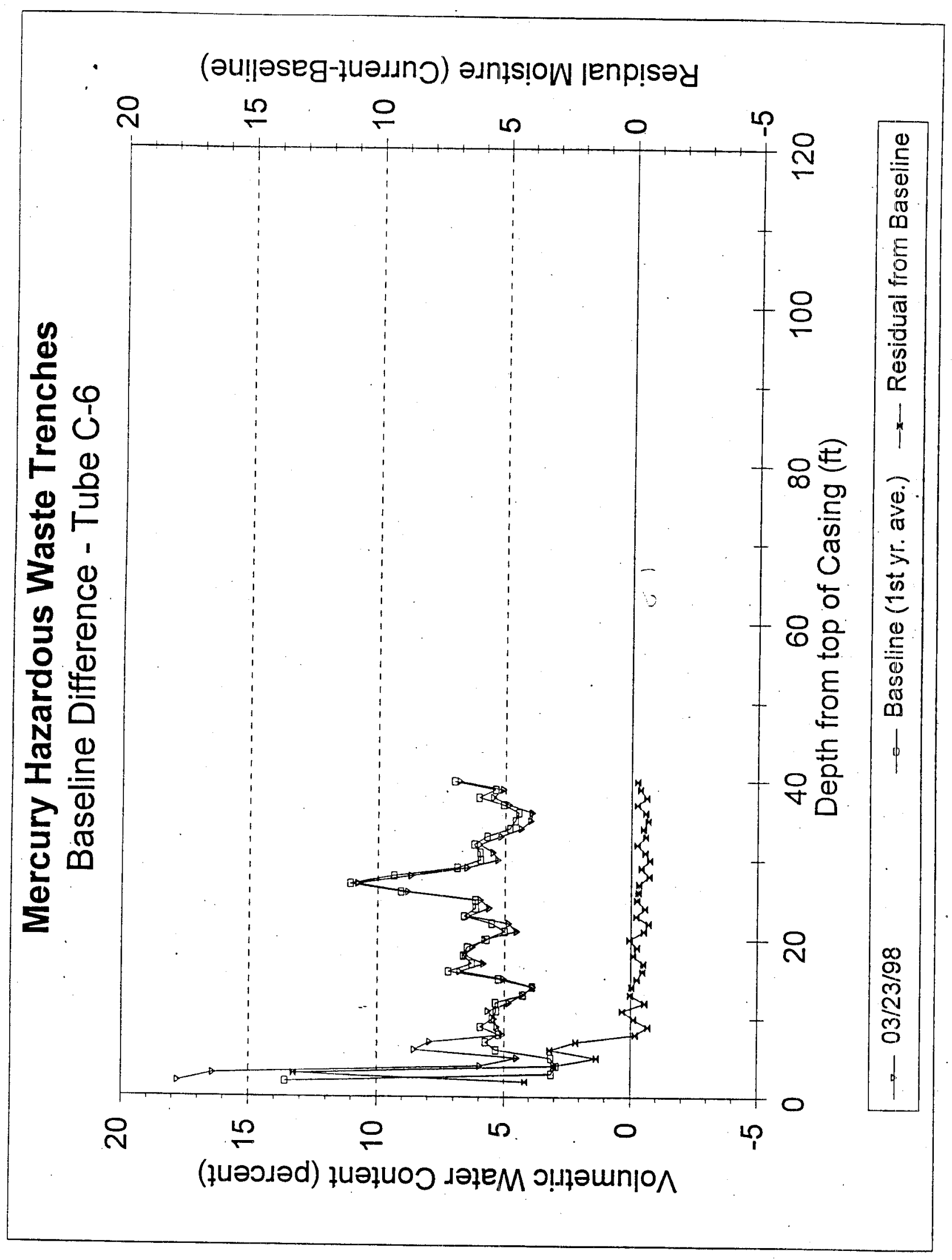




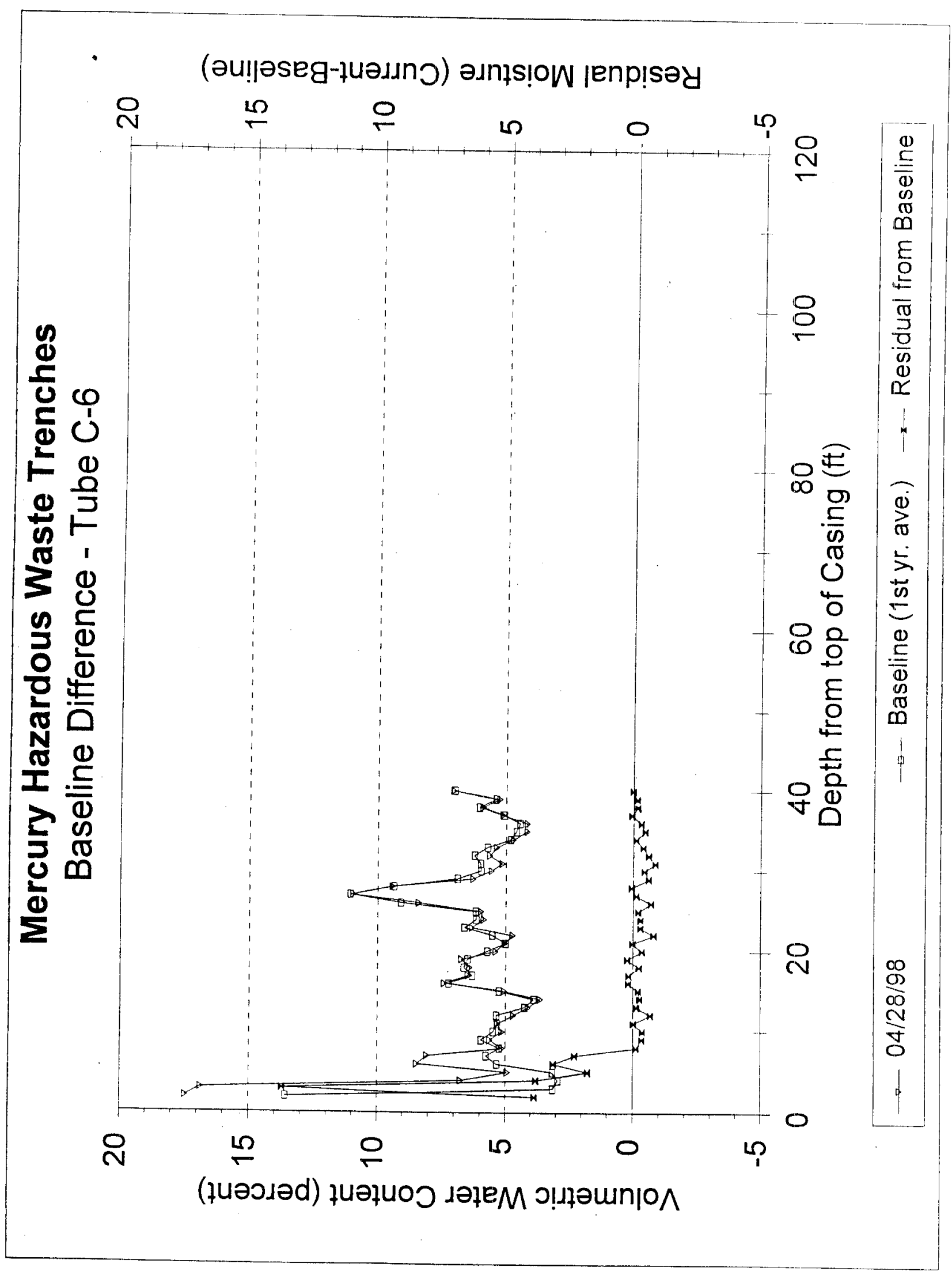




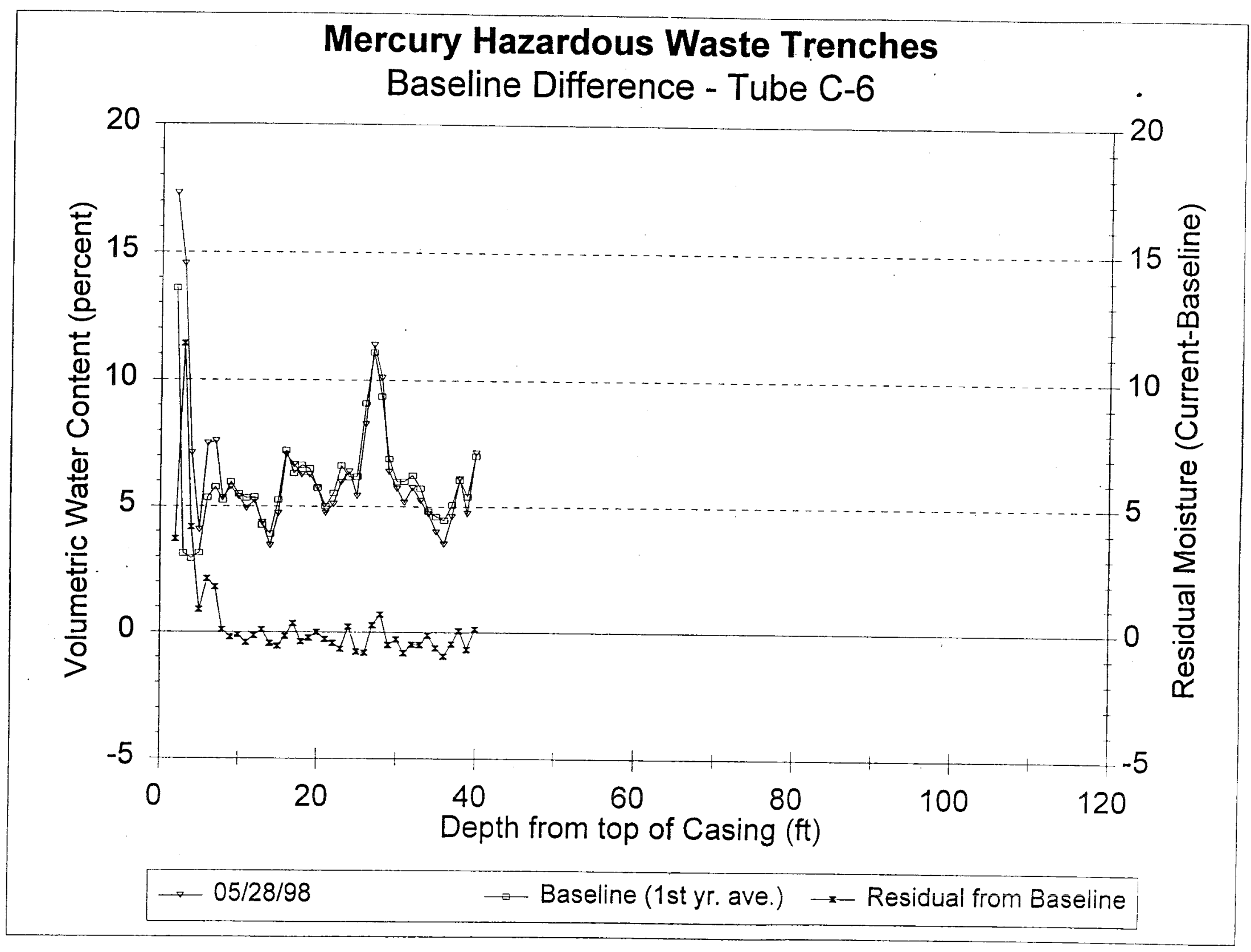




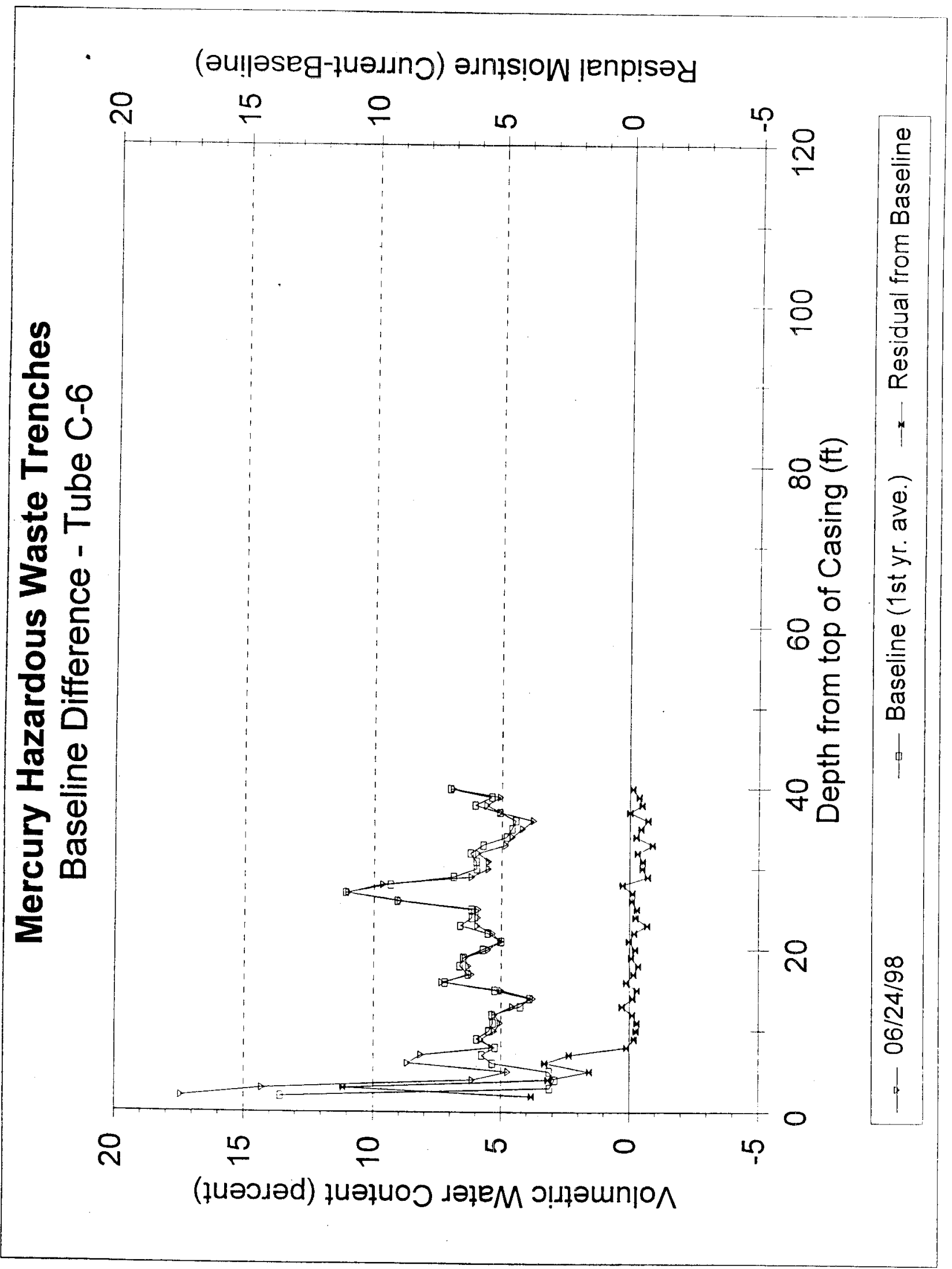




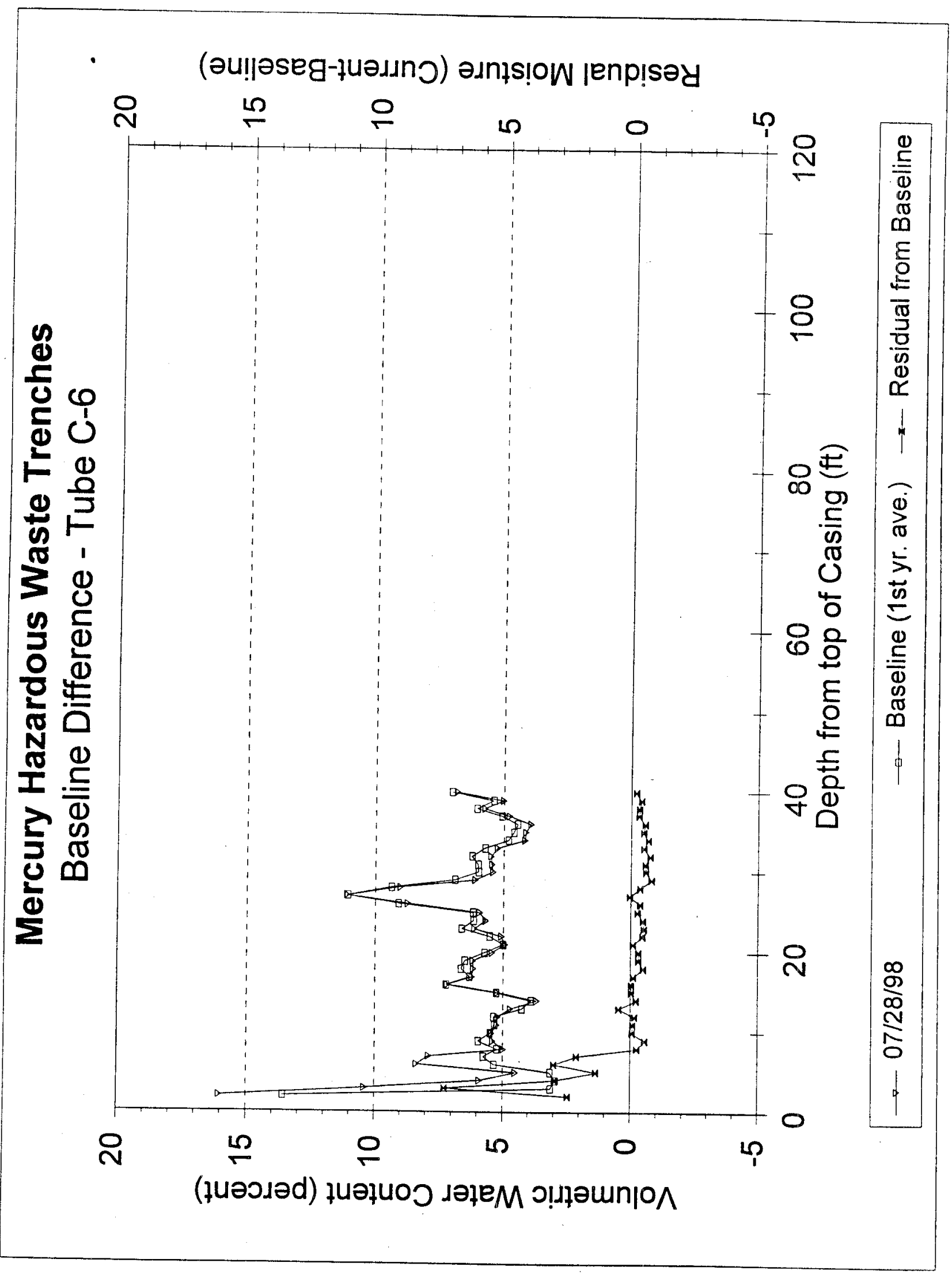




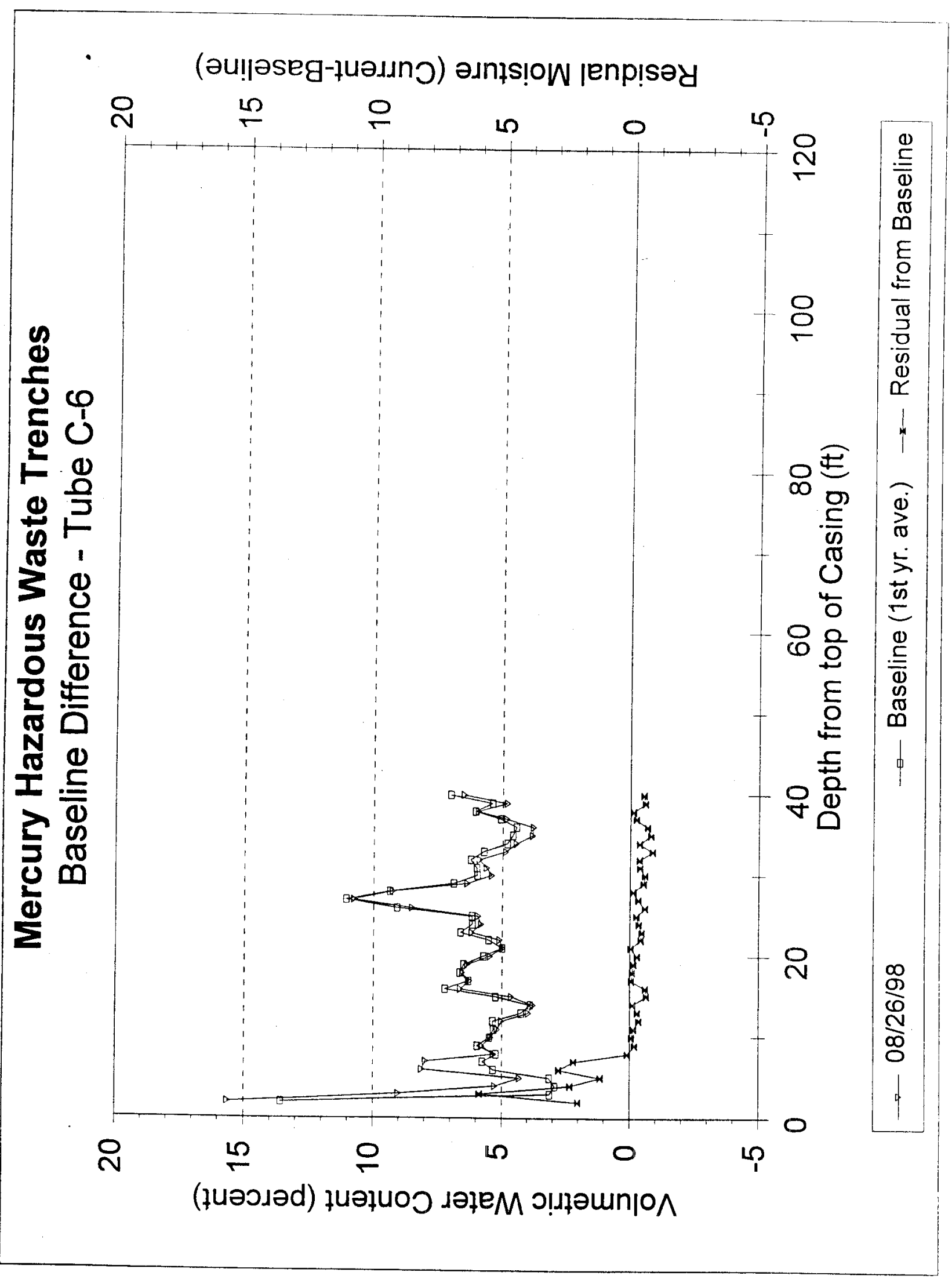




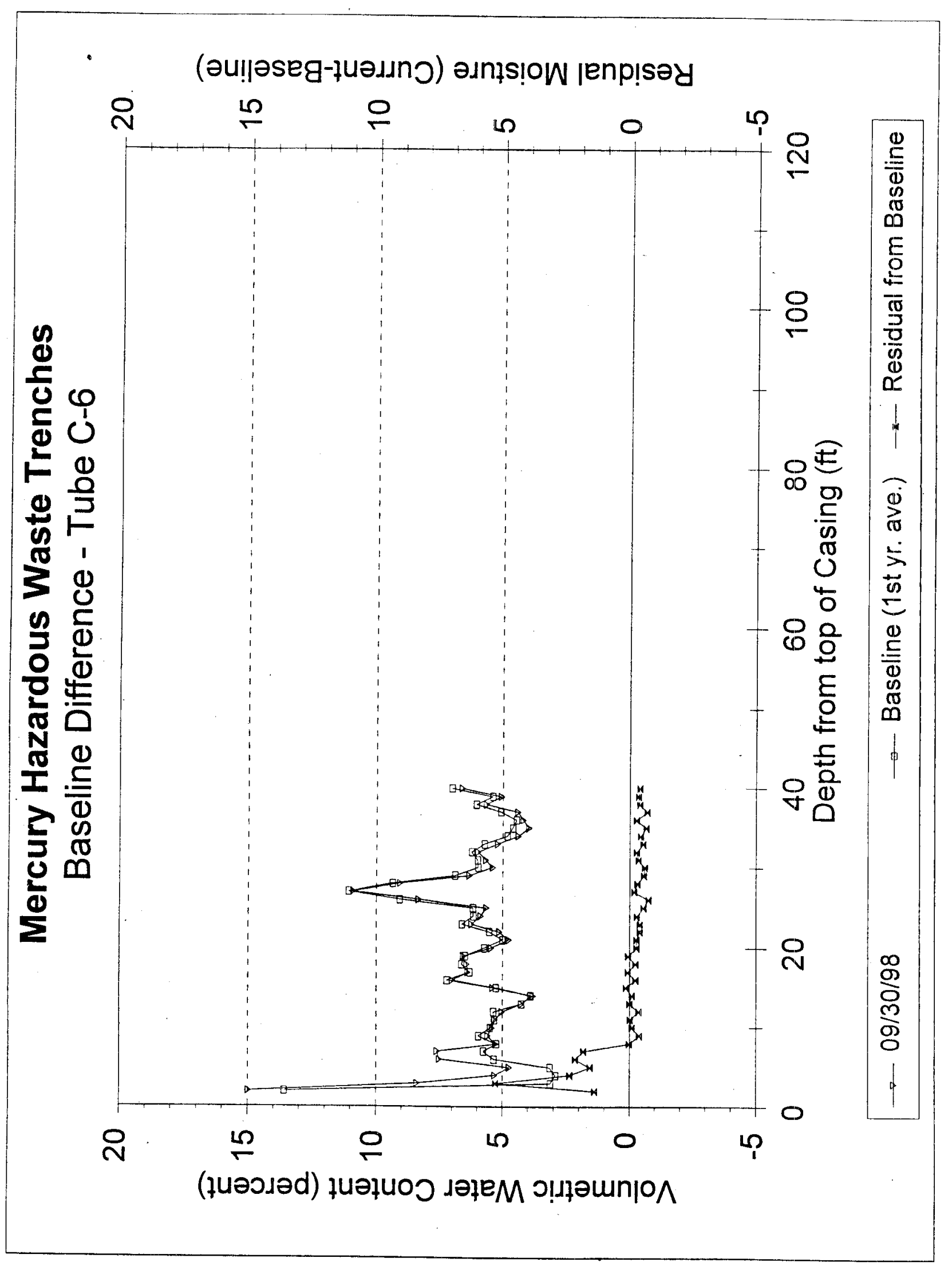




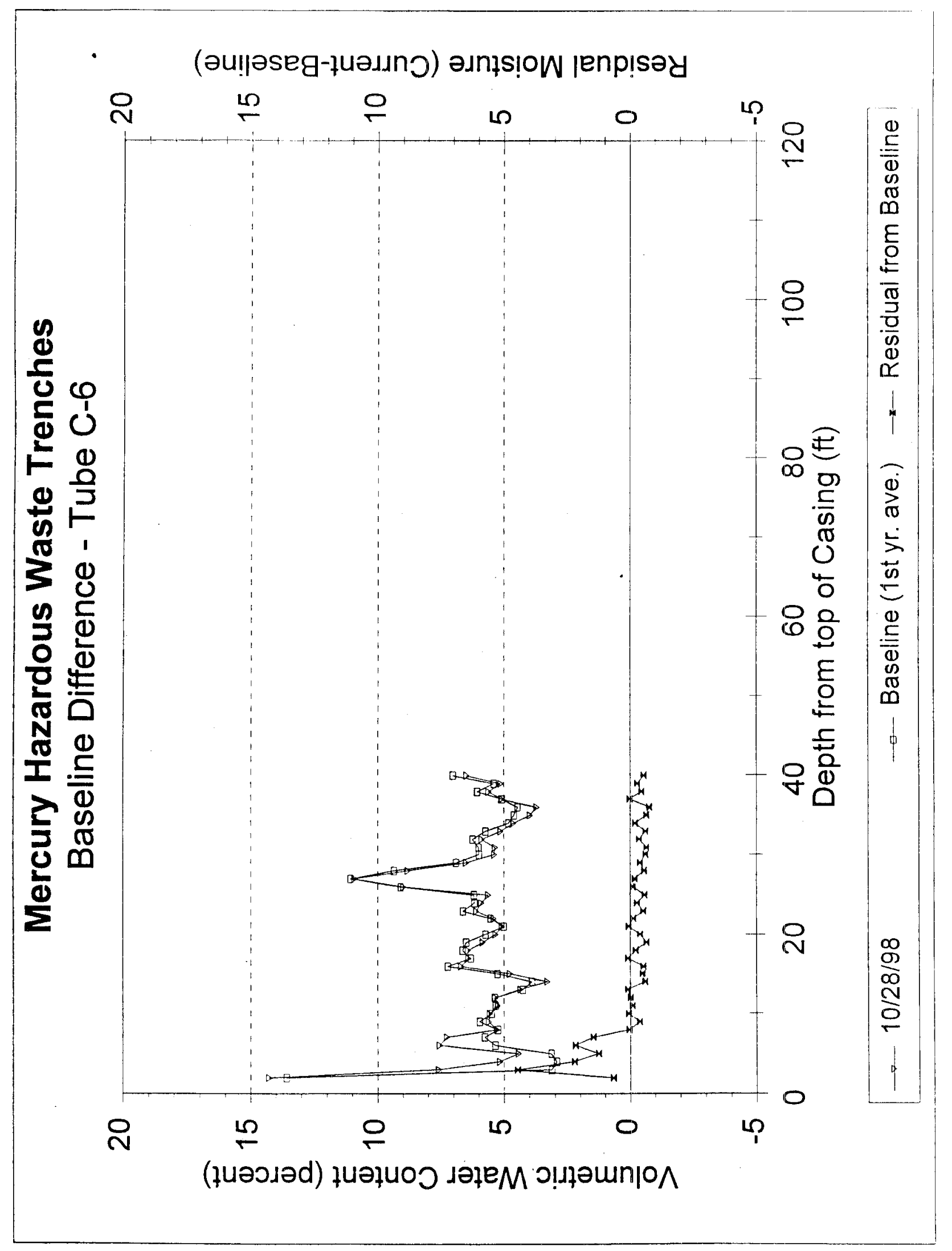




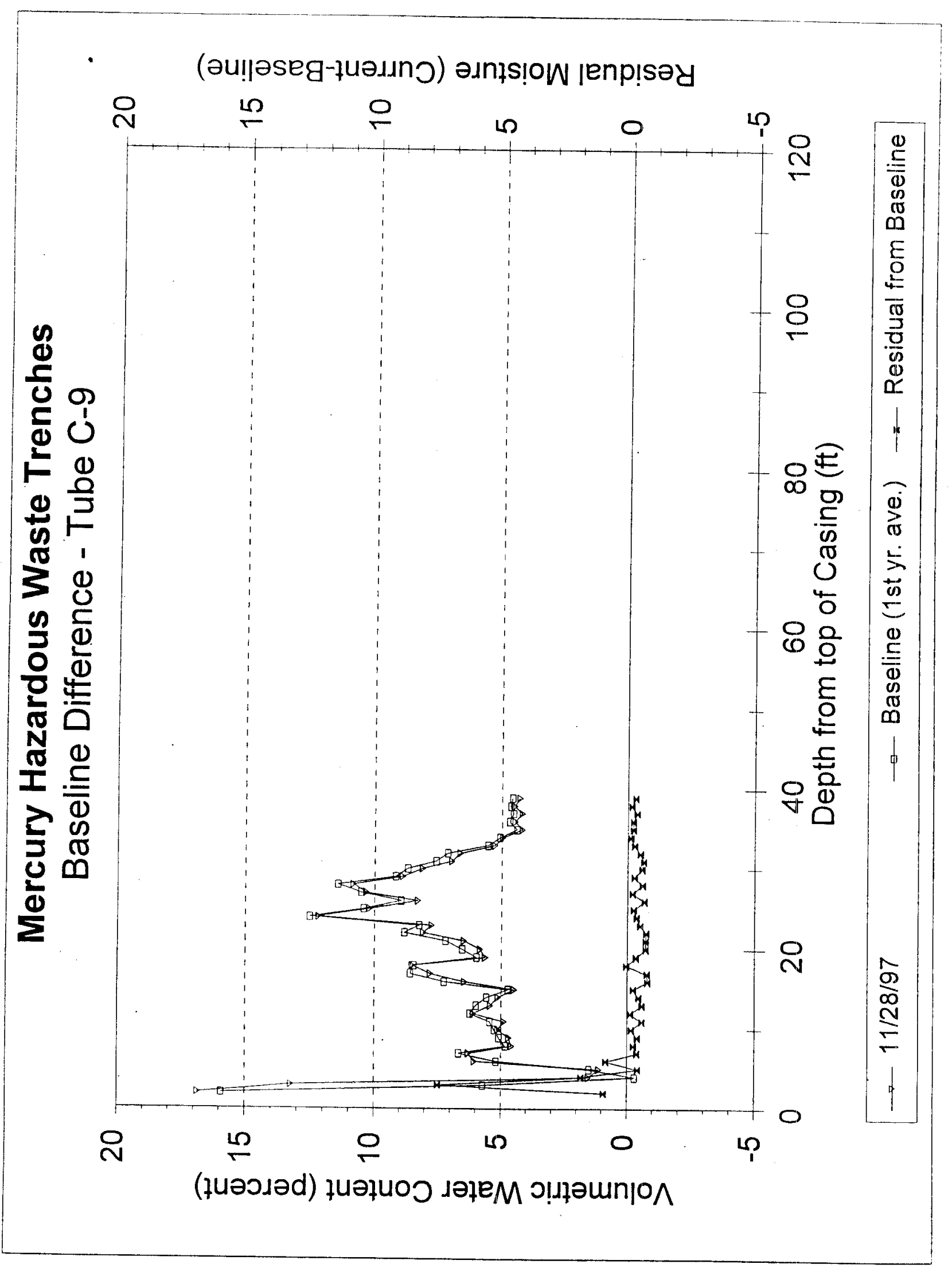




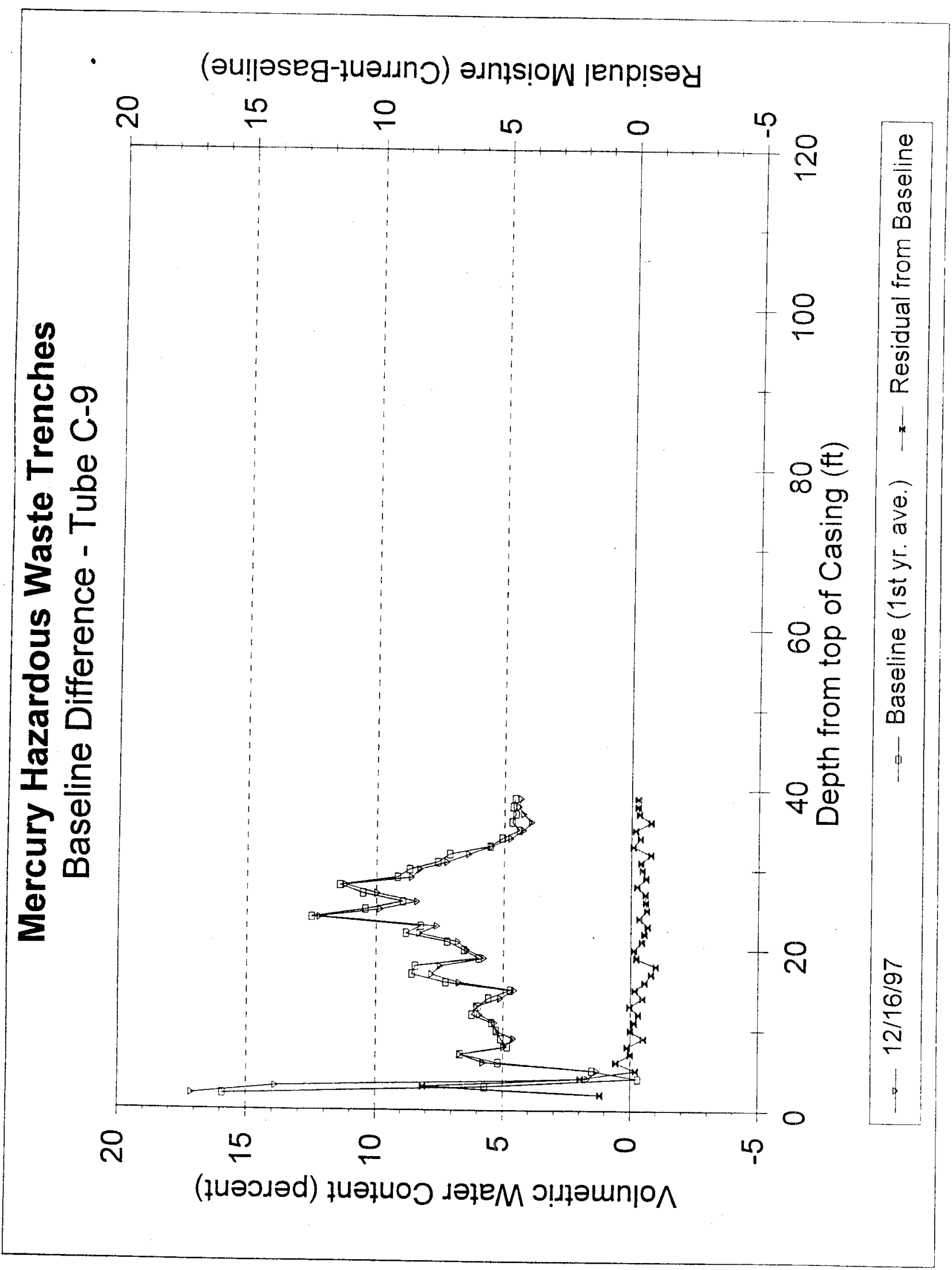




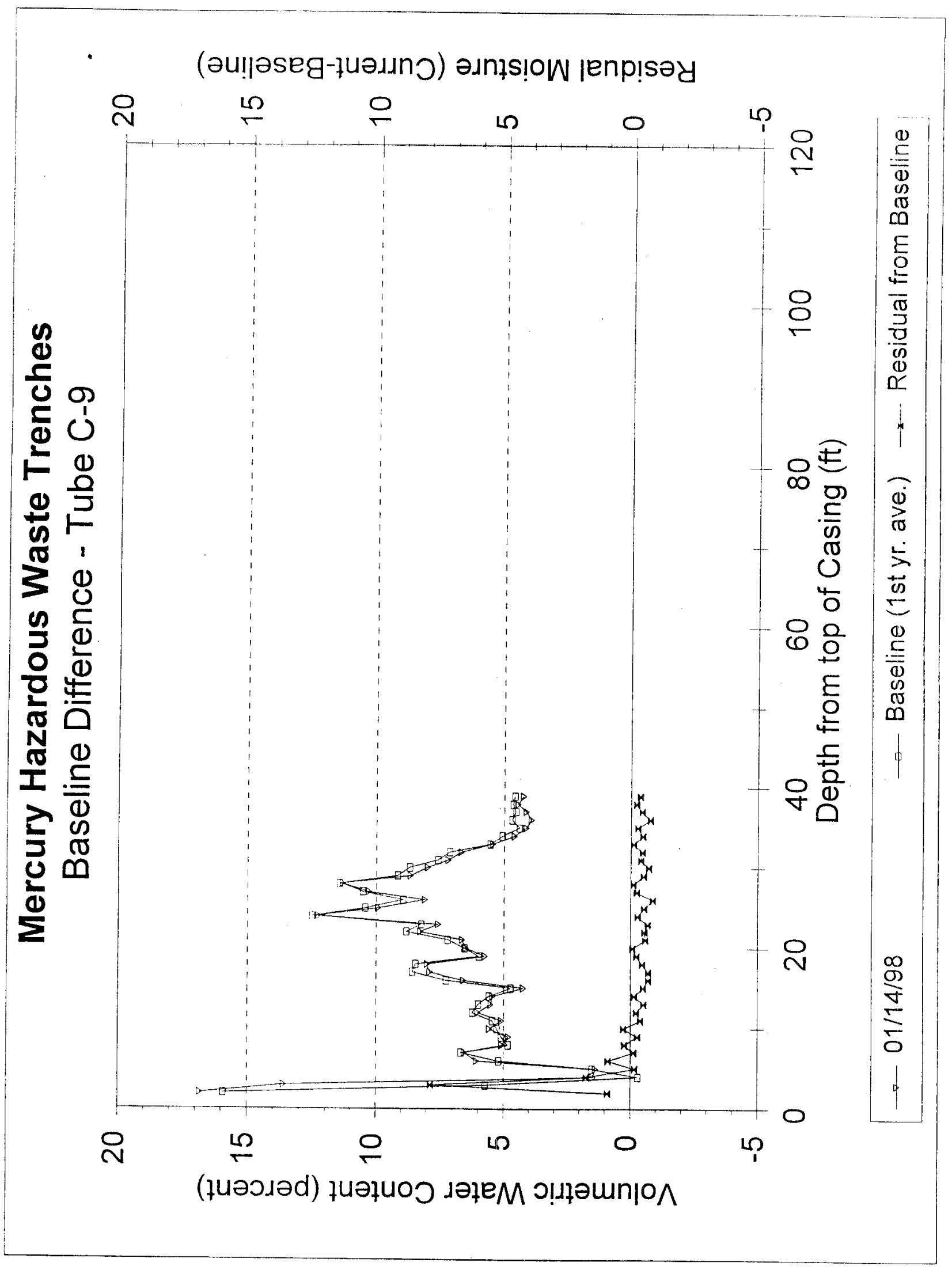




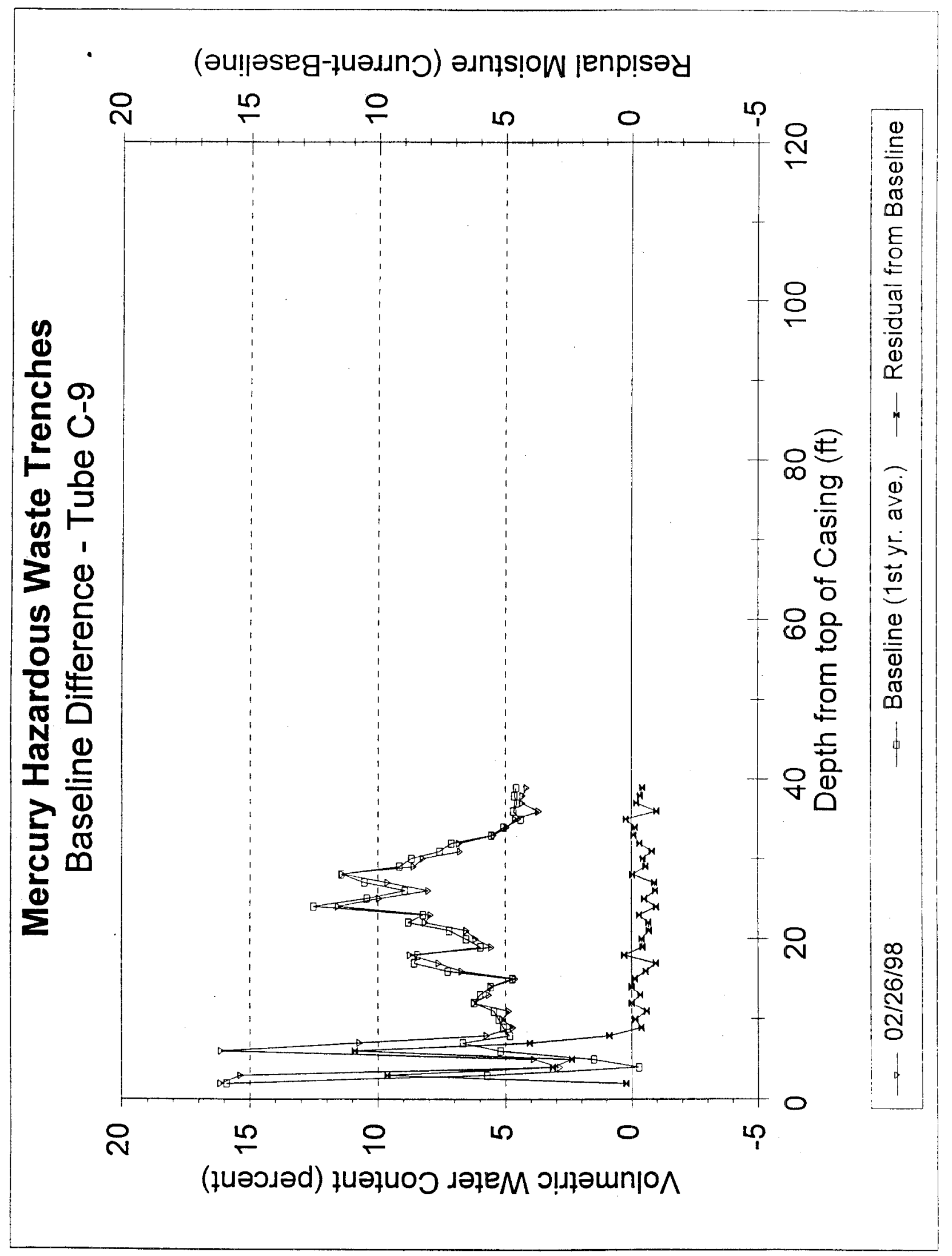




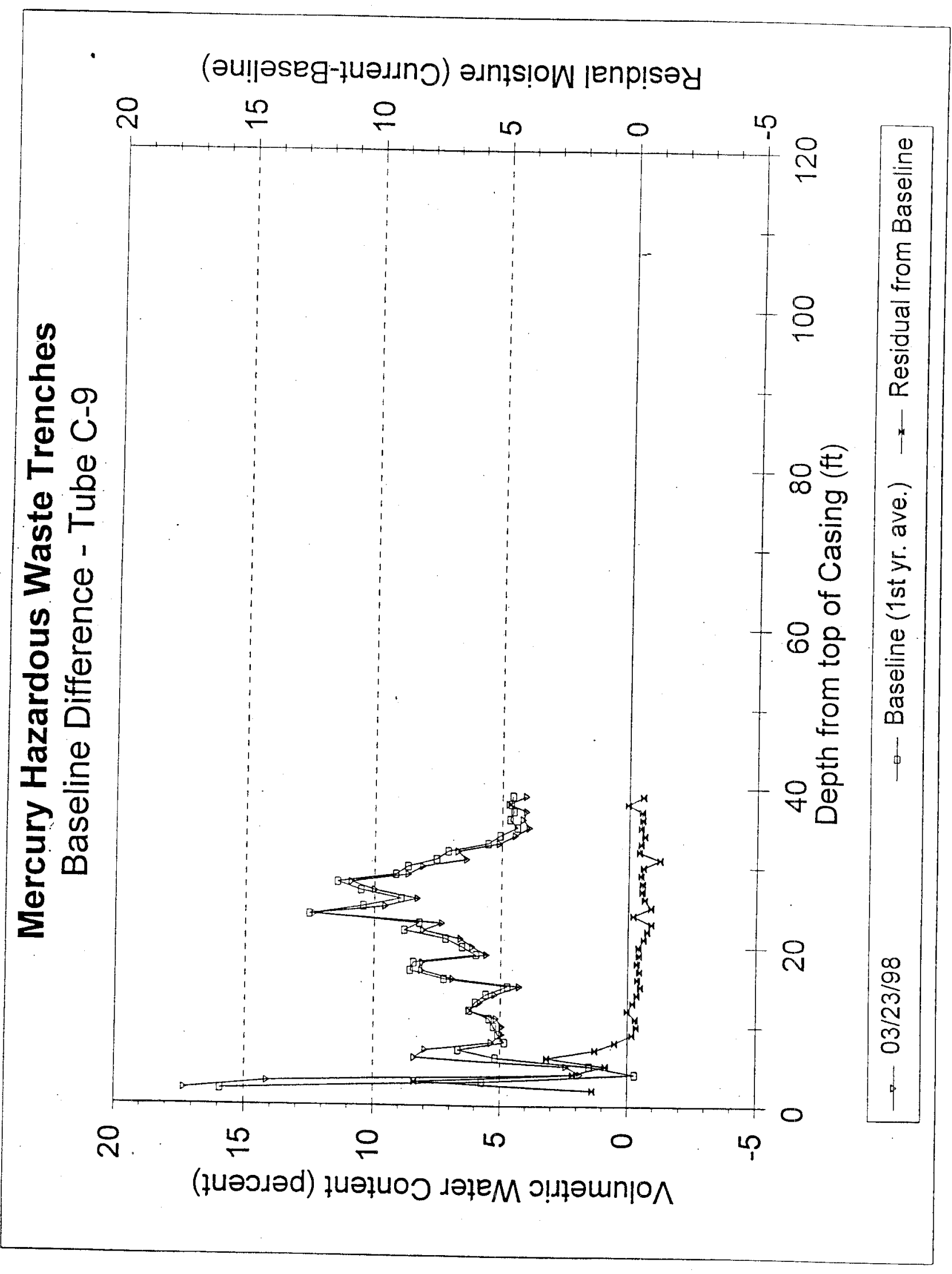




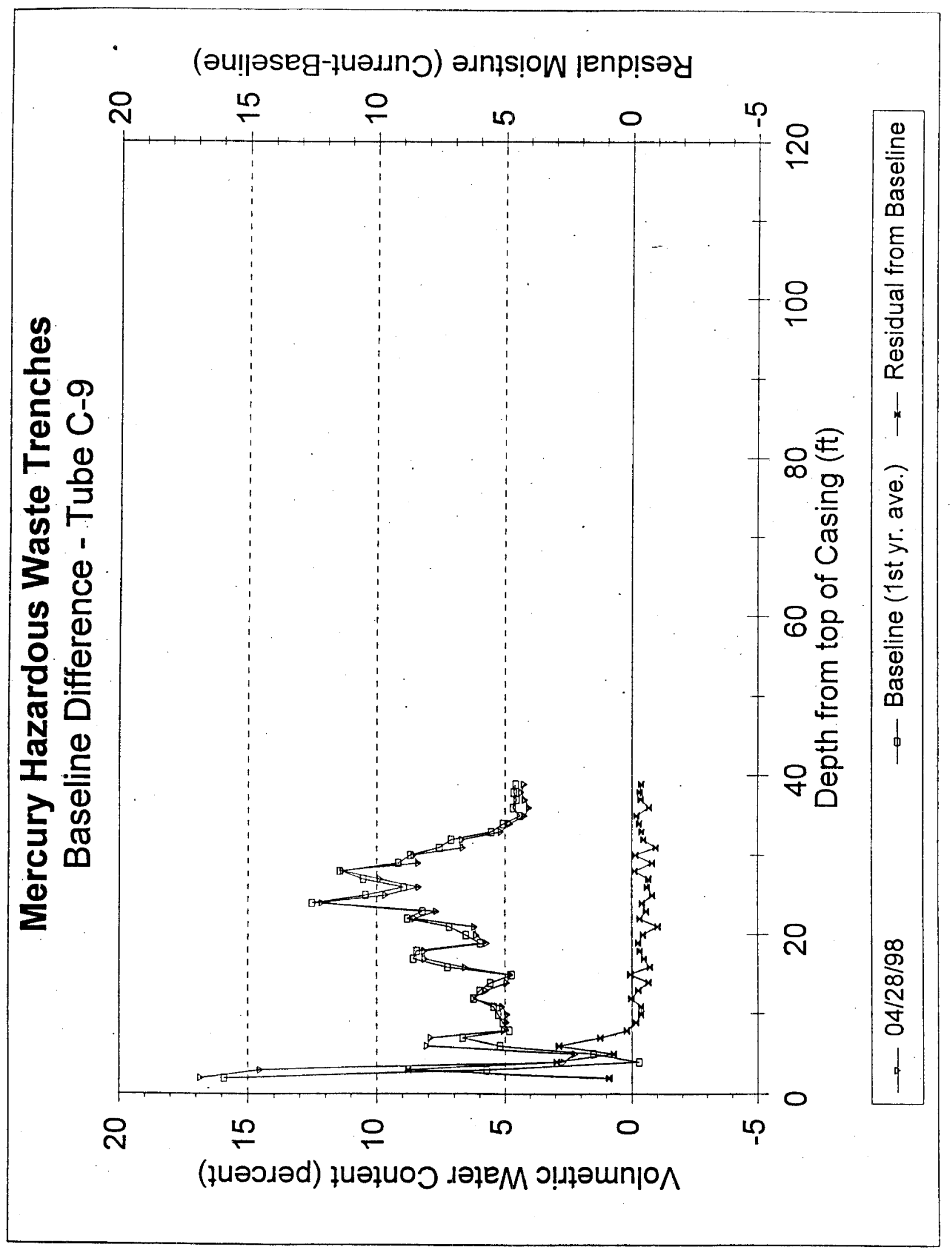




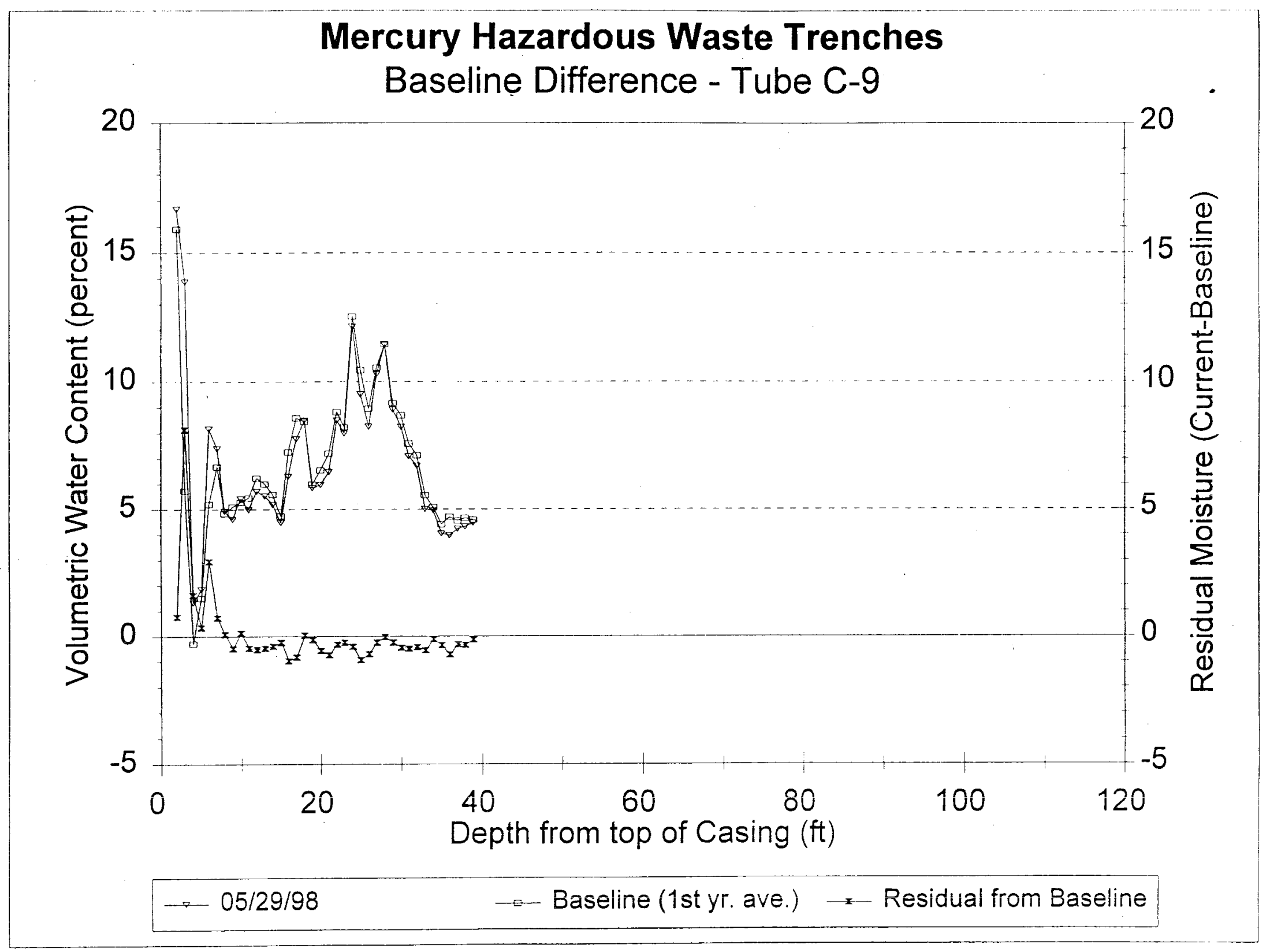




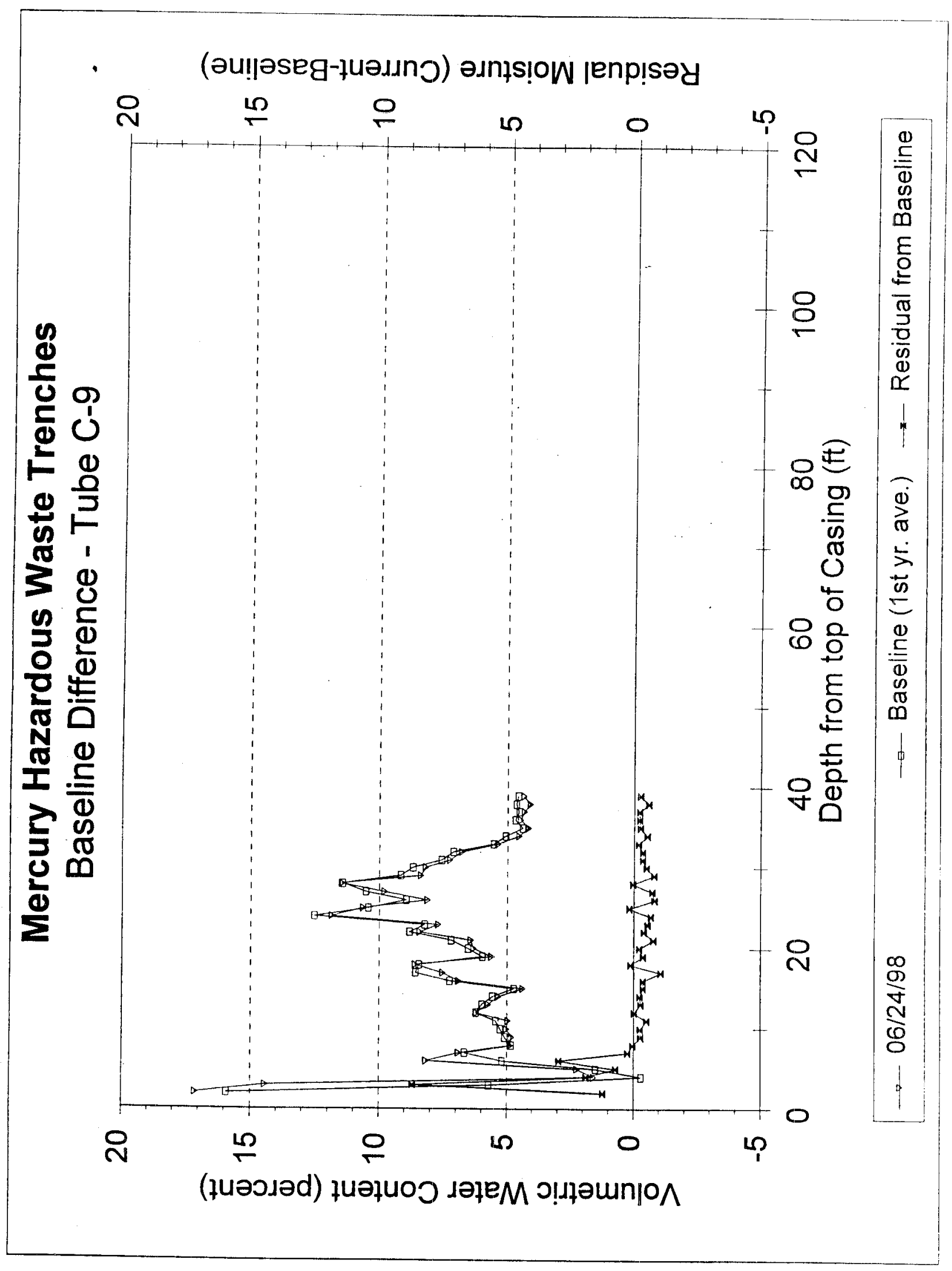




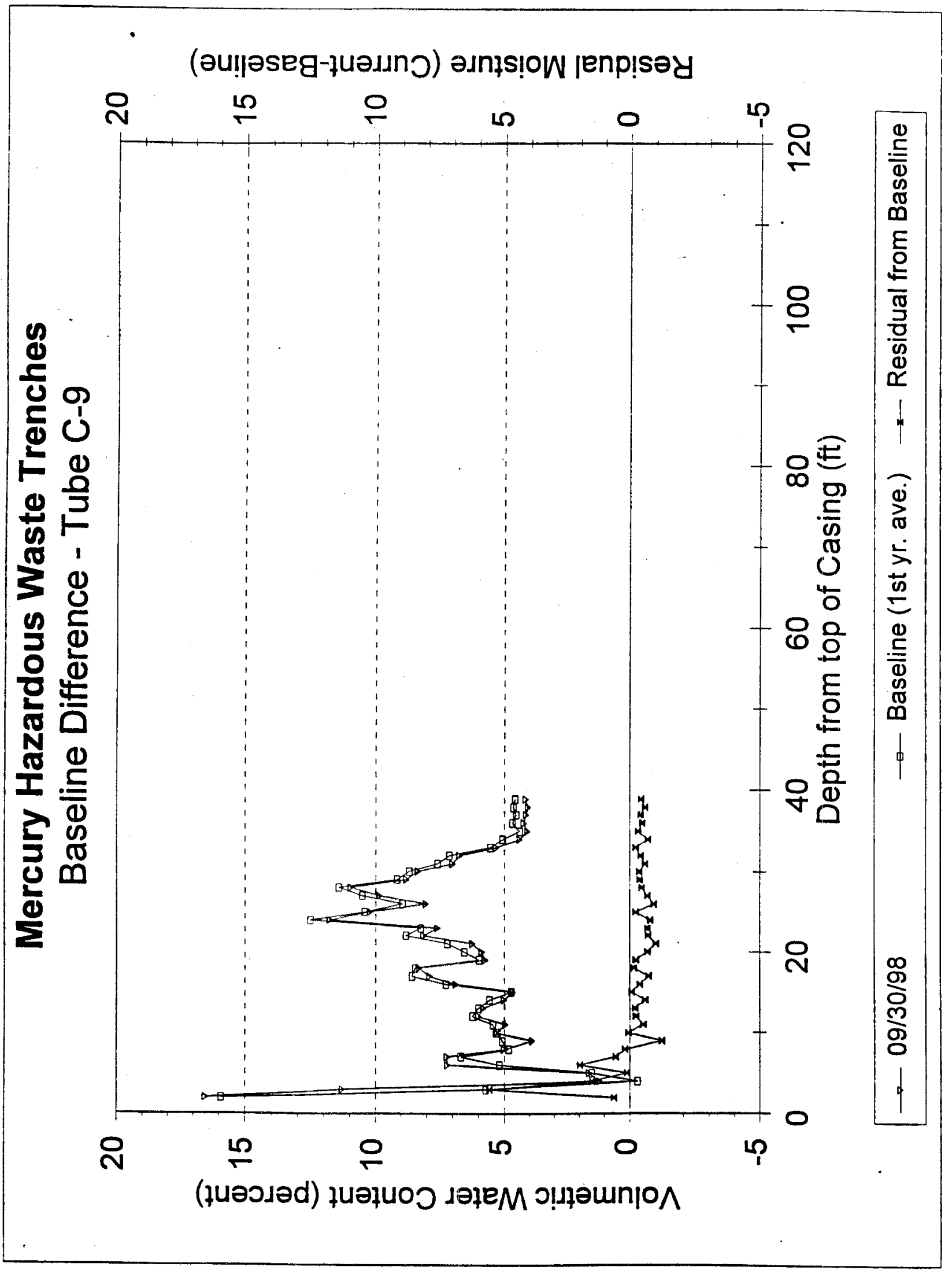




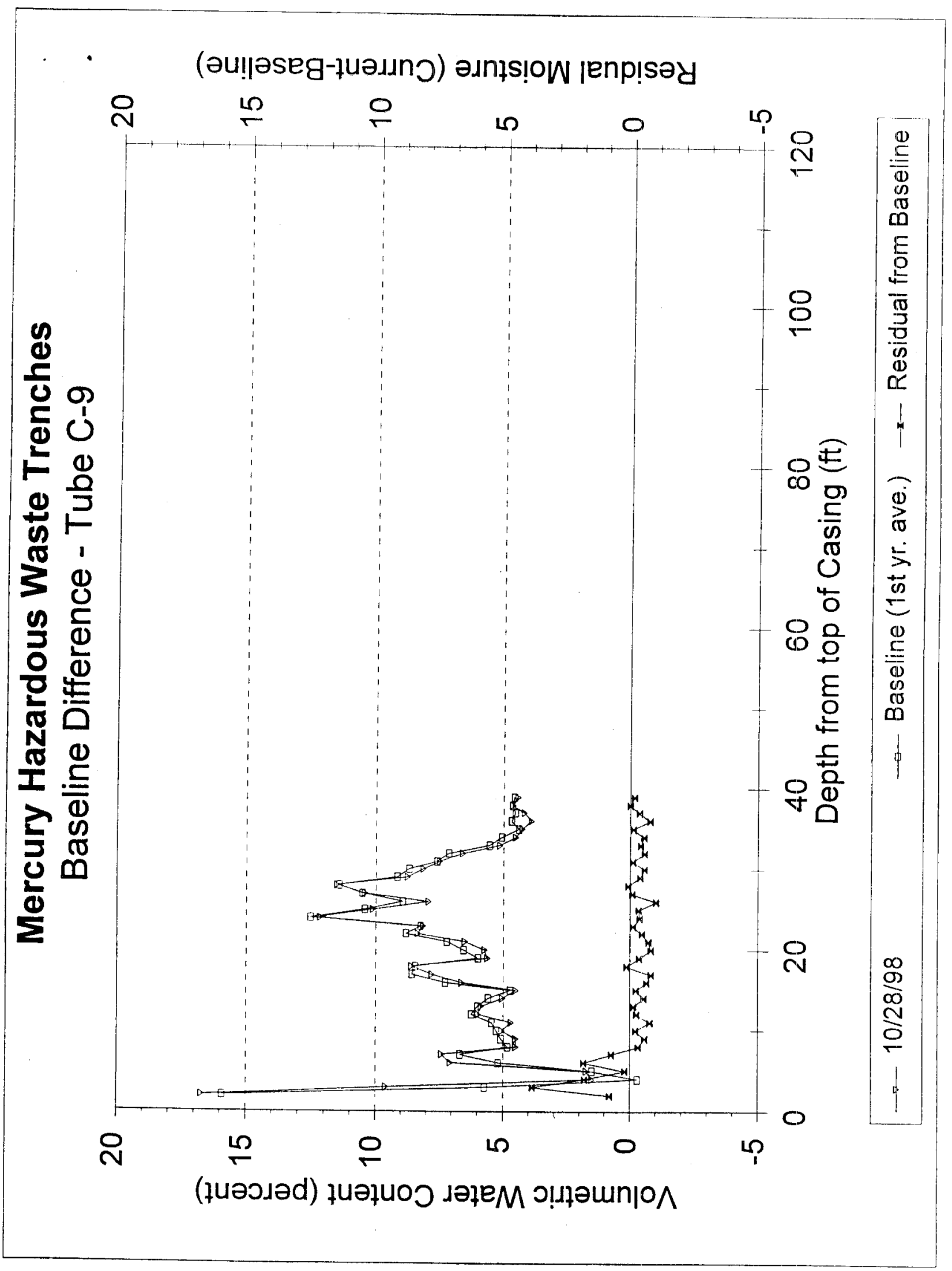




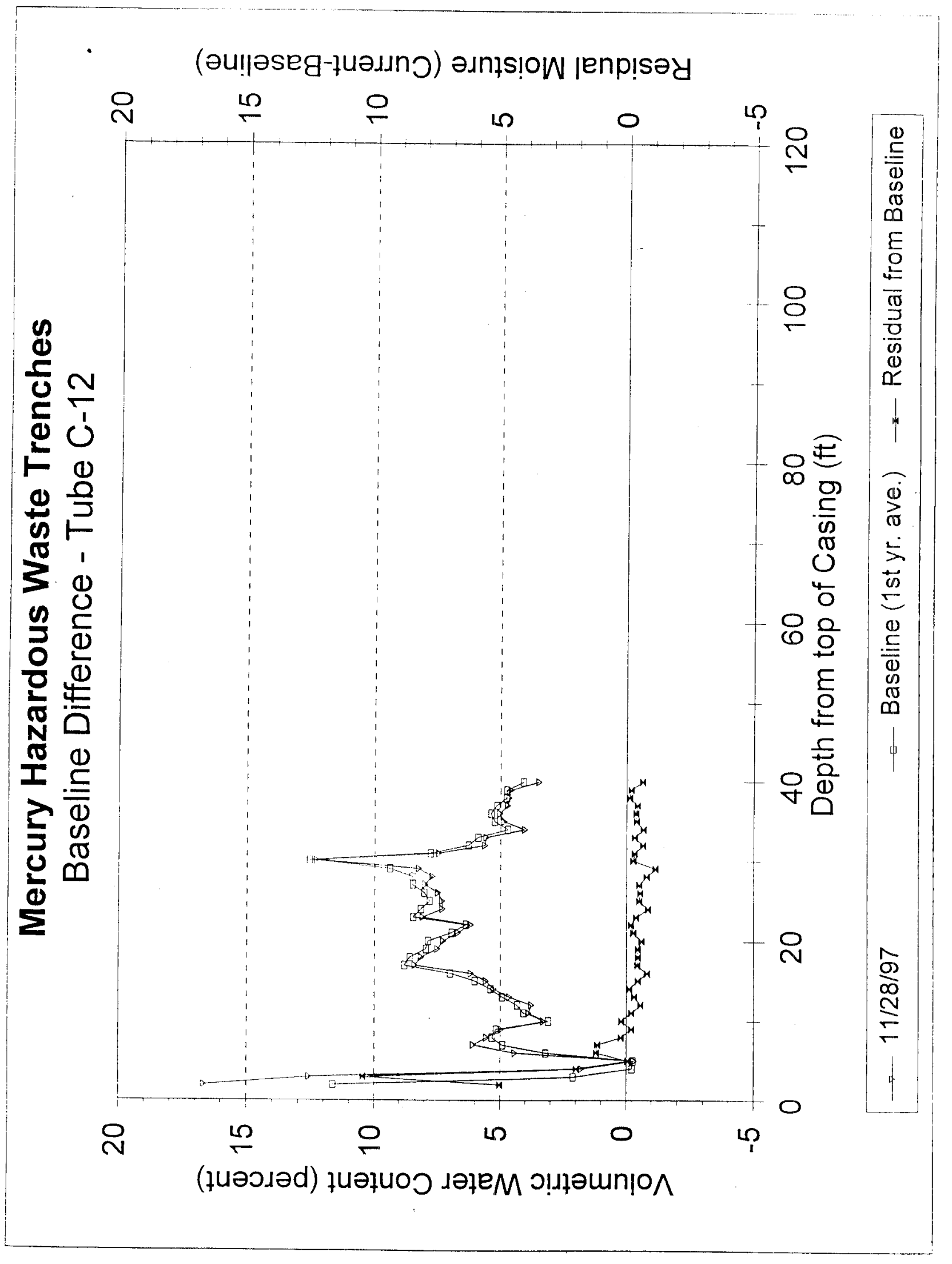




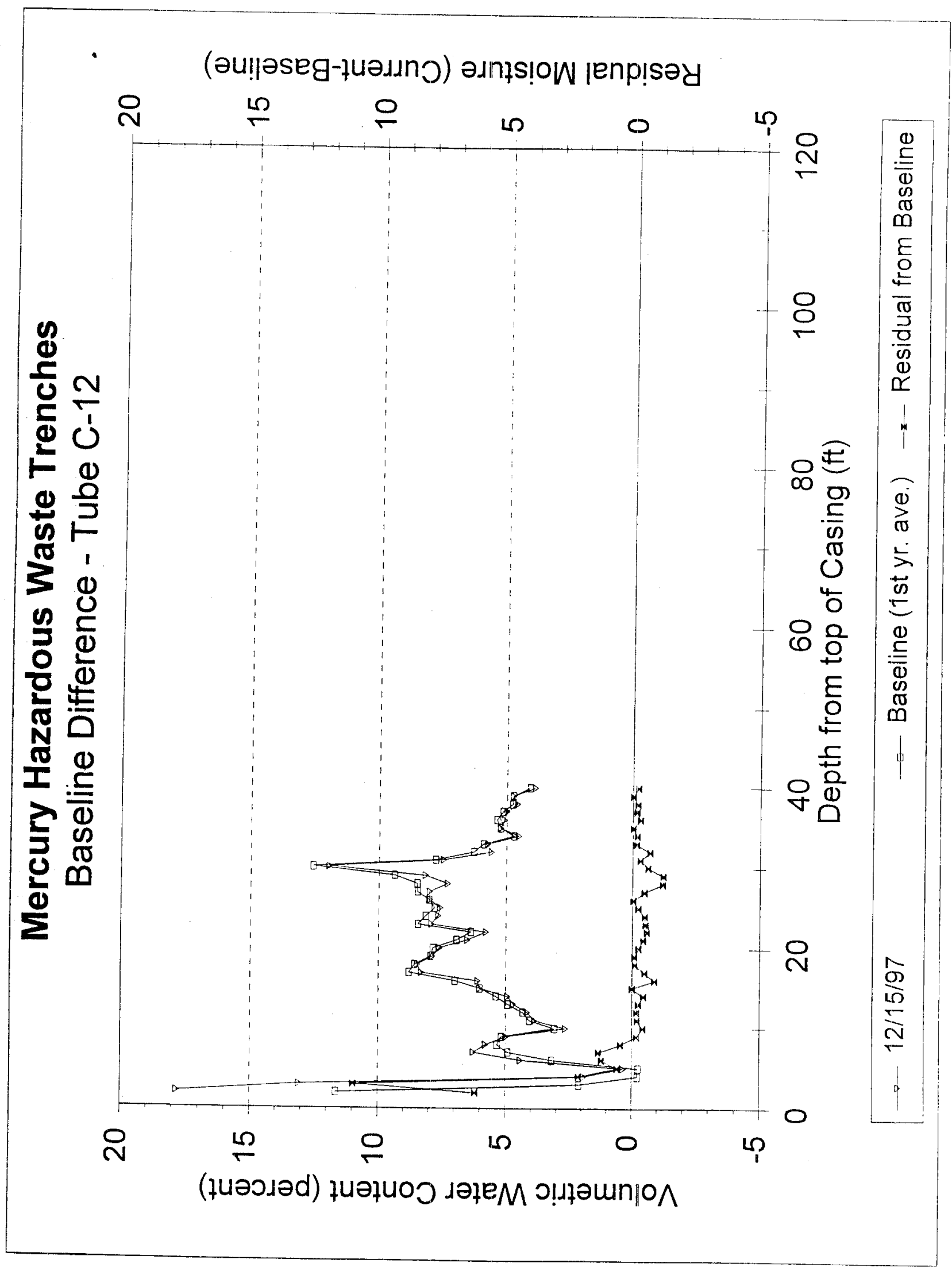




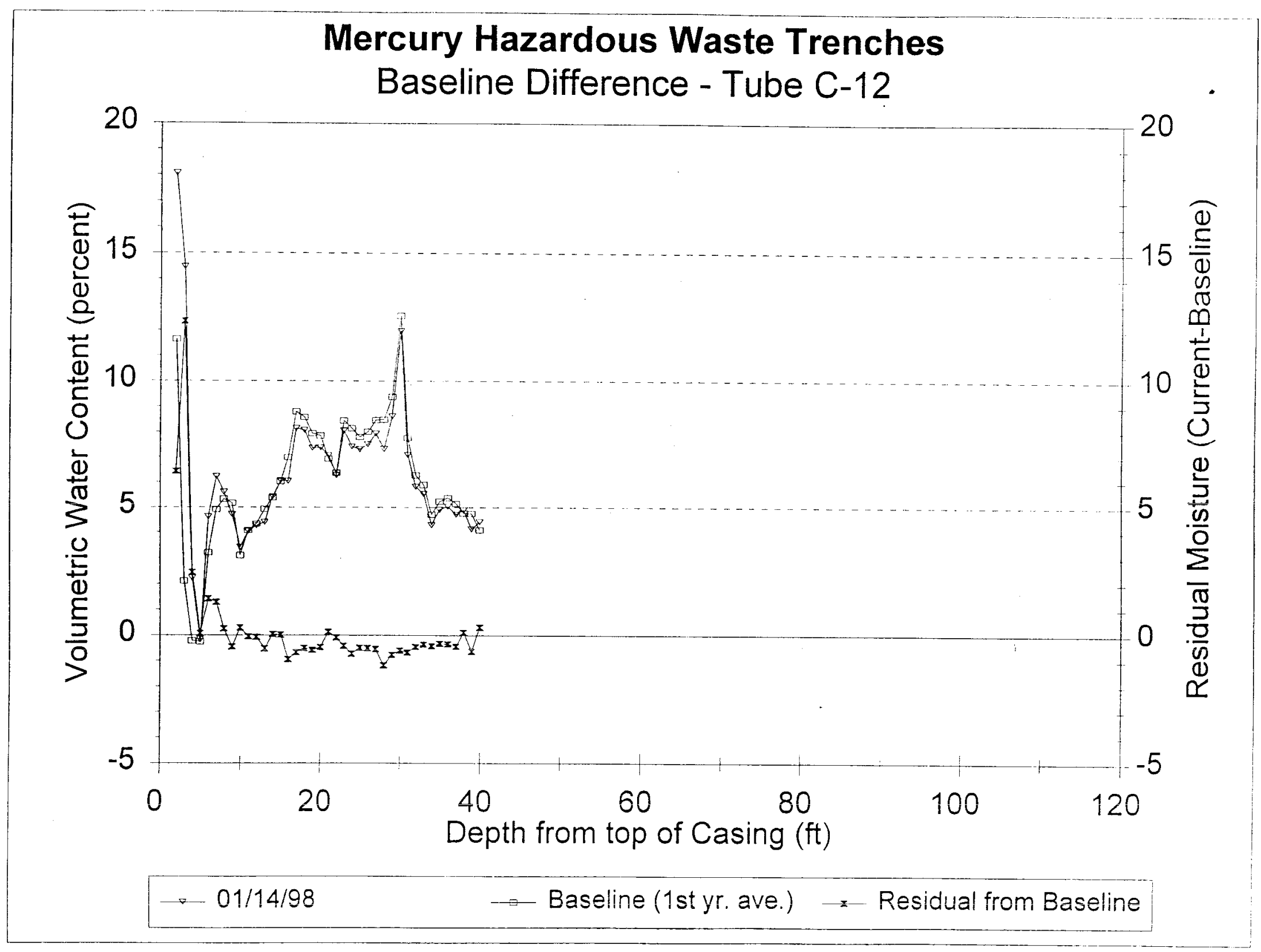




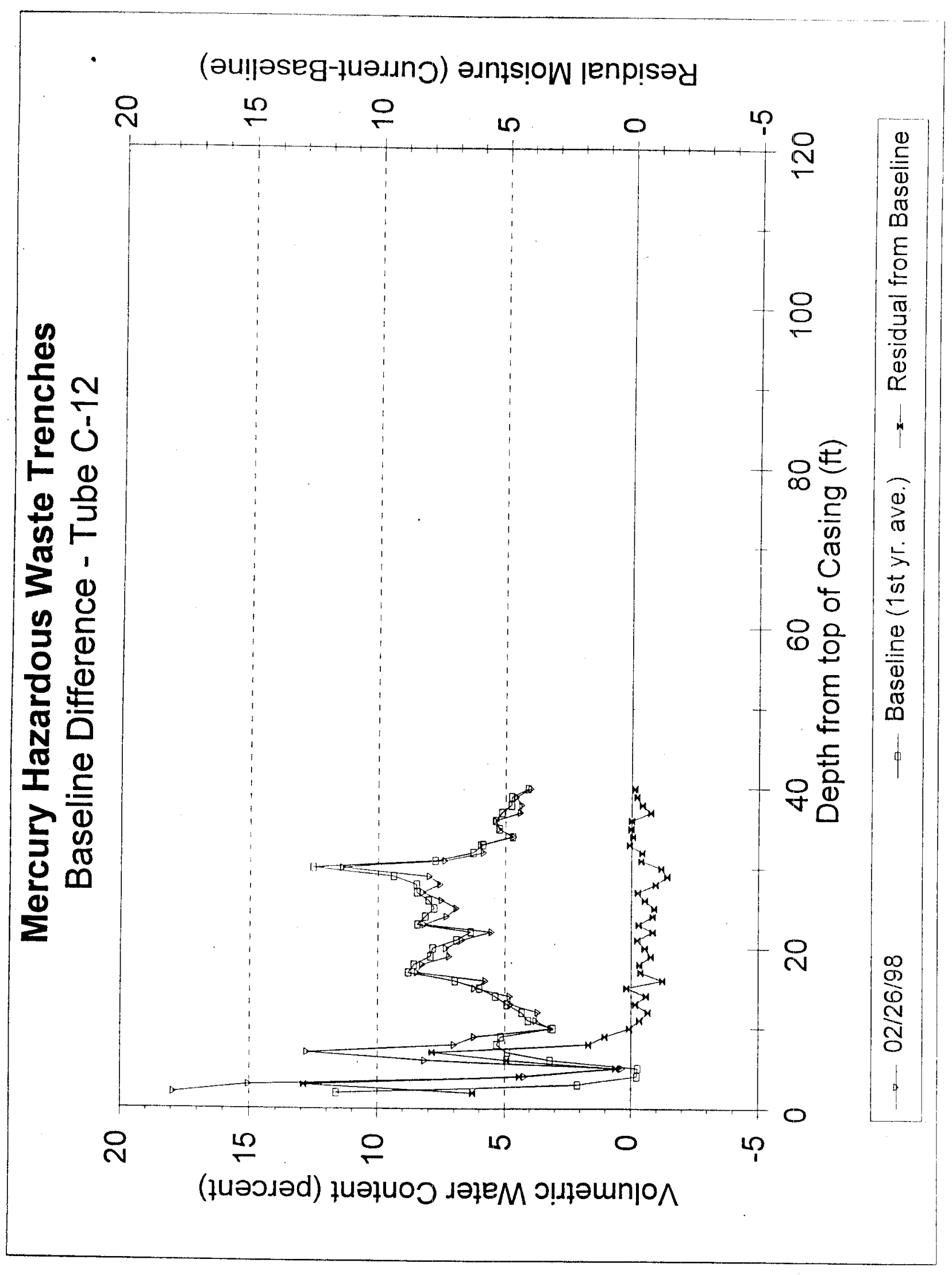




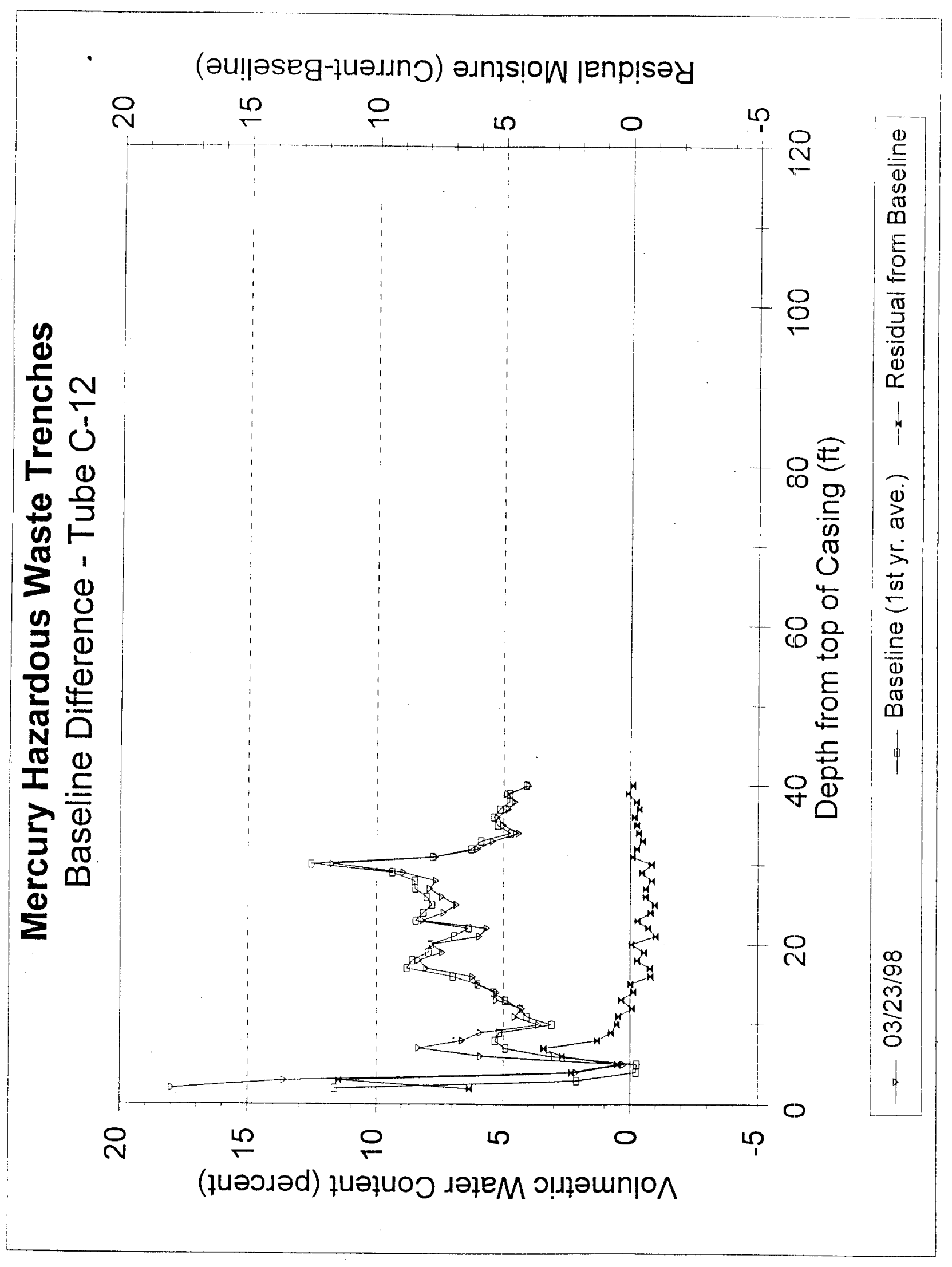




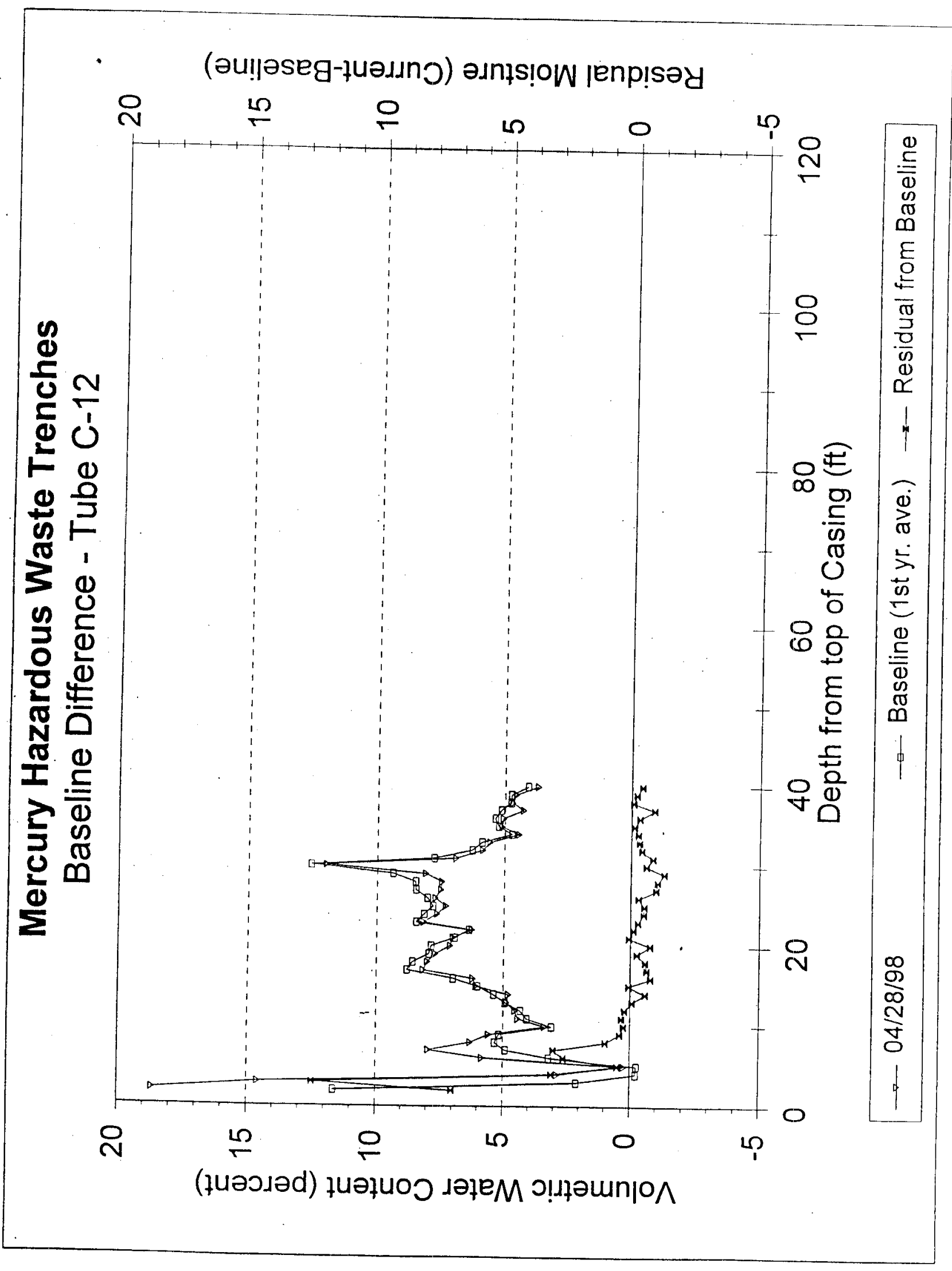




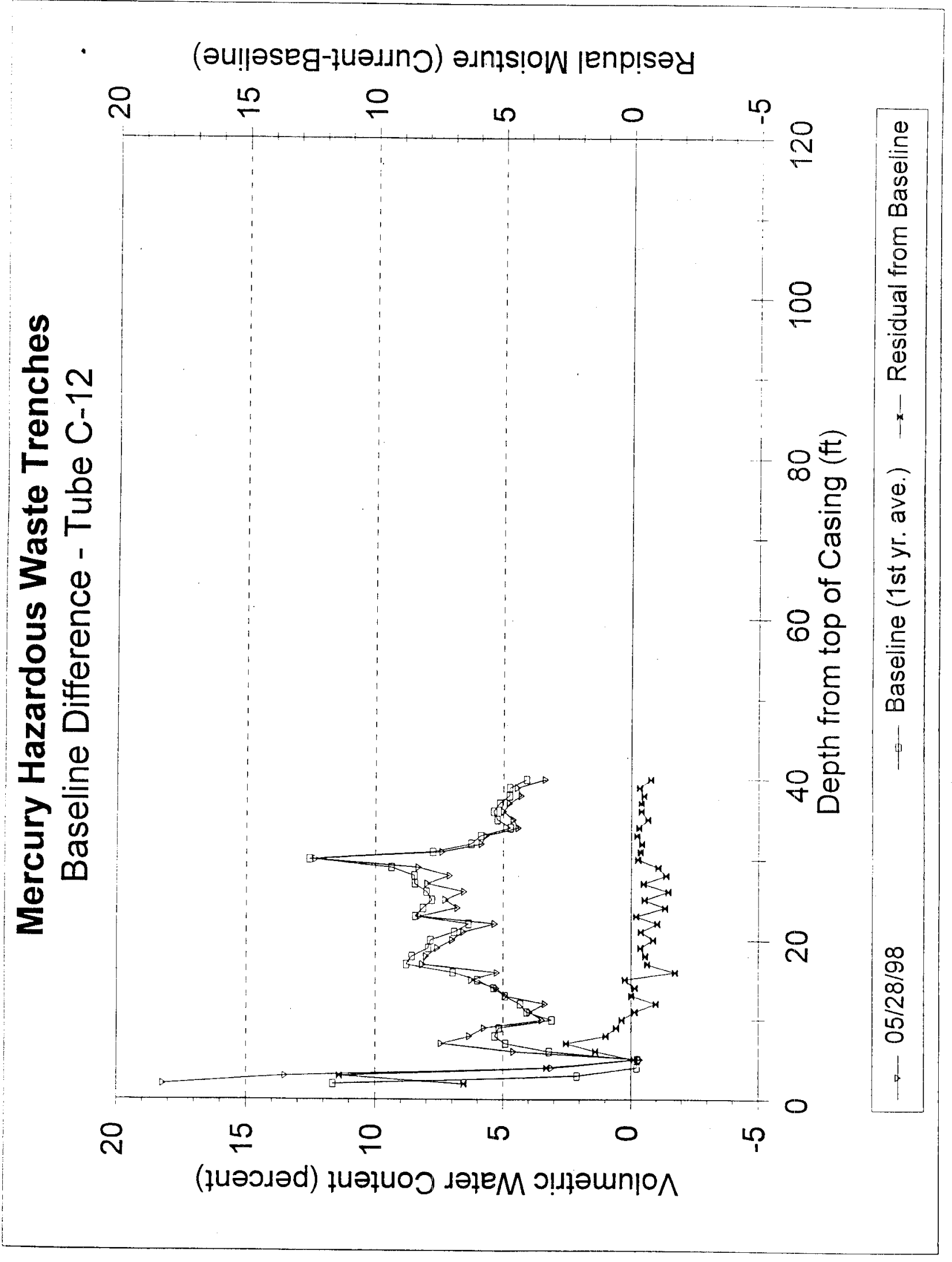




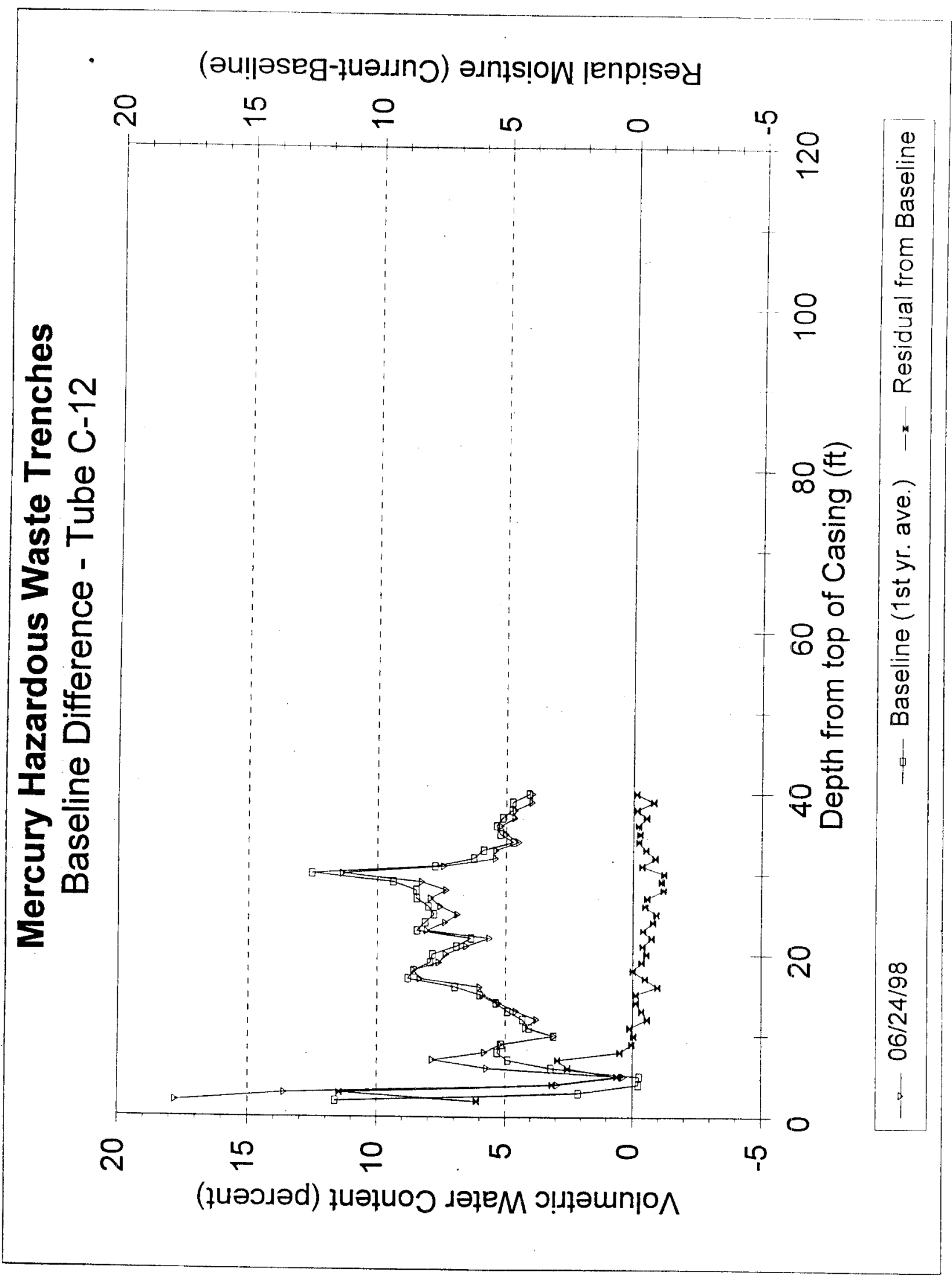




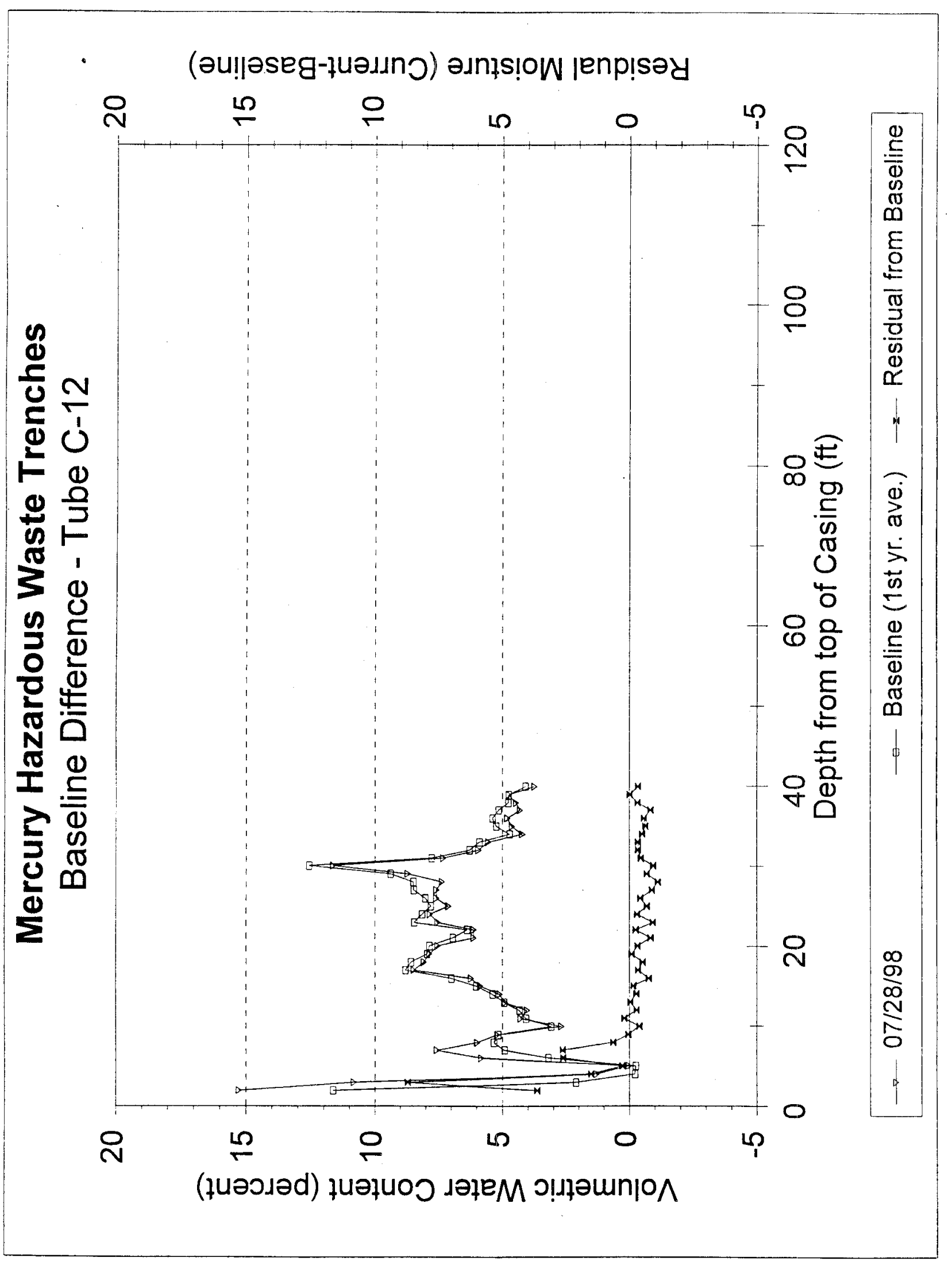




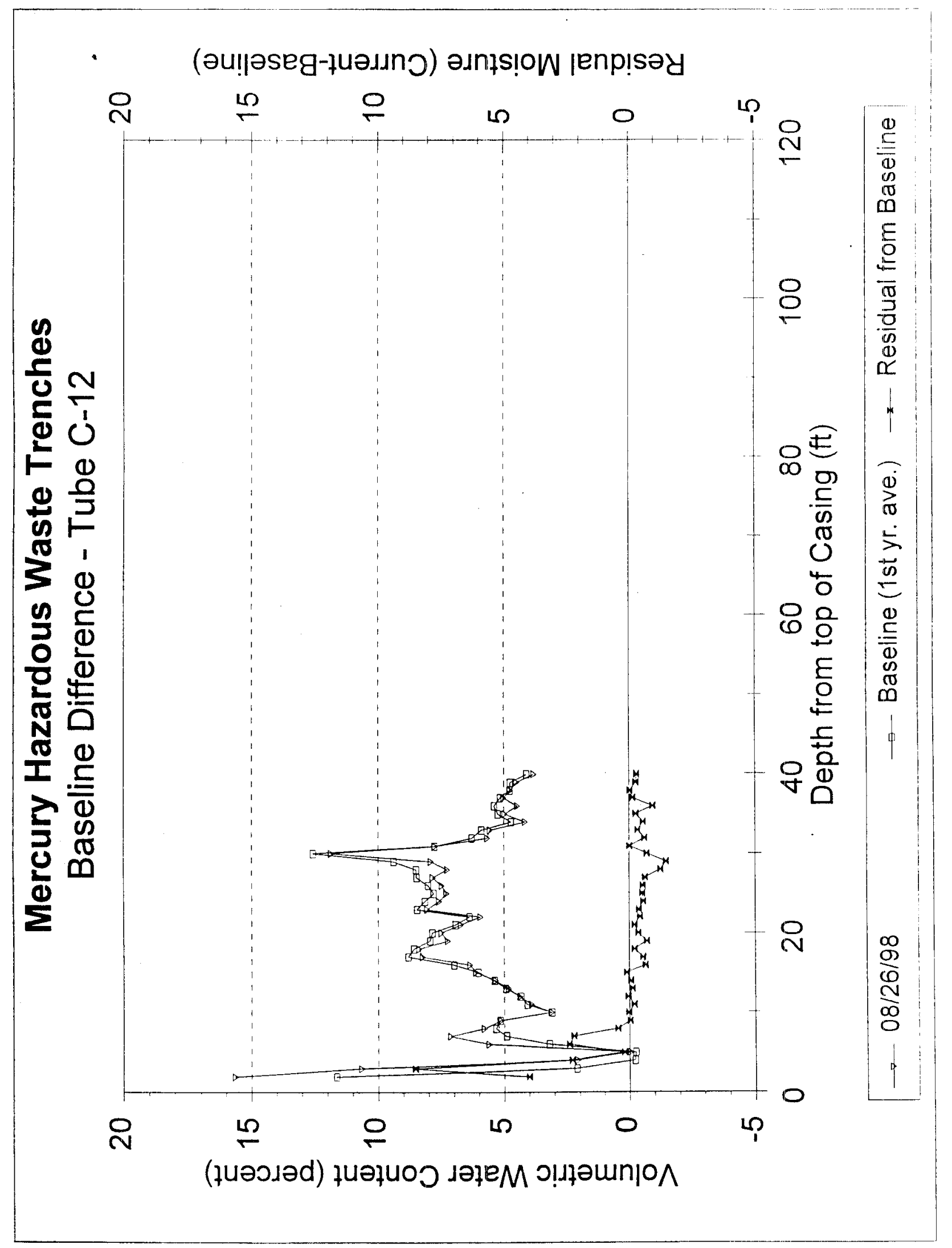




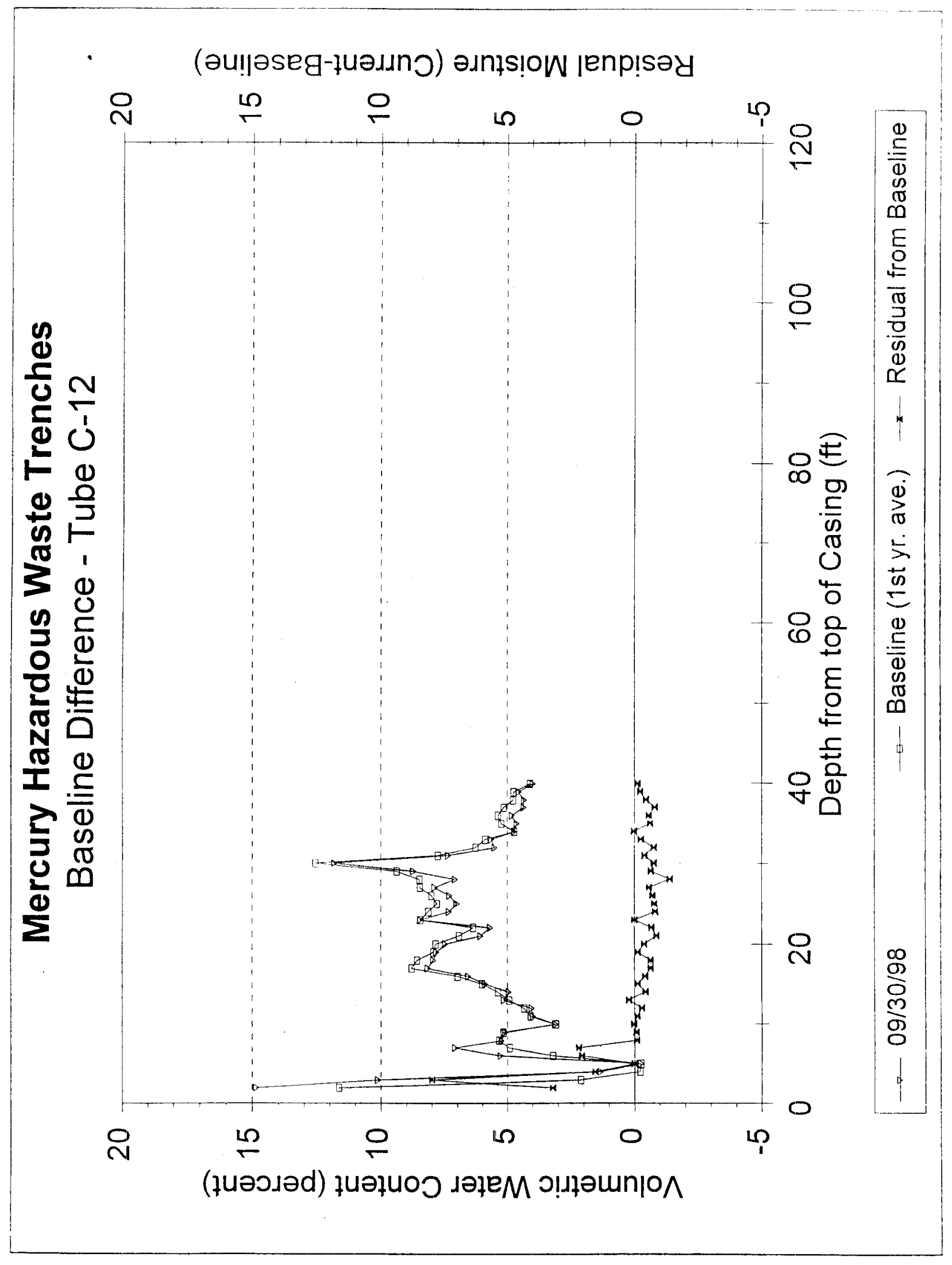




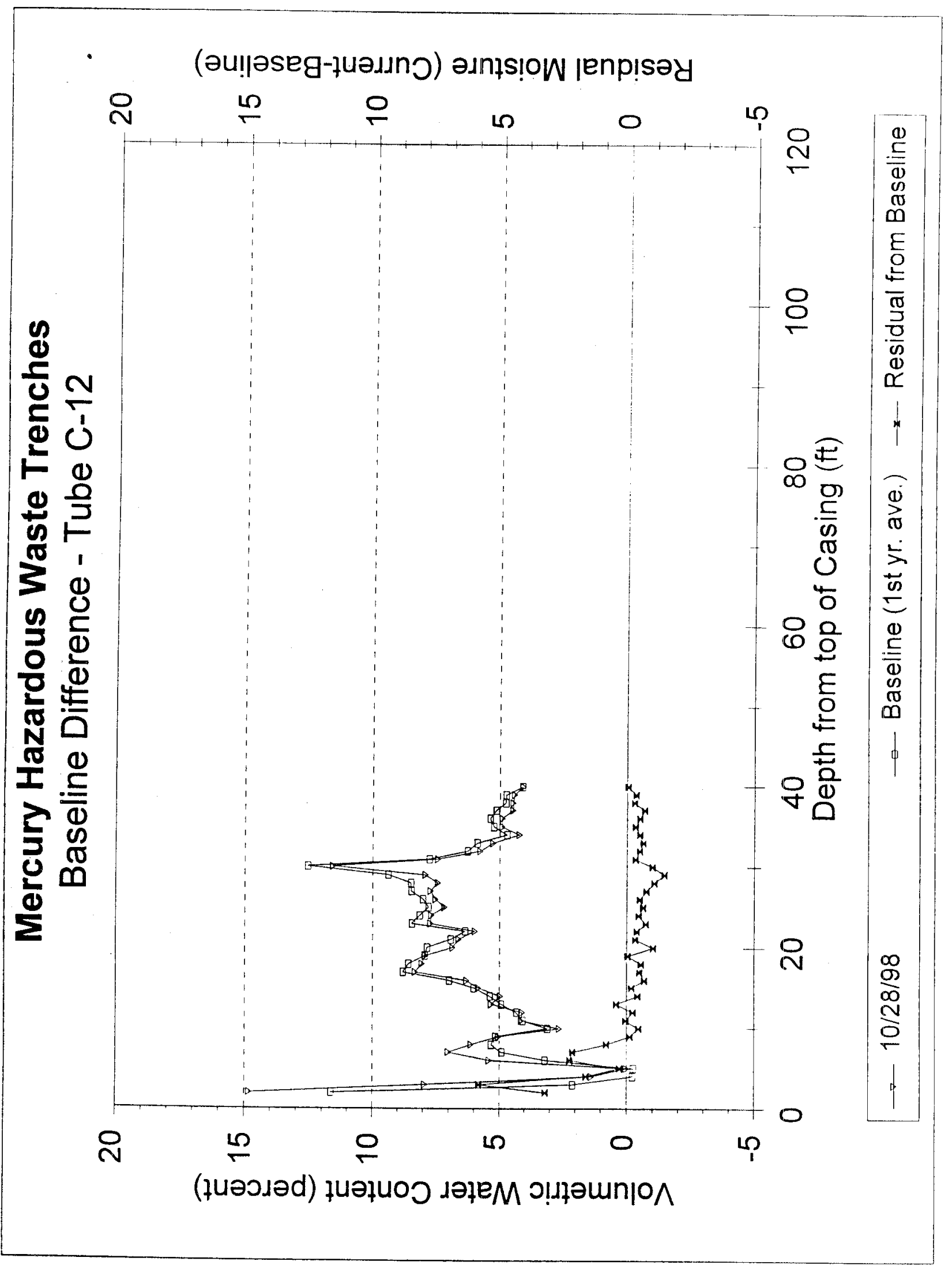




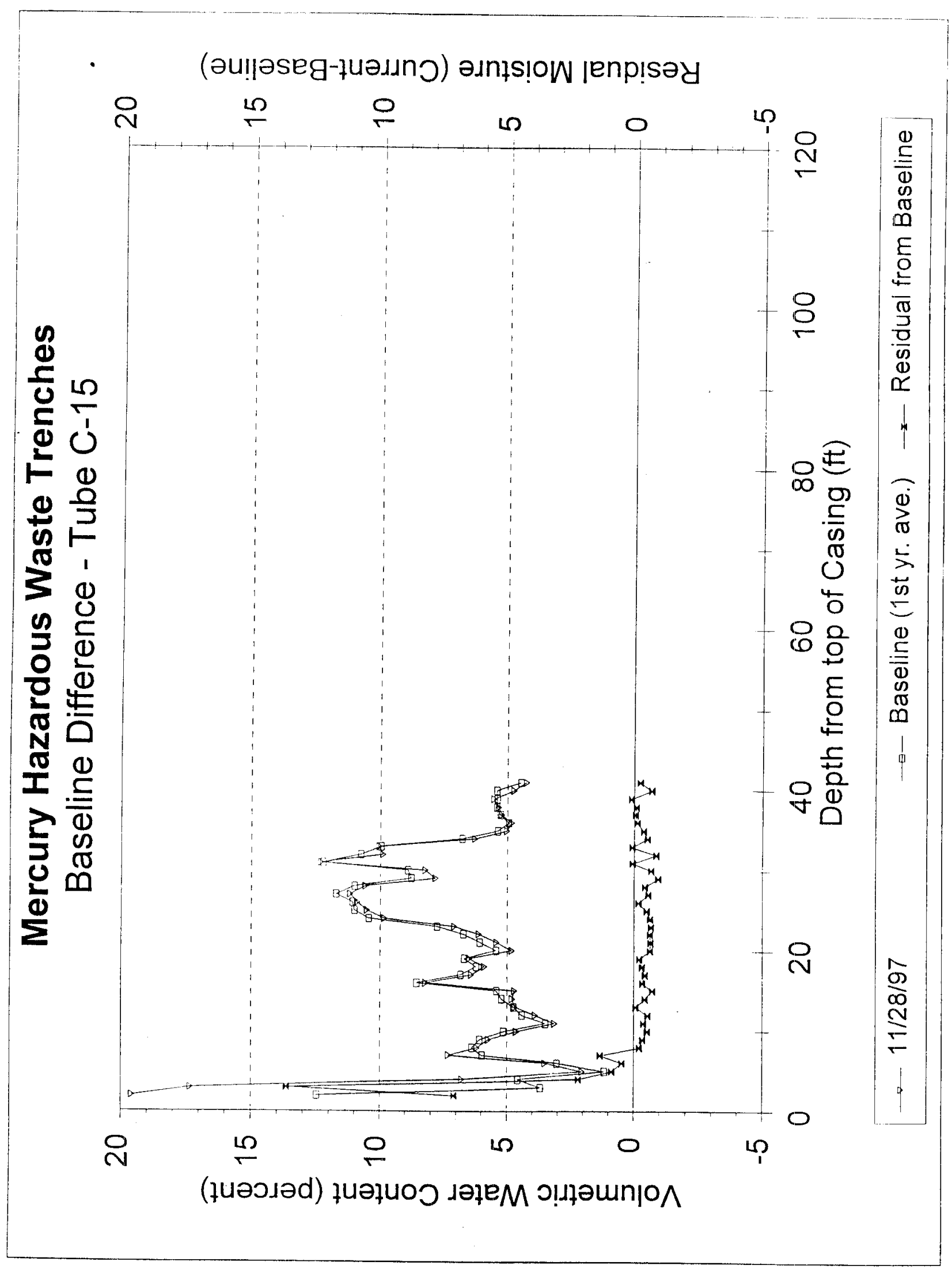




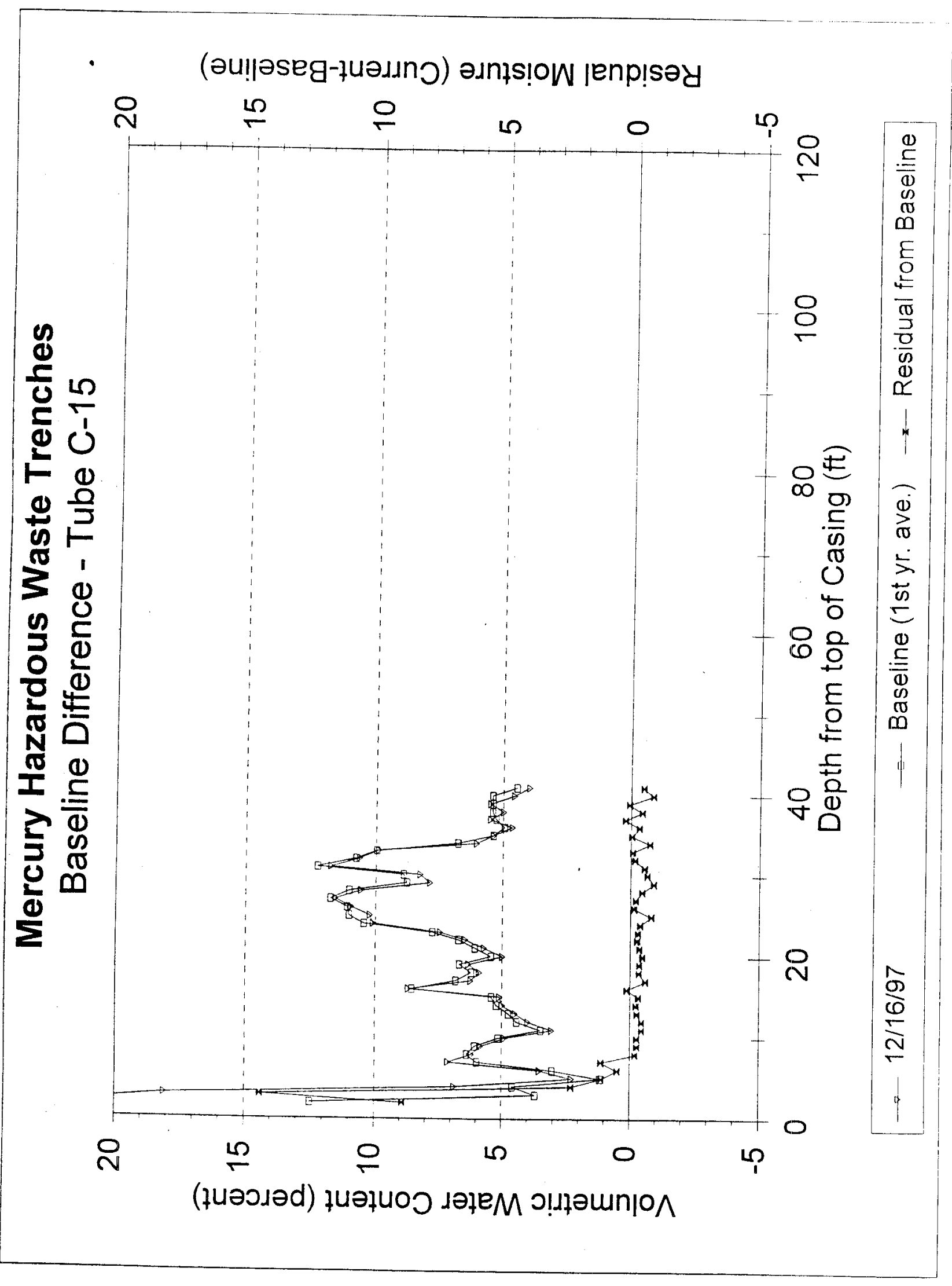




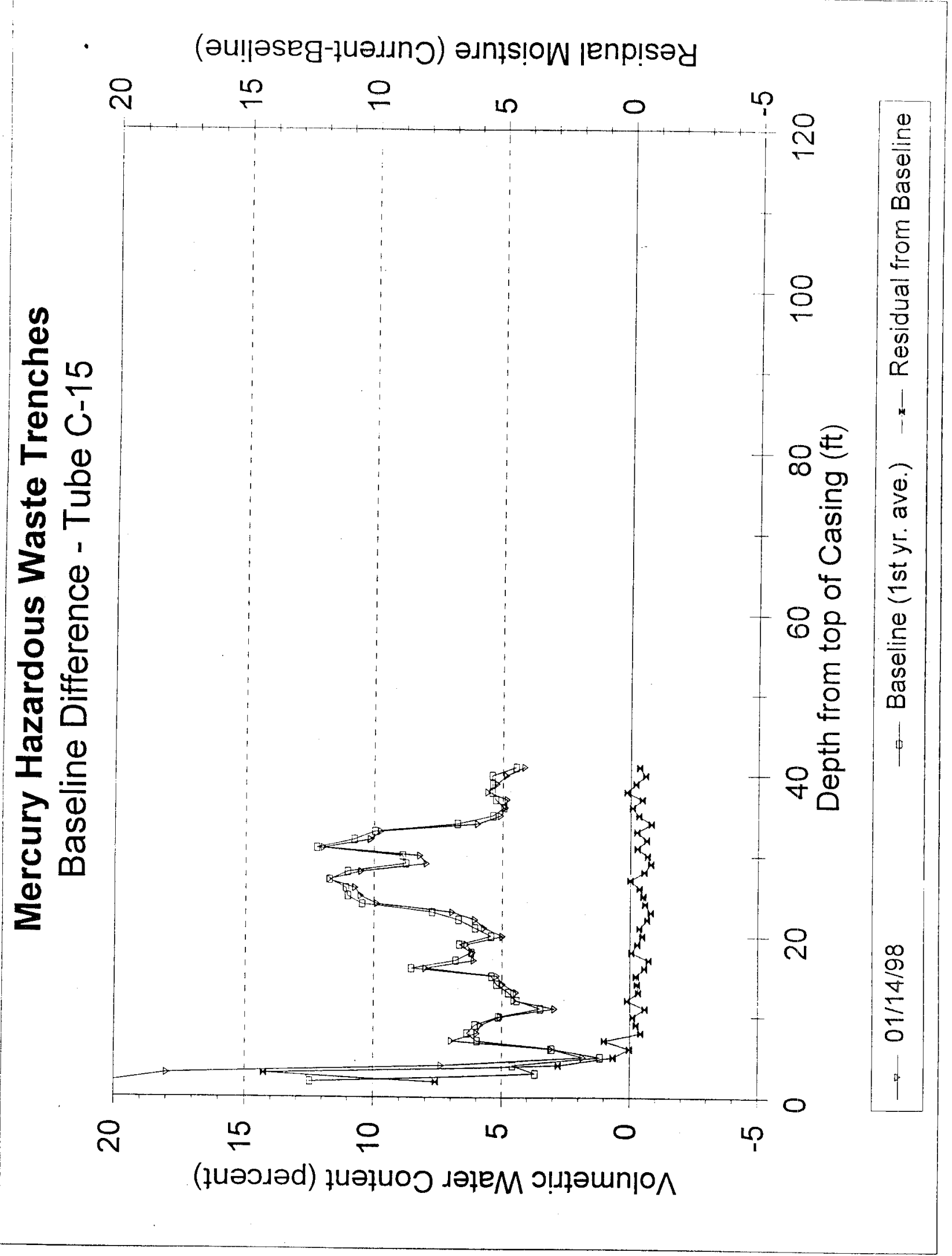




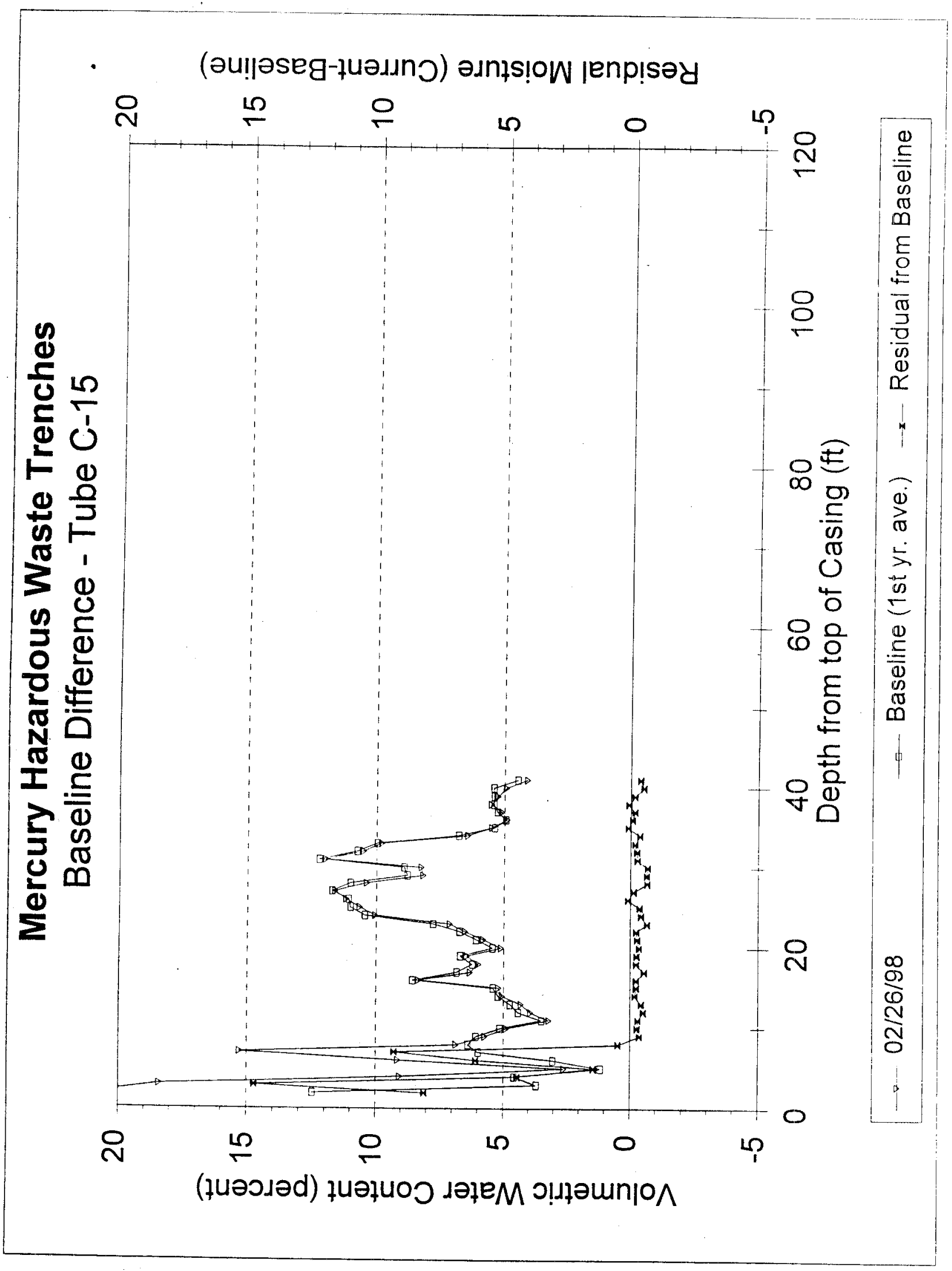




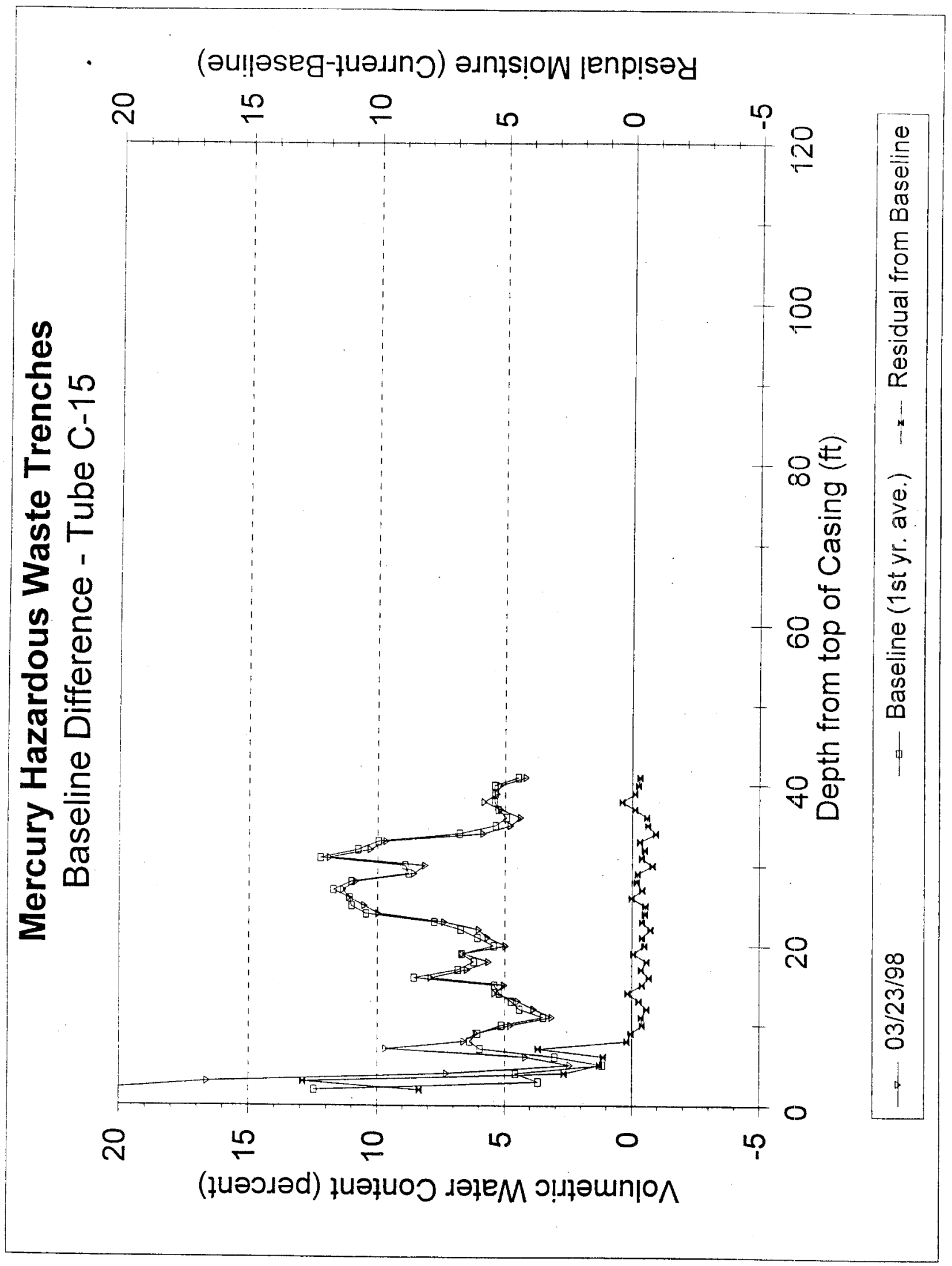




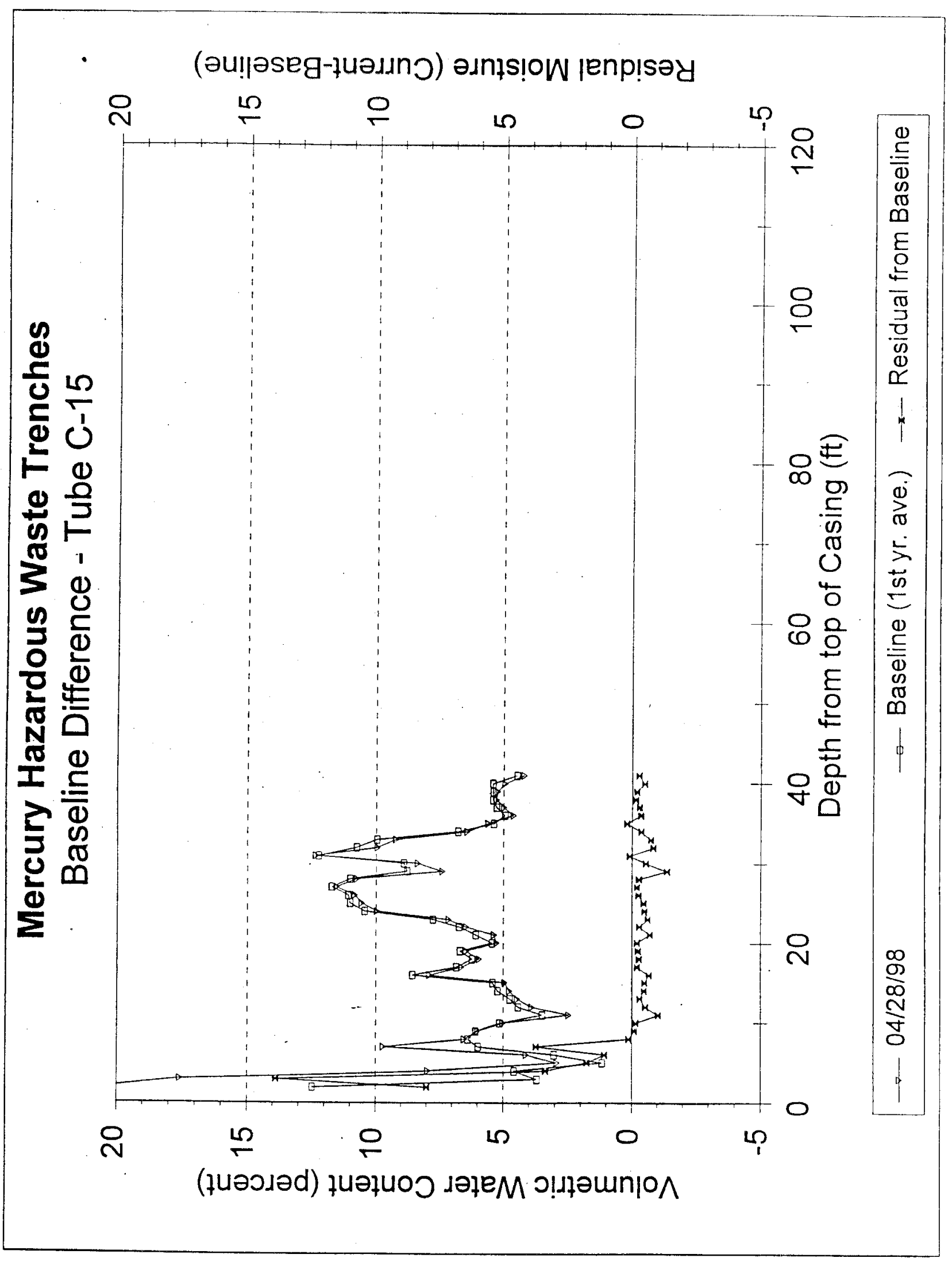




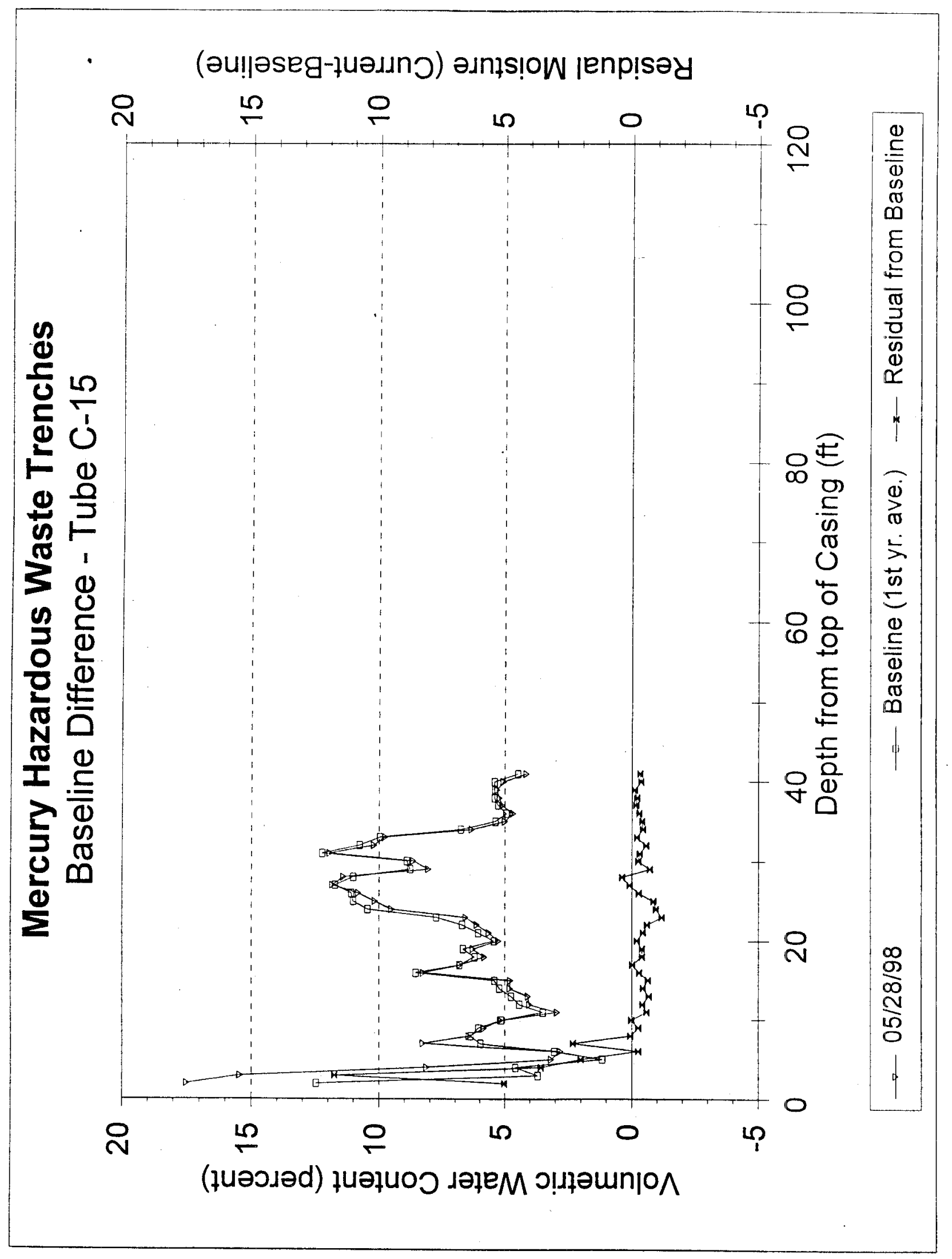




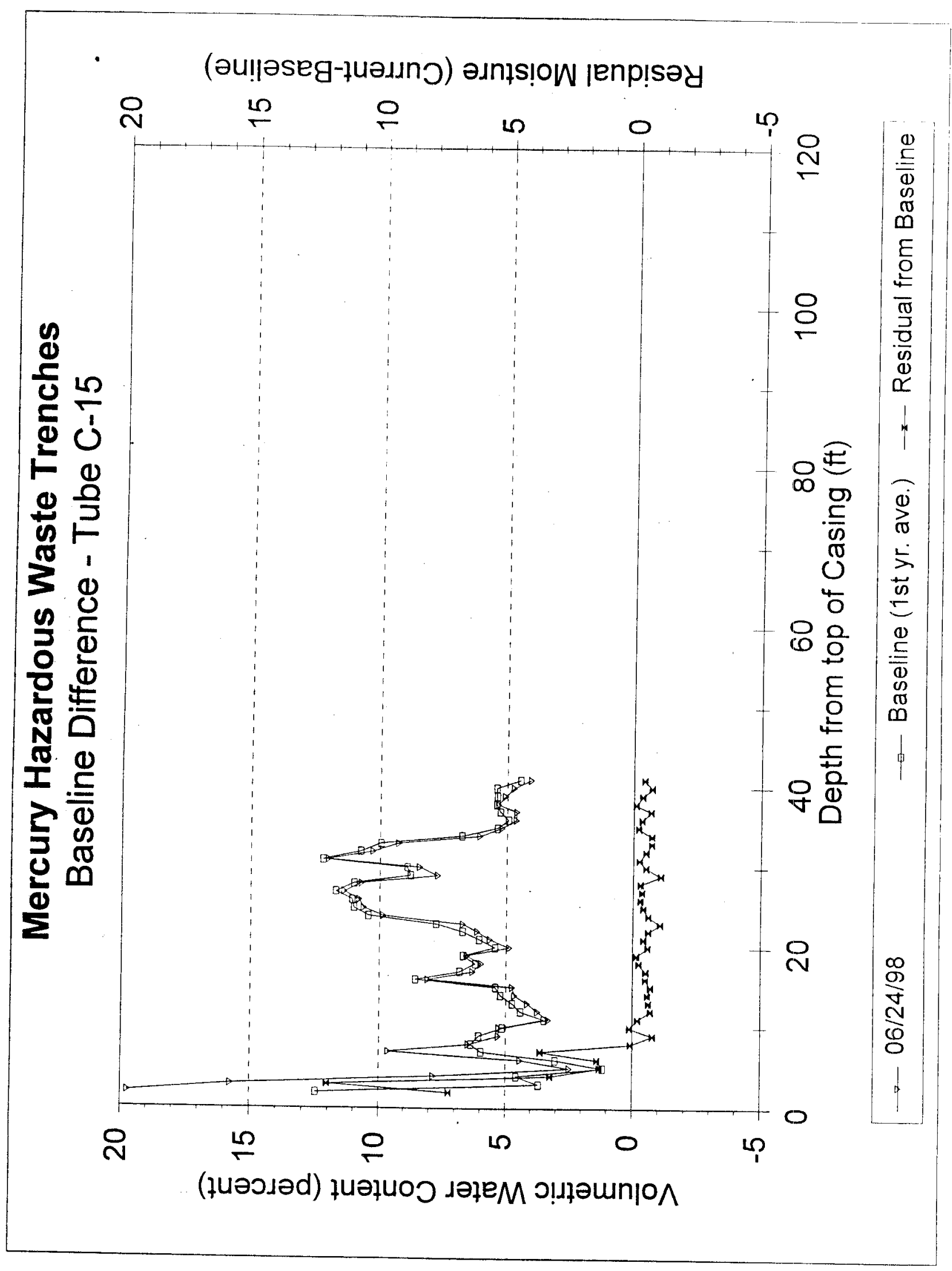




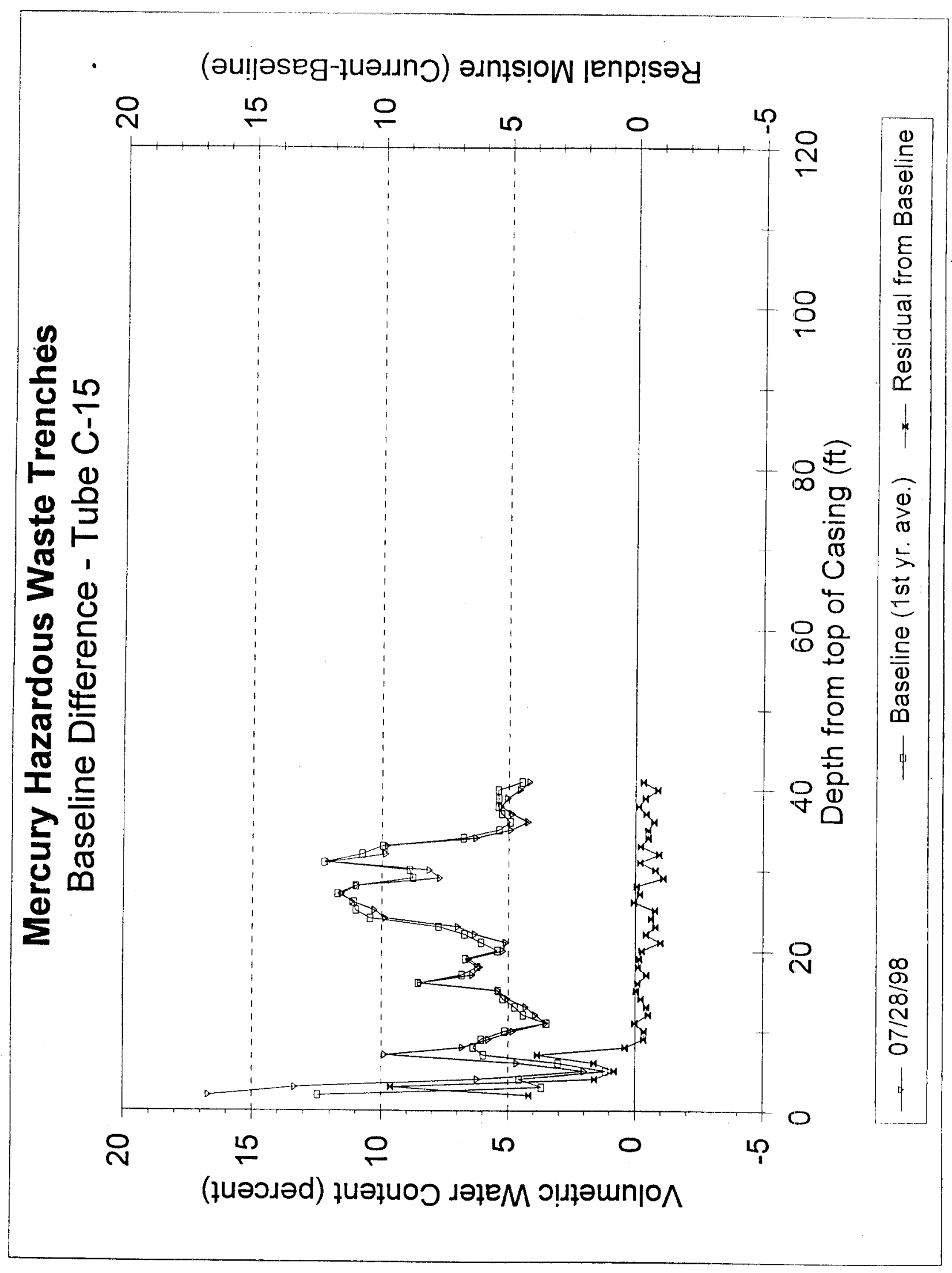




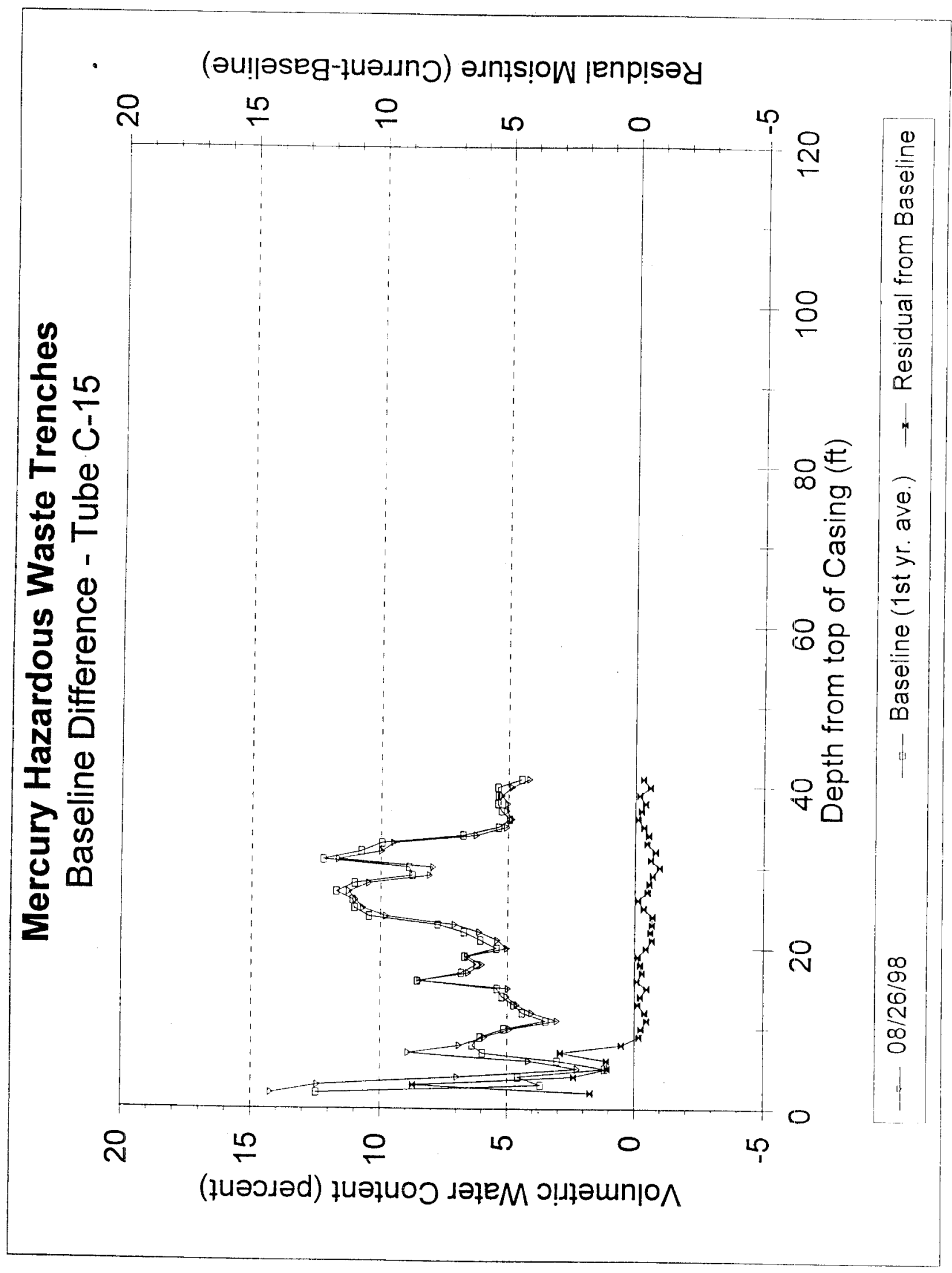




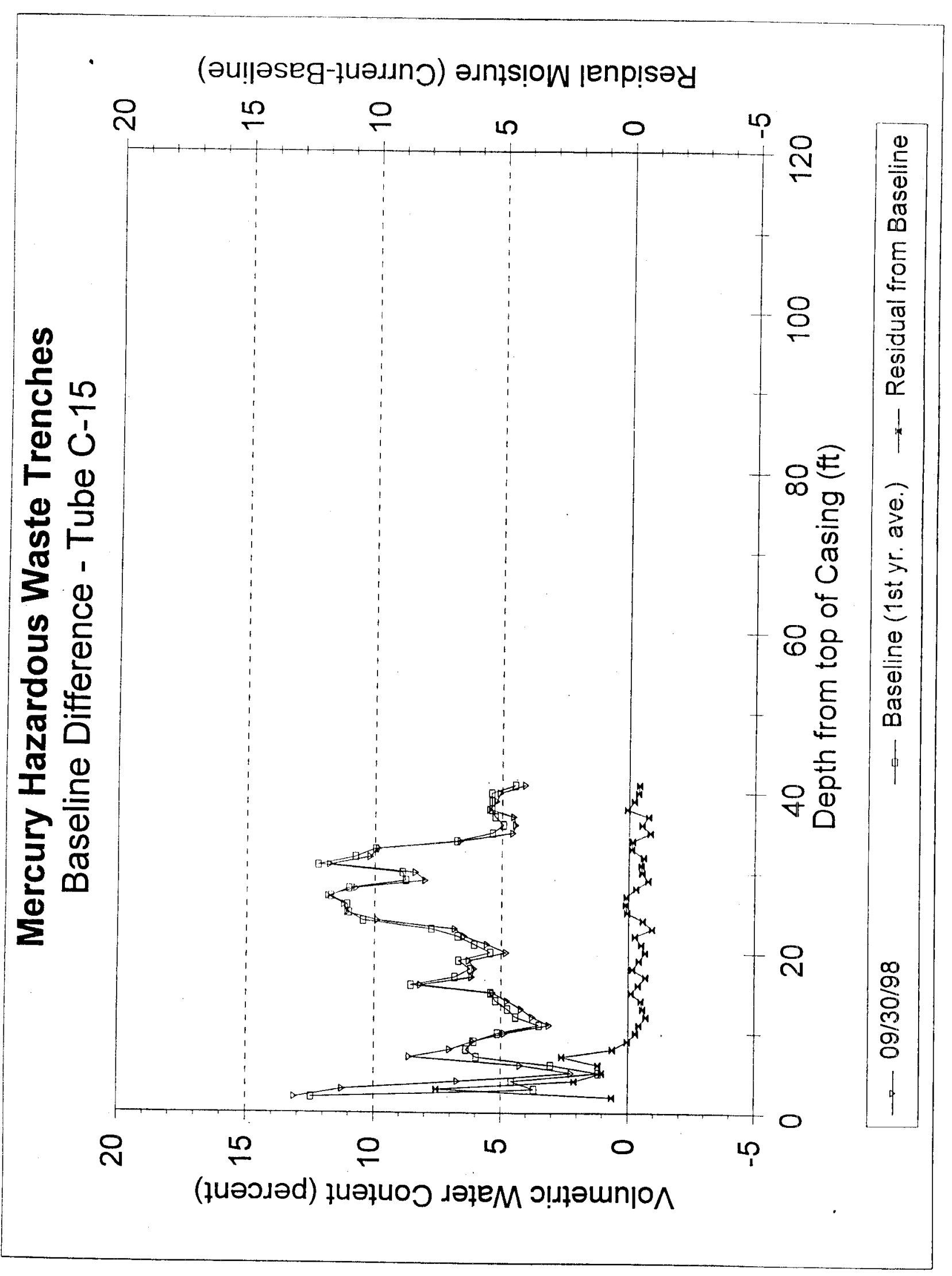




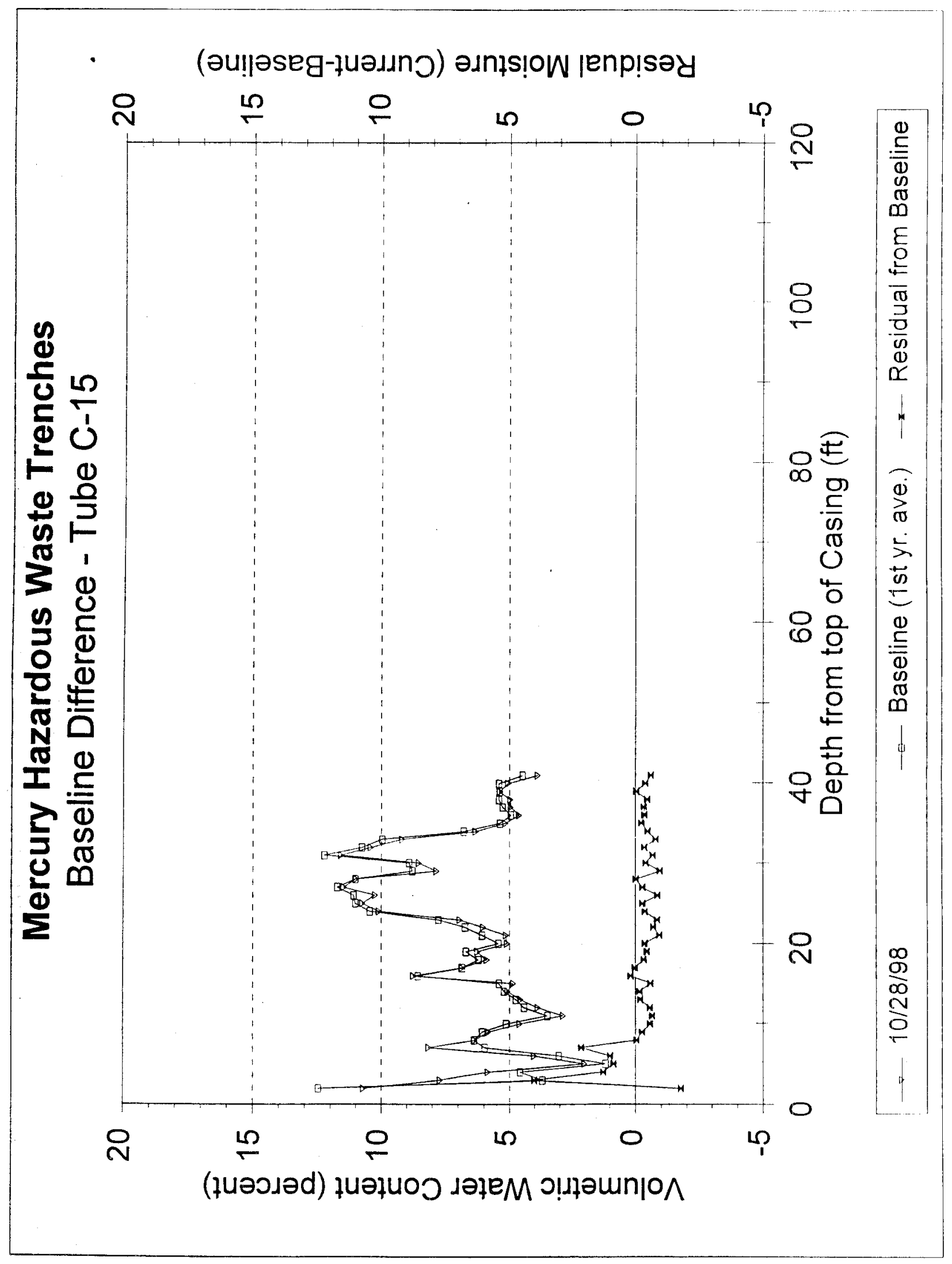




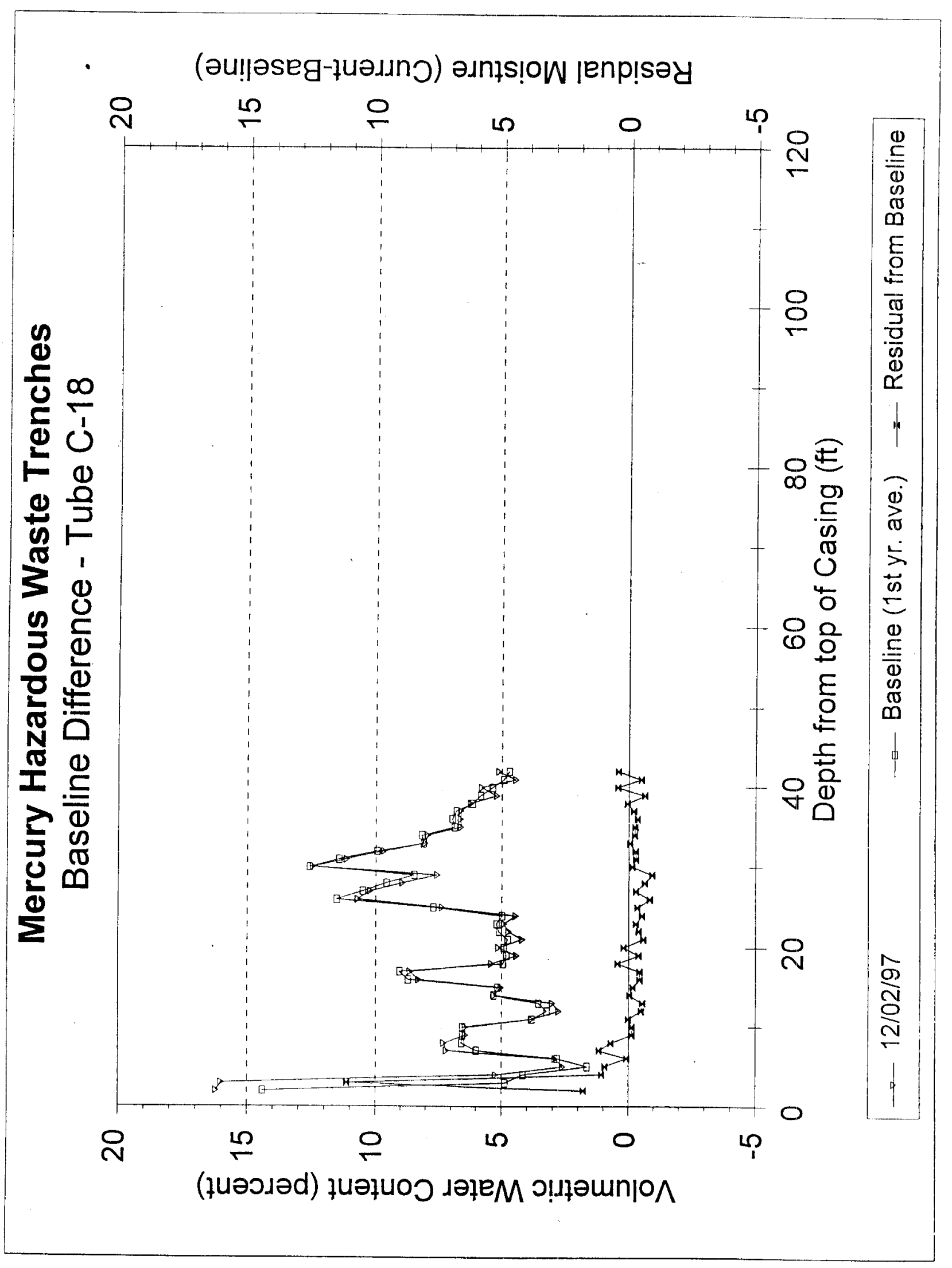




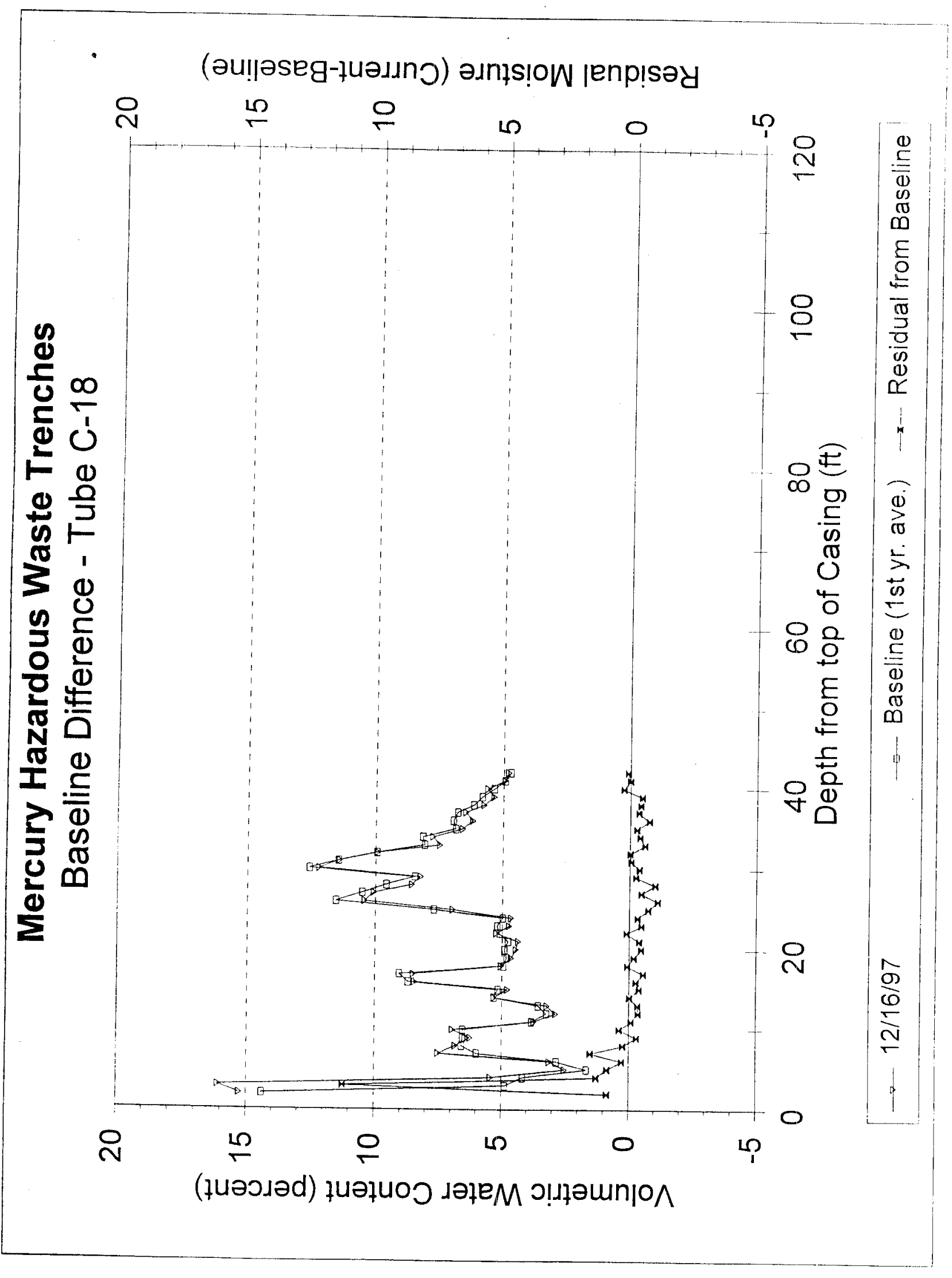




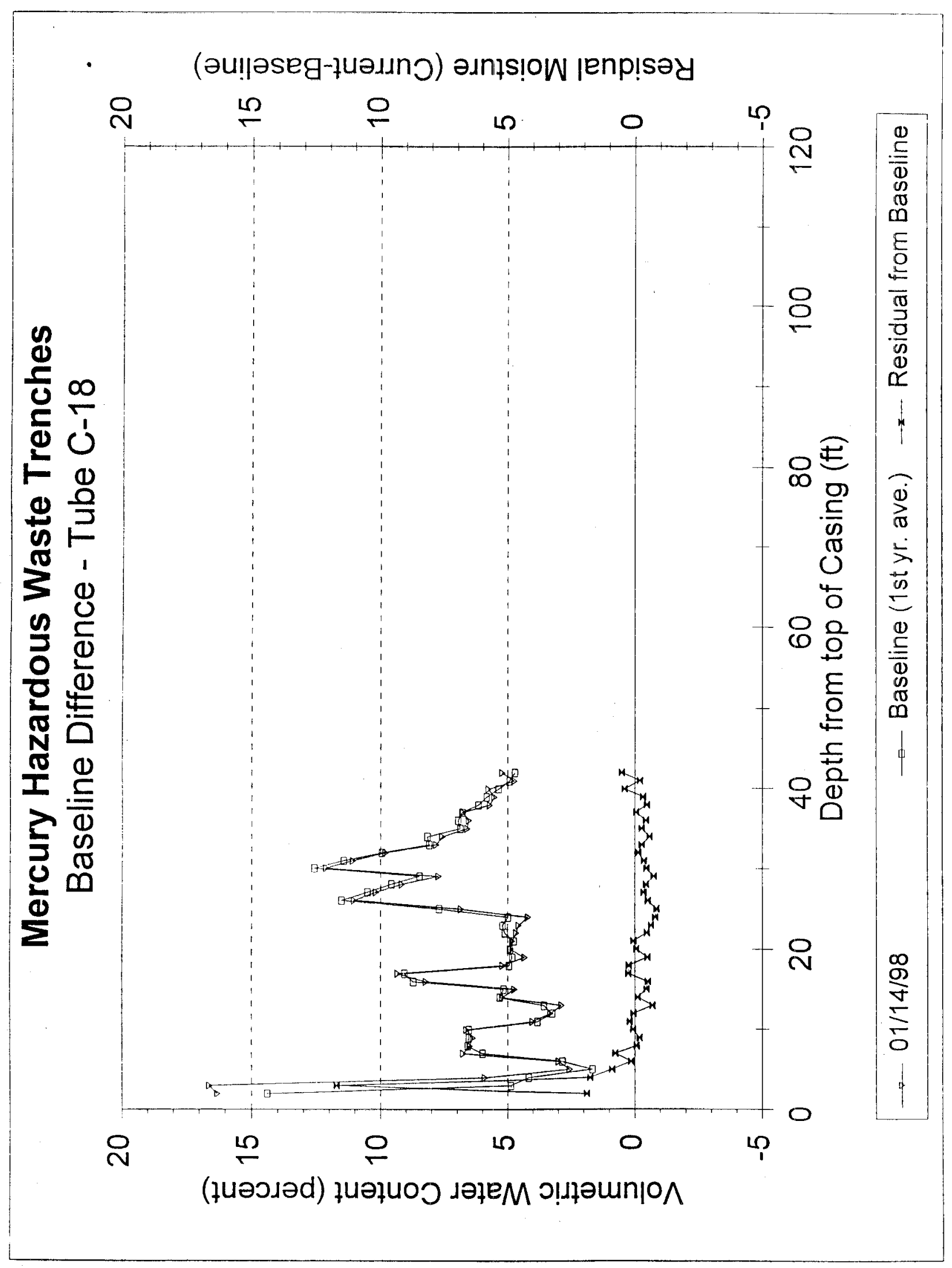




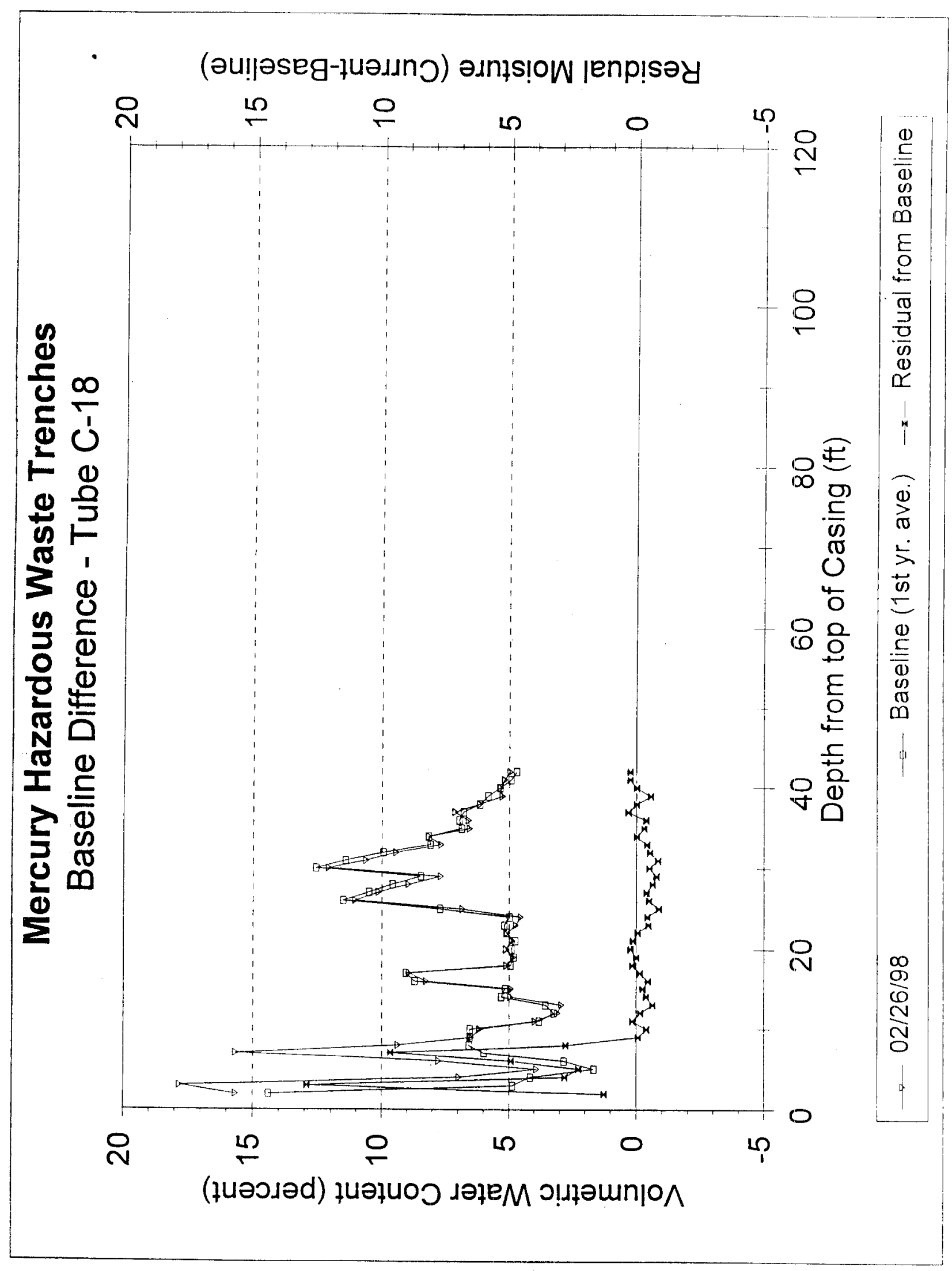




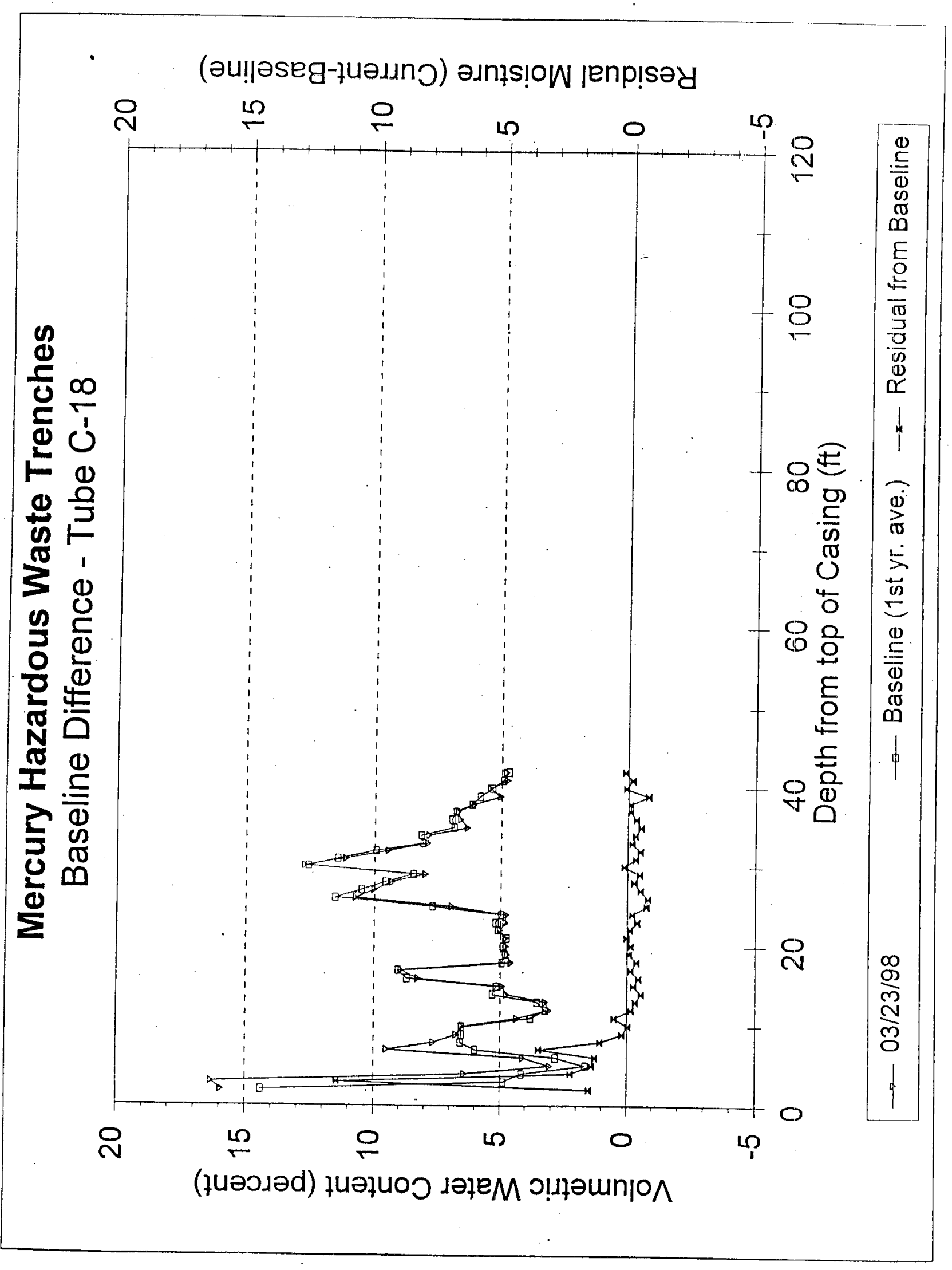




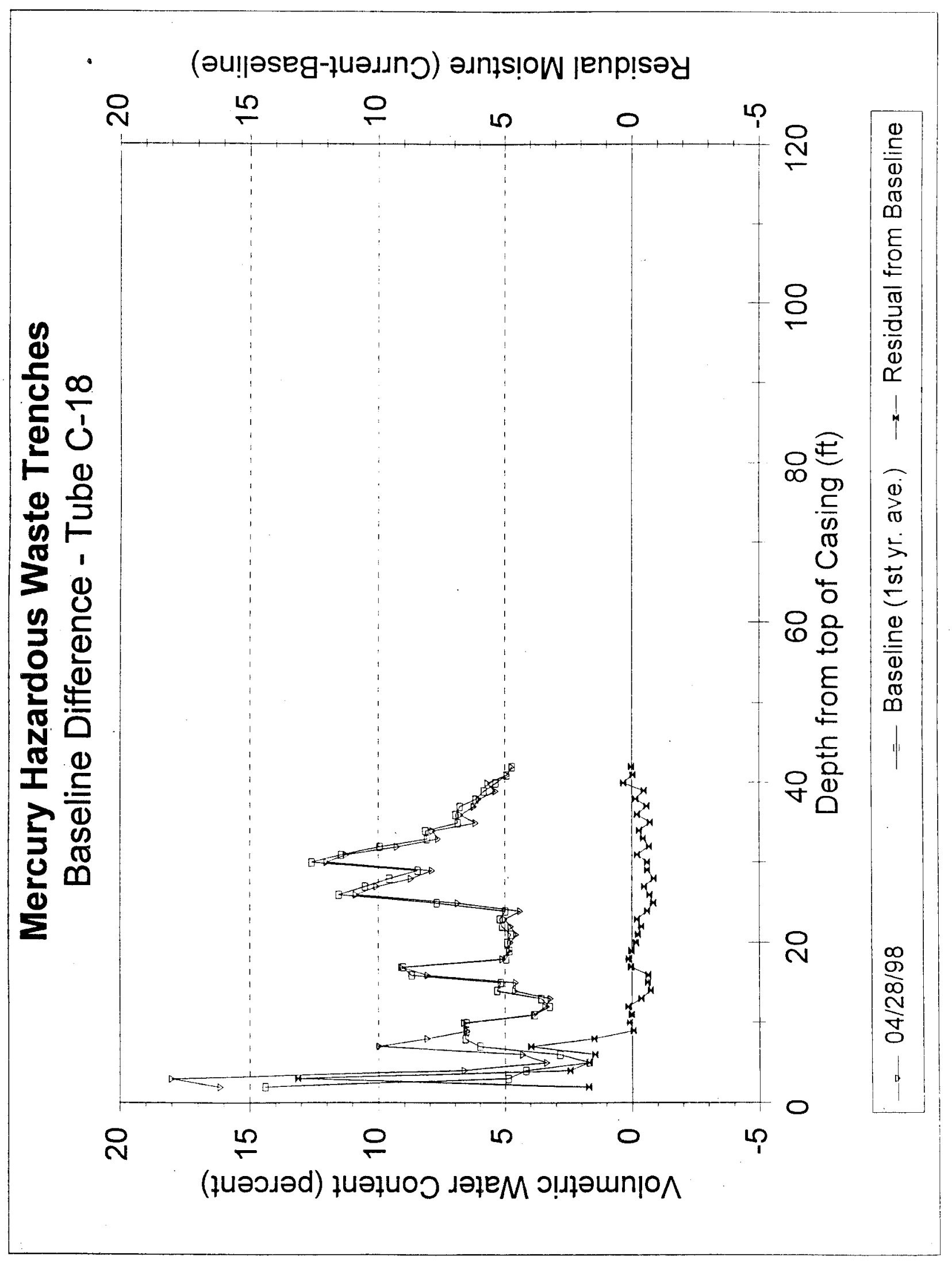




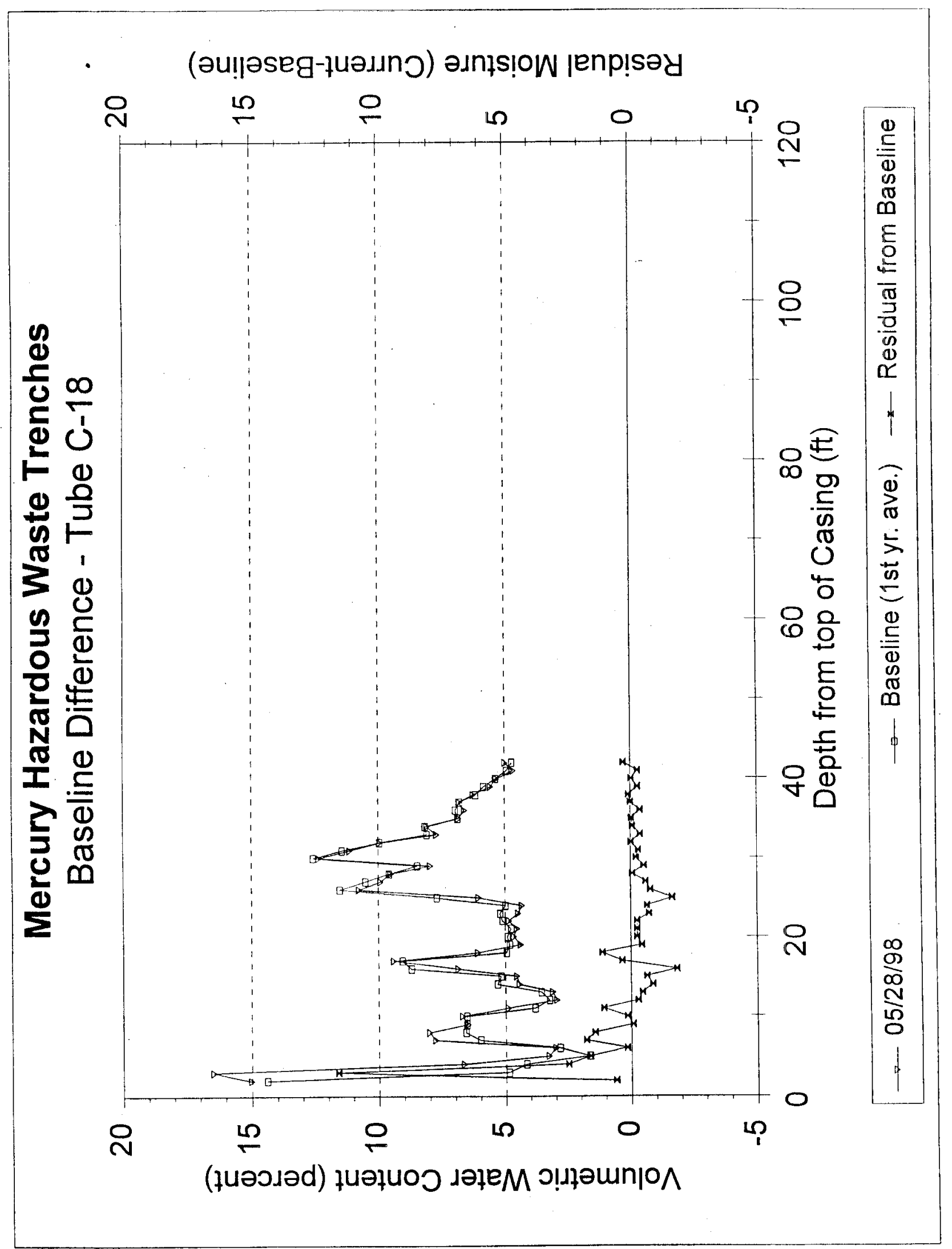




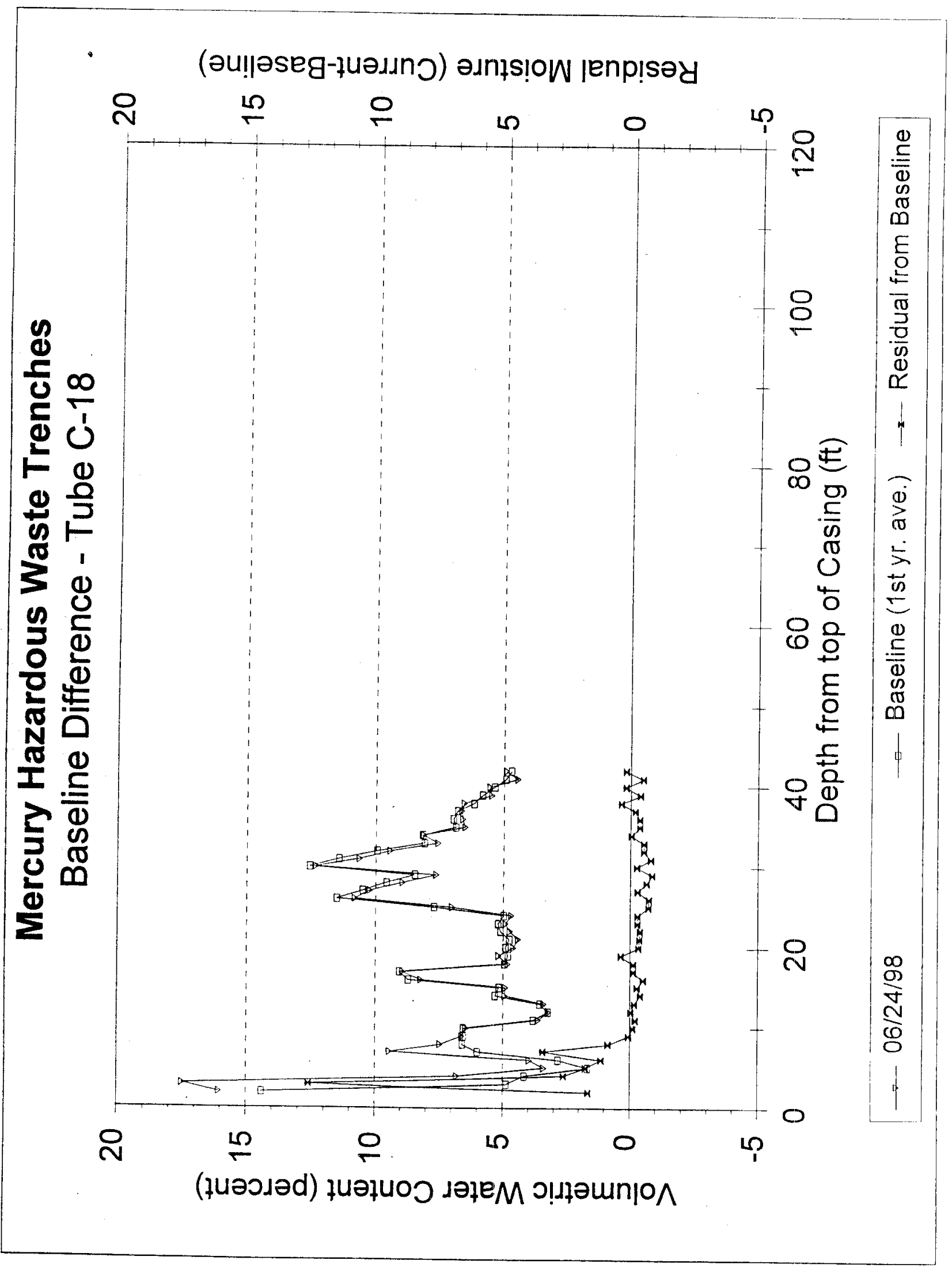




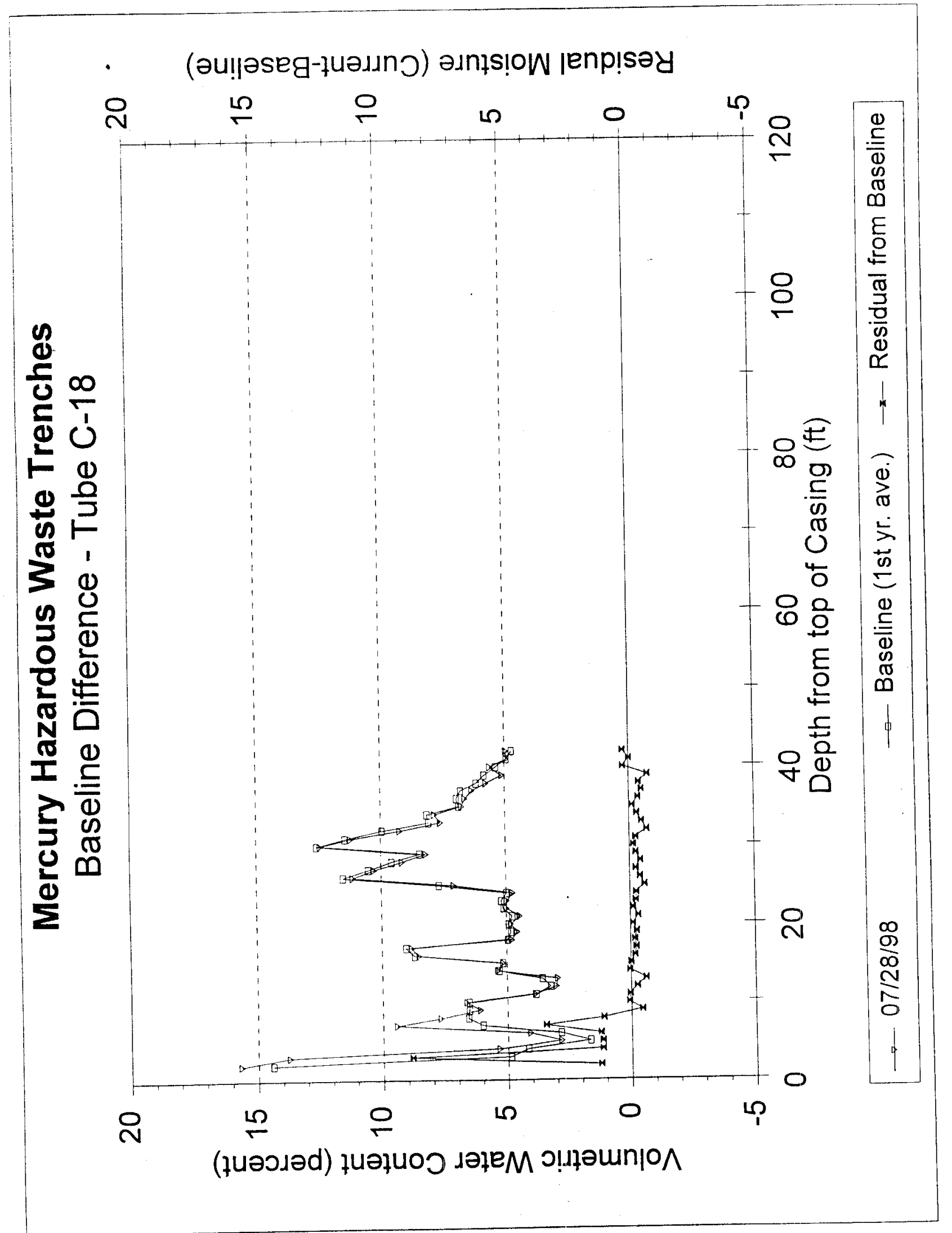




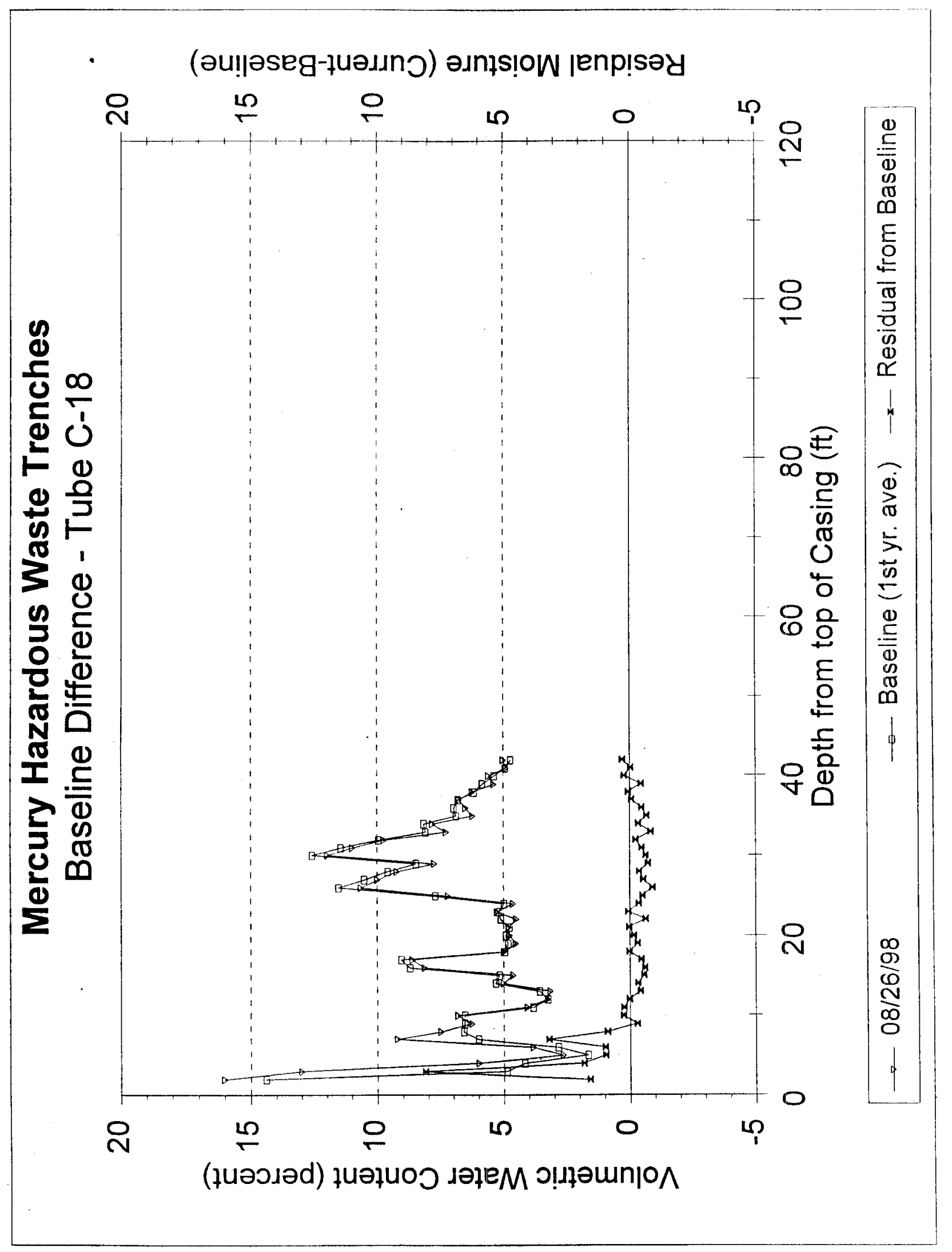




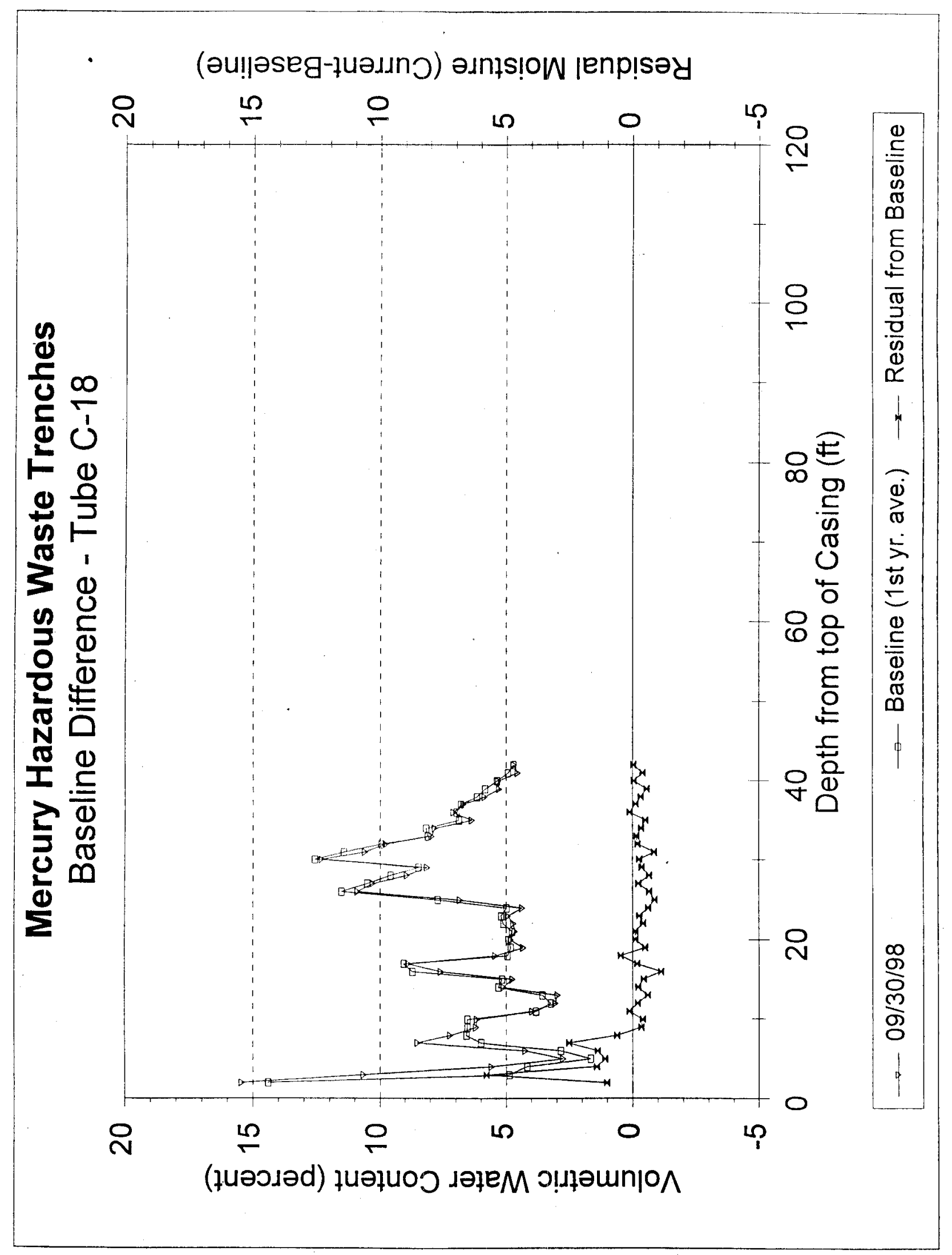




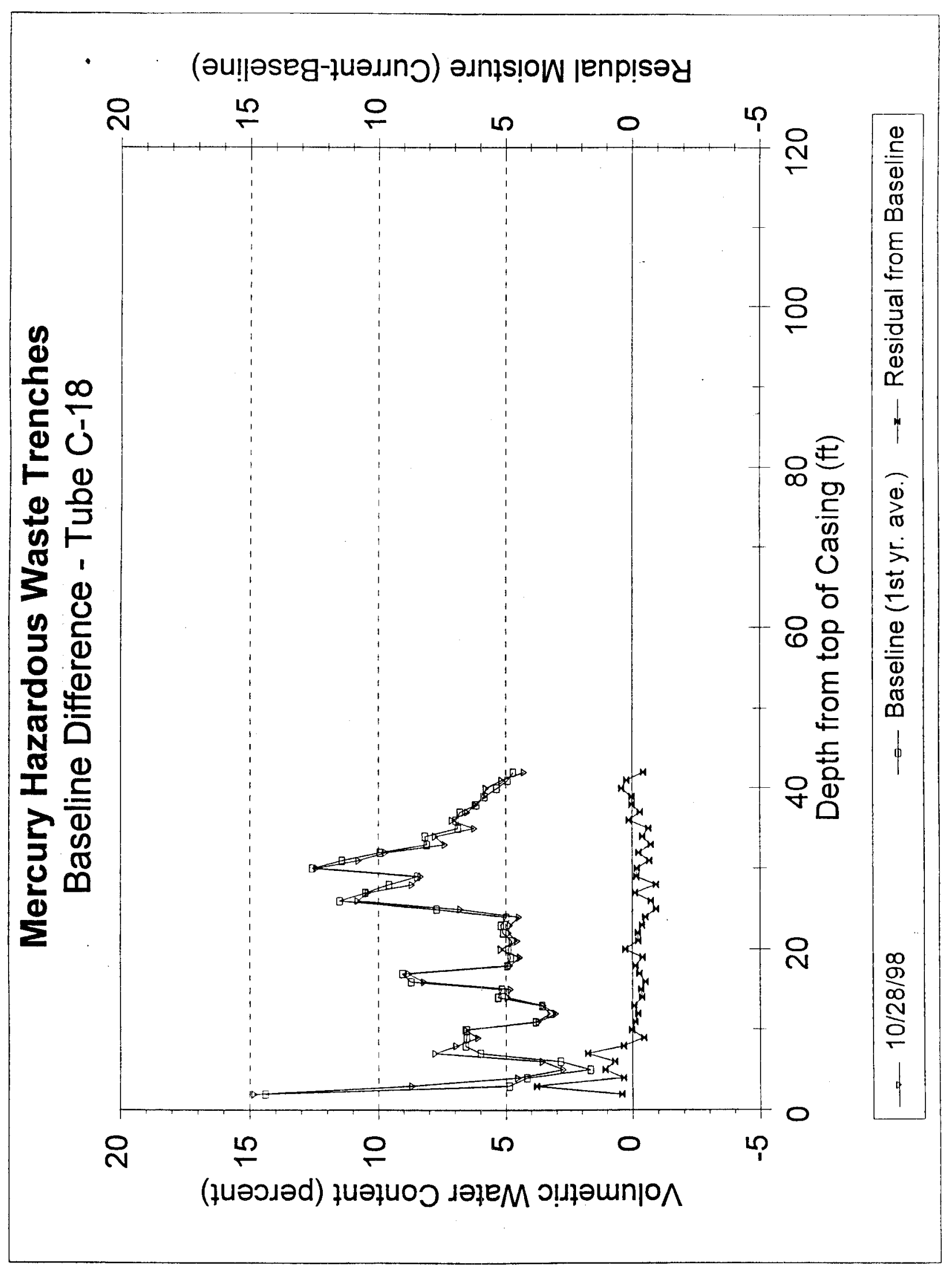




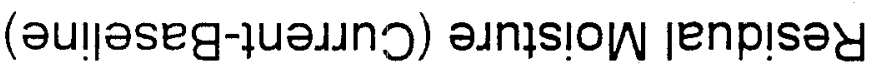

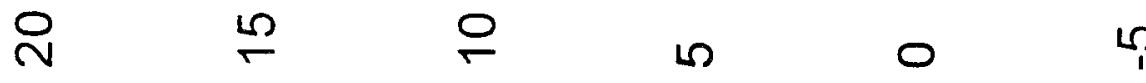

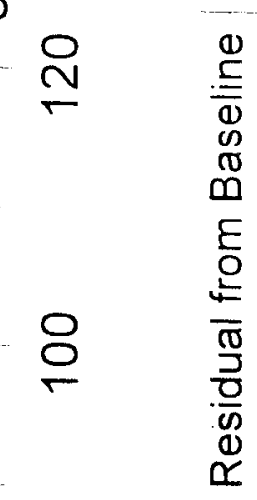

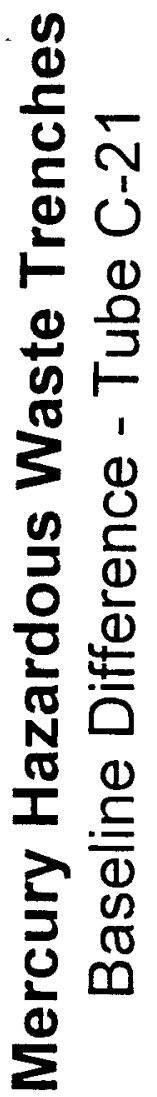




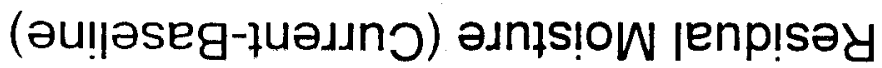
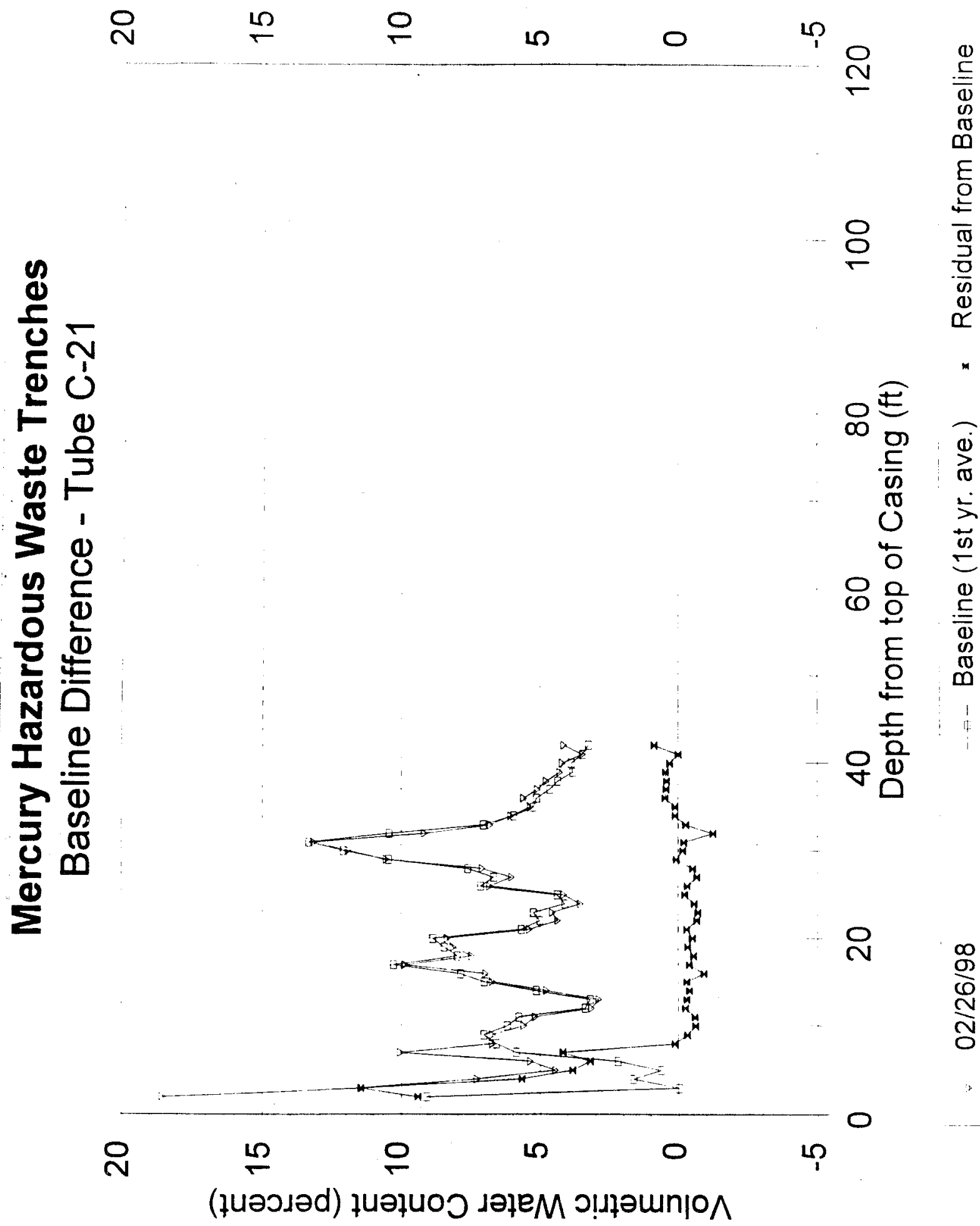


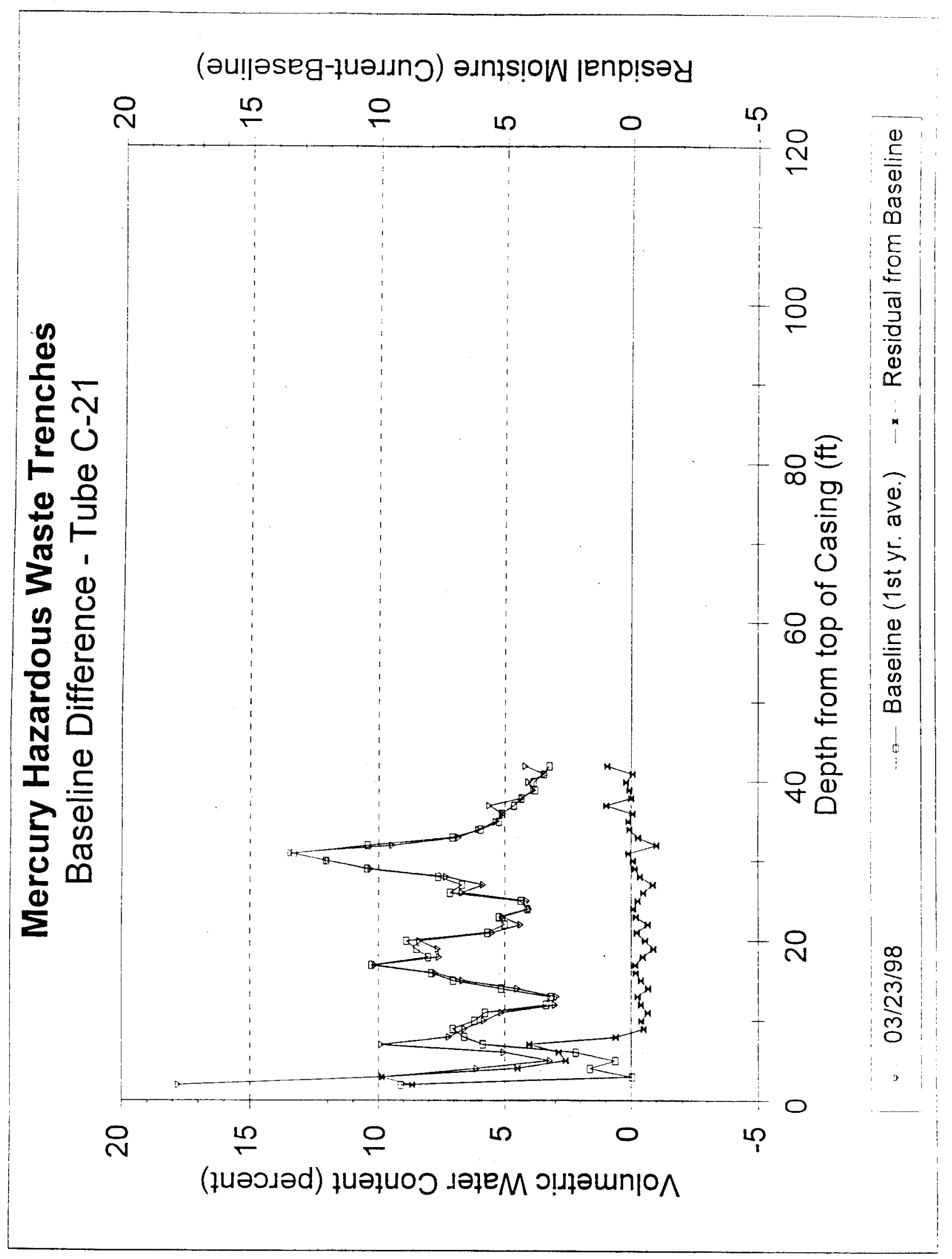




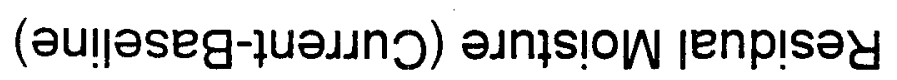
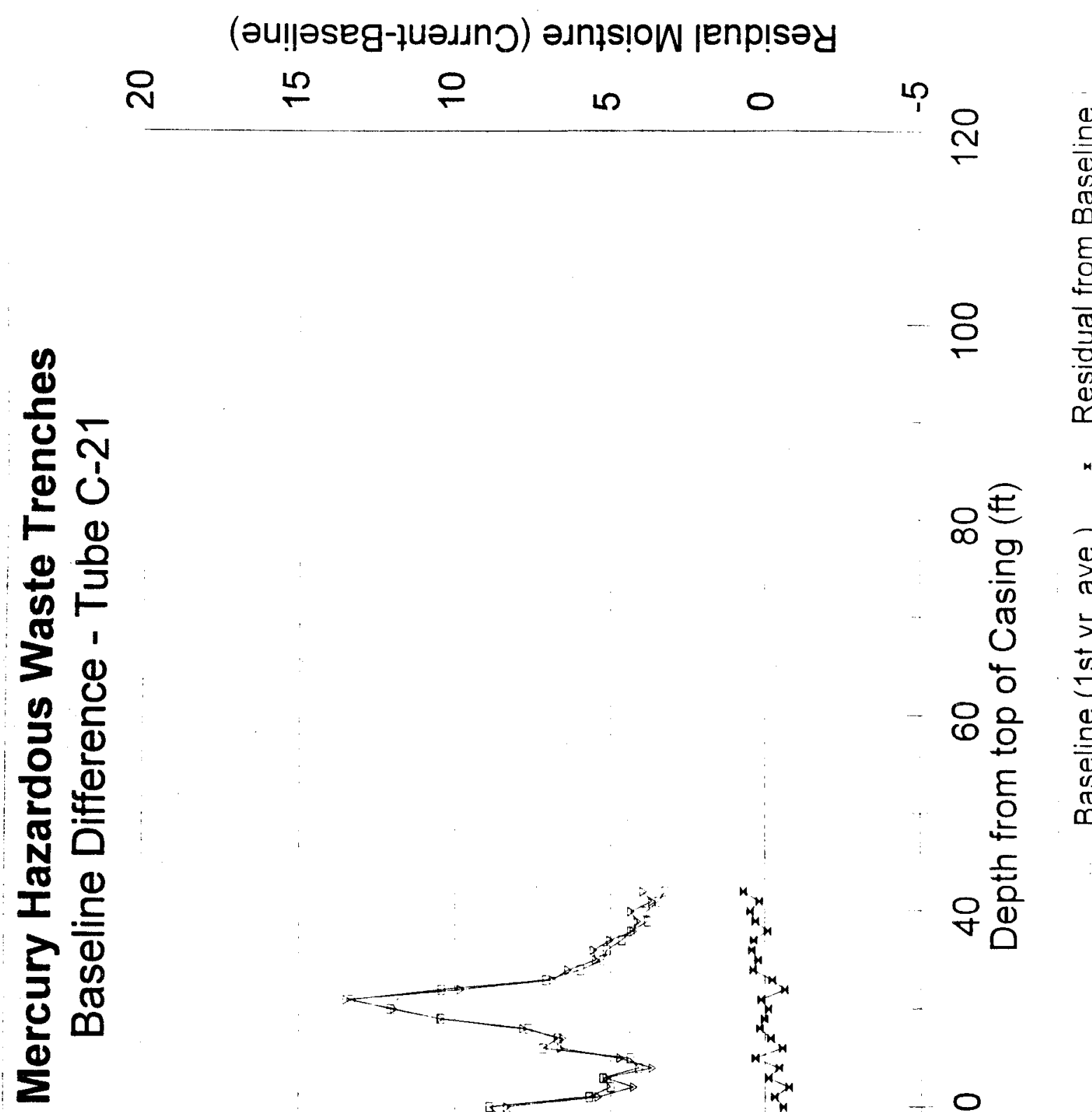


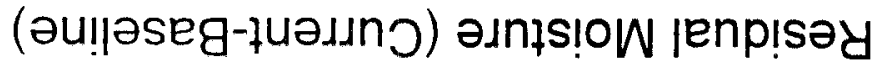
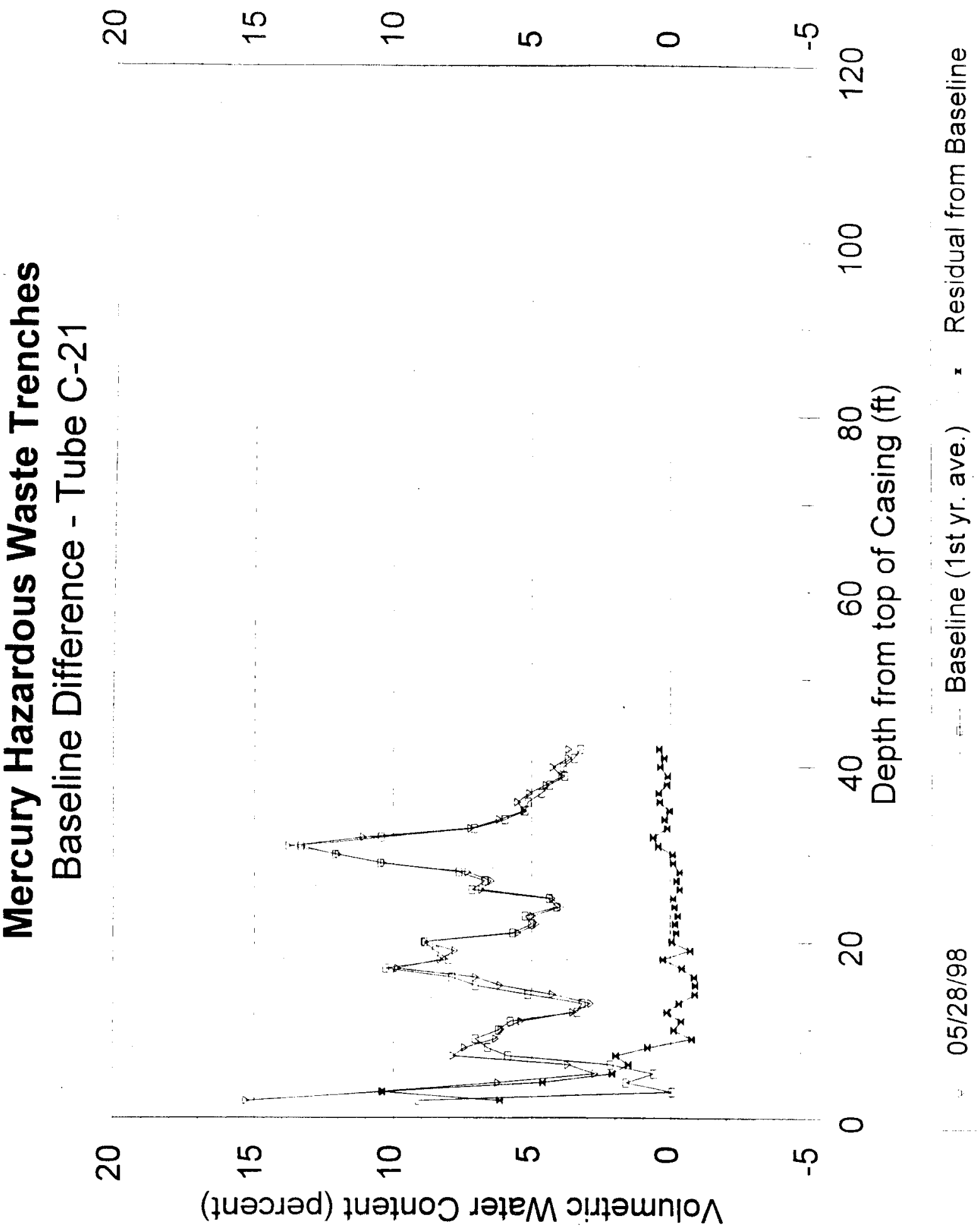


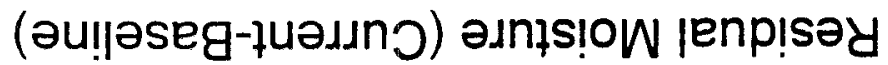

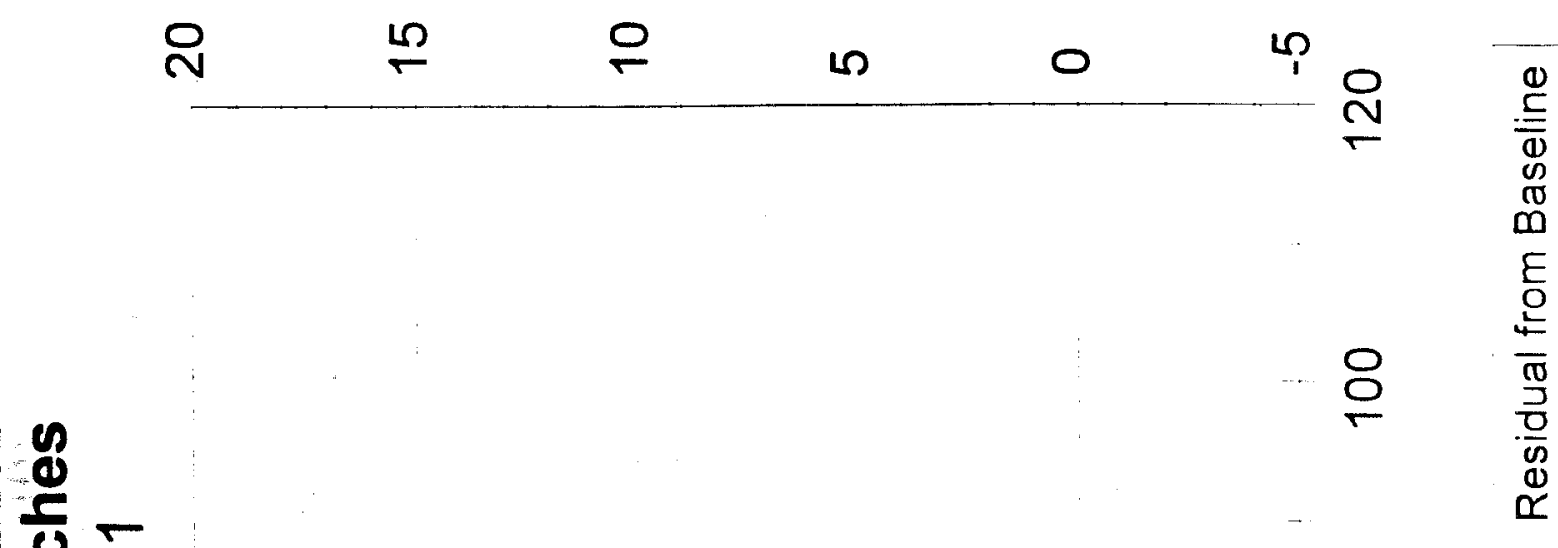

E

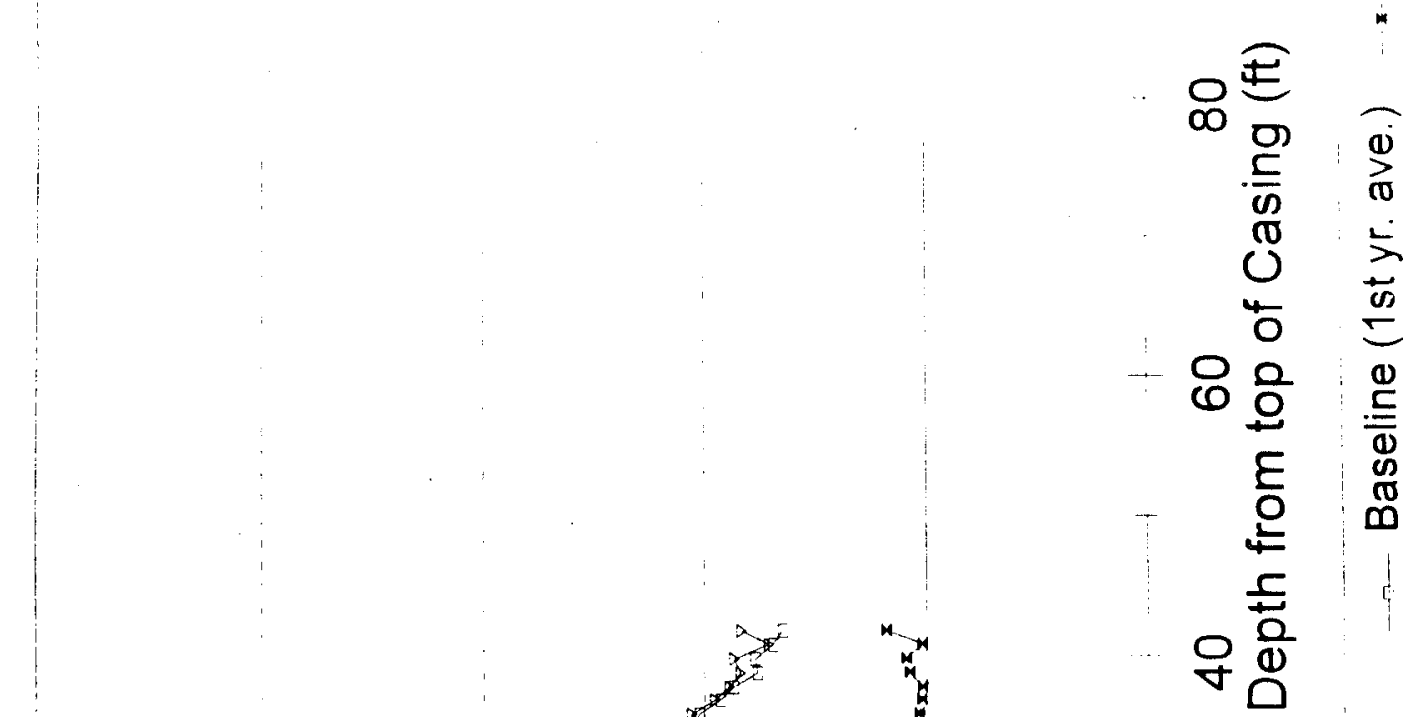

a $=$

30

o

(0)

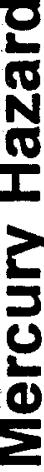

(0)
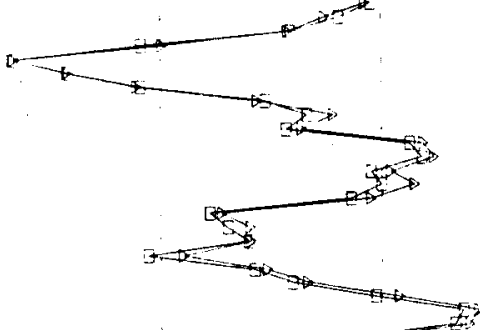

$=$
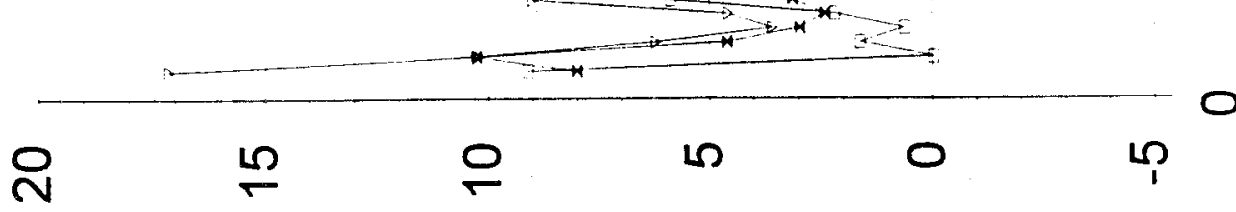

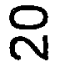

$\frac{\substack{0 \\ 0 \\ \multirow{2}{*}{}}}{0}$

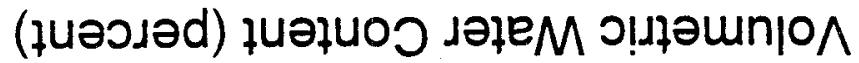




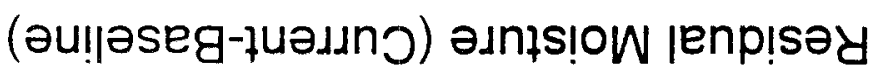
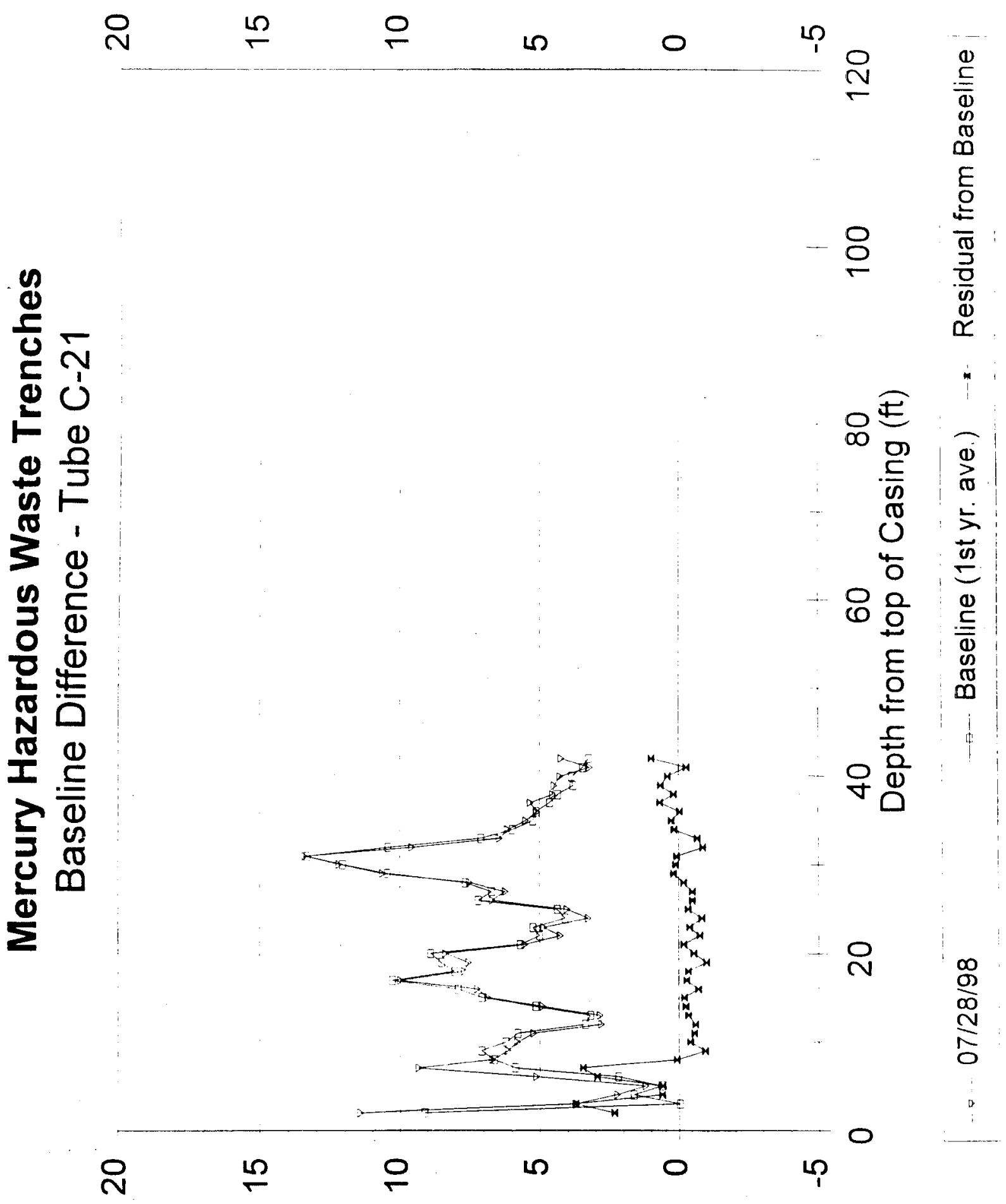

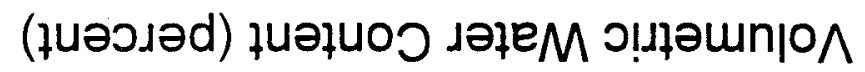




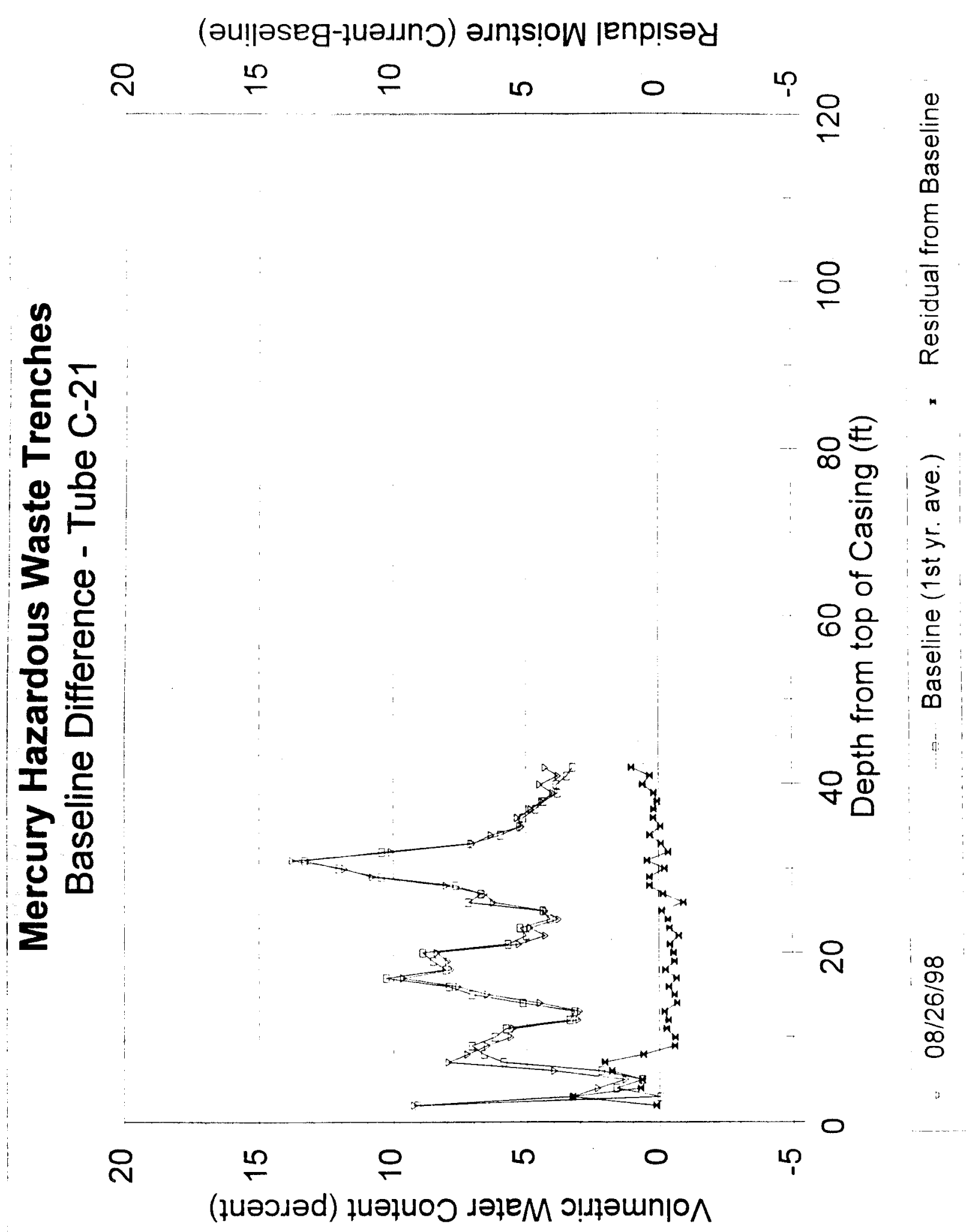



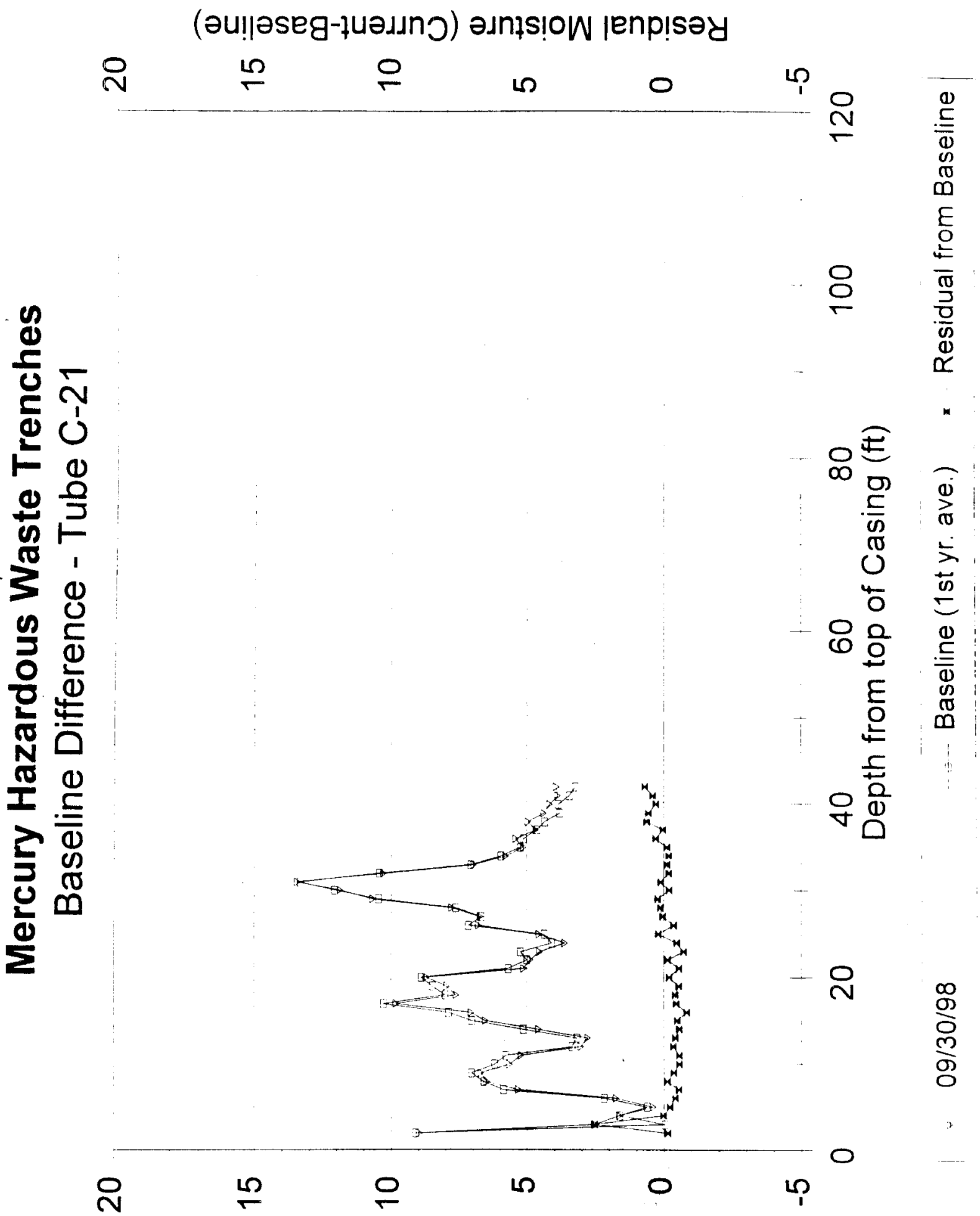

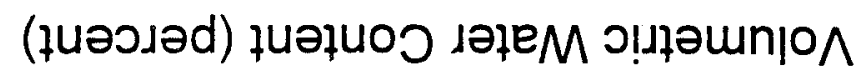




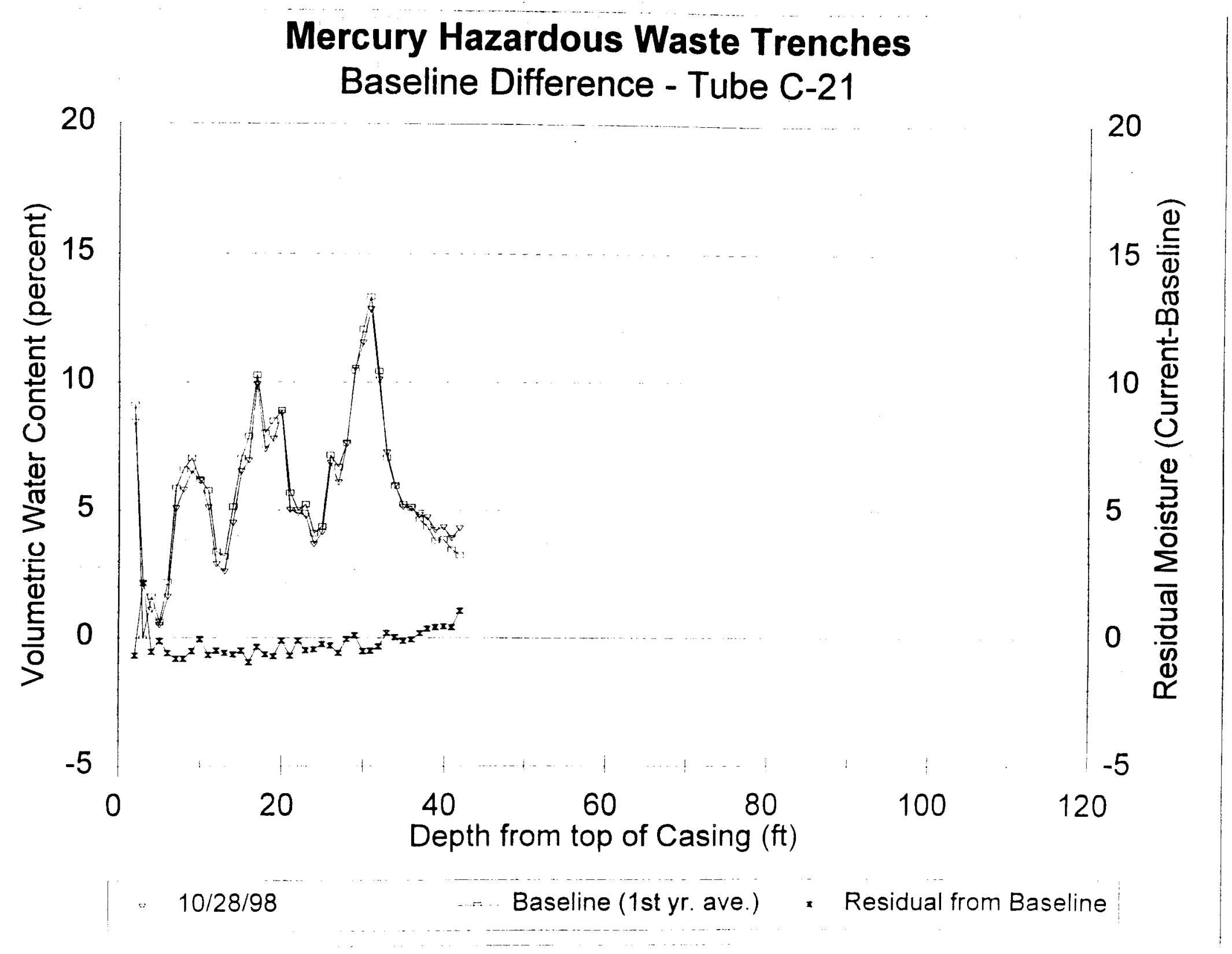




\section{BASELINE DIFFERENCE}

\section{ROW S1}




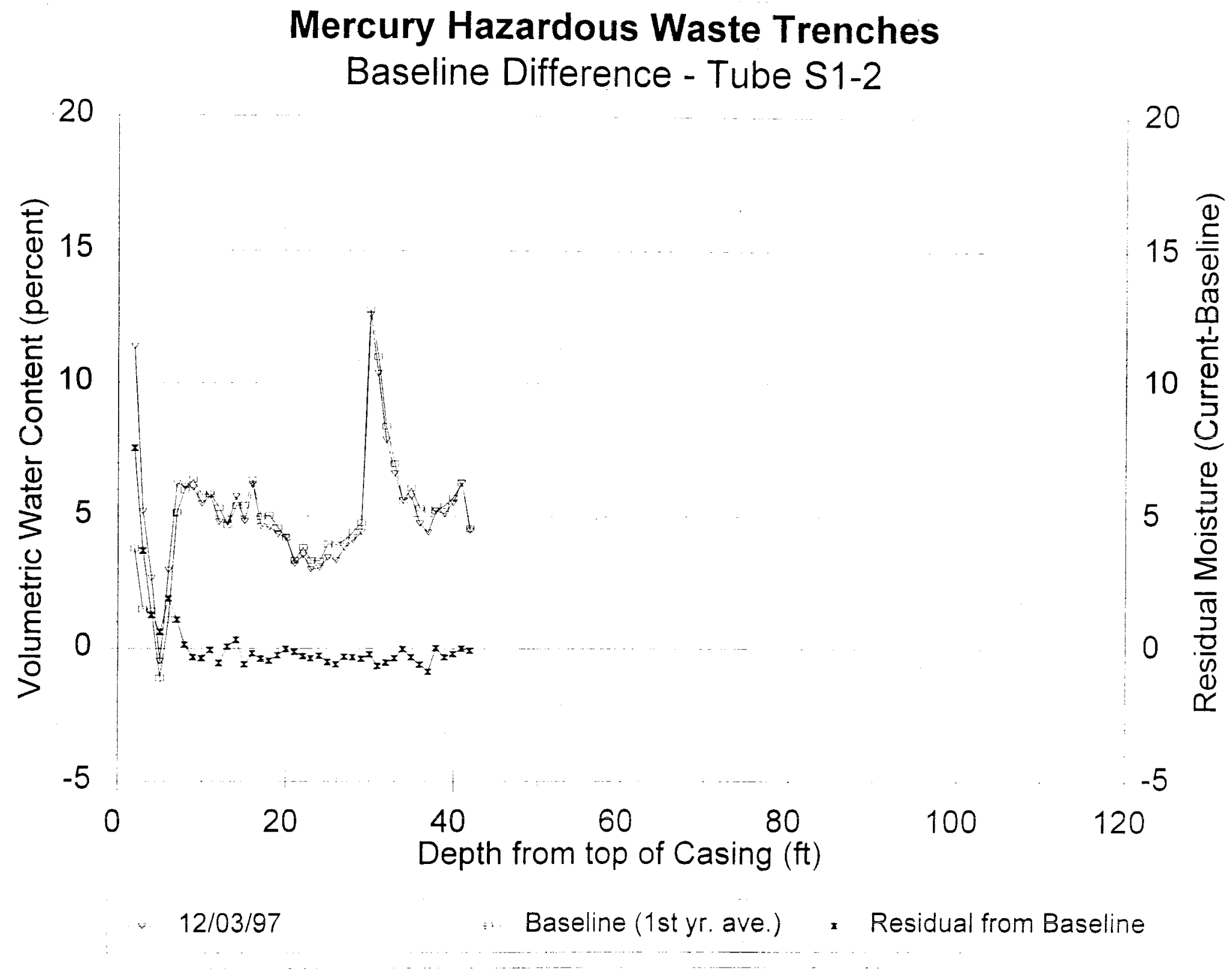




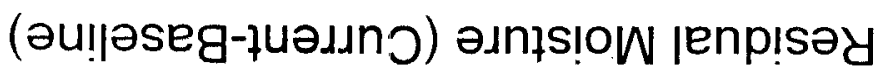
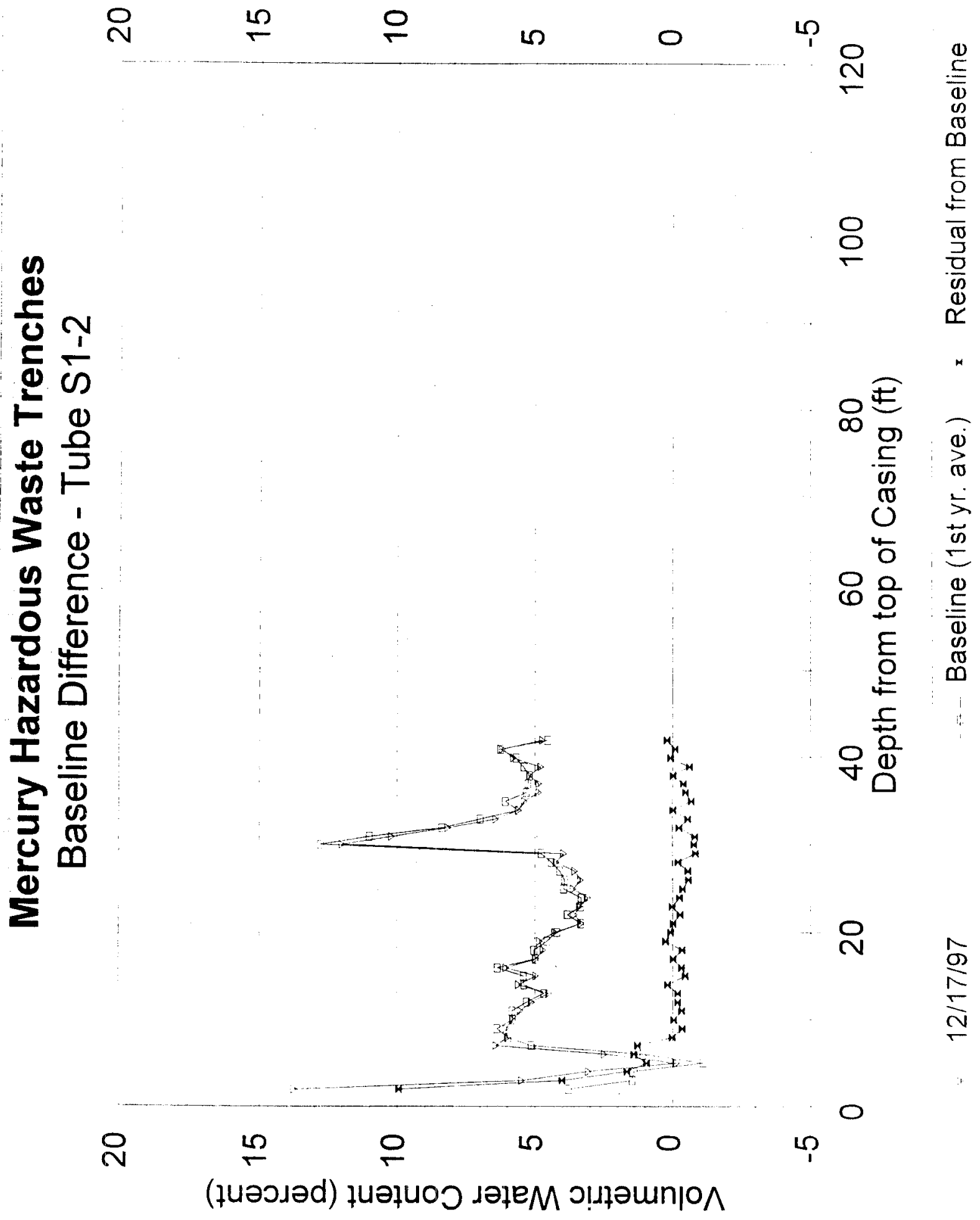


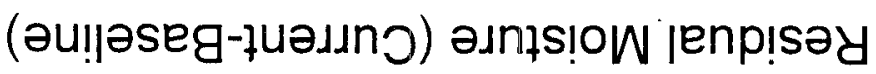

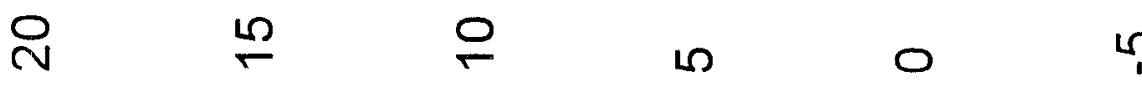

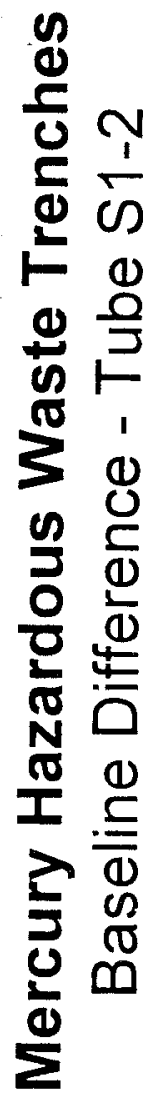

$\stackrel{ }{\simeq}$

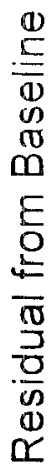

$\therefore \quad \frac{0}{\frac{2}{0}}$

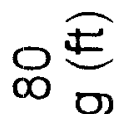

$\stackrel{\frac{\pi}{\omega}}{\stackrel{D}{\infty}}$

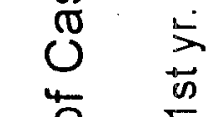

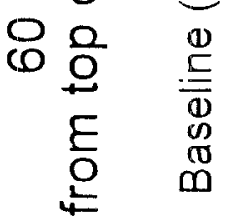

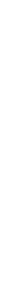

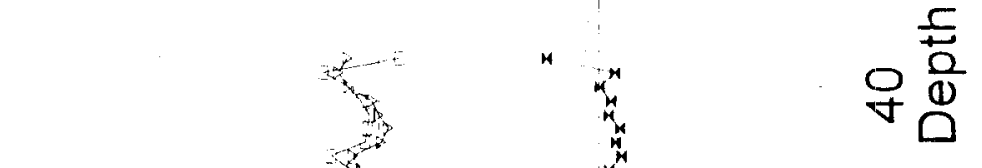

요

$\frac{\frac{\infty}{0}}{\frac{1}{10}}$

유 $\quad$ 으 $n$ n

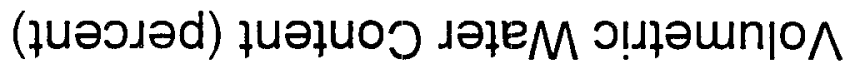




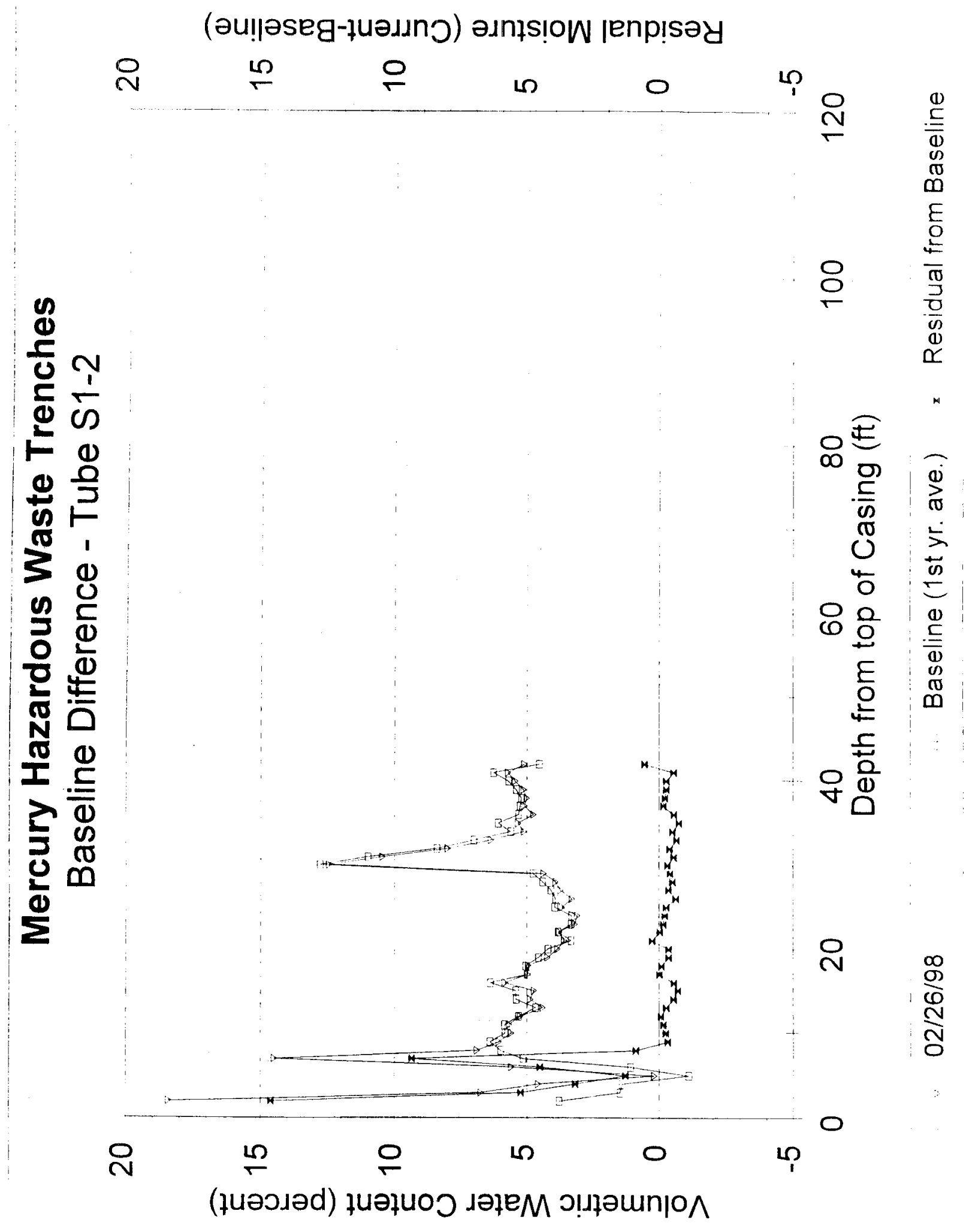




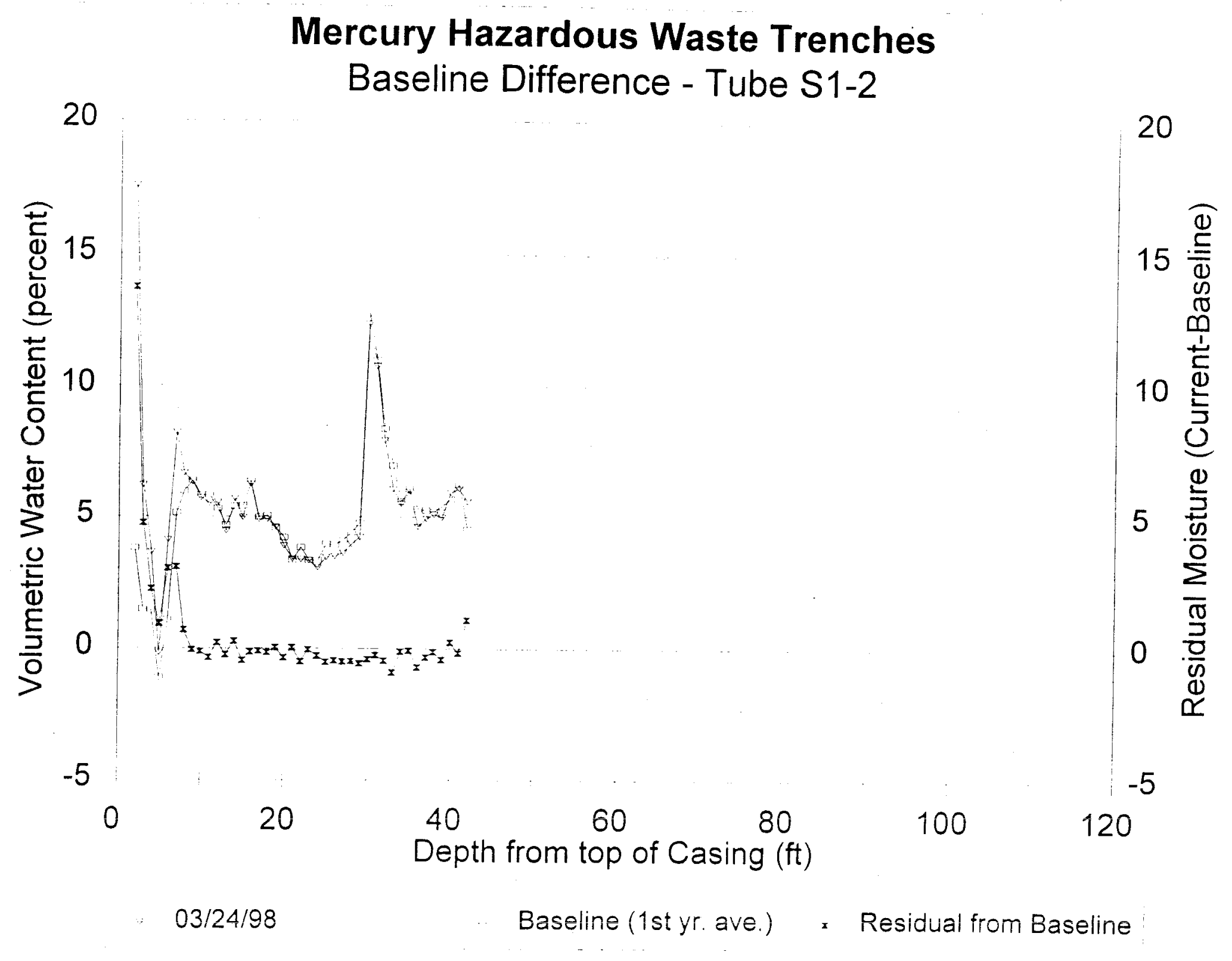




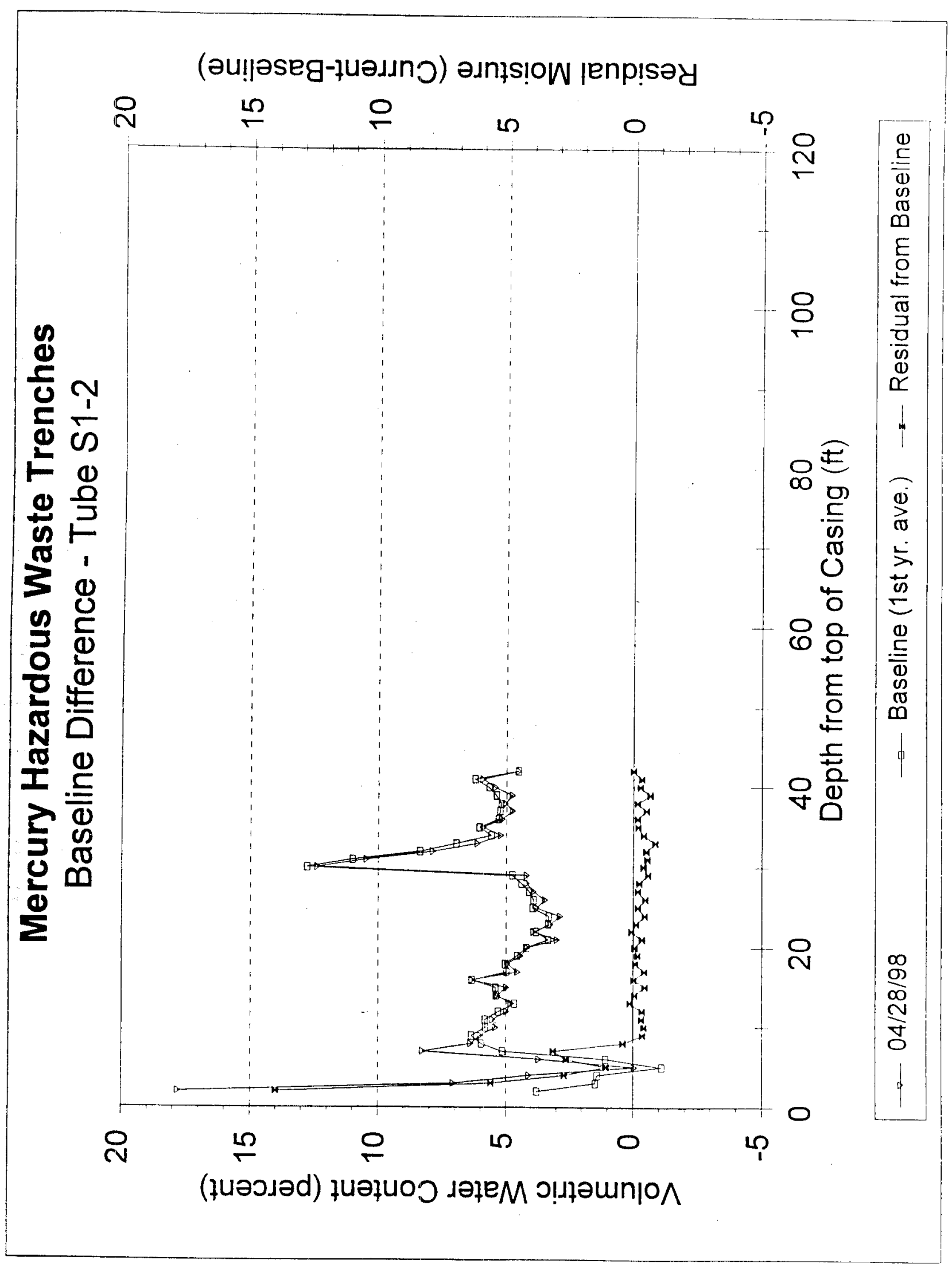




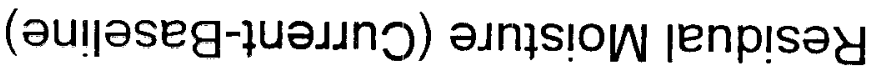

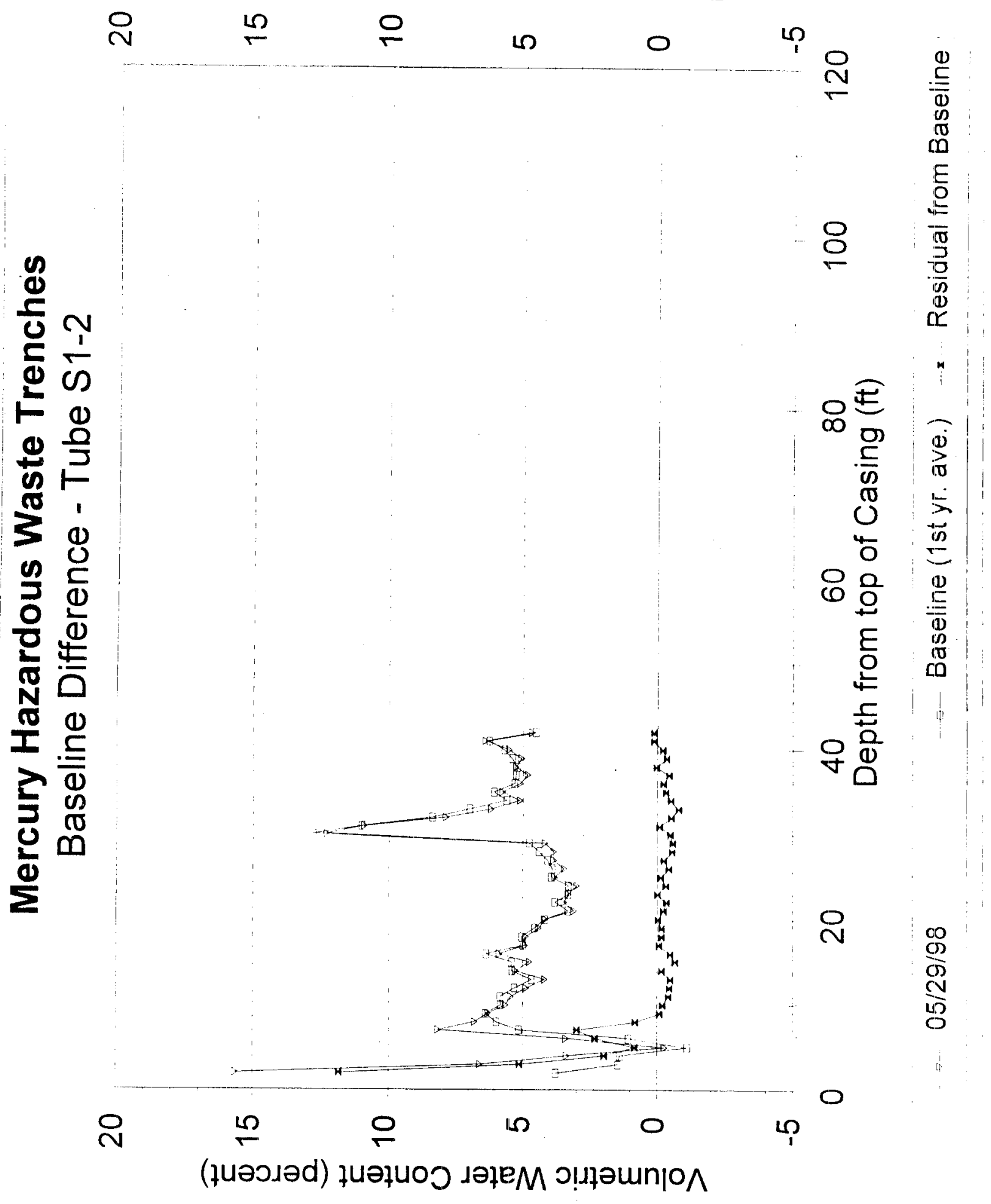




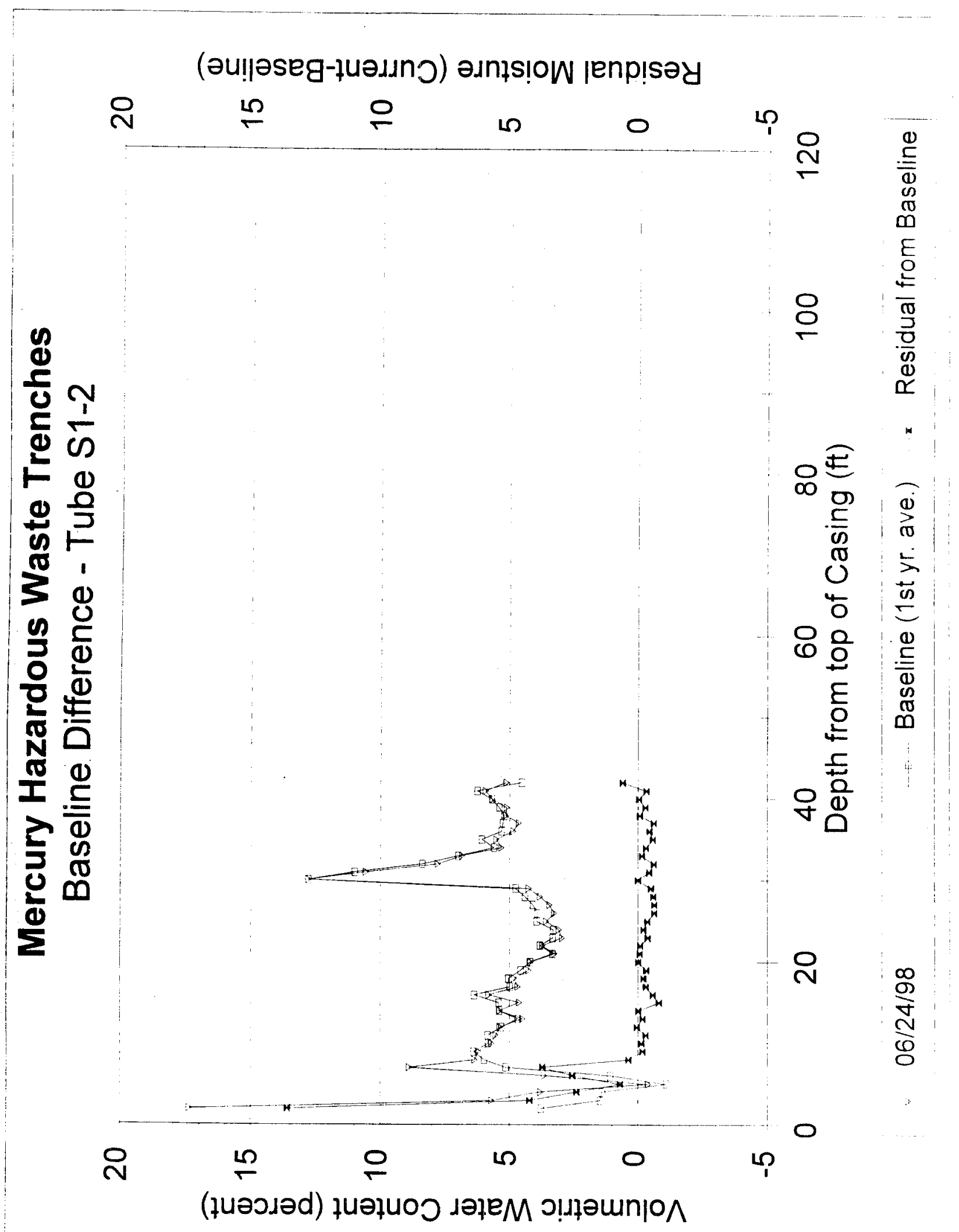




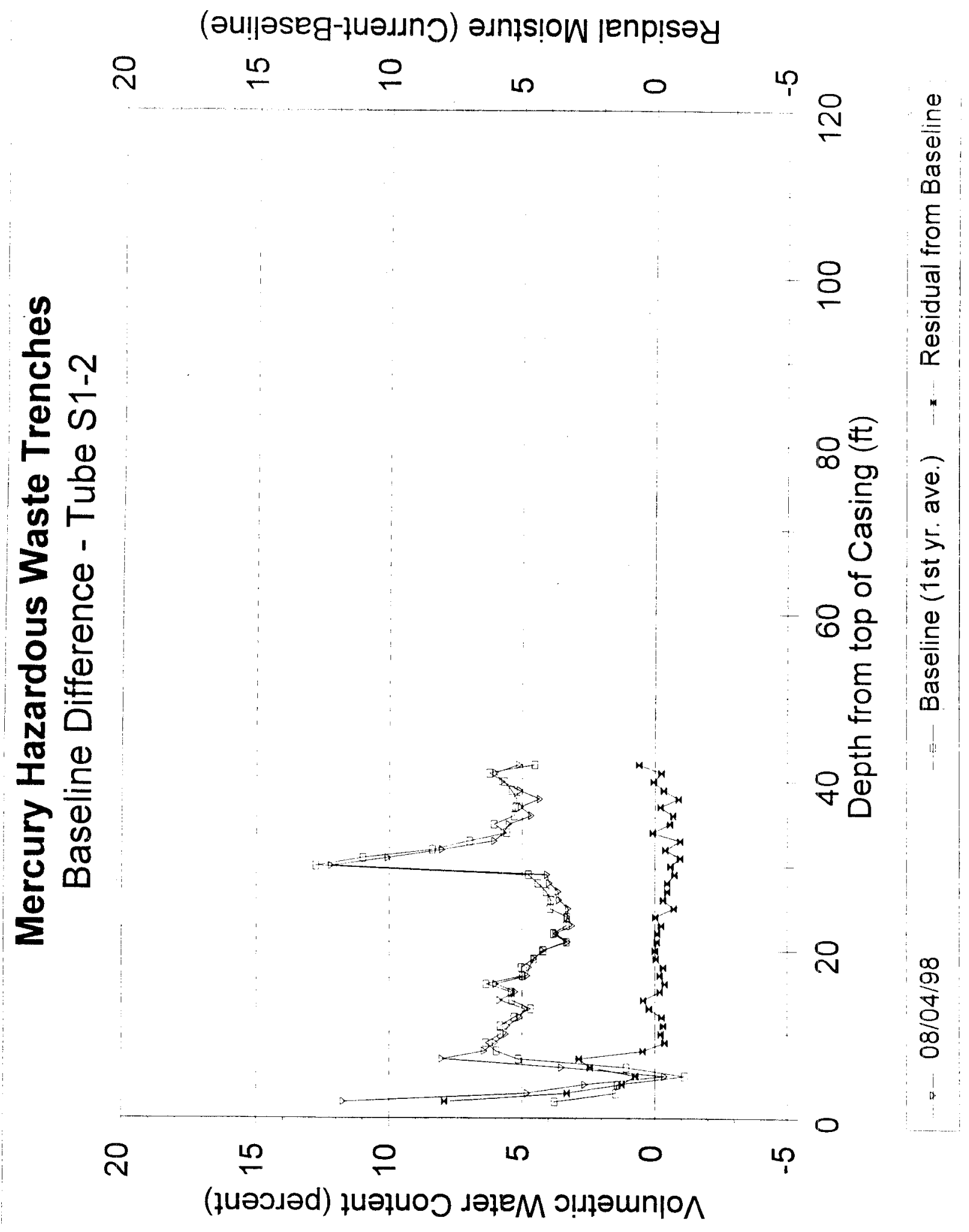




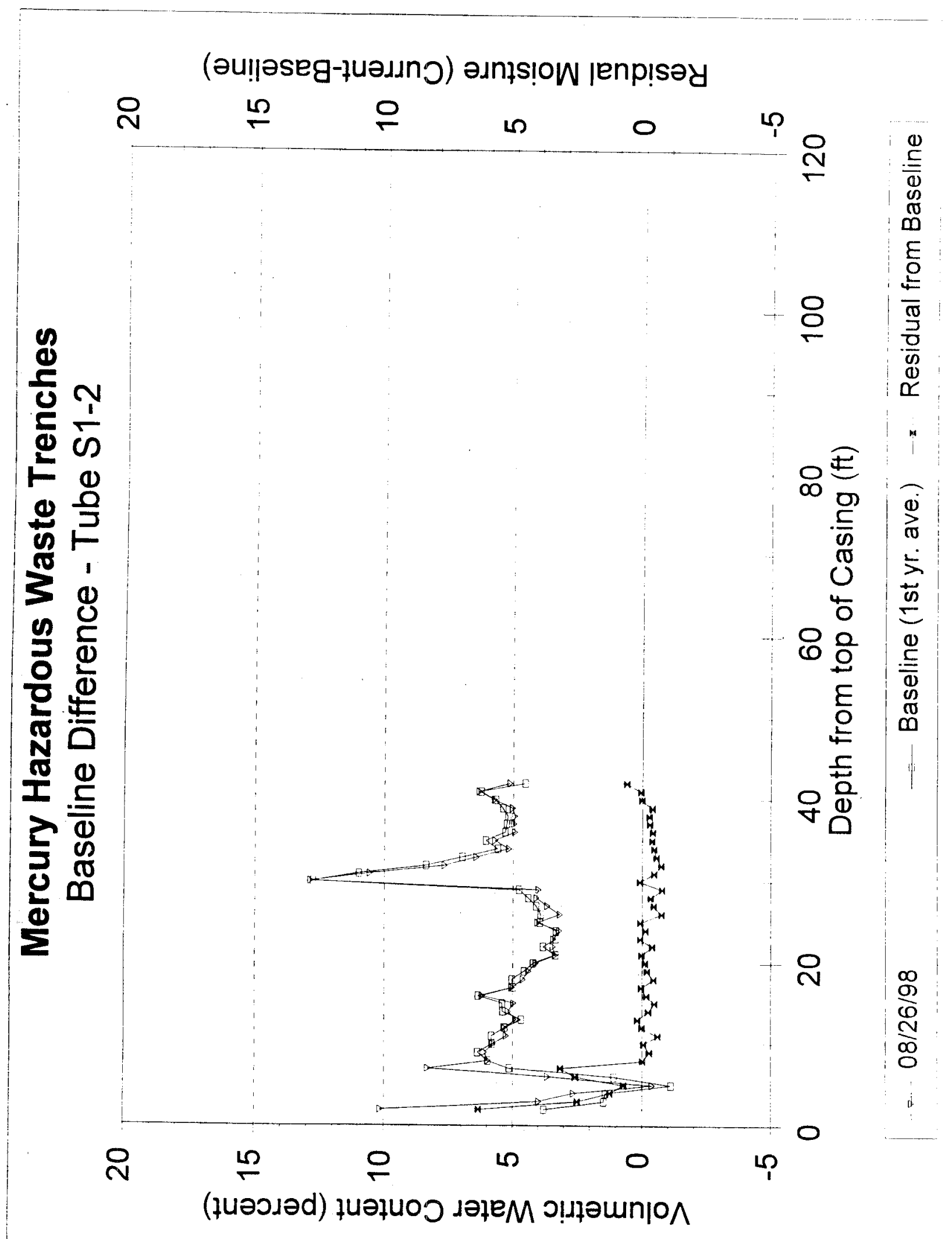




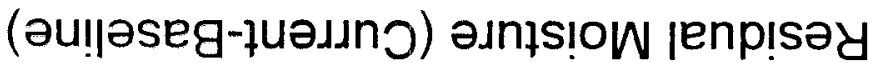

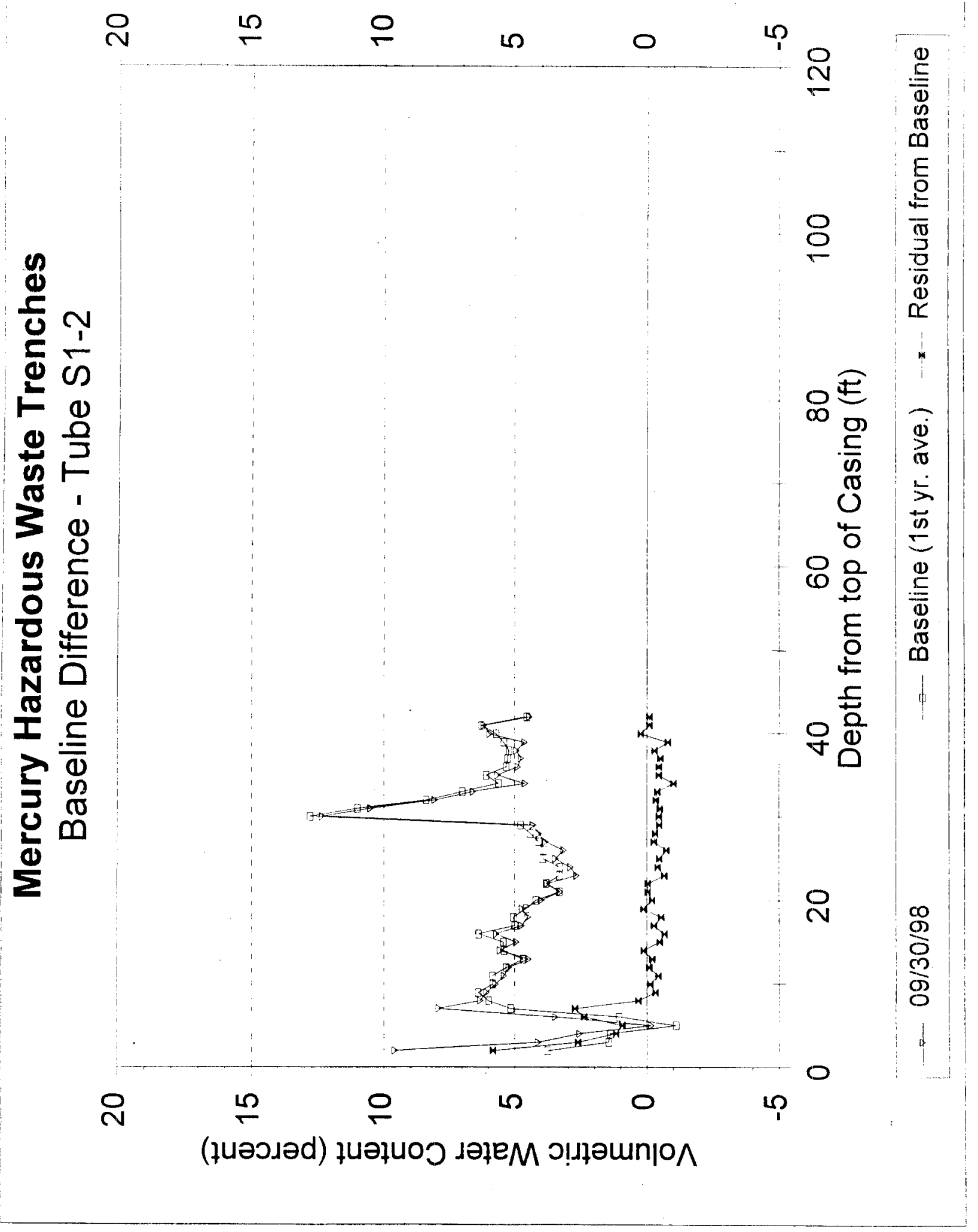




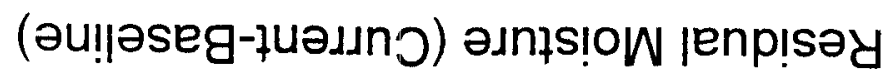
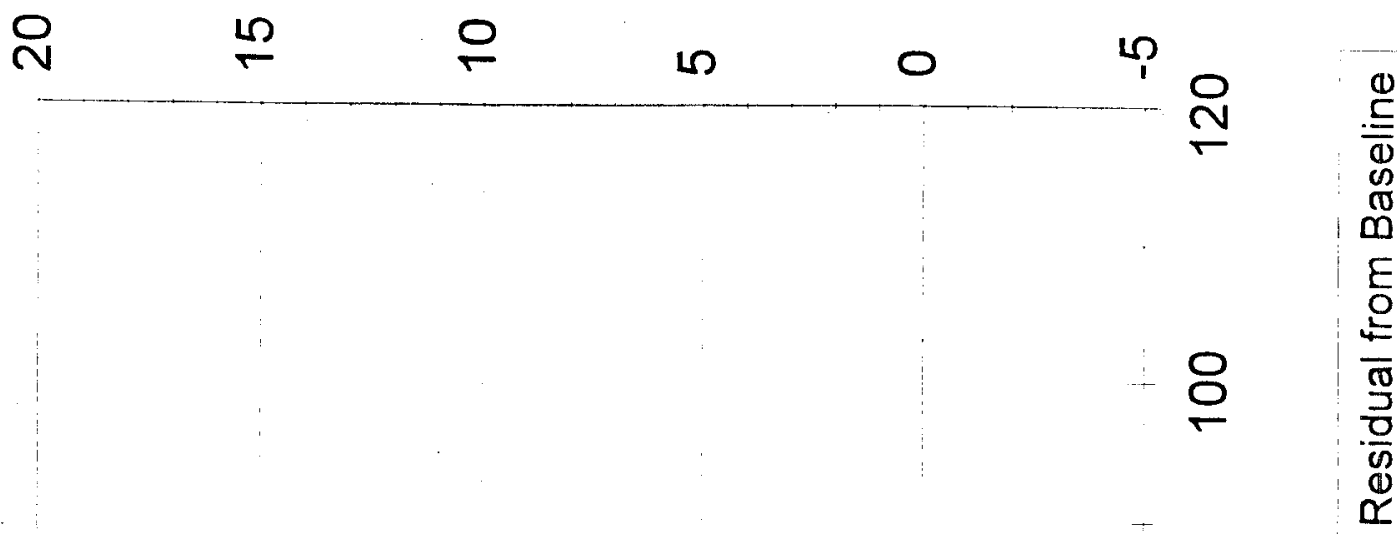

$\frac{y}{d} \frac{1}{\infty}$

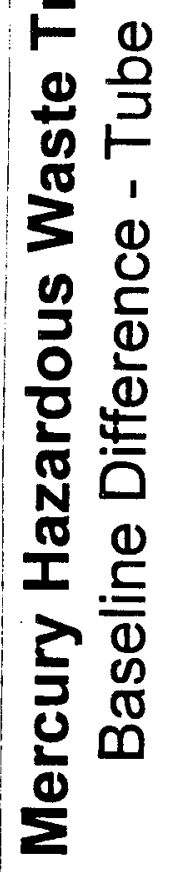

$\frac{1}{5}$
0
$\frac{0}{3}$
1
0
$\frac{0}{0}$
$\frac{1}{0}$
0

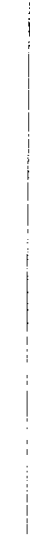

○ $\frac{\overparen{E}}{0}$

员



范

응요용

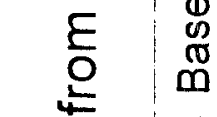

ㅇํㅁ
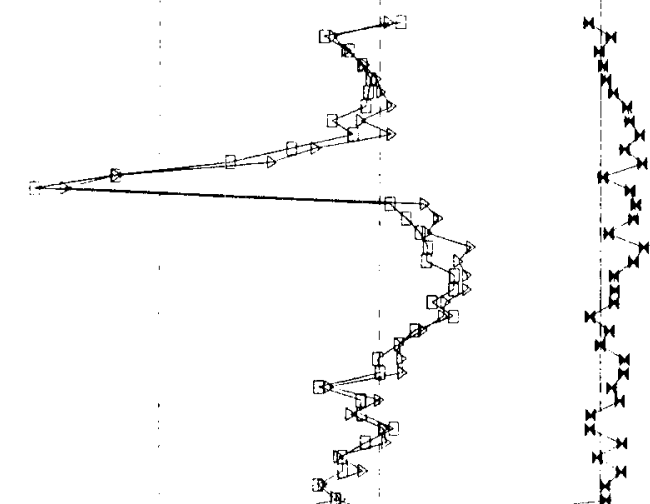

N

$\infty$
$\stackrel{\infty}{O}$
$\infty$
$\stackrel{N}{0}$
$\stackrel{O}{~}$

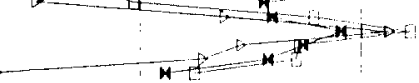

0

$\stackrel{2}{\sim}$

으

10

0

10

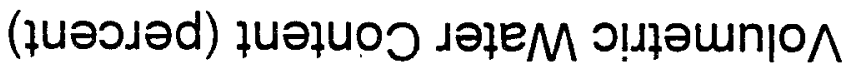




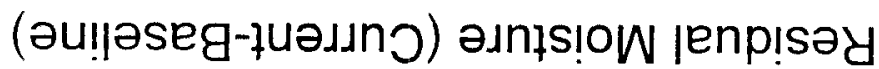

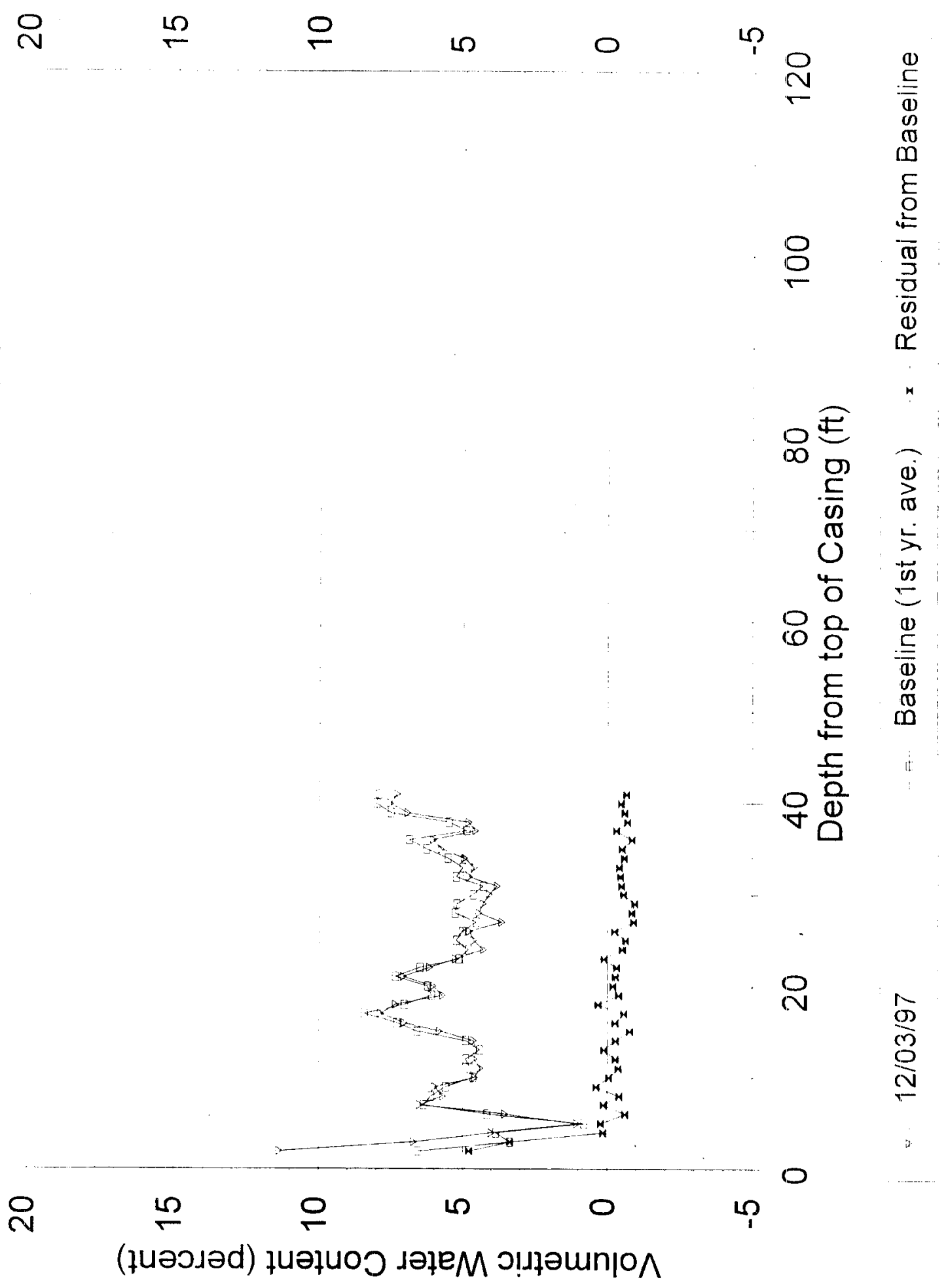




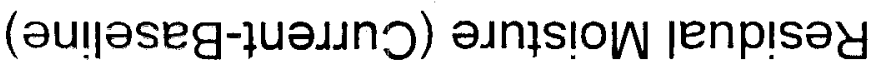

은

$\stackrel{4}{-}$

으

10

0
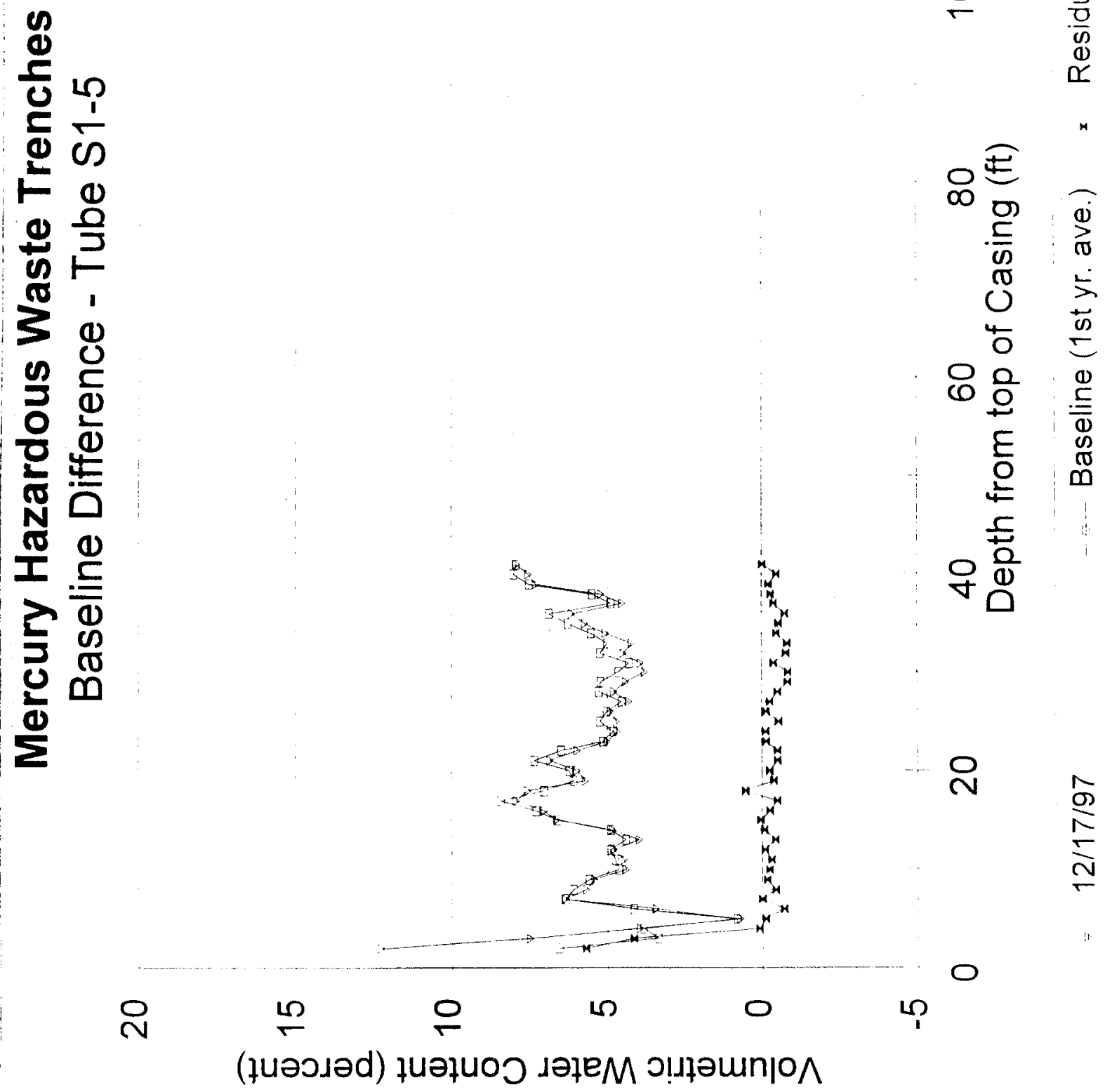


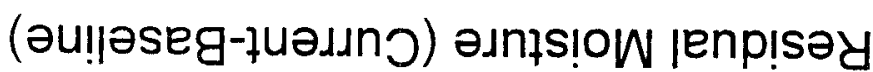

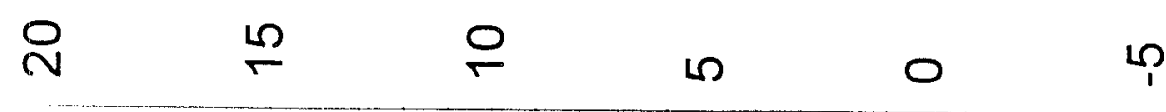

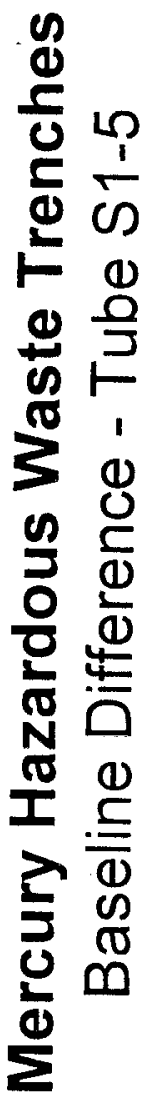

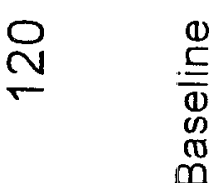

$\frac{\frac{E}{0}}{0} \quad \frac{\frac{5}{0}}{\frac{\pi}{3}}$

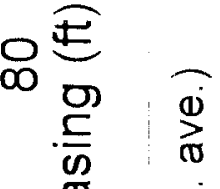

U

范 莫

응응 $\stackrel{0}{\frac{.}{0}}$

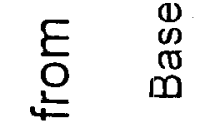
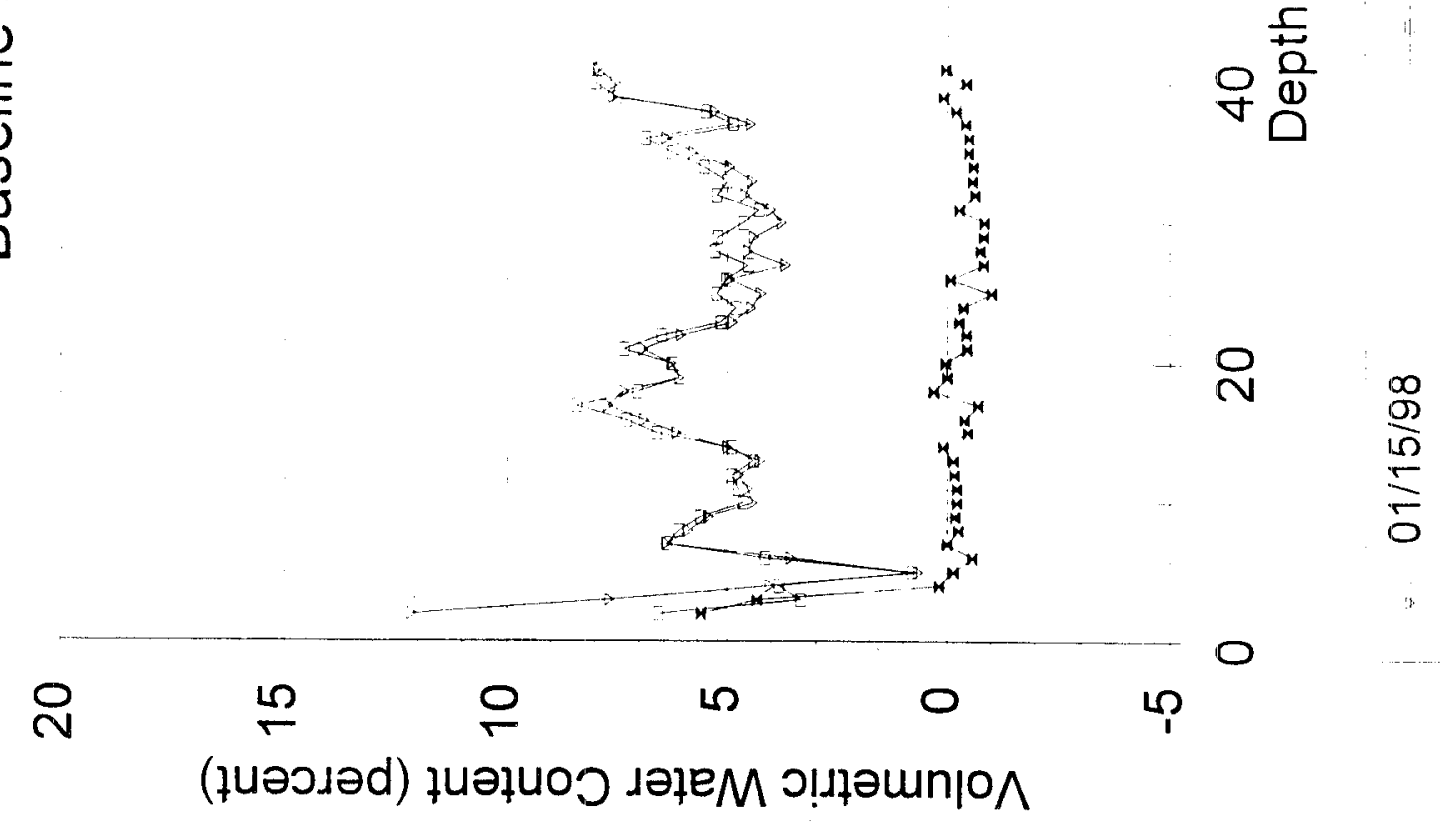

$\frac{\frac{\infty}{0}}{\frac{1}{10}}$ 


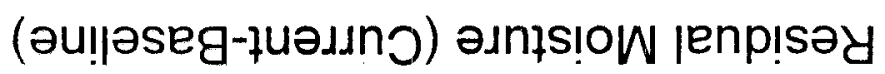

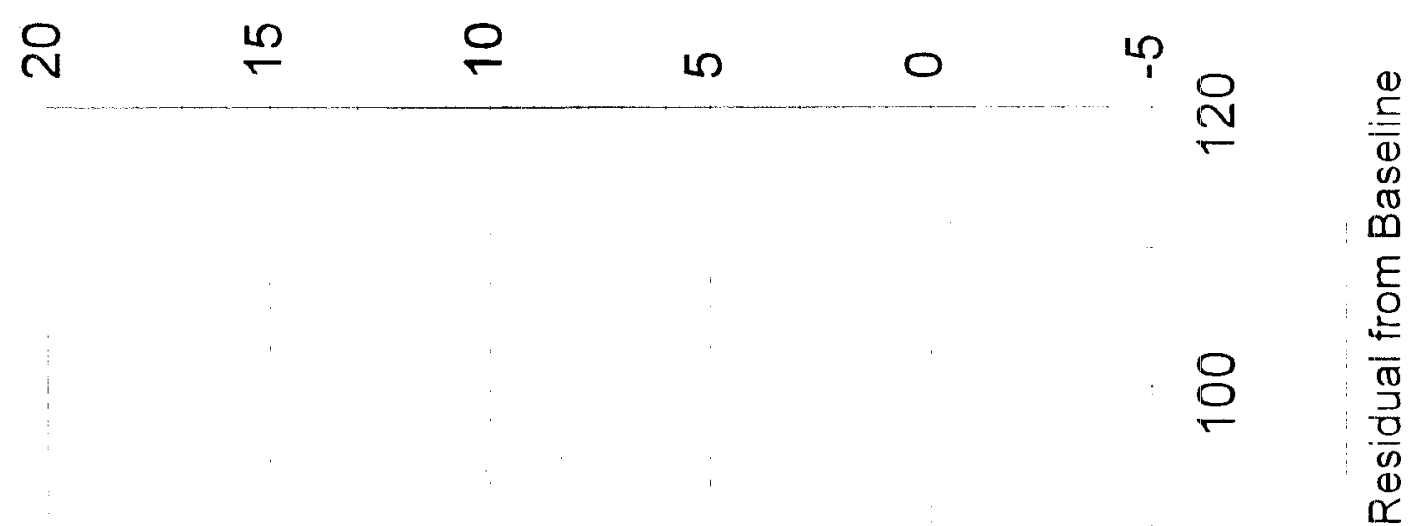

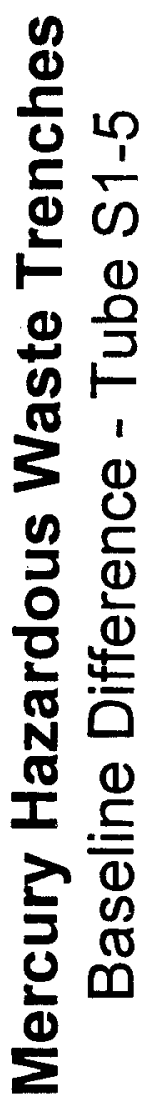




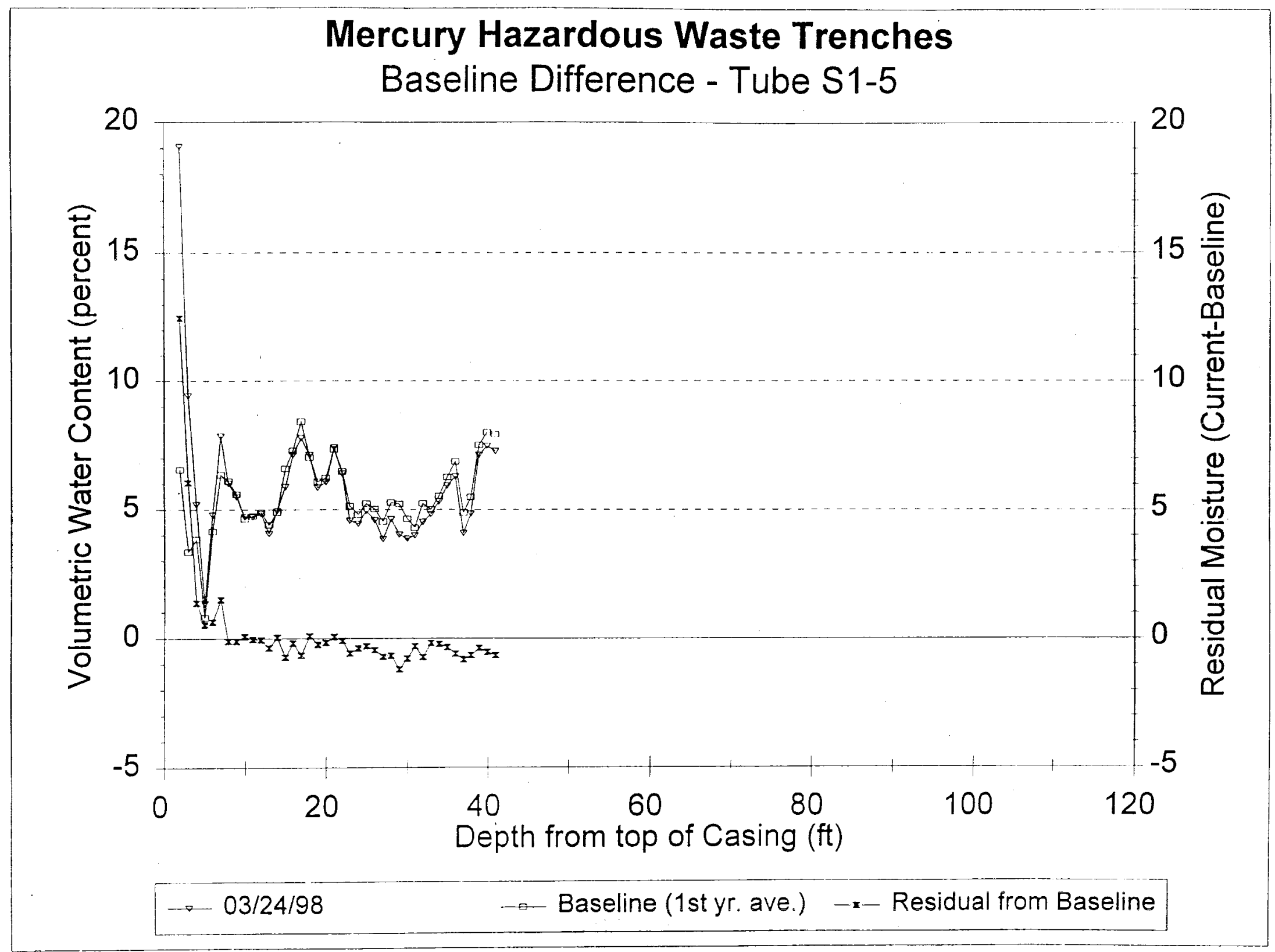




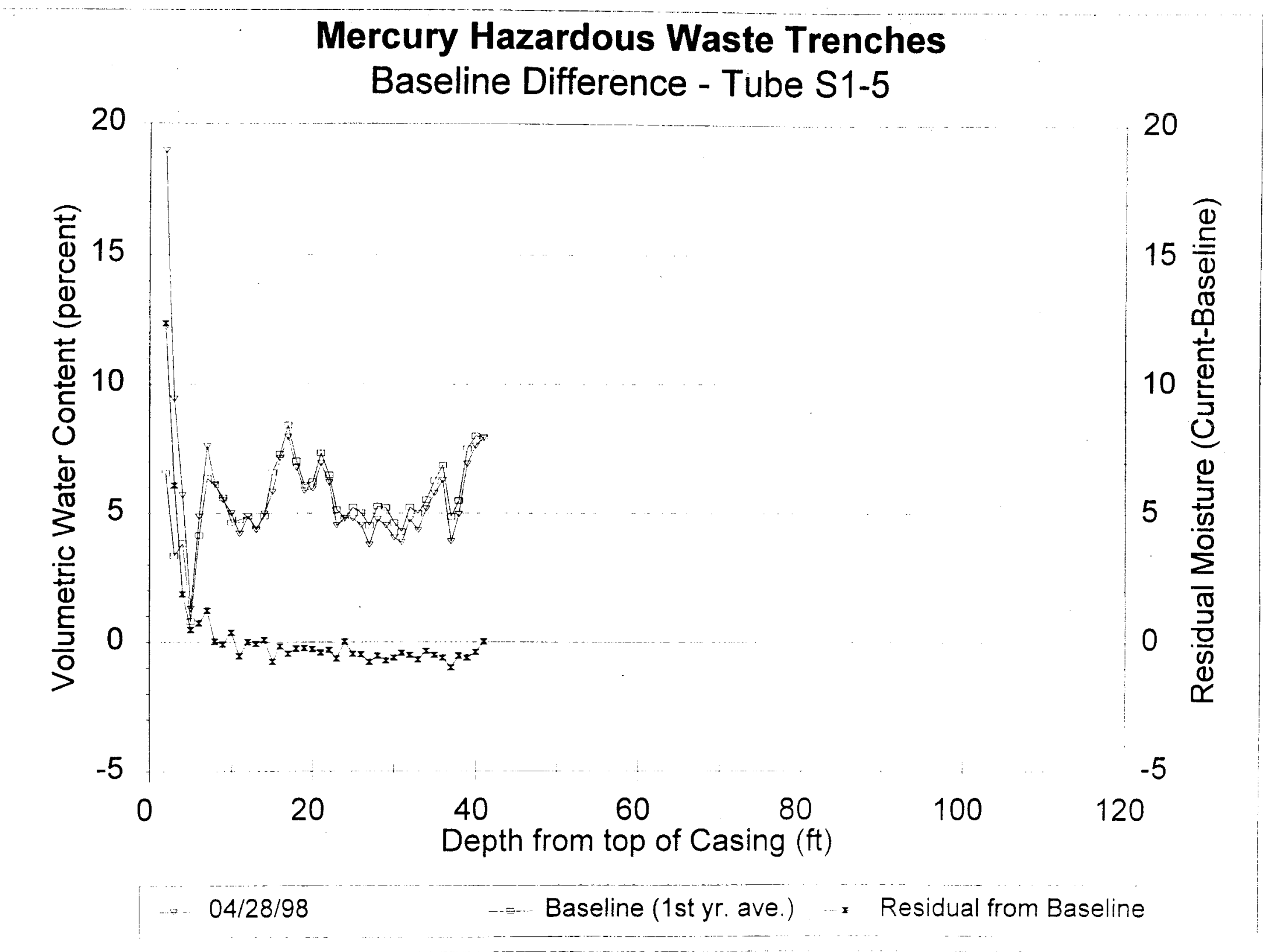




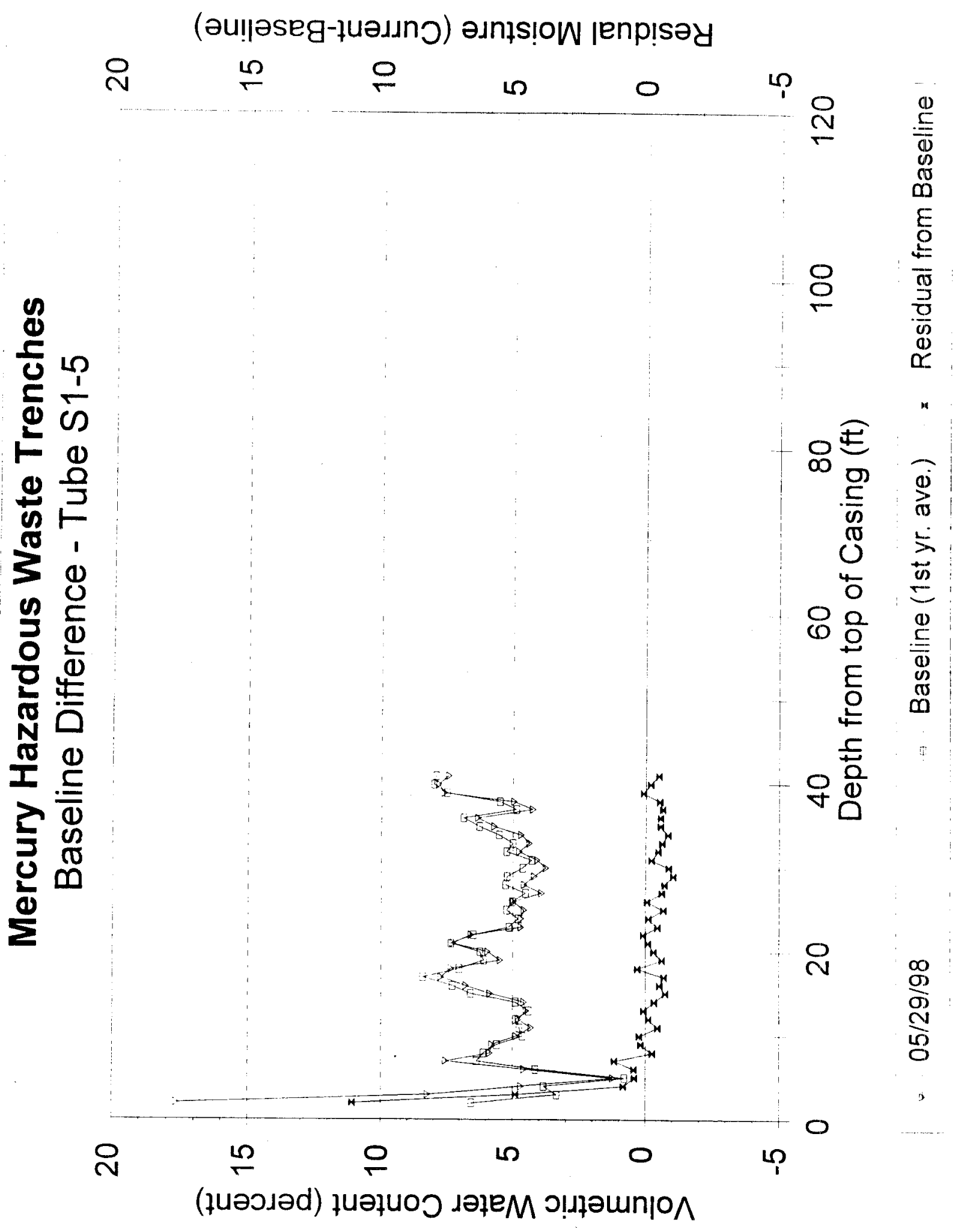




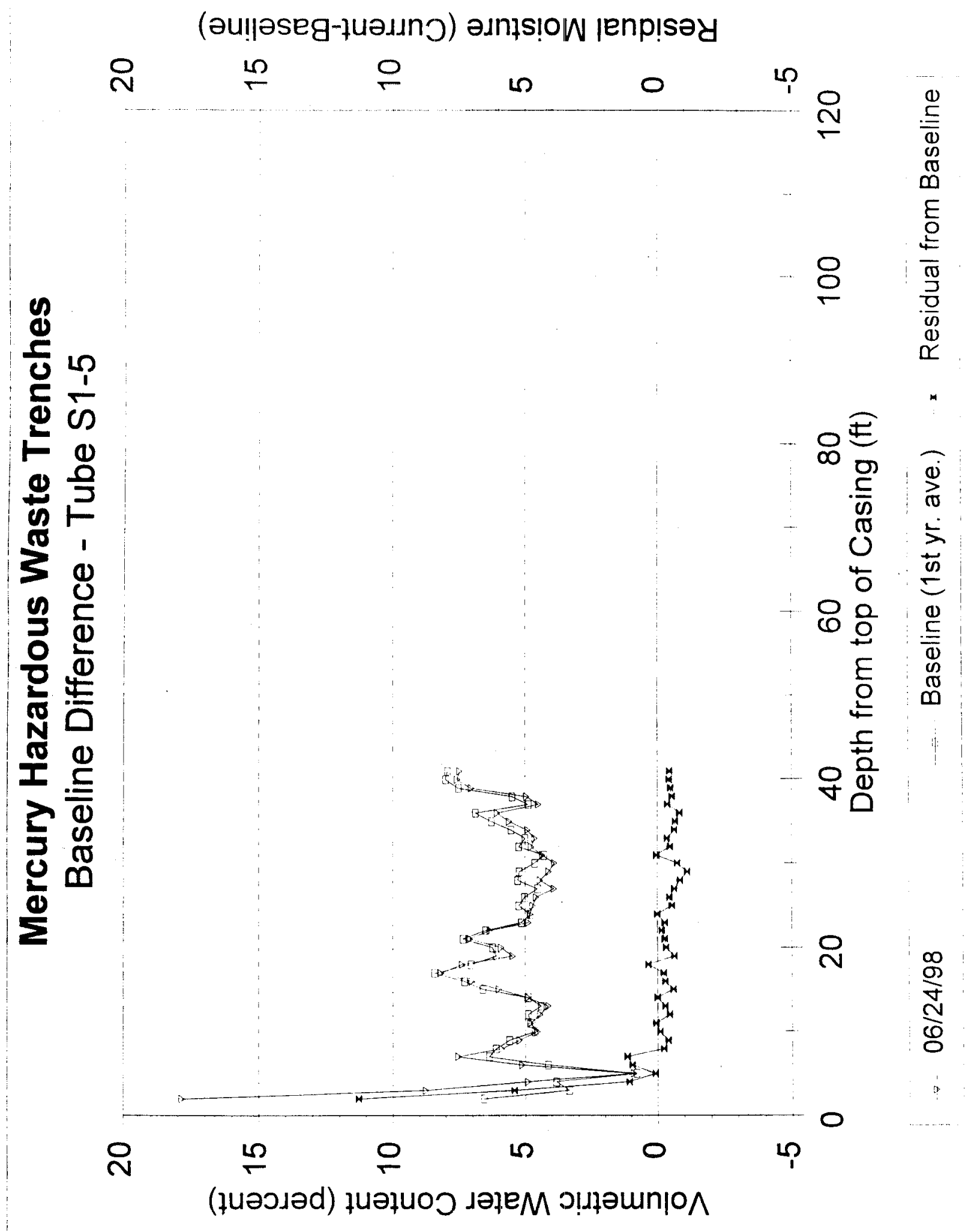




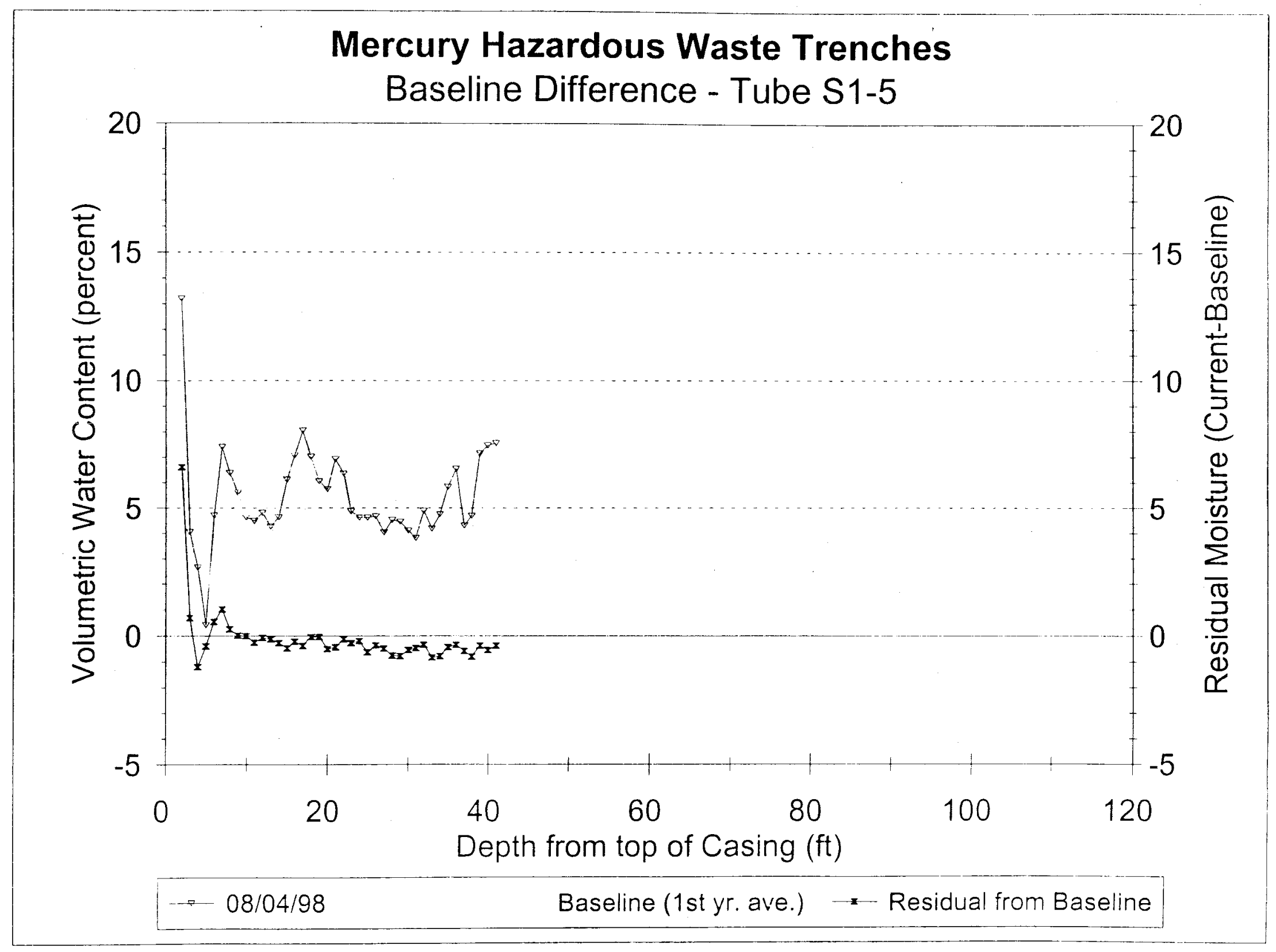




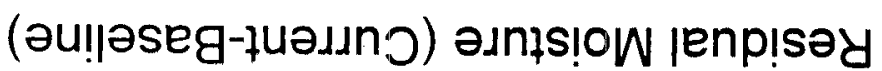
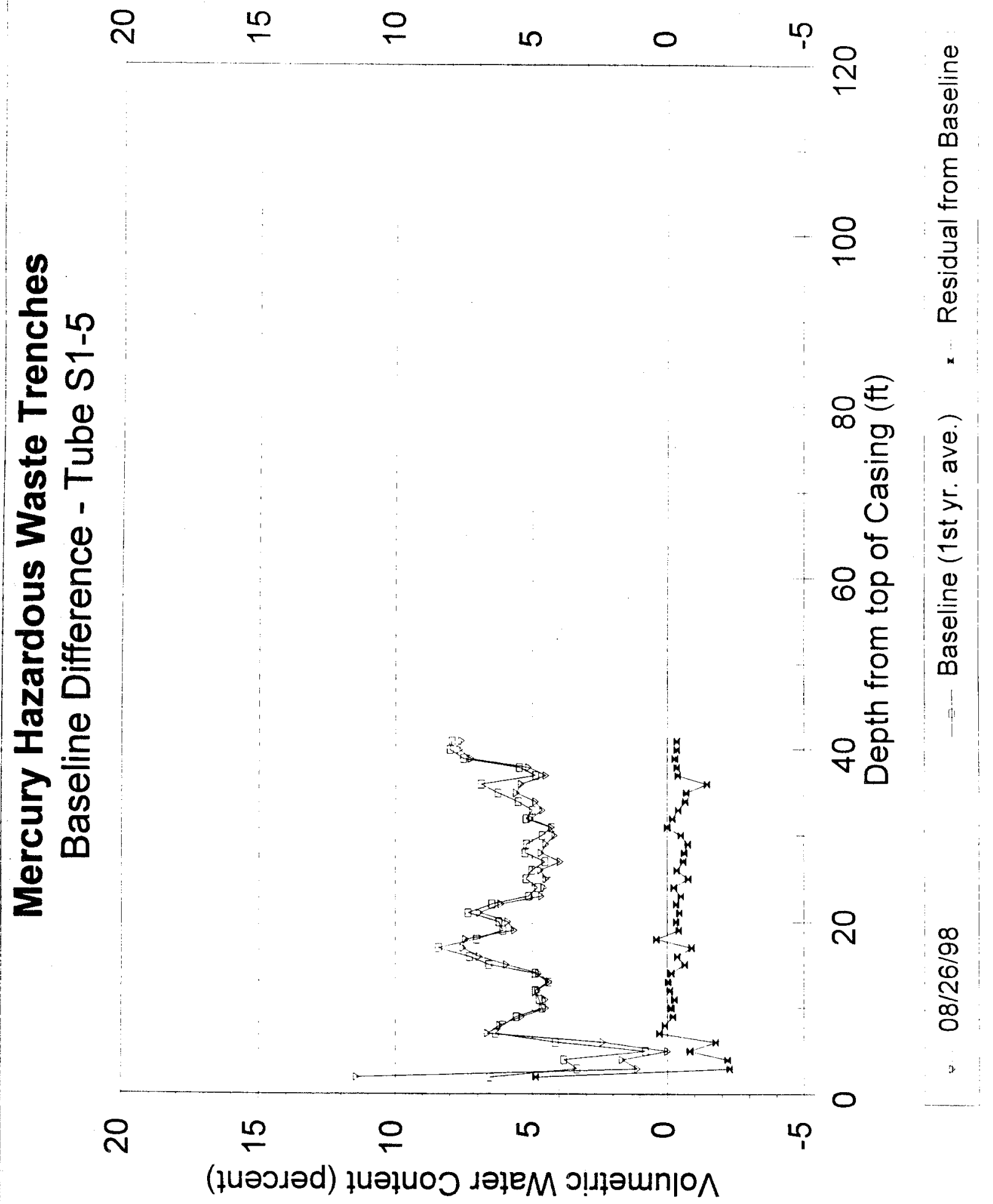

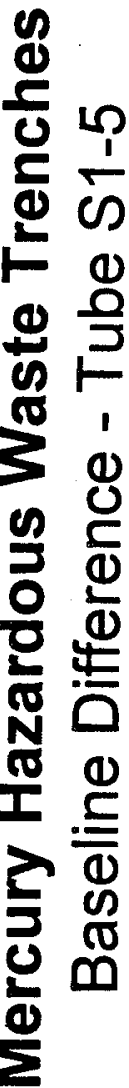




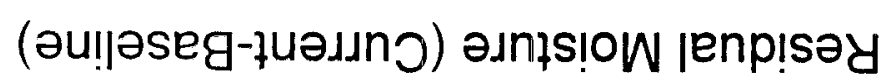
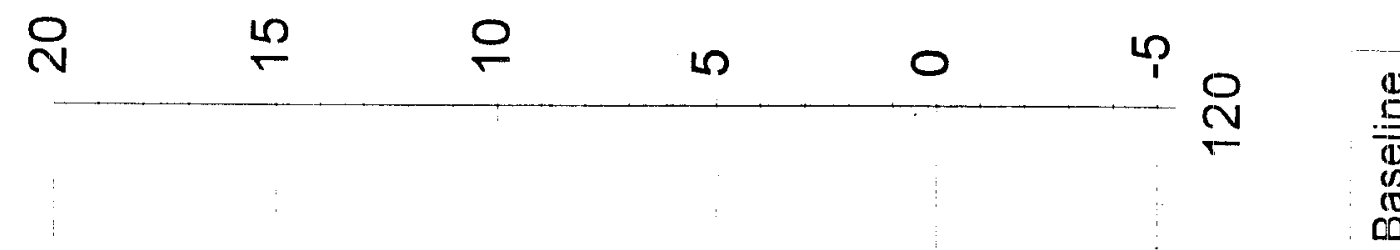

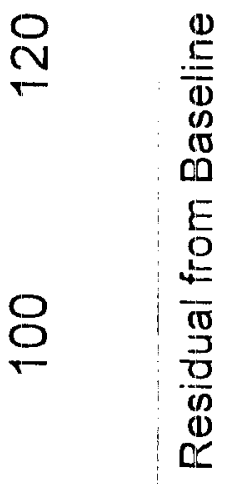

$\frac{d}{\frac{g}{0}}$

至

31

을

응 넌

웅

(ิ)

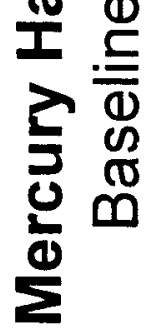$$
\frac{0}{d}
$$

용
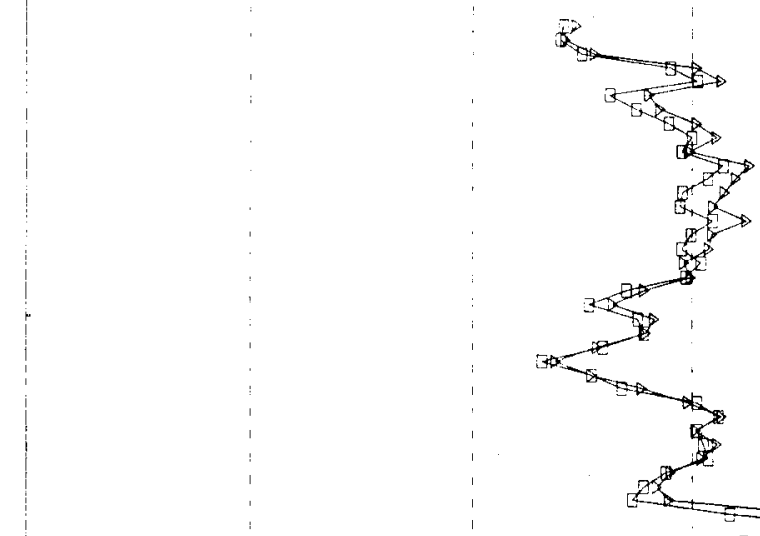

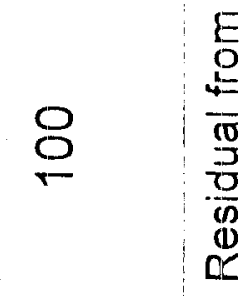

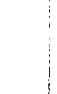

(

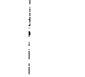




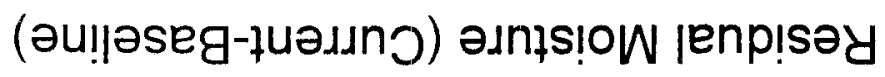

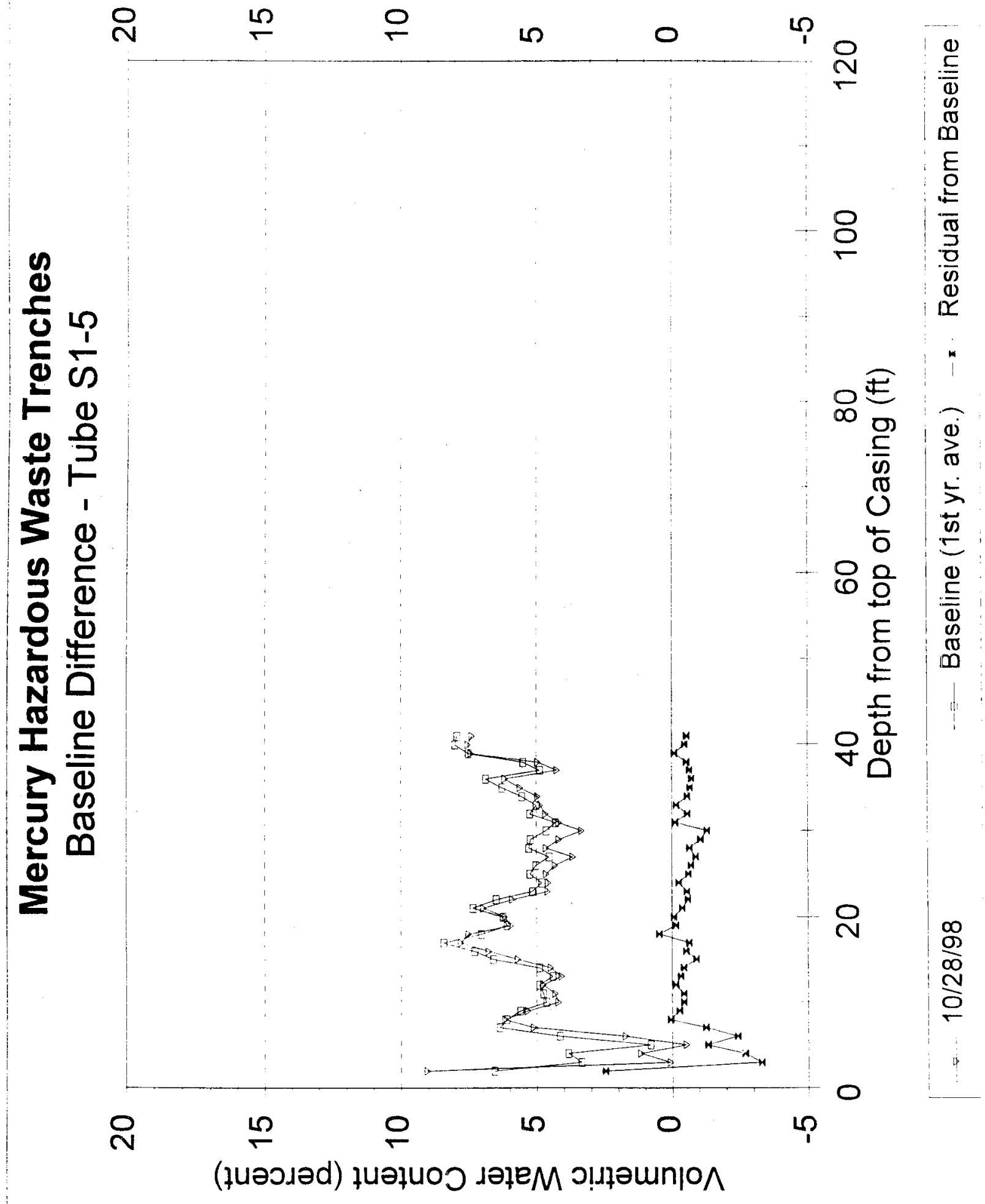




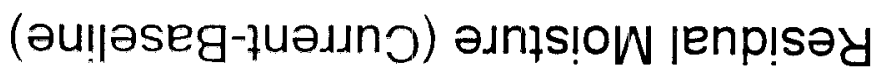
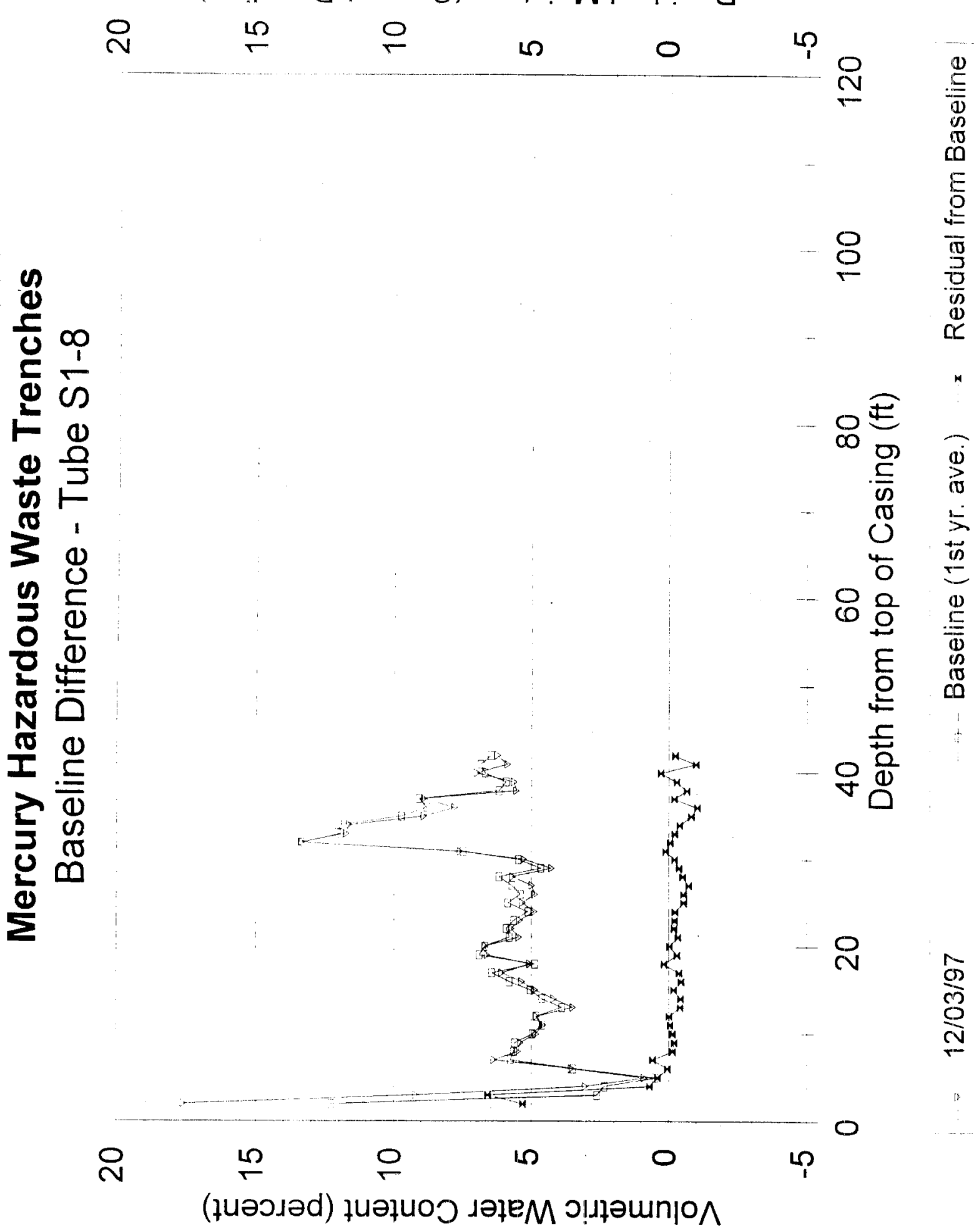


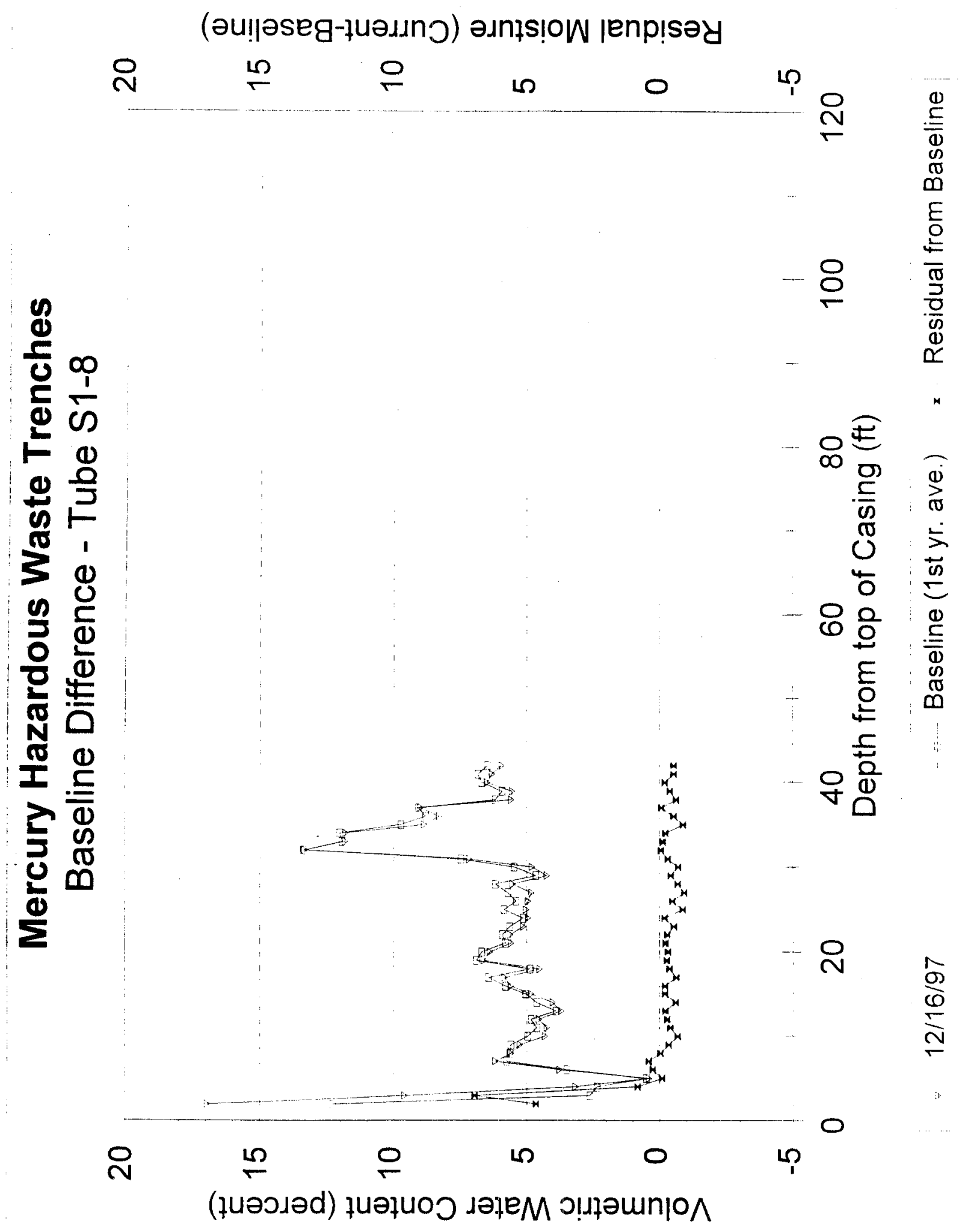


(әu!|əseg-łuəunว) əınıs!oW jenp!səy

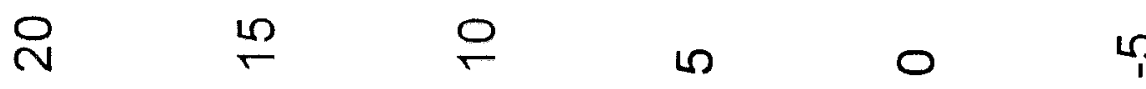
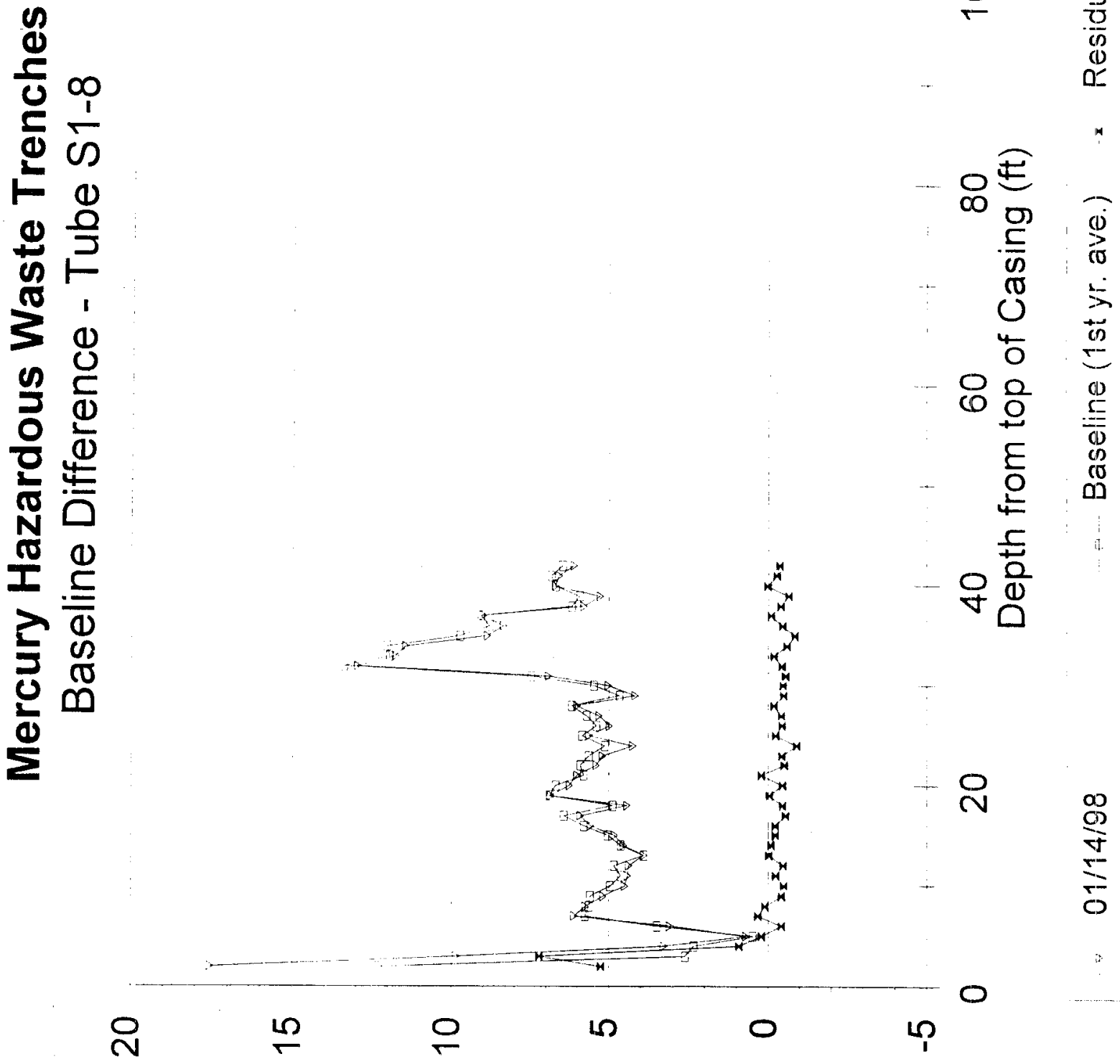

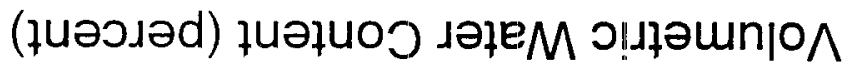




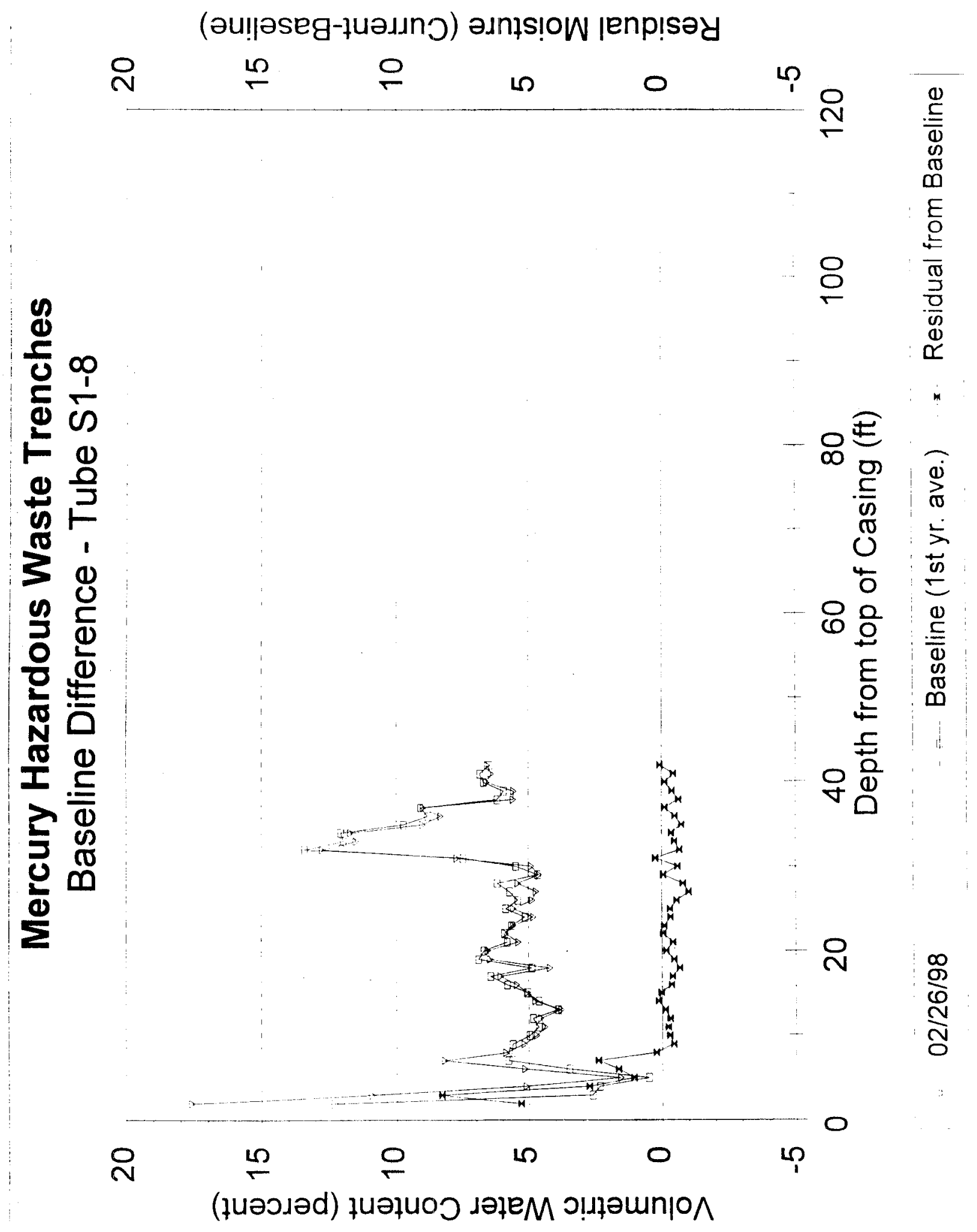




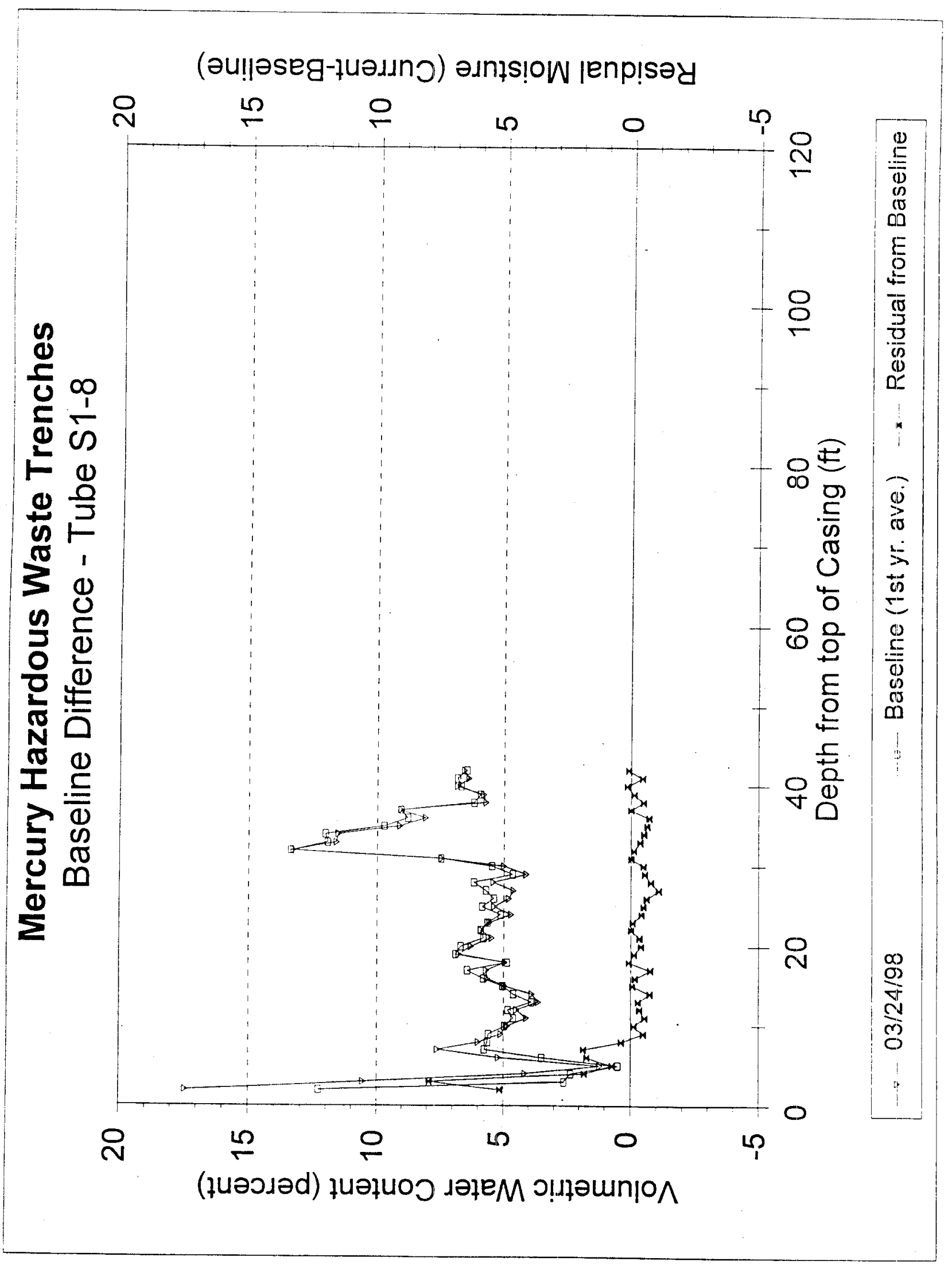




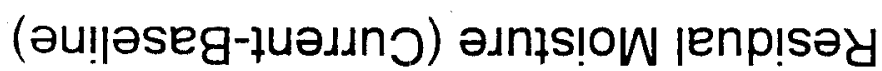

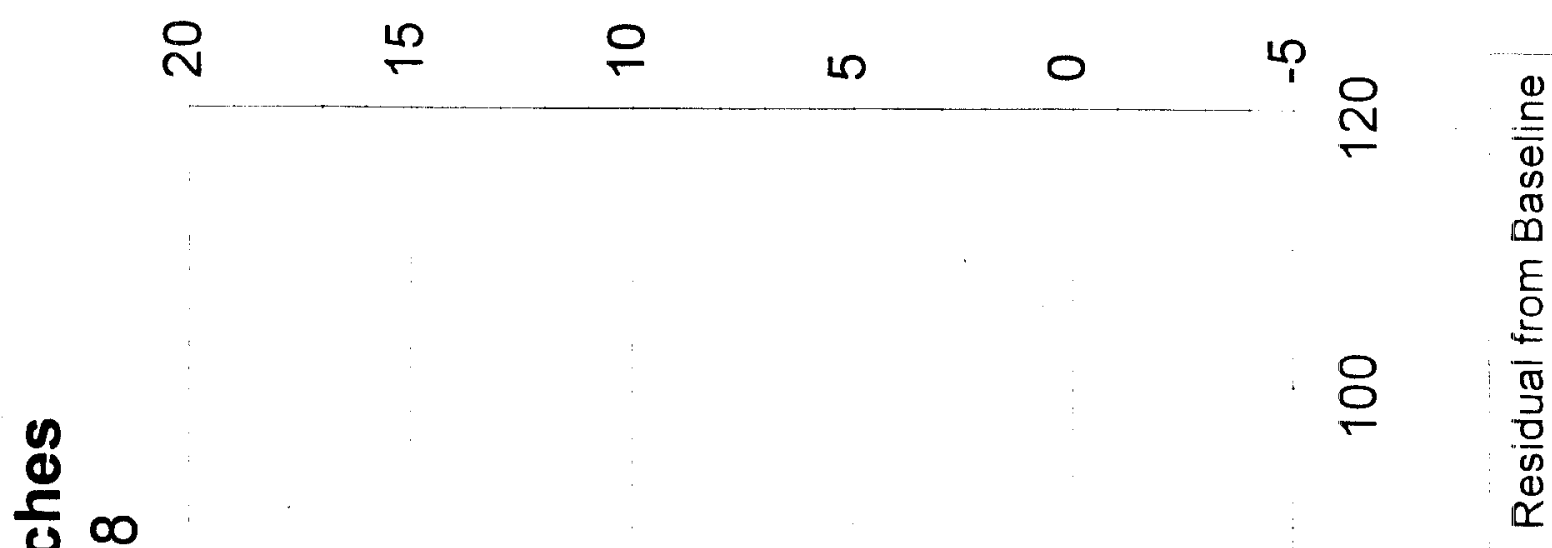

인 $\frac{1}{\infty}$

里

$\rightarrow 1$

$\sum 0$

$\frac{1}{0}$

운

กั

(1)

$>\overline{\overline{0}}$

$5 \%$

$0 \mathrm{~m}$

인

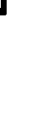

\section{.}

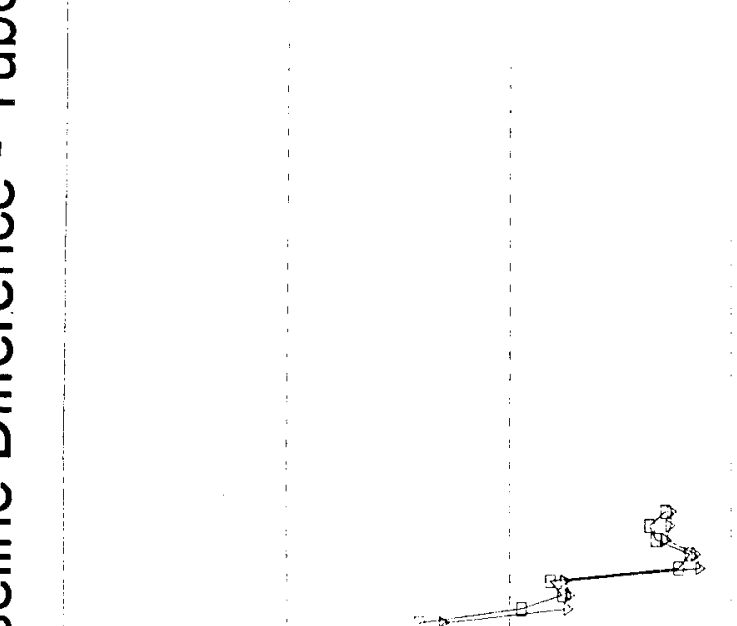

: 1
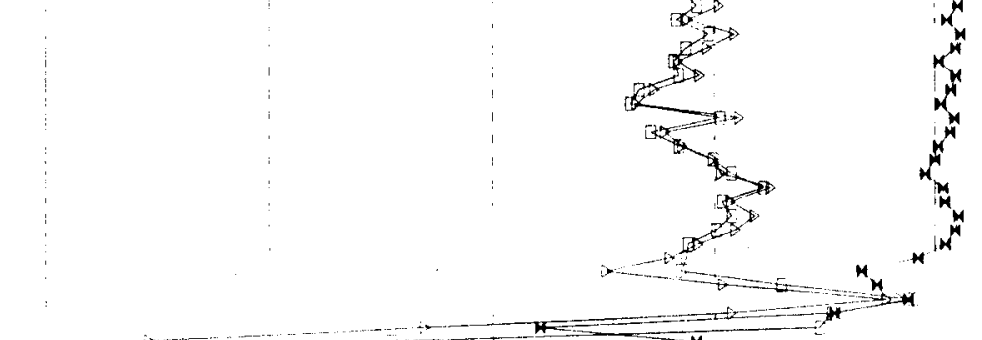

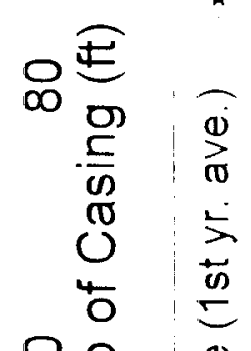

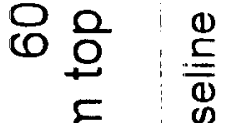

\begin{tabular}{l|l|l|}
$E$ & $\infty$ \\
\hline & $\infty$ \\
\hline & $\infty$
\end{tabular}
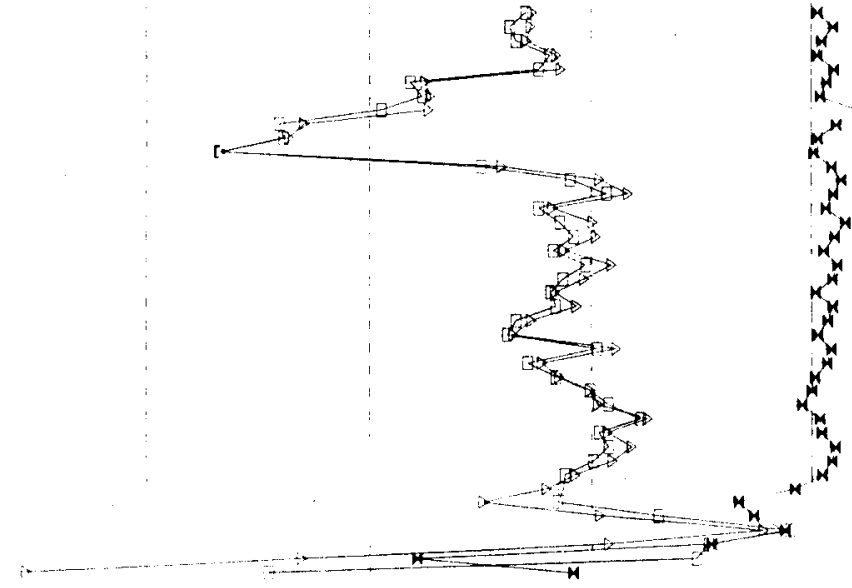

จ $\frac{\text { 둥 }}{0}$

$-\stackrel{\bigcirc}{\sim}$

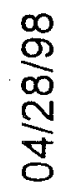

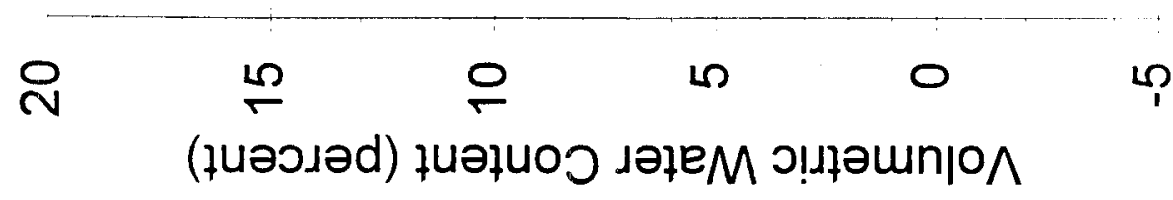




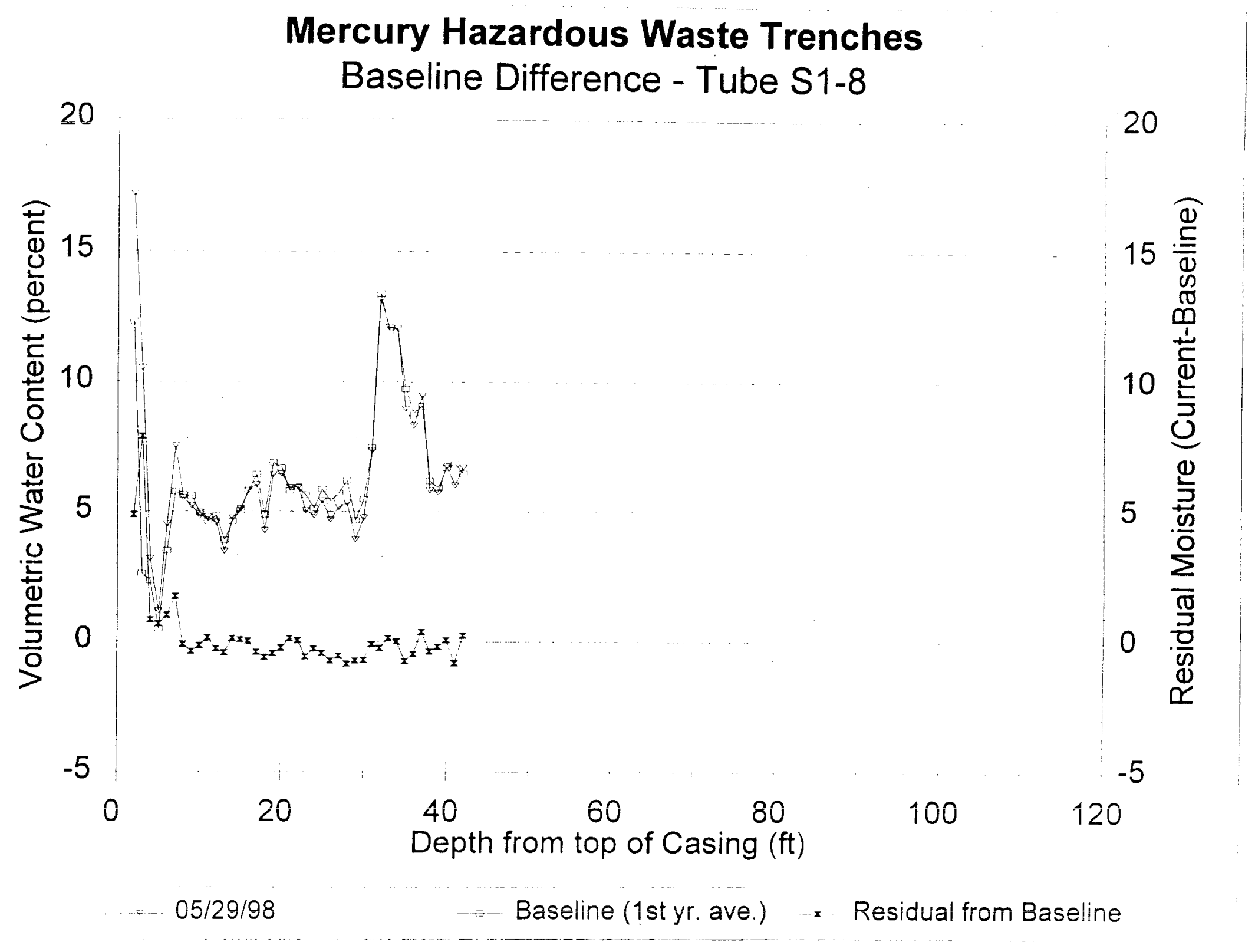




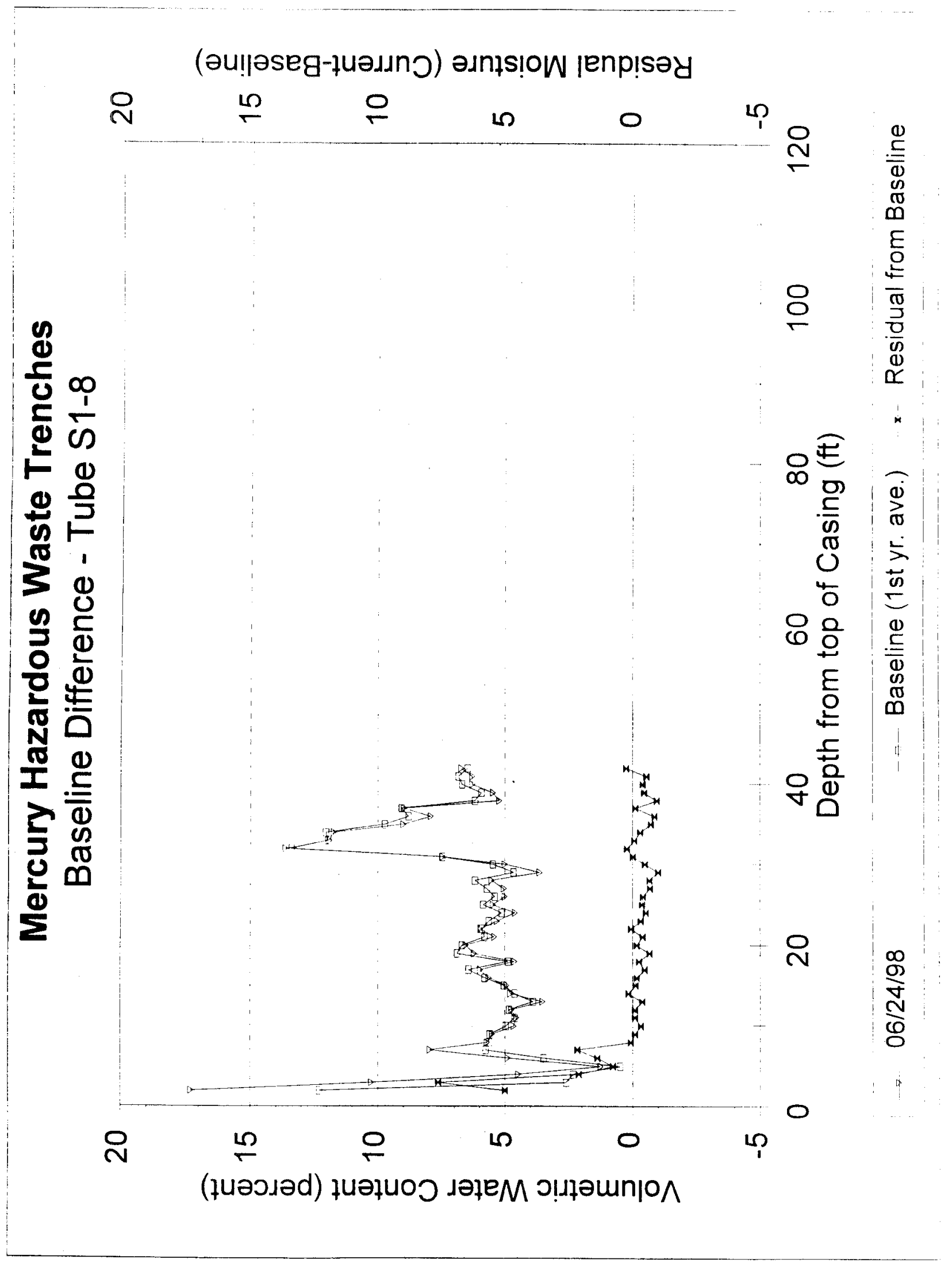




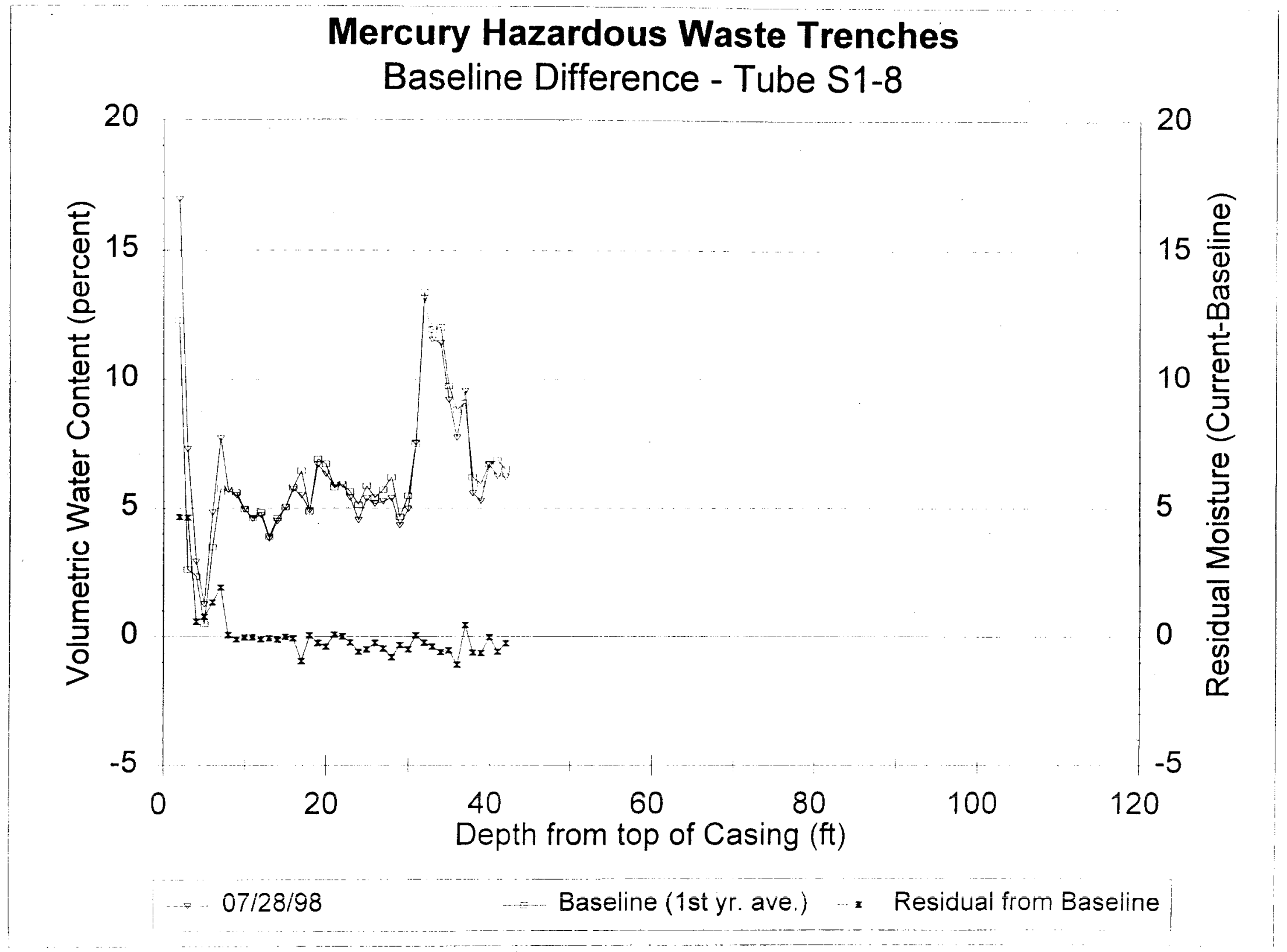




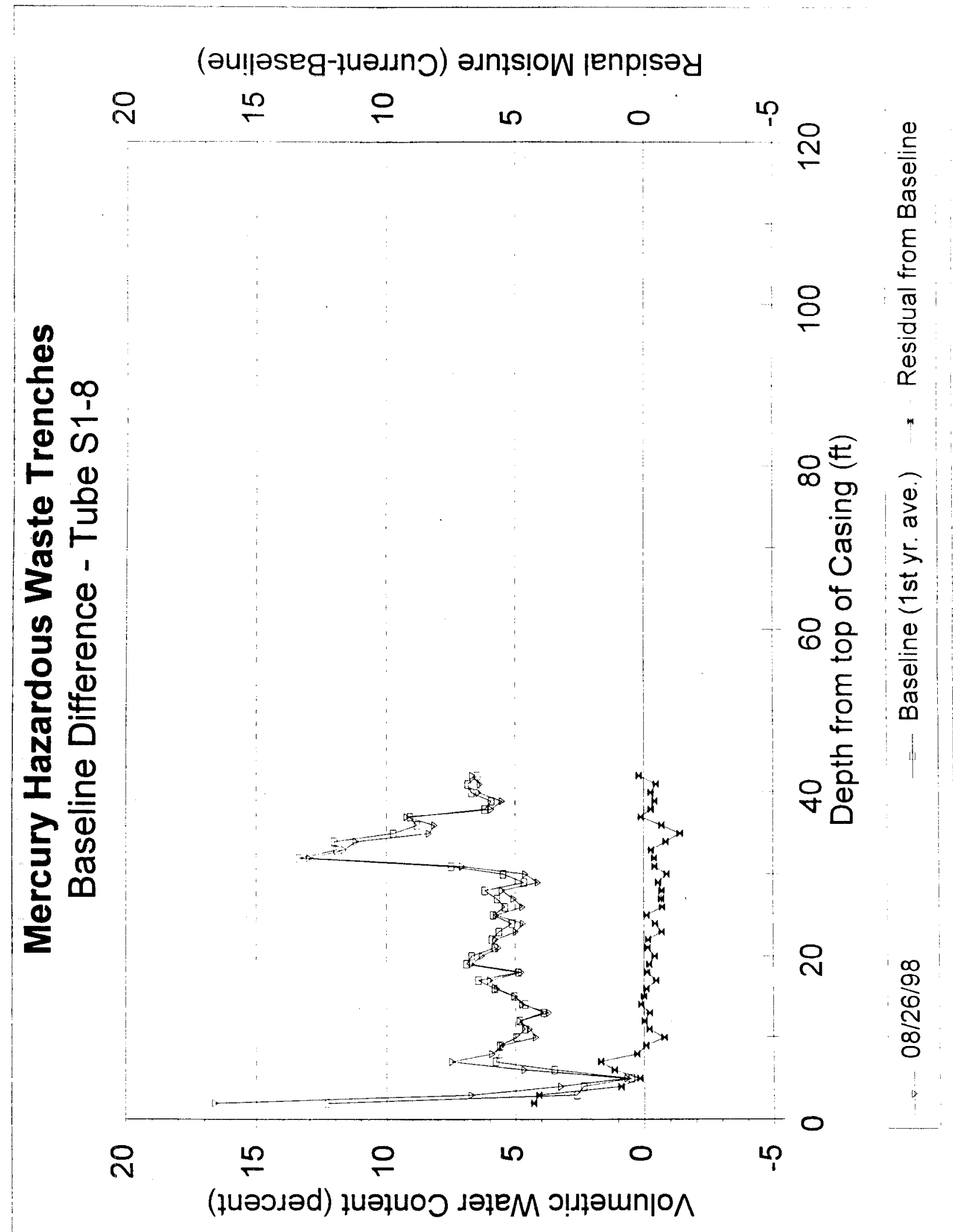




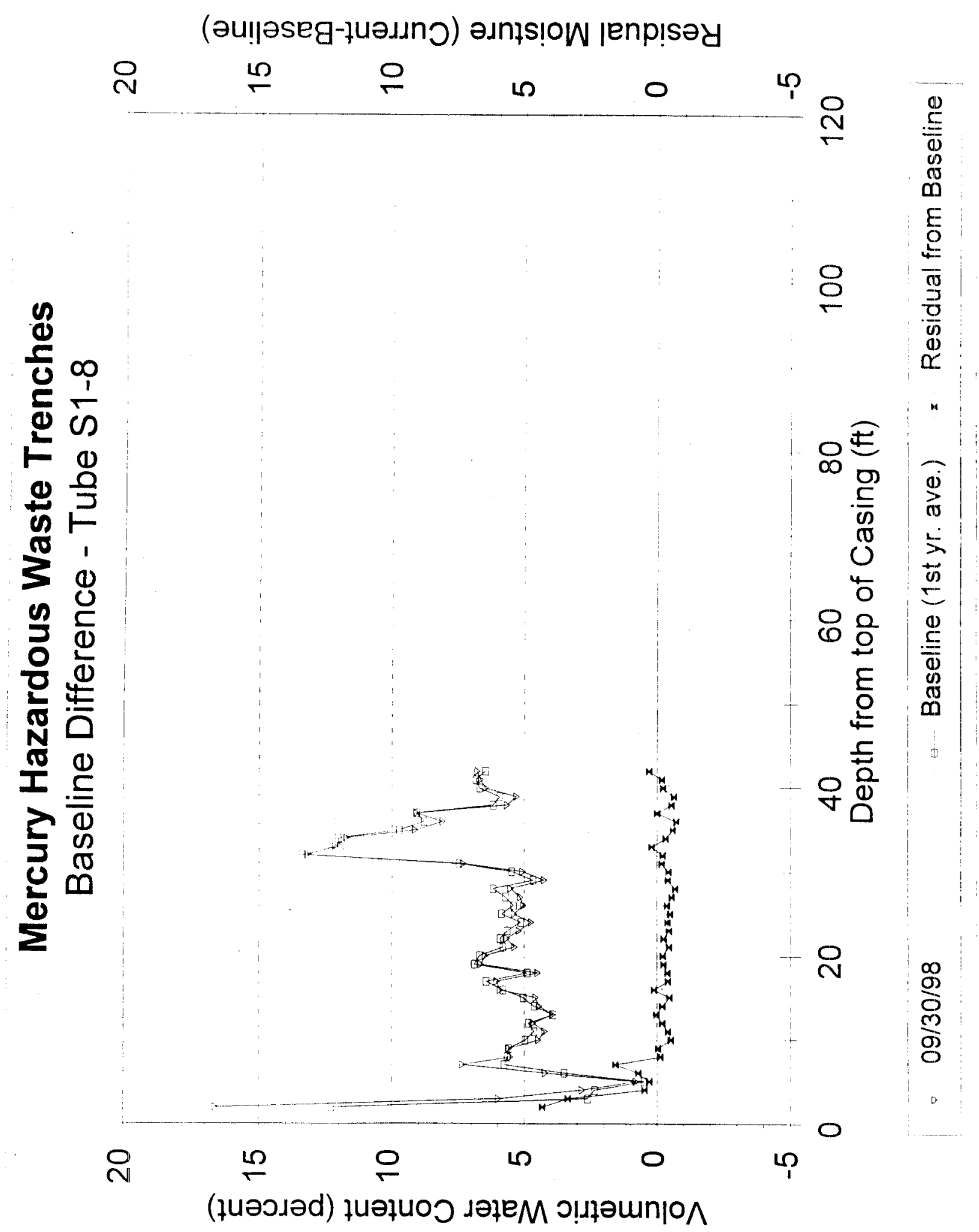




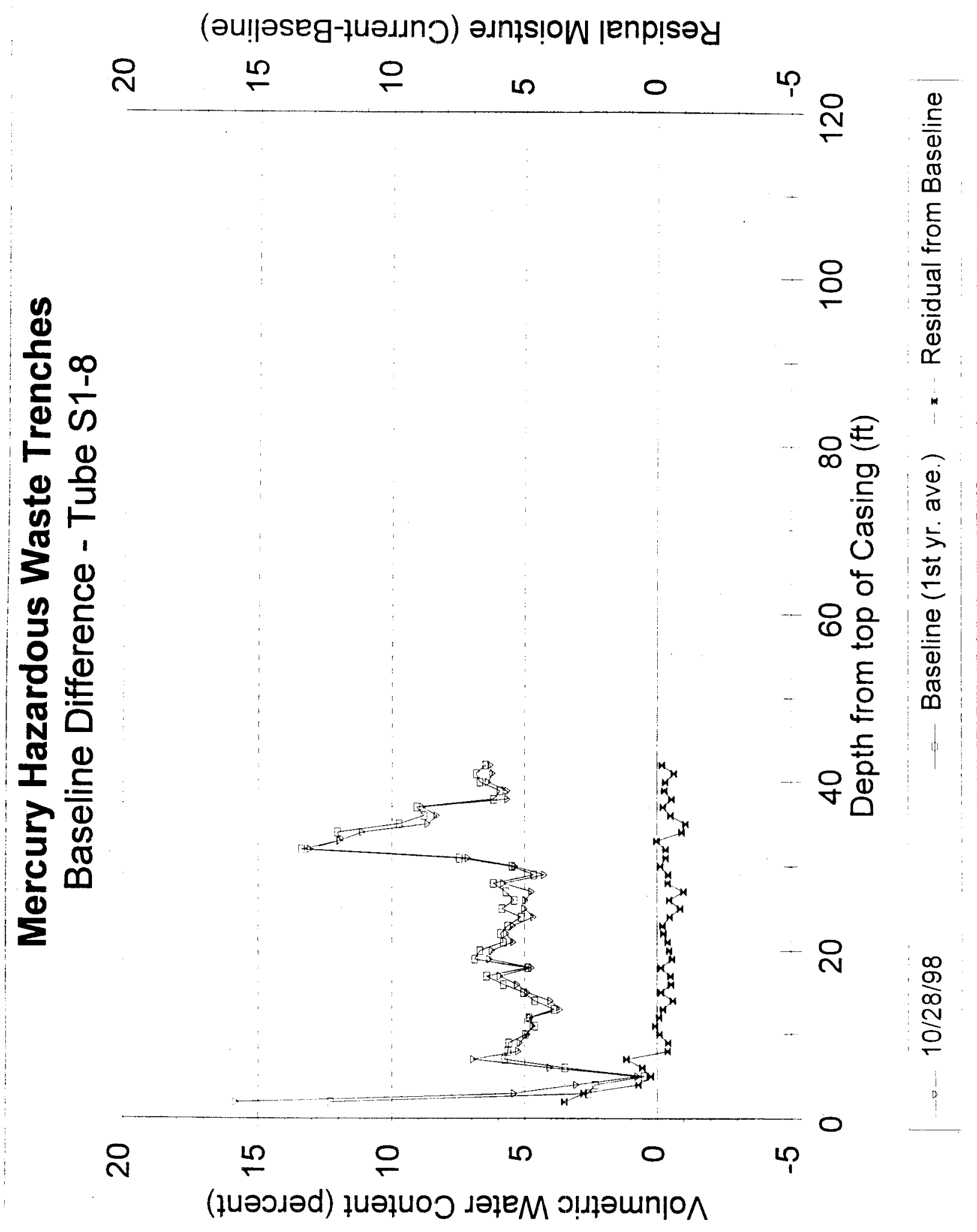




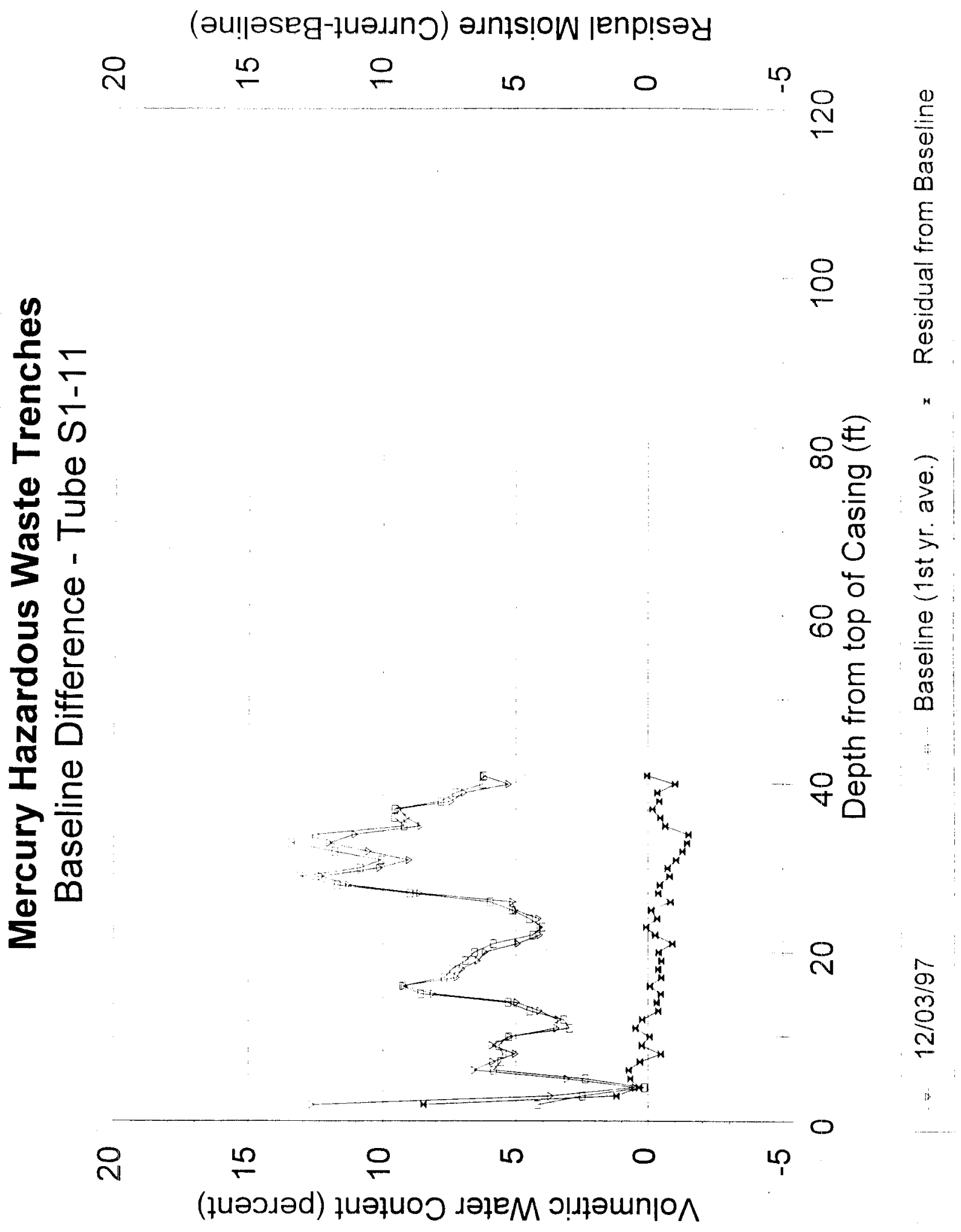




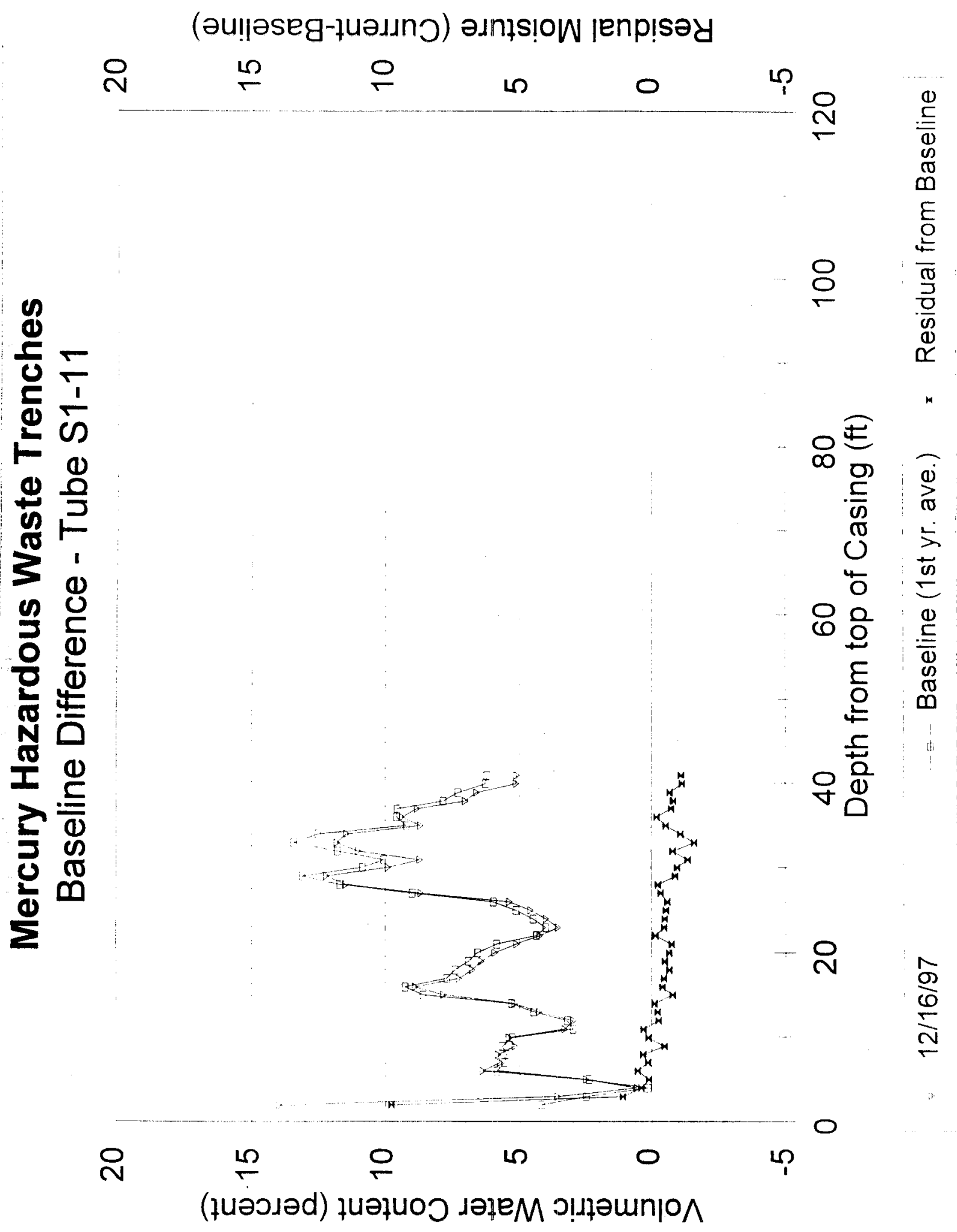




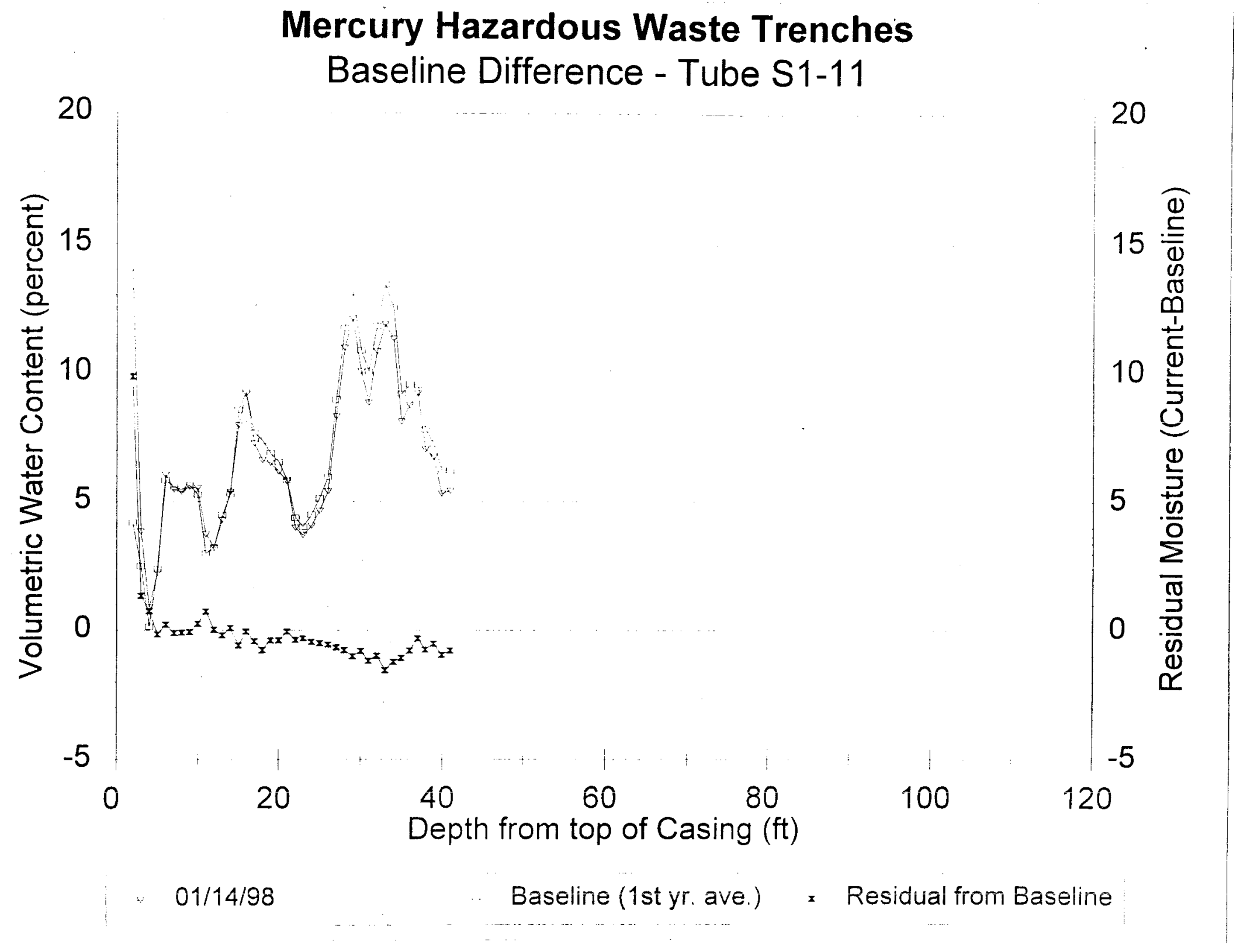




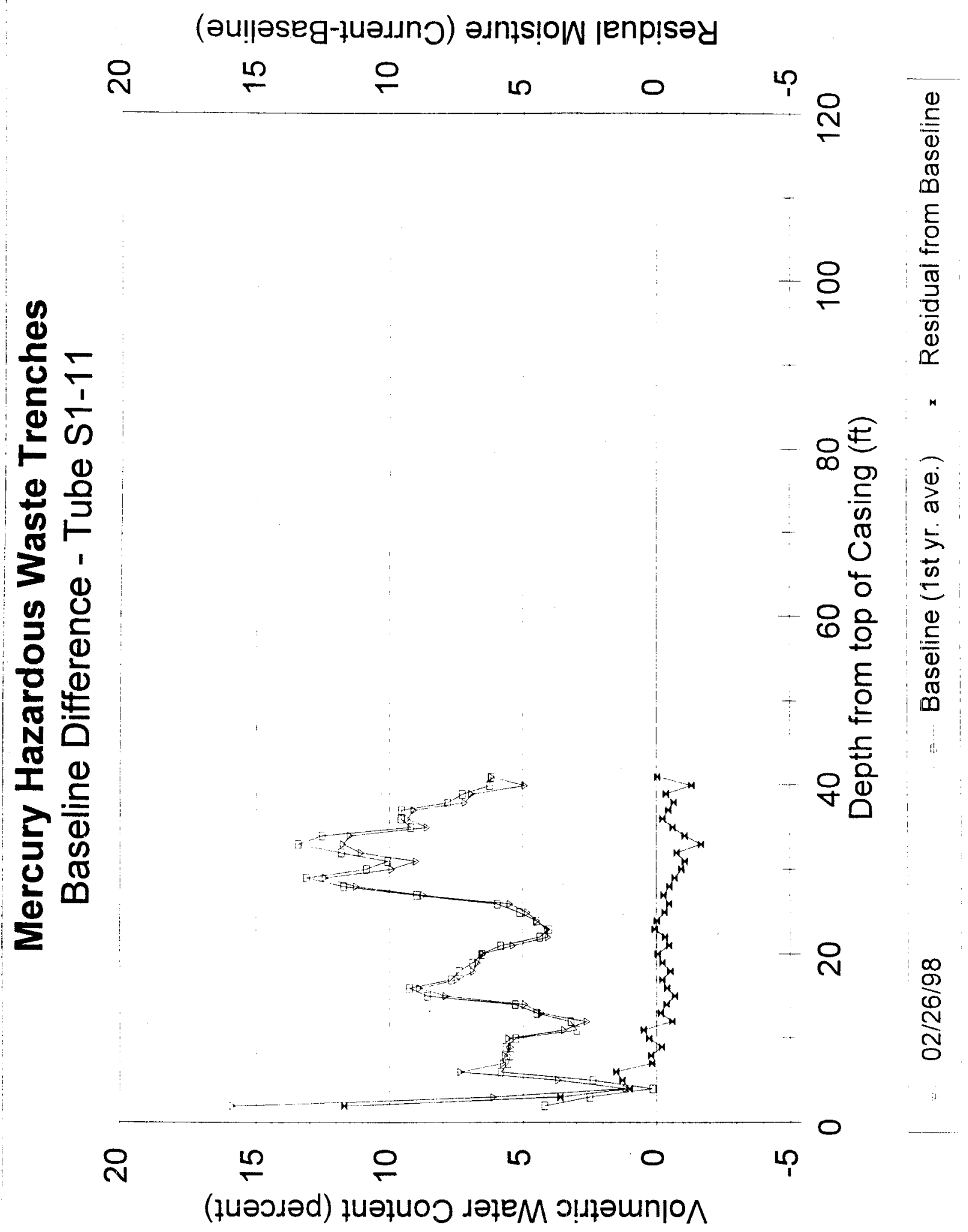




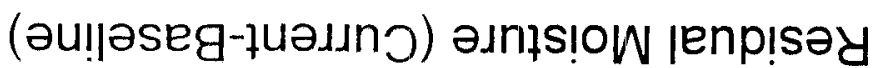
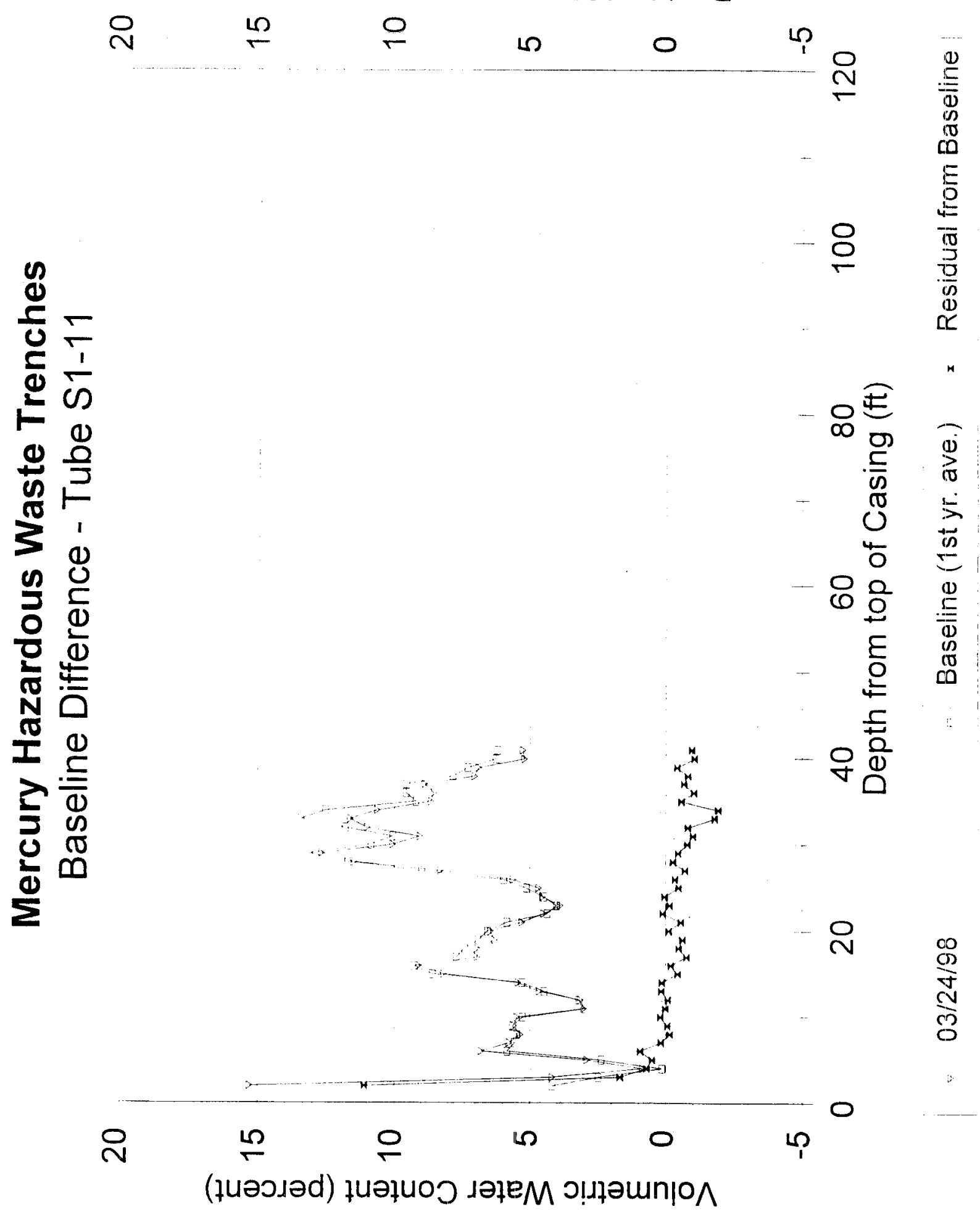


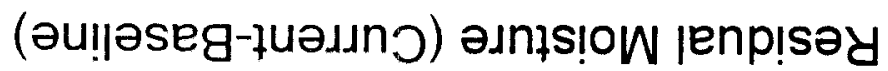

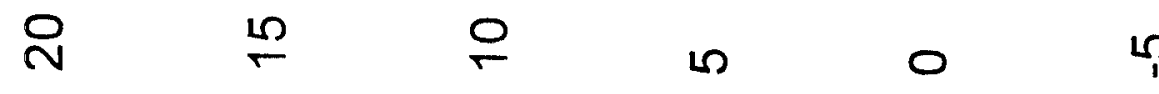

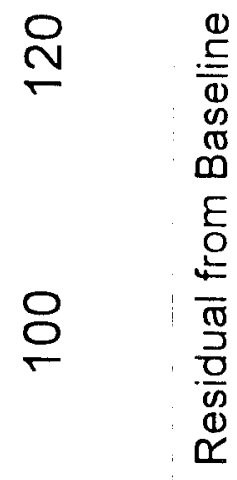

g

$\frac{0}{0} \frac{5}{0} \frac{1}{0}$

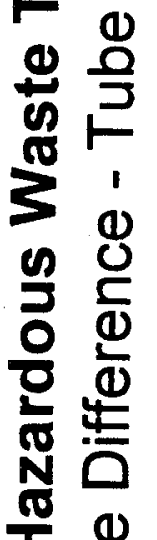

I $\stackrel{9}{\Xi}$

곤

(⿻)

은

인

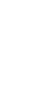
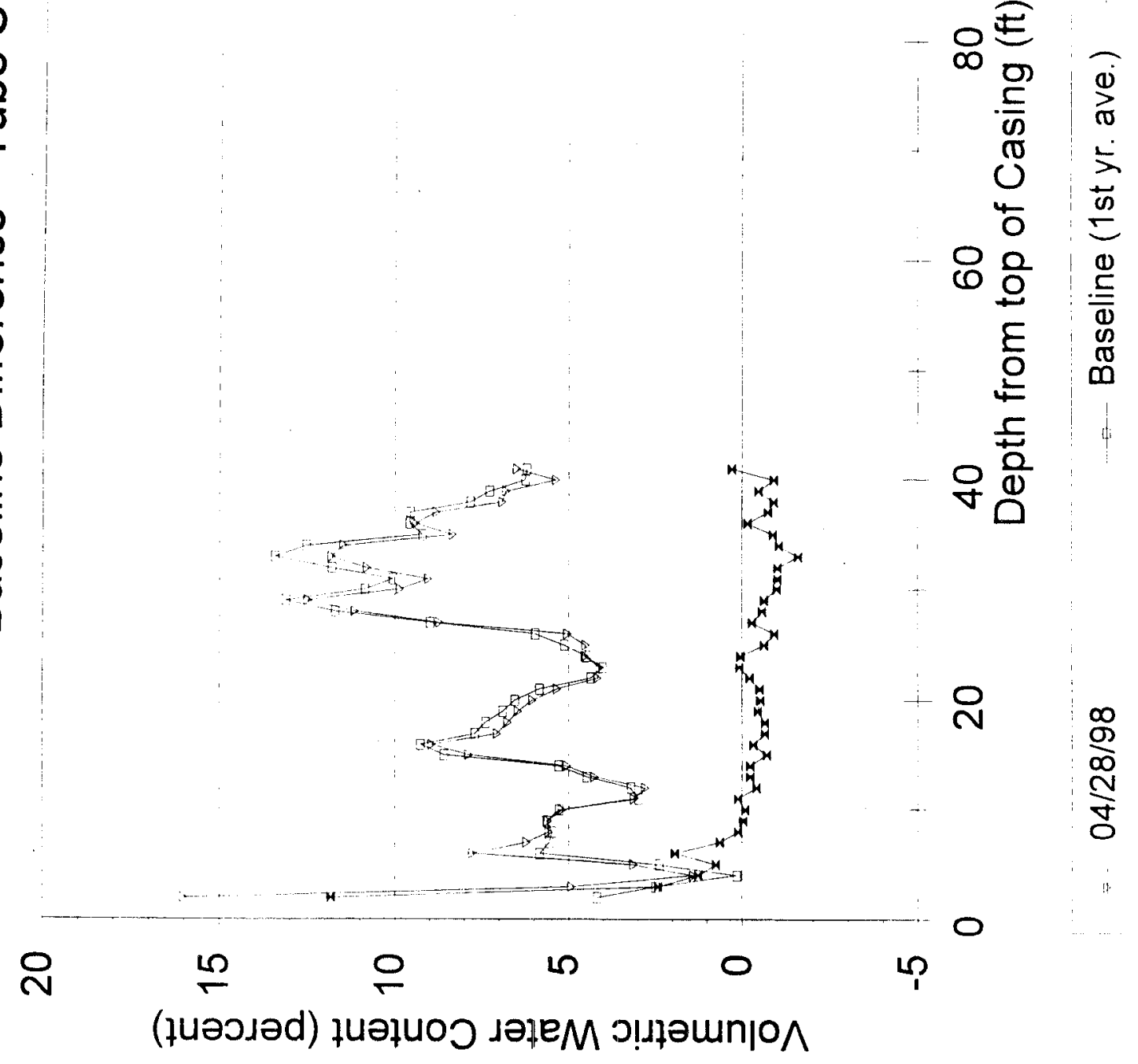


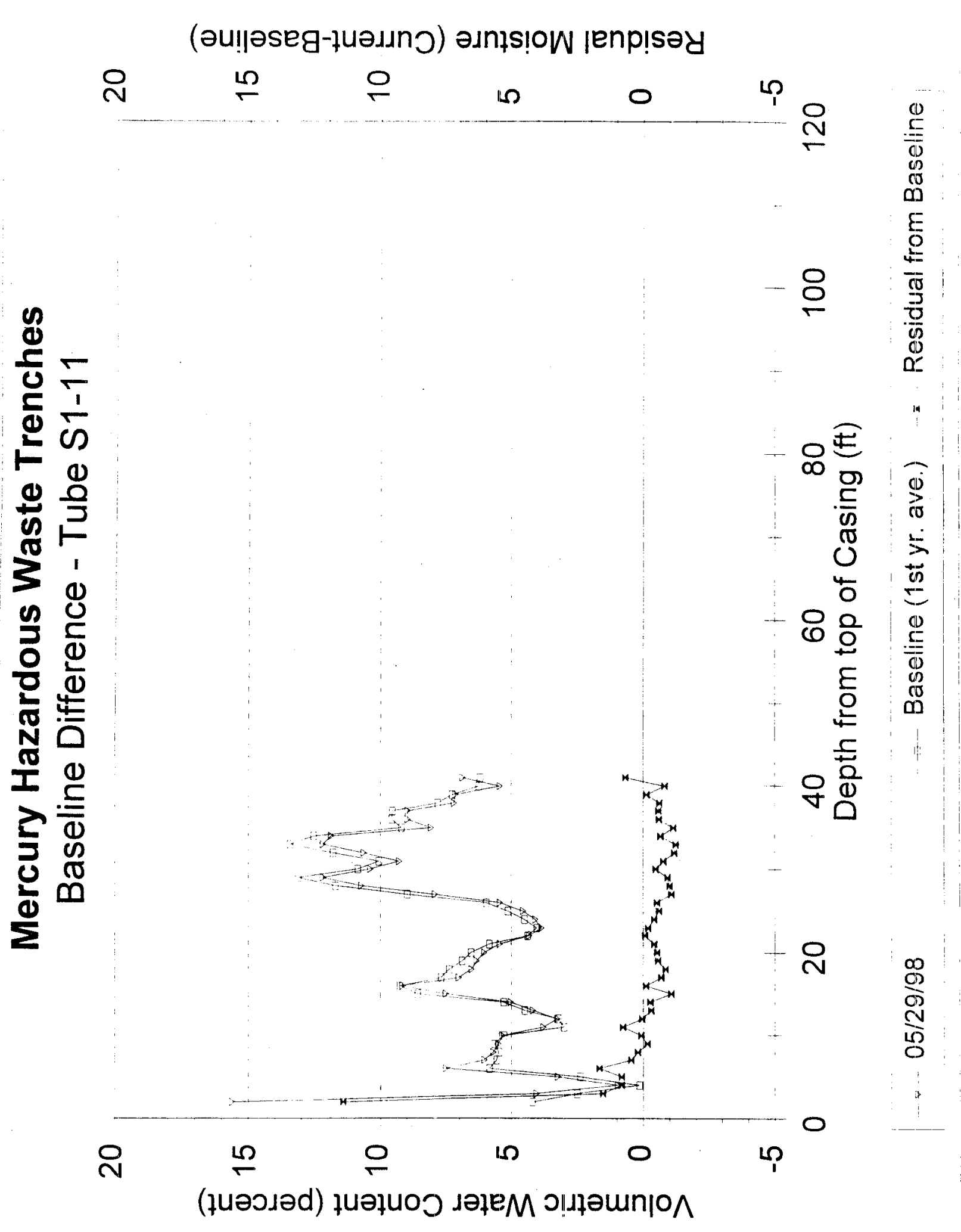




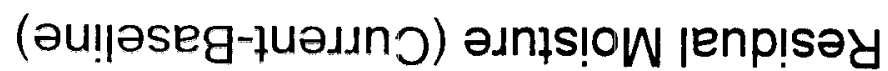

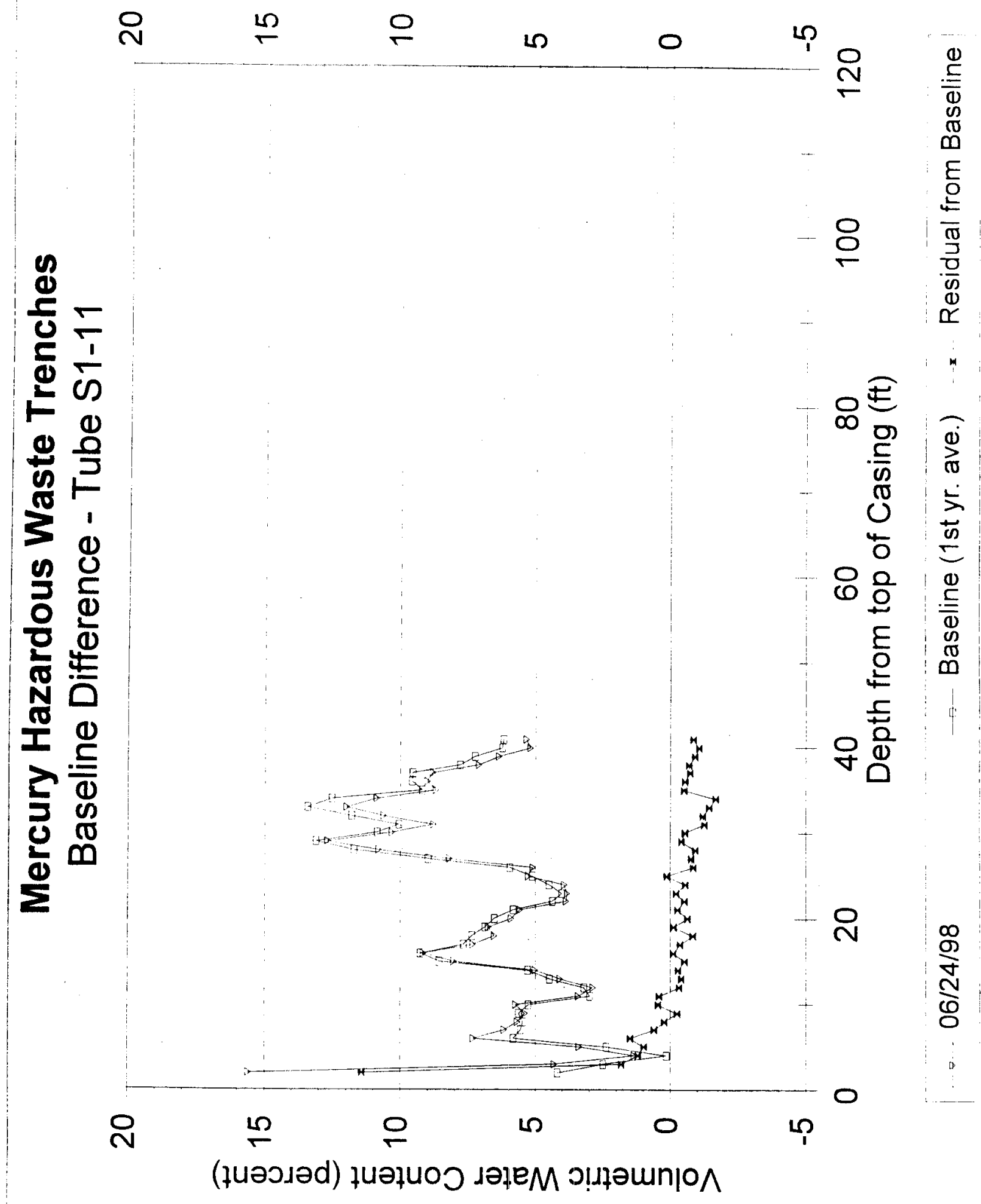




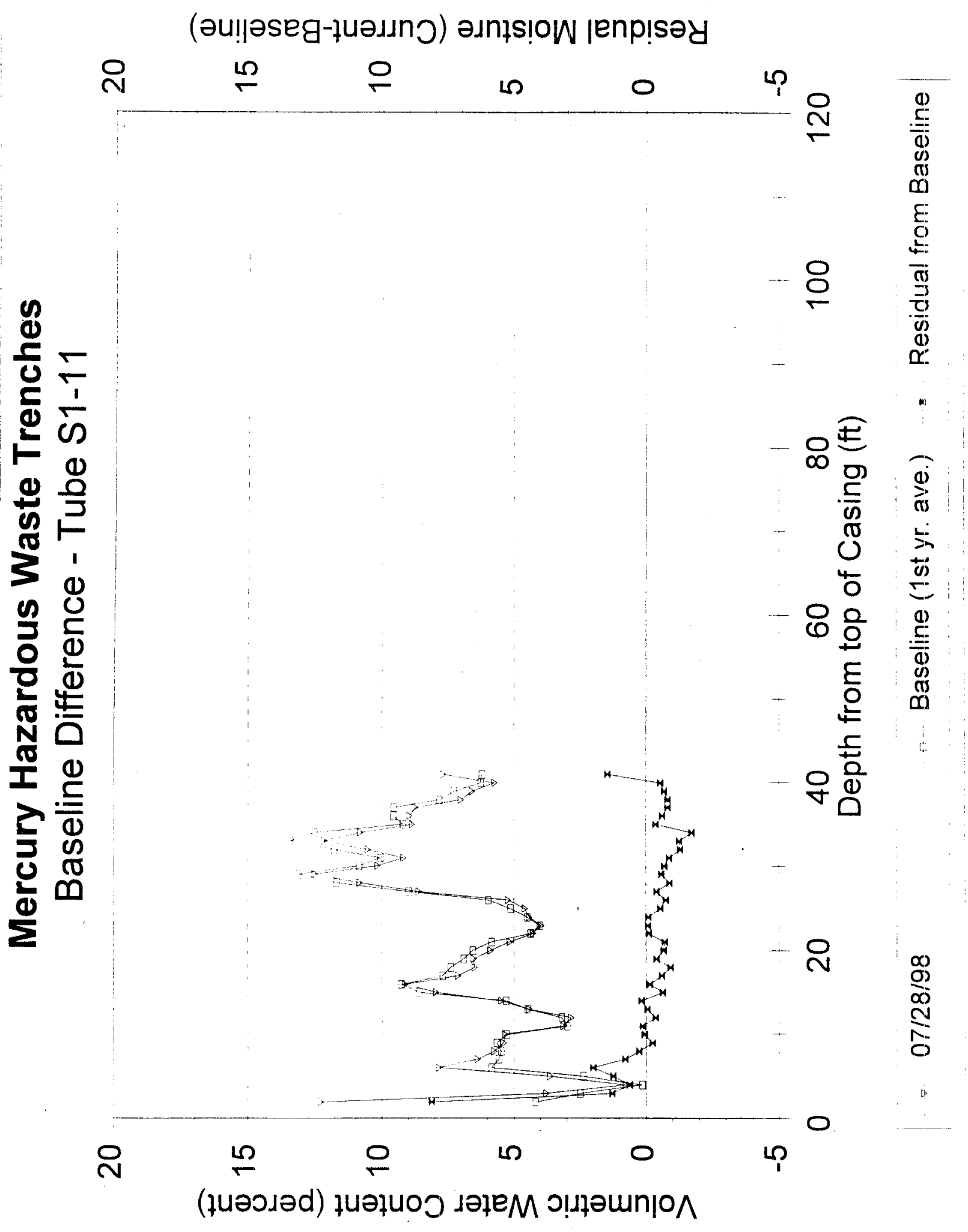




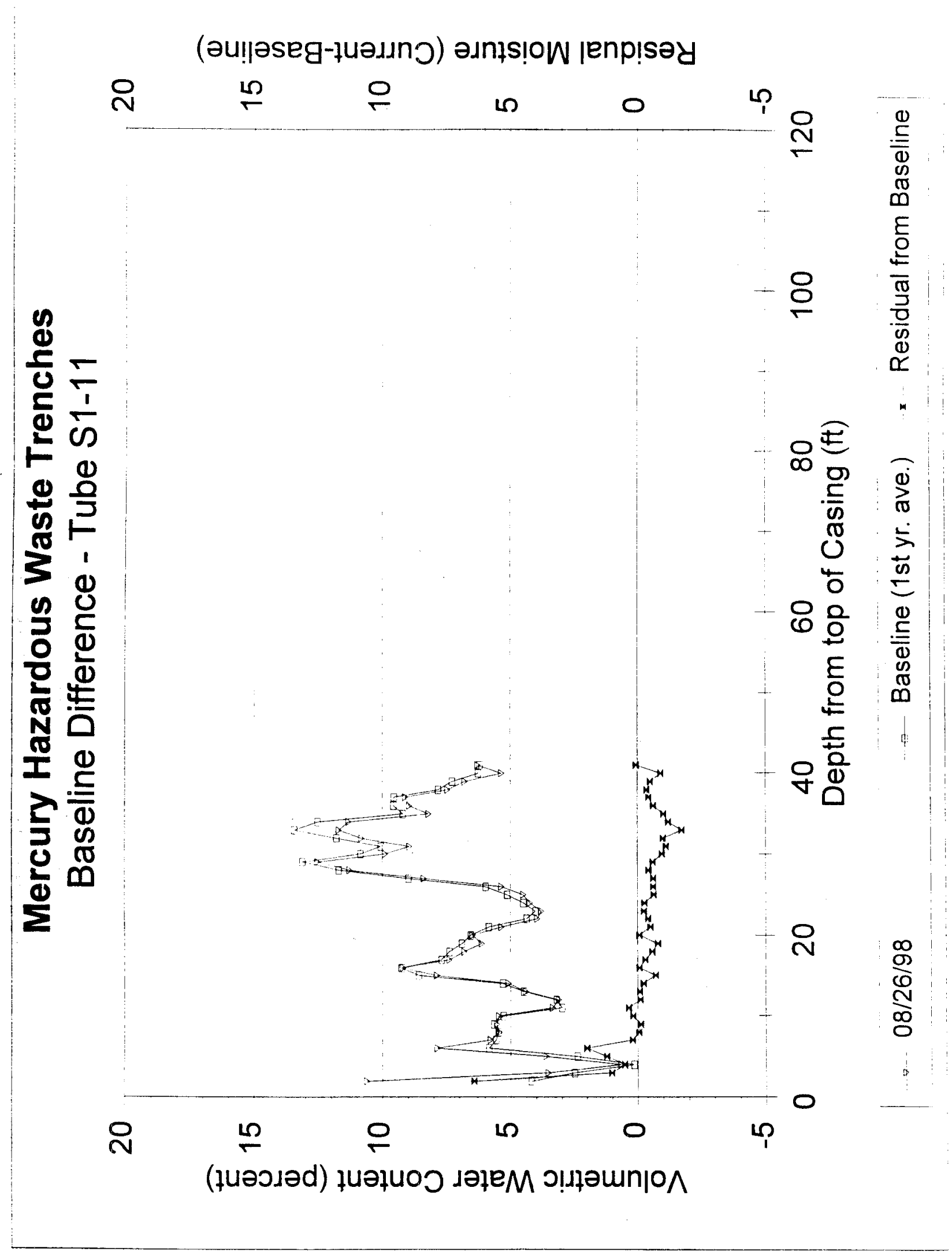




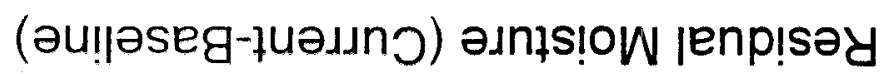

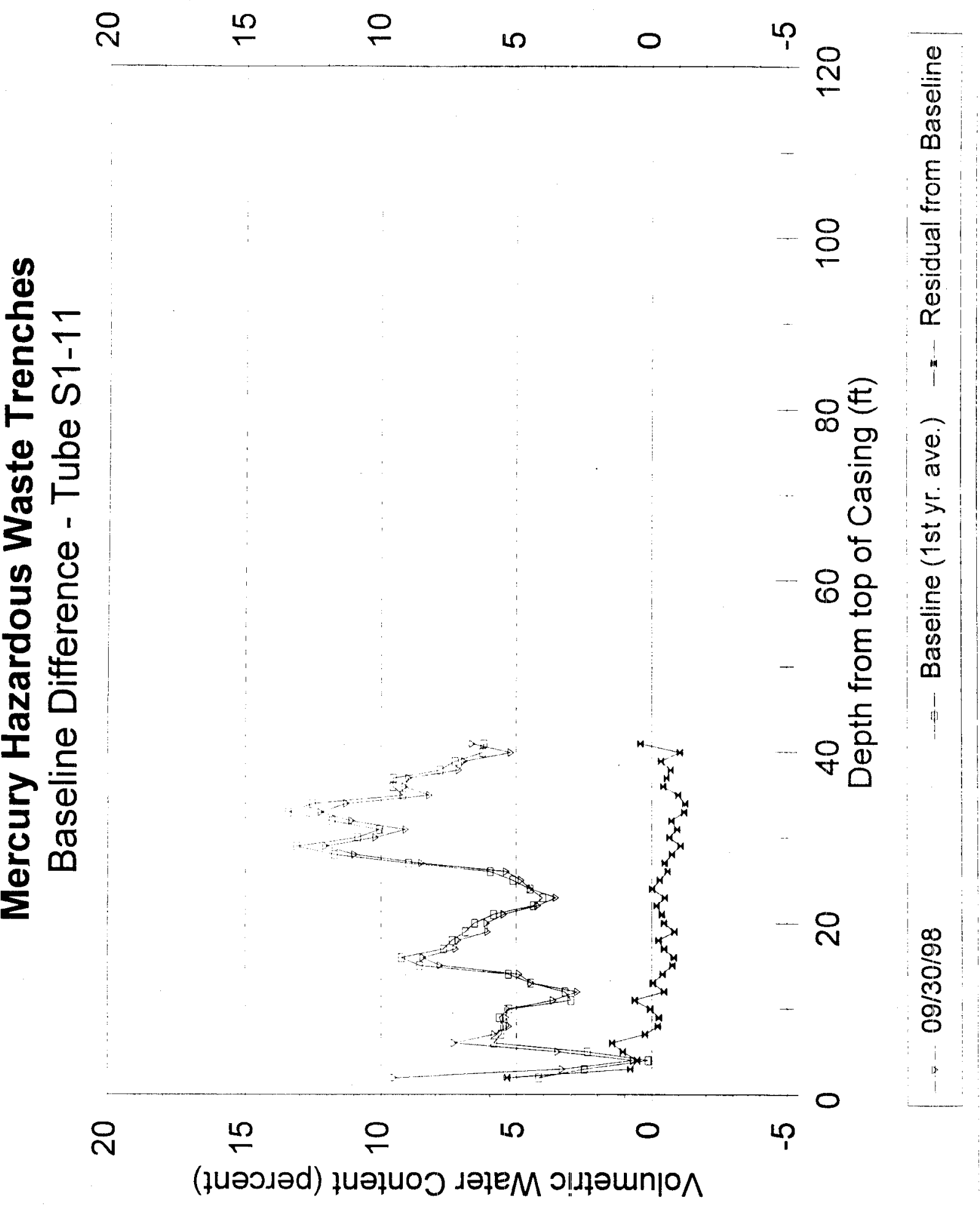

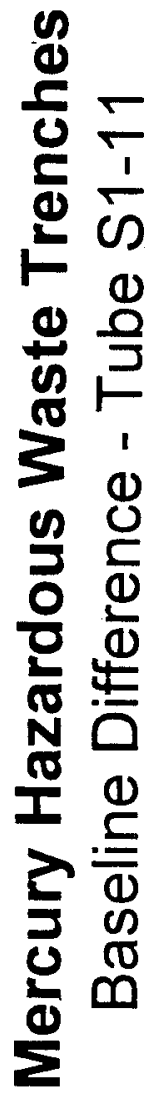




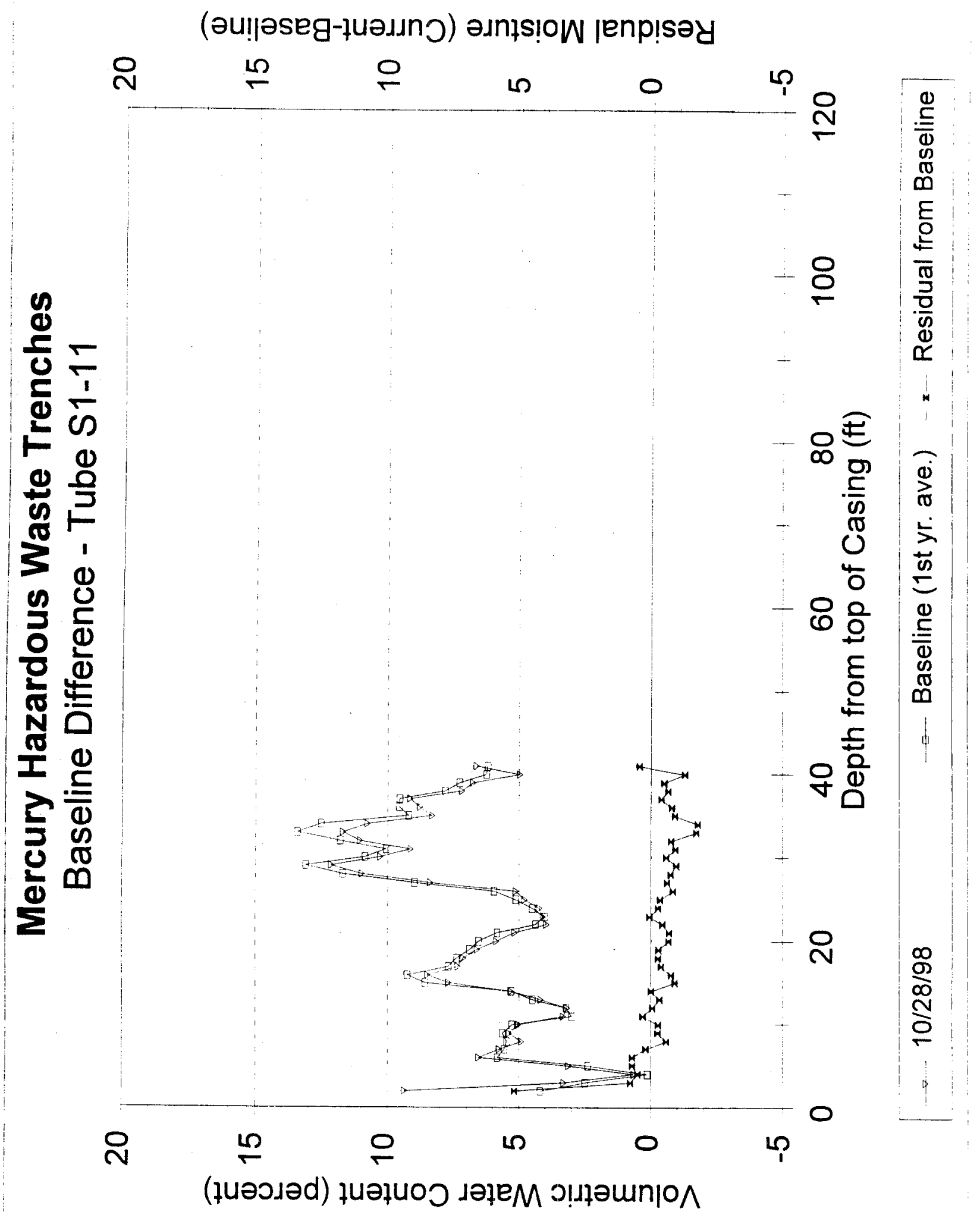




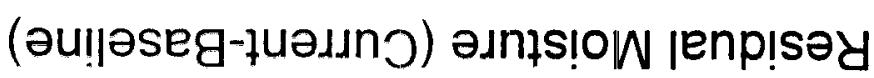

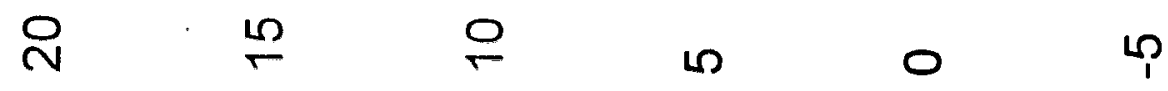

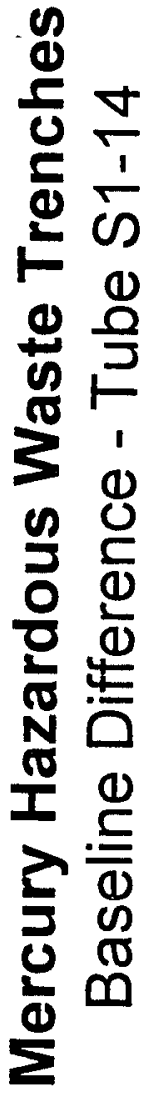

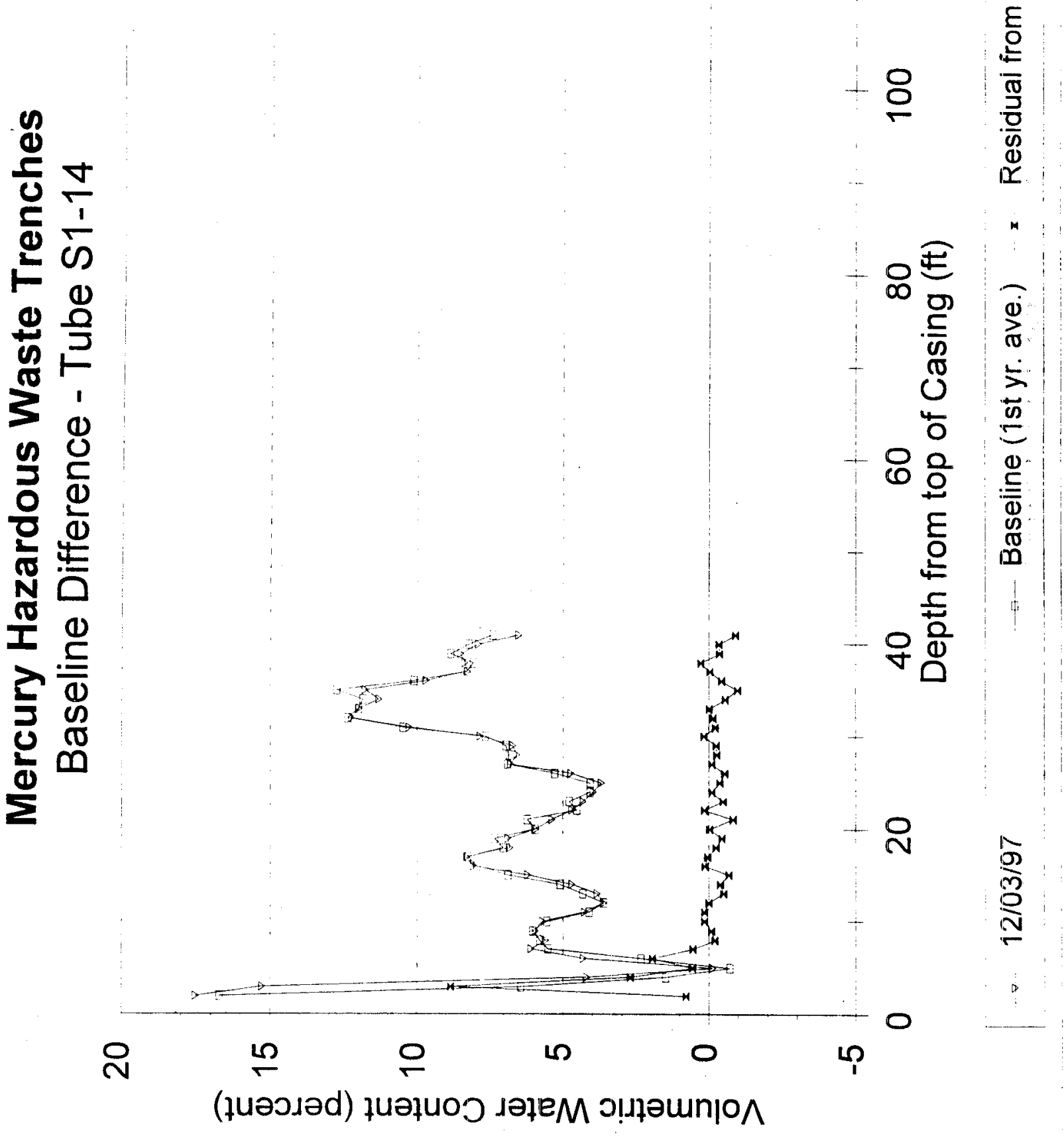




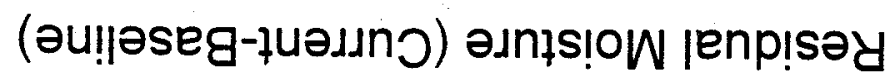

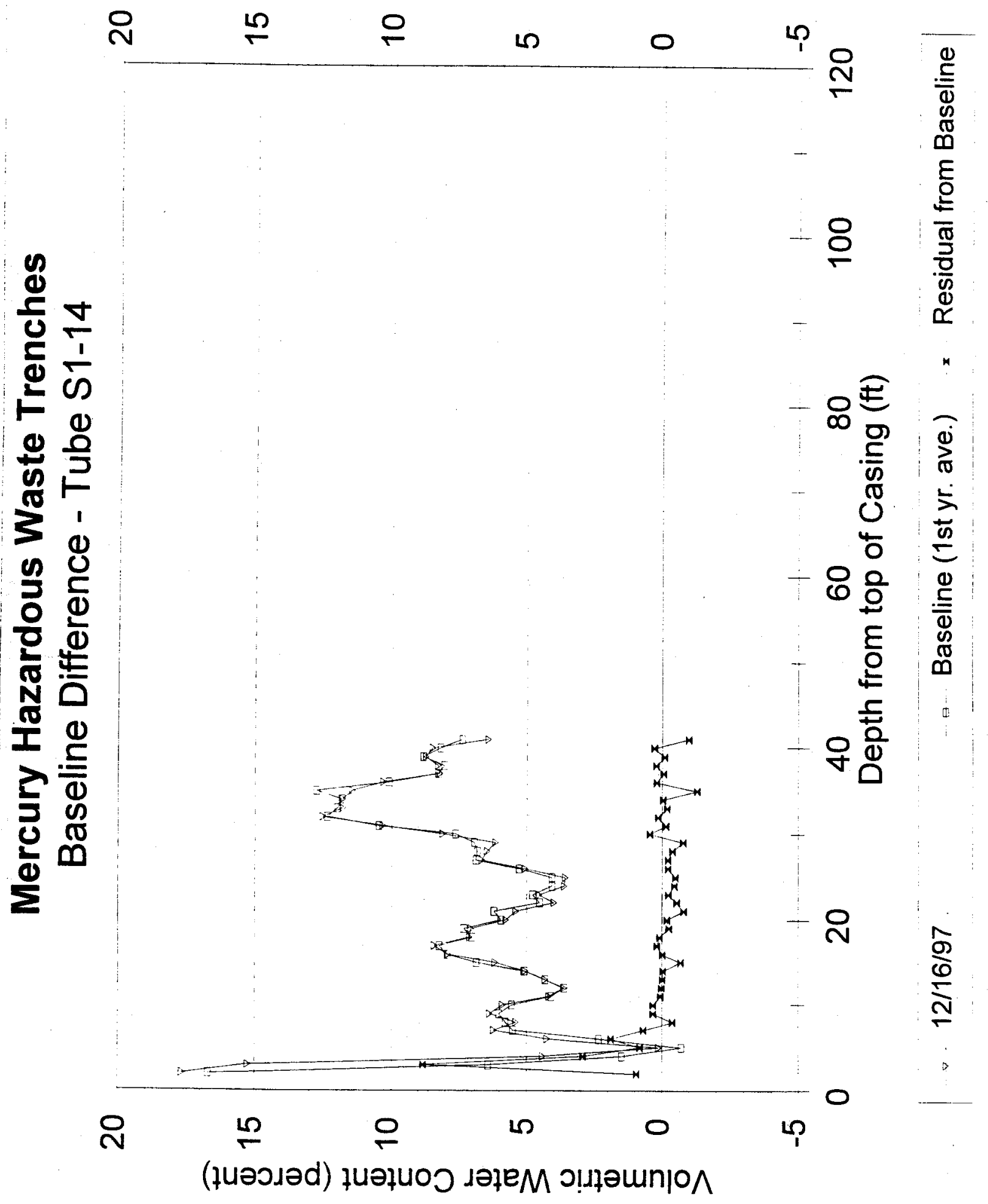




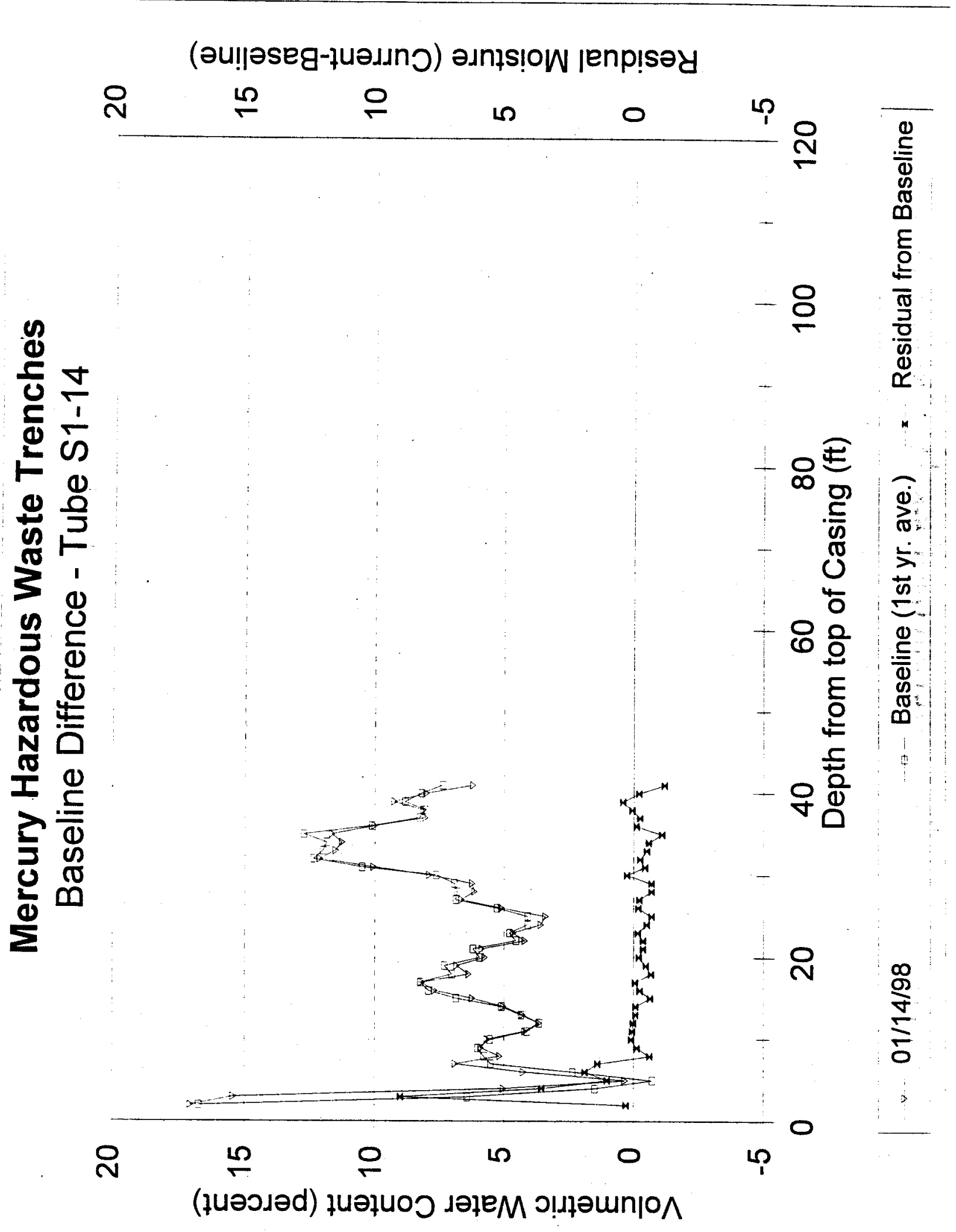




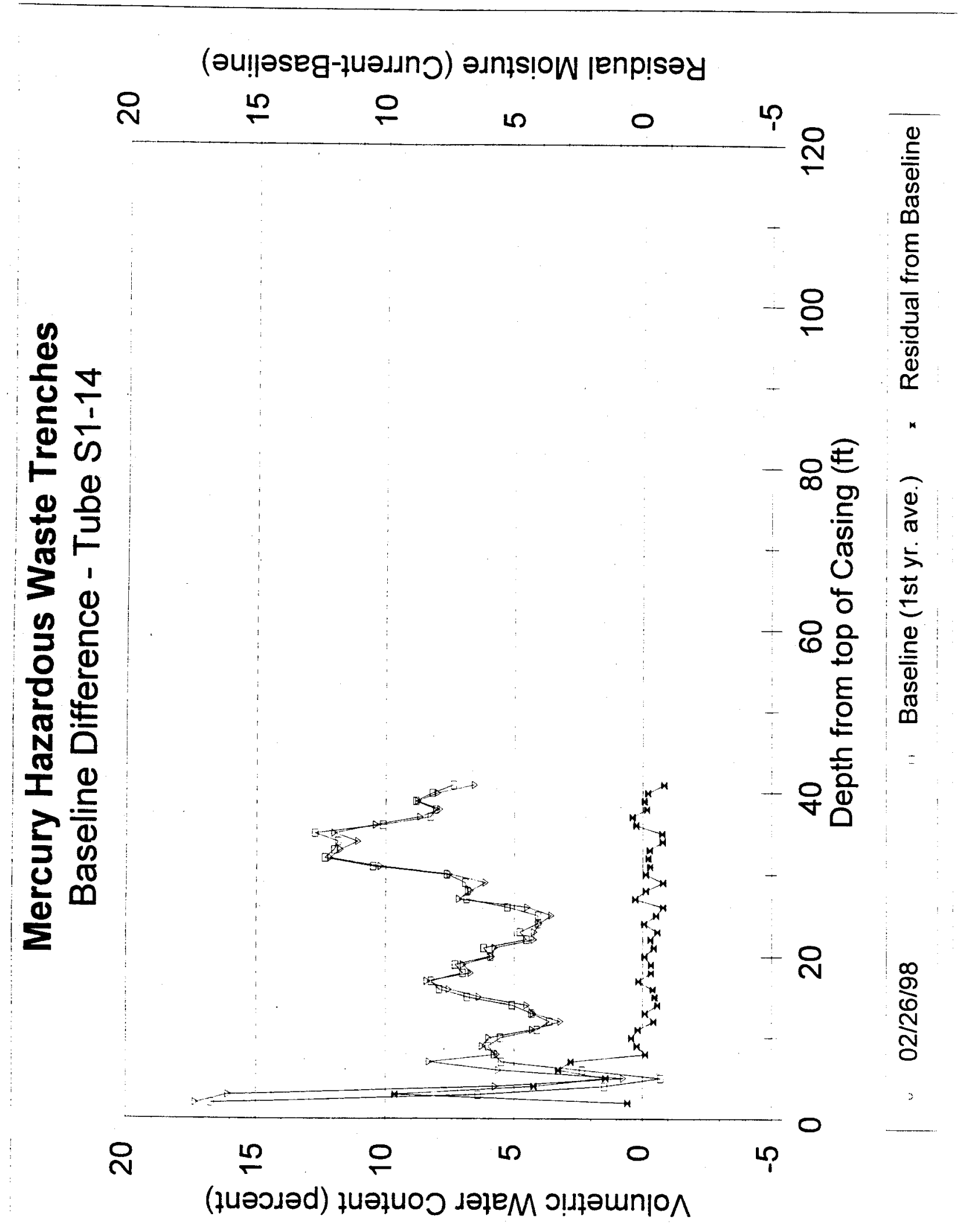




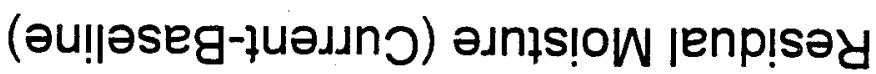

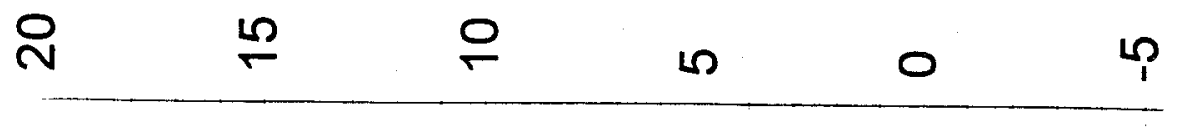

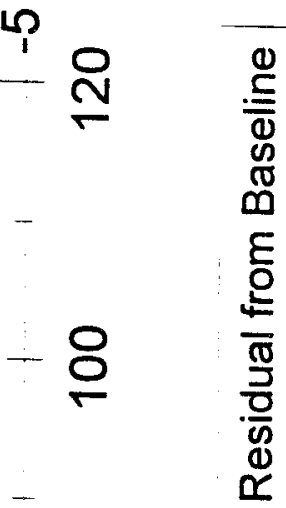
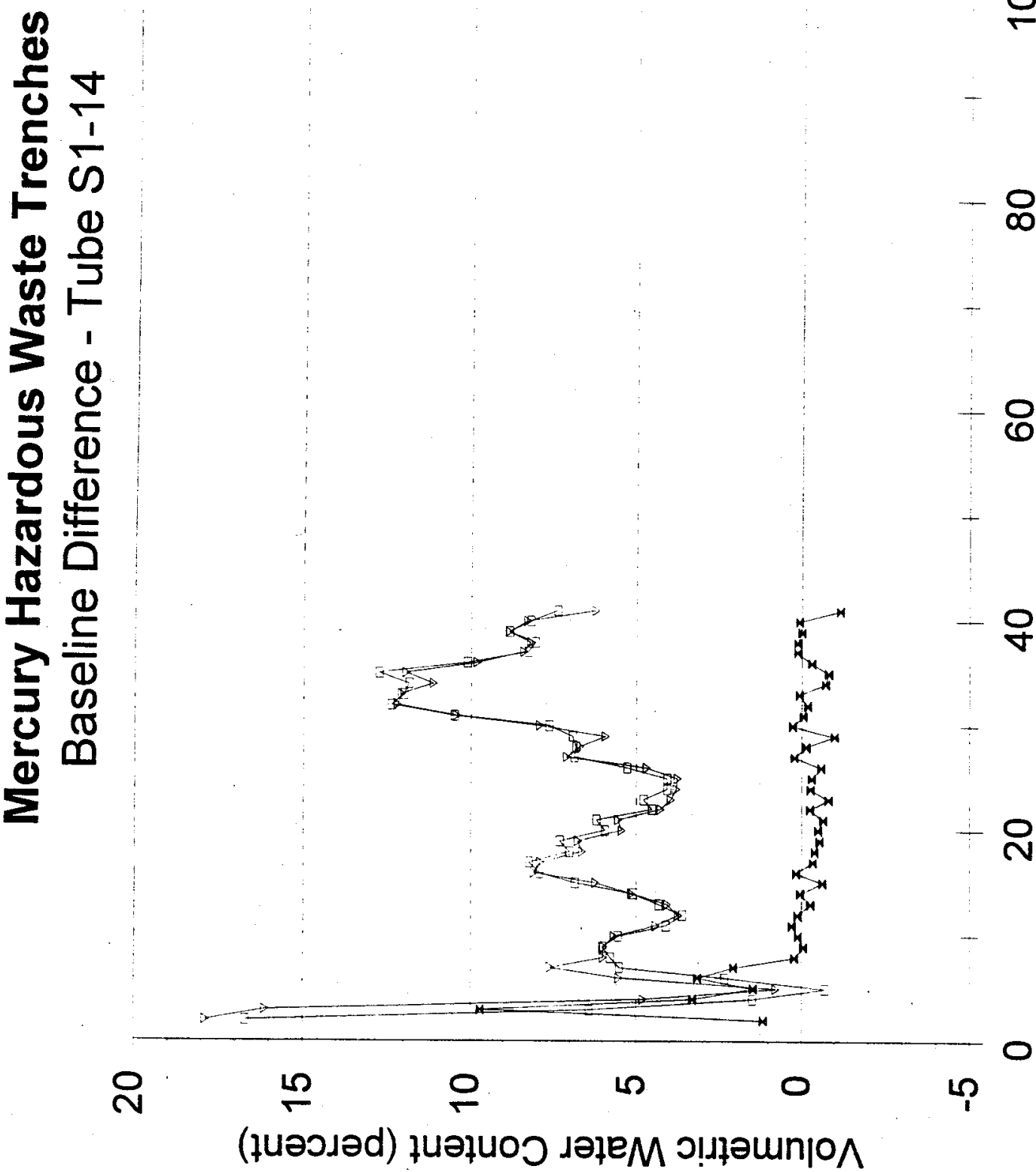


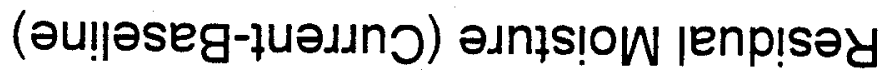

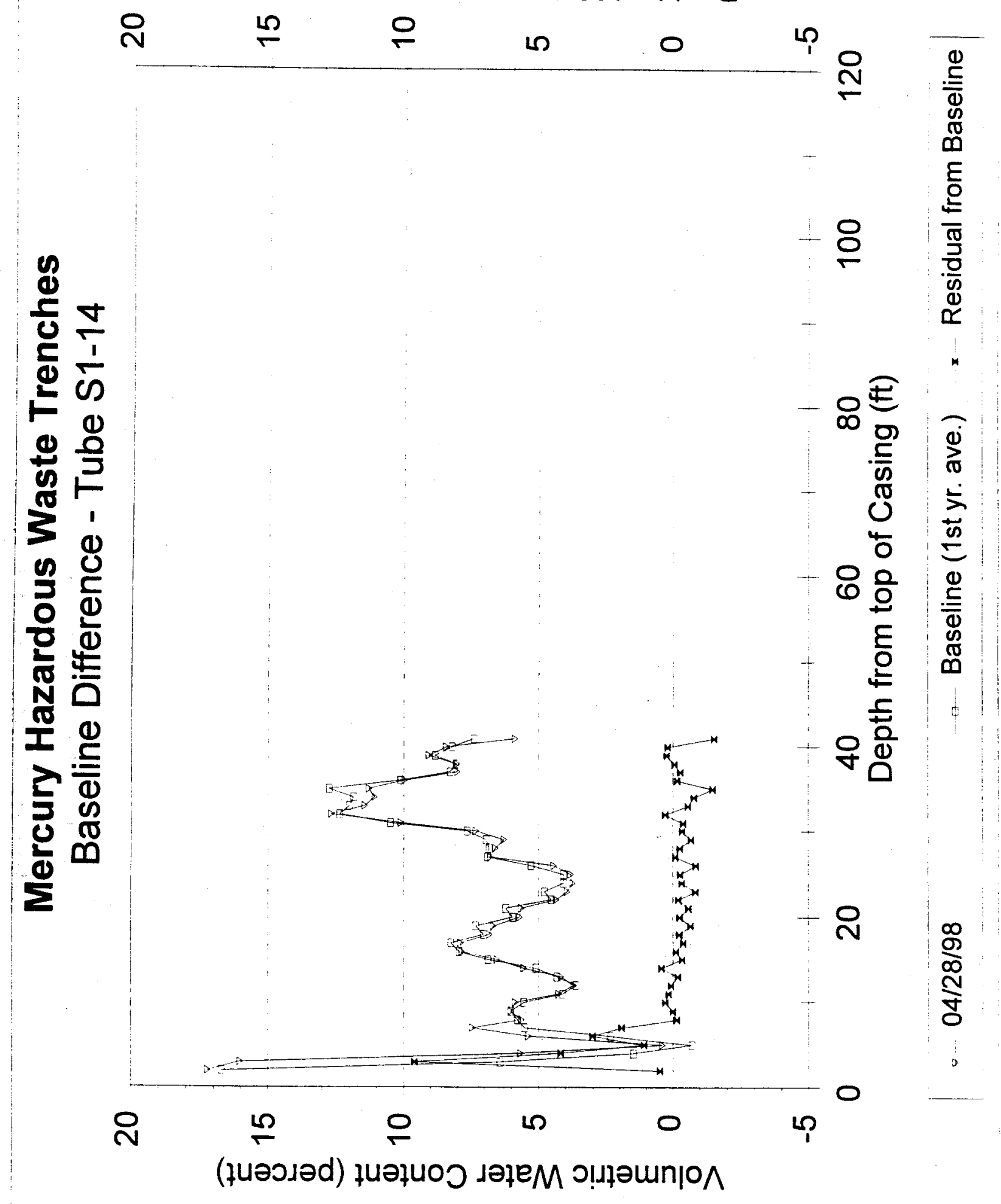




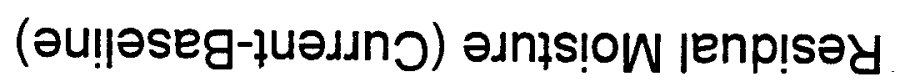

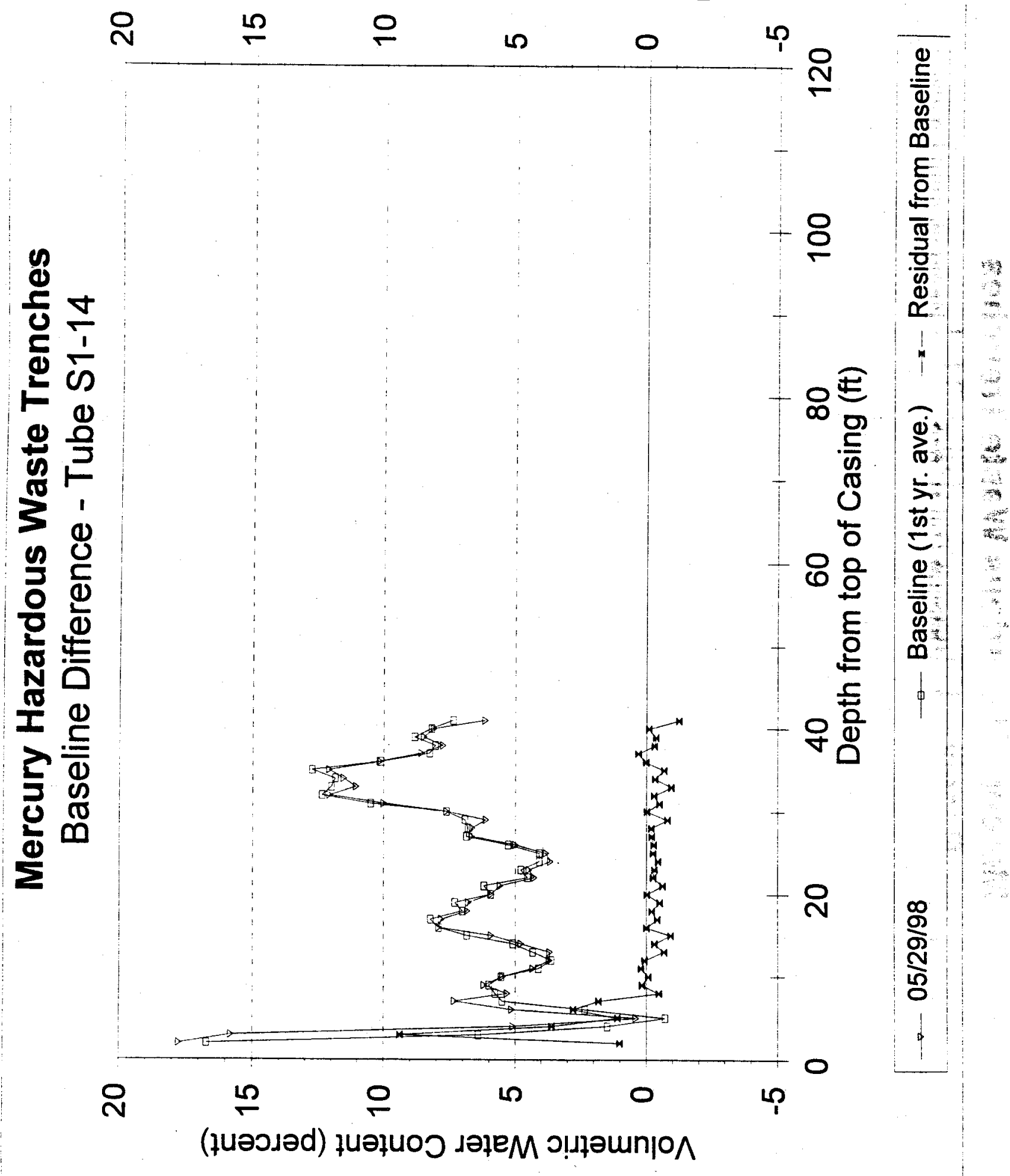




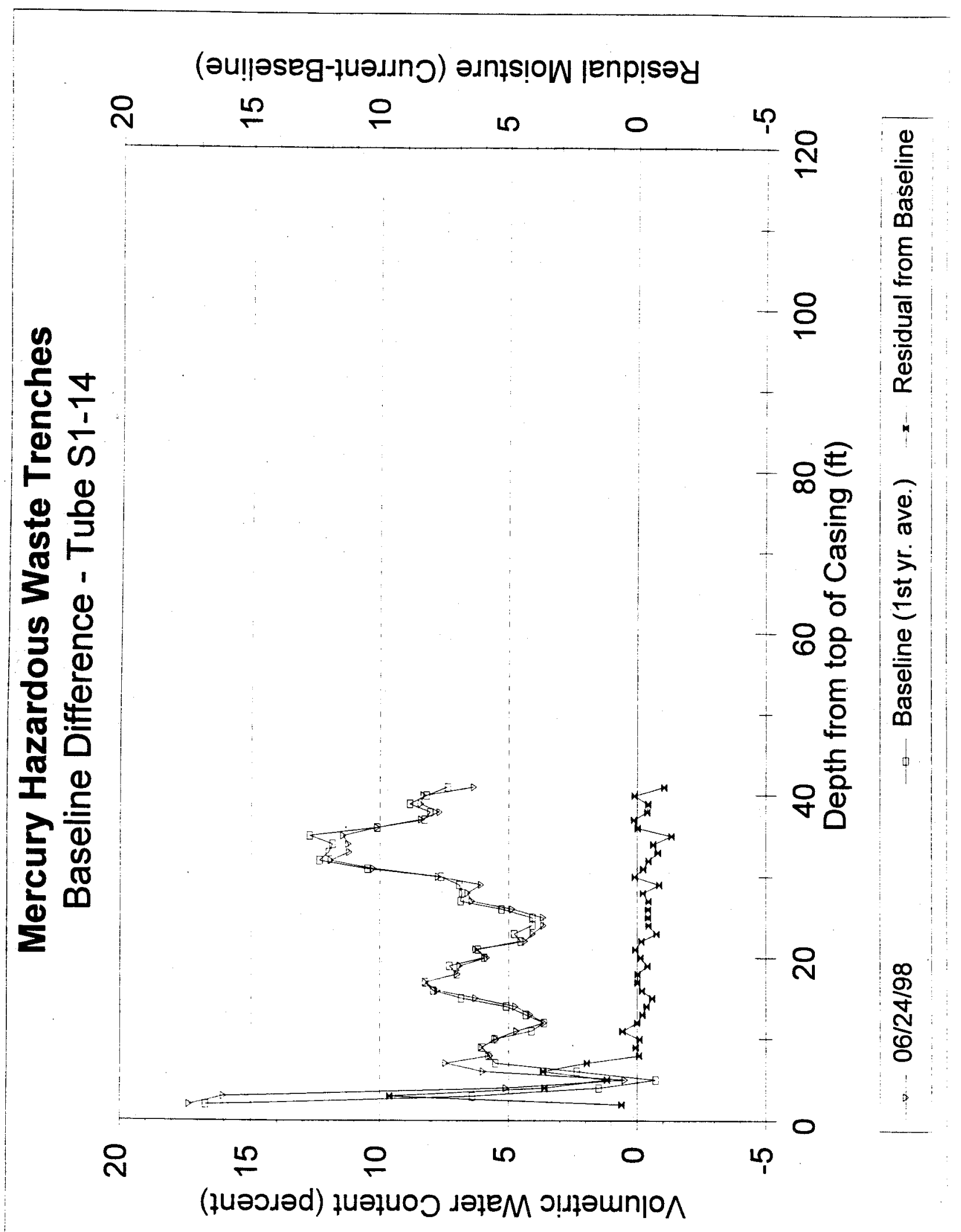




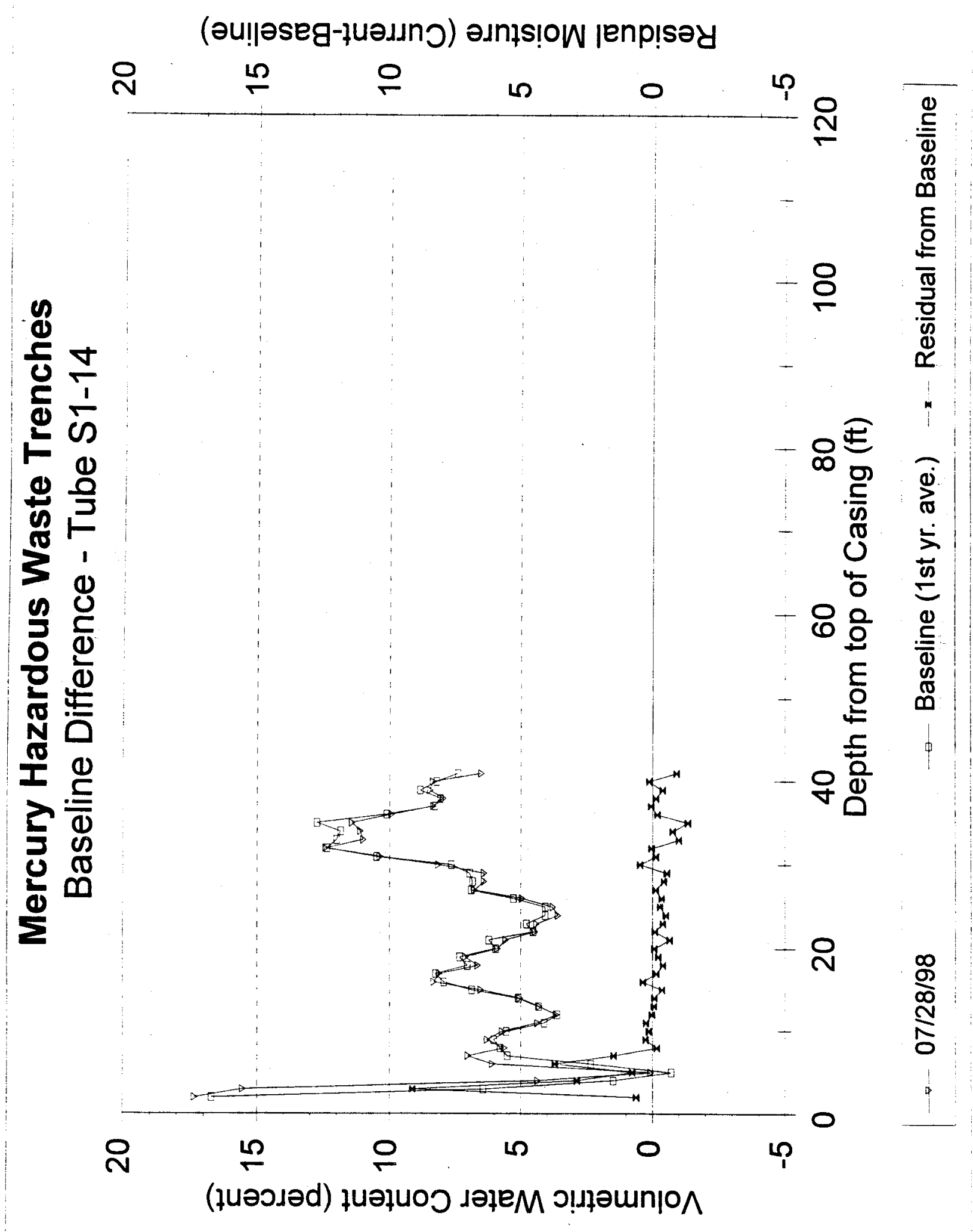




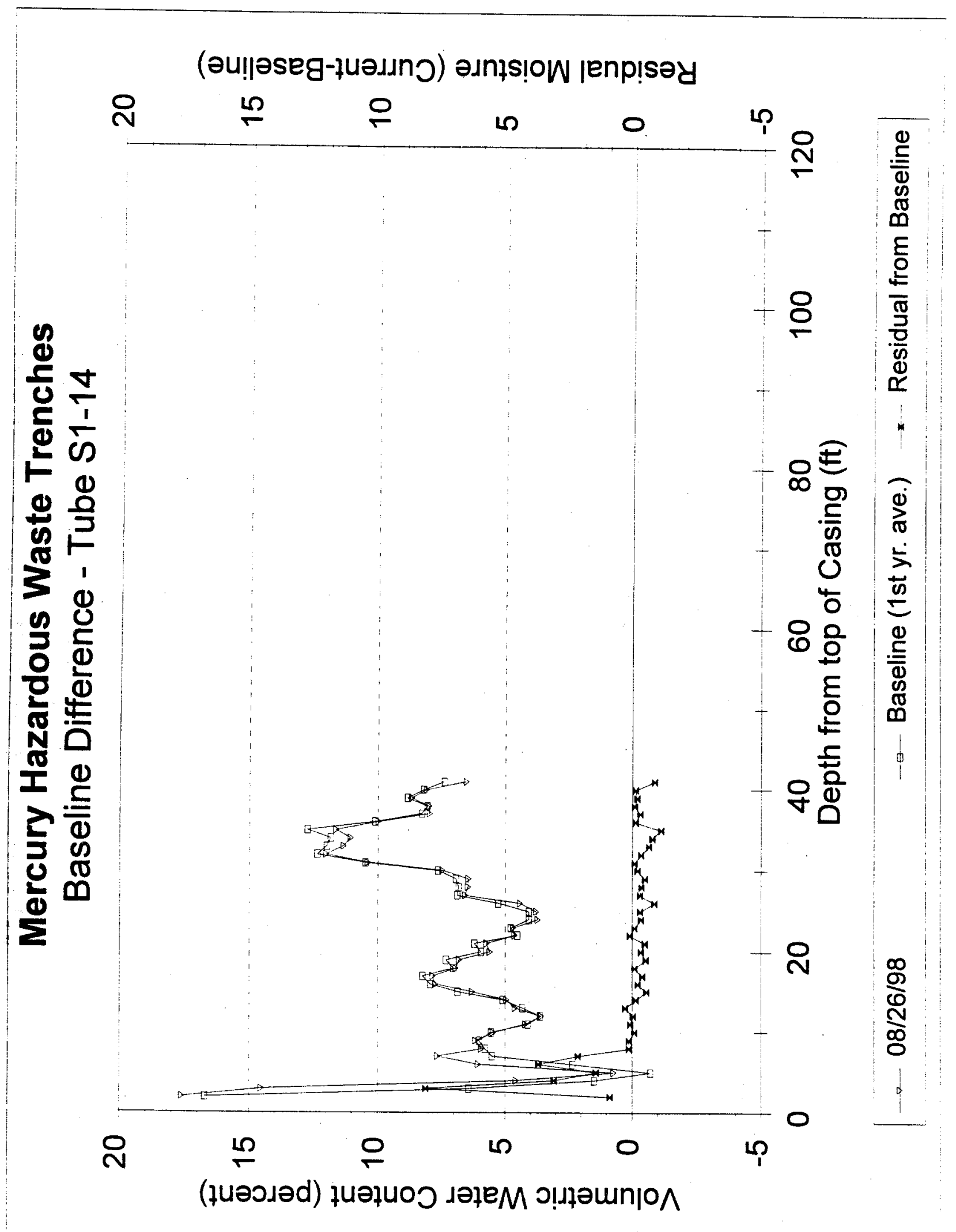




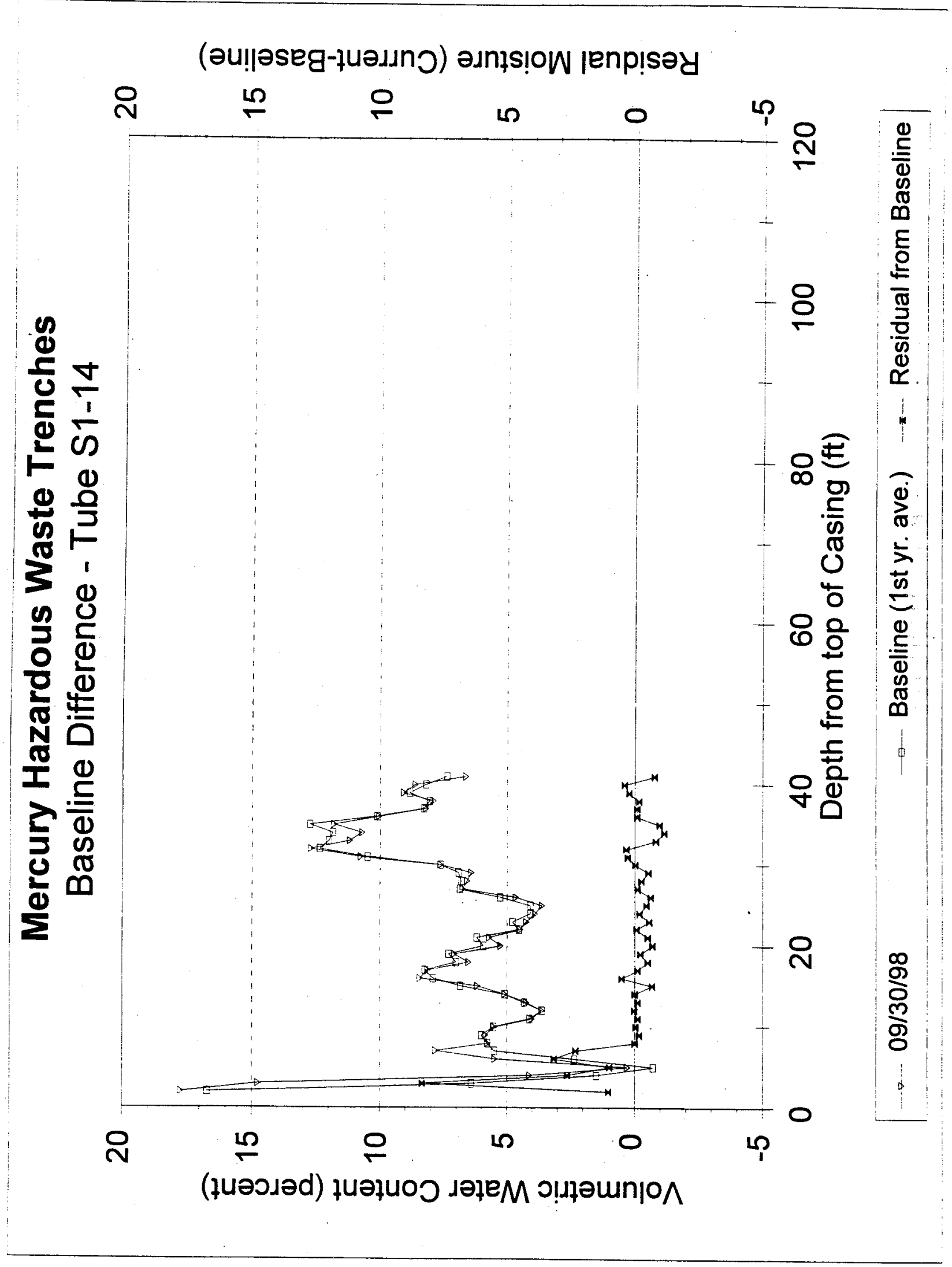




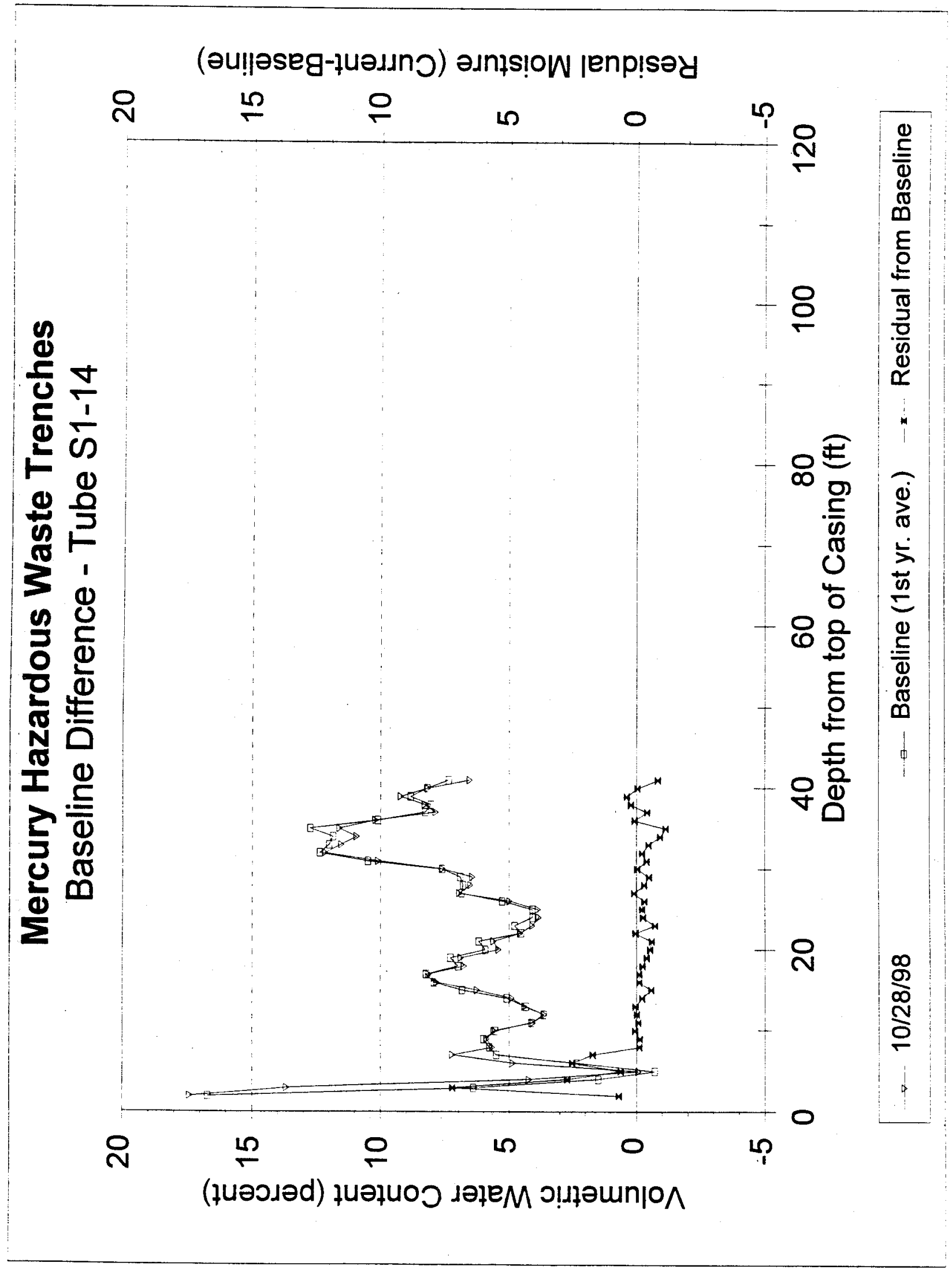




\section{BASELINE DIFFERENCE}

\section{ROW S2}




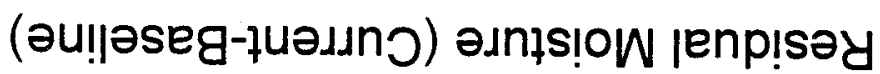

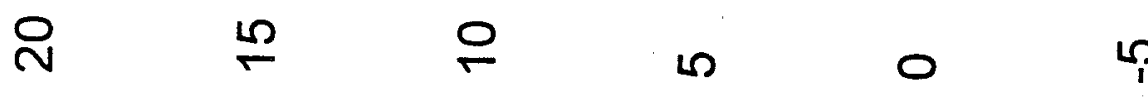

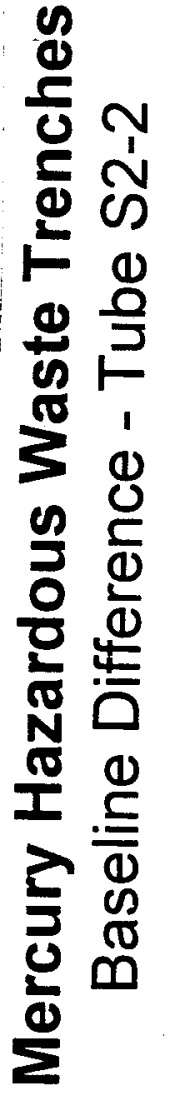
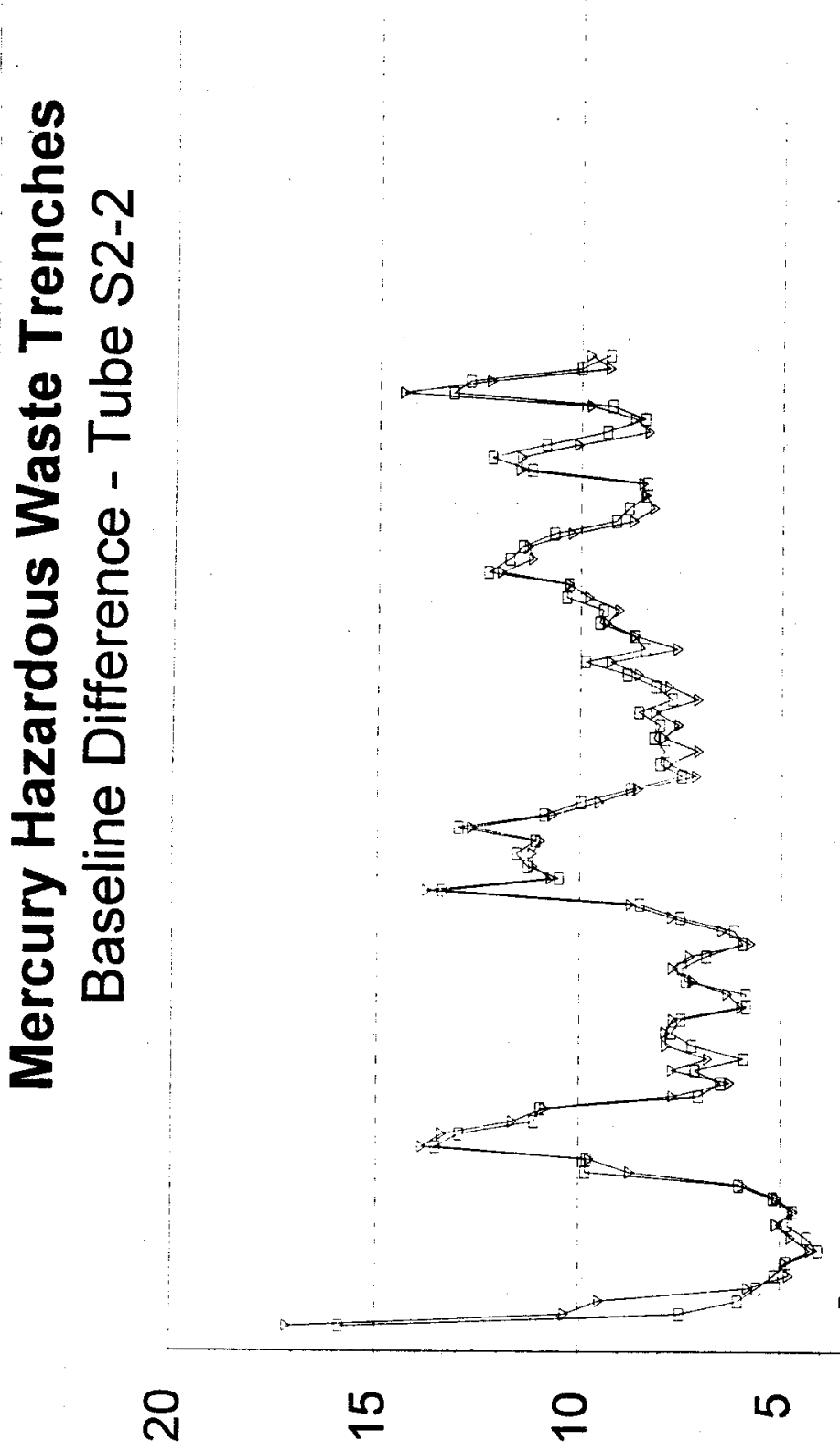

ก

운

L

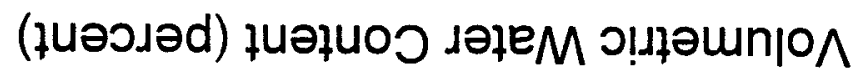

?

$\stackrel{?}{2}$

$\stackrel{8}{\circ}$

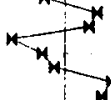

4

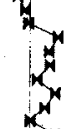

88

$\varnothing \underset{0}{\Phi}$

员

4

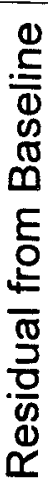

市

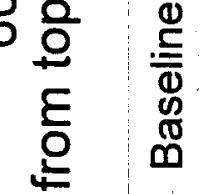

- 용

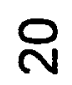

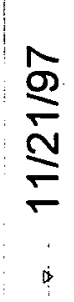

$\frac{N}{N}$

? 


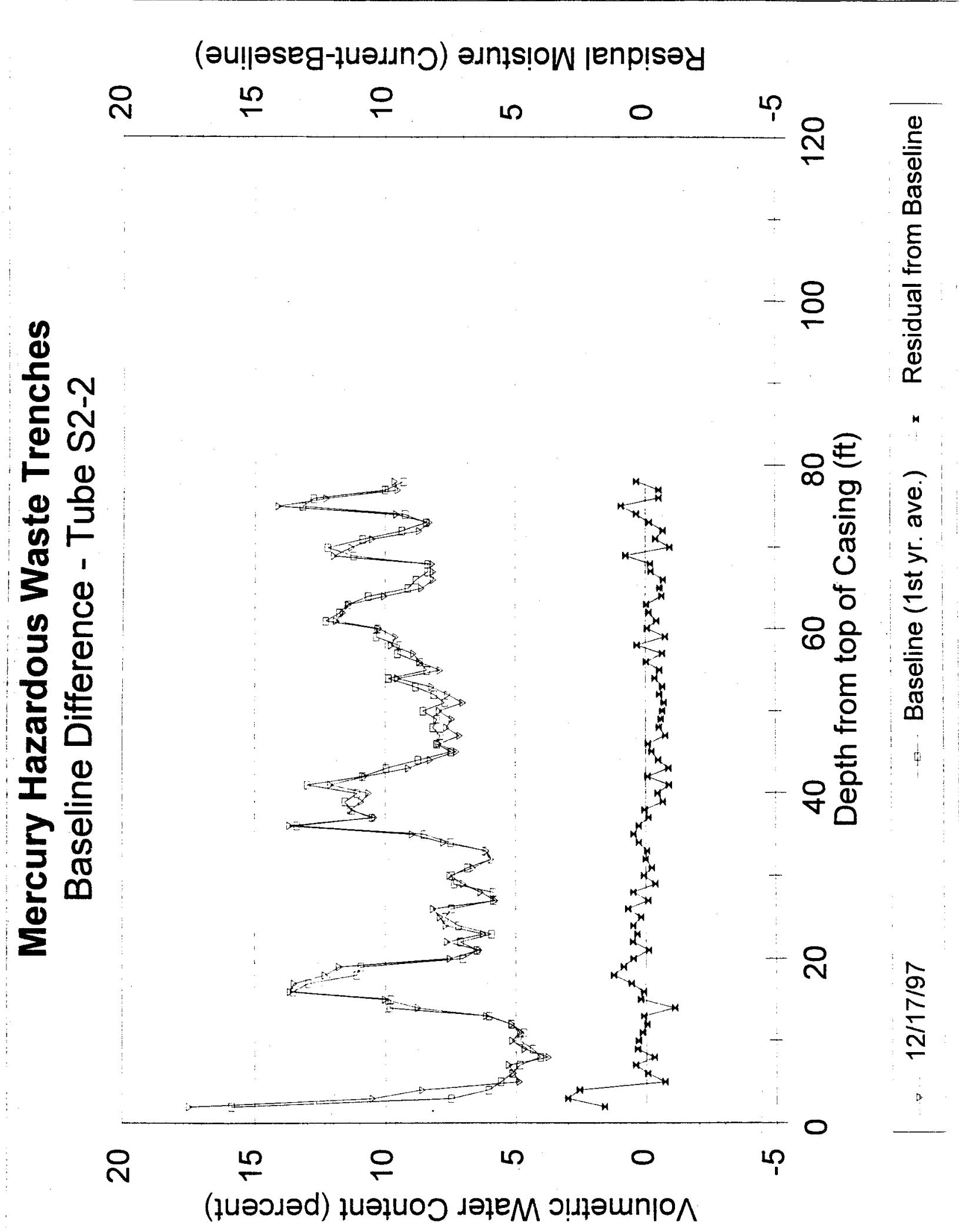




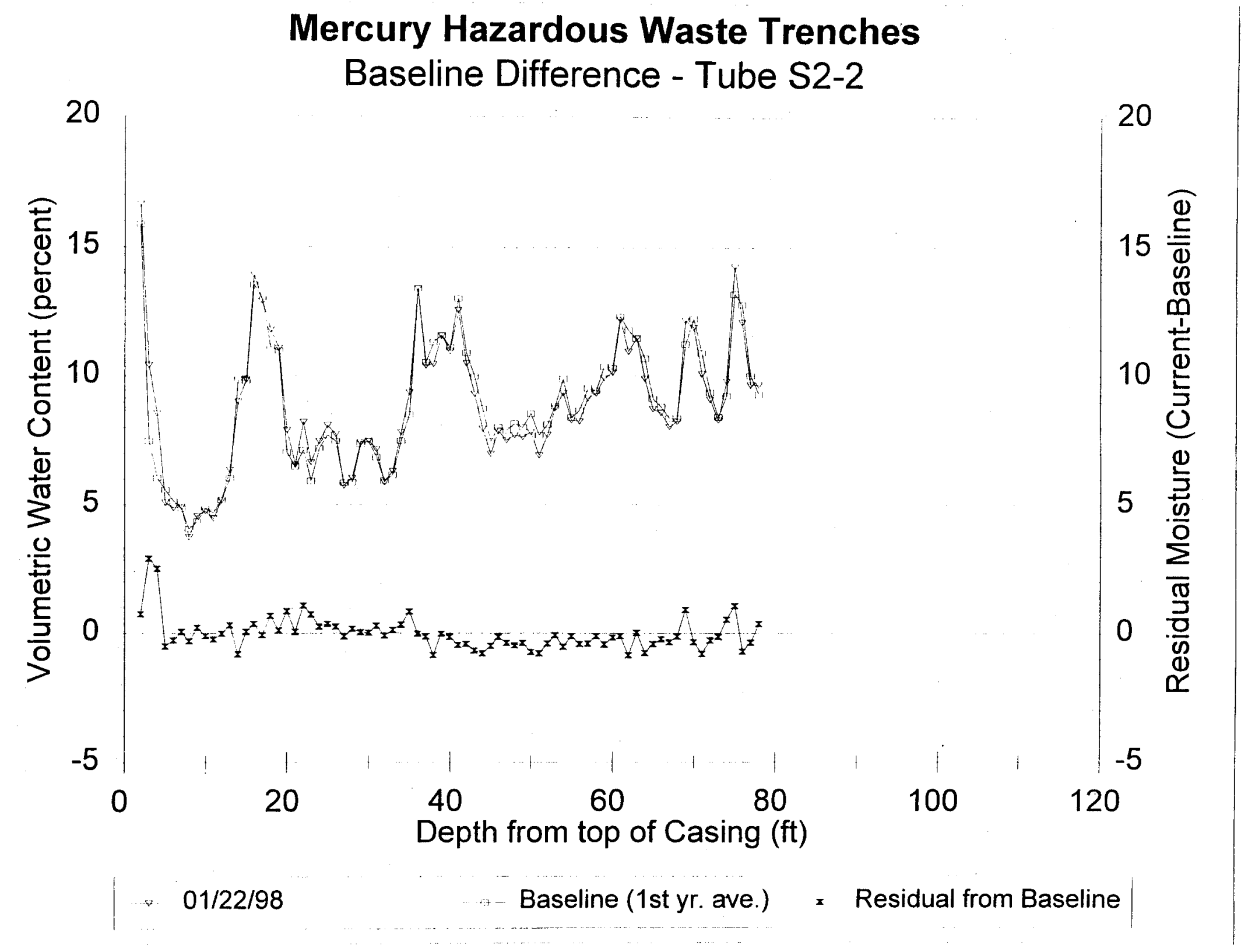




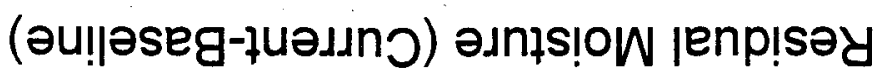
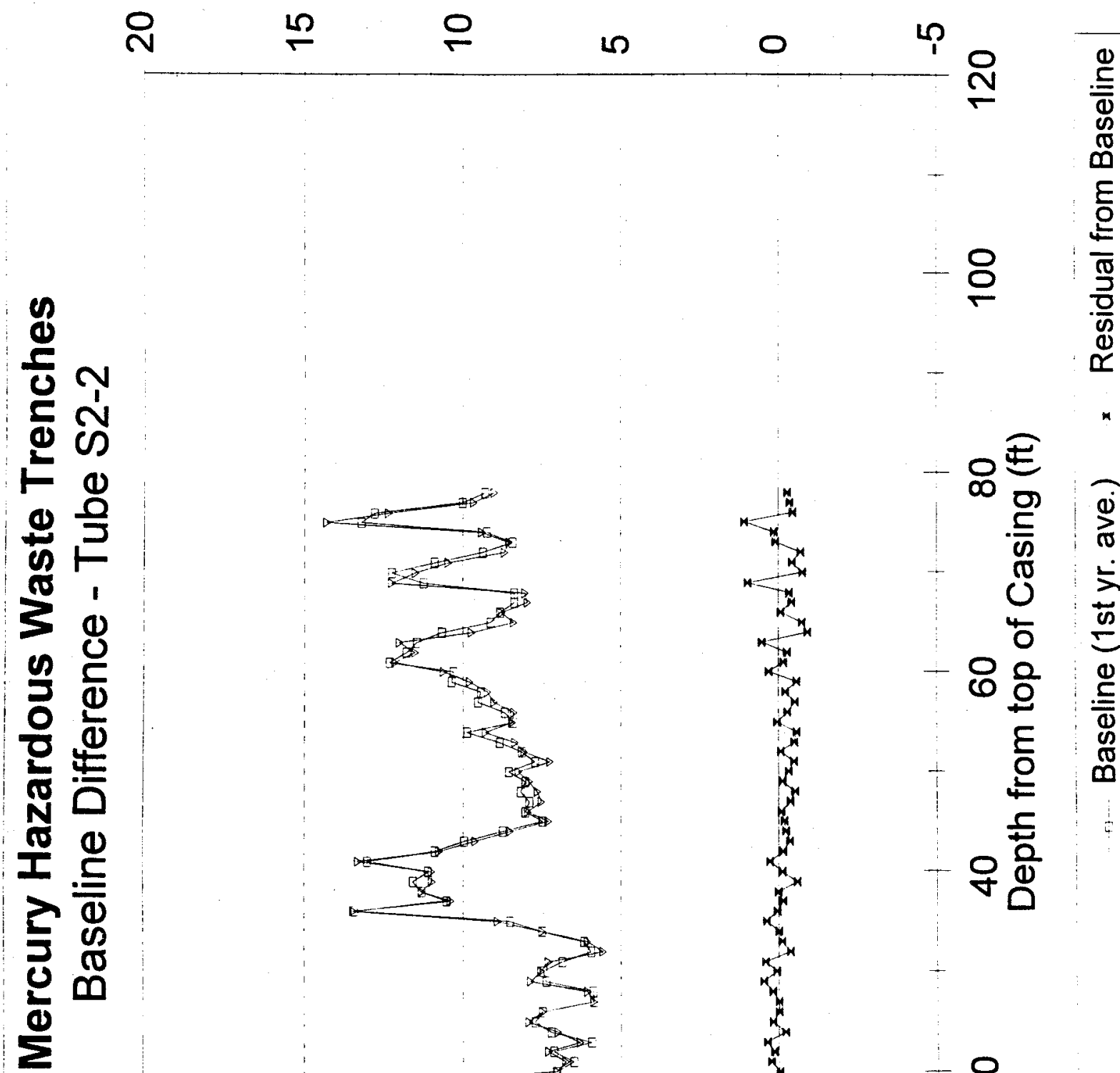

的 


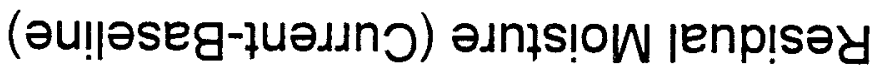
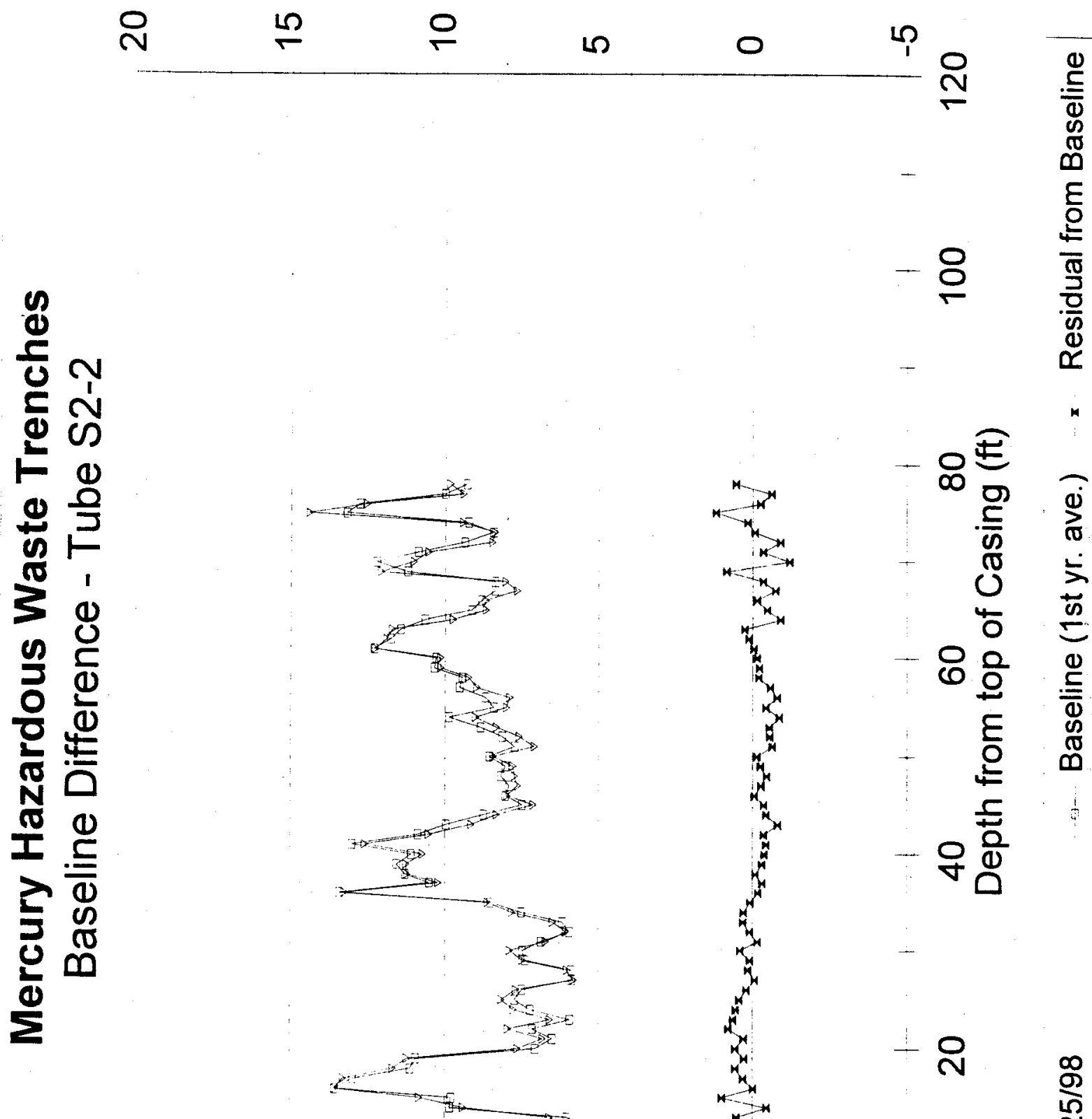

-

n
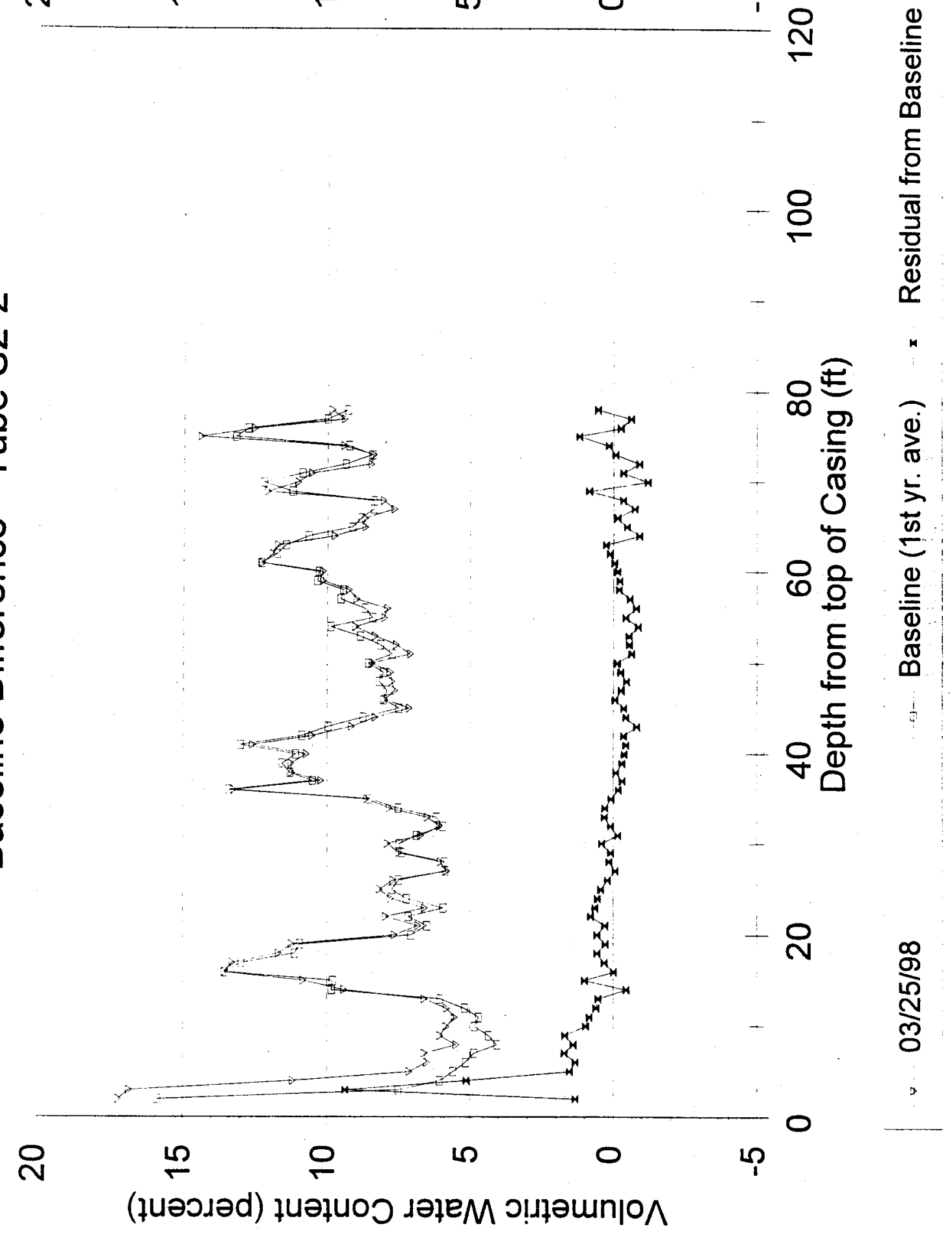


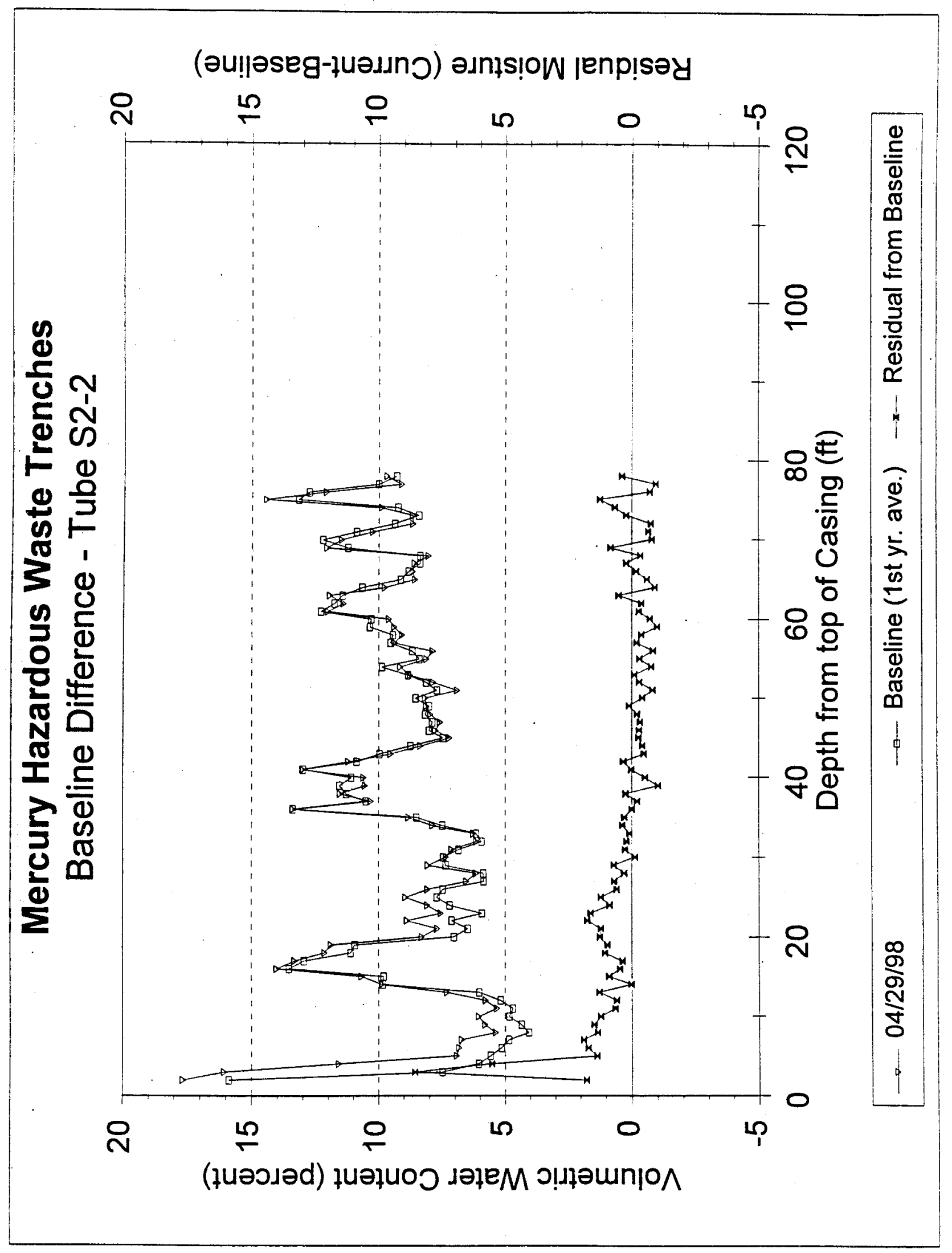




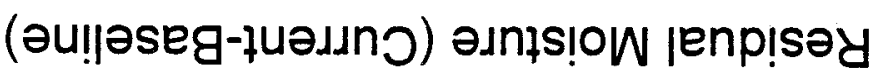

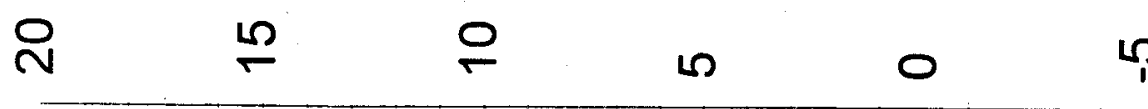

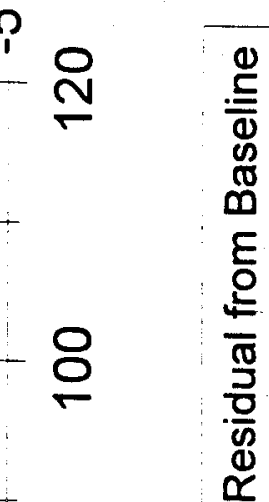

है

Ф

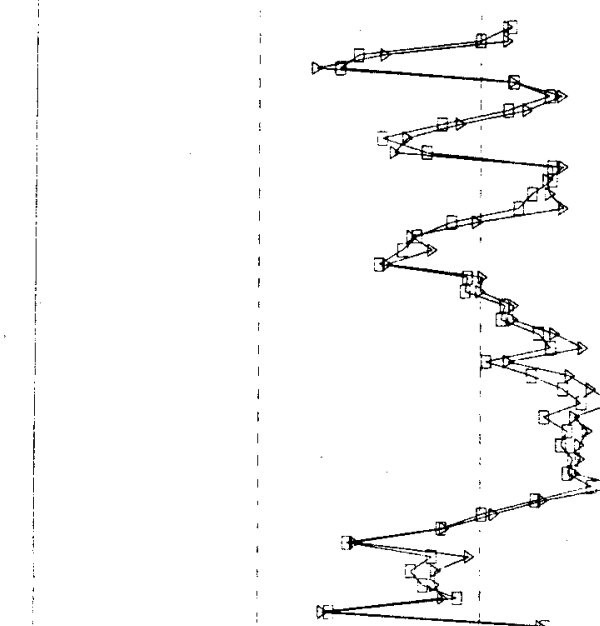

30

a
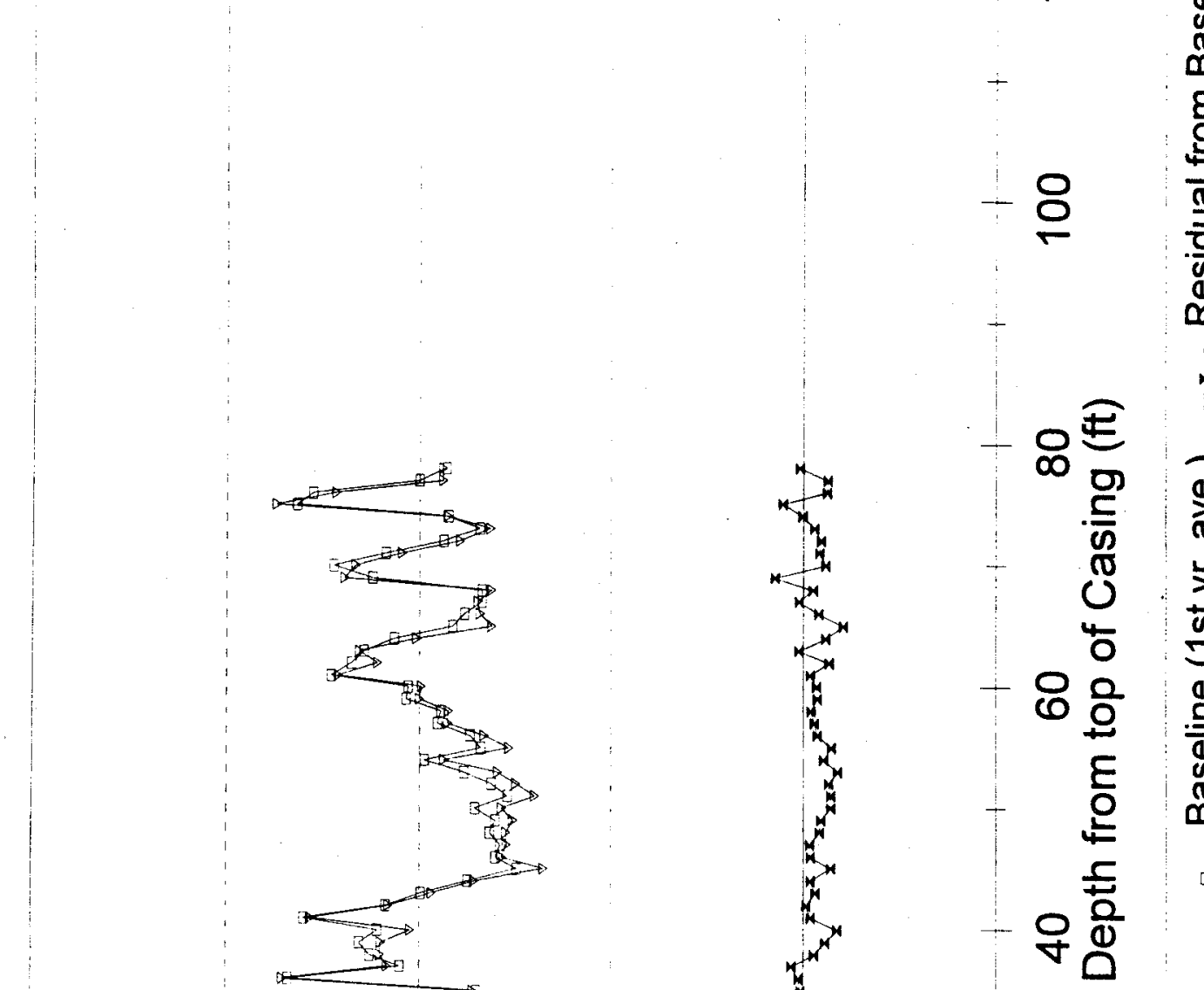

ㅇํㅇ

음

刃ㅇ

$>$ 트

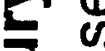

उ

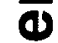

$\sum$
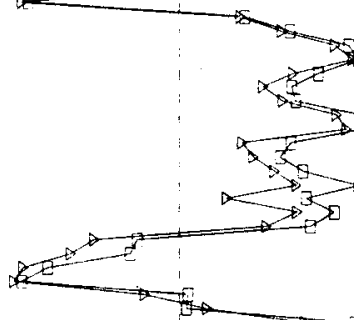

$-\infty$

0

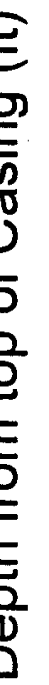

㐫

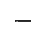

0
$-\quad 8$

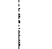

-

禀

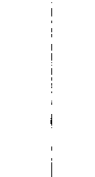

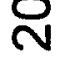

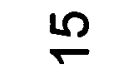

은

10

0

- 요

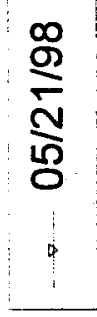

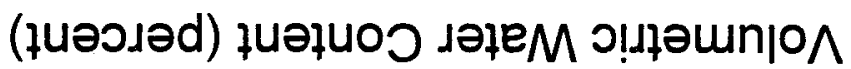




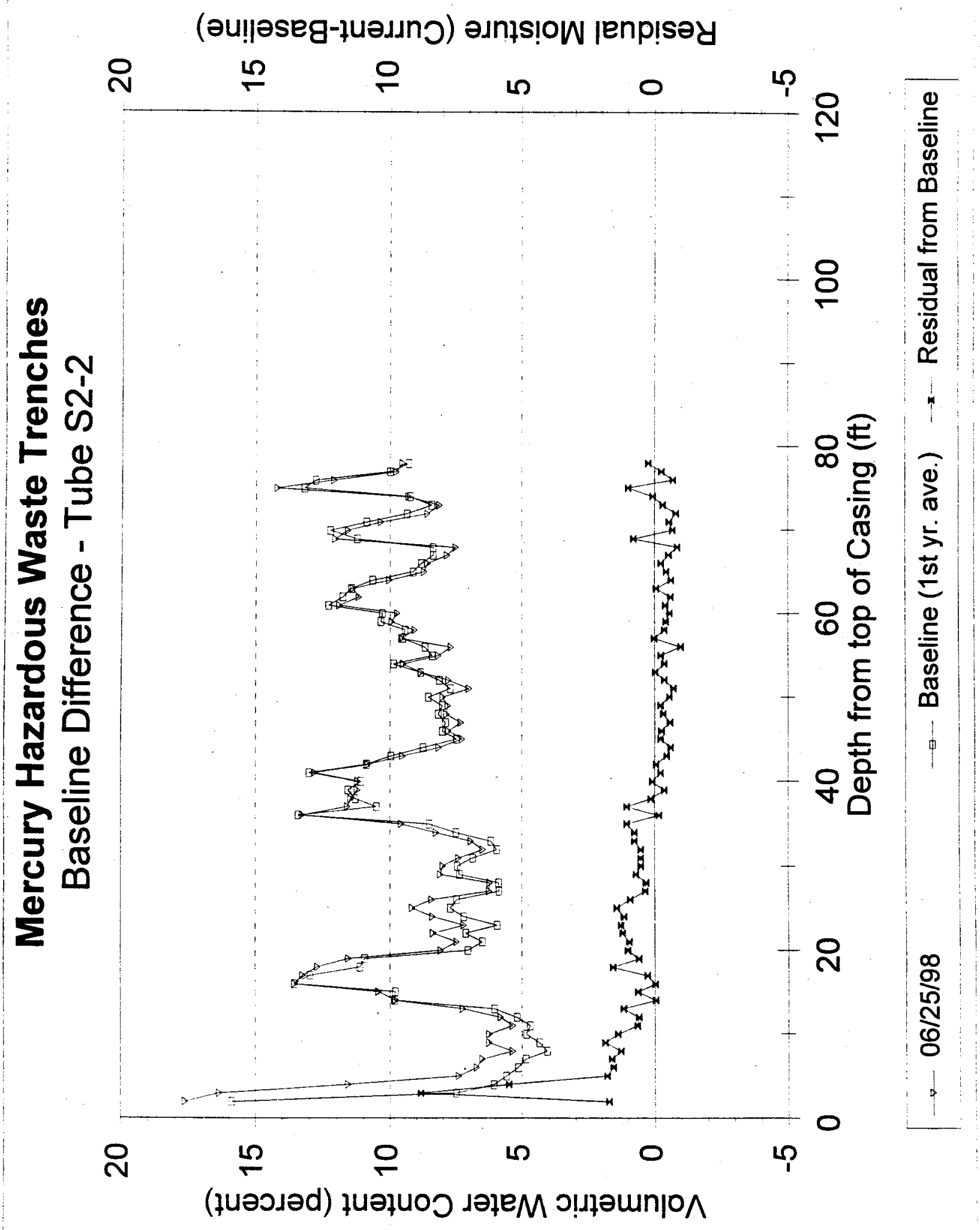




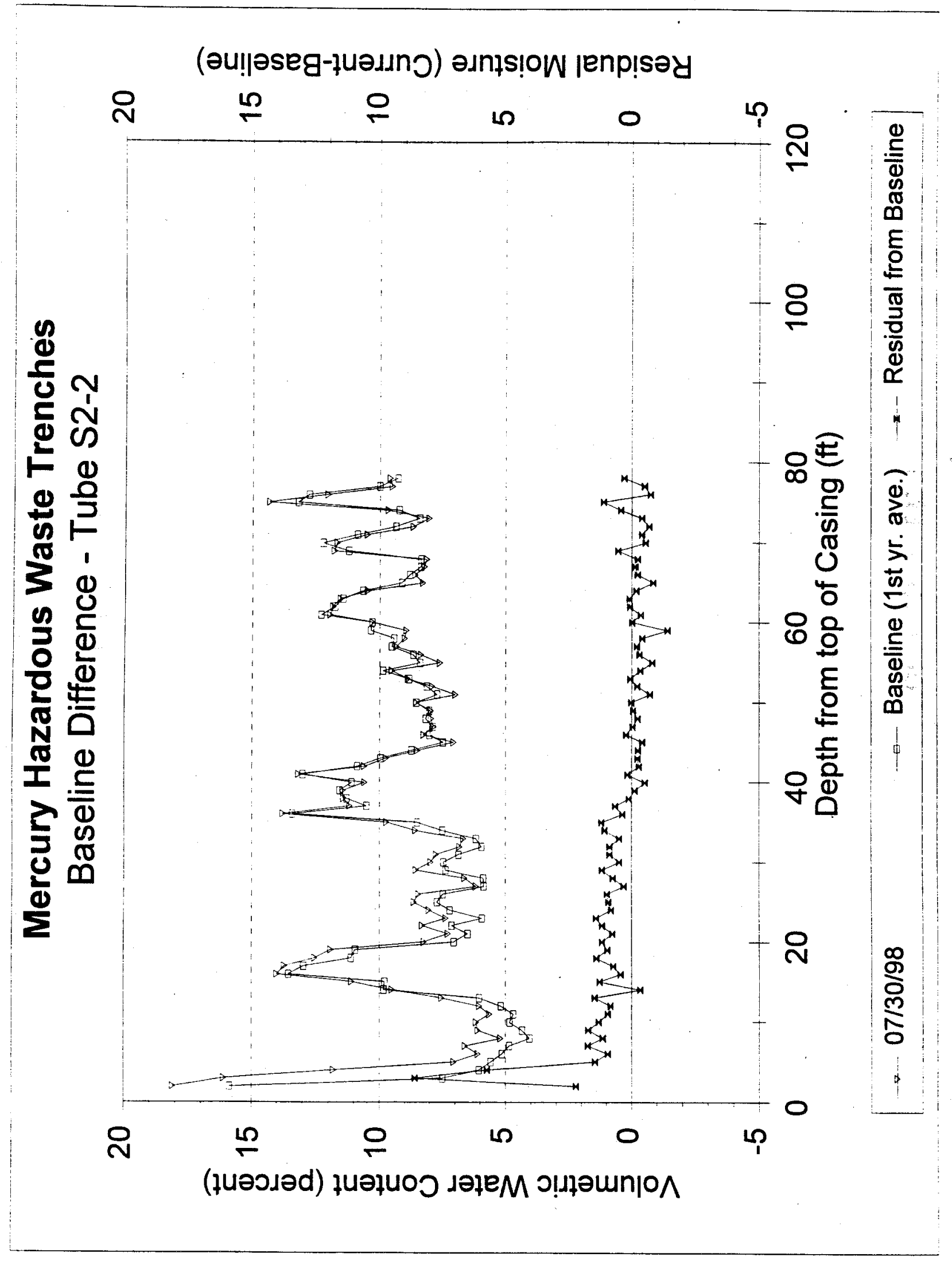




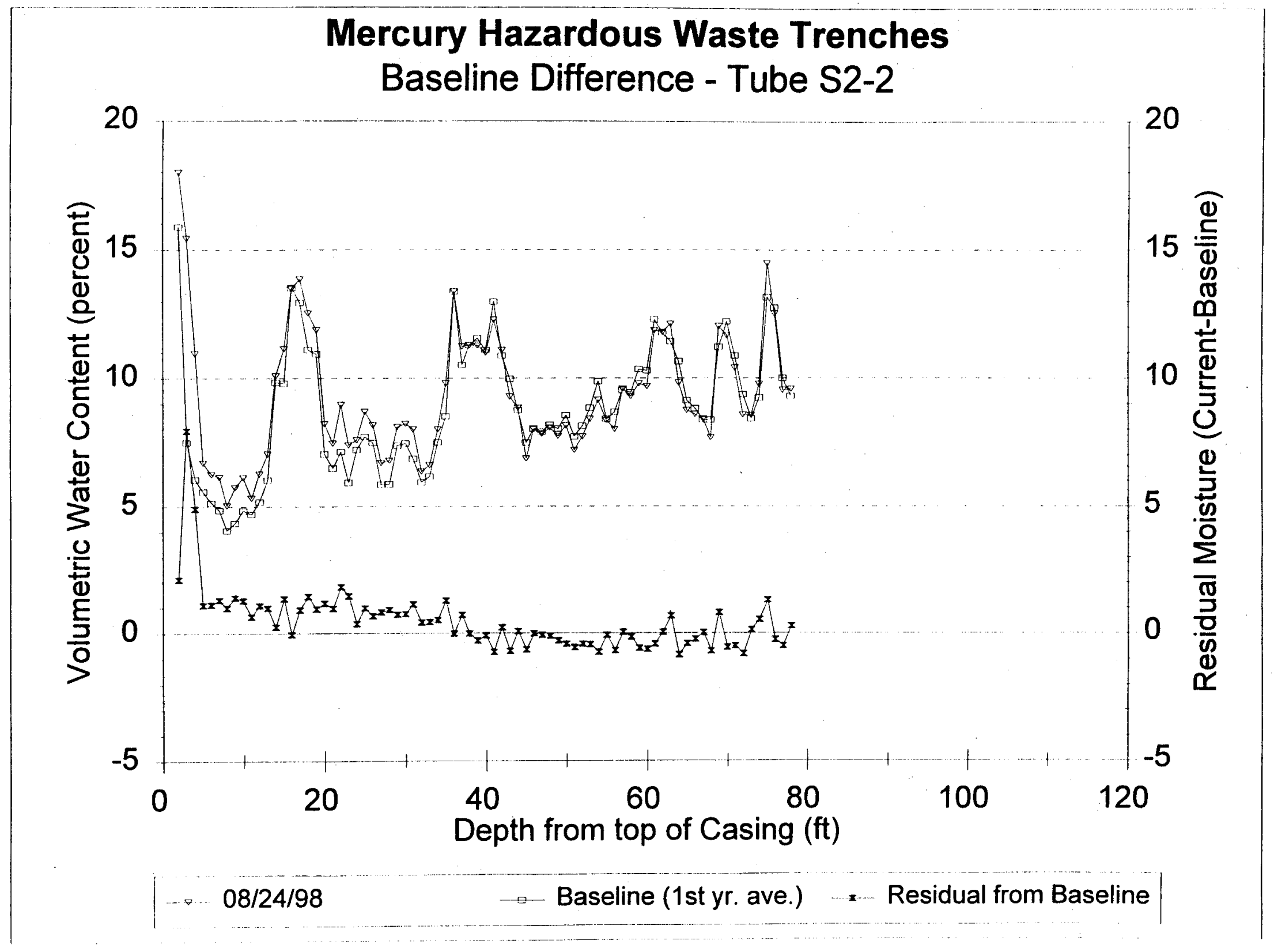




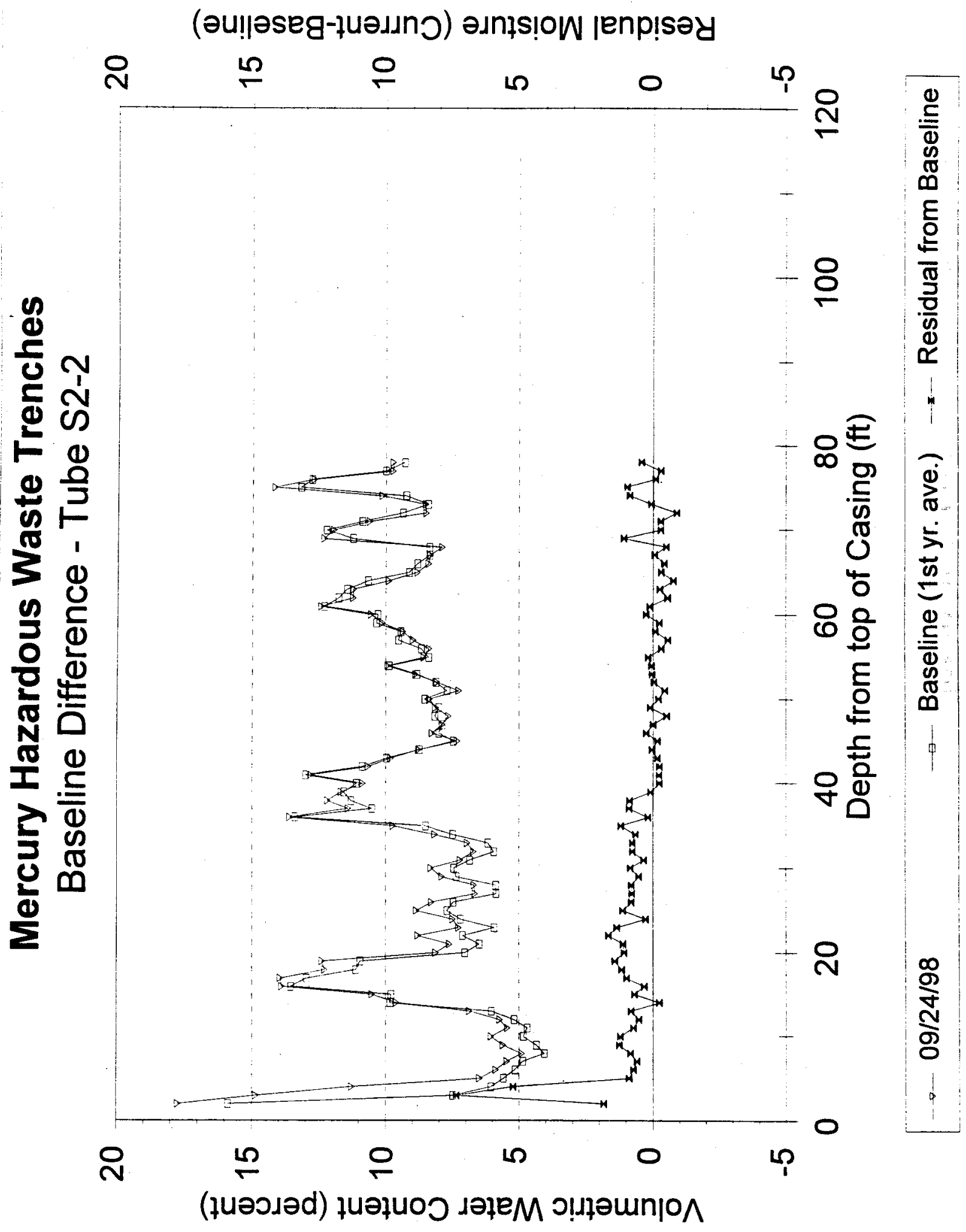




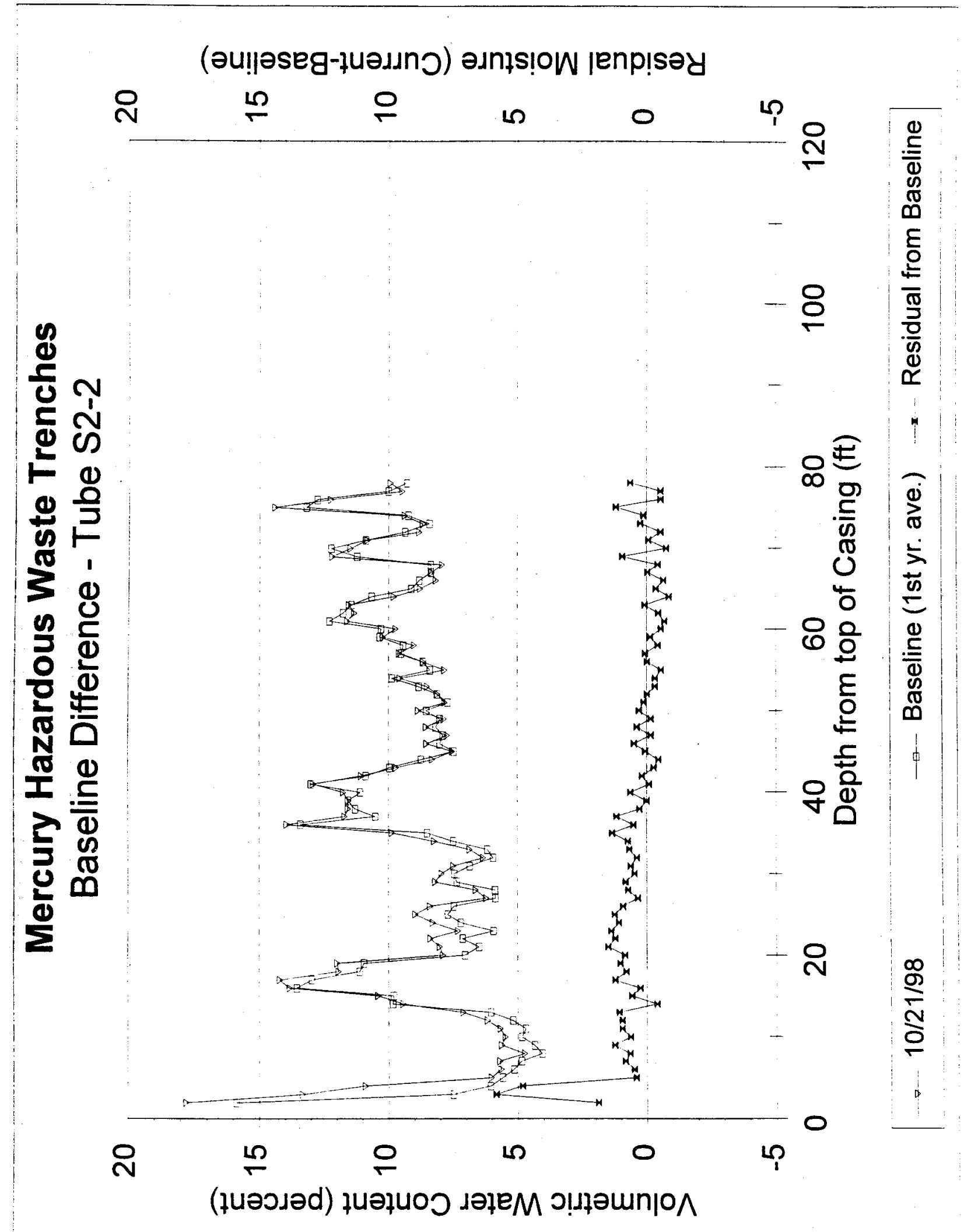




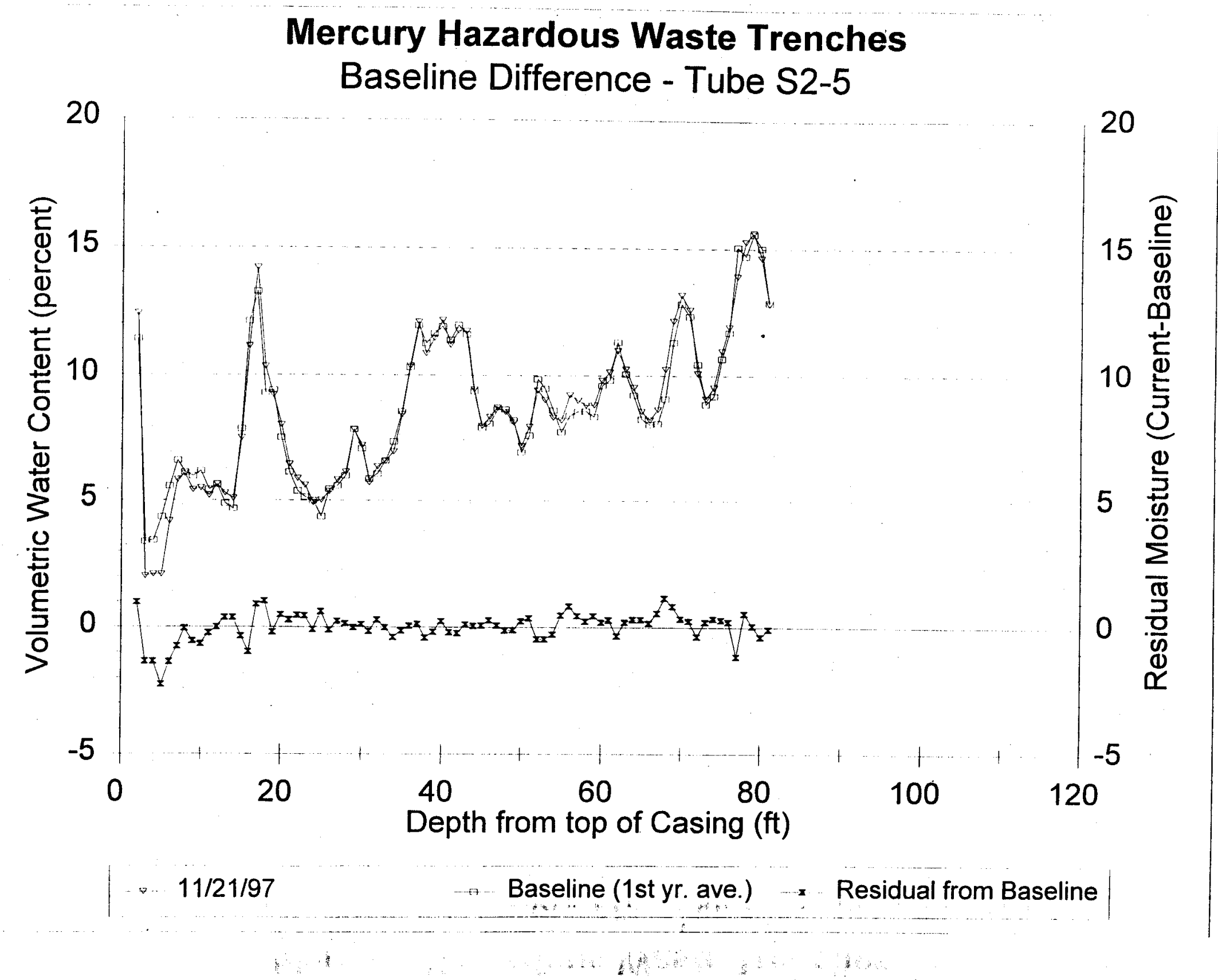




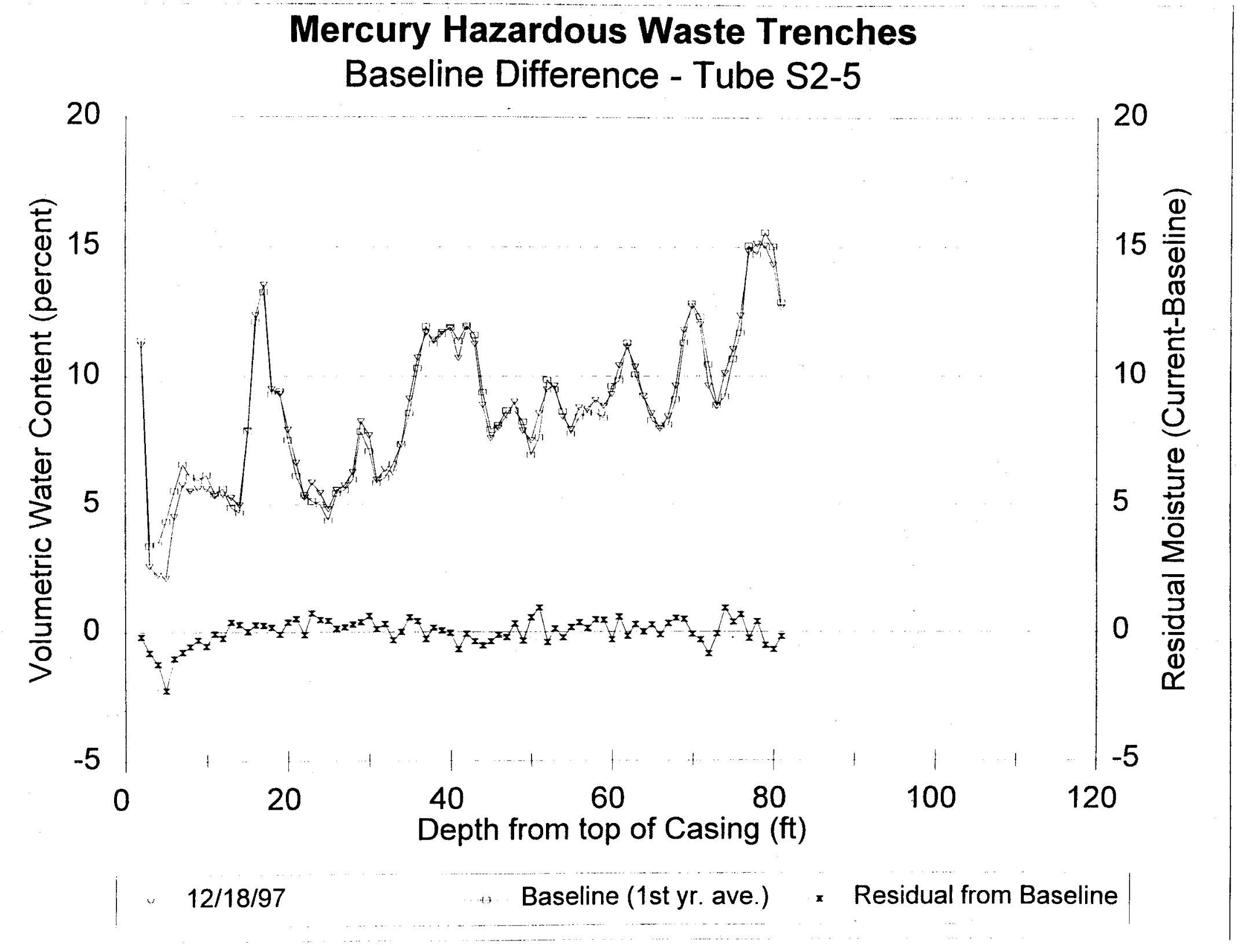




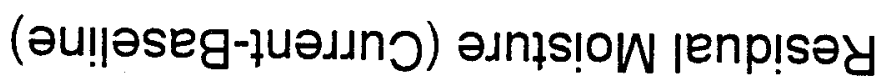
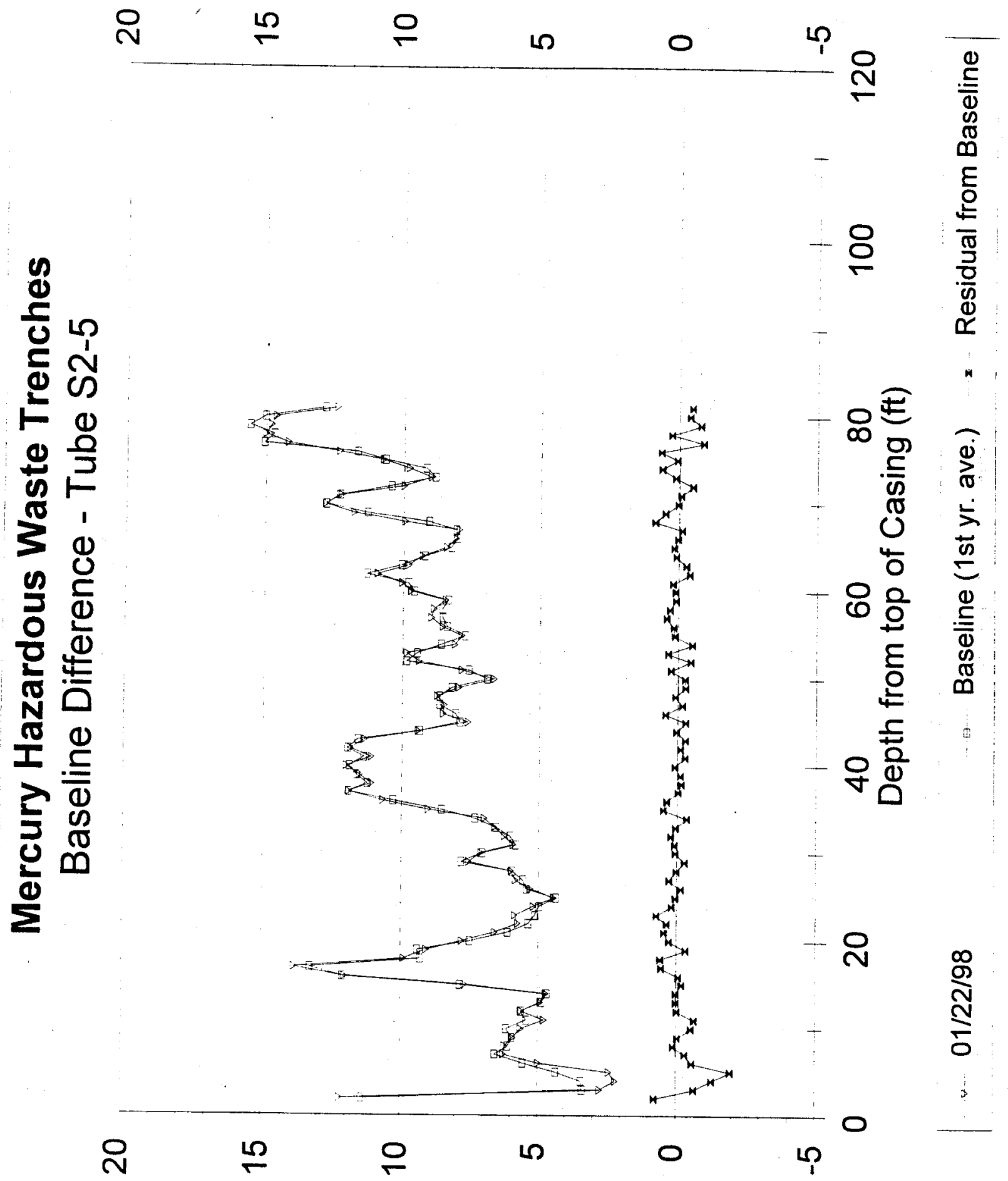

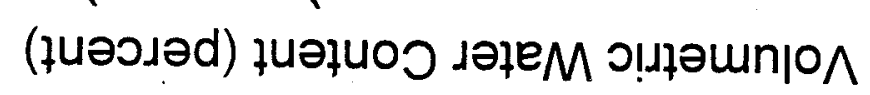




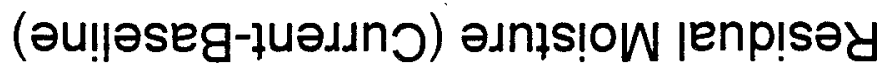
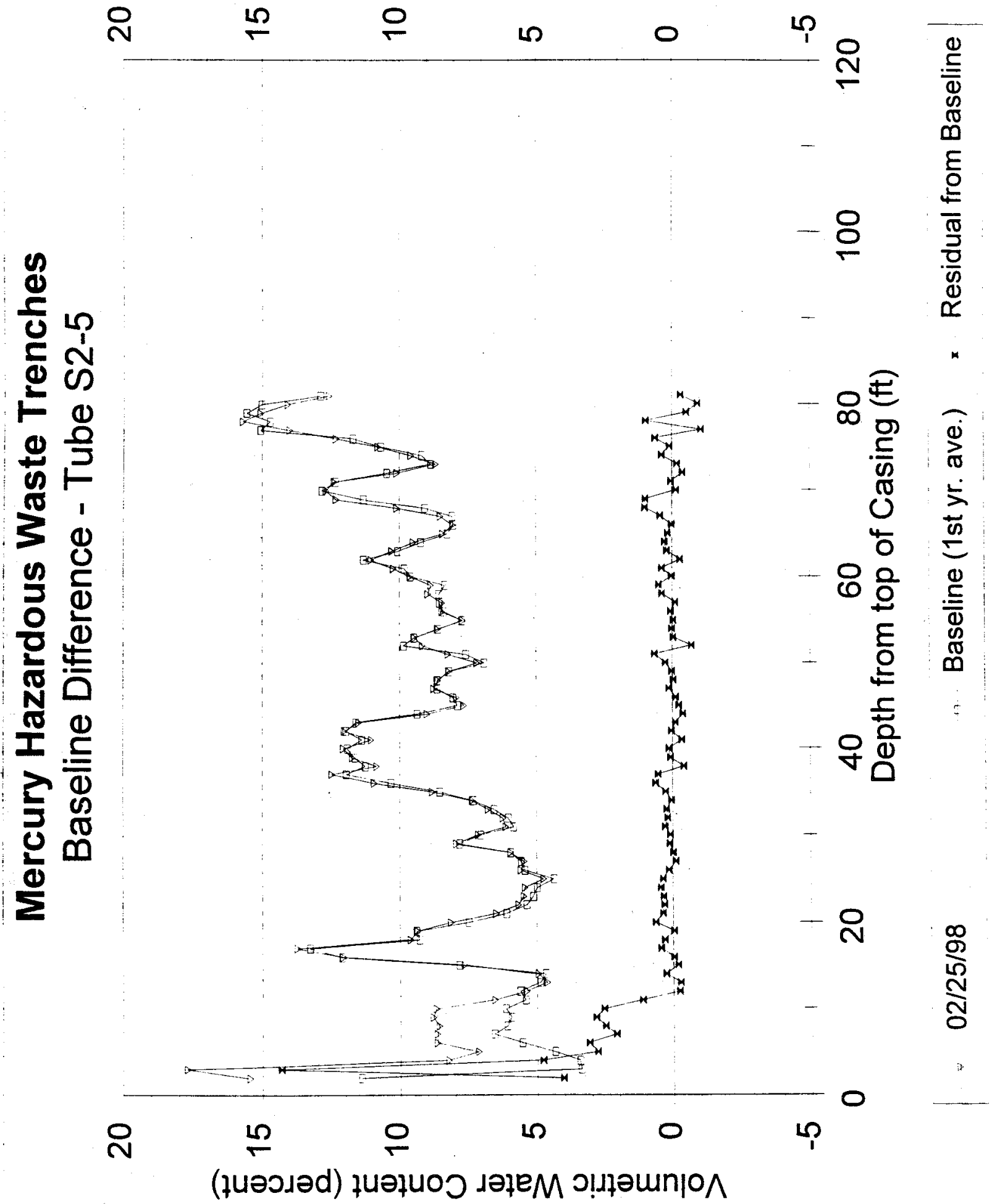


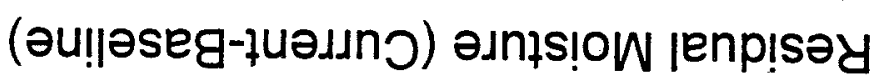

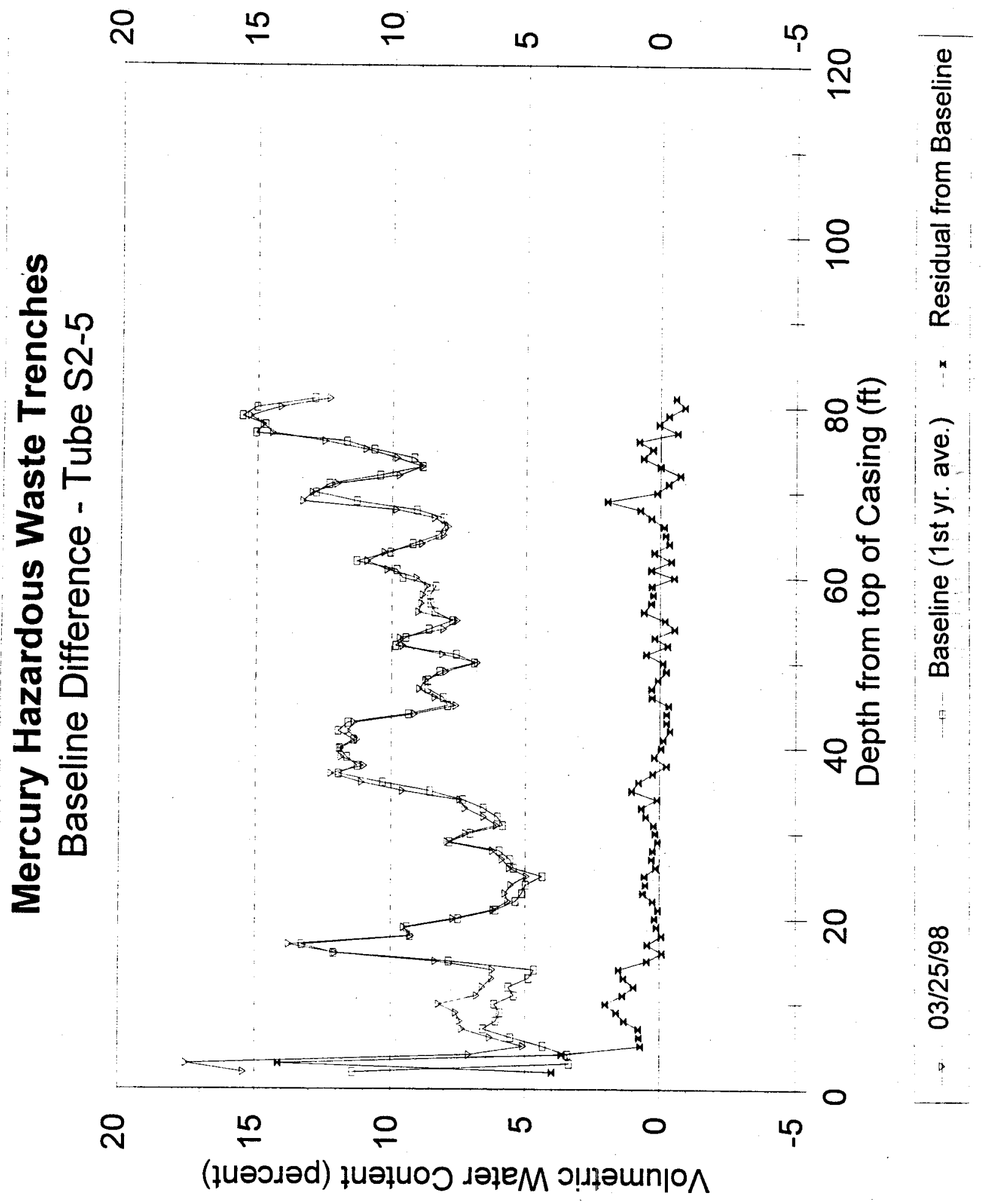




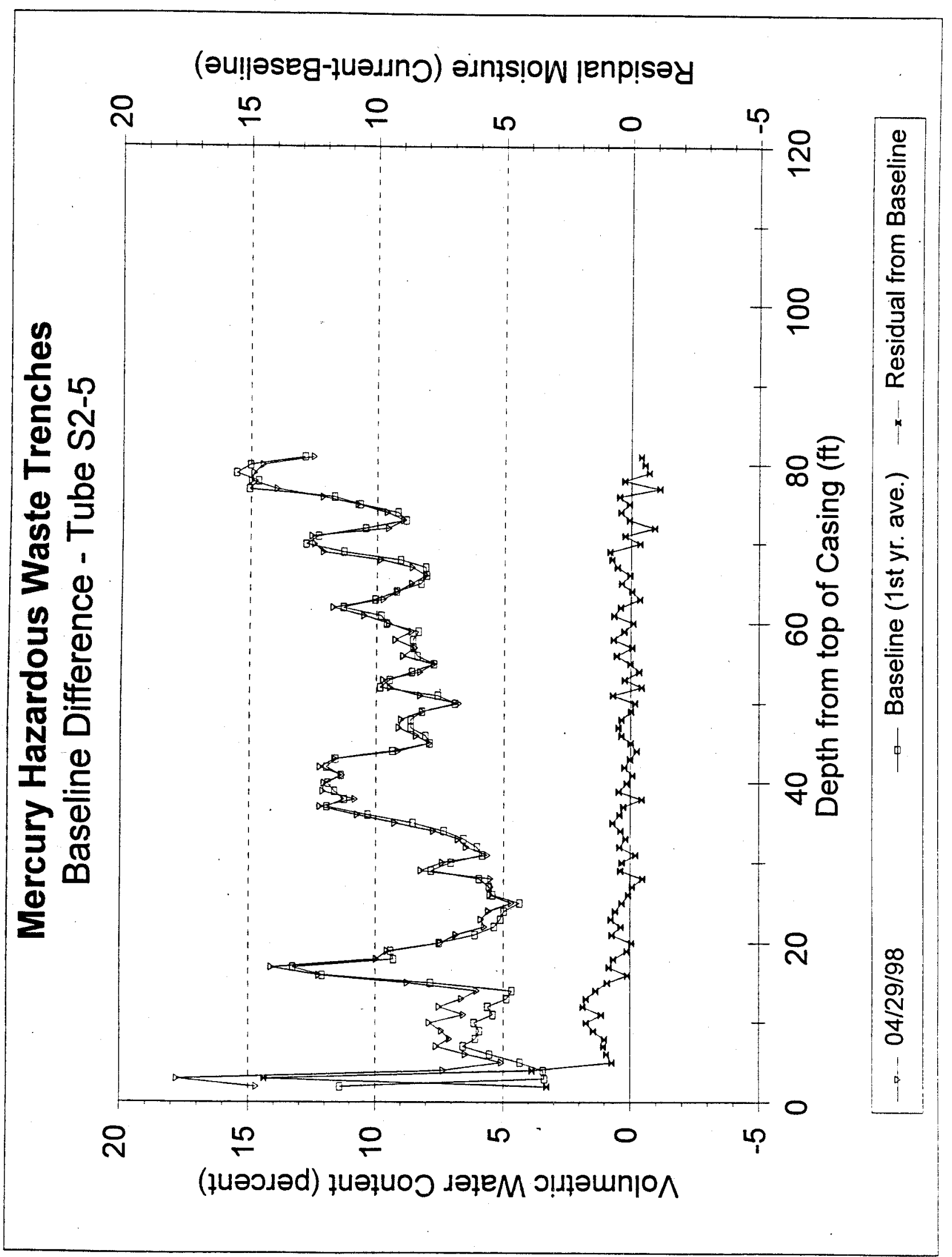




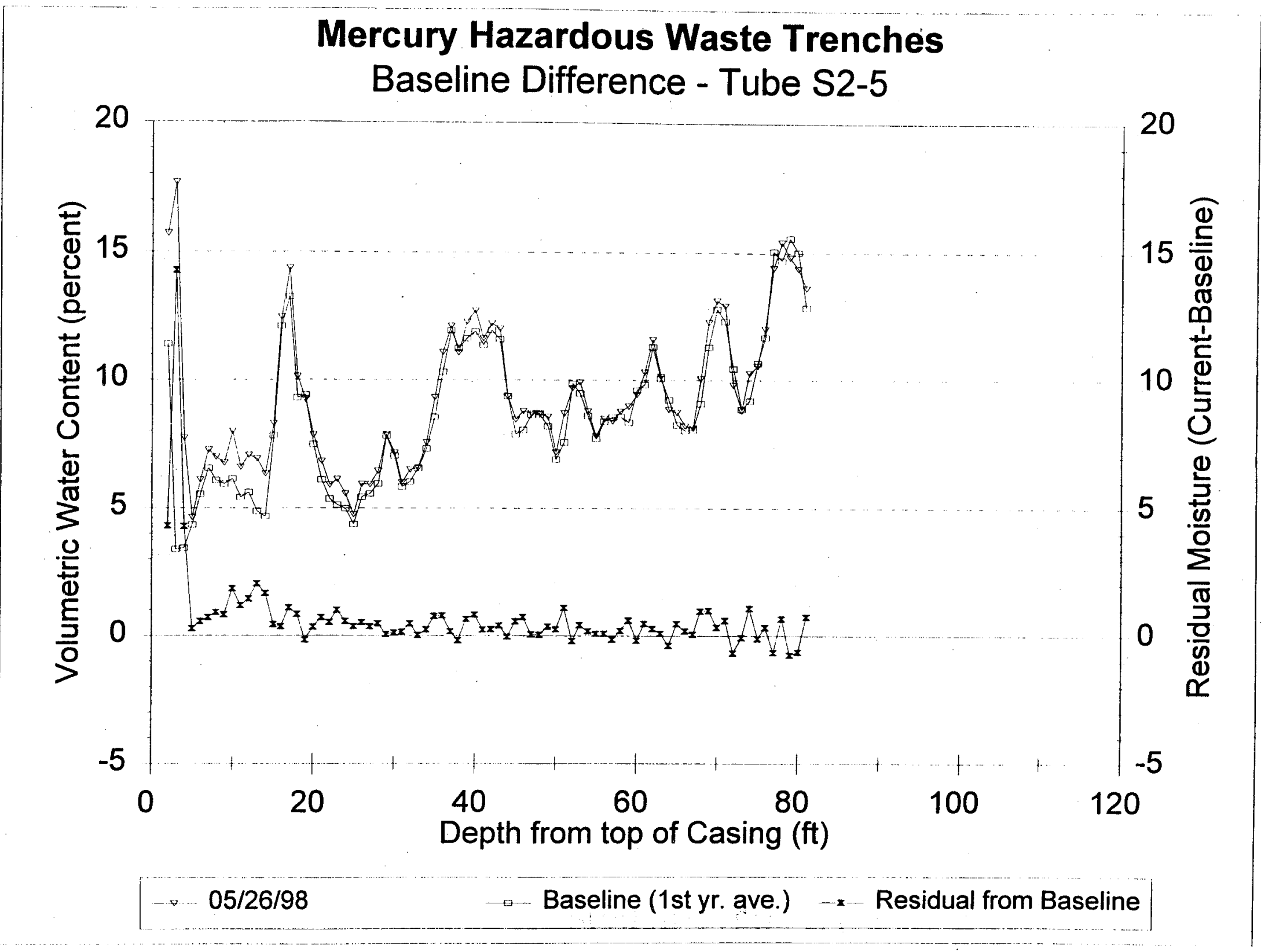




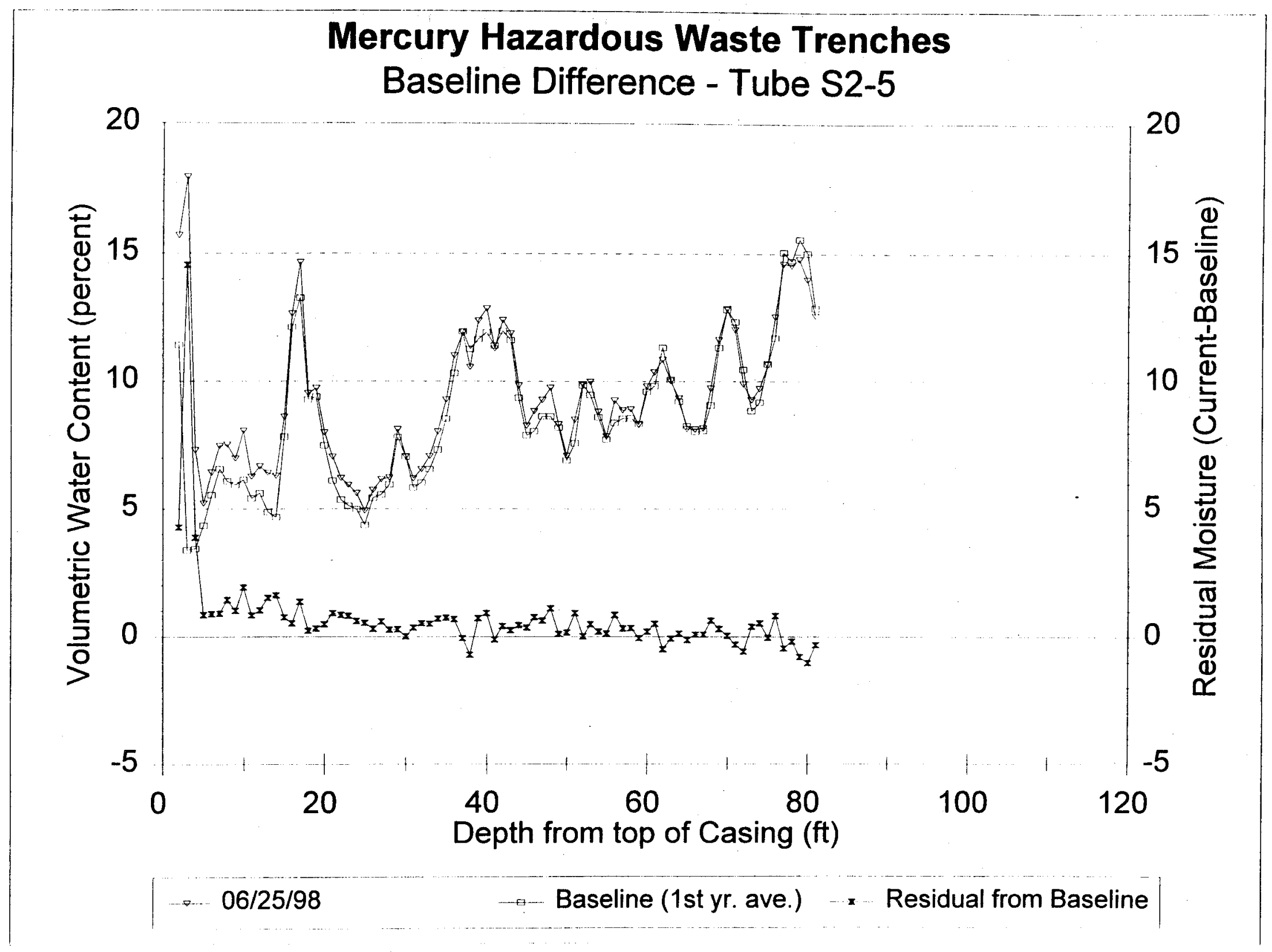




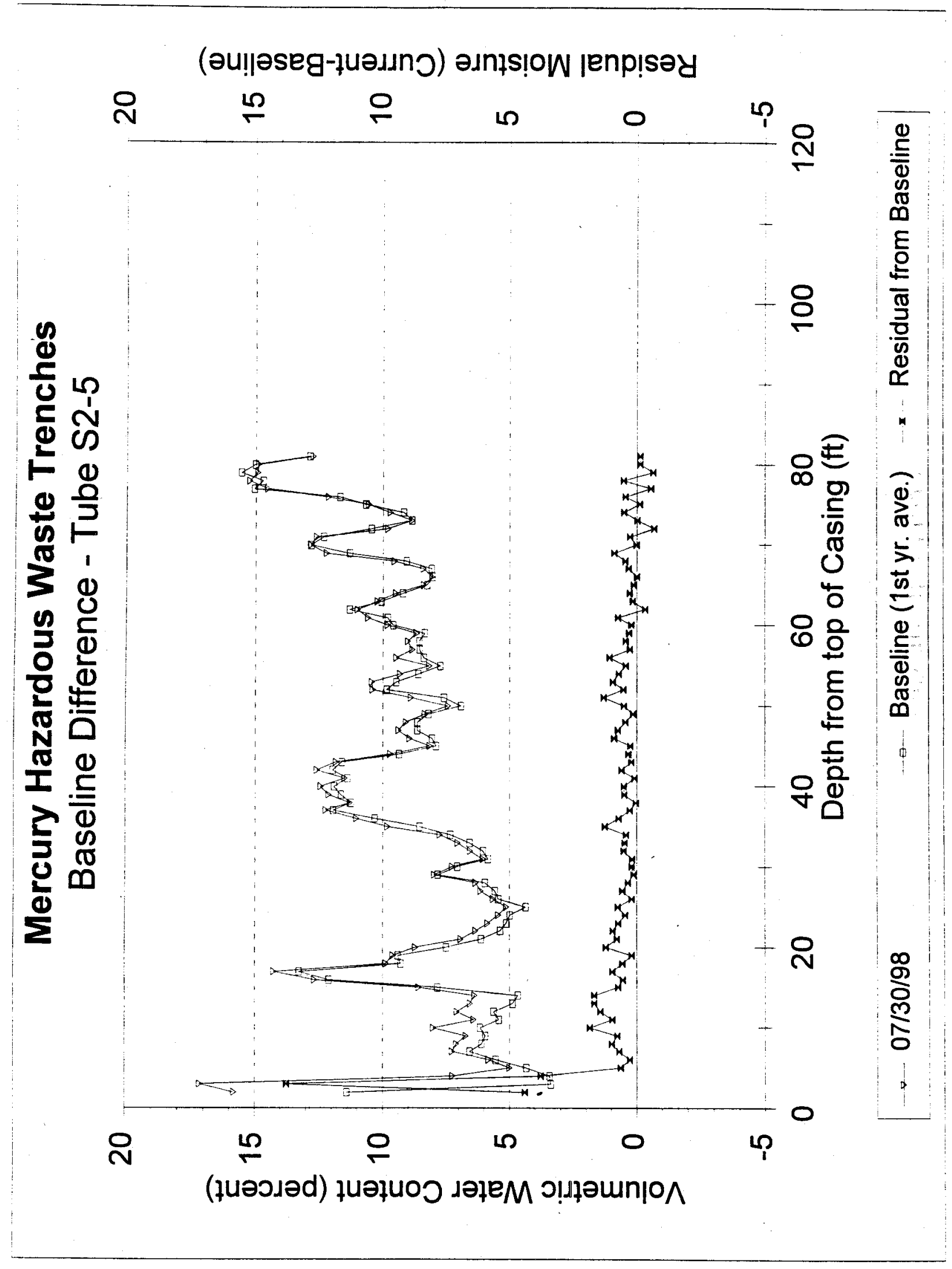




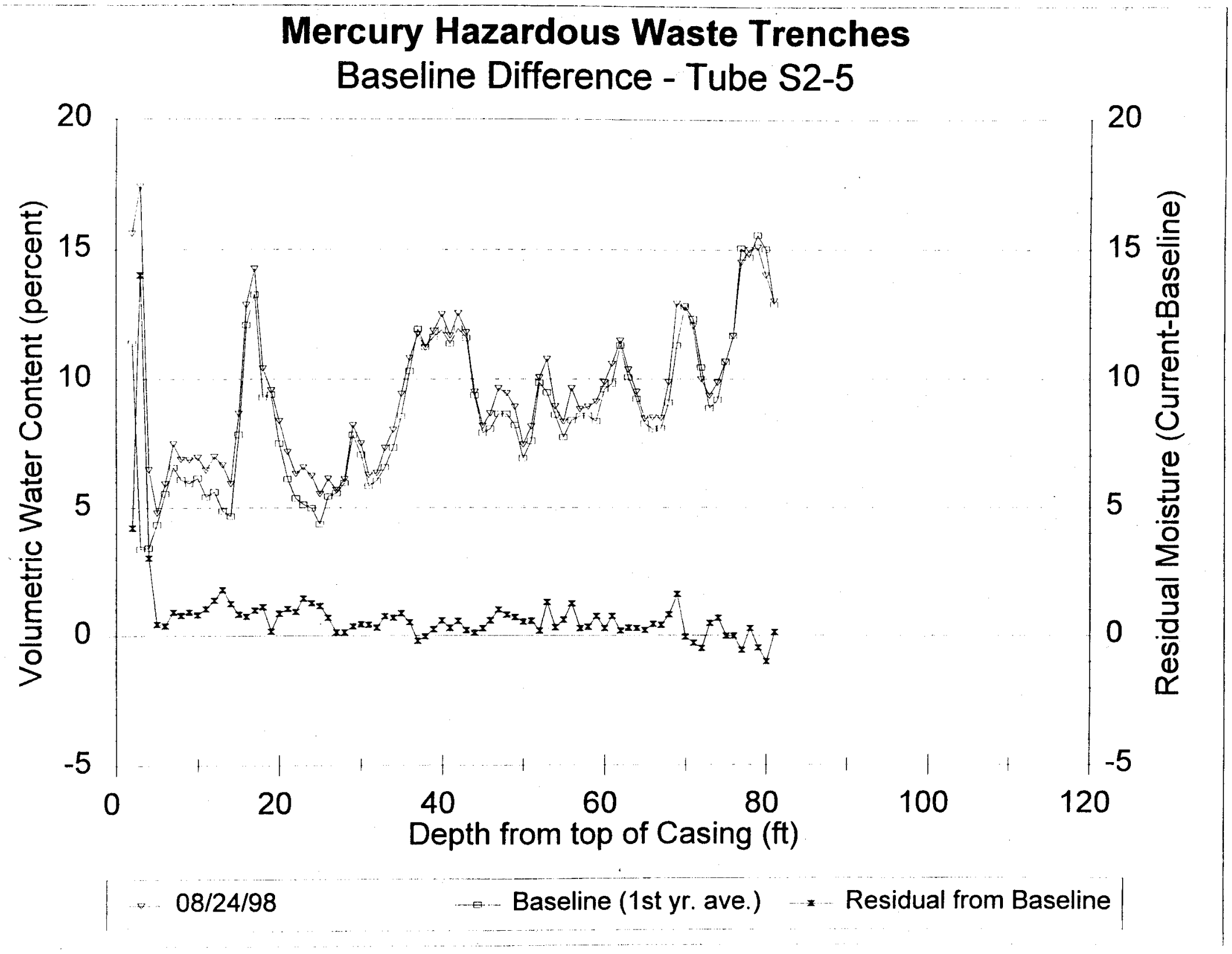




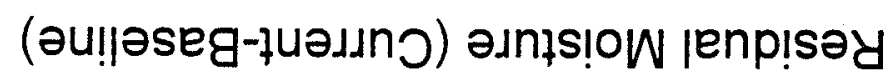

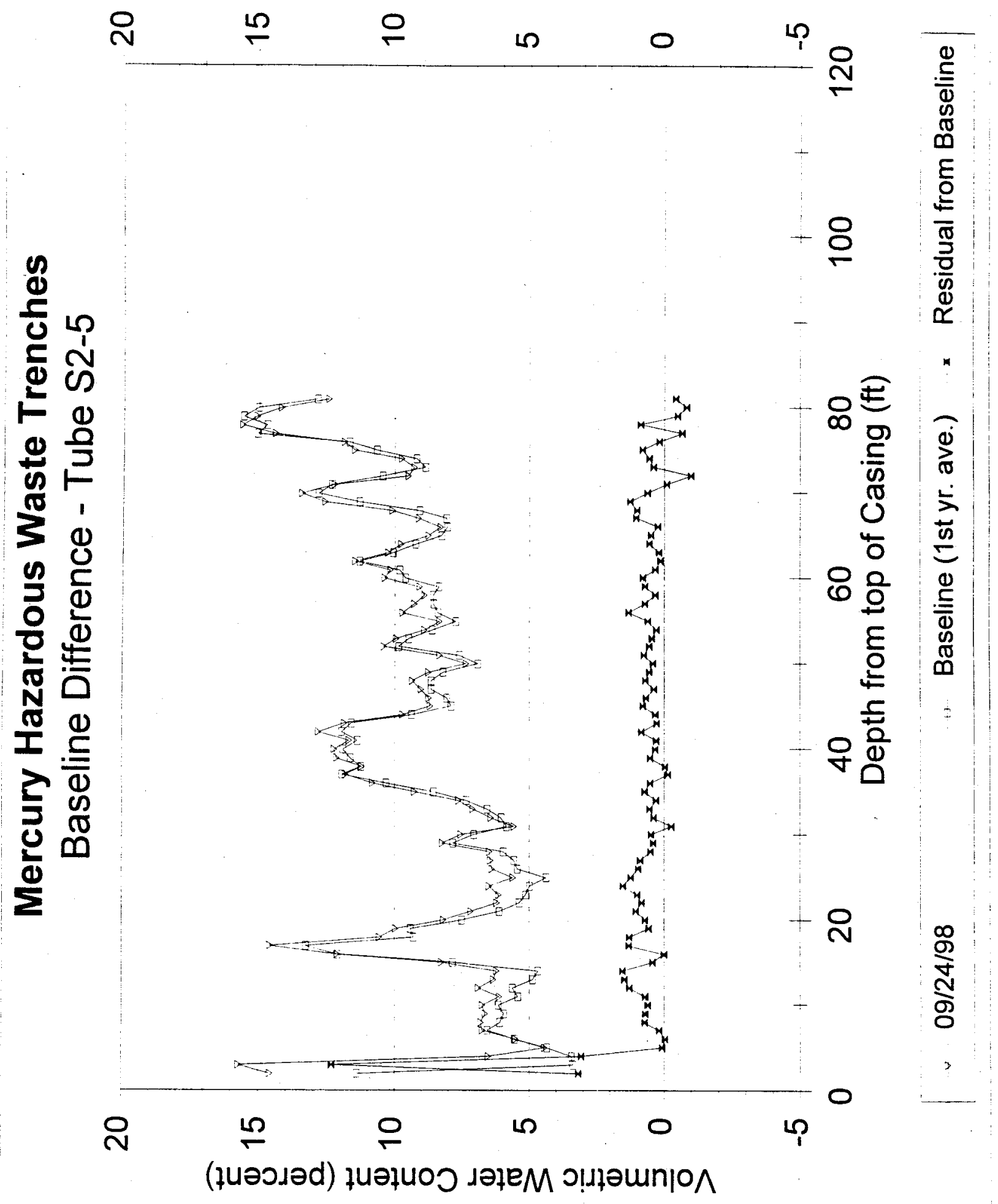




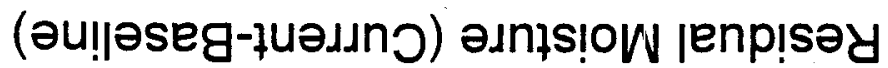

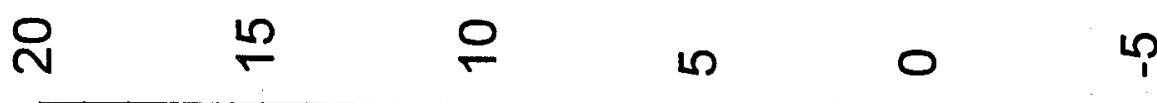

$\because$

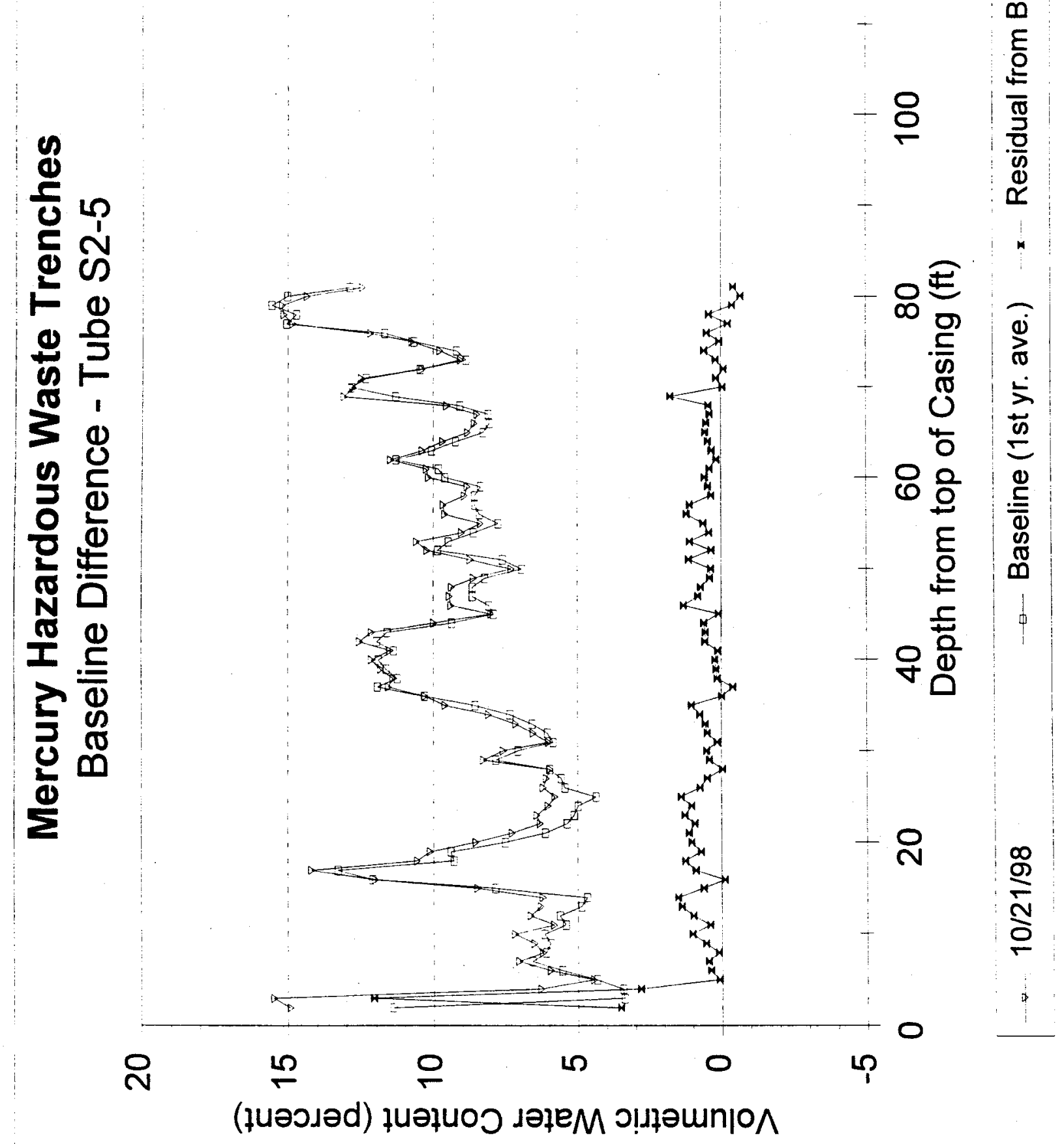




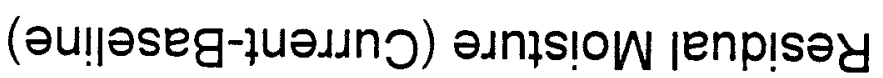
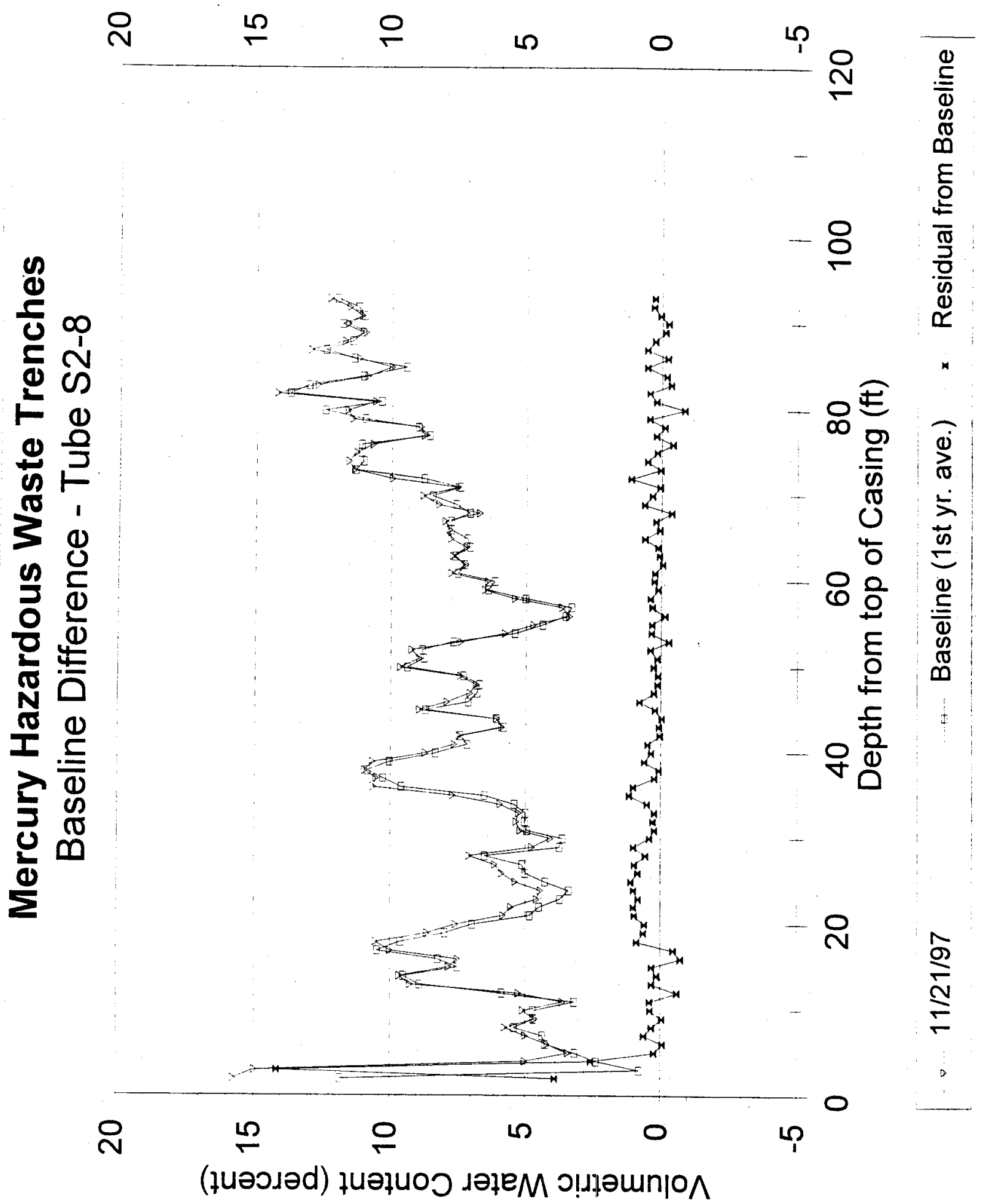


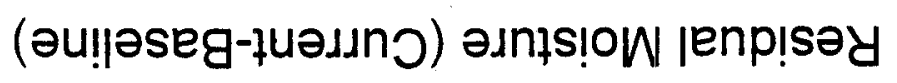
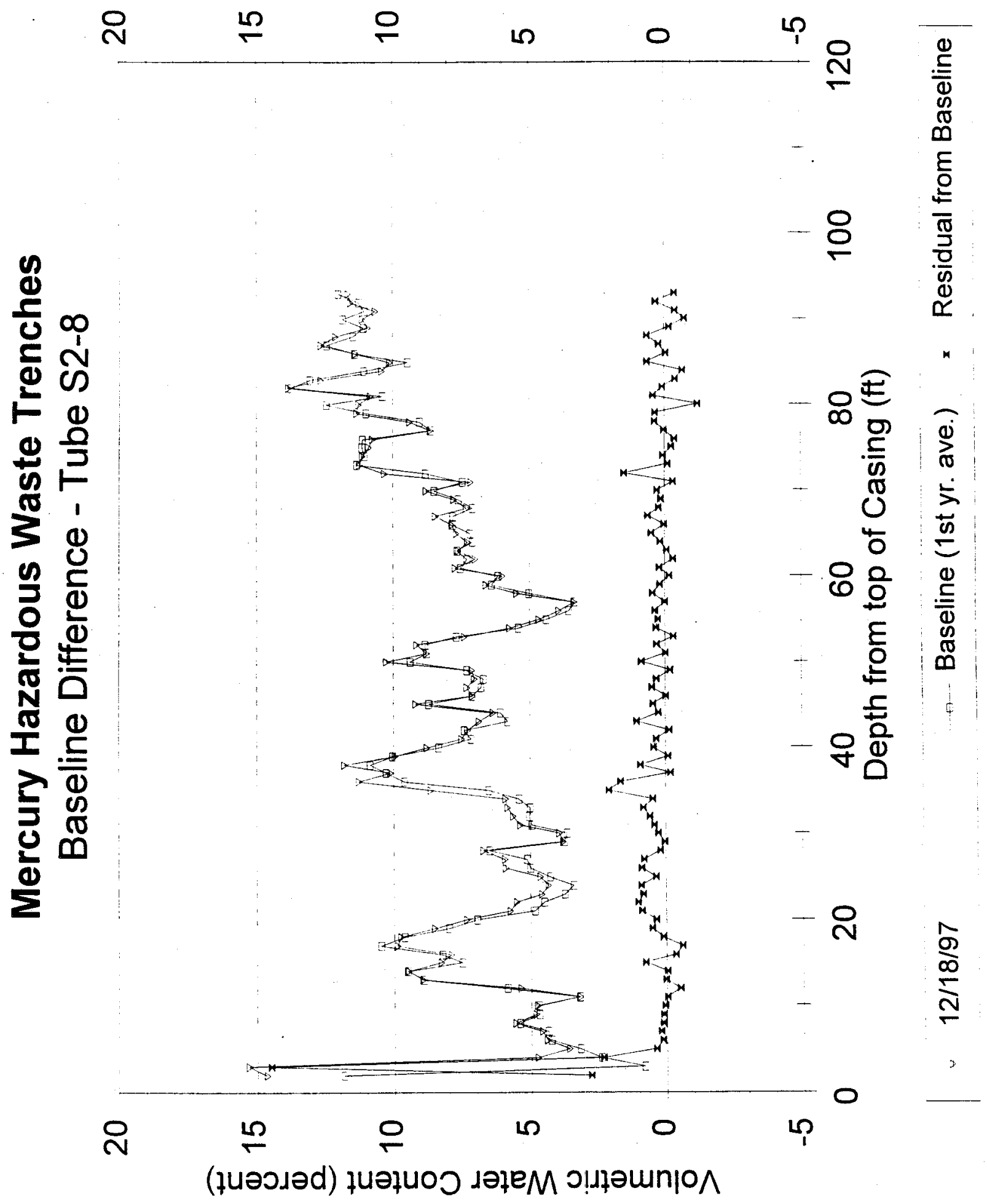


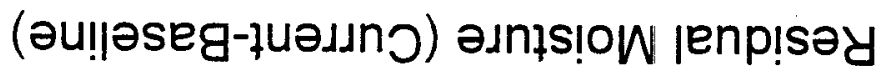
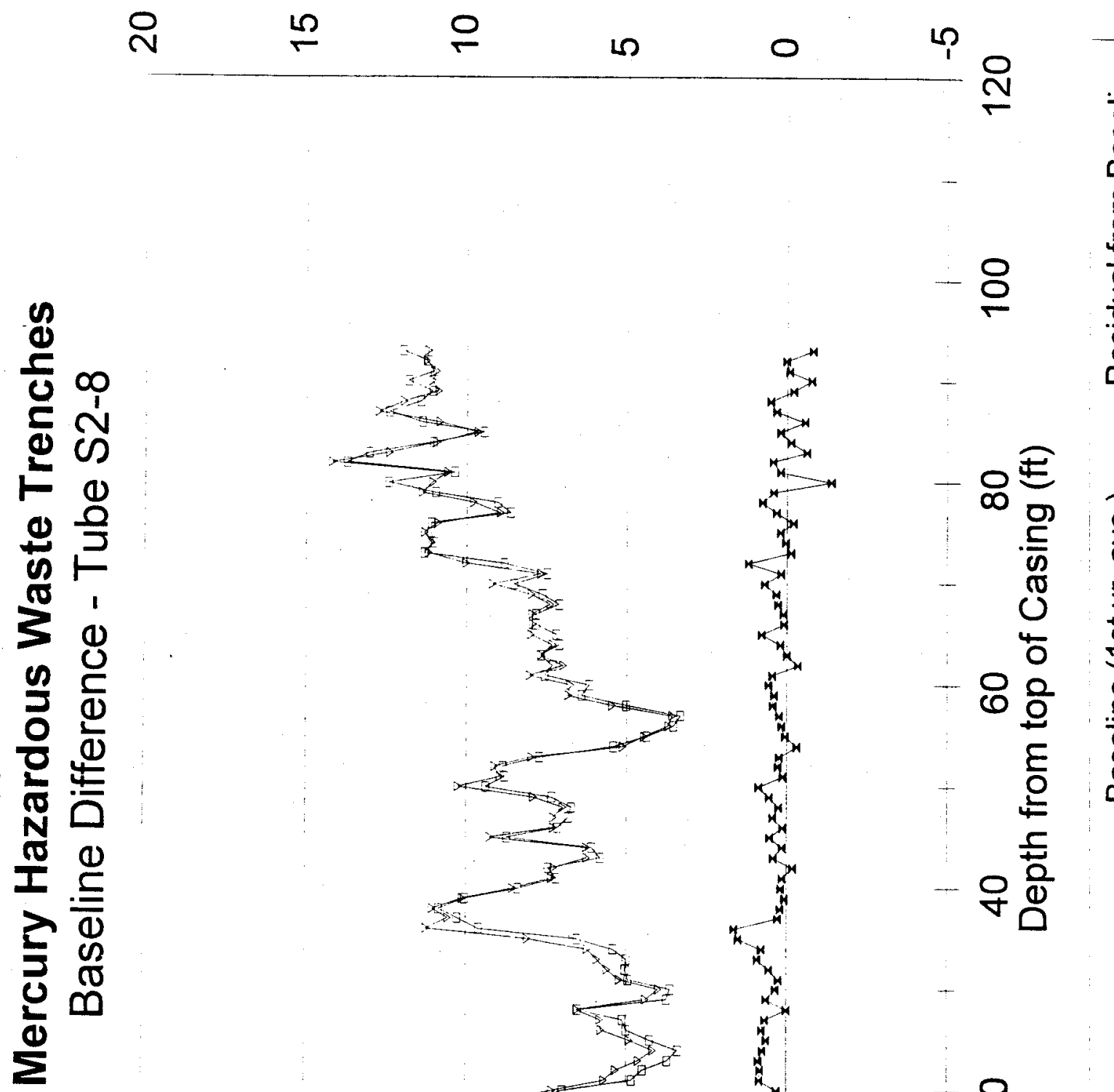

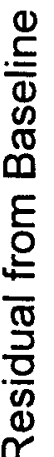

.
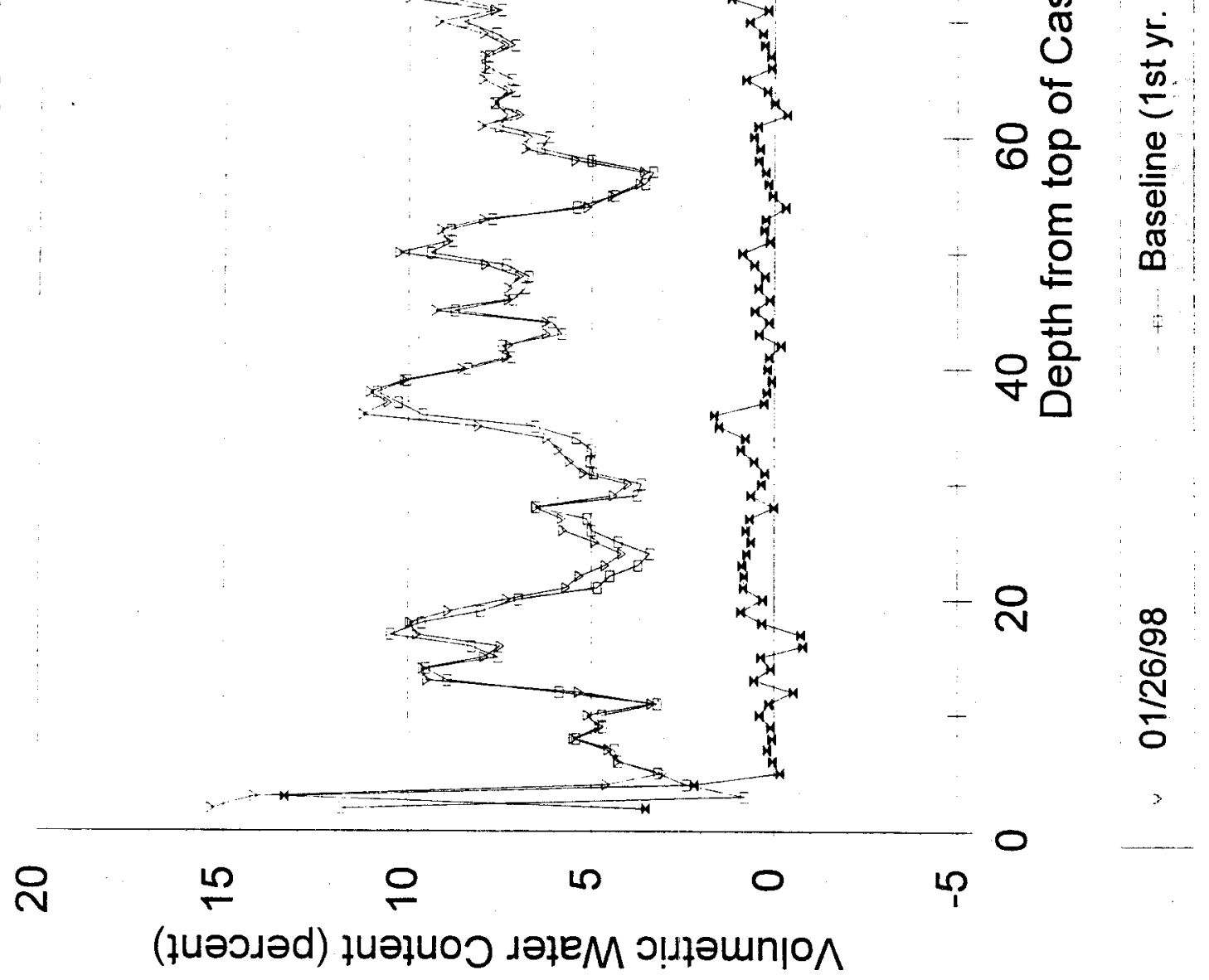


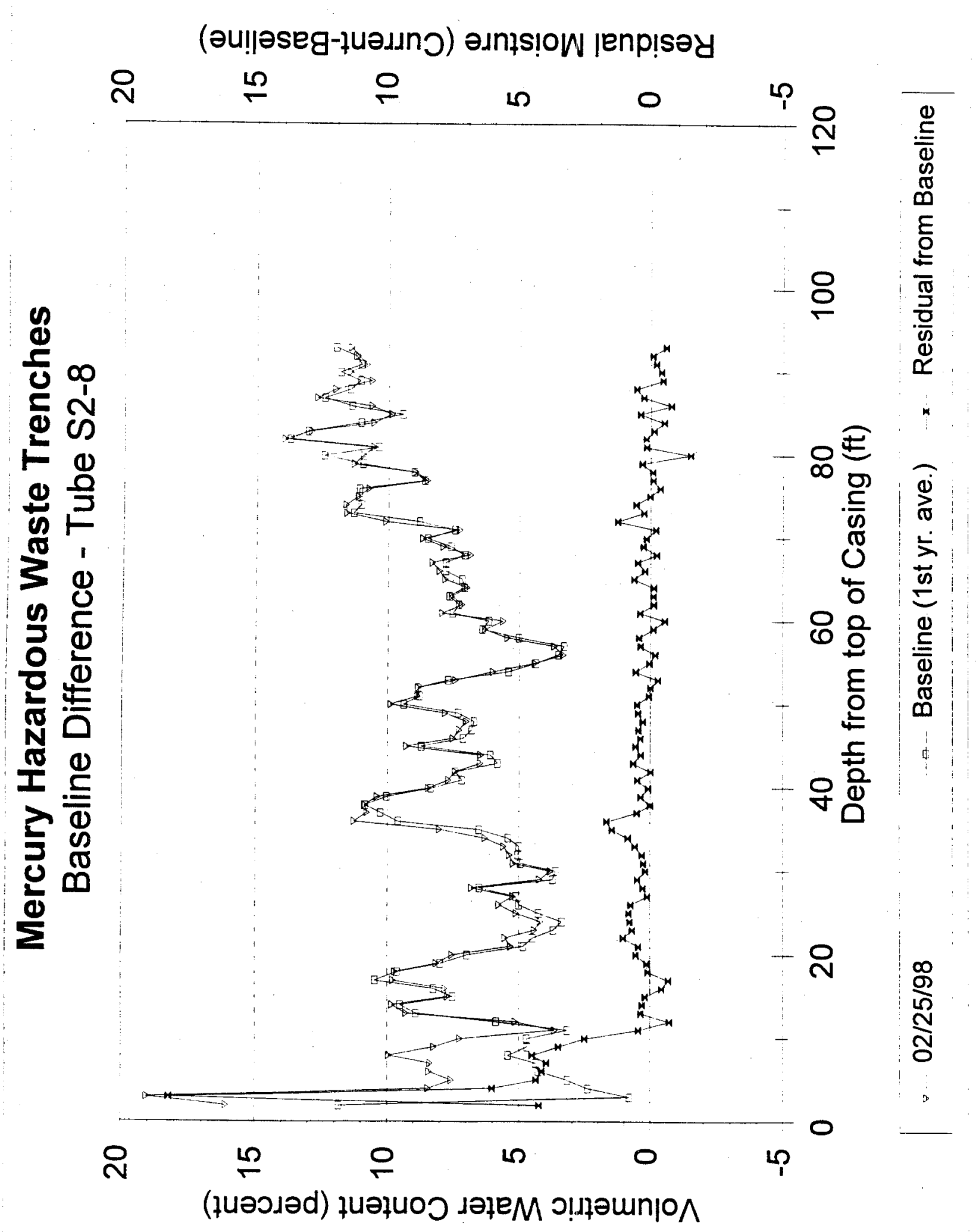




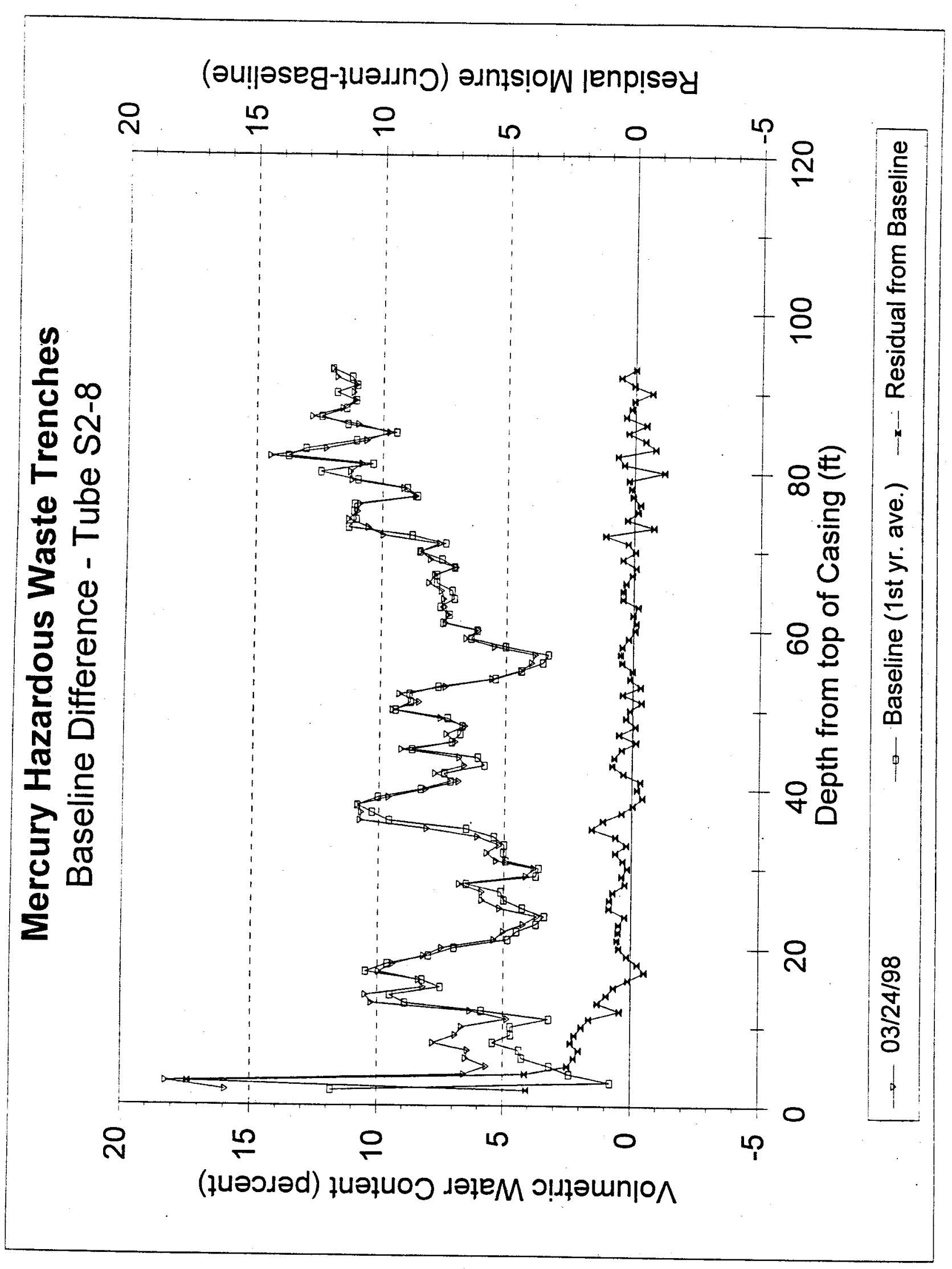




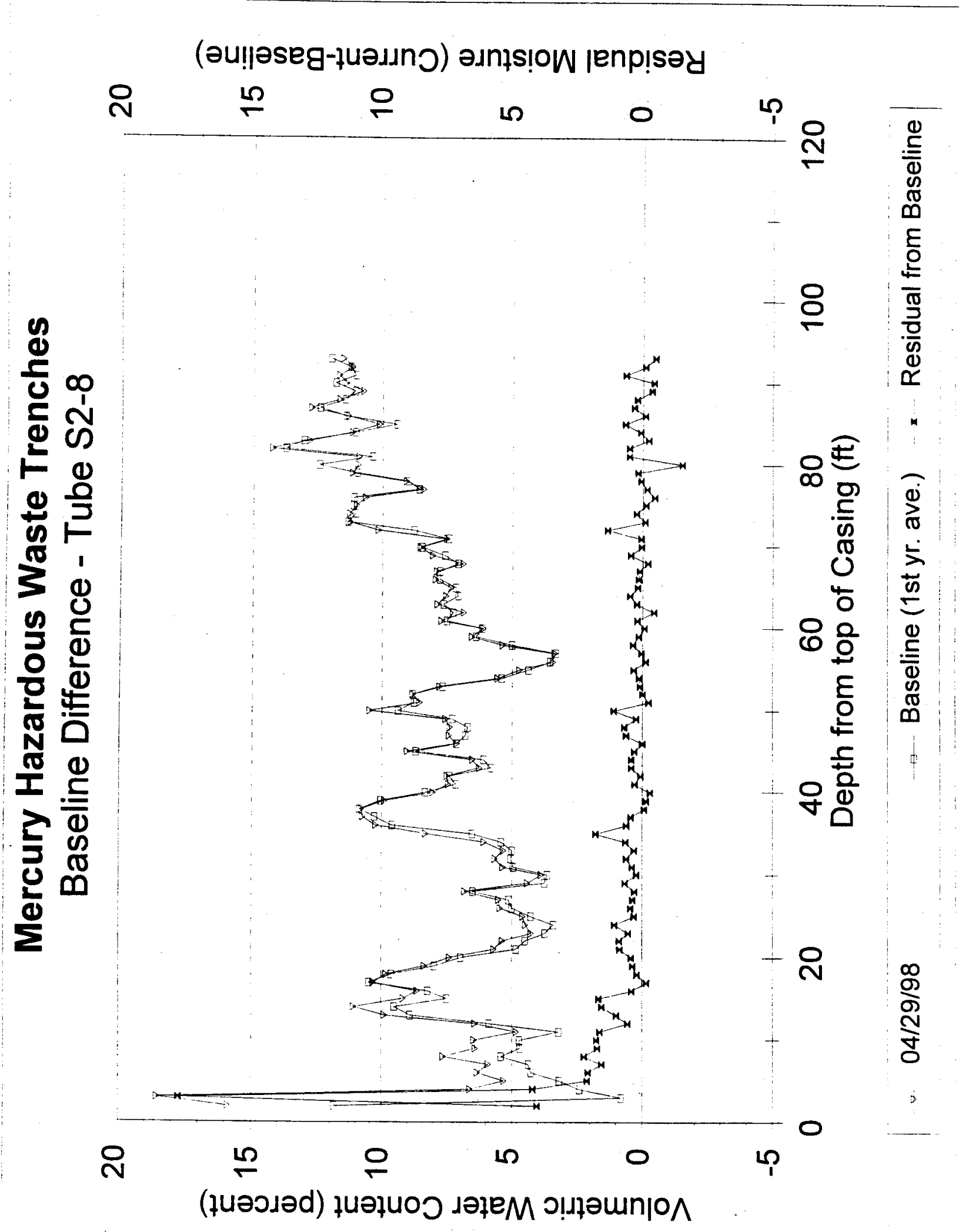




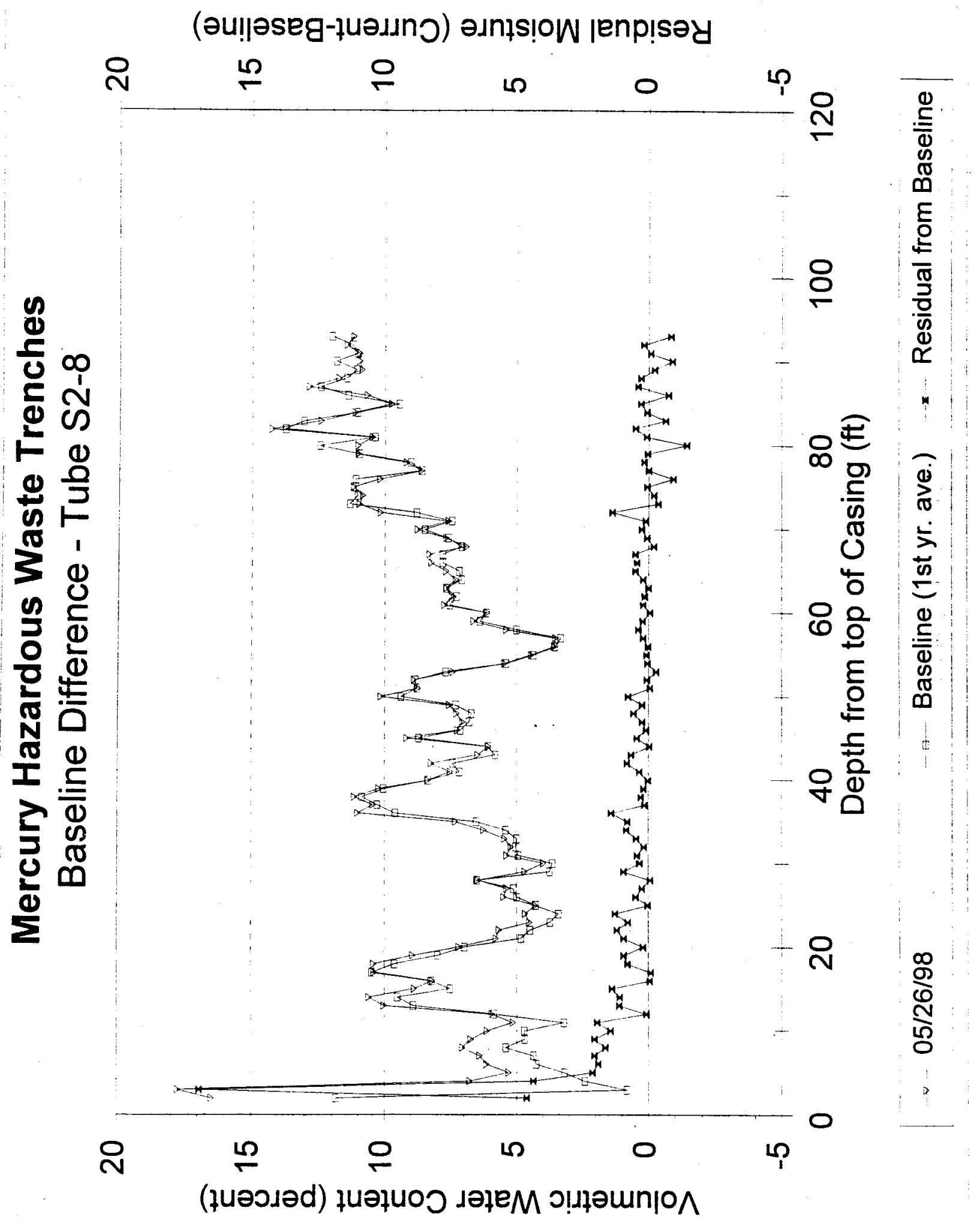




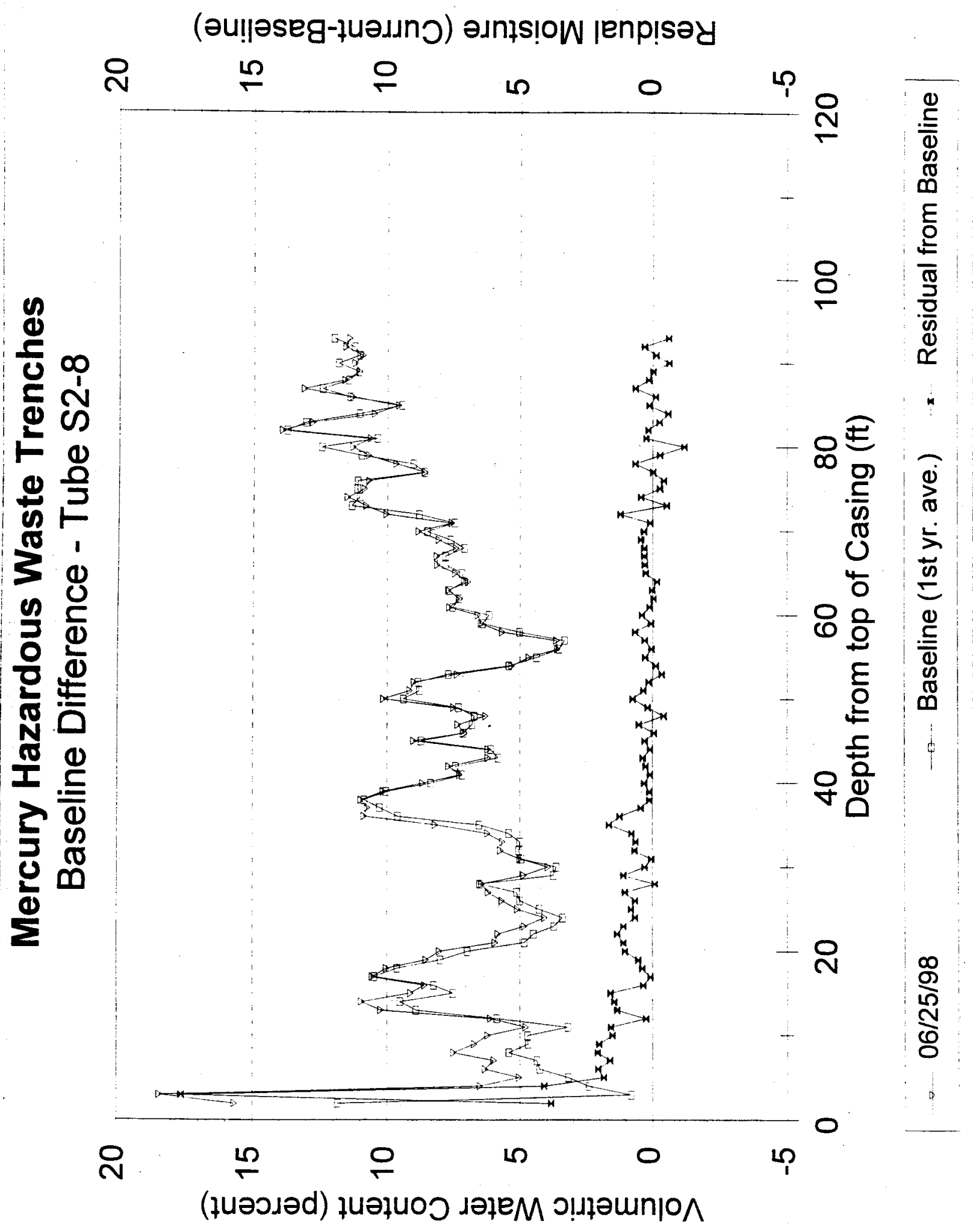




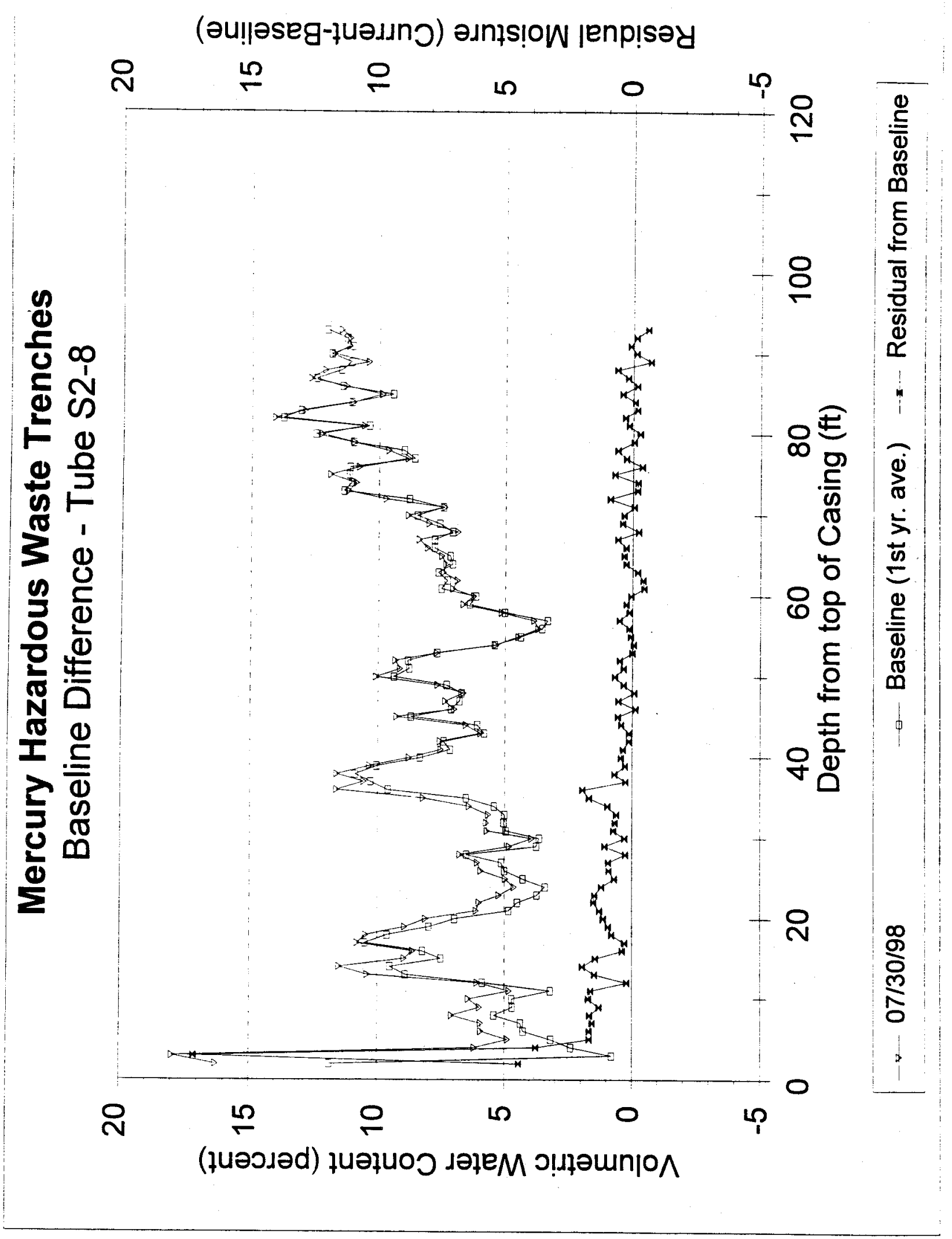




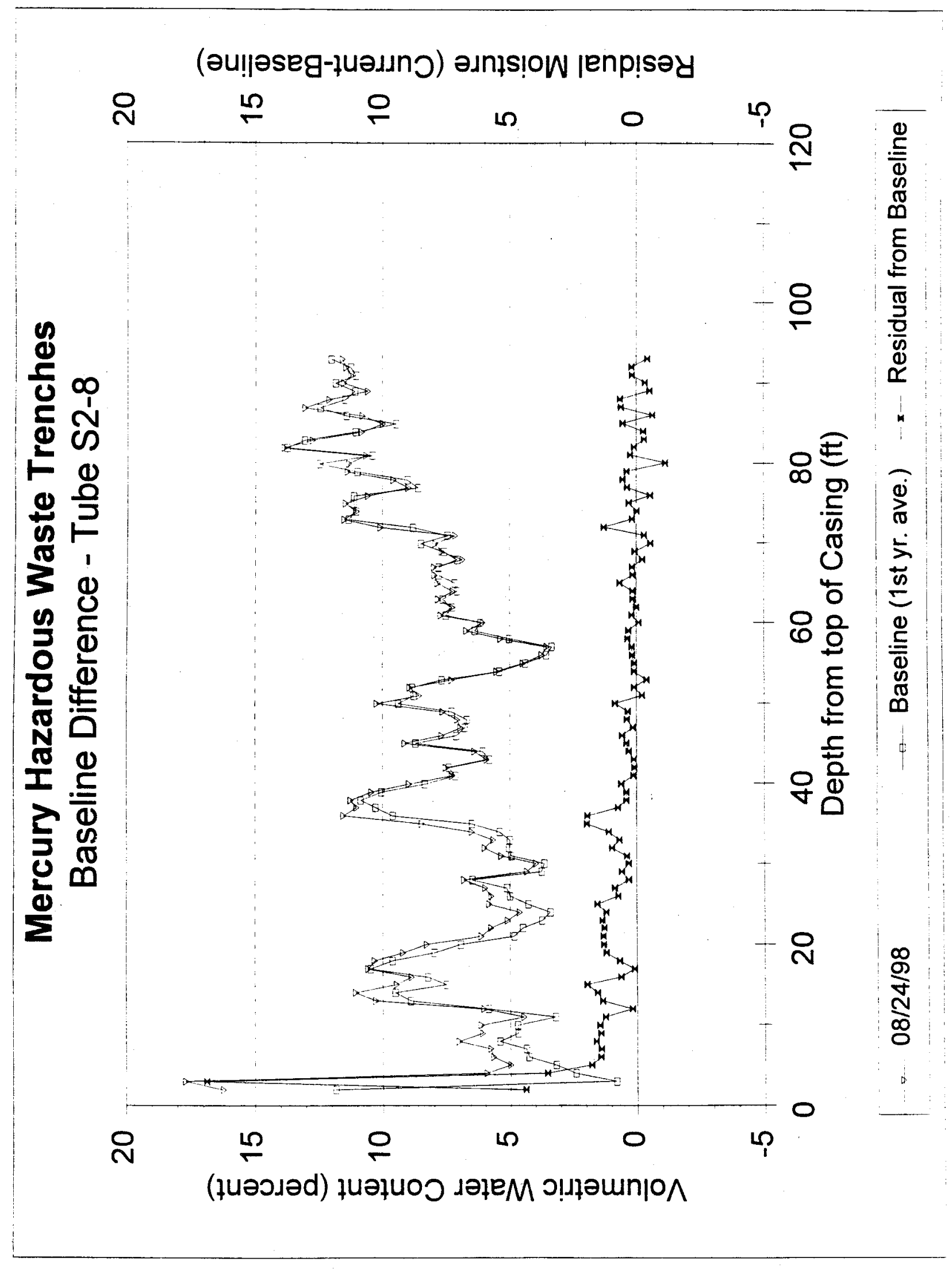




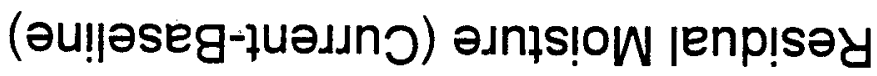

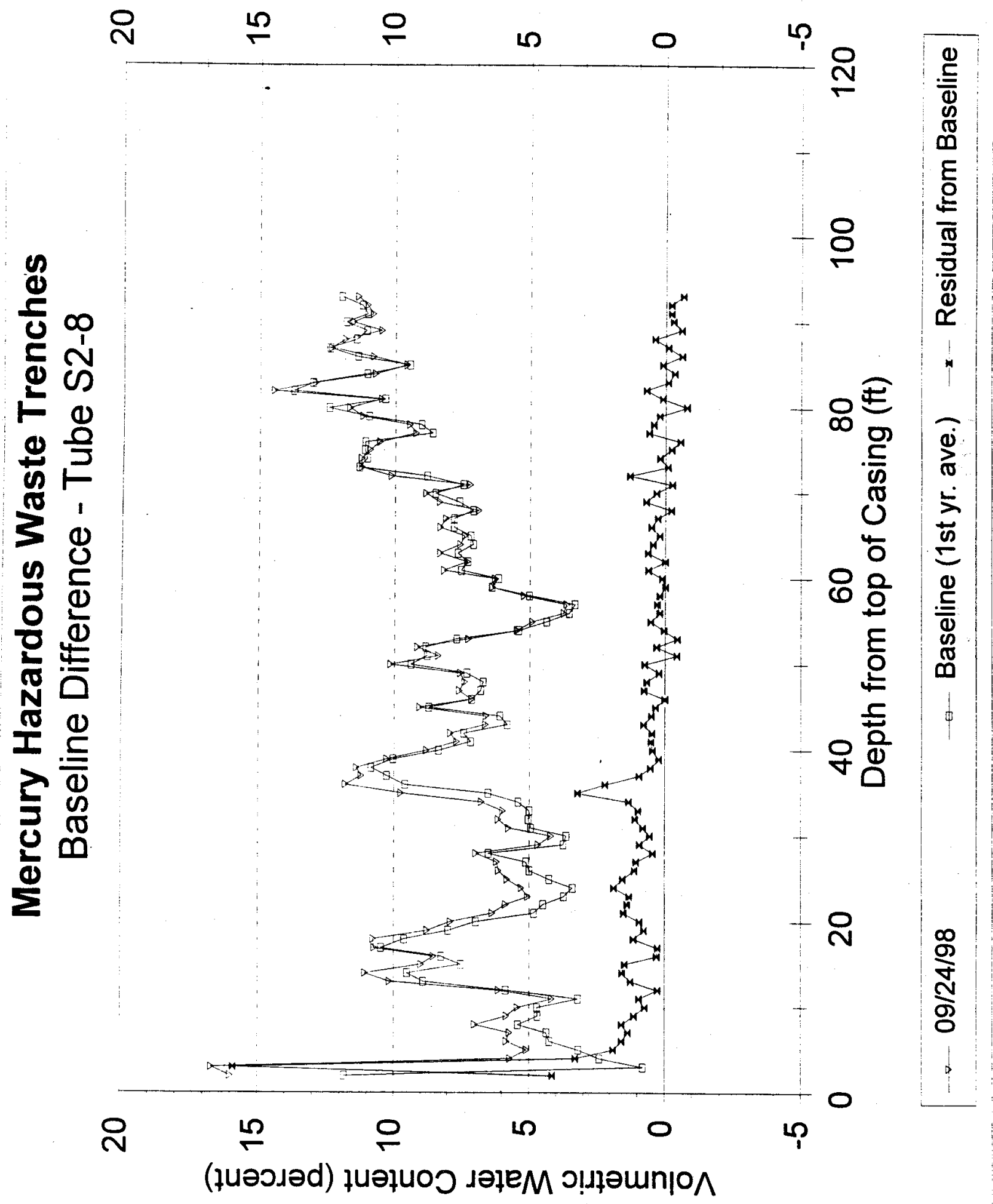




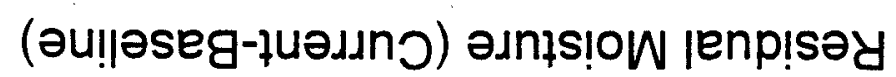

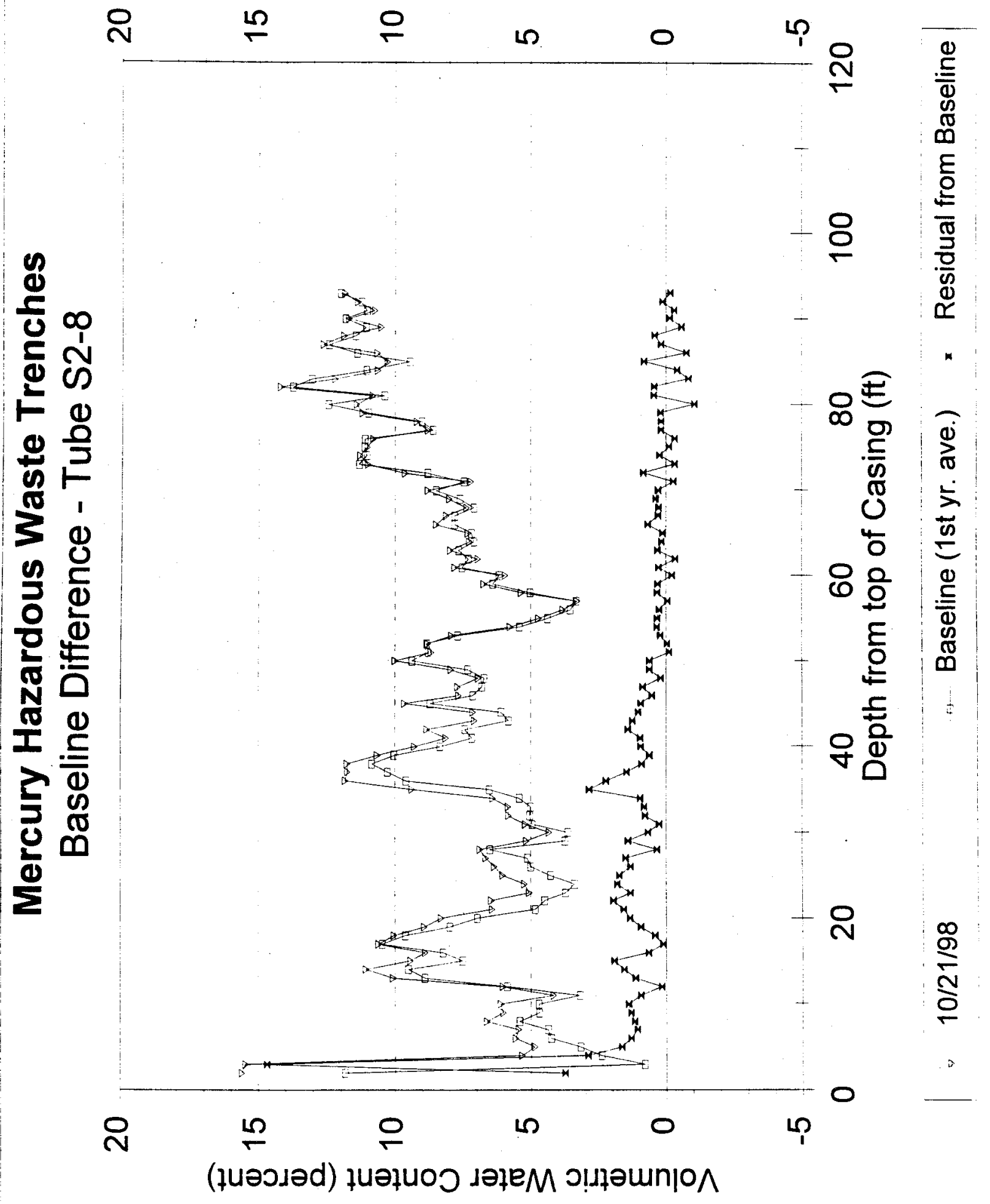




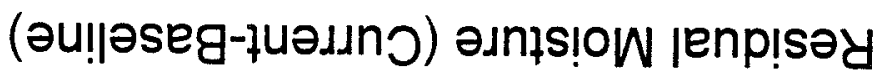

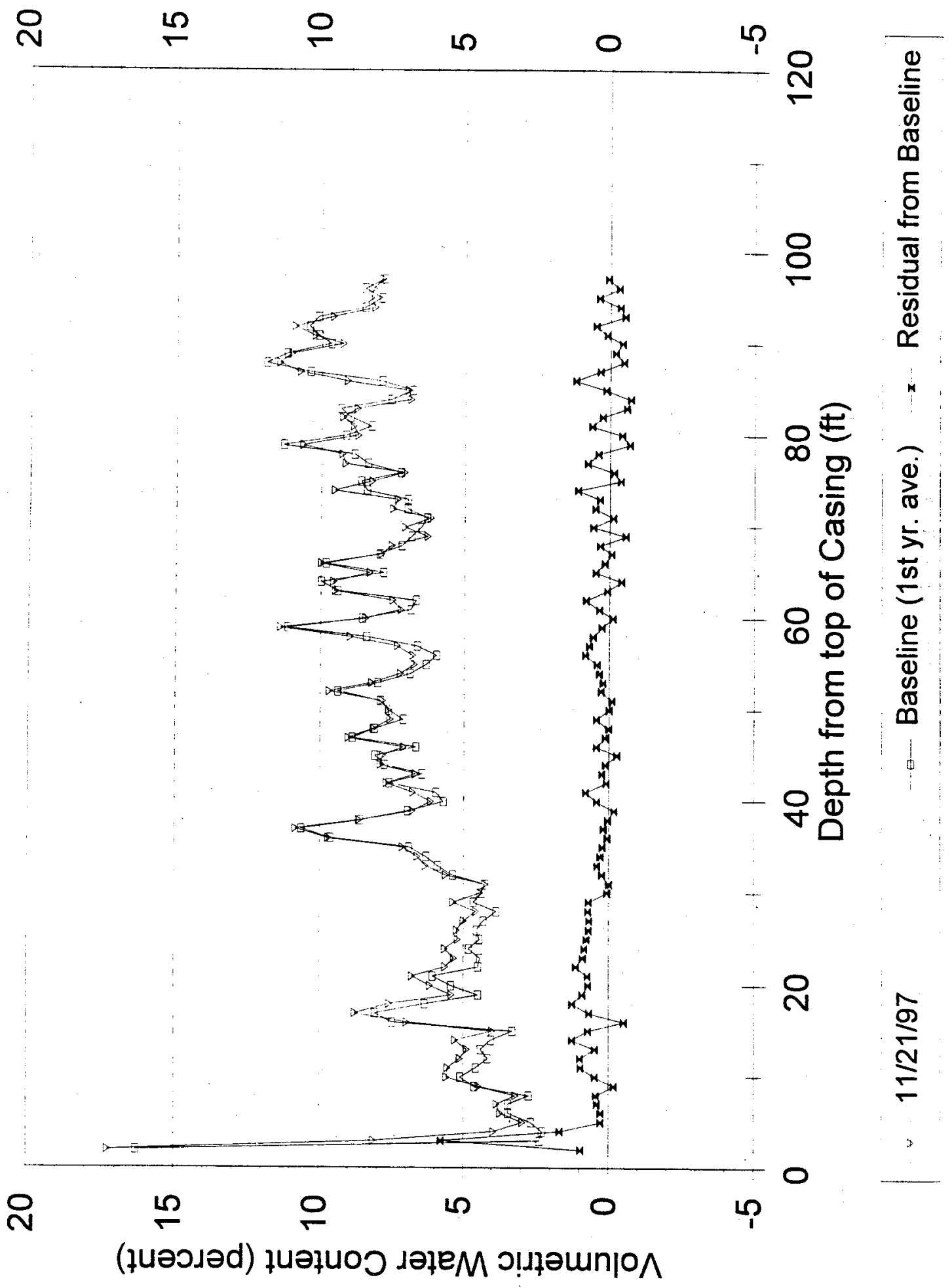




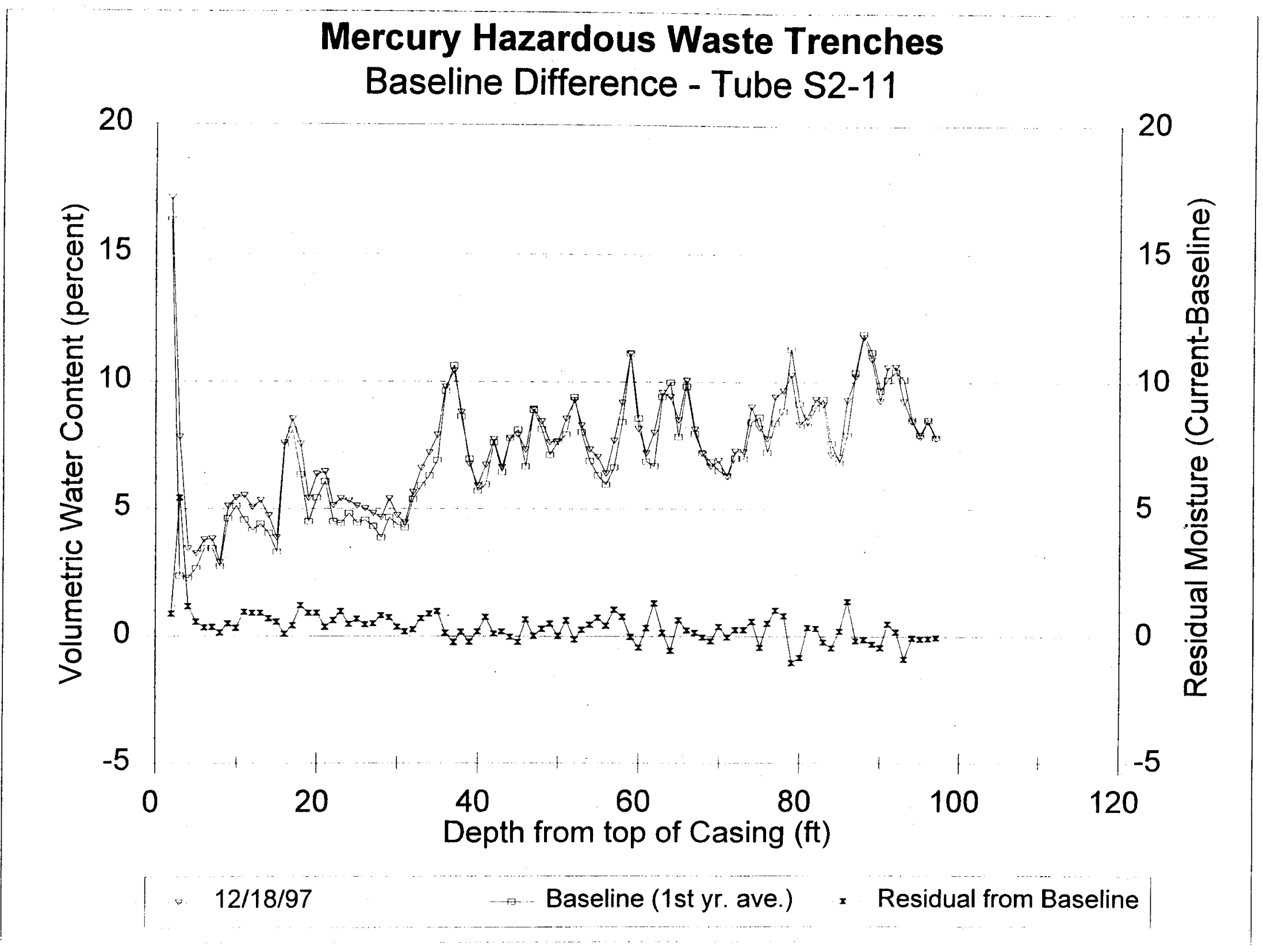




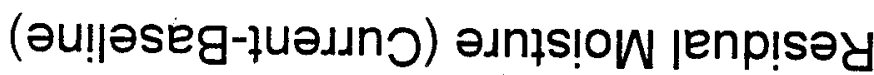
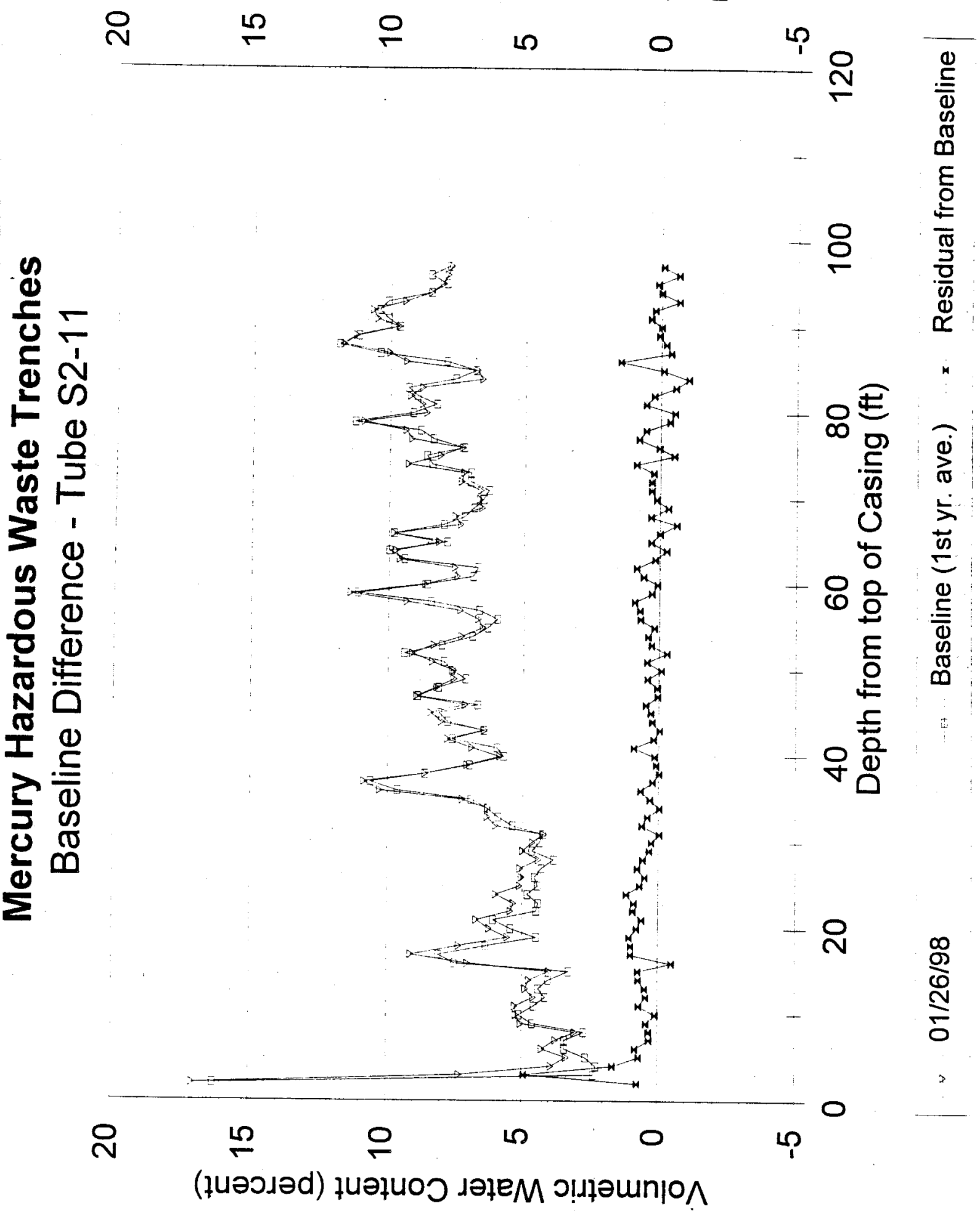

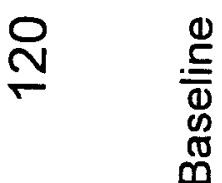

은

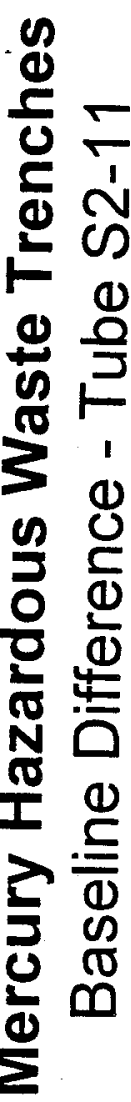




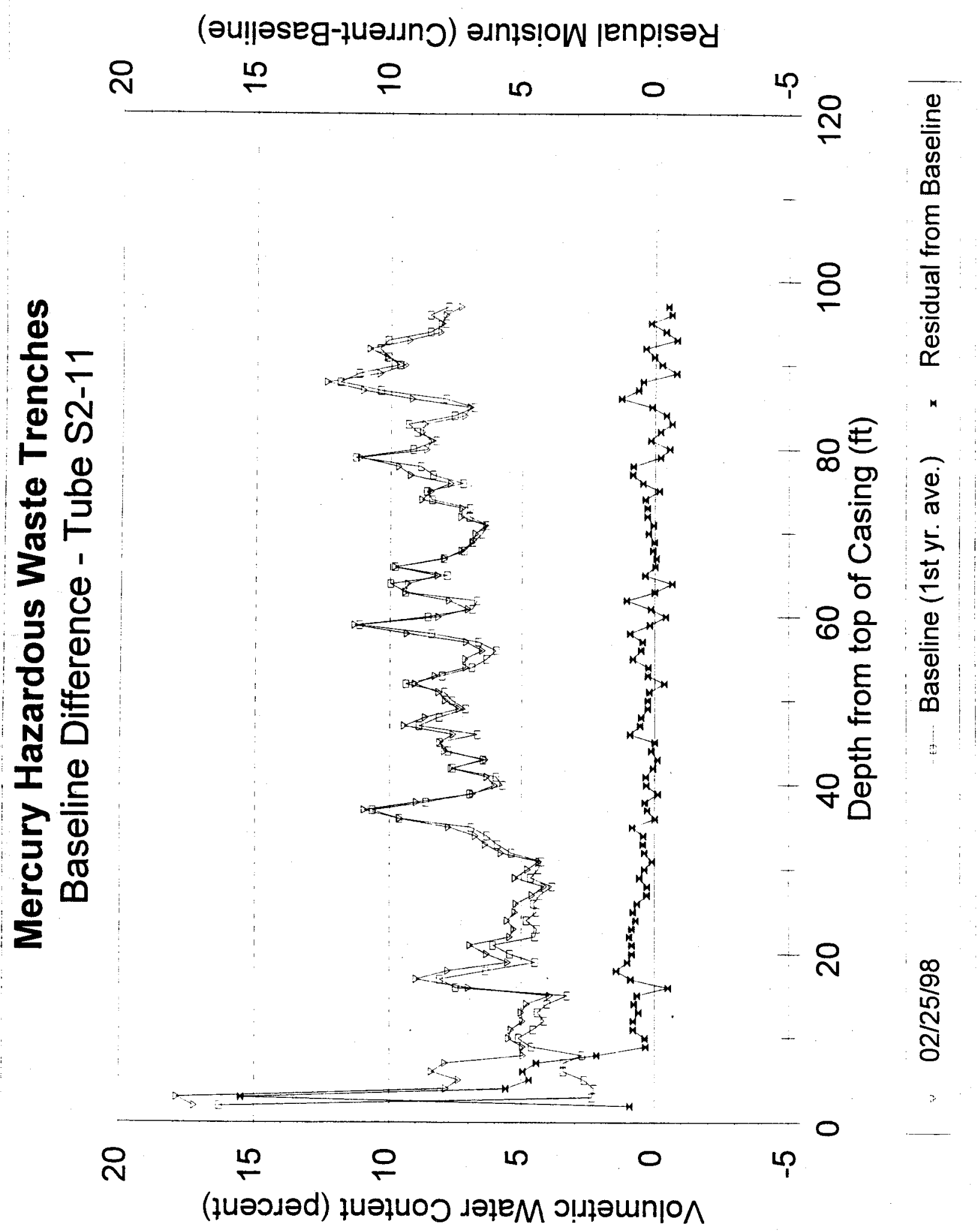




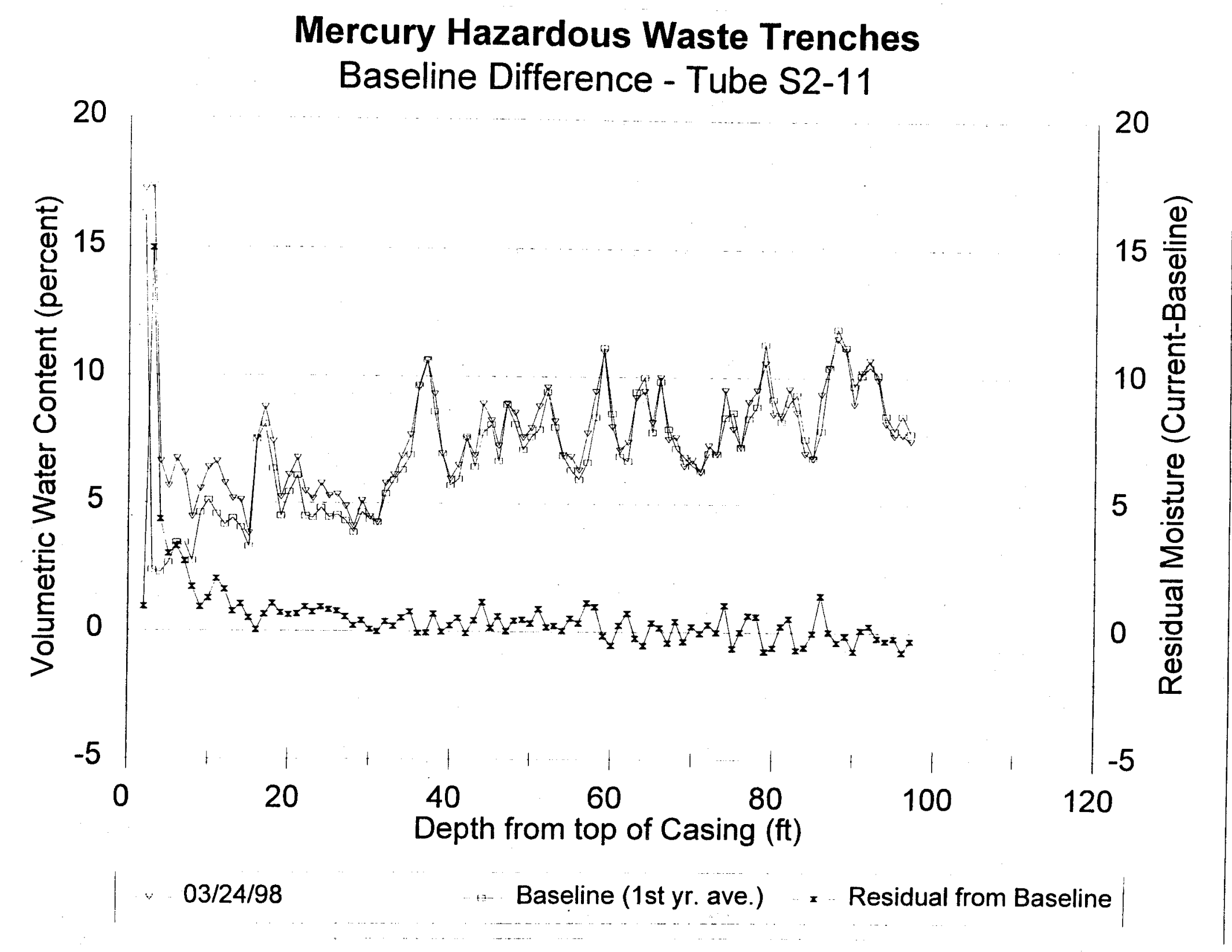




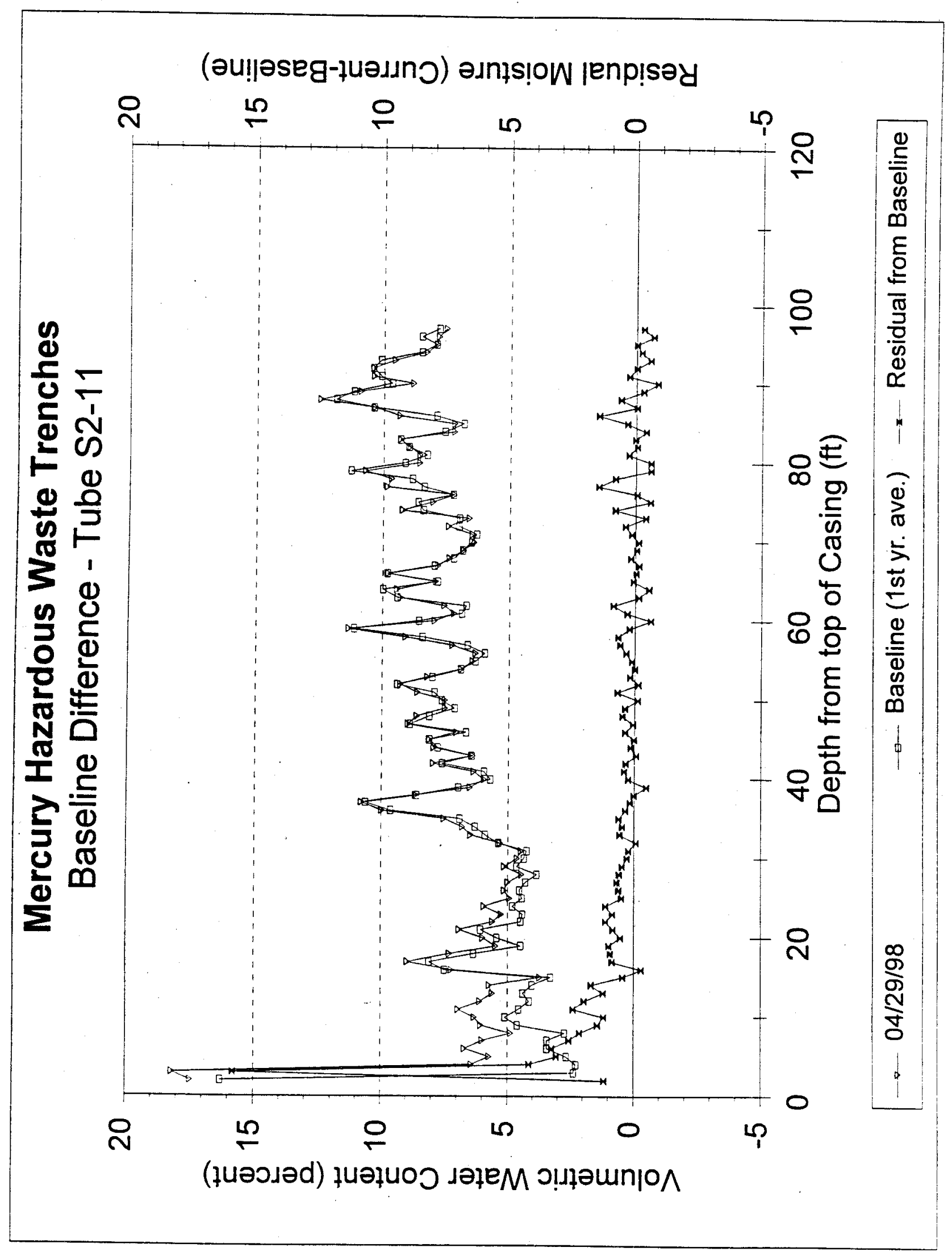




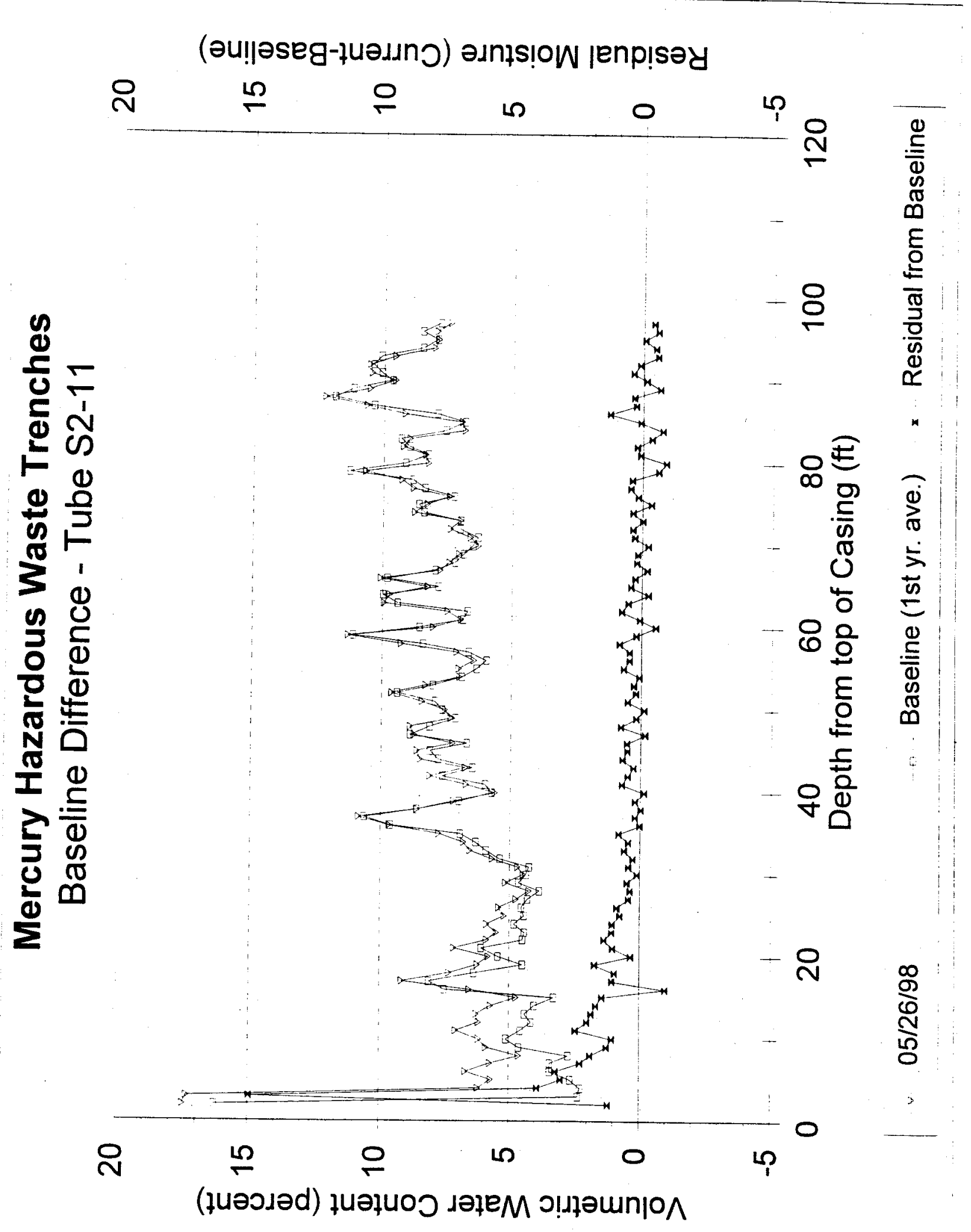




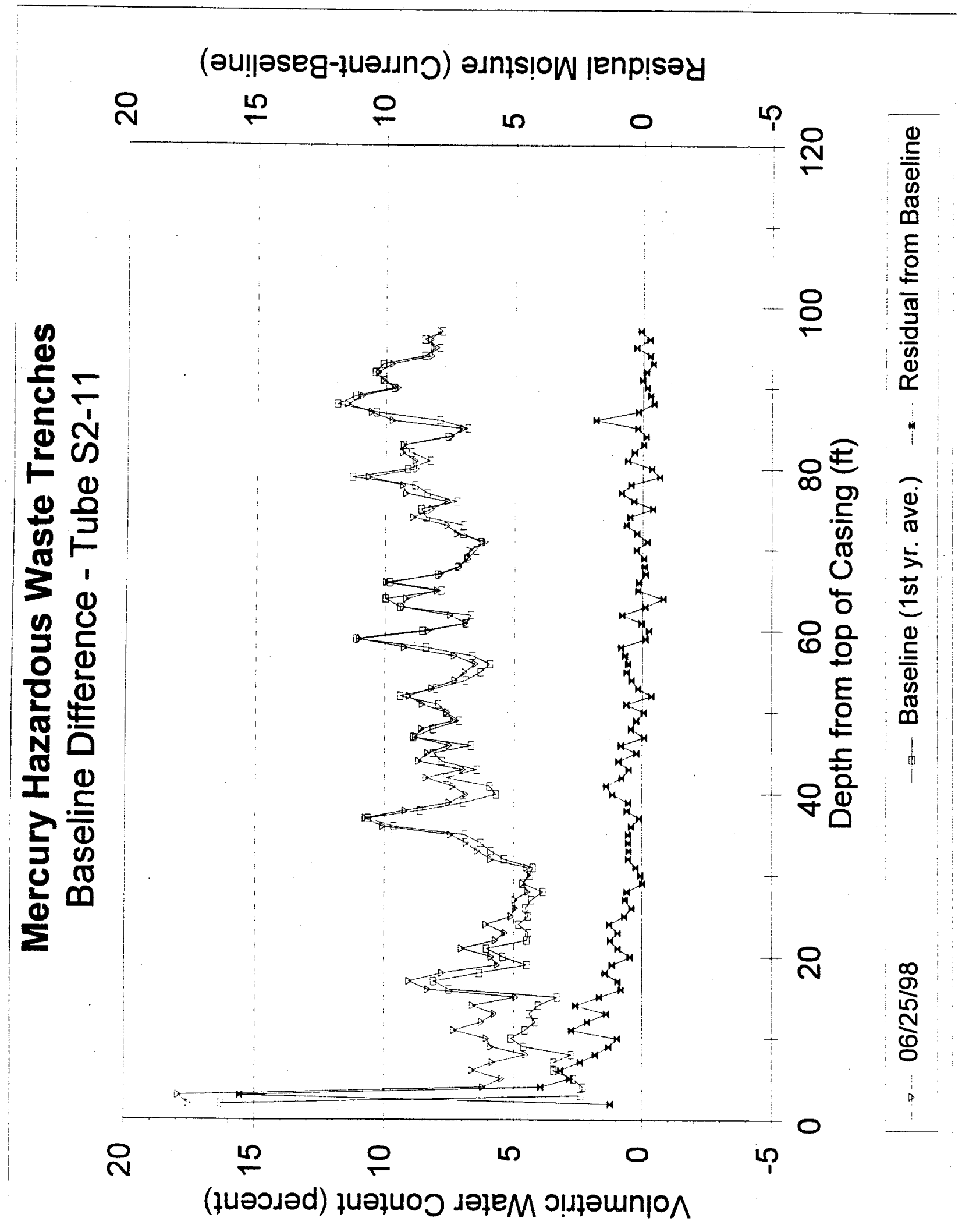




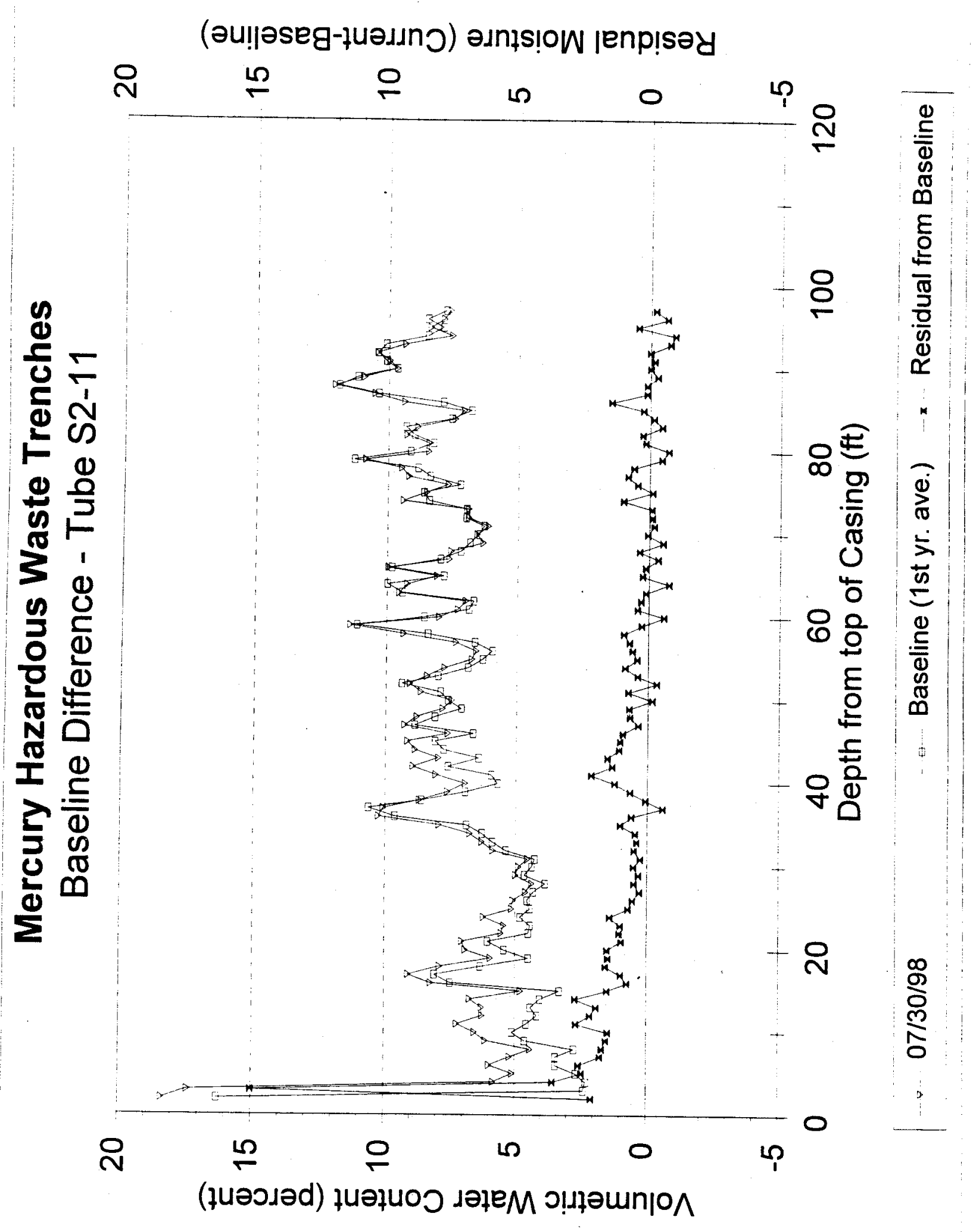




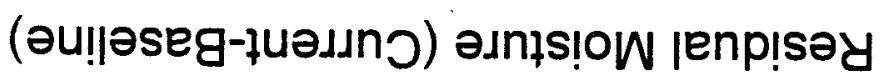

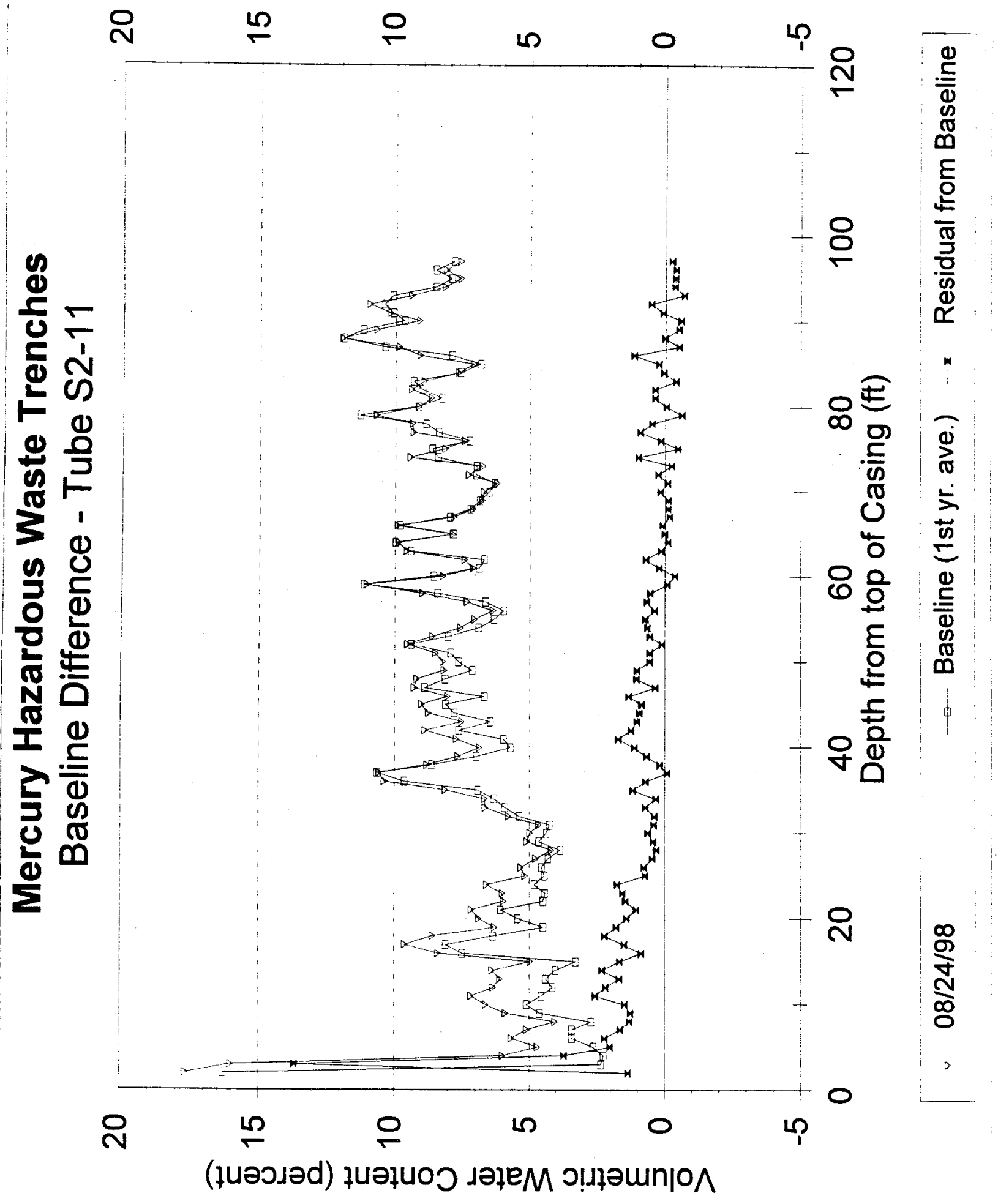




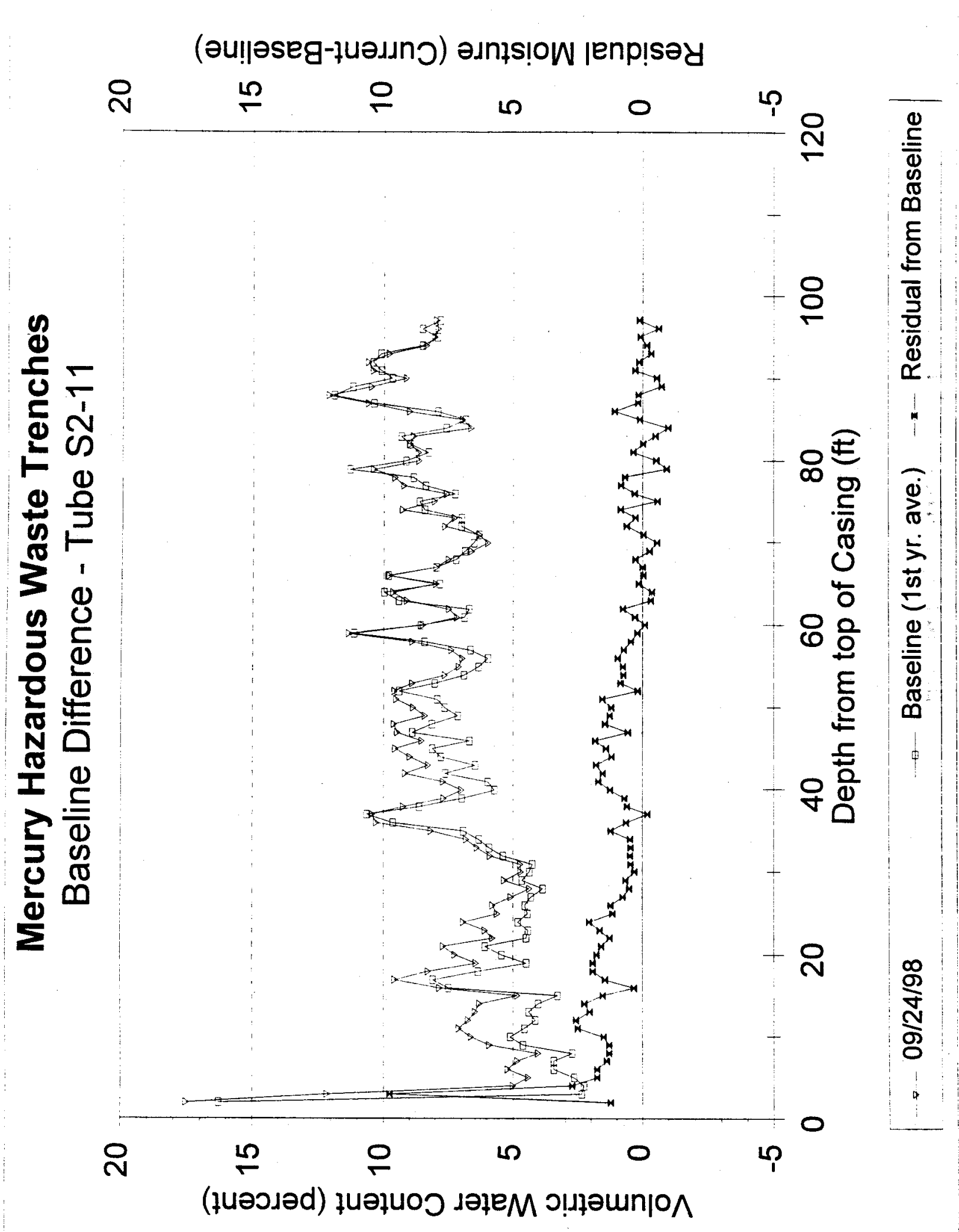




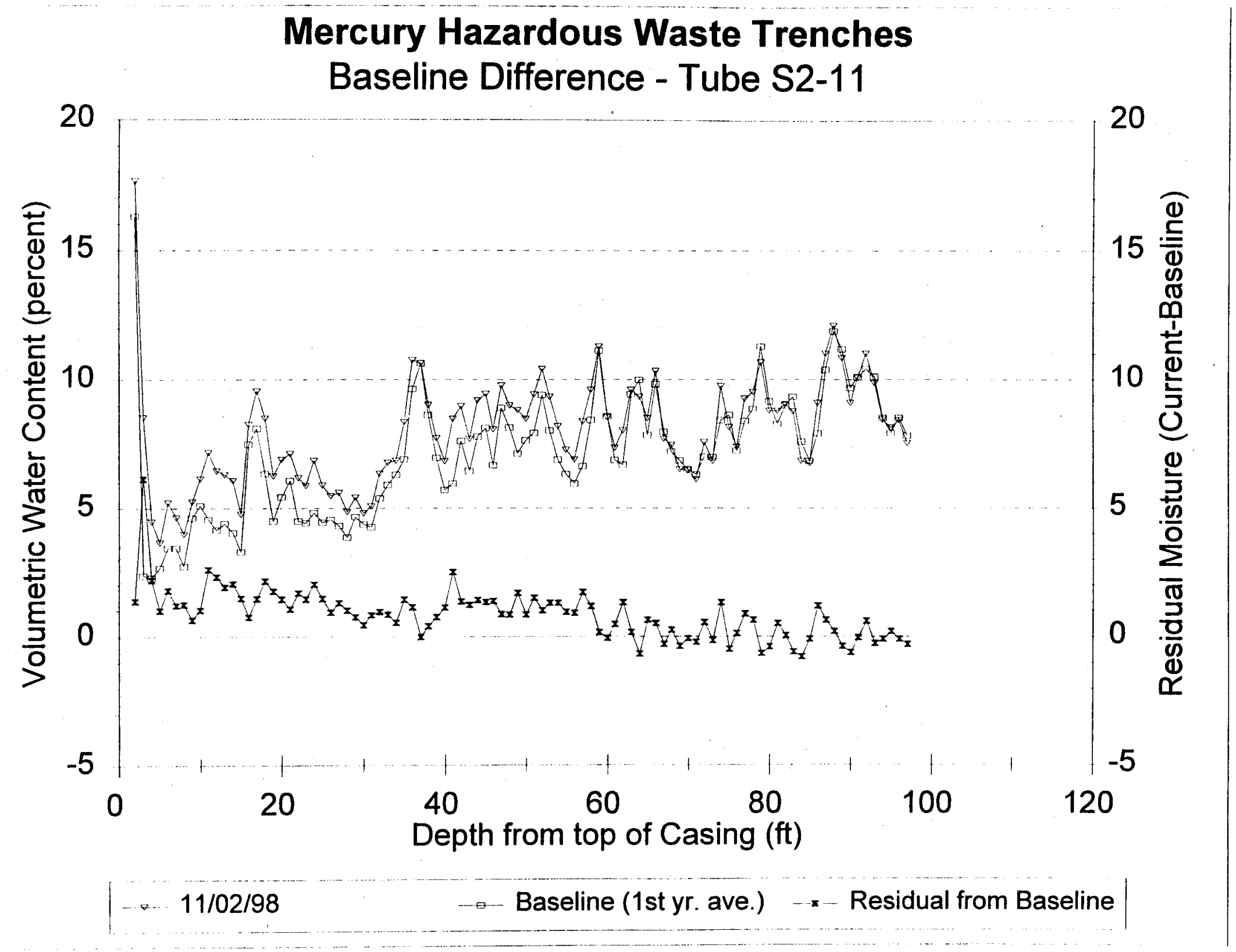




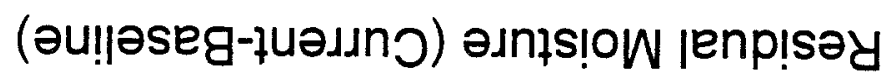

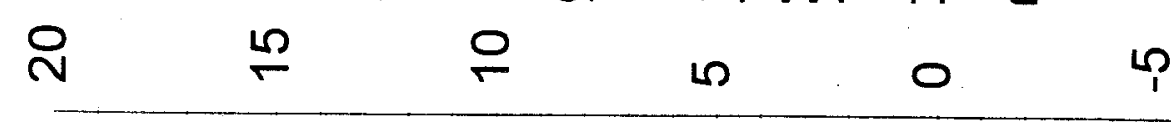

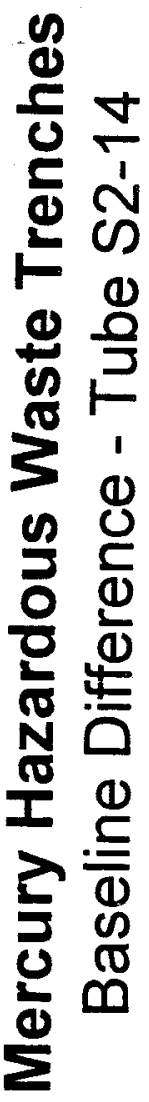

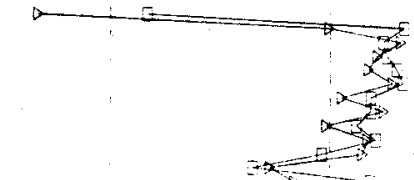

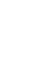

(1) 


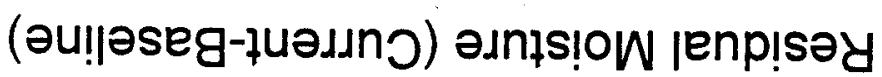

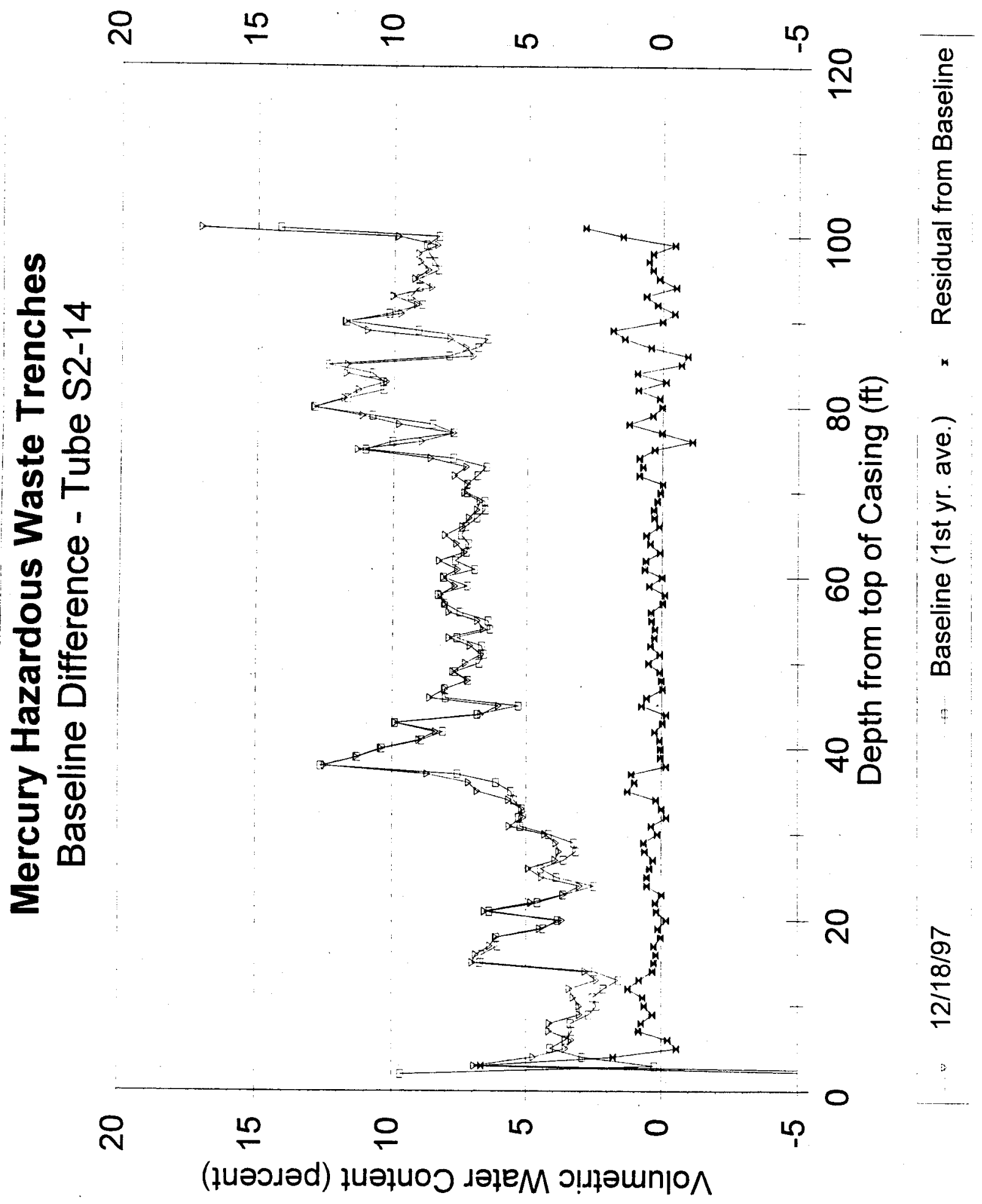




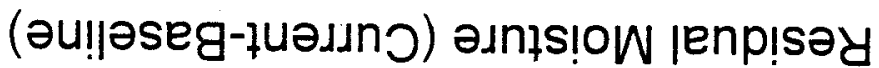
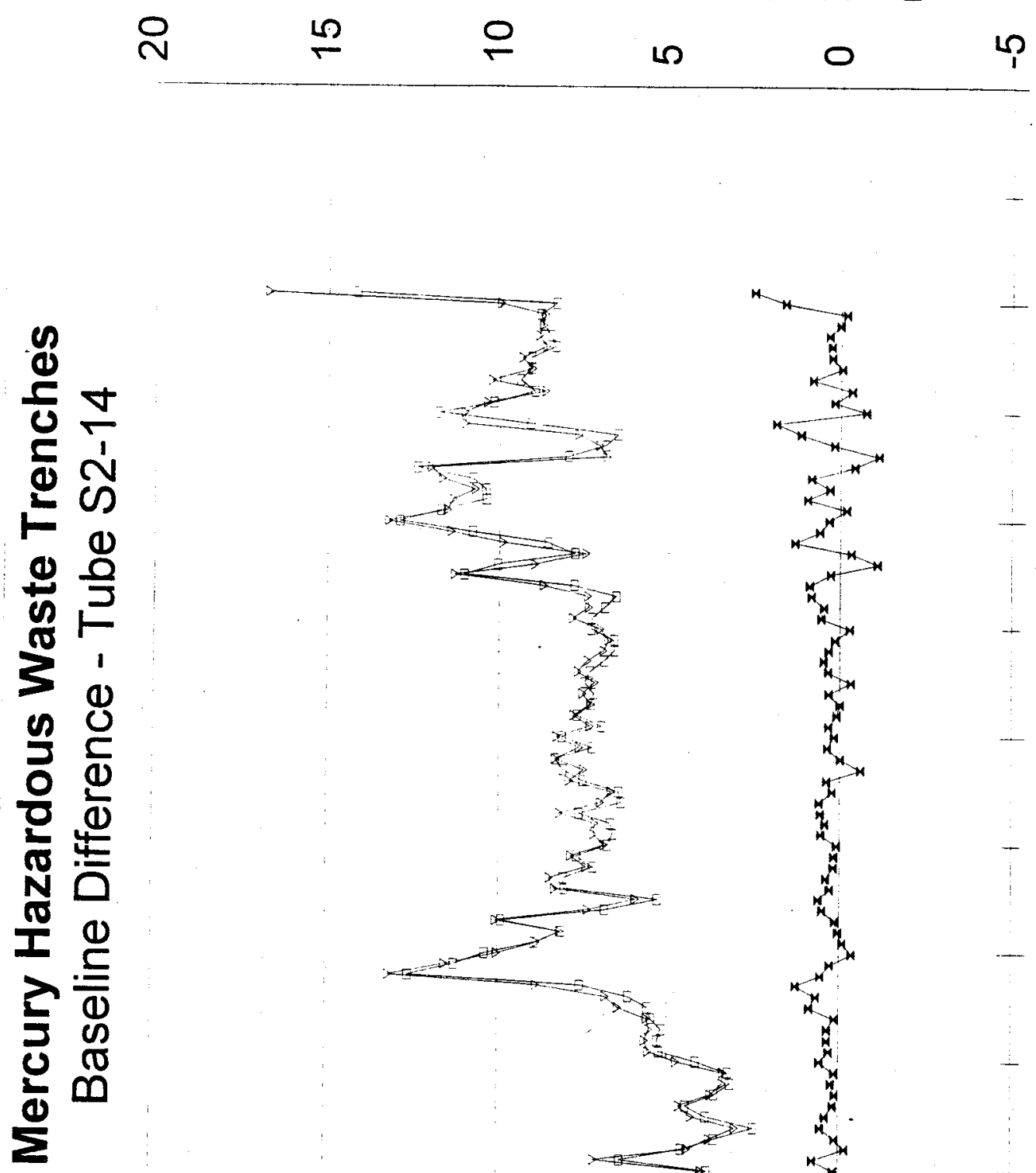
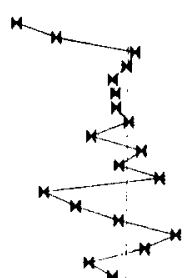

$-\stackrel{\circ}{\circ}$

$\stackrel{2}{\stackrel{2}{2}}$

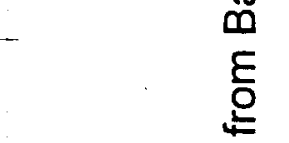

$\div \infty$

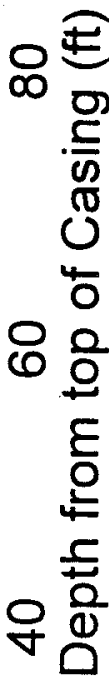

ㅇ

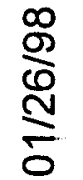

요

$\stackrel{2}{2}$

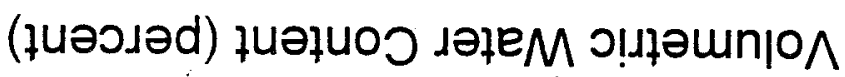




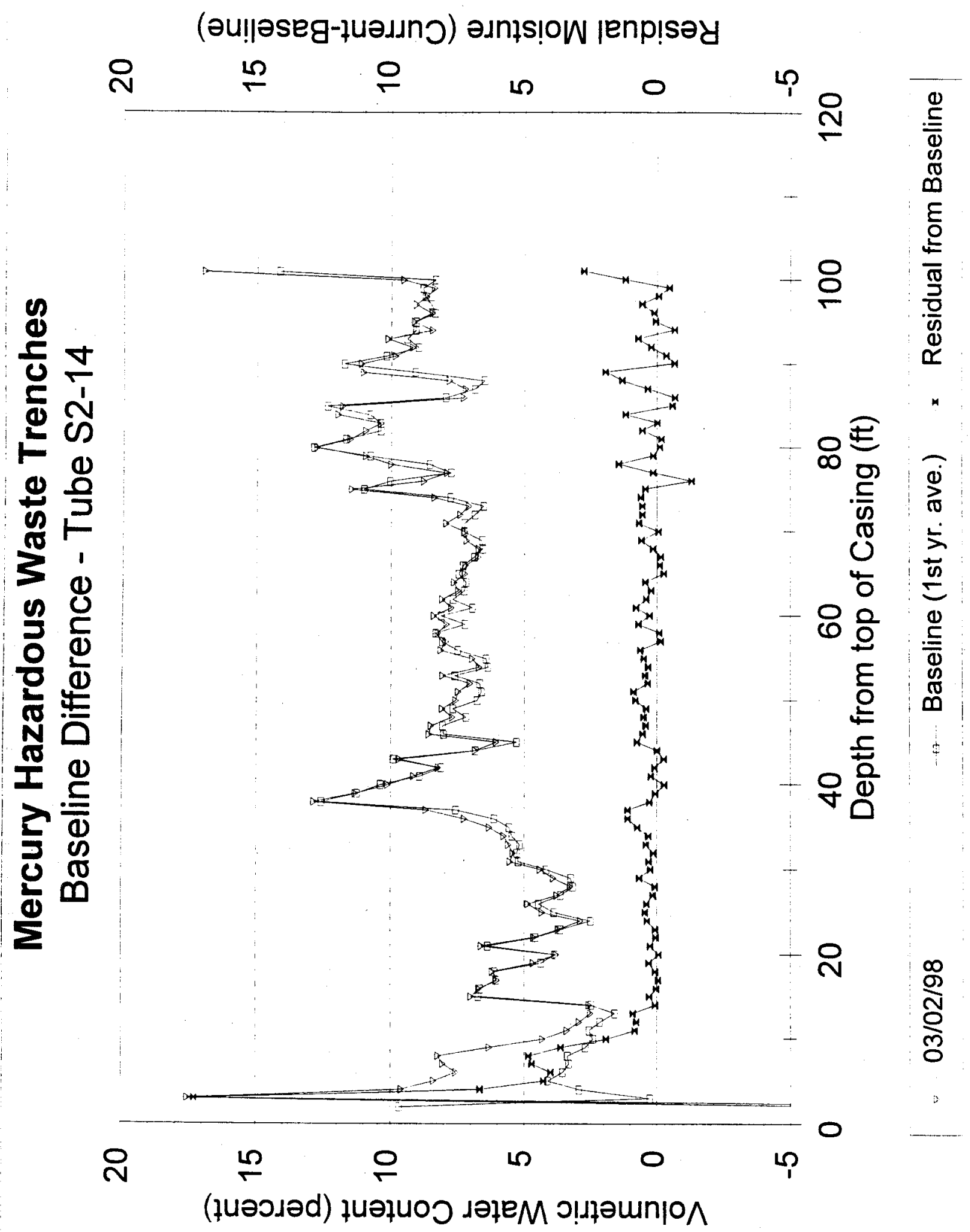




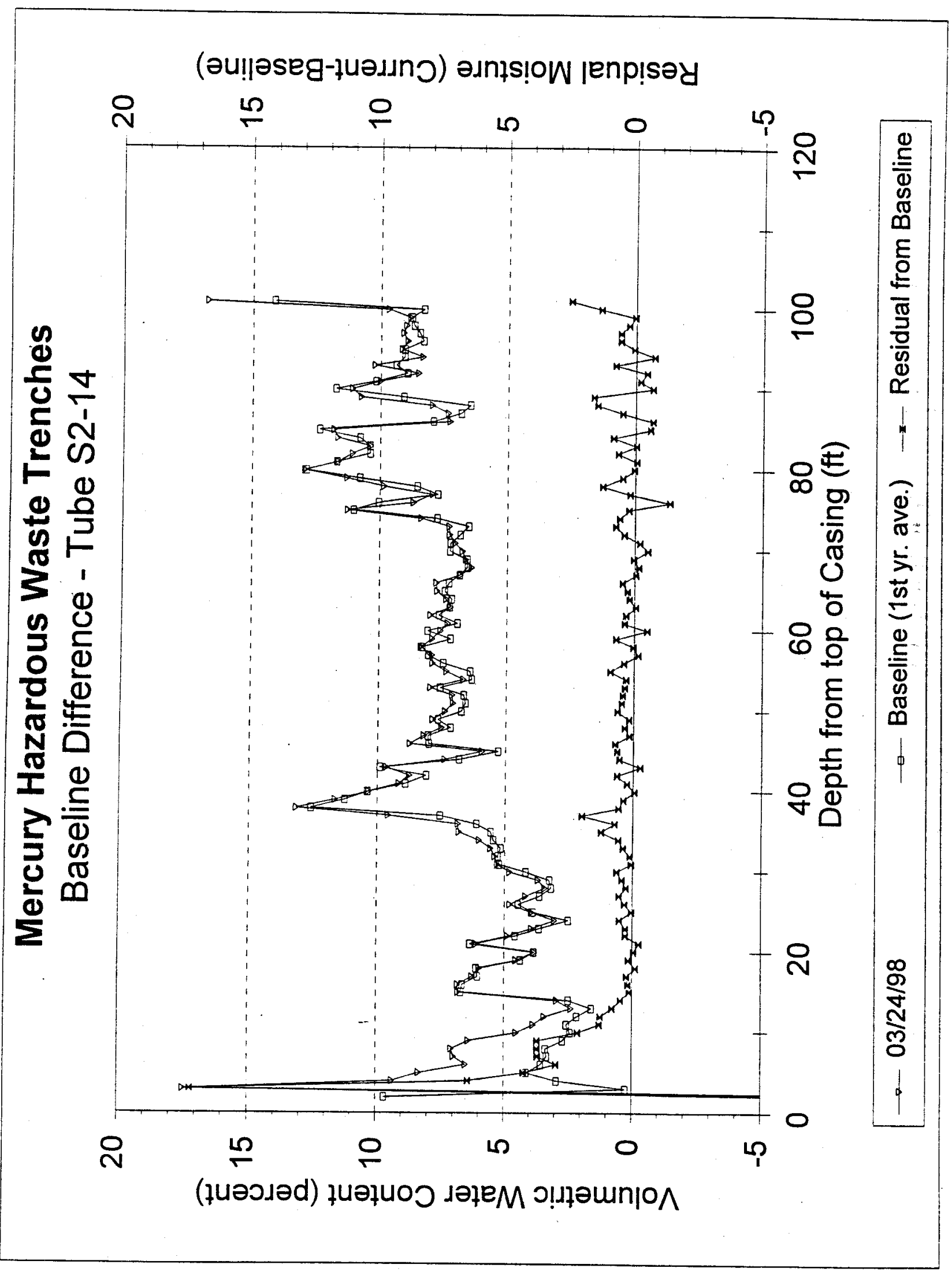




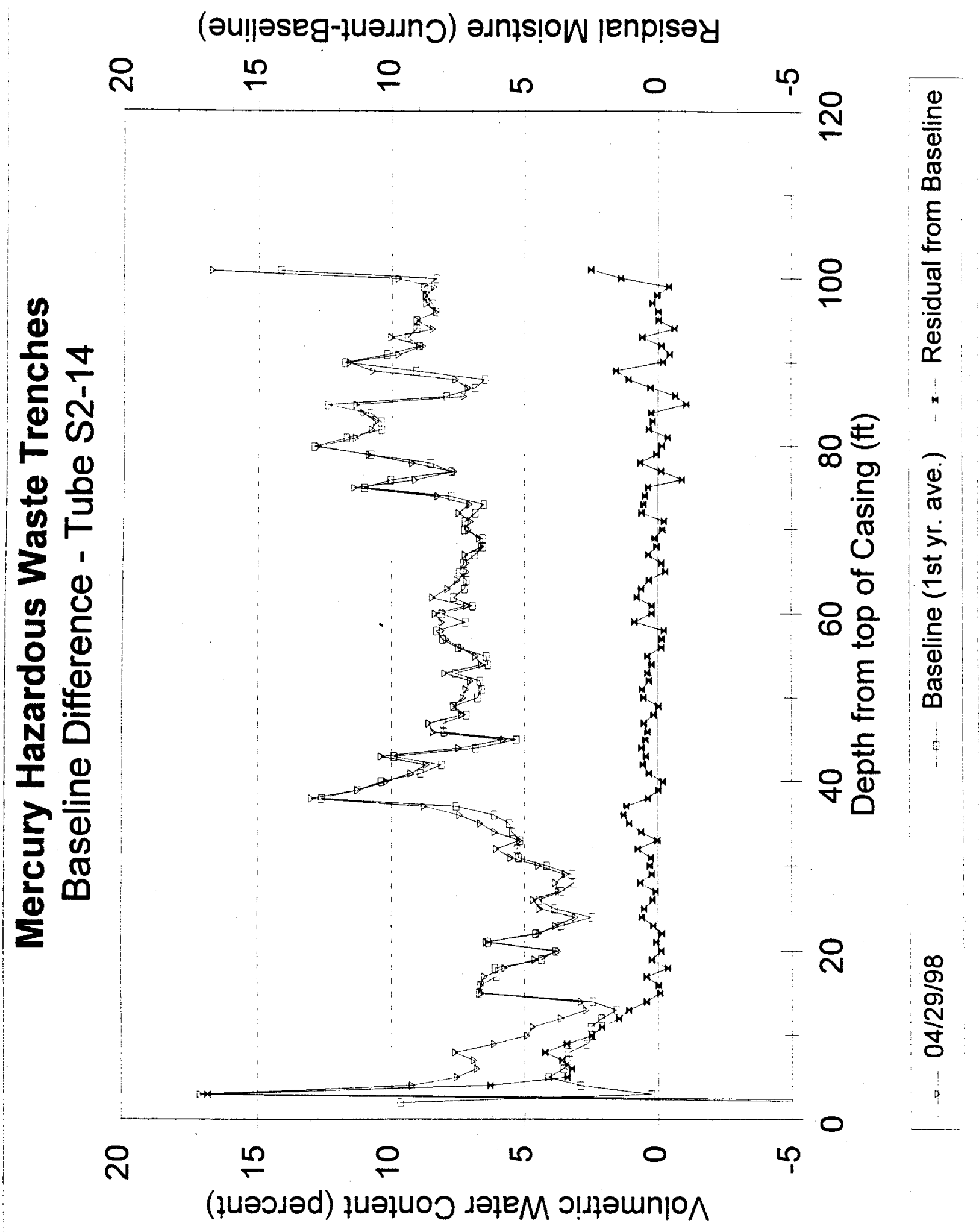




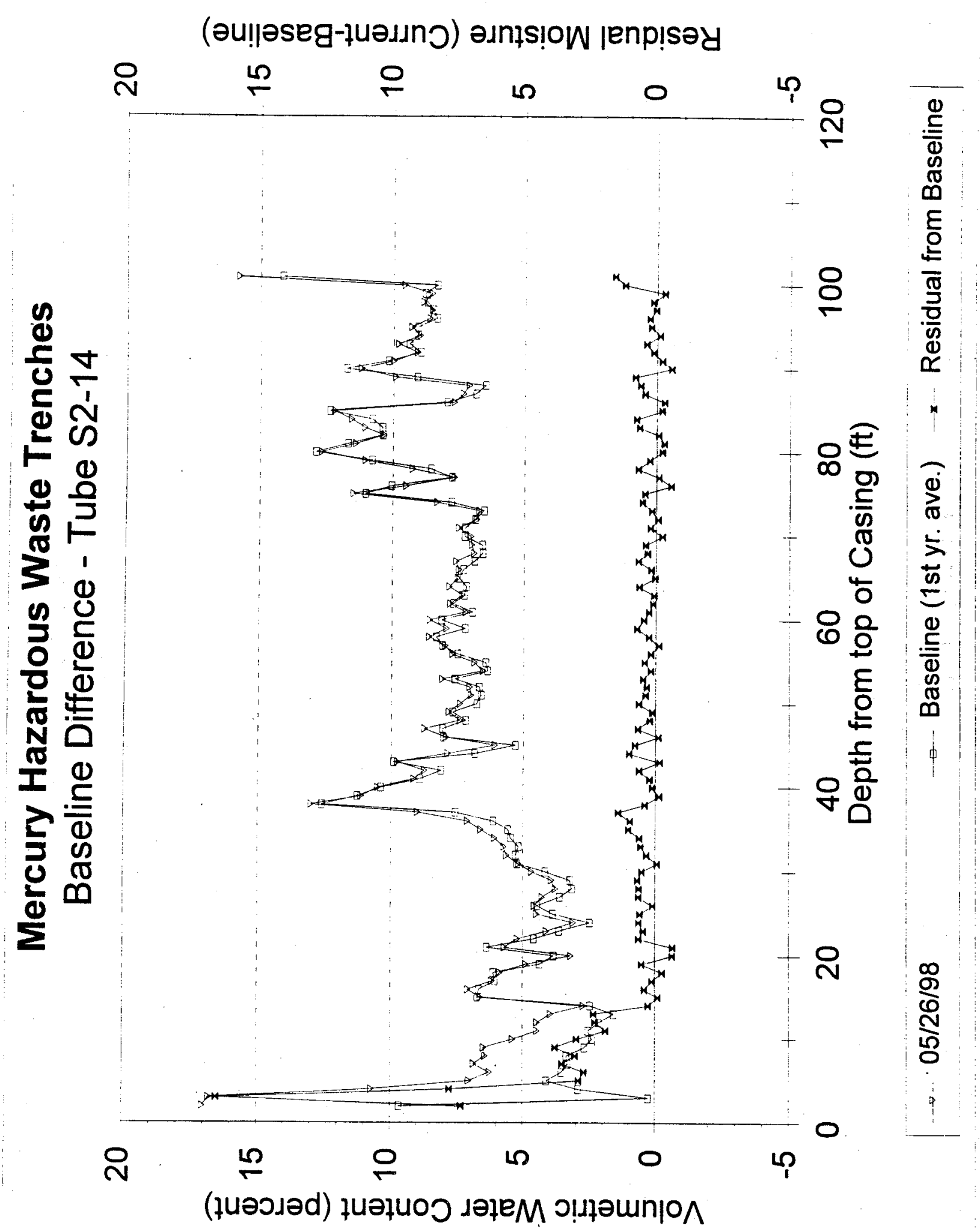




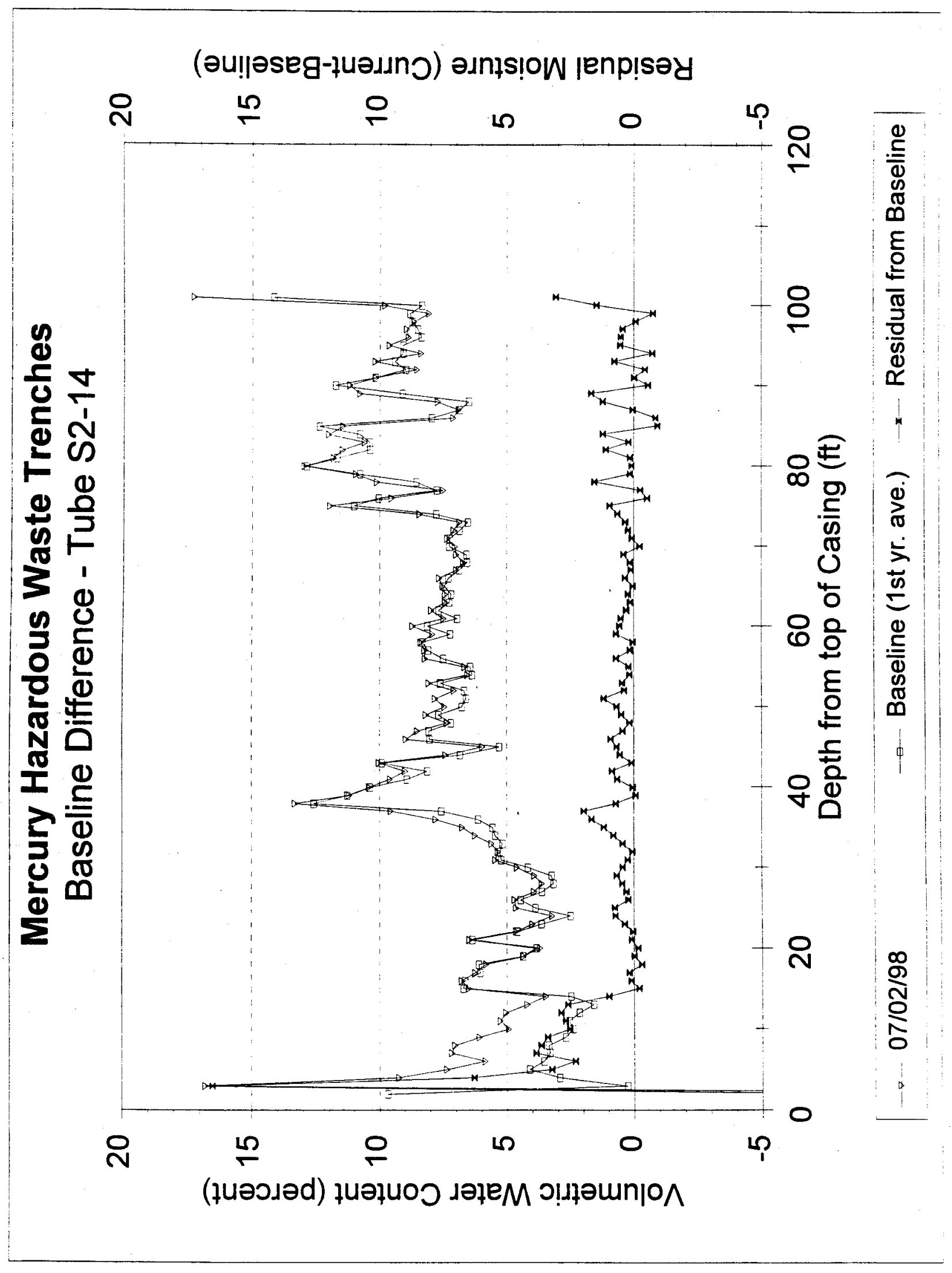




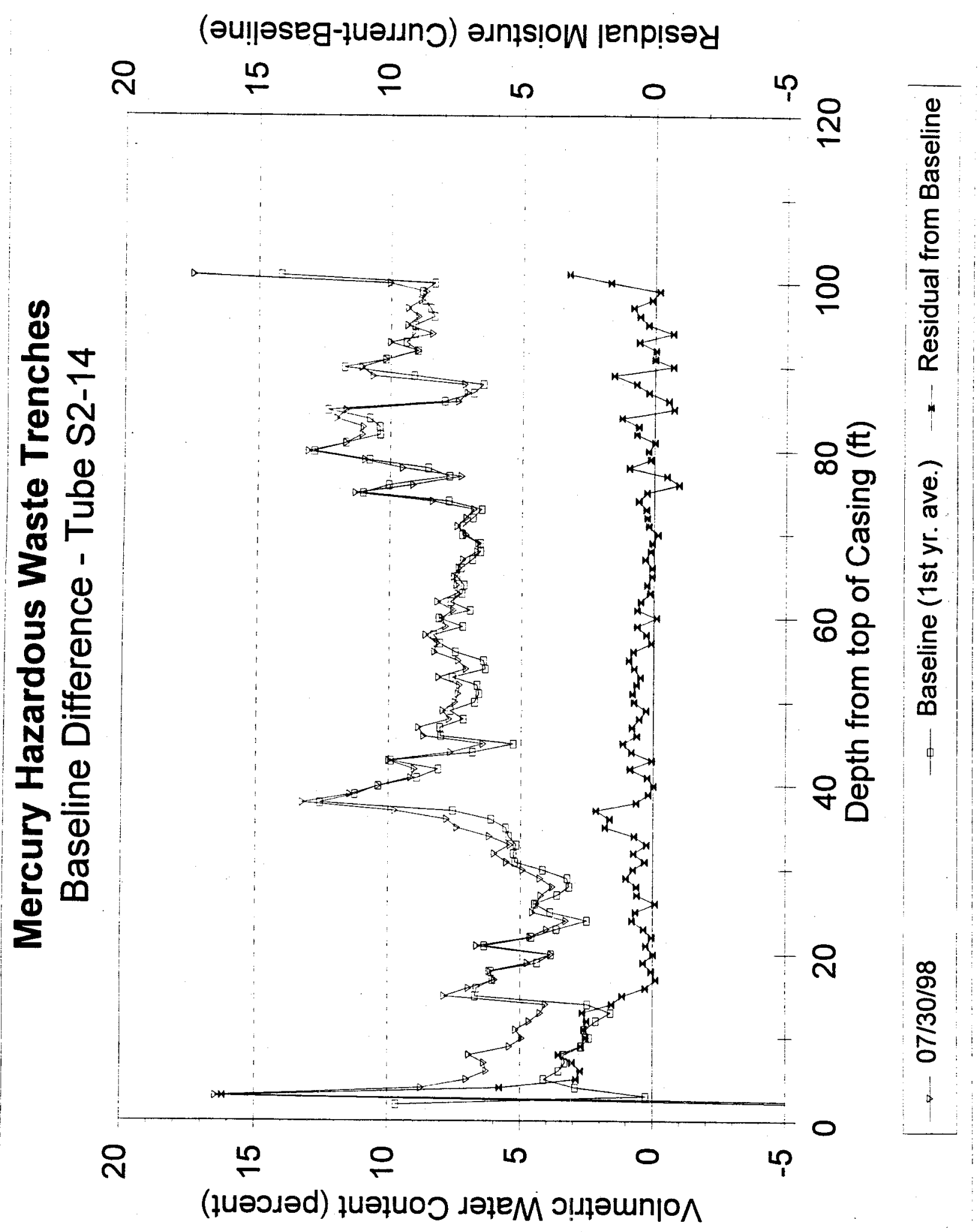




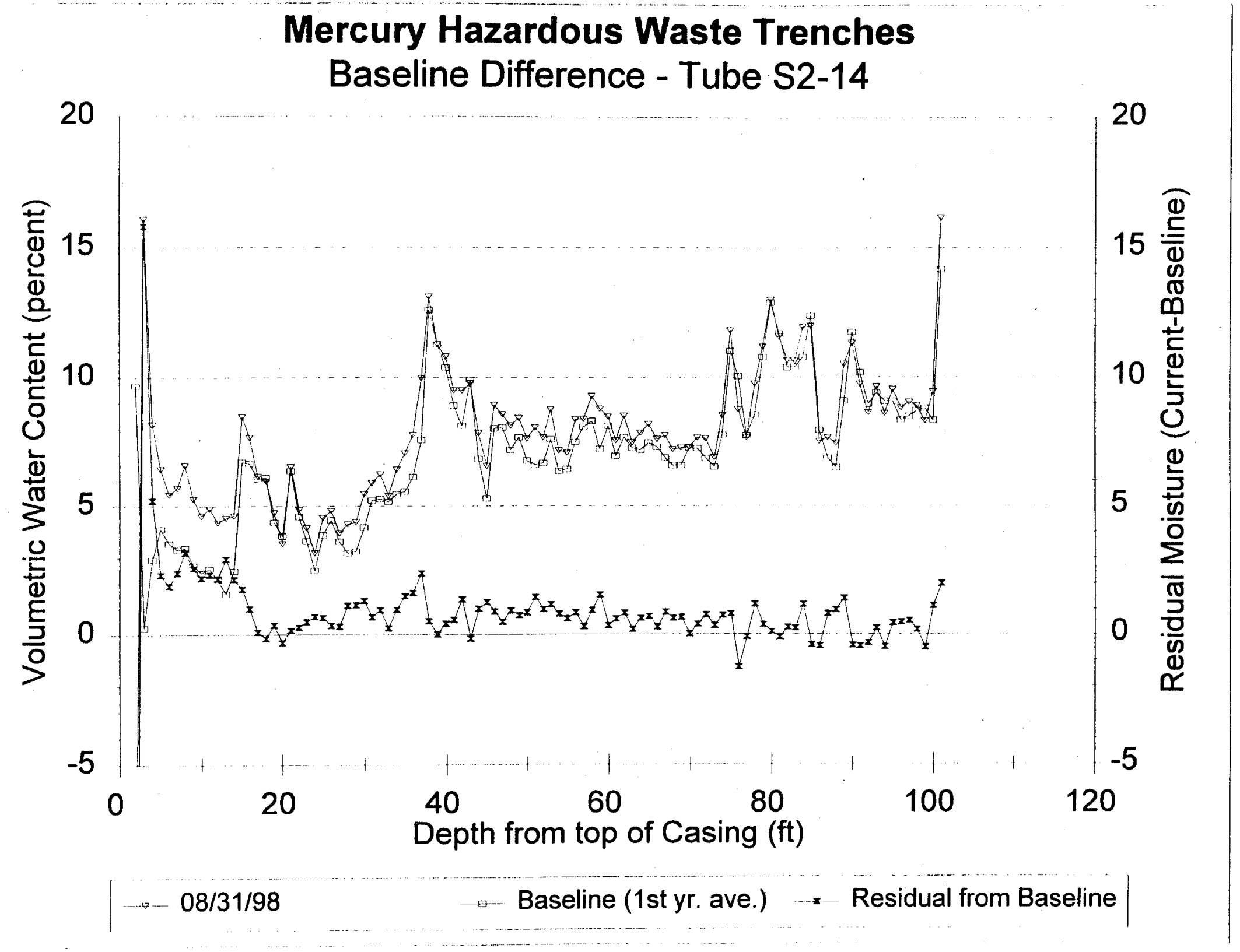




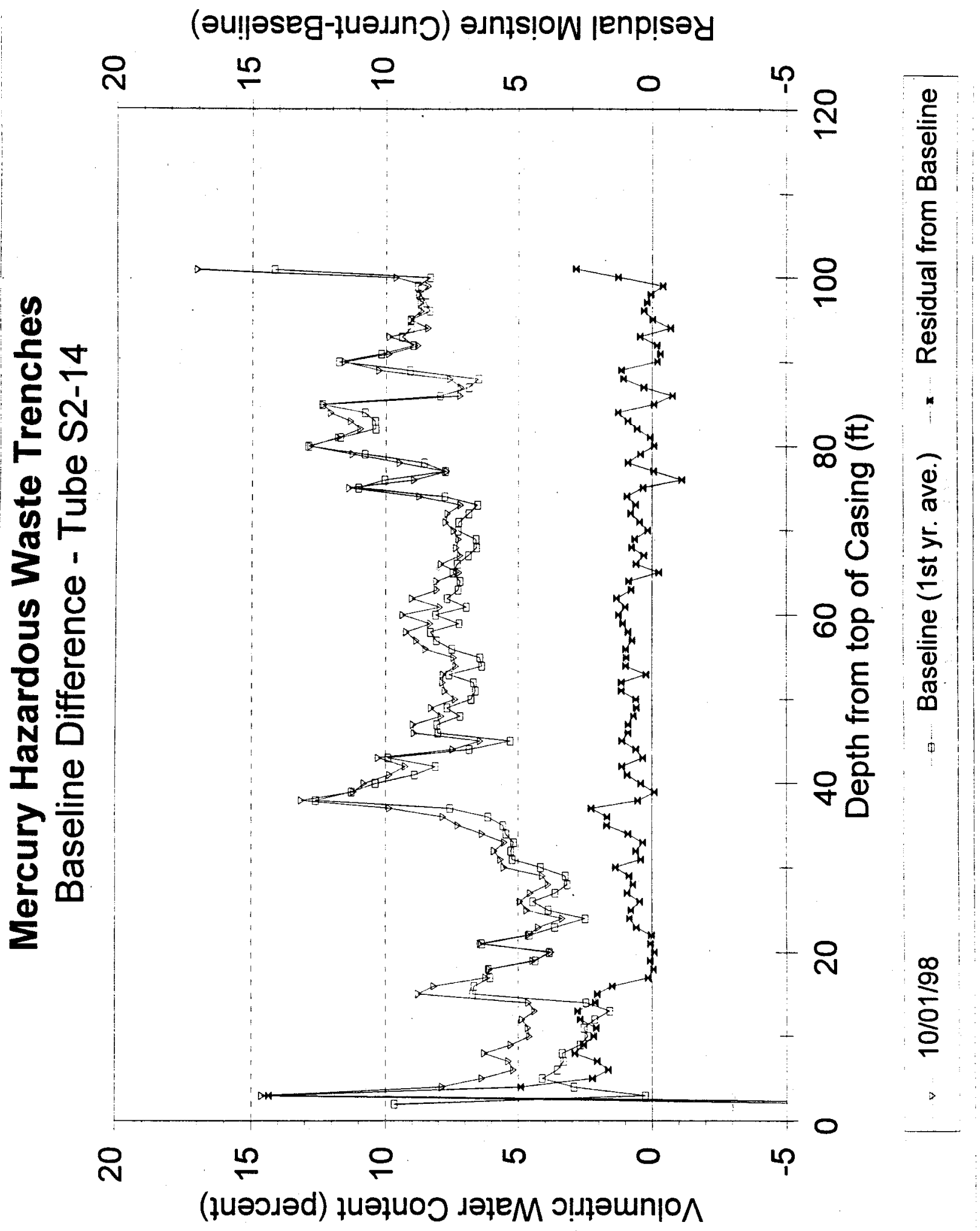




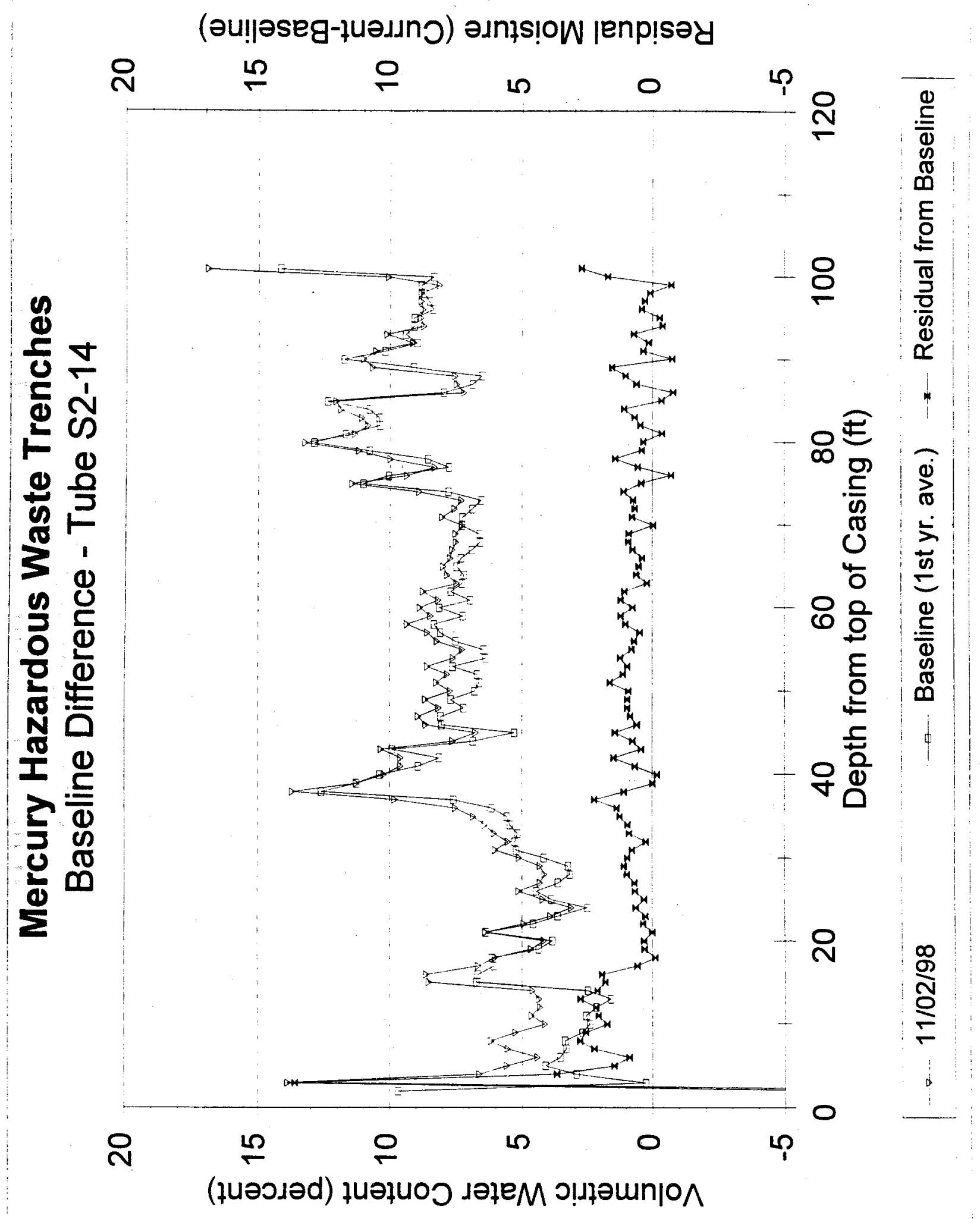




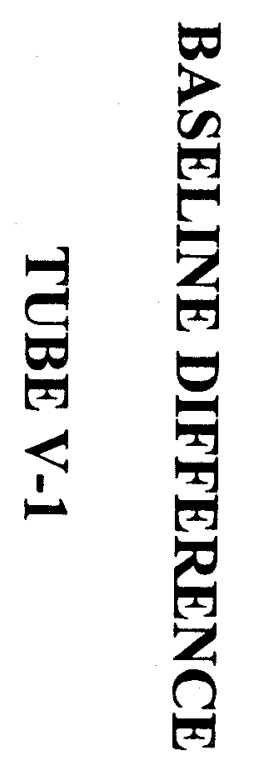




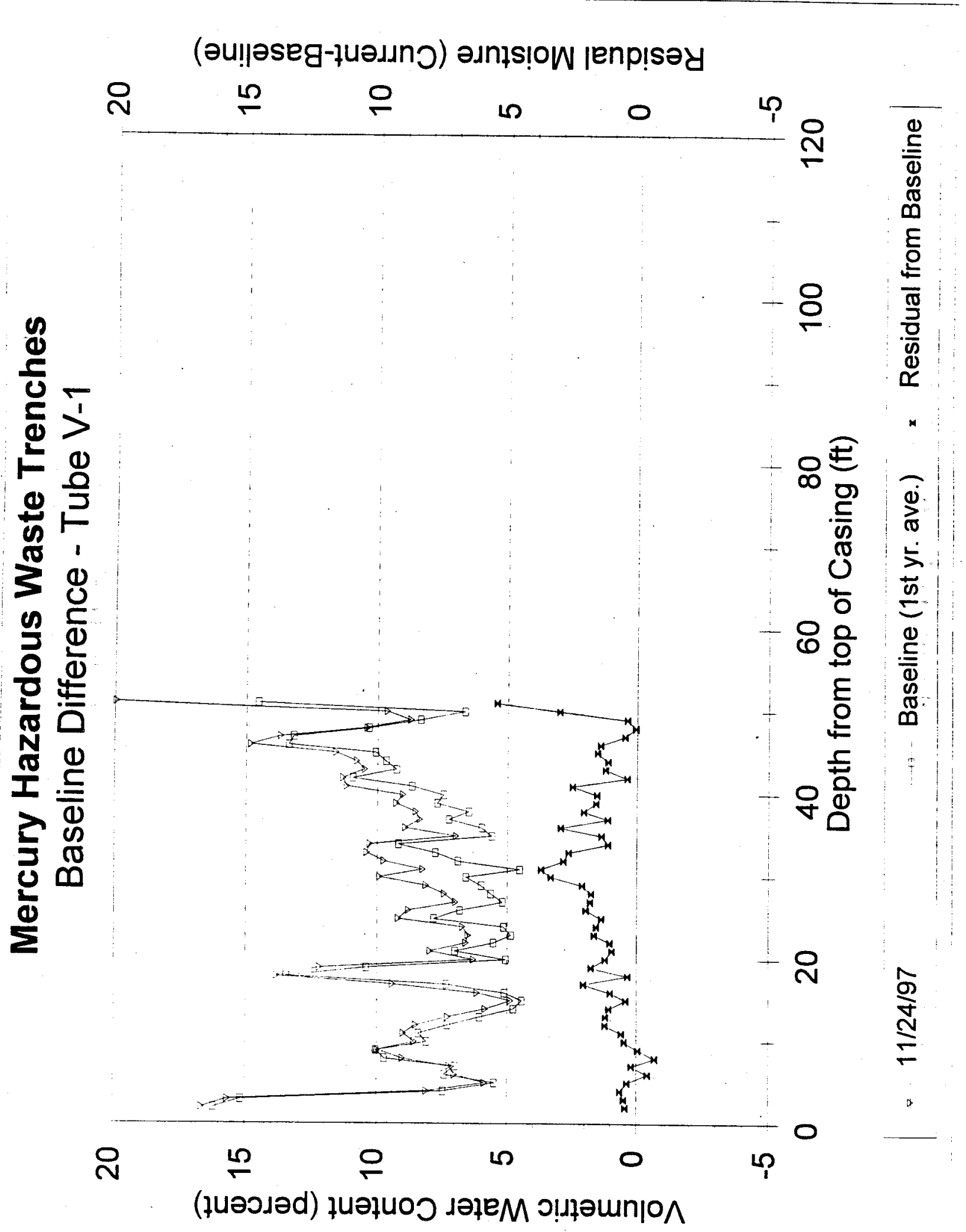




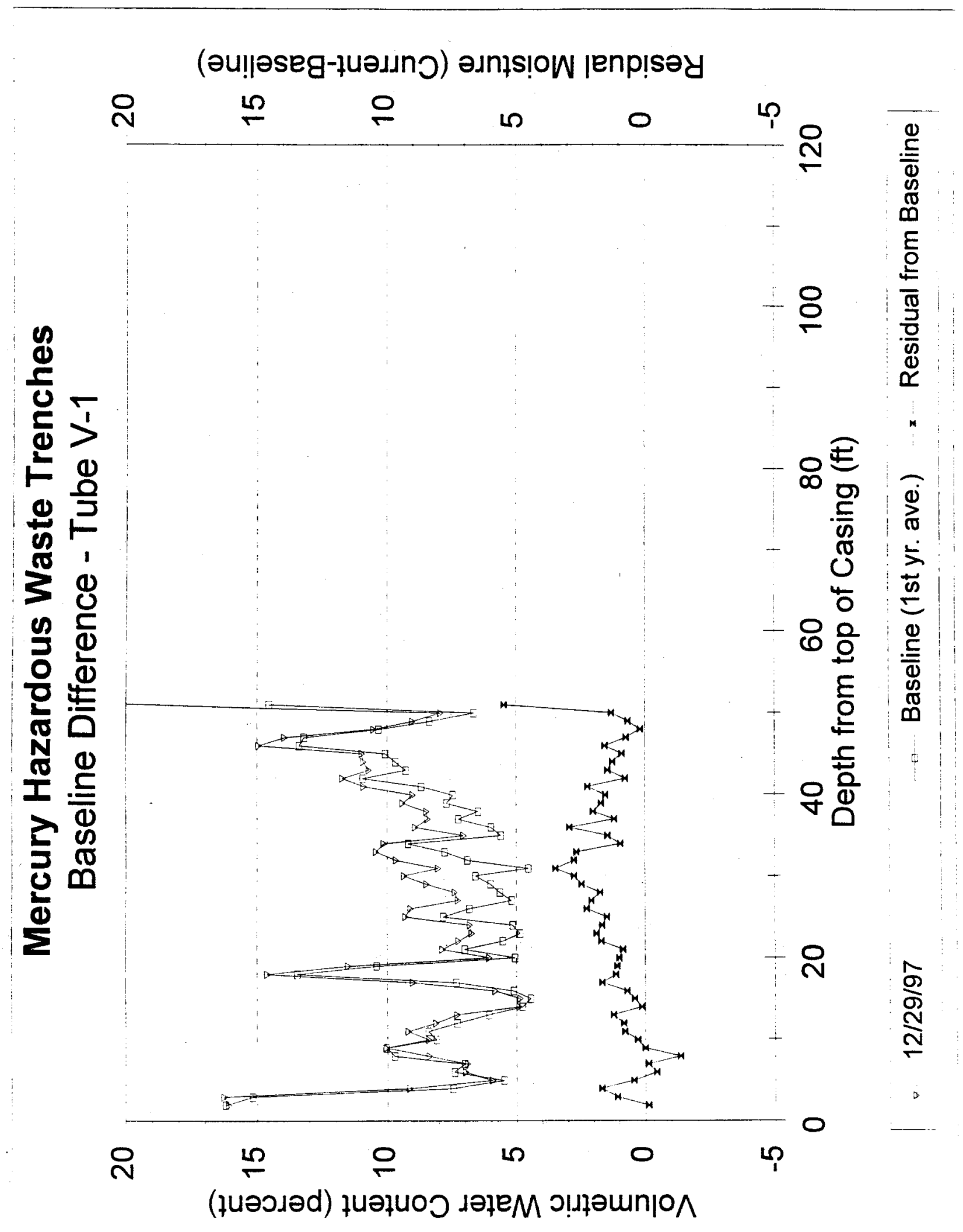




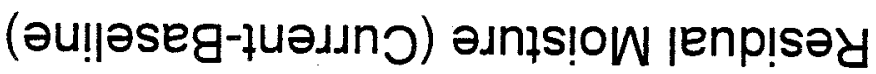
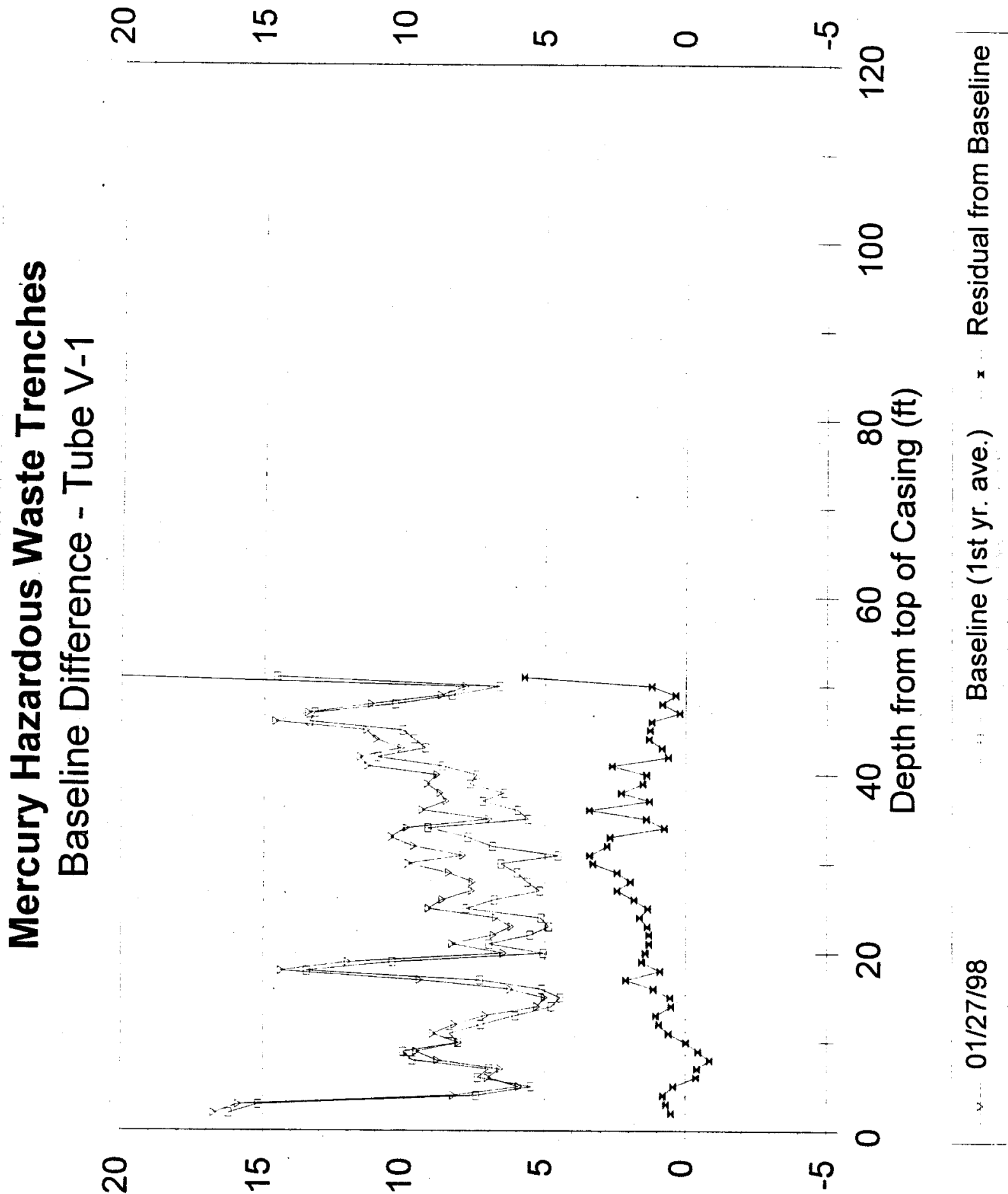

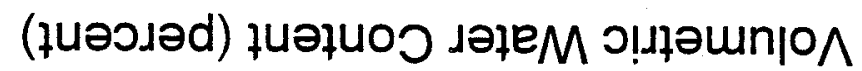




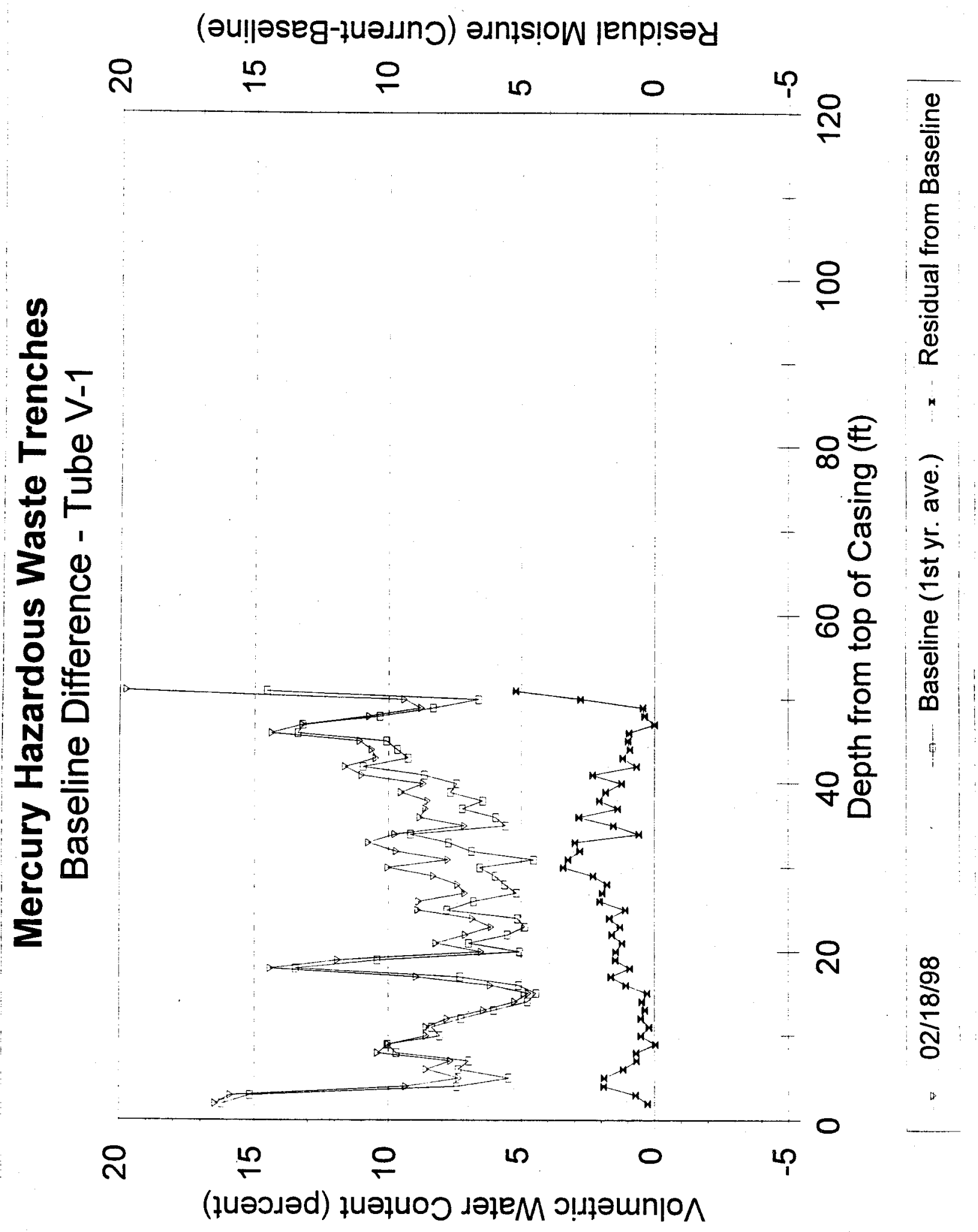




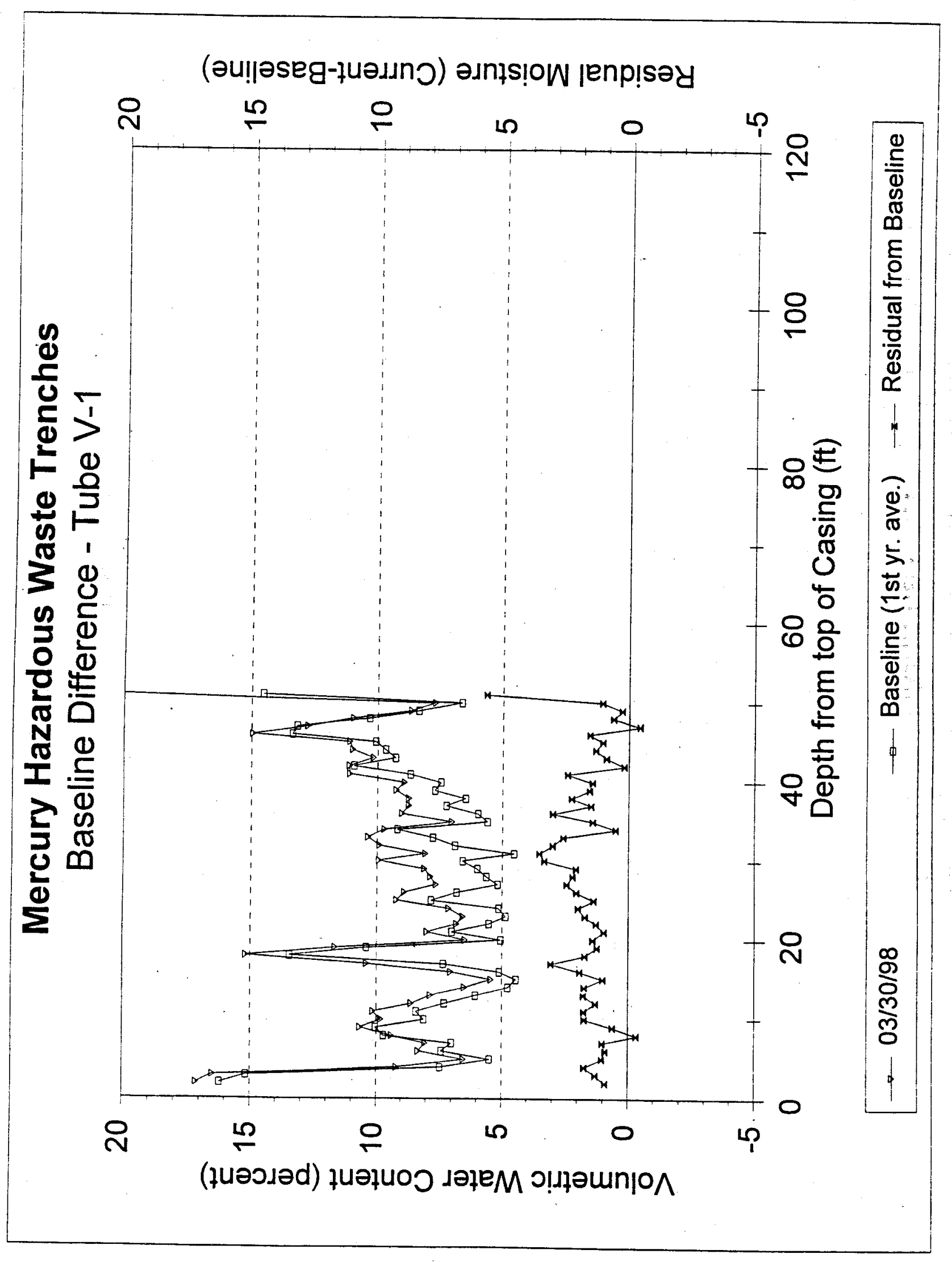




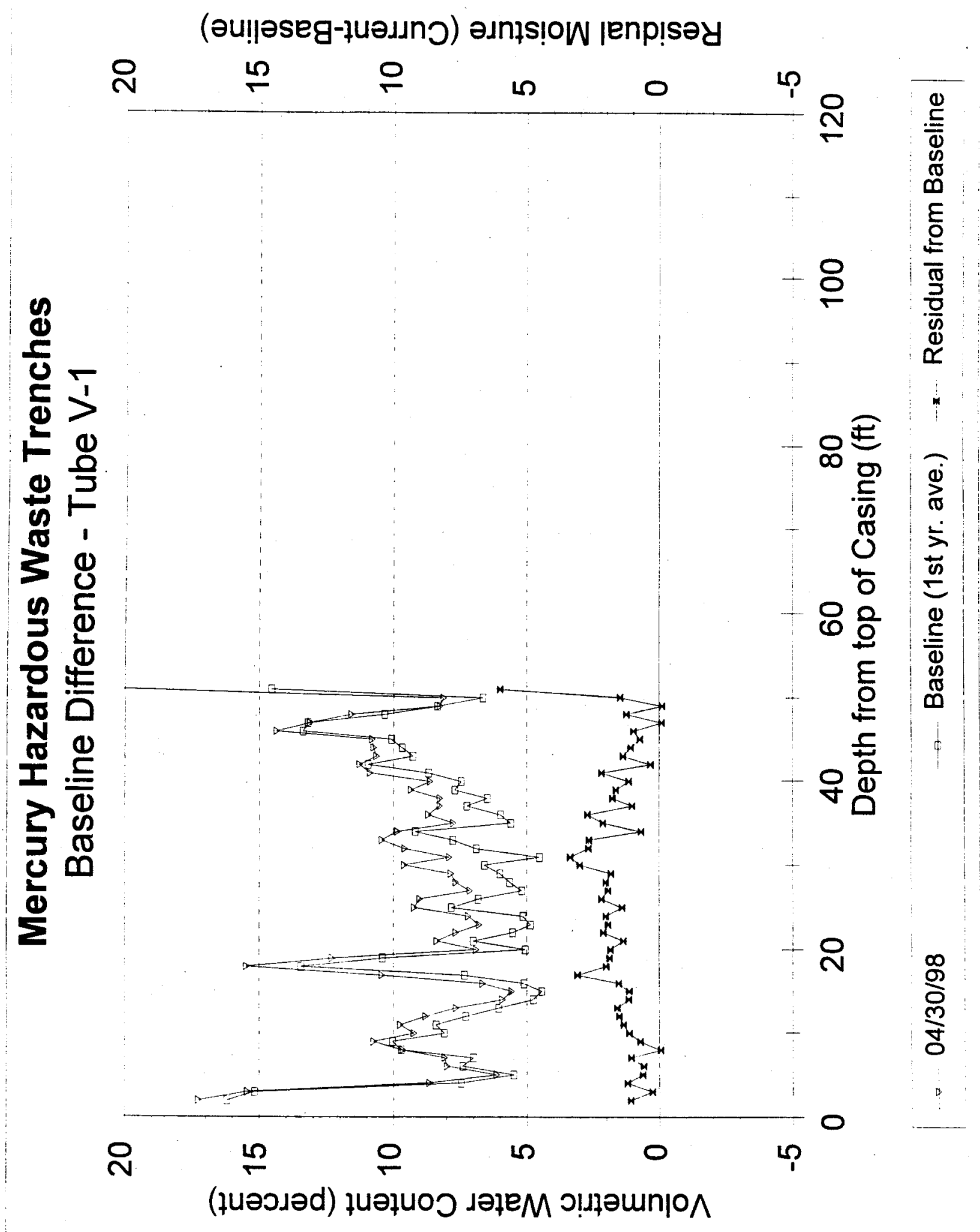




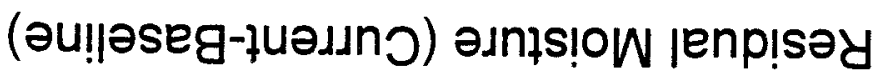

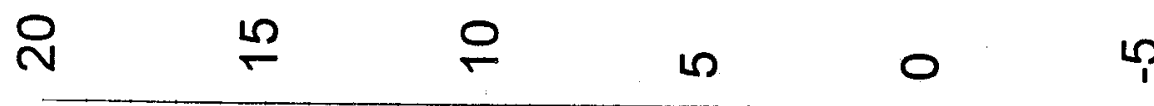

i

$\stackrel{2}{9}$

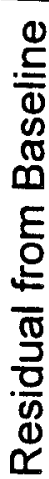

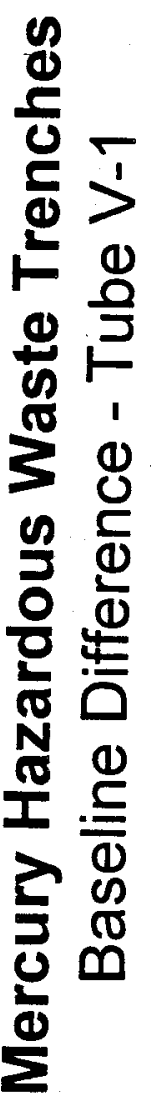
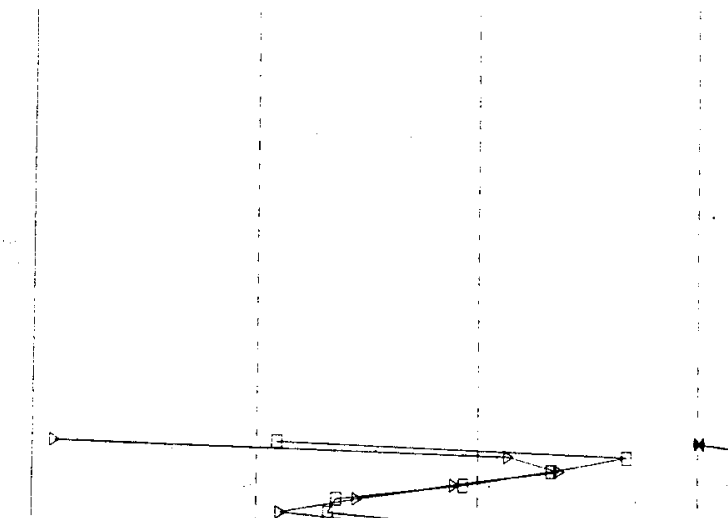

$-8$

$8 \frac{\frac{E}{0}}{\frac{0}{0}}$
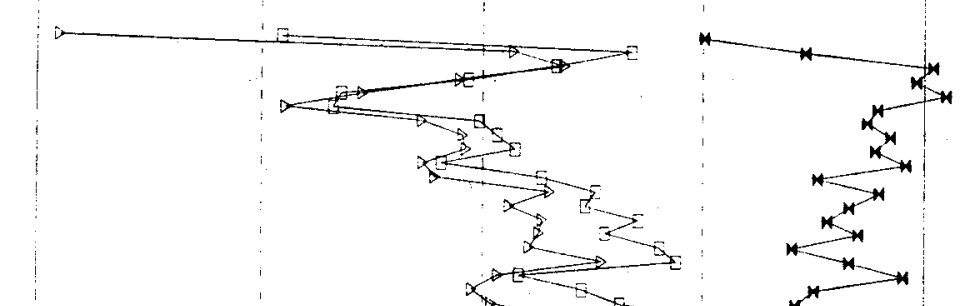

$-\infty$

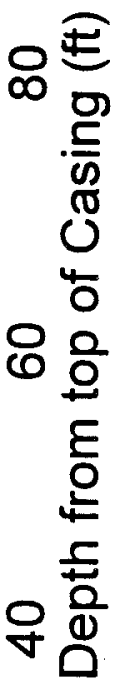

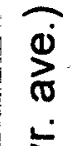

$\bar{i}$

交

$+8$

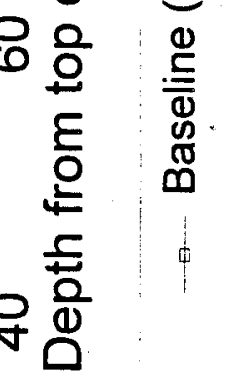

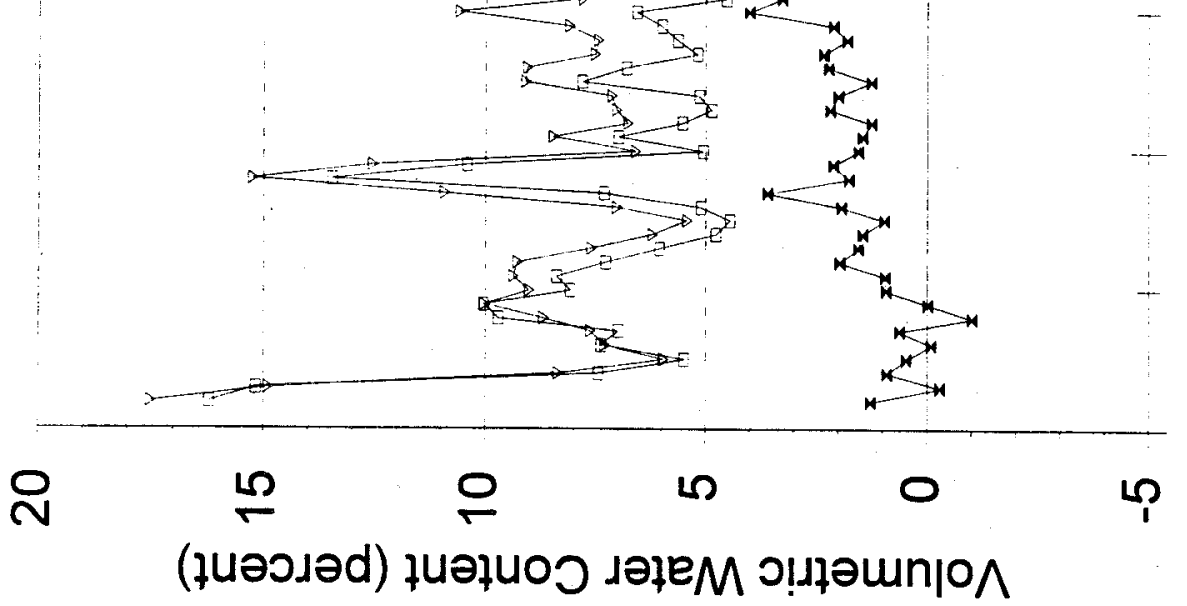

오

足

0

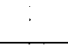




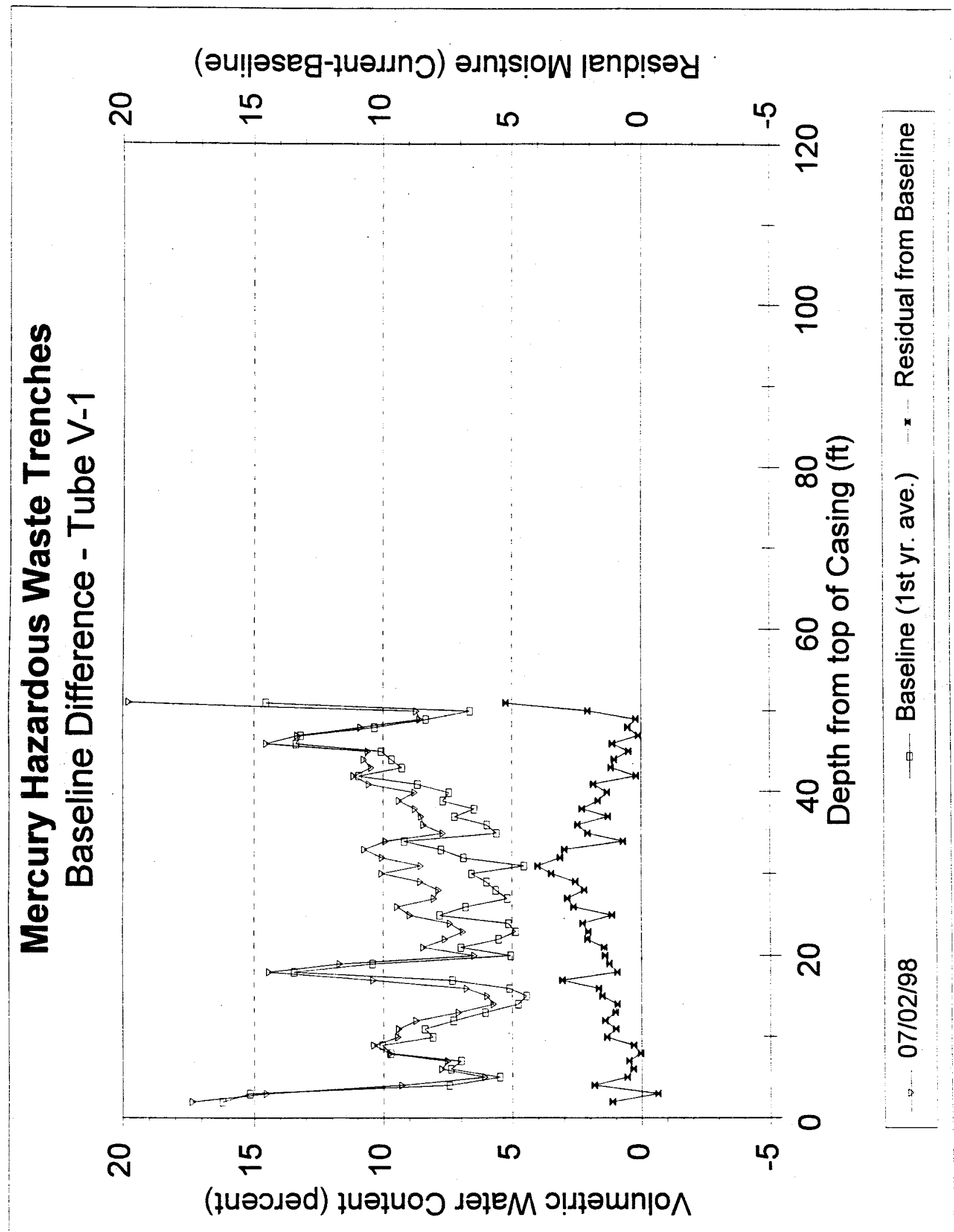




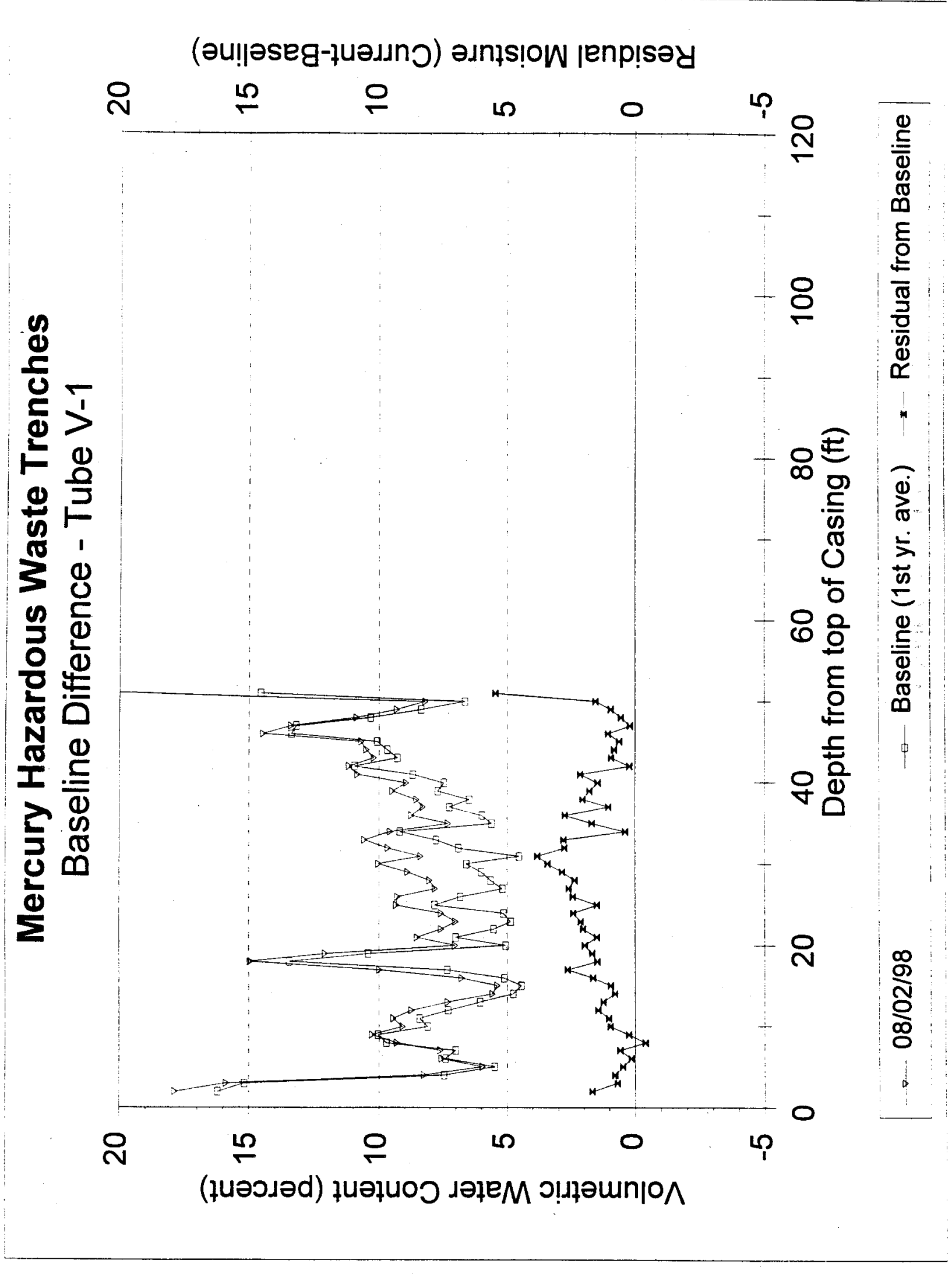




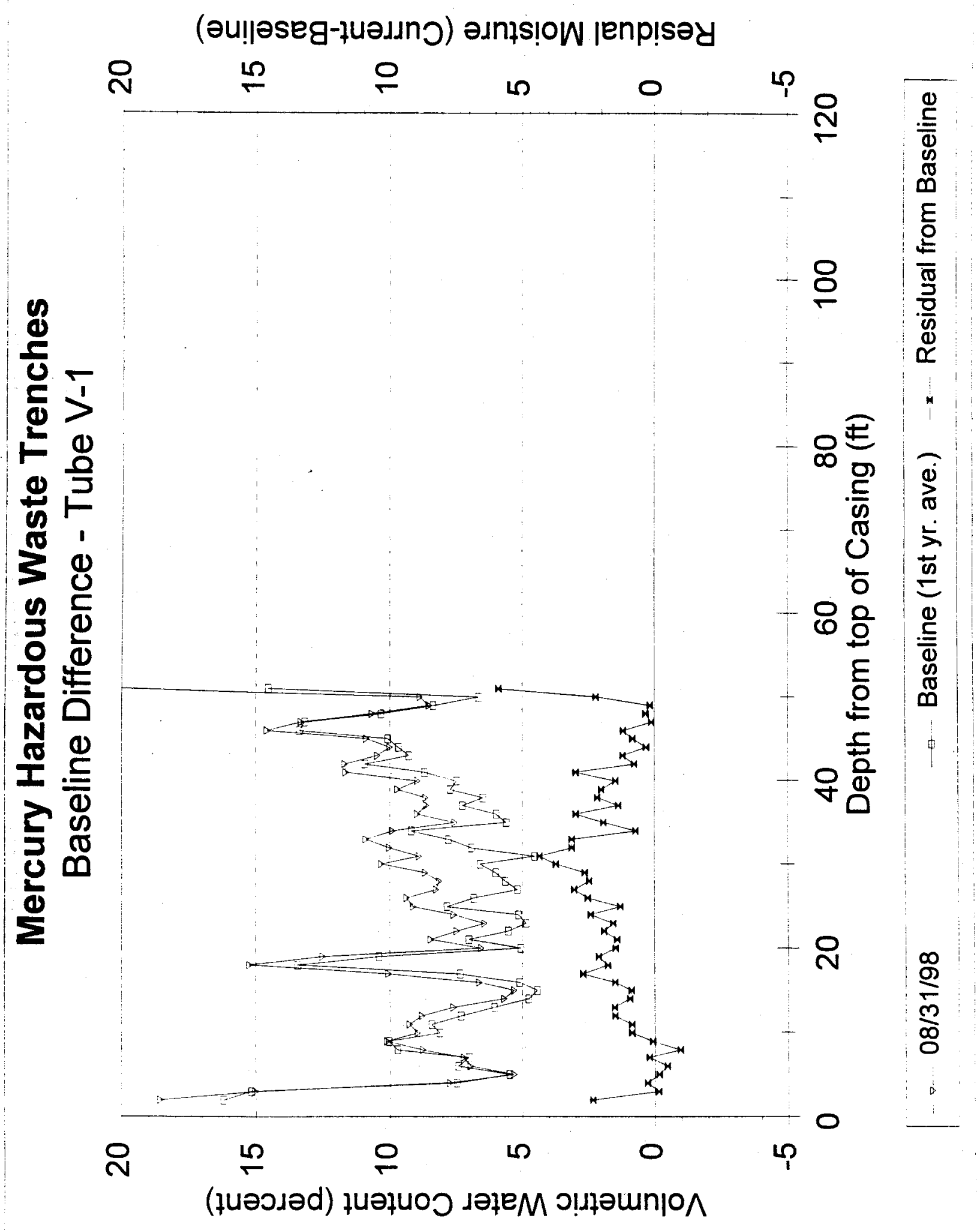




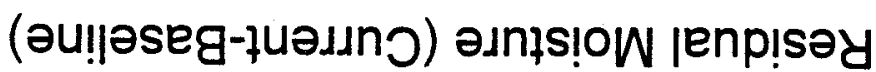

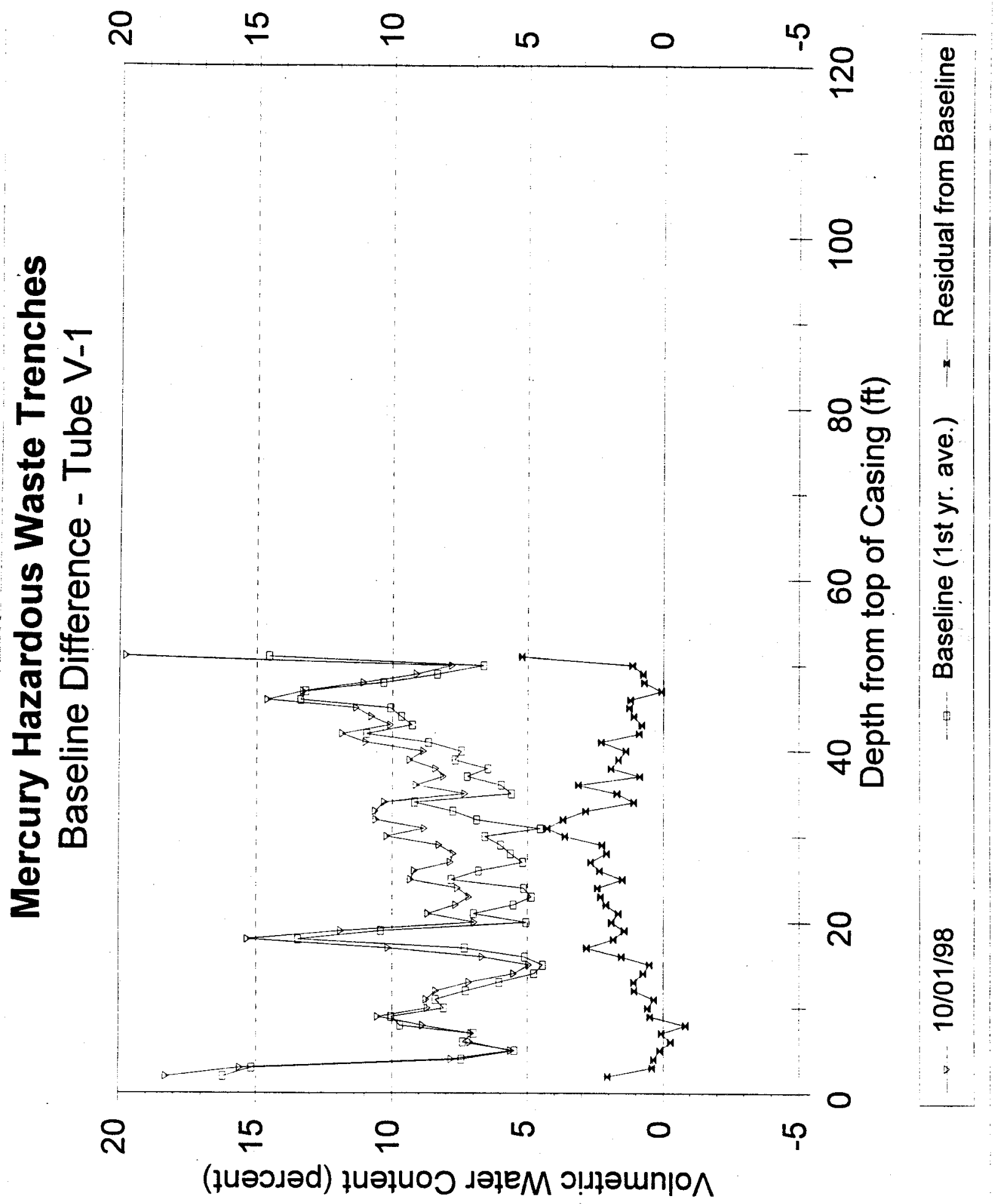




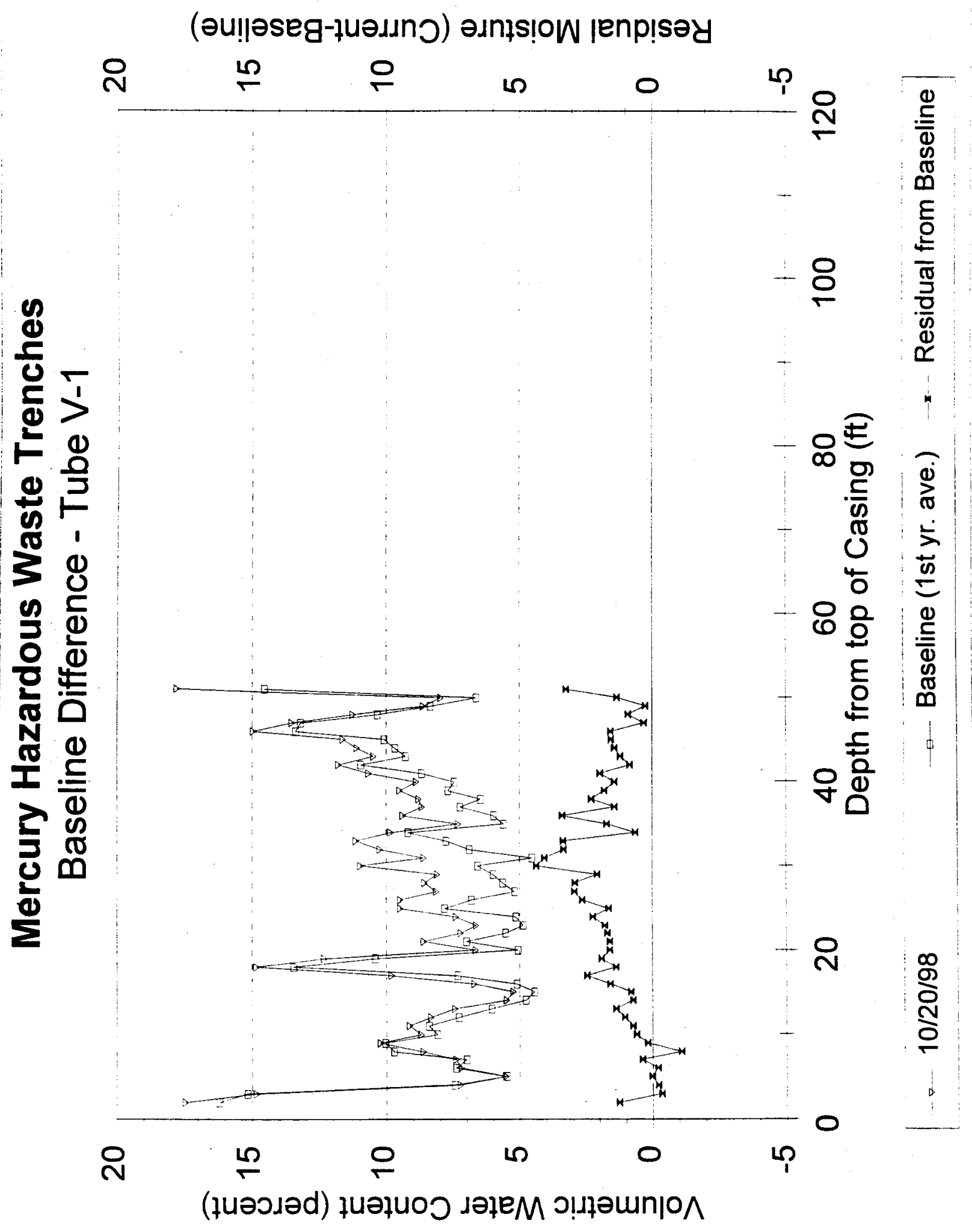




\section{DISTRIBUTION LIST}

\section{Controlled Copies}

Paul Liebendorfer

Bureau of Federal Facilities

Division of Environmental Protection

333 W. Nye Lane, Room 13B

Carson City, NV 89706-0866

Micheal McKinnon

Bureau of Federal Facilities

Division of Environmental Protections

555 E. Washington, Suite 4300

Las Vegas, NV 89010

Sabrina Lawrence

Environmental Restoration Division

U.S. Department of Energy, Nevada Operations Office

P.O. Box $98518 \mathrm{M} / \mathrm{S} 505$

Las Vegas, NV 89193-8518

Uncontrolled Copies

Janet Appenzeller-Wing

Environmental Restoration Division

U.S. Department of Energy, Nevada Operations Office

P.O. Box $98518 \mathrm{M} / \mathrm{S} 505$

Las Vegas, NV 89193-8518

Sabine Curtis

Environmental Restoration Division

U.S. Department of Energy, Nevada Operations Office

P.O. Box $98518 \mathrm{M} / \mathrm{S} 505$

Las Vegas, NV 89193-8518

DOE Public Reading Facility

P.O. Box $98521 \mathrm{M} / \mathrm{S}$ NLV040

Las Vegas, NV 89193-8521 


\section{DISTRIBUTION LIST (Continued)}

$\underline{\text { Uncontrolled Copies }}$

DOE/Nevada Operations Office

Technical Information Resource Center

P.O. Box $98521 \mathrm{M} / \mathrm{S} 505$

Las Vegas, NV 89193-8521

U.S. Department of Energy

Office of Scientific and Technical Information

175 Oak Ridge Turnpike

P.O. Box 62

Oak Ridge, TN 37831-0062

Correspondence Control

Bechtel Nevada

P.O. Box $98521 \mathrm{M} / \mathrm{S}$ NLV008

Las Vegas, NV 89193-8521

Environmental Management Correspondence Control

Bechtel Nevada

P.O. Box $98521 \mathrm{M} / \mathrm{S}$ NLV080

Las Vegas, NV 89193-8521

David Cowser

Bechtel Nevada

P.O. Box $98521 \mathrm{M} / \mathrm{S}$ NLV082

Las Vegas, NV 89193-8521

Anne Heidema

Bechtel Nevada

P.O. Box $98521 \mathrm{M} / \mathrm{S}$ NLV022

Las Vegas, NV 89193-8521

Steve Nacht

Bechtel Nevada

P.O. Box $98521 \mathrm{M} / \mathrm{S}$ NTS306

Las Vegas, NV 89193-8521

Jeff Smith

Bechtel Nevada

P.O. Box $98521 \mathrm{M} / \mathrm{S}$ NTS306

Las Vegas, NV 89193-8521 